UNIVERSIDADE DE BRASÍLIA - UNB

CENTRO DE DESENVOLVIMENTO SUSTENTÁVEL - CDS

\title{
INFLUÊNCIA DA PARTICIPAÇÃo SOCIAL Na CONSERVAÇÃo da \\ BIODIVERSIDADE EM UNIDADES DE CONSERVAÇÃO BRASILEIRAS
}

Danielle Calandino

Orientador: Fernando Paiva Scardua

Tese de doutorado apresentada no Programa de pós-graduação do Centro

de Desenvolvimento Sustentável da Universidade de Brasília.

Brasília-DF, 02 fevereiro de 2016 
Calandino, Danielle

Influência da Participação social na Conservação da Biodiversidade em Unidades de Conservação Brasileiras

Brasília, 2016.

243p.:il.

Tese de Doutorado. Centro de Desenvolvimento Sustentável.

Universidade de Brasília.

1. Unidade de conservação. 2. Participação social 3.

Conservação da biodiversidade. I. Universidade de Brasília.

CDS. II. Título.

É concedida à Universidade de Brasília permissão para reproduzir cópias desta tese e emprestar ou vender tais cópias, somente para propósitos acadêmicos e científicos. A autora reserva outros direitos de publicação e nenhuma parte desta tese de doutorado pode ser reproduzida sem a autorização por escrito da mesma.

Danielle Calandino 
UNIVERSIDADE DE BRASÍLIA

CENTRO DE DESENVOLVIMENTO SUSTENTÁVEL

\section{INFLuÊnCIA da PARTICIPAÇÃo SOCIAL Na CONSERVAÇÃo da BIODIVERSIDADE EM UNIDADES DE CONSERVAÇÃo BRASILEIRAS}

Danielle Calandino

Tese de Doutorado submetida ao Centro de Desenvolvimento Sustentável da Universidade de Brasília, como parte dos requisitos necessários à obtenção do Grau de Doutora em Desenvolvimento Sustentável, área de concentração em Política e Gestão Ambiental.

Aprovado por:

Fernando Paiva Scardua

Orientador

UnB - Centro de Desenvolvimento Sustentável

José Luiz Andrade

Examinador Interno 1

UnB - Centro de Desenvolvimento Sustentável

Thomas Ludewigs

Examinador Interno 2

UnB - Centro de Desenvolvimento Sustentável

Cristiane Gomes Barreto

Examinador Interno 3

UnB - Centro de Desenvolvimento Sustentável

Roseli Senna Ganem

Examinador Externo

Câmara dos Deputados

Brasília, 02 de fevereiro de 2016. 
Dedico esta Tese à minha avó, Iracema Barbosa da Silva (in memorian), quem habita, desde sempre, o nosso amor; e aos meus filhos Lucas, Vicente e Iara, fontes diárias de inspiração e ensinamento. 


\section{AGRADECIMENTOS}

Este trabalho foi fruto da influência de muitas pessoas, que emprestaram de algum modo características, informações, sentimentos que deram tônica e personalidade a esta construção. Gratidão especial a três delas, sem as quais, certamente, esta tarefa não teria sido concluída: Rodrigo Koblitz, meu companheiro de vida; minha mãe, minha alegria e minha madrinha, aquela que crê (e que eu creio), Teresa Cristina.

Muito obrigada a vocês pelo apoio incondicional em todos os momentos da minha vida e por sempre insistir em compassar nossas caminhadas, em qualquer lugar, sob qualquer circunstância.

Obrigada ao meu pai, Cezar Calandino, pelo amor, exemplo de simplicidade e determinação e minha irmã, Bárbara Calandino, por confiar.

Meus filhos, meu maior legado, meu propósito, minha maior felicidade: Lucas, Vicente e Iara Calandino Koblitz.

Tia Rosa, Juju e Felipe, sempre atenciosos.

Ao melhor orientador que eu poderia ter, Fernando Scardua. Muito obrigada, pela sua compreensão, paciência, rigor e profissionalismo. Aprendi muito com você.

Á Alessandra Ninis e Daniela Oliveira que me incentivaram no momento que decidi iniciar esta jornada e a Angélica Brunacci que me apoiou em um dos momentos mais críticos.

Às queridas amigas Marla Weihs, Patrícia Mesquita, Renata Amorim, Juliana Castro, Ângela Zanelato, Michele Midori, Aline Lopes, Andreia Mello, Vanina Antunes e Juliana Penna. Tudo se enche de vida com estes encontros.

Aos demais companheiros da nossa especial turma de doutorado: Jair Schimith, João Tasso, Antonio Juliani, Carolina de Araújo, James Tibúrcio, Márcia Camargo e Daniela Rocco.

Àqueles que contribuíram com recomendações nas versões anteriores deste trabalho: Professores Drummond, Thomas Ludewigs, José Luiz Franco, Cristiane Barreto e Roseli Ganem.

Ao Funbio, pela possibilidade de aproximar a teoria da prática. Agradeço em especial a Fábio Leite e Fernanda Marques, pelo apoio e à Nathalia Dreyer pelos incentivos constantes.

Ao ICMBio pelas informações disponibilizadas, em especial à Lilian Hangae, Marcelo Kinouchi e aos gestores do instituto que contribuíram no repasse de informações.

Por fim, agradeço ao Centro de Desenvolvimento Sustentável da UnB, pelo aprendizado e ao CNPq, pela bolsa concedida. 


\section{RESUMO}

As áreas protegidas tem sido a principal estratégia global para a conservação da biodiversidade, com efetividade diretamente proporcional a sua implementação. A participação da sociedade, mais que um direito cidadão, tem sido percebida como um potente instrumento na consolidação destas áreas. Analisar os fatores que influenciam na intensidade da participação social e sua influência na consecução dos objetivos de conservação das unidades de conservação foram os objetivos principais deste estudo. Foram avaliados os dados disponíveis sobre a participação social em 299 unidades de conservação (UC) federais decorrentes da aplicação do método RAPPAM e veiculados formulários eletrônicos, direcionados aos gestores de UCs, para coleta de informações complementares. Os dados foram consolidados e utilizados para caracterização geral da participação social nessas UCs. O método estatístico de análise de correspondência multivariada (MCA) foi utilizado para possibilitar a construção de uma medida de participação que permitiu analisar variações na sua intensidade e torná-la comparável com as medidas de conservação da biodiversidade. Um grupo de variáveis, selecionadas pelo MCA, foi utilizado como fator de dimensionamento da participação social. Constatou-se que os fatores de maior influência sobre a participação social na gestão das UCs foram: capacitação das comunidades locais e conselhos; resolução de conflitos; importância estética e alto valor recreativo da unidade de conservação; infraestrutura apropriada para visitação; comunicação efetiva entre as comunidades locais; transparência na tomada de decisões do manejo; comunicação efetiva com as comunidades locais; colaboração regular dos funcionários da UC com parceiros, comunidades locais e outras organizações. A relação entre participação social e a conservação da biodiversidade foi avaliada a partir da análise entre o fator de dimensionamento proposto e o desmatamento no interior das unidades de conservação federais brasileiras na Amazônia, novamente a partir da análise de agrupamento espacial de MCA. Foi verificada uma tendência de redução do desmatamento no interior das UCs onde a participação social foi trabalhada mais intensamente, sobretudo nas UCs de uso sustentável. Os resultados sugerem que a participação social em unidades de conservação de uso direto influencia de forma positiva a conservação da biodiversidade nestas áreas. Tal afirmativa abre múltiplas possibilidades de aprofundamento sobre o tema, além de contribuir para a formulação de políticas públicas ambientais voltadas à conservação da biodiversidade.

Palavras-chave: Participação social, conservação da biodiversidade, unidades de conservação, desmatamento, Amazônia. 


\begin{abstract}
Protected areas have been the main global strategy for biodiversity conservation, with directly proportional effective implementation. The participation of society, rather than a citizen right, has been perceived as a powerful instrument in the consolidation of these areas. Analyze the factors that influence the intensity of social participation and influence in achieving the conservation objectives of the protected areas were the main objectives of this study. We evaluated the available data on social participation in 299 federal protected areas (PAs) resulting from the application of RAPPAM method and transmitted electronic forms targeted to PAs managers to collect additional information. The data were consolidated and used for general characterization of social participation in these protected areas. The statistical method of multivariate correspondence analysis (MCA) was used to enable the construction of a measure of participation that allowed us to analyze variations in intensity and make it comparable with biodiversity conservation measures. A group of variables selected by MCA, was used as a scaling factor of social participation. It was found that the most influential factors on social participation in protected areas management were: training of local councils and communities; conflict resolution; aesthetic importance and high recreational value of the conservation area; appropriate infrastructure for visitation; effective communication between local communities; transparency in making management decisions; effective communication with local communities; regular collaboration of protected areas employees with partners, local communities and other organizations. The relationship between social participation and biodiversity conservation was evaluated from the analysis of the proposed scaling factor and deforestation within the Brazilian federal protected areas in the Amazon, again from the spatial cluster analysis of MCA. A deforestation reduction trend was observed within protected areas where social participation has worked more intensively, particularly in sustainable use PAs. The results suggest that social participation in direct use conservation areas positively influences biodiversity conservation in these areas. This statement opens multiple possibilities of deepening on the subject, and contribute to the formulation of environmental policies for the conservation of biodiversity.
\end{abstract}

Keywords: Social participation, biodiversity conservation, protected areas, deforestation, Amazon. 


\section{RESUMÉ}

Les zones protégées ont été la principale stratégie mondiale pour la conservation de la biodiversité, de manière efficace directement proportionnelle à sa mise en œuvre. La participation de la société, plutôt que d'un droit de citoyen, a été perçu comme un instrument puissant dans la consolidation de ces zones. Analyser les facteurs qui influent sur l'intensité de la participation sociale et leur influence dans la réalisation des objectifs de conservation des aires protégées ont été les principaux objectifs de cette étude. Nous avons évalué les données disponibles sur la participation sociale dans 299 unités de conservation (UC) du gouvernement fédéral résultant de l'application de la méthode RAPPAM et les formulaires électroniques transmis ciblées aux gestionnaires AP recueillir des renseignements supplémentaires. Les données ont été regroupées et utilisées pour la caractérisation générale de la participation sociale dans ces zones protégées. La méthode statistique d'analyse de la correspondance multivariée (MCA) a été utilisé pour permettre la construction d'une mesure de participation qui nous a permis d'analyser les variations de l'intensité et de la rendre comparable à des mesures de conservation de la biodiversité. Un groupe de variables sélectionnées par le MCA, ont été utilisés comme facteur d'échelle de la participation sociale. Il a été constaté que les facteurs les plus influents sur la participation sociale dans la gestion des aires protégées ont été: Donner des conseils et des communautés locales; la résolution des conflits; importance esthétique et une grande valeur récréative de la zone protégée; une infrastructure appropriée pour les visites; une communication efficace entre les communautés locales; la transparence dans la prise de décisions de gestion; une communication efficace avec les communautés locales; collaboration régulière des employés de communications unifiées avec des partenaires, des communautés locales et d'autres organisations. La relation entre la participation sociale et conservation de la biodiversité a été évaluée sur la base de la confrontation entre le facteur d'échelle proposée et la déforestation dans les unités de conservation fédérale brésilienne de l'Amazonie, à nouveau a partir de l'analyse de cluster spatiale de MCA. Une tendance de réduction de la déforestation a été observée dans les zones protégées où la participation sociale a été travaillé plus fort, surtout dans les zones protégées de l'utilisation durable. Les résultats suggèrent que la participation sociale dans les unités de conservation d'usage direct influence positivement conservation de la biodiversité dans ces domaines. Cette déclaration ouvre de multiples possibilités d'approfondissement sur le sujet, et de contribuer à la formulation de politiques publiques environnementales pour la conservation de la biodiversité.

Mots-clés: la participation sociale, conservation de la biodiversité, des zones protégées, la déforestation, Amazon. 


\section{RESUMEN}

Las áreas protegidas han sido la principal estrategia mundial para la conservación de la biodiversidad, con eficacia directamente proporcional a su puesta en práctica. La participación de la sociedad, en lugar de un derecho ciudadano, se ha percibido como un poderoso instrumento en la consolidación de estas áreas. Analizar los factores que influyen en la intensidad de la participación social y su influencia en el logro de los objetivos de conservación de las áreas protegidas fueron los objetivos principales de este estudio. Se evaluaron los datos disponibles sobre la participación social en 299 unidades de conservación (UC) federales que resulta de la aplicación del método RAPPAM y formularios electrónicos transmitidos dirigidos a gestores de esas áreas para recoger información adicional. Los datos se consolidaron y se utilizan para la caracterización general de la participación social en estas áreas protegidas. El método estadístico de análisis de correspondencias multivariado (MCA) para permitir la construcción de una medida de participación que nos permitió analizar las variaciones en intensidad y hacerla comparable con las medidas de conservación de la biodiversidad. Un grupo de variables seleccionadas por el MCA, se utiliza como factor de escala de la participación social. Se encontró que los factores más influyentes sobre la participación social en la gestión de áreas protegidas fueron: Capacitar a los consejos y las comunidades locales; resolución de conflictos; importancia estética y alto valor recreativo del área protegida; infraestructura adecuada para la visita; comunicación efectiva entre las comunidades locales; la transparencia en la toma de decisiones de gestión; comunicación efectiva con las comunidades locales; la colaboración regular de los empleados de la UC con los socios, las comunidades locales y otras organizaciones. La relación entre la participación social y la conservación de la biodiversidad se evaluó sobre la base de la confrontación entre el factor de escala propuesta y la deforestación dentro de las unidades de conservación federales brasileños en el Amazonas, de nuevo desde el análisis de agrupamiento espacial de MCA. Se observó una tendencia de reducción de la deforestación dentro de las áreas protegidas en las que la participación social se trabajó más duro, especialmente en las áreas de uso protegidas sostenibles. Los resultados sugieren que la participación social en el uso directo de las unidades de conservación influye positivamente en la conservación de la biodiversidad en estas áreas. Esta declaración abre múltiples posibilidades de profundizar en el tema, y contribuir a la formulación de las políticas públicas ambientales para la conservación de la biodiversidad.

Palabras clave: participación social, conservación de la biodiversidad, las áreas protegidas, la deforestación, el Amazonas. 


\section{LISTA DE ILUSTRAÇÕES}

Figura 1. Ciclo de gestão e avaliação proposto pela Comissão Mundial de Áreas Protegidas da União Internacional para a Conservação da Natureza.

Figura 2. Mapa das unidades de conservação federais da Amazônia, categorizadas de acordo com a efetividade de gestão (segundo RAPPAM 2010) e desmatamento na região nos últimos cinco anos. 60

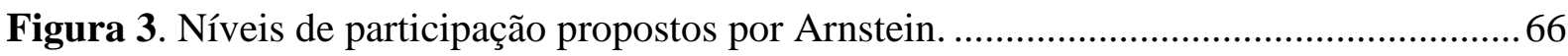

Figura 4. Diferentes tipos de participação propostos por Mannigel..........................................66

Figura 5. Fluxo metodológico adotado para consecução de cada objetivo específico.............73

Figura 6. Área efetivamente destinada para criação unidades de conservação até 2014 ........ 86

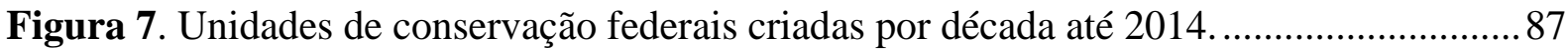

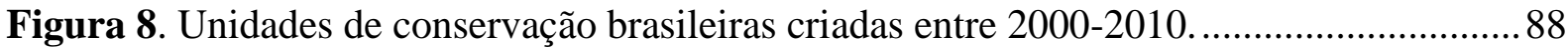

Figura 9. Áreas Protegidas criadas no mundo entre 2000-2014 ............................................ 88

Figura 10. Percentual de área destinado à unidade de conservação em cada bioma continental

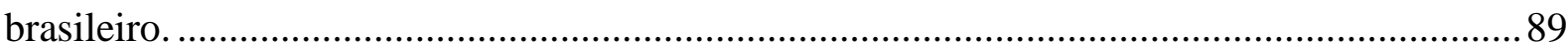

Figura 11. Áreas protegidas no mundo por classe de tamanho........................................... 89

Figura 12. Proporção de UCs em cada bioma por classe de tamanho....................................90

Figura 13. Distribuição percentual das unidades de conservação por bioma..........................90

Figura 14. Localização das áreas protegidas federais por região geográfica. .........................91

Figura 15. Localização das Unidades de Conservação federais por unidade federativa......... 91

Figura 16. Ano de criação das unidades de conservação federais avaliadas...........................92

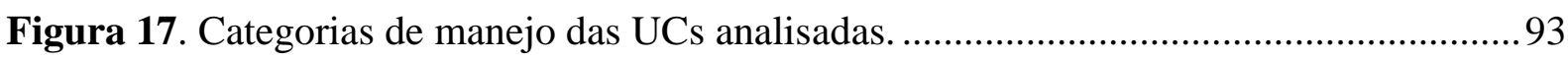

Figura 18. Percepção dos gestores de unidades de conservação federais em relação a comunidade. 94

Figura 19. Percepção da comunidade em relação à unidade de conservação. .94

Figura 20. Estratégia de conservação prioritariamente adotada pelas UCs. 96

Figura 21. Percentual de respostas para a questão "Quais os cinco canais de participação mais utilizados pela sociedade na gestão da sua unidade? ", com base no formulário da tese. 99

Figura 22. Diversidade de canais de participação utilizados pelas unidades de conservação federais

Figura 23. Proporção de unidades de conservação com conselhos gestores criados anualmente entre 2000-2010. 
Figura 24. Percentual de unidades de conservação dentro de cada classe de tamanho do conselho gestor.

Figura 25. Tipos de entraves à participação social por tipo de conselho gestor.

Figura 26. Tipos de entraves à participação social em unidades que recebem apoio financeiro do Programa ARPA e UCs que não são apoiadas pelo programa.

Figura 27. Efetividade dos conselhos gestores de unidades de conservação em unidades apoiadas ou não pelo ARPA.

Figura 28. Tipos de entraves à participação social nas reuniões dos conselhos gestores de unidades conservação por bioma brasileiro.

Figura 29. Legitimidade da representação dos conselheiros por grupo de UC.

Figura 30. Percentual de unidades de conservação com conselhos gestores criados e operantes em cada bioma brasileiro.

Figura 31. Mapa de fatores da Análise de Correspondência Múltipla das variáveis de dimensionamento

Figura 32. Mapa de fatores da Análise de Correspondência Múltipla entre variáveis de dimensionamento e variáveis explicativas $(\mathrm{n}=292)$.

Figura 33. Mapa de fatores do MCA para fator de dimensionamento e desmatamento das unidades de conservação da Amazônia (proteção e integral e uso sustentável).

Figura 34. Mapa de fatores do MCA entre fator de dimensionamento e desmatamento das unidades de conservação da Amazônia para unidades de proteção integral.

Figura 35. Mapa de fatores do MCA para fator de dimensionamento e desmatamento das unidades de conservação da Amazônia para unidades de uso sustentável.

\section{LISTA DE TABELAS}

Tabela 1. Comparação dos índices de efetividade de gestão de unidades de conservação federais auferidos com base nos indicadores de efetividade do RAPPAM

Tabela 2. Categorização das variáveis analisadas em cada fonte de dados de acordo com a sua função.

Tabela 3. Número de unidades de conservação avaliadas por cada método e ano de aplicação considerado na análise.

Tabela 4. Grupos e categorias de manejo das UCs analisadas.

Tabela 5. Distribuição percentual das UCs analisadas por bioma 85 


\section{LISTA DE QUADROS}

Quadro 1. Categorias brasileiras de unidades de conservação de proteção integral.

Quadro 2. Categorias brasileiras de unidades de conservação de uso sustentável.

Quadro 3. Tipos de conselhos gestores por categoria de unidades de conservação.

Quadro 4. Fluxo metodológico representado na Figura 5 de acordo com cada objetivo específico.

Quadro 5. Categorização das variáveis de participação, por método utilizado (RAPPAM 2010 ou formulário eletrônico).

Quadro 6. Variáveis de dimensionamento selecionadas para compor o fator de dimensionamento.

Quadro 7. Variáveis explicativas selecionadas por proximidade no agrupamento espacial decorrente da análise multivariada, dentre o grupo de onze variáveis explicativas do RAPPAM consideradas no estudo.

\section{LISTA DE ABREVIATURAS E SIGLAS}

AP - Área Protegida.

BID - Banco Interamericano de Desenvolvimento.

CDB - Convenção sobre Diversidade Biológica.

CG - Conselho Gestor de Unidade de Conservação.

COP - Conferência das Partes.

DEGRAD - Sistema de Monitoramento de Áreas de Florestas Degradadas na Amazônia.

ENB - Estratégia Nacional de Conservação da Biodiversidade.

FAUC - Ferramenta de avaliação de Unidades de Conservação.

FBCN - Fundação Brasileira para a Conservação da Natureza.

FUNATURA - Fundação Pró-Natureza.

FUNBIO - Fundo Brasileiro para Biodiversidade.

ICMBio - Instituto Chico Mendes de Conservação da Biodiversidade.

INPE/MCT - Instituto de Pesquisas Espaciais / Ministério da Ciência e Tecnologia.

MCA - Multiple Correspondence Analysis.

MPOG - Ministério do Planejamento Orçamento e Gestão.

PNMA - Política Nacional de Meio Ambiente.

PRODES - Programa de Cálculo do Desflorestamento da Amazônia.

PS - Participação Social.

RAPPAM - Rapid Assessment and Prioritization of Protected Areas Management. 
SISNAMA - Sistema Nacional de Meio Ambiente

SNUC - Sistema Nacional de Unidades de Conservação.

UC - Unidade de Conservação.

UICN - União Internacional para a Conservação da Natureza.

WWF - World Wildlife Fund. 


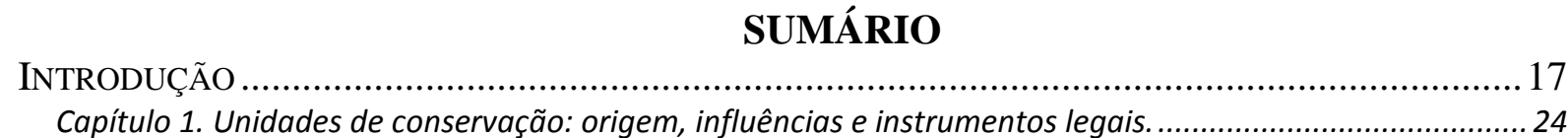

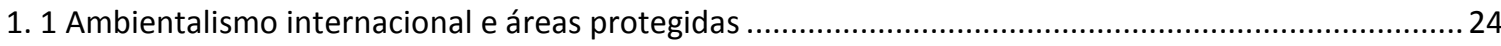

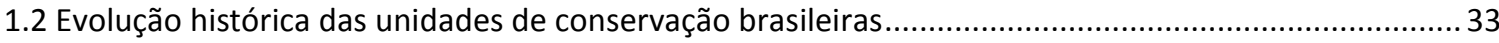

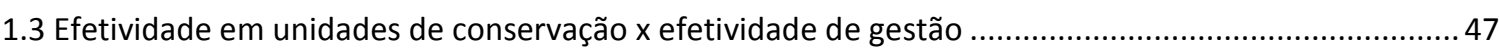

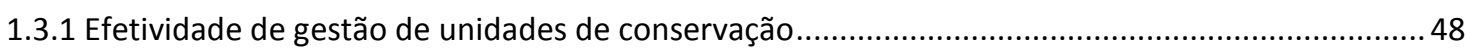

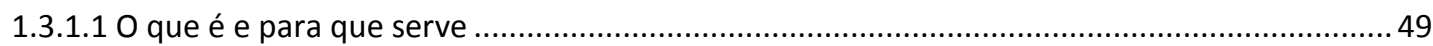

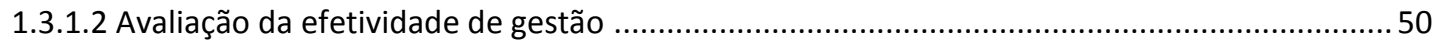

1.3.2 Status e influências sobre a efetividade de gestão de unidades de conservação federais ...............56

1.3.2.1 Uma perspectiva com base nos dados do RAPPAM ................................................................ 56

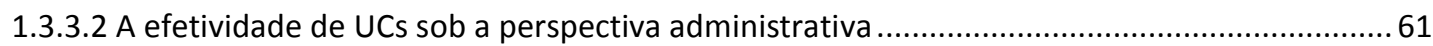

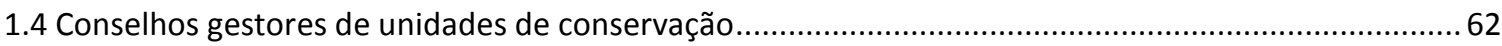

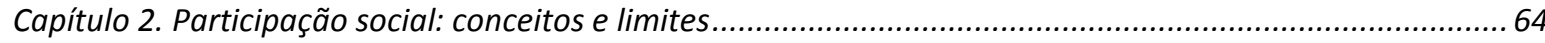

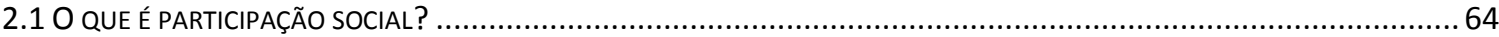

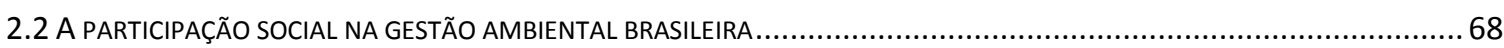

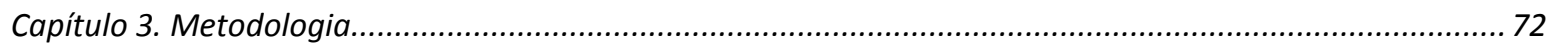

3.1.1 Efetividade de unidades de conservação ..................................................................................74

3.1.2 Participação social............................................................................................................... 74

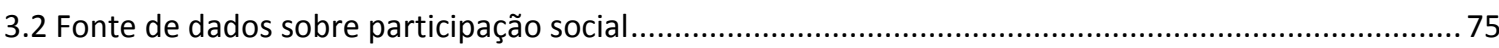

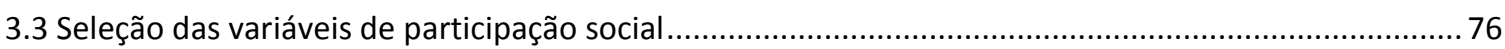

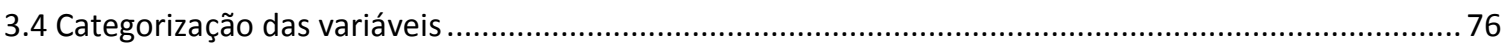

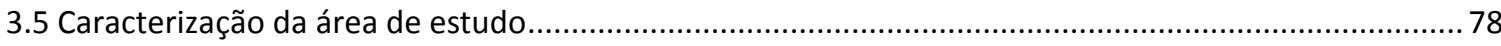

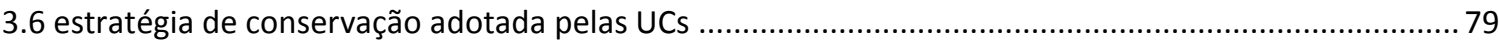

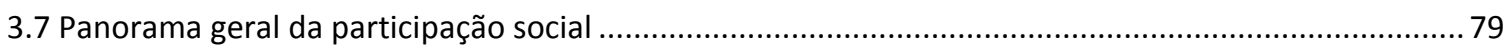

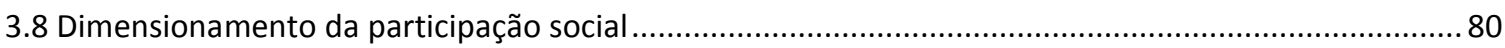

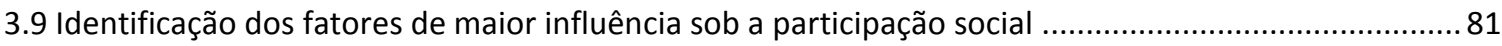

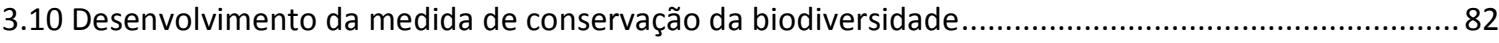

3.10.1 Desmatamento como proxy de conservação da biodiversidade ................................................... 82

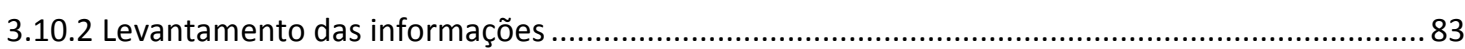

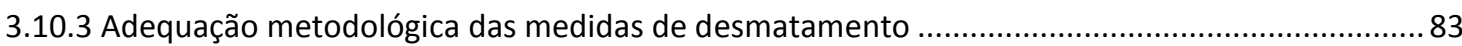

3.10.4 Análise de correlação entre as variáveis de participação social e de conservação da

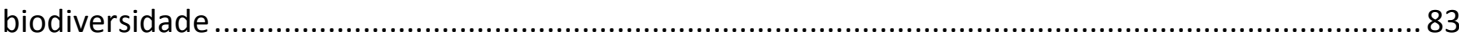

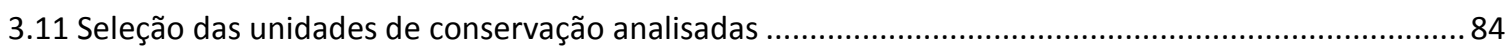

Capítulo 4. Caracterização da área de estudo e da estratégia de conservação adotadas................................. 84

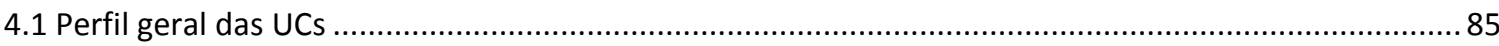

4.2 Estratégias de conservação da biodiversidade em unidades de conservação .........................................95

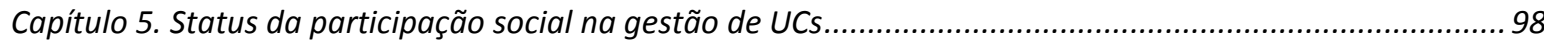




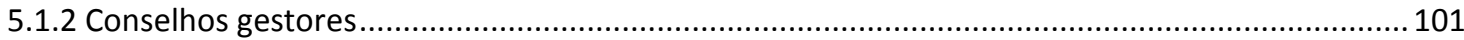

5.1.2.1 Tamanho dos conselhos gestores e frequência dos conselheiros às reuniões ...................... 102

5.1.2.2 Fatores limitantes à operacionalização dos conselhos gestores ....................................... 103

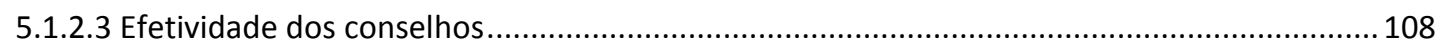

Capítulo 6. Dimensionamento da participação social ........................................................................ 110

6.1 Considerações sobre o delineamento conceitual proposto .......................................................... 110

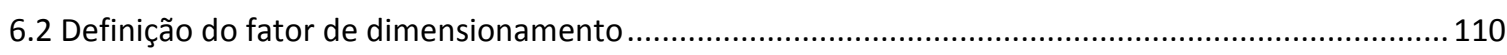

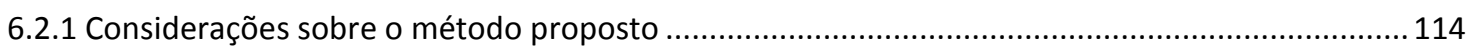

Capítulo 7. Participação social na gestão de UCs: uma análise de intensidade para duas dimensões...........114

7.1 Alguns caminhos para potencializar a participação social.......................................................... 115

7.2 Influência da participação social na conservação da biodiversidade brasileira de UCs brasileiras .......118

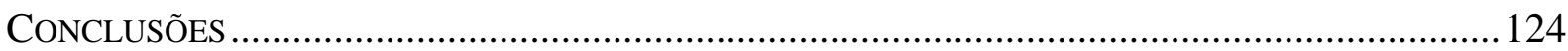

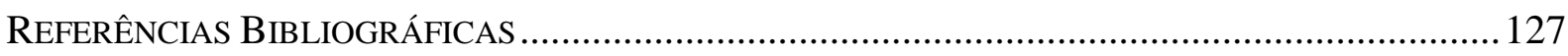

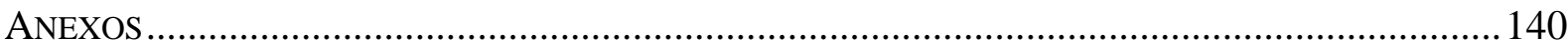

Anexo I. Lista de indicadores de efetividade de gestão avaliados no RAPPAM 2010 por elemento e

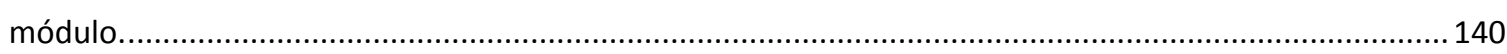

Anexo II. Lista de unidades de conservação estudadas de acordo com o método utilizado.......................150

Anexo III. Formulário eletrônico enviado aos gestores de unidades de conservação federais..................158

Anexo IV. Metadados do formulário de participação social.............................................................. 161

Anexo V. Dados consolidados provenientes do formulário eletrônico. ................................................ 164

Anexo VI. Dados utilizados na análise de correspondência multivariada ( $m c a$ ) para determinação do fator de dimensionamento da participação social.

Anexo VII. Dados utilizados na análise de correspondência multivariada $(m c a)$ para determinação das variáveis de maior influência sob a participação social.

Anexo VIII. Tabela de entrada de dados para MCA entre desmatamento em UCs federais (todas as UCS proteção integral e uso sustentável).

Anexo IX. Tabela de entrada de dados para MCA entre desmatamento em UCs federais de uso sustentável.

Anexo X. Tabela de entrada de dados para MCA entre desmatamento em UCs federais de proteção integral.

Anexo XI. Tabela de saída do MCA entre variáveis de dimensionamento. 200

Anexo XII. Tabela de saída do MCA entre variáveis explicativas e fator de dimensionamento. 204

Anexo XII.Tabela de saída do MCA entre fator de dimensionamento e desmatamento das unidades de conservação da Amazônia (PI+US)

Anexo XIII.Tabela de saída do MCA entre fator de dimensionamento e desmatamento das unidades de conservação de proteção integral. 
Anexo XIV.Tabela de saída do MCA entre fator de dimensionamento e desmatamento das unidades de conservação de uso sustentável. . 


\section{INFLUÊNCIA DA PARTICIPAÇÃO SOCIAL NA CONSERVAÇÃO DA BIODIVERSIDADE EM UNIDADES DE CONSERVAÇÃO BRASILEIRAS}

\section{INTRODUÇÃO}

A cada 40 dias, uma cidade da dimensão de Nova Iorque é adicionada à Terra. A cada quatro anos o equivalente a toda a população atual dos Estados Unidos - mais de 300 milhões de habitantes, é adicionada ao mundo. Foram mais pessoas adicionadas ao globo terrestre durante o século XX do que em toda a história humana (BONAR, 2012). Ao mesmo tempo, o crescimento populacional alicerçado nas bases de um modelo de desenvolvimento orientado para resultados econômicos imediatos, ambientalmente insustentáveis e socialmente injustos, intensificam os conflitos socioambientais (PORTO \& MILANEZ, 2009; DIEGUES, 2001). Trata-se de um crescimento socialmente perverso, apoiado no aprofundamento das desigualdades sociais (SACHS, 2007).

O contraste entre crescimento econômico e perda socioambiental e cultural já foi largamente abordado. A questão transcende a discussão de como, quando e quanto devemos alterar deste modelo de desenvolvimento. Trata-se de reinventar a relação do homem com a natureza e encontrar motivações para a participação da sociedade e transformar hábitos, independente do modelo adotado. Surgem daí as questões: o que leva a sociedade a se organizar em torno das causas ambientais e evitar a tragédia dos comuns? O engajamento social na conservação dos espaços protegidos pode contribuir para uma maior conservação ambiental? Como? Quanto? Que canais dispomos para tanto? Explorar estas questões de modo a contribuir para a identificação de estratégias de inclusão social na conservação das unidades de conservação brasileiras é parte dos objetivos deste estudo.

A consciência crítica ambiental brasileira, no que se refere a conservação in situ da biodiversidade, recebeu diversas influências do ambientalismo internacional ao longo da sua história, adquirindo personalidade própria em função das suas especificidades naturais, territoriais, políticas. Embora a sua origem esteja fundamentada na tradução das bases do iluminismo europeu para a realidade nacional, outros fatores também foram determinantes: a influência das correntes preservacionista e conservacionista (PÁDUA, 2002), e a tradução dessas para um País de dimensões continentais, extremamente biodiverso, de imensurável riqueza cultural e que abriga uma variedade de tradições ancestrais, baseadas na implantação de sistemas mais sustentáveis do ponto de vista ambiental. 
Como resultado dessas influências, tem-se um sistema nacional de unidades e conservação ${ }^{1}$ que contempla as duas principais correntes de conservação em categorias de manejo compatíveis com o que exigem as particularidades regionais do espaço geográfico brasileiro. No entanto, apesar de nosso ordenamento jurídico refletir a diversidade do território brasileiro, grande parte da base legal possui traços marcantes do preservacionismo norte-americano - a exemplo da Lei $\mathrm{n}^{\mathrm{o}}$ 9.985, de 18/07/2000, que institui o Sistema Nacional de Unidades de Conservação - SNUC (MERCADANTE, 2001).

A dicotomia homem-natureza, presente no cotidiano das pessoas e, mesmo em algumas abordagens ambientalistas, contribui para o distanciamento da sociedade no gerenciamento dos recursos naturais. Frequentemente, textos sagrados - como o Gênesis - apresentam os humanos como membros à parte do mundo natural, identificando-os como seus senhores, criados à imagem de um Deus masculino e celestial, únicos seres possuidores de alma e passíveis de salvação eterna, superiores ao restante da criação divina (BARBOSA \& DRUMMOND, 1994). Mesmo dentro da abordagem conservacionista, as ações de gestão dos espaços protegidos são, majoritariamente, de natureza coercitiva, e o povo é visto muitas vezes como obstáculo para a proteção da natureza.

Ademais, a história brasileira, marcada pelo autoritarismo, sob uma estrutura desigual e excludente, também contribui para o afastamento da sociedade e natureza, afeta o exercício da cidadania e restringe a abertura de canais institucionais diretos e democráticos de decisão (LOUREIRO et. al., 2007). Assume-se uma relação clientelista entre sociedade e Estado que pouco contribui para que as experiências de gestão assumam uma radicalidade democrática, que amplia concretamente o potencial participativo (JACOBI, 2002).

Até a década de 1970, a participação era um instrumento para se conseguir a submissão voluntária do povo aos objetivos pré-estabelecidos das áreas protegidas ${ }^{2}$. Assim, não era mais que um exercício de relações públicas, no qual o povo era um ator passivo (RODARY \& MILIAN, 2011).

\footnotetext{
${ }^{1}$ Espaço territorial e seus recursos ambientais, incluindo as águas jurisdicionais, com características naturais relevantes, legalmente instituído pelo Poder Público, com objetivos de conservação e limites definidos, sob regime especial de administração, ao qual se aplicam garantias adequadas de proteção (Lei $\mathrm{n}^{\circ} 9.985 / 2000$, art. $2^{\circ}$, I). No cenário internacional, protected areas (áreas protegidas) é o termo equivalente.

2 Definida pela União internacional de Conservação da Natureza (UICN) como uma área com limites geográficos definidos e reconhecidos, cujo intuito, manejo e gestão buscam atingir a conservação da natureza, de seus serviços ecossistêmicos e valores culturais associados de forma duradoura, por meios legais ou efetivos. Embora tratado como sinônimo de unidades de conservação na literatura estrangeira, no Brasil representa um grupo maior, que contempla além das unidades de conservação, os territórios quilombolas, as terras indígenas (definido no PNAP) e áreas de preservação permanente (Lei 12.651 de 25/05/2012).
} 
Foi somente no final do século XX, que a participação da população local se tornou dominante na retórica conservacionista, como uma medida política - por meio da descentralização, e ao mesmo tempo econômica - a partir da redistribuição das receitas geradas pelos recursos naturais e mediante o emprego local (AUBERTIN et. al., 2011).

O envolvimento de organizações da sociedade civil representa um grande aliado na defesa do meio ambiente, com resultado e eficiência em geral, maiores que os obtidos por programas puramente governamentais (SOUZA, 2002). Se a sociedade não estiver envolvida com a gestão da unidade de conservação e percebê-la apenas como um meio de restrição ao uso da terra, sua percepção será negativa e dificilmente assumirá uma posição de proteção ambiental. No entanto, a falta de diálogo entre os órgãos ambientais e os atores sociais envolvidos na temática das unidades de conservação tem gerado uma mútua desconfiança em relação aos interesses defendidos por cada grupo, resultando em um afastamento entre os mesmos e dificultando a reversão do cenário centralizado de gestão ambiental dominante no País (FRANCA, 2006). Essa postura preventiva por parte da sociedade e governo propicia interferências no uso sustentável dos recursos naturais, em decorrência da dificuldade de comunicação e diálogo entre atores; insegurança e instabilidade, decorrentes da falta de comprometimento dos interessados na UC; aumento dos custos de execução da gestão, devido à falta de adesões voluntárias (SOUZA, 2012)

A conservação da biodiversidade in situ, a partir da criação de áreas protegidas (APs), tem sido a principal estratégia global para a conservação da biodiversidade (LEVERINGTON et. al., 2010; CHAPE et. al., 2005; DIEGUES, 2001; MEDEIROS, et. al., 2004; RODRIGUES et. al., 2004;) e dos modos de vida tradicionais no mundo. Com isso, aproximadamente $13 \%$ da superfície terrestre encontram-se classificados como APs (JENKINS \& JOPPA, 2009), que representam uma das principais formas de uso da terra em todo o mundo (RODARY \& MILIAN, 2011).

Os efeitos sobre a conservação da biodiversidade nas unidades de conservação são significativos, e traduzem-se em diversas realidades, dentre as quais se destaca a inibição do desmatamento (FERREIRA et. al., 2005; DRUMMOND et. al., 2006; LEMOS DE SÁ, 2008; FEARNSIDE, 2008). Entretanto, em algumas regiões como a Amazônica, essa relação tende a se enfraquecer em função dos baixos níveis de governança a que as UCs estão submetidas, podendo significar, em longo prazo, uma perda de até $40 \%$ da sua cobertura vegetal (SOARESFILHO et al., 2005). Estima-se, por exemplo, que a maioria das UCs estaduais de Rondônia, perdeu de 23 a $68 \%$ de sua cobertura florestal nos últimos anos (RIBEIRO et al. 2006). 
Houve um crescimento do sistema de unidade de conservação nas últimas décadas, nas quais quase $87 \%$ das UCs federais brasileiras foram criadas entre os anos 1980 e a década atual. Contudo, isso não se traduziu necessariamente em efetividade de gestão, nem tampouco em eficácia quanto aos objetivos de conservação de biodiversidade. Em 2010, embora tenham sido verificados importantes progressos na consolidação das UCs por meio de sua demarcação, proteção, elaboração e avanços na implementação dos seus instrumentos de gestão apenas $23 \%$ das unidades de conservação brasileiras encerravam altos índices de efetividade de gestão (ICMBIO \& WWF - Brasil, 2011).

Em nível global, os esforços de consolidação de unidades e conservação têm sido considerados insuficientes pela maioria das autoridades governamentais e pesquisadores. Os resultados da $10^{\mathrm{a}}$ conferência das Partes (COP 10) da Convenção sobre Diversidade Biológica ${ }^{3}$ (CDB) refletem essa percepção, em que a necessidade de expansão do sistema de áreas protegidas e, sobretudo, a sua implementação foram reconhecidos formalmente por 193 Países (COP, 2010). Diversos autores procuram identificar fatores que contribuem para deficiências na gestão de unidades de conservação (ARAÚJO, 2007; ARAÚJO et. al., 2009; ICMBIO \& WWF - Brasil, 2011; MACIEL, 2007; FARIA, 2003). Quais fatores são esses que os autores listam? Há certo consenso de que o modelo convencional de gestão - burocrático, valorizador de processos em detrimento dos objetivos de conservação, e, portanto, com pouco foco estratégico, gera uma lista com numerosas atividades consideradas fundamentais à implementação, cuja consecução nem sempre implica ganhos de efetividade. Dessa forma, sem uma estratégia de priorização, e com pequeno orçamento federal destinado à consolidação de UCs, os custos financeiros e humanos para implantação das UCs são insuficientes. Tomando como exemplo, para se consolidar $^{4}$ uma UC federal brasileira seria necessário um investimento médio de $\mathrm{R} \$ 3,3$ milhões, para unidades sem visitação e R \$ 5,5 milhões, para aquelas que admitem visitação. Com base nessa estimativa de custo e considerando-se o grau de implementação das UCs em 2009, a consolidação de todas as unidades de conservação federais representaria algo em torno de R \$ 665 milhões, excluídos os gastos com consolidação territorial, pessoal (funcionários públicos) e despesas correntes (MUANIS et. al.; 2009), em geral muito mais expressivos. Para se ter uma ideia da lacuna orçamentária para implementação do SNUC, somente os custos recorrentes anuais das unidades de conservação federais ultrapassavam a margem dos $\mathrm{R} \$ 500$

\footnotetext{
${ }^{3}$ A COP 10 da CDB foi realizada em 2010, na cidade Japonesa de Nagoya.

${ }^{4}$ Consideramos aqui como unidades de conservação consolidada aquela com, no mínimo, todos os seus instrumentos de gestão legalmente previstos implementados.
} 
milhões em 2009, ao passo que o Orçamento Federal destinado para as mesmas UCs um ano antes correspondeu a R\$ 316 milhões (MMA, 2009).

Um dos elementos trabalhados mais intensivamente por esse modelo de gestão é a participação social. Prevista ainda na Constituição Federal de 1988, a participação social é considerada um dos princípios da política ambiental brasileira, presente em grande parte dos instrumentos legais da Política Nacional de Meio Ambiente (Lei no 6.938, de 31 de agosto de 1981). É entendida como um meio de inclusão da diversidade sociocultural na gestão das UCs, uma forma de exercício da cidadania, de potencializar o desenvolvimento sustentável e de promover o controle social (BRASIL, 2000; 2002; 2006; MMA, 2004). No caso das unidades de conservação, a participação da sociedade nos processos de gestão territorial é considerada premissa fundamental para a conservação da biodiversidade (SOUZA, 2012).

No entanto, apesar da importância conferida nos últimos trinta anos à questão da governança em áreas protegidas, a avaliação do processo de gestão participativa em unidades de conservação no Brasil é ainda pouco desenvolvida, necessitando de uma adequada abordagem metodológica (ANDRADE et. al., 2007).

Os esforços financeiros e humanos com vista à promoção dessa participação, não têm sido, necessariamente, exitosos, pois, com frequência, ao invés de ampliar a representatividade social, tendem, apenas, a legitimar decisões unilaterais (GRAU, 1996). Muito menos se têm obtido indícios consistentes de que essa participação esteja contribuindo para a conservação da biodiversidade nas áreas onde ela é trabalhada.

Assim, até que ponto a participação social pode colaborar para o aumento da efetividade das unidades de conservação? Que medidas podemos usar para fundamentar a análise dessa relação, considerando que as ferramentas utilizadas para medir a efetividade de gestão de unidades de conservação pouco nos dizem sobre o estado de conservação dessas áreas e sendo o conceito de participação social tão complexo e multifacetado?

A hipótese deste trabalho é que uma maior aproximação da sociedade na gestão dos recursos naturais em unidades de conservação favorece o alcance dos objetivos de conservação dessas áreas.

Partindo-se desta suposição, este trabalho encontra-se apoiado no objetivo geral de analisar a influência que a participação social na gestão das unidades de conservacão brasileiras tem sobre a conservacão da biodiversidade.

Para tanto, este estudo procurou atender aos seguintes objetivos específicos:

i. $\quad$ Fornecer um panorama geral da participação social na gestão de UCs brasileiras; 
ii. Estabelecer um parâmetro de dimensionamento da participação social e de quantificação da biodiversidade;

iii. Verificar a inter-relação entre participação social na gestão de unidades de conservação federais brasileiras e a conservação da biodiversidade.

iv. Analisar que fatores explicam as variações na intensidade da participação social na gestão de unidades conservação;

A tese foi estruturada em sete capítulos, além desta introdução e conclusões gerais, conforme detalhado a seguir.

O capítulo 1 consistiu na explanação da origem e evolução histórica das unidades de conservação, dentro do contexto nacional e internacional. Também trouxe à tona a discussão sobre efetividade de unidades de conservação, efetividade de gestão e metodologias de mensuração, em especial o método RAPPAM. No capítulo 2 foram percorridos alguns caminhos conceituais referentes à participação social para, então, se aprofundar na sua origem no âmbito da gestão participativa de unidades de conservação. $\mathrm{O}$ capítulo 3 descreveu o delineamento conceitual adotado na Tese para os termos efetividade de unidades de conservação e participação social. Adicionalmente, pormenorizou a metodologia utilizada para caracterizar a participação social na gestão das áreas protegidas brasileiras e analisar sua influência na conservação da biodiversidade. Nele foram detalhados: i. o universo amostral da pesquisa; ii. as variáveis de participação social consideradas; iii. a construção metodológica (apoiada na estatística descritiva e análise subjetiva dos dados) para mensuração da participação social e estabelecimento de um gradiente de intensidade, comparável com a medida de conservação da biodiversidade; iv. o estabelecimento da medida de desmatamento como proxy de conservação da biodiversidade.

No capítulo 4 é apresentada a caracterização da área de estudo e a estratégia de conservação utilizada prioritariamente pelas UCs, de modo a contextualizar a área de estudo. O capítulo 5 descreveu o status da participação social em UCs, importante subsídio para análises diversas da participação social no âmbito da gestão de UCs.

No capítulo 6, foi proposta uma metodologia de dimensionamento da participação social com base em uma análise multivariada. O capítulo 7 apresentou duas distintas perspectivas à análise da participação social na gestão de UCs: i. participação social enquanto finalidade, meio de conquista democrática (seção 7.1) e ii. participação social enquanto processo - especificamente, para consecução dos objetivos de conservação da biodiversidade (seção 7.2). Na abordagem finalística é descrito o perfil geral da participação social nas UCs federais brasileiras, apoiando- 
se nos dados provenientes do RAPPAM e da aplicação de um formulário eletrônico, próprio desta pesquisa, direcionado à equipe gestora das UCs. Buscou-se também explorar alguns fatores potencialmente mais importantes para a promoção da participação social. Essa priorização fundamentou-se na análise de correspondência múltipla entre o fator de dimensionamento da participação social e as variáveis explicativas, ambos definidos no capítulo 3. Na seção 7.2, é realizada a análise, propriamente dita, da influência da participação social na gestão de UCs sobre a conservação da biodiversidade. Para tanto, foi utilizado como proxy de conservação da biodiversidade, os índices de desmatamento em UCs, obtidos do Programa de Cálculo do Desflorestamento da Amazônia (PRODES).

Por fim, são apresentadas as conclusões do estudo onde se atesta que a participação social na gestão das unidades de conservação brasileiras contribuiu para a redução do desmatamento em UCs de uso sustentável na Amazônia e, portanto, para a conservação da biodiversidade em escala nacional. Já nas unidades de conservação de proteção integral, esta relação não foi observada. 
CAPÍTULO 1. UNIDADES DE CONSERVAÇÃO: ORIGEM, INFLUÊNCIAS E INSTRUMENTOS LEGAIS.

As raízes históricas das áreas protegidas são antigas e responderam ao dinamismo das sociedades ao longo da história, modificando-se tanto pelo avanço do conhecimento referente à biologia da conservação, quanto em função da relação homem-natureza, construída e/ou desconstruída repetidas vezes.

A evolução histórica deste conceito, suas influências e aspectos legais são objeto do presente capítulo. Aqui são reunidos os principais momentos históricos e marcos legais como forma de contextualizar no tempo a discussão desenvolvida na próxima seção.

O termo áreas protegidas apresenta um sentido mais amplo no Brasil do que no cenário internacional, englobando outras categorias de áreas sob regime especial de uso, com vista a conservação da biodiversidade, além das unidades de conservação (territórios quilombolas, terras indígenas e áreas de preservação permanente). O foco desta pesquisa concentrou-se nas unidades de conservação propriamente ditas e, sempre que abordou a realidade brasileira, se resumiu a este grupo.

\section{1 AMBIENTALISMO INTERNACIONAL E ÁREAS PROTEGIDAS}

A degradação ambiental associada a atividades humanas data períodos muito remotos, tendo sido percebida em diferentes partes do mundo há milhares de anos. No entanto, as respostas às preocupações ambientais mais antigas, traduzidas em medidas de conservação, ocorriam no nível local, fundamentadas na utilização desses recursos naturais por uma parte privilegiada da população (MCCORMICK, 1992).

As primeiras diretrizes sobre conservação que se tem registro e que resultaram em limitações de formas de uso da terra foram promulgadas na Índia, no século IV (DAVENPORT \& RAO, 2002). No ocidente, iniciou-se na Europa durante a Idade Média, quando se determinou a proteção dos habitats que abrigavam recursos da fauna silvestre apreciados para caça pela realeza e aristocracia rural (MILANO, 2001).

Contudo, uma mudança mais ampla nas atitudes humanas começou somente após a Revolução Industrial, quando os sinais de deterioração tornaram-se evidentes para mais pessoas, e não apenas para uns poucos observadores perspicazes da condição da natureza (MCCORMICK, 1992; PÁDUA, 2002).

Essa consciência intelectual com as questões ambientais, em formação na sociedade em fins do século XVIII, foi se formando em tempos, lugares e em função de motivos diferentes. Não houve um acontecimento isolado que marcasse a origem do movimento ambientalista e que 
pudesse ser considerado reconhecidamente seu difusor seminal e exclusivo (MCCORMICK, 1992).

Há, no entanto, certo entendimento que o conceito áreas protegidas tenha sido proposto em torno de 1830, apenas, com o pintor e explorador norte-americano, George Catlin ${ }^{5}$, dentro de uma lógica de preservação da natureza em seu estado selvagem.

Concomitantemente, a Grã-Betanha avançou em direção a uma preocupação intelectual mais estruturada com as questões ambientais, onde, em meados do século XIX são identificados os primeiros grupos de protecionistas. A esse grupo são atribuídas as raízes do movimento de proteção à natureza.

Em 1865, é fundado o primeiro grupo ambientalista privado do mundo, o britânico Commons, Foot-paths, and Open Spaces Preservation Society que ganhou notoriedade por suas campanhas de sucesso pela preservação de áreas verdes, sobretudo em regiões urbanas. $\mathrm{Na}$ mesma época, a Grã-Betanha iniciou uma estratégia de administração de florestas como fonte direta de renda para o Estado, valendo-se dos conhecimentos da escola alemã, na qual foram introduzidos os conceitos de manejo produtivo e sustentado das florestas. Essa escola foi amplamente testada pelos Alemães e difundida pela Índia, que também recebeu fundações para conservação global (MCCORMICK, 1992).

Há paralelos entre o crescimento do interesse pelo ambiente natural na Europa Ocidental e na América do Norte, e a influência do romantismo nas duas regiões era comparável, assim como o interesse pela história natural. Contudo, o fato de que a Europa fora de há muito colonizada e explorada, enquanto que vastas áreas da América do Norte estavam sendo abertas para a colonização, fazia com que as florestas americanas fossem percebidas como simples obstáculos ao progresso - à semelhança do que havia acontecido na Austrália e África do Sul (MCCORMICK, 1992).

A beleza da natureza norte-americana inspirou autores românticos, filósofos e viajantes nas últimas décadas do século XVIII. Intensificaram-se as argumentações que condenavam a visão da natureza como máquina e o sentimento de superioridade humana em relação a ela (DIEGUES, 2001).

À medida que os naturalistas aprendiam mais sobre a natureza, passaram a reconhecer seu valor e a magnitude das ameaças decorrentes da atividade humana. Com maior conhecimento sobre

${ }^{5}$ George Catlin (1796-1872), pintor e explorador norte-americano descreveu o que deveria ser um Parque Nacional (Morsello, 2001). 
história natural e diante da grande degradação dos ambientes naturais, a natureza norteamericana se viu ameaçada ao longo do século XVIII (MCCORMICK, 1992).

Cientistas americanos e britânicos ora descreviam as belezas naturais, ora alertavam para a amplitude das mudanças ambientais em curso. Os escritos de Ralph Waldo Emerson ${ }^{6}$ e Henry David Thoreau ${ }^{7}$ tiveram grande influência na filosofia americana sobre o homem e a natureza, difusores do transcendentalismo, eram críticos do modernismo e reconheciam uma conexão orgânica entre o homem e a natureza. Thoreau percebia as áreas selvagens como um bem americano, um atributo da nova nação, que a fazia superior às áreas totalmente colonizadas da Europa (ARAÚJO, 2007). A independência da Inglaterra foi o principal motivador da disseminação desse sentimento em torno das florestas e ambientes naturais nos Estados Unidos da América (EUA). Os EUA buscavam ressaltar aspectos que os diferenciasse da antiga metrópole europeia e como não tinham um patrimônio cultural comparável ao da Europa, as paisagens naturais selvagens passaram a ser exaltadas, entendidas sua importância para a afirmação da identidade nacional norte-americana. Assim, as maravilhas naturais começaram a substituir, no imaginário do povo americano, as realizações humanas encontradas na Europa. Isso ajuda a explicar por que a ideia de parque nacional se consolidaria tão fortemente nos Estados Unidos no início do século XX (RUNTE, 2010).

Na virada do século XIX para XX, ecoavam dos EUA para o restante do mundo, duas correntes de pensamento distintas sobre a conservação de áreas protegidas, que acabaram por embasar diferentes estratégias de conservação: a corrente preservacionista e a conservacionista. A primeira defende uma proteção da natureza pela criação de áreas nas quais não é permitido nenhum uso humano. A restrição de acesso do homem à natureza considerada selvagem alicerçava-se na crença da impossibilidade de interação harmônica. Esta linha de pensamento esteve predominantemente inspirada em valores românticos, o qual valorizou uma relação imediata, pessoal e afetiva com a natureza (ARAÚJO, 2007). A abordagem romântica despertava o imaginário do paraíso perdido, próprios do Cristianismo, do refúgio de beleza e do sublime (DIEGUES, 2001). Um dos principais ícones do preservacionismo, John Muir ${ }^{8}$, acreditava que a natureza seria fruto da manifestação divina e que o contato com ambientes selvagens seria uma forma de libertação da humanidade (NASH, 2014).

\footnotetext{
${ }^{6}$ Ralph Waldo Emerson (1803-1882), escritor, filósofo e poeta estado-unidense.

7Henry David Thoreau (1817-1862), autor estadunidense, poeta, naturalista, ativista anti-impostos, crítico da ideia de desenvolvimento, pesquisador, historiador, filósofo e transcendentalista.

${ }^{8}$ John Muir (1838-1914), explorador e escritor escocês/norte-americano.
} 
Em contraposição, a corrente conservacionista, fundamentada na tradição de uma ciência florestal racional da variedade alemã, tem como valor fundamental a interação dos seres humanos com o meio natural, envolvendo o uso direto racional, democrático e eficiente da natureza (MCCORMICK, 1992; DIEGUES, 2001). Essa corrente teve como um dos principais mentores o engenheiro florestal Gifford Pinchot ${ }^{9}$ que fez forte oposição aos ideais 88acionistas defendidos por Muir ao defender o uso racional da natureza. Pinchot argumentava que o uso adequado dos recursos naturais deveria servir como instrumento para desenvolver uma democracia eficiente no acesso aos recursos naturais. Seu conservacionismo foi um dos primeiros movimentos teórico-práticos contra o desenvolvimento a qualquer custo (DIEGUES, 2001).

Em 1872, embalado pela rápida expansão urbano-industrial e pelos ideários da natureza intocada, foi criado, em terras norte-americanas, o Parque Nacional de Yellowstone. Apesar da grande repercussão mundial, a criação do primeiro Parque Nacional ocorreu sob fortes conflitos sociais que não alcançaram com vigor a grande mídia. Yellostone foi criado sob o território dos índios Crow, Blackfeet e Shoshone-Bannock e totalmente esvaziado de forma não espontânea, tendo sido proibida qualquer tipo de ocupação posterior, desconsiderando a identidade cultural daqueles povos (KEMF, 1993; DIEGUES, 2001; BENSUSAN, 2006).

$\mathrm{Na}$ sequência de Yellowstone e nos mesmos moldes, outros Países criaram seus primeiros Parques, a saber: Canadá - Parque Nacional de Banff, em 1885; Nova Zelândia - Parque Nacional de Tongariro, em 1894; África do Sul - Parque Nacional Kruger, em 1898 (também o primeiro do mundo a tornar-se patrimônio da humanidade) e Austrália - Parque Nacional Promontorio Wilsons, em 1898.

Décadas depois de Yellowstone, em 1983, é criada a National Trust com objetivo de proteger a herança natural e cultural da nação contra os efeitos do desenvolvimento industrial. A ONG britânica adquiria terras com significado cultural e histórico para preservação, dando origem à criação de pequenos parques locais. A iniciativa era, no entanto, criticada por não abranger áreas com valor natural (MCCORMICK, 1992).

Ao final do século XIX, a crença otimista numa prosperidade sem limites foi minada pela depressão econômica da década de 1880 que sublinhava a crença crescente de que a indústria não seria necessariamente a grande provedora de poder econômico e político. Ao contrário, a industrialização era retratada agora como destruidora da moral e da ordem social, da saúde humana, dos valores tradicionais, do meio ambiente físico e da beleza natural. Nesse momento

${ }^{9}$ Gifford Pinchot (1865-1946), engenheiro florestal e político norte-americano. 
histórico, embora tenham sido fundadas algumas organizações internacionais na Europa e na América do Norte, elas não foram bem sucedidas em função da eclosão da Primeira Guerra Mundial (MCCORMICK, 1992).

As questões ambientais tiveram uma menor atenção política no início do século $\mathrm{XX}$. $\mathrm{Na}$ Inglaterra, apesar de alguns esforços empreendidos, como a criação do Council for the Preservation (e, mais tarde, Protection) of Rural England (CPRE) em 1926, os parques nacionais foram criados somente após a Segunda Guerra Mundial.

A tensão política na Europa, entre 1930-1940, prejudicou ainda mais os debates conceituais sobre a proteção da natureza. Ainda assim, foram realizadas duas importantes conferências. A primeira consistiu na I Conferência Internacional para a Proteção da Fauna e Flora (1933Inglaterra), onde foi ratificada a Convenção sobre a Preservação da Fauna e Flora Natural um dos instrumentos jurídicos precursores das concepções atuais relativas ao meio ambiente (CYSNE \& AMADOR, 2000). Nele, pela primeira vez, foi apresentado um conceito universal de áreas protegidas e foi onde se reconheceu que estas deveriam ser controladas pelo Poder Público. A outra, realizada em Washington - 1940, foi a Conferência para a Proteção da Flora, Fauna e das Belezas Cênicas Naturais dos Países da América, na qual se estabeleceu que os Países deveriam adotar ações apropriadas para evitar a extinção de espécies, além de tomar medidas para regulamentação das importações, exportações e trânsito de espécies protegidas da flora e da fauna.

As necessidades específicas dos Países considerados pobres no cenário internacional do pós-guerra induziram a uma integração das políticas de áreas protegidas com aquelas de promoção do desenvolvimento (FRANCO et. al., 2015).

Em 1948, com objetivo de facilitar a cooperação entre governos e organizações nacionais e internacionais preocupadas com a proteção da natureza, é fundada a organização não governamental União Internacional para Conservação da Natureza e dos Recursos Naturais ${ }^{10}$ - UICN. Dentre as principais tarefas da UICN estavam a promoção da preservação da vida selvagem e do ambiente natural; divulgação, educação, pesquisa científica e legislação ambiental. Também deveriam ser iniciados trabalhos para a preparação de uma convenção global para a proteção da natureza. Considerada ainda hoje uma das principais organizações ambientais do mundo, modificou sua abordagem influenciada pela evolução do pensamento ambiental. Atualmente, a UICN tem sede na Suíça e reúne 84 governos nacionais, 112 agências de governo, 735 ONGs e milhares de especialistas e cientistas de 181 Países (CHRISTOFFERSEN, 1997).

\footnotetext{
${ }^{10}$ Antiga International Union for the Protection of Nature - IUPN.
} 
Entre as décadas de 1940-1950, outra percepção da natureza fundamentada em novas descobertas das ciências naturais, em especial da ecologia, influenciou as estratégias de proteção da natureza. A partir da noção de equilíbrio natural dos ecossistemas e das discussões de ecologia evolutiva surge a chamada Ética Evolutiva-ecológica da Terra. Da nova perspectiva emergiu uma nova moralidade acerca da relação do homem com a natureza, na qual ele deixou de desempenhar o papel de conquistador para ser parte de uma ampla comunidade da vida. Essa concepção mais sistêmica do ambiente natural e das inter-relações entre sociedade e natureza refletiu na ampliação do foco de atuação da UICN para contemplar as inter-relações entre atividades humanas e o ambiente natural (FRANCO et. al., 2015).

A dimensão humana passou a ser objeto de maiores considerações nas ações de proteção à natureza e o seu foco nas espécies ameaçadas deu lugar a uma abordagem mais ecossistêmica (FRANCO et. al., 2015).

Na década de 1960, a IUCN concluiu haver pouca conexão e grande isolamento entre os parques nacionais de diferentes Países, os quais respondiam unicamente a necessidades locais. Visando alcançar uma maior coordenação na criação e na gestão de parques, a UICN convocou, em 1962, o Primeiro Congresso Mundial de Parques Nacionais, realizado em Seattle (EUA). O Congresso de Seattle destacou a importância da conservação como parte dos programas de desenvolvimento, além de enfocar a necessidade de que os órgãos de auxílio ao desenvolvimento, como Banco Mundial e Banco Interamericano de Desenvolvimento, incorporassem considerações ambientais em suas ações de planejamento (FRANCO et. al., 2015).

Os anos seguintes foram de intensa movimentação para a área ambiental. A revolução ambiental propriamente dita, embora iniciada no pós-guerra (1945), assumiu maior expressão na década de 1960, fortemente influenciada pelo livro Primavera Silenciosa (1962), de Rachel Carson (MCCORMICK, 1992). Embora o livro trate em primeiro plano dos efeitos danosos do DDT à saúde animal, ele questiona de forma eloquente a confiança cega da humanidade no progresso tecnológico, ajudando a abrir espaço para o movimento ambientalista que se seguiu.

Em abril de 1970, cerca de trezentos mil americanos participaram do Dia da Terra, a maior manifestação ambientalista da história. A imprensa proclamou o advento do ambientalismo como uma questão pública fundamental dos anos 1970. Iniciou-se a preparação de uma das maiores conferências das Nações Unidas jamais realizada, a qual reuniu representantes de 113 nações em Estocolmo, para discutir os problemas do meio ambiente global (MCCORMICK, 1992).

A Conferência das Nações Unidas sobre Meio Ambiente Humana (Conferência de Estocolmo) consagrou a interdependência entre conservação e desenvolvimento. Realizada na capital da 
Suécia, em 1972, objetivou avaliar os problemas do meio ambiente global e sugerir ações corretivas, do ponto de vista científico, social, político e econômico (MCCORMICK, 1992; FRANCO et. al., 2015).

Ainda em 1972, foi realizado o Segundo Congresso Mundial de Parques Nacionais, em Yellowstone - EUA, no qual a UICN destacou a necessidade de um sistema de classificação internacional para as áreas protegidas. O trabalho foi liderado por Kenton Miller ${ }^{11}$ e sua versão final publicada em 1978 (ARAÚJO, 2007).

A Partir de da década de 1970, ao associar de modo cada vez mais frequente o conceito de proteção à natureza com a ideia de conservação do ambiente humano e com o pleno desenvolvimento, as possibilidades de impactos sociais das áreas protegidas ganharam maior visibilidade (FRANCO et. al., 2015). Nesse período, vários eventos internacionais ajudaram a consolidar a ideia conservacionista no mundo e a modificar a visão a respeito das áreas protegidas, além da Conferência das Nações Unidas sobre Meio Ambiente Humano: a Conferência da Biosfera, em 1968; a Convenção sobre Zonas Úmidas de Importância Internacional (Convenção Ramsar), em 1971 e a Convenção para Proteção do Patrimônio Mundial, Cultural e Natural, em 1972 (ARAÚJO, 2007).

A década de 1980 trouxe novos avanços nos conhecimentos biológicos básicos sobre os processos ecológicos que, por sua vez, influenciaram as visões de natureza e as estratégias para sua preservação e conservação. Ao final dessa década, o conceito de biodiversidade ganhou notoriedade e teve o seu uso difundido, para tratar da diversidade biológica em escala genética, de espécies e de ecossistemas (FRANCO et. al., 2015). O aumento do conhecimento acerca dos padrões de distribuição e das ameaças à biodiversidade favoreceu o surgimento da Biologia da Conservação, como contraponto tanto ao preservacionismo quanto ao utilitarismo. Com a biologia da conservação foram gerados conceitos e modelos que procuram orientar o planejamento, a criação e a gestão de áreas protegidas, bem como o manejo de espécies e ecossistemas, visando maximizar os resultados da conservação da biodiversidade (FRANCO, 2013; FRANCO et. al., 2015).

Em 1982 é realizado em Bali o III Congresso Mundial de Parques Nacionais da UICN. O evento foi marcado principalmente pela abertura para discussão de questões sociais, econômicas e culturais das nações menos favorecidas (SOUZA, 2013), além de representar um marco na evolução no conceito de parque nacional no tocante a sua integração com o desenvolvimento socioeconômico (ARAÚJO, 2007). Consolidou-se a ideia de que sem a

${ }^{11}$ Kenton Miller (1939) cientista norte-americano, conservacionista, foi diretor e presidente da UICN, contribuindo para criação de sistemas nacionais de unidades de conservação. 
redução do consumismo nos Países industrializados e elevação da qualidade de vida nos Países em desenvolvimento, a população se veria forçada a superexplorar os recursos naturais. A degradação de muitos parques nacionais no Terceiro Mundo era tida como resultado da pobreza crescente das populações locais, o que levou o Congresso de Bali a reafirmar os direitos das sociedades tradicionais e a recomendar que as ações de gestão e manejo dessas áreas ocorressem com a participação das comunidades locais (DIEGUES, 2001).

A escolha do local do congresso por si só representa nesse sentido, uma quebra de paradigma no mundo da conservação ambiental. A indicação de Bali intencionou contemplar um País com poucos parques, a fim de elaborar esforços para ampliar o debate e fortalecer as áreas mais necessitadas de assistência. A base das sessões técnicas concentrou-se nos temas justificativa econômica para as áreas protegidas, demandas das populações locais e da sociedade civil e em propostas de maior abertura do conceito dos parques nacionais (SOUZA, 2013).

Em suma, na década de 1980, acentuou-se uma mudança na perspectiva das relações entre seres humanos e natureza e, consequentemente, sobre as estratégias de criação e manejo de áreas protegidas (FRANCO et.al., 2015).

No IV Congresso Mundial de Parques da IUCN, realizado em Caracas, em 1992, se consolidou o uso do termo áreas protegidas. O foco esteve centrado na necessidade de se incluir outros setores da sociedade nas discussões ambientais, como representantes de ONGs, populações indígenas e proprietários privados. Outros temas até então menos abordados nas outras conferências como as mudanças climáticas e a poluição também foram contemplados. Foram pactuadas seis categorias básicas de áreas protegidas, válidas ainda hoje: Reserva Natural Estrita, Área Silvestre, Parque Nacional, Monumento Natural, Área de manejo de habitats/espécies, Paisagem terrestre/marítima protegida e Área protegida de Recursos Manejados. No Congresso foram ratificados os direitos dos povos indígenas sobre as suas terras, sempre que houvesse sobreposição com áreas protegidas e também convocados os Países a estabelecerem Planos de Ação para a criação e gestão das áreas protegidas. Esses Planos foram levados para discussão à Conferência das Nações Unidas para o Meio Ambiente e o Desenvolvimento (Eco 92) realizada no Rio de Janeiro, em 1992 (FRANCO et. al., 2015).

Na Eco 92 foi estabelecida a Convenção sobre Diversidade Biológica (CDB), um tratado da Organização das Nações Unidas e um dos mais importantes instrumentos orientadores das principais políticas internacionais de conservação da biodiversidade. A Conferência das Partes (COP) é o órgão diretivo da CDB, composto por todos os governos e organizações regionais de integração económica que ratificaram o tratado. A COP se reúne a cada dois anos, ou em 
intervalo menor, caso haja necessidade) para avaliar o progresso na implementação da CDB e fornecer orientações políticas vinculadas à implementação da CDB. A última reunião da COP foi a de número 12 e ocorreu em 2014, na Coréia do Sul.A CDB está estruturada sobre três bases principais - a conservação da diversidade biológica, o uso sustentável da biodiversidade e a repartição justa e equitativa dos benefícios provenientes da utilização dos recursos genéticos - e se refere à biodiversidade em três níveis: ecossistemas, espécies e recursos genéticos.

Em 1997 a UICN realizou a conferência As áreas protegidas no século XXI onde a aproximação das comunidades locais na gestão das áreas protegidas foi identificada como um dos maiores desafios a serem enfrentados (ARAÚJO, 2007).

Em 1998 é celebrada a Aliança Florestal, um acordo de cooperação entre Banco Mundial e WWF para conservação e uso sustentável das florestas, que apoiou a criação e consolidação de áreas protegidas.

O V Congresso Mundial de Parques da IUCN, realizado em Durban, África do Sul, em 2003, no qual foi publicado o acordo de mesmo nome. Entre outras questões, o documento fundamenta o compromisso da conservação da biodiversidade em dois pilares: as áreas protegidas e as populações humanas. O Congresso sedimentou de forma definitiva o caminho para o desenvolvimento da gestão participativa das áreas protegidas, fornecendo ainda as bases para o programa de trabalho sobre áreas protegidas, adotado em 2004 pela Convenção sobre Diversidade Biológica, (BENSUSAN, 2006; ARAÚJO, 2007).

Em 2010, foi realizada a 10 ${ }^{a}$ Conferência das Partes (COP 10) da Convenção sobre Diversidade Biológica (CDB), em Nagoya, no Japão, onde foram estabelecidas 20 metas globais de conservação da biodiversidade (conhecidas como Metas de Aichi) que deveriam ser perseguidas na próxima década (2010 - 2020) e que são a base para a construção das metas nacionais de cada País signatário. A meta 11 aborda especificamente as áreas protegidas e determina que até 2020 deverão ser protegidos pelo menos $17 \%$ de áreas terrestres e de águas continentais e $10 \%$ de áreas marinhas e costeiras, por meio de sistemas nacionais de áreas protegidas (UICN et. al, 2012). Define ainda que não é suficiente a criação de tais áreas, elas devem ser geridas de maneira efetiva e equitativa, ser ecologicamente representativas $e$ satisfatoriamente interligadas e por outras medidas espaciais de conservação, e integradas em paisagens terrestres e marinhas mais amplas. Com o objetivo de estabelecer ações concretas para deter a crescente perda de biodiversidade do planeta, foi instituído o Plano Estratégico de Biodiversidade para o período de 2011 a 2020. Ao ratificarem as metas de Aichi, os Países signatários da CDB se comprometeram a elaborar seus próprios planos de ação para implementação do Plano Estratégico Nacional de Biodiversidade. 
Em novembro de 2014, a UICN realizou, em Sydney, Austrália, o VI Congresso Mundial de Parques Nacionais. Os principais resultados do Congresso foram sintetizados em um documento chamado The Promise of Sidney que define uma agenda com recomendações de diversos atores (ONGs, lideranças comunitárias e indígenas, setor privado, academia e governos) para que o desenvolvimento humano possa acontecer cada vez mais em harmonia com a conservação da natureza e dos modos de vida tradicionais. O objetivo de conciliar desenvolvimento, conservação da biodiversidade e promoção da qualidade de vida e da cultura de sociedades indígenas e tradicionais permaneceu como foco principal (FRANCO et. al., 2015).

\subsection{EVOLUÇÃO HISTÓRICA DAS UNIDADES DE CONSERVAÇÃO BRASILEIRAS}

A consciência crítica brasileira diante da destruição ambiental tem sido considerada uma questão recente, importada do modelo preservacionista norte-americano. No entanto, ainda no século XVIII, antes, portanto, do acalorado debate entre preservacionistas e conservacionistas, Pádua (2002) encontrou registros de importantes reflexões sobre a destruição do meio ambiente por um pequeno grupo de pensadores brasileiros.

Esse grupo de intelectuais nascidos no País era formado por acadêmicos da elite social do Brasil, que estudaram em Portugal - já que não havia universidades brasileiras - e que absorveram as concepções de filosofia natural e também o espírito pragmático e progressista do iluminismo europeu. Nas palavras de Pádua (2002, página 14): “foi do interior de uma elite intelectual, constituindo uma minoria dentro da minoria, que emergiram os fundadores da crítica ambiental brasileira".

Os precursores da crítica ambiental brasileira apresentaram certa unidade intelectual em relação a questão ambiental, ainda que divergissem em pontos políticos de grande relevância como a defesa ou não da escravatura. José Bonifácio ${ }^{12}$, o mais ilustre acadêmico dessa elite, chegou a estabelecer um nexo causal entre a produção escravista e a destruição do meio ambiente, em um de seus estudos, no qual defendia que enquanto vigorasse a escravidão não seria possível estabelecer uma relação saudável entre humanos e a terra no Brasil.

A matriz ambiental predominante não teve tanta influência do romantismo, como na tradição norte-americana ou observou-se grandes cisões de pensamento, que configurassem distintas correntes como em outras partes do mundo (PÁDUA, 2002). A identidade brasileira original assumiu um viés predominantemente desenvolvimentista, na qual a natureza era vista como um objetivo político, um recurso essencial para o avanço social e econômico do País (SCHITTINI,

\footnotetext{
12 José Bonifácio (1763-1838), naturalista, estadista e poeta brasileiro.
} 
2009; FRANCO \& DRUMMOND, 2012). Em outras palavras, a natureza representava um valor político instrumental para o progresso nacional (PADUA, 2002).

Apesar do viés utilitarista e da inserção política relativamente forte do grupo de pensadores, houve apenas avanços pontuais decorrentes dos primeiros esforços de proteção da natureza (FRANCO \& DRUMMOND, 2012).

A partir da segunda metade do século XIX, no entanto, a criação de áreas protegidas se consolidou como a estratégia de proteção da natureza mais disseminada no Brasil, seguindo a tendência global (DRUMMOND et. al., 2010).

André Rebouças ${ }^{13}$ propôs em 1876 a criação de alguns Parques Nacionais, fundamentado no progresso que o turismo poderia promover nos seus locais de implantação (BENSUSAN, 2006; PÁDUA, 2002).

Importantes instituições de pesquisa foram criadas nos dois principais centros urbanos tornando-se importantes fontes geradoras de conhecimento sobre a natureza brasileira: Jardim Botânico e Museu Nacional, no Rio de Janeiro e Museu Paulista e Instituto Serum therápico (atual Instituto Butantan).

Em 1896 foi instituída na Serra do Mar a Estação Biológica do Alto da Serra. Criada com recursos privados de Herman von Ihering ${ }^{14}$, a essa Estação Ecológica foi doada em 1909 ao Museu Paulista. Ihering considerado um estudioso visionário, antecipou muitos instrumentos legais adotados décadas depois. Propôs em 1911, por exemplo, um documento muito próximo de um anteprojeto do código florestal, desenvolvido pelo Brasil duas décadas depois (FRANCO \& DRUMMOND, 2009; FRANCO \& DRUMMOND, 2012). Em 1913 é criada a Estação Biológica de Itatiaia, situada na cidade de Itatiaia, onde foi criado o Parque Nacional de Itatiaia em 1937.

$\mathrm{O}$ século $\mathrm{XX}$ trouxe consigo mudanças ambientais profundas e globais que abalaram a percepção da relação seres humanos-natureza. O cenário internacional reagiu a essas transformações, inserindo de forma crescente a temática ambiental na sua agenda política, articulada nas convenções e conferências, consideradas por Ribeiro (2010) como a maior expressão do movimento de regulação da ação humana na Terra.

A tendência internacional influenciava cada vez mais a política ambiental brasileira de tal modo que contribuiu com o rompimento do imobilismo governamental frente a questão ambiental que vigorou em um período de quase meio século desde a instituição da República. Em apenas três

\footnotetext{
${ }^{13}$ André Rebouças (1838-1898), engenheiro, inventor e abolicionista brasileiro.

14 Herman von Ihering (1850-1930), pesquisador alemão, também fundador e diretor do Museu Paulista, especialista em zoologia e botânica.
} 
anos - de 1934 a 1937, foi estabelecida grande parte dos instrumentos legais que daria o suporte necessário para a criação de áreas protegidas no Brasil: Código de Caça e Pesca (Decreto $\mathrm{n}^{\mathrm{o}}$ 23.672 de 02/01/1934) Código Florestal (Decreto $n^{\circ} 23.793$ de 23/01/1934) e o Decreto de $n^{\circ}$ 24.645 de 10/07/1934, de proteção aos animais (MEDEIROS, 2006).

O Governo de Getúlio Vargas ${ }^{15}$ deu início a um processo mais amplo de defesa das riquezas nacionais, quando o Estado intervencionista, reconhecido como principal agente político, estava seguro de que seria a lei o mais potente orientador das condutas humanas (FRANCO, 2002; PETERS, 2003). Diversas estratégias políticas foram adotadas com o intuito de colocar o Brasil rumo à modernidade: novas leis trabalhistas, incentivos à industrialização e a expansão e ocupação do oeste brasileiro ditaram o ritmo das mudanças (MEDEIROS et. al., 2004).

No Brasil, a competência de proteção da natureza, mais especificamente das belezas naturais, foi atribuída ao Poder Público um ano após a Convenção sobre a Preservação da Fauna e Flora Natural ser ratificada. Por intermédio da promulgação da Constituição de 1934, essa passou a fazer parte do arcabouço legal brasileiro. Ainda em 1934, o Brasil aprovou o código das águas (Decreto 24.643 de 10/07/1934) e seu primeiro código florestal (Decreto 23.793 23/01/1934) no qual as florestas são declaradas como áreas de uso comum, mas sujeitas a limitações de uso “As florestas existentes no território nacional, consideradas em conjunto, constituem bem de interesse comum a todos os habitantes, do País, exercendo-se os direitos de propriedade com as limitações que as leis em geral, e especialmente este código, estabelecem". O código florestal além de regular a exploração madeireira, tratou de forma um pouco mais abrangente os recursos florestais, definindo categorias de proteção de florestas e outras formas de vegetação de acordo com a finalidade. Nele, foram estabelecidas quatro tipologias classificadas de acordo com a função desempenhada pela floresta em questão: Floresta Protetora - antecedente das áreas de preservação permanente; Floresta Remanescente; Floresta de Rendimento e Floresta Modelo - manejadas e/ou plantadas para fins comerciais, prenúncio das florestas nacionais (DRUMMOND et.al. 2010). A tradição brasileira de criação de espaços protegidos por categorias, em função dos objetivos e finalidades da área criada, foi uma de suas heranças mais importantes do Código Florestal de 1934.

O modelo de áreas protegidas brasileiro já se expressava nesse primeiro código, abarcando tanto a concepção norte-americana de criação de espaços protegidos, com objetivos estritos de preservação, como também aqueles vinculados à sua conservação, na linha do uso sustentável (MEDEIROS et. al., 2004).

\footnotetext{
${ }^{15}$ Getúlio Vargas (1882-1954), ex-presidente do Brasil em dois períodos: de 1930 até 1945 e entre 1951 e 1954.
} 
À estratégia regulatória assumida pelo Estado brasileiro dentro de um novo projeto político que almejava maior inserção internacional e maior modernização de suas políticas, e à tendência das políticas ambientais globais, somou-se uma maior influência e pressão dos movimentos organizados voltados à proteção da natureza. Ademais, conforme retratado por Franco e Drummond (2009), o caráter cientificista e nacionalista atribuído à proteção da natureza acabava por facilitar a circulação e efetivação de algumas das propostas de grupos sociais organizados em torno de preocupações com a proteção da natureza no ambiente político do regime autoritário de Getúlio Vargas. Para os autores, o relativo sucesso desses atores sociais engajados na proteção da natureza no contexto político-intelectual da época é decorrência da relação estabelecida entre proteção da natureza e identidade nacional. Êxito, no entanto, pontual, em função do papel secundário da natureza em um Estado hegemonicamente desenvolvimentista.

As ideias de Alberto Torres ${ }^{16}$ tiveram um papel fundamental na constituição do ambiente político-intelectual da época, influenciando fortemente o grupo identificado com a proteção da natureza. Torres, o primeiro brasileiro a usar o termo conservação, defendia que o progresso do industrialismo vinha acelerando a exaustão dos recursos naturais finitos do planeta e que os recursos proporcionados pelo progresso social e tecnológico não haviam sido capazes de compensar os estragos resultantes do conflito entre seres humanos e a natureza (FRANCO \& DRUMMOND, 2009).

Todo esse ambiente favoreceu a criação dos primeiros parques nacionais: o Parque Nacional de Itatiaia (incorporando a Estação Biológica de Itatiaia), o Parque Nacional do Iguaçu, em 1937, e o Parque Nacional da Serra dos Órgãos, em 1939.

Em 1940, a Conferência para a Proteção da Flora, da Fauna e das Belezas Cênicas Naturais dos Países da América, a "Convenção de Washington" ou Convenção Pan-americana, propuseram algumas tipologias de áreas protegidas: Reserva Nacional, Monumento Natural e Reserva de Região Virgem.

Em 1958, é criada a Fundação Brasileira para a Conservação da Natureza (FBCN), principal organização da sociedade civil brasileira dedicada à preservação e conservação da natureza até a década de 1990. A FBCN assumiu um discurso mais pendente para uma estratégia preservacionista, baseada na criação e manejo de unidades de conservação. Todavia, isto não significou um abandono das estratégias e do esforço para a conservação dos recursos naturais.

${ }^{16}$ Alberto Torres (1865-1917), jurista, jornalista e pensador político. 
Franco et. al. (2015) consideram que os cientistas, técnicos e ativistas da FBCN podem ser considerados preservacionistas-conservacionistas, bastante tocados, também, por concepções mais recentes como o ecocentrismo de Aldo Leopold e os conceitos e percepções desenvolvidos pela Biologia da Conservação. A instituição assumia uma posição mais de colaboração do que confrontação com o Estado, favorecendo a interação entre cientistas, técnicos e Governo. Dessa parceira resultaram as principais formulações de políticas ambientais do período, geralmente ligadas à administração de parques e reservas e a pesquisas de biodiversidade (FRANCO et. al., 2015).

Ao longo de toda a década, vão surgindo novas tipologias de APs. Na $1^{\mathrm{a}}$ Conferência Mundial sobre Parques Nacionais, realizada em 1962, nos EUA, são propostas mais tipologias de APs, inspirando a adoção brasileira aos conceitos de Parque Nacional, Reserva Biológica, Floresta Nacional e Parque de Caça (MILANO, 2001), previstos no Código Florestal de 1965 e na Lei de Proteção à Fauna (Lei no 5.197 de 03/01/1967). Outras categorias de manejo, que não encontravam equivalência em outros Países, foram criadas em função da grande heterogeneidade espacial, ecológica e cultural do País (MEDEIROS et. al., 2004).

As décadas que seguiram à criação dos primeiros parques brasileiros até a instalação do regime militar no Brasil (1964-1985) foram caracterizadas pela construção de um arcabouço legal capaz de favorecer um regime diferenciado de proteção e gestão de parcelas do território nacional. No entanto, a criação de unidades de conservação não seguiu o mesmo ritmo, tendo se mantido insipiente até o período da ditadura militar. A criação de parques e florestas nacionais, por exemplo, tiveram uma pausa na sua criação de 20 e 15 anos, respectivamente, durante esse período (MEDEIROS, 2006).

Até a década de 1960, a criação de áreas protegidas não obedecia nenhum planejamento mais abrangente, sendo estabelecidas principalmente por razões estéticas ou devido a circunstâncias políticas favoráveis, acompanhando a tendência mundial (MERCADANTE, 2001).

A ditadura militar estabeleceu profundas mudanças no sistema político brasileiro. No campo ambiental, a criação de parques compôs o instrumental estratégico utilizado pelo Estado nas ações de expansão, integração e controle do território nacional (MEDEIROS et. al., 2004), assumindo assim, forte conotação geopolítica. O lema era ocupar para não ser conquistado. Ao mesmo tempo, em função do grande endividamento externo brasileiro, o Brasil estava cada vez mais dependente de entidades multilaterais, como o Banco Mundial e o Banco Interamericano de Desenvolvimento (BID). Aliado a isso, tais entidades passaram a incluir cláusulas de conservação ambiental nos contratos de grandes projetos (criação de unidades de 
conservação, áreas indígenas), cobrando o seu cumprimento, sobretudo na Amazônia. Como consequência, esse foi um dos períodos em que mais unidades de conservação foram criadas no Brasil. No entanto, como esperado em um regime autoritário, havia pouca mobilização social para a criação dessas áreas, sendo o processo dependente da ação de cientistas ou conservacionistas que tinham algum acesso ao governo militar (DIEGUES, 2001).

Em 1965, já sob o efeito do regime militar, foi criado o novo código florestal (Lei n 4.771 de 15/09/1965) que, com objetivos semelhantes ao primeiro código, trouxe uma atualização nas categorias de áreas protegidas previstas. Assim, extinguiu as tipologias criadas em 1934 e as substitui por quatro outras: Parque Nacional e Floresta Nacional (anteriormente categorias específicas), as Áreas de Preservação Permanente (APP) e a Reserva Legal (RL). Claramente, essas duas últimas tiveram origem na intenção de se conter os avanços sobre a floresta (MEDEIROS, 2006). O novo código refletia as duas estratégias de proteção da natureza, separando as áreas protegidas ${ }^{17}$ em dois grupos, de acordo com seu tipo de uso: uso indireto (parques e reservas biológicas) - de cunho preservacionista; e as de outro de uso direto (florestas, reservas florestais e parques de caça), que permitiam a exploração direta dos recursos naturais, tal como a lógica conservacionista.

O forte esforço de mobilização global para a implantação de uma agenda ambiental pode ser verificado pelo aumento considerável dos fóruns de discussão durante o regime militar: Conferência da Biosfera (1968); 10 ${ }^{\mathrm{a}}$ Assembleia Geral da União Internacional para a Conservação da Natureza - UICN (1969 - Índia); II Conferência Mundial sobre Parques Nacionais (1972 -Yellowstone) e a Conferência de Estocolmo (1972 - Suécia), na Suécia. Esse cenário impulsionou ainda mais a temática ambiental no País e a tradução dos ideais e instrumentos das políticas ambientais globais para a realidade nacional.

Em 1967, a Lei de Proteção aos Animais (Lei no 5.197, de 03/01/1967) é revista ressaltando a necessidade de proteção de espécies animais em seus ambientes nativos e regulamentando a criação de espaços destinados à sua preservação (as reservas biológicas) e de outros específicos ao exercício da caça (parques de caça). No mesmo ano, é criado o Instituto Brasileiro de Desenvolvimento Florestal - IBDF (Decreto-lei no 289, de 28/02/1967), autarquia federal vinculada ao Ministério da Agricultura, instituído pelo Decreto-Lei Federal $\mathrm{n}^{\circ} 289$ de 28/02/1967 cujas competências primordiais eram formular a política florestal, gerir as áreas

\footnotetext{
17 Termo empregado aqui para designar as unidades de conservação criadas até então, uma vez que a terminologia "unidades de conservação" só passou a ser adotada a partir do ano de 2000.
} 
protegidas do País e fazer com que se cumprissem os diversos instrumentos legais criados que as regulamentavam.

Apesar de assumir crescente importância na agenda política brasileira, as preocupações ambientais durante a ditadura militar, mais especificamente, durante o sonho do milagre econômico $^{18}$, eram facilmente relegadas a título do tão buscado desenvolvimento.

Ao mesmo tempo, o receio por parte dos Países subdesenvolvidos, dentre eles o Brasil, de que ações de proteção à natureza propostas pelos Países industrializados viessem a restringir as possibilidades de desenvolvimento, obrigou os participantes da conferência a adotarem uma solução de compromisso, ligando a conservação da natureza ao desenvolvimento humano (FRANCO et. al., 2015).

Em decorrência dos debates na Conferência de Estocolmo e no Clube de Roma ${ }^{19}$ (MEDEIROS, 2006) foi criada em 1973 a Secretaria Especial do Meio Ambiente (SEMA), vinculada ao Ministério do Interior, com objetivo de monitorar e controlar a poluição (Decreto $\mathrm{n}^{\circ} 73.030 \mathrm{de}$ 30/10/1973). Dean (1996), ao ressaltar o extremo desprezo com que as preocupações ambientais eram recebidas pelo governo militar e seus auxiliares, justificou a criação da SEMA como um ato político de fachada, executado de modo a acalmar as críticas estrangeiras.

A SEMA dividiu com o IBDF a responsabilidade pela gestão e fiscalização da política brasileira para as áreas protegidas. A sobreposição de atribuições e a falta de articulação entre a SEMA e o IBDF, somadas ao crescimento em número das áreas protegidas estaduais e municipais, sem que houvesse uma orientação legal mais abrangente, contribuiu sobremaneira para que as tipologias mais variadas de UCs fossem criadas posteriormente com a instituição do Sistema Nacional de Unidades de Conservação da Natureza em 2000.

Somente no final dos anos 1970, sob a influência de organizações ambientalistas internacionais, começou a ser cogitada a criação de um sistema nacional de unidades de conservação articulado (SANTILLI, 2005). Em 1979 e 1982, o IBDF e a Fundação Brasileira para a Conservação da Natureza $(\mathrm{FBCN})$ apresentaram estudos $(\mathrm{IBDF} / \mathrm{FBCN}, 1982)$ os quais identificavam as áreas mais importantes para a conservação da natureza no País, propondo a criação de um conjunto integrado de áreas protegidas e onde pela primeira vez se utilizava formalmente a terminologia

\footnotetext{
${ }^{18}$ Nome dado à época de excepcional crescimento econômico brasileiro, entre 1968 e 1973.

${ }^{19}$ Entidade criada em 1968, formada por intelectuais e empresários de diversas nacionalidades, com o objetivo de analisar e propor medidas alternativas para se enfrentar crises decorrentes da escassez de recursos naturais. Ganhou atenção internacional ao publicar o relatório The limits to growth, em 1992, que indicava que os limites para o crescimento no planeja seriam atingidos rapidamente se tendências em relação ao crescimento populacional mundial, poluição, produção e alimentos e depleção e recursos não fossem alteradas (SIRKIS \& TRIGUEIRO, 2005).
} 
"unidades de conservação" (UC) para designar o conjunto de áreas protegidas que seriam contempladas pelo sistema (MEDEIROS, 2006).

De 1976 até a década de 1990, o Brasil fez um grande investimento em parques e outras unidades de conservação federais, estaduais, municipais e privadas - bem maior que qualquer outro País tropical e comparável ao de Países em desenvolvimento (MITTERMIER, et. al., 2005). Muito desse avanço se deve a atuação do movimento socioambientalista, na segunda metade da década de 1980. O movimento, originou-se a partir do fim do regime militar, no processo de redemocratização do País e da aproximação entre os movimentos sociais (sindicais, de trabalhadores rurais, dentre outros) e ambientalistas. Um dos marcos desse movimento foi a Aliança dos Povos da Floresta, que defendia o modo de vida das populações tradicionais amazônicas, cuja sobrevivência dependia da conservação das florestas. Esse movimento influenciou decididamente a história mais recente das áreas protegidas no Brasil (FRANCO et. al., 2015).

Novas categorias de unidades de conservação foram instituídas pela Lei $\mathrm{n}^{0} 6.902$, de abril de 1981 e Decreto $\mathrm{n}^{\circ}$ 89.336, de janeiro de 1984 - estações ecológicas e áreas de proteção ambiental decorrentes do primeiro instrumento e reservas ecológicas e áreas de relevante interesse ecológico, do segundo (DRUMMOND et. al., 2010). Em 1987, a Portaria $n^{\circ} 627$ do Instituto Nacional de Colonização e Reforma Agrária, cria a tipologia Projeto de Assentamento Extrativista, reconhecida como reserva extrativista pelo Decreto 98.897, de 30 de janeiro de 1990. A criação dessa tipologia foi resultado da luta dos seringueiros pela floresta, visando a garantia de suas formas de vida, autonomia econômica e cultural.

Foram criados em 1981, a Política Nacional de Meio Ambiente (PNMA) e o Sistema Nacional de Meio Ambiente (SISNAMA), ambos instituídos pela Lei $n^{\circ} 6.938$ de 31/08/1981. O SISNAMA e a PNMA foram importantes na tarefa de conferir maior unidade à causa ambiental. A relação entre populações locais e áreas protegidas começou a ser delineada em 1982 durante o III Congresso Mundial de Parques Nacionais, realizado na Indonésia (BENSUSAN, 2006). Com o fim da ditadura brasileira, em 1985, os movimentos socioambientais se reorganizaram e se fortaleceram conferindo energia à lógica conservacionista. Com a promulgação da Constituição de 1988, a participação direta do cidadão nos processos decisórios, como forma de complementação do sistema eleitoral, representativo, ganhou institucionalidade no Brasil (DOMBROWSKI \& PARMIGIANI, 2009). À medida que essa encerrou princípios gerais de cidadania, instrumentos para seu exercício, leis orgânicas específicas, pós 1988, passaram a regulamentar o direito constitucional à participação (SOUZA, 2012).

A nova constituição concedeu à sociedade - além do Poder Público - o dever de proteger e preservar o meio ambiente, colocando num mesmo patamar de direitos e obrigações o público 
e o privado, eliminando assim uma antiga dicotomia civilista (BENATTI, 1999). Foi tempo de uma maior busca pela participação social nas políticas ambientais dentro e fora do País.

No final do século XX, diante da pluraridade tipológica de UCs, foi empreendido outro esforço de consolidação de um sistema nacional, desenvolvido pela Fundação Pró-Natureza (Funatura) por encomenda do IBDF. O trabalho, iniciado em 1988, teve por objetivo intuito levantar as categorias de proteção existentes no País e elaborar um anteprojeto de lei que instituísse um Sistema Nacional de Unidades de Conservação - SNUC (SANTILLI, 2005), que deveria ser apresentado durante a Conferência do Rio-92. O estudo foi entregue em 1989 ao recém-criado Instituto Brasileiro do Meio Ambiente e dos Recursos Naturais Renováveis (IBAMA) - pela fusão da SEMA, IBDF, Superintendência de Pesca (SUDEPE) e Superintendência da Borracha (SUDHEVEA) (BURSZTYN \& PERSEGONA, 2008), pela Lei $\mathrm{n}^{\circ} 7.735$, de 22 fevereiro de 1989.

O Projeto de Lei ${ }^{\circ}$ 2892/92 foi encaminhado ao Congresso Nacional pelo Presidente Fernando Collor de Mello, tramitando por oito anos, até sua aprovação em 2000 (MEDEIROS, 2006; SANTILLI, 2005). O processo de elaboração legislativa evidenciou ainda mais as diferentes posições entre os movimentos ambientalistas no Brasil. Preservacionistas, conservacionistas, socioambientalistas e ruralistas travaram uma verdadeira batalha que tomou vulto com a mobilização da imprensa. Entre os pontos mais polêmicos destacavam-se: a presença de populações tradicionais, a participação popular no processo de criação e gestão de UCs e as indenizações para desapropriações (MEDEIROS, 2006). Na proposta original, a ideia de que a presença humana representava uma ameaça à conservação dos recursos naturais e a pouca valorização social e econômica da biodiversidade eram incontestes (SANTILLI, 2005). No entanto, a despeito da tendência inicial, a Lei que instituiu o SNUC abrigou as perspectivas de conservação com e sem presença humana, refletidas em diversas categorias de manejo.

A Lei $\mathrm{n}^{0}$ 9.985, de julho de 2000, que institui o SNUC, delimitou conceitualmente o termo unidade de conservação e definiu as tipologias oficiais de unidades de conservação:

Espaço territorial e seus recursos ambientais, incluindo as águas jurisdicionais, com características naturais relevantes, legalmente instituído pelo Poder Público, com objetivos de conservação e limites definidos, sob regime especial de administração, ao qual se aplicam garantias adequadas de proteção

As 12 categorias de manejo definidas pelo SNUC estão organizadas em dois grupos principais que buscam contemplar estratégias distintas de proteção: preservação (UCs de proteção integral ou uso indireto) e conservação (UCs de uso sustentável ou uso direto). 
A criação das tipologias reservas extrativistas (RESEXs) e reservas de desenvolvimento sustentável (RDS) representaram um importante passo na concepção de áreas protegidas no Brasil, pois incorporam aos objetivos da conservação, ações de inclusão social e econômica das populações diretamente afetadas, além de auxiliarem na redução de conflitos fundiários (MEDEIROS, 2006).

A gênese das reservas extrativistas é merecedora de um capítulo à parte na história ambiental brasileira, tanto pelo seu caráter precursor (que remete ao século XIX e, portanto, anterior à criação do primeiro parque brasileiro) quanto por representar um projeto estruturado a partir da base, da luta corajosa de extrativistas seringueiros - que buscavam na borracha sua subsistência - contra toda uma elite de fazendeiros, com grande prestígio político.

As categorias de manejo definidas no SNUC, inalteradas ainda hoje, encontram-se resumidas nos Quadros 1 e 2.

Quadro 1. Categorias brasileiras de unidades de conservação de proteção integral.

\begin{tabular}{|c|c|c|c|c|}
\hline $\begin{array}{l}\text { CATEGORIA DE } \\
\text { MANEJO }\end{array}$ & $\begin{array}{l}\text { OBJETIVOS ALÉM DA } \\
\text { CONSERVAÇÃO DA } \\
\text { BIODIVERSIDADE }\end{array}$ & DOMÍNIO & $\begin{array}{l}\text { POPULAÇÃO } \\
\text { RESIDENTE }\end{array}$ & VISITAÇÃO \\
\hline $\begin{array}{l}\text { Estação Ecológica } \\
\text { (ESEC) }\end{array}$ & $\begin{array}{l}\text { Preservação da natureza e realização de } \\
\text { pesquisas científicas }\end{array}$ & Público & Não & $\begin{array}{l}\text { Apenas para } \\
\text { fins educativos }\end{array}$ \\
\hline $\begin{array}{l}\text { Reserva Biológica } \\
\text { (REBIO) }\end{array}$ & $\begin{array}{l}\text { Preservação integral da biota e demais } \\
\text { atributos naturais existentes em seus limites, } \\
\text { sem interferência humana direta ou } \\
\text { modificações ambientais }\end{array}$ & Público & Não & $\begin{array}{l}\text { Apenas para } \\
\text { fins educativos }\end{array}$ \\
\hline $\begin{array}{l}\text { Parque Nacional } \\
\text { (PARNA) }\end{array}$ & $\begin{array}{l}\text { Preservação de ecossistemas naturais de } \\
\text { grande relevância ecológica e beleza cênica, } \\
\text { realização de pesquisas científicas e atividades } \\
\text { de educação ambiental e de turismo ecológico }\end{array}$ & Público & Não & Sim \\
\hline $\begin{array}{l}\text { Monumento Natural } \\
\text { (MONA) }\end{array}$ & $\begin{array}{l}\text { Preservar sítios naturais raros, singulares ou de } \\
\text { grande beleza cênica }\end{array}$ & $\begin{array}{l}\text { Pública e/ou } \\
\text { privado }\end{array}$ & Sim & Sim \\
\hline $\begin{array}{l}\text { Refúgio da Vida Silvestre } \\
\text { (RVS) }\end{array}$ & $\begin{array}{l}\text { Assegurar condições para a existência ou } \\
\text { reprodução de espécies ou comunidades de } \\
\text { flora local e de fauna residente ou migratória }\end{array}$ & $\begin{array}{l}\text { Público e/ou } \\
\text { privado }\end{array}$ & Sim & Sim \\
\hline
\end{tabular}

Quadro 2. Categorias brasileiras de unidades de conservação de uso sustentável. 


\begin{tabular}{|c|c|c|c|c|}
\hline $\begin{array}{l}\text { CATEGORIA DE } \\
\text { MANEJO }\end{array}$ & $\begin{array}{l}\text { OBJETIVOS ALÉM DA } \\
\text { CONSERVAÇÃO }\end{array}$ & DOMÍNIO & $\begin{array}{l}\text { POPULAÇÃO } \\
\text { RESIDENTE }\end{array}$ & VISITAÇÃO \\
\hline $\begin{array}{l}\text { Área de Proteção } \\
\text { Ambiental (APA) }\end{array}$ & $\begin{array}{l}\text { Área em geral extensa, com um certo grau de } \\
\text { ocupação humana, dotada de atributos } \\
\text { abióticos, bióticos, estéticos ou culturais } \\
\text { especialmente importantes para a qualidade de } \\
\text { vida e o bem-estar das populações humanas, e } \\
\text { tem como objetivos básicos proteger a } \\
\text { diversidade biológica, disciplinar o processo } \\
\text { de ocupação e assegurar a sustentabilidade do } \\
\text { uso dos recursos naturais }\end{array}$ & $\begin{array}{l}\text { Público e/ou } \\
\text { privado }\end{array}$ & Sim & Sim \\
\hline $\begin{array}{ll}\text { Área de } & \text { Relevante } \\
\text { Interesse } & \text { Ecológico } \\
\text { (ARIE) } & \end{array}$ & $\begin{array}{l}\text { Área em geral de pequena extensão, com } \\
\text { pouca ou nenhuma ocupação humana, com } \\
\text { características naturais extraordinárias ou que } \\
\text { abriga exemplares raros da biota regional, e } \\
\text { tem como objetivo manter os ecossistemas } \\
\text { naturais de importância regional ou local e } \\
\text { regular o uso admissível dessas áreas, de modo } \\
\text { a compatibilizá-lo com os objetivos de } \\
\text { conservação da natureza }\end{array}$ & $\begin{array}{l}\text { Público e/ou } \\
\text { privado }\end{array}$ & Sim & Sim \\
\hline Floresta (FLONA ou FE) & $\begin{array}{l}\text { Área com cobertura florestal de espécies } \\
\text { predominantemente nativas que tem como } \\
\text { objetivo básico o uso múltiplo sustentável dos } \\
\text { recursos naturais }\end{array}$ & $\begin{array}{l}\text { Público, com } \\
\text { concessão } \\
\text { real de direito } \\
\text { de uso }\end{array}$ & Sim & Sim \\
\hline $\begin{array}{l}\text { Reserva } \quad \text { Extrativista } \\
(\text { RESEX) }\end{array}$ & $\begin{array}{l}\text { Área utilizada por populações extrativistas } \\
\text { tradicionais, cuja subsistência baseia-se no } \\
\text { extrativismo e, complementarmente, na } \\
\text { agricultura de subsistência e na criação de } \\
\text { animais de pequeno porte, e tem como } \\
\text { objetivos básicos proteger os meios de vida e } \\
\text { a cultura dessas populações, e assegurar o uso } \\
\text { sustentável dos recursos naturais da unidade }\end{array}$ & $\begin{array}{l}\text { Público, com } \\
\text { concessão } \\
\text { real de direito } \\
\text { de uso }\end{array}$ & Sim & Sim \\
\hline Reserva de Fauna (RV) & $\begin{array}{l}\text { Área natural com populações animais de } \\
\text { espécies nativas, terrestres ou aquáticas, } \\
\text { residentes ou migratórias, adequadas para } \\
\text { estudos técnico-científicos sobre o manejo } \\
\text { econômico sustentável de recursos faunísticos }\end{array}$ & Público & Sim & Sim \\
\hline $\begin{array}{ll}\text { Reserva } & \text { de } \\
\text { Desenvolvimento } & \\
\text { Sustentável (RDS) } & \end{array}$ & $\begin{array}{l}\text { É uma área natural que abriga populações } \\
\text { tradicionais, cuja existência baseia-se em } \\
\text { sistemas sustentáveis de exploração dos } \\
\text { recursos naturais, desenvolvidos ao longo de } \\
\text { gerações e adaptados às condições ecológicas } \\
\text { locais e que desempenham um papel } \\
\text { fundamental na proteção da natureza e na } \\
\text { manutenção da diversidade biológica }\end{array}$ & $\begin{array}{l}\text { Público com } \\
\text { CDRU }\end{array}$ & Sim & Sim \\
\hline $\begin{array}{l}\text { Reserva Particular do } \\
\text { Patrimônio } \\
\text { (RPPN) }\end{array}$ & $\begin{array}{l}\text { Área privada, gravada com perpetuidade, com } \\
\text { o objetivo de preservar a diversidade biológica }\end{array}$ & Privado & Sim & Sim \\
\hline
\end{tabular}




\begin{tabular}{|l|l|l|l|l|}
\hline $\begin{array}{l}\text { CATEGORIA DE } \\
\text { MANEJO }\end{array}$ & $\begin{array}{l}\text { OBJETIVOS ALÉM DA } \\
\text { CONSERVAÇÃO }\end{array}$ & DOMÍNIO & $\begin{array}{l}\text { POPULAÇÃO } \\
\text { RESIDENTE }\end{array}$ & VISITAÇÃo \\
\hline & & & & \\
& & & & \\
\hline
\end{tabular}

Apesar de ter sido objeto de intensos debates e do longo caminho trilhado até sua publicação, o SNUC foi alvo de muitas críticas (MERCADANTE, 2001). Dentre as mais frequentes, estão o seu elevado grau de isolamento em relação ao meio que está inserido, formando as chamadas “ilhas de conservação" e a forma como devem ser propostas novas UCs - calcadas em estudos técnico-científicos encaminhados pelo Poder Público, onde, embora esteja a consulta popular ${ }^{20}$, não há referência aos mecanismos de assimilação de críticas e sugestões da sociedade. Ademais, a categoria de unidade de conservação a que uma área será submetida não é objeto a ser discutido com a sociedade, cabendo nas consultas apenas a identificação de sua localização, dimensão e limites (MMA, 2004). A despeito das limitações expostas, o SNUC trouxe ganhos substanciais, representando o principal marco na criação das unidades de conservação brasileiras. Ao rever as categorias criadas em diferentes épocas, com diferentes objetivos, possibilitou um ordenamento territorial em nível nacional, compatível com as múltiplas realidades sociais, ambientais e econômicas do Brasil. Ao mesmo tempo, o enquadramento segundo os critérios da União Internacional para Conservação da Natureza (UICN), permitiu ao sistema brasileiro uma adequação aos padrões e normas internacionais. Essa adequação facilitou a implementação de estratégias para captação de recursos, a realização de pesquisas científicas e o intercâmbio de informações e experiências, o diálogo com agências internacionais de outros Países, a adoção de padrões diferenciados de gestão e a gestão de áreas transfronteiriças. Além disto, as principais preocupações contempladas pela Lei do SNUC estão em sintonia com os objetivos da Convenção sobre Diversidade Biológica (CDB), reforçando a adesão brasileira à CDB. Ratificam esta posição: i. o enfoque da conservação da biodiversidade no nível de diversidade genética, de espécies e ecossistemas; ii. o uso sustentável dos recursos naturais; iii. A participação social e iv. a distribuição equitativa dos benefícios decorrentes da criação, implementação e gestão das UCs (DRUMMOND et. al., 2010).

Entre os anos que se passaram de construção do SNUC, o ambientalismo nacional foi se fortalecendo com a criação de novos instrumentos jurídicos, maior articulação e inserção internacional.

${ }^{20}$ Com exceção das Reservas Biológicas e Estações Ecológicas 
A Lei do SNUC foi respaldada em 2002 a partir de um decreto que estabelece regras para o estabelecimento de UCs e mosaicos de unidades de conservação, para criação da unidade, elaboração de plano de manejo, criação de conselhos gestores, gestão compartilhada, compensação ambiental, reassentamento de populações tradicionais gerenciamento das reservas da biosfera (Decreto $n^{\circ} 4.340$ de 22/08/2002). A regulamentação foi de extrema importância, pois os anos que separaram a Lei do Decreto foram caracterizados por incertezas no modus operandi da consolidação de UCs, dada as lacunas deixadas pela Lei do SNUC.

Em 2006, em atenção aos compromissos assumidos pelo Brasil no plano de trabalho sobre áreas protegidas da Convenção sobre Diversidade Biológica (CDB) é instituído o Plano Nacional Estratégico de Áreas Protegidas - PNAP (Decreto 5.758 de 2006). Mesmo optando por abordar prioritariamente parte das APs (somente unidades de conservação e mosaicos, as terras indígenas e os territórios quilombolas), o plano abarca 20 diretrizes de execução que visam o estabelecimento de um amplo sistema de áreas protegidas até 2015. O PNAP não se resume a metas numéricas de criação e estabelecimento de APs, a ele importa que o sistema seja ecologicamente representativo, efetivamente manejado, participativo e justo na repartição dos benefícios e capaz de integrar os ambientes terrestres e marinhos.

Em 2010, ao ratificarem as Metas de Aichi durante a COP 10, os Países signatários se comprometeram a definir suas próprias metas, levando em conta as necessidades e prioridades nacionais e tendo em mente a contribuição nacional para o cumprimento das metas globais. Para tanto, deveriam elaborar seus próprios Planos Estratégicos Nacionais de Biodiversidade. O Brasil iniciou o processo de construção da Estratégia Nacional de Conservação da Biodiversidade (ENB). Para tanto, procedeu uma ampla consulta à sociedade com intuito de recolher percepções e propostas para adequação das metas globais à realidade brasileira.

Em paralelo, o Ministério do Meio Ambiente, em parceria com o Fundo Brasileiro para a Biodiversidade (Funbio) e o Ministério do Planejamento Orçamento e Gestão (MPOG), deram início à construção do Plano de Ação para a implantação da ENB, ainda em elaboração.

Em 2012, a sociedade brasileira se vê dividida em mais uma calorosa discussão ambiental, dessa vez está em pauta a revisão do código florestal. De um lado, a bancada ruralista luta por maior flexibilidade nas regras que permitem a exploração florestal; de outro, ambientalistas tentavam garantir que a proteção das florestas não perdesse espaço, uma vez que as alterações propostas decorriam de interesses econômicos e imediatistas cujos efeitos recairiam diretamente sobre o desmatamento de florestas e outros tipos de vegetação remanescentes, 
sobretudo na Amazônia. Por fim, a revisão do código foi realizada e sancionada pela Lei $\mathrm{n}^{\circ}$ 12.561 de 25/05/2012.

De um modo geral, apesar do contexto político invariavelmente hostil na qual a temática proteção da natureza esteve inserida no Brasil, sempre representada por minorias e defensores de causas de baixa popularidade (FRANCO \& DRUMMOND, 2012), a causa ambiental obteve grandes avanços. Consolidou-se um aparato jurídico e institucional favorável à criação de áreas protegidas no País decorrente, nomeadamente, do fortalecimento e aparelhamento do Estado e da participação e influência de diferentes segmentos da sociedade e do contexto internacional (MEDEIROS et. al., 2004). Os instrumentos normativos vinculados à sua proteção encontramse muito bem estruturados, apesar de algumas questões ainda carecerem de alguma revisão regulatória. $\mathrm{O}$ maior desafio da conservação da biodiversidade via unidades de conservação reside na implementação das normas vigentes que orientam a construção do aparato de gestão dessas áreas.

Isso significa elaborar e implementar instrumentos básicos de gestão como termos de compromisso, planos de manejo, conselhos gestores de unidades de conservação, planos de proteção, planos de consolidação territorial, além de investir em infraestrutura e equipamentos necessários à gestão da UC.

Não bastassem as dificuldades inerentes à implementação do seu aparato de gestão, a maioria das UCs brasileiras estão inseridas em um contexto de escassez de recursos humanos e financeiros. $\mathrm{O}$ orçamento federal destinado à gestão de UCs historicamente (MUANIS et al., 2009; MMA, 2009; TCU, 2013; GELUDA \& SERRÃO, 2015; GELUDA, 2015; TCU) encontra-se ainda mais ameaçado por possíveis cortes decorrentes da crise econômica pela qual atravessa o país. Como agravante, os, até então, expressivos recursos da cooperação internacional para financiamento de UCs, apresentam tendência de queda, pois estão sendo deslocados para países considerados menos desenvolvidos (GELUDA \& SERRÃO, 2015).

Significativa é a carência de recursos humanos na gestão de unidades de conservação, a qual é expressa em uma das maiores relações de área protegida por funcionário do mundo (PÁDUA, 2011).

A forte escassez de recursos humanos e financeiros, vinculada ao foco de curto prazo de muitas agências de financiamento, restringem o alcance e a durabilidade dos processos participativos (ADAMS \& HULME, 2001; DEARDEN et. al., 2005; MENZIES, 2007). 
Como alternativa, são exaltadas estratégias de efeito mais imediato, mais coercitivas, como a fiscalização, as quais muitas vezes não têm sido exitosas nem para ações mais objetivas, como a contenção do desmatamento (ANDAM et. al., 2008; PORTER-BOLLAND et. al., 2012).

Esse capítulo discorreu sobre a fundamentação da concepção das unidades de conservação. Conclui-se que ela se deu pela da ação de correntes de pensamento distintas e, pela necessidade de adaptação às variadas realidades em um território com dimensões continentais, uma flora extremamente diversificada e povos culturalmente diversos, que ainda guardam consigo tradições ancestrais, baseadas em uma relação humano-natureza com menor impacto ambiental do que as sociedades urbano-industriais. Como resultado, temos um sistema que abriga com certo equilíbrio as duas principais estratégias de conservação e uma diversidade de categorias de manejo compatível com o que exige nossa especificidade territorial e cultural. O desafio maior é a consolidação desses espaços, sobretudo, porque não se trata de tarefa que se conclua e nem de moldes prontos, mas ao contrário, exige constante renovação e adaptação a contextos diversos e realidades imprevisíveis.

No próximo capítulo será trabalhado o conceito de participação social e como ele foi inserido na agenda ambiental brasileira. Serão apresentadas as bases para delimitação do objeto de pesquisa e fundamento teórico para as discussões.

\subsection{EFETIVIDADE EM UNIDADES DE CONSERVAÇ̃̃O X EFETIVIDADE DE GESTÃO}

É consenso que a simples delimitação territorial e legal de regimes especiais de uso seja insuficiente para a conservação da biodiversidade, se não houver a gestão adequada desses espaços. Tal constatação tem embalado discussões em nível global e nacional desde meados do século passado. Como resultado, desde então vem sendo desenvolvidas uma grande diversidade de metodologias para avaliação da efetividade de APs (CIFUENTES, et. al. 2000; ERVIN, 2003; HOCKINGS et. al., 2000 e 2006; LEVERINGTON et. al., 2010). A maioria, entretanto, baseia-se nos processos de gestão em detrimento dos resultados esperados. Pouca ou nenhuma importância é conferida à verificação do êxito das UCs brasileiras no alcance de seus objetivos de conservação. Assim, a maioria dos métodos acaba por considerar tão somente, ou em um peso muito maior, a implementação dos instrumentos de gestão da unidade e não o seu progresso em relação as suas metas (OLIVEIRA, 2012).

Embora se defenda que a efetividade de gestão seja condição essencial para o cumprimento dos objetivos de criação das unidades (HOCKINGS et. al., 2006), não se pode afirmar que seja suficiente. Em outras palavras, não há garantia de que a implementação adequada dos instrumentos de gestão da UC se traduza em proteção da sua biodiversidade, dos ecossistemas 
e paisagens naturais, na garantia de manutenção dos serviços ecológicos essenciais e de direitos das comunidades tradicionais afetadas por sua criação. Poucas são as ferramentas que avaliam a efetividade da UC pela observação direta dos atributos naturais. Leverington et. al. (2010) ao analisarem mais de 30 ferramentas de avaliação da efetividade de gestão ao redor do mundo, observaram que apenas nove destas incorporavam a avaliação de indicadores de impacto/efeito para a conservação ou de integridade ecológica.

Alguns esforços têm sido empreendidos pelo Governo Federal na busca de um modelo, mas o fato é ainda hoje não foi acordada e institucionalizada uma metodologia de monitoramento da biodiversidade e do seu uso sustentável para ser aplicada em âmbito nacional.

Alguns protocolos de monitoramento da biodiversidade têm sido propostos, mas a falta de decisão política sobre a adoção de um protocolo-padrão no âmbito do Sistema Nacional de Unidades de Conservação, faz com que os esforços de amostragem sejam pulverizados em distintos grupos taxonômicos e em distintas localidades, utilizando-se parâmetros muitas vezes não replicáveis. Assim, cada pesquisador segue utilizando sua própria metodologia e construindo bases de dados individuais que não conversam entre si. Ao mesmo tempo, a amostragem raramente é projetada para cobrir grandes áreas, representativas da paisagem. A falta de tal cobertura prejudica a generalização e muitas vezes pode levar a conclusões errôneas. Sem a orientação dos esforços de amostragem e diante da imensidão territorial brasileira, os custos financeiros limitam a amplitude dos estudos de biodiversidade (COSTA \& MAGNUSSON, 2010). No lugar de dados brutos de fauna e flora são utilizados proxies de conservação, como a cobertura vegetal e/ou estratégias de modelagem para preenchimento das lacunas de conhecimento que muitas vezes resultam an utilização de grosseiros preditores da biodiversidade entre gerentes e planejadores (LOPES et. al., 2010).

\subsubsection{EFETIVIDADE DE GESTÃO DE UNIDADES DE CONSERVAÇÃO}

Embora a mensuração da efetividade das UCs neste estudo não tenha sido realizada com base em ferramentas de avaliação de efetividade de gestão, os resultados da aplicação fornecem uma valiosa base de dados sobre a gestão das unidades de conservação brasileiras. As respostas delas decorrentes se baseiam em indicadores relevantes, as quais, em estado bruto podem ser, e foram, utilizadas como subsídios a outras interpretações e estudo de relações.

A avaliação da efetividade de gestão de unidades de conservação, via análise da implementação de seus instrumentos gerenciais, confere ainda, e principalmente, massa crítica à discussão de possíveis caminhos capazes de potencializar a conservação da biodiversidade.

Em função disto, esta seção se dedicou ao aprofundamento dessa temática. 


\subsubsection{O que é e para que serve}

Embora não se possa afirmar que efetividade de gestão resulte, necessariamente em efetividade no alcance dos objetivos de criação da UC, a primeira, não dever ser avaliada de modo dissociado da última, pois é esta que lhe confere significado. Caso contrário, seria a burocracia pela burocracia, o que não seria estratégico. Dessa forma, alguns autores, ao conceituar efetividade de gestão, resumem no conceito a meta que se pretende alcançar. Em outras palavras, os instrumentos de gestão são avaliados, mas essa análise deve procurar vinculá-los com os resultados, no caso, metas de conservação (CIFUENTES et. al., 2000; OLIVEIRA, 2012). Cifuentes et. al. (2000) destacam que, no âmbito da gestão das áreas protegidas, efetividade é o conjunto de ações que influenciadas pelas atitudes, habilidades e competências específicas permitem cumprir os objetivos de criação de determinada área. Sendo mantido, assim, o elo com uma meta maior, que confere estratégia a execução de ações de gestão, tipicamente ações-meio. Oliveira (2012) manteve o mesmo elo na sua conceituação, na qual efetividade de gestão seria uma condição de eficiência e gestão em decorrência de um impacto positivo no estado de conservação da biodiversidade e/ou nas comunidades diretamente envolvidas na utilização sustentável dos recursos naturais.

Diversos autores destacam a importância da avaliação da efetividade de gestão de UCs e o modo como os resultados decorrentes deste acompanhamento podem ser utilizados para alcance dos objetivos de conservação (WATSON et. al., 2014; HOCKINGS, 2000; HOCKINGS et. al., 2006; HOCKINGS et. al. 2008; ARAÚJO, 2007; CIFUENTES et. al., 2000):

- Permite visualizar o grau de implantação ou desenvolvimento da área, a eficiência dos recursos disponíveis e orienta paras as questões que exigem maiores esforços;

- Provê aos tomadores de decisão, informação condensada e de fácil visualização sobre a gestão de determinada UC ou conjunto e sobre as necessidades de mudanças de estratégias e políticas;

- Possibilita que organismos financiadores de projetos acompanhem as necessidades reais e as melhorias alcançadas com seu auxílio, facilitando o requerimento de futuros investimentos;

- Permite a análise da relação entre esforços empreendidos e resultados alcançados;

- Favorece o dimensionamento das tarefas, com vista a divisão de responsabilidade entre os participantes do processo de gestão; 
- Possibilita o monitoramento regional, continental e internacional da efetividade de gestão das áreas protegidas de modo homogêneo ao se usar uma rotina metodológica comum ou adaptável às diferentes regiões;

- Permite a construção com base na sua própria experiência e o constante realinhamento entre o curso da gestão e os resultados desejáveis (manejo adaptativo);

- Fornece insumos à priorização de ações visando a melhoria gerencial nas UCs individuais e no sistema como um todo;

- Subsidiam a identificação de lacunas de capacidade técnica ou gerencial;

- Possibilita visualizar a distância entre a gestão desejada e a realidade atual da unidade ou sistema;

- Dão suporte a construção e diretrizes para fortalecimento institucional.

Desde que sejam inseridos indicadores de impacto na metodologia de avaliação de efetividade de gestão, os benefícios podem ser potencializados:

- Identificação de lacunas de representatividade ecossistêmica e funcional dentro dos sistemas nacionais ou regionais de unidades de conservação;

- Identificação de UCs sob maior ameaça de degradação;

- Acompanhamento de performance das metas de conservação;

- Apoio a priorização de esforços e investimentos para a conservação.

\subsubsection{Avaliação da efetividade de gestão}

De uma forma geral, pode-se dizer que a avaliação da efetividade de gestão mede como as unidades de conservação protegem os valores que almejam proteger e quão eficientemente estão sendo alcançadas suas metas e objetivos (HOCKINGS et. al., 2006).

A percepção da necessidade de construção de metodologias para monitoramento da gestão de UCs começou a ser destaque em fóruns globais há pouco mais de trinta anos, no III e VI Congresso Mundial de Parques, realizados em Bali - 1982 e Caracas - 1992, respectivamente (ARAÚJO, 2007).

Em resposta a essa tendência e diante da força da conservação in situ como estratégia de proteção da biodiversidade em um mundo com taxas crescentes de extinção de espécies, após o congresso de Bali, a UICN, por meio da Comissão Mundial de Parques (CMPA OU WCPA, em inglês) esboçou um primeiro questionário de avaliação da gestão de unidades de conservação. Em 1997, também no âmbito CMAP/UICN é criado o Grupo de Trabalho da Efetividade de Gestão de Áreas Protegidas, o qual em 2000 passou a ser representado por um programa temático dentro da CMAP. No mesmo ano, a UICN publicou o primeiro documento 
com o marco conceitual e diretrizes para a avaliação da efetividade de gestão de áreas protegidas. De forma simultânea, outros grupos e indivíduos de outras partes do mundo, produziram diretrizes, metodologias e ferramentas para avaliação de suas áreas protegidas (HOCKINGS et. al., 2000; HOCKINGS et. al., 2006).

O V Congresso de Parques (Durban, 2003) definiu pontos críticos que deveriam ser objeto de maior atenção por parte de pesquisadores e gestores de áreas protegidas:

- Identificação de modelos, metodologias e ferramentas de avaliação da efetividade;

- Avaliação nas suas diferentes escalas: sistema de APs e área protegida individual;

- Identificação de métodos de avaliação da integridade ecológica das áreas protegidas, de indicadores sociais e econômicos e de gestão e do nível de satisfação das necessidades das comunidades locais;

- Avaliação da efetividade de gestão frente aos processos globais em curso, como as mudanças climáticas.

Em 2004, a Convenção sobre a Diversidade Biológica adotou o Programa de Trabalho para as Áreas Protegidas, que determinou a implementação da avaliação da efetividade de gestão nos sistemas de áreas protegidas dos países signatários. Muito antes disso, ainda na década de 1960, há registros de esforços pontuais no Brasil para avaliação das unidades de conservação a partir de distintas metodologias.

A primeira avaliação mais abrangente aconteceu em 1966, por uma comissão nomeada pelo Ministério da agricultura. Em 1999, o WWF realizou um amplo esforço de avaliação que abarcou 86 UCs de proteção integral federais (LEMOS DE SÁ \& FERREIRA, 1999; ARAÚJO, 2007), desenvolvido em consonância com a ênfase dada pela Aliança Florestal com o Banco mundial, firmada um ano antes. Com metas pautadas no progresso da gestão de UCs, a Aliança desenvolveu uma ferramenta própria para avaliar a efetividade de gestão de APs: o Tracking Tool, aplicado em 37 países da Europa, Ásia, África e América Latina (ARAÚJO et. al.; 2007). Diversas outras iniciativas vêm se manifestando desde então, de tal modo que em 2009, Leverington et. al. (2010) identificaram 54 diferentes metodologias para a avaliação da efetividade de gestão em diversos países, já aplicadas em quase 7.000 áreas protegidas.

A maioria das ferramentas ou metodologias desenvolvidas baseiam-se, no entanto, nas diretrizes da CMAP/UICN para avaliação da efetividade de APs, as quais consideram as necessidades e particularidades das avaliações quanto a escala, natureza dos objetivos, ameaças e impactos, e disponibilidade de informações. Hockings et. al. (2000) recomendam que as avaliações de efetividade devam ser realizadas considerando-se os objetivos de criação de cada 
AP e as restrições de uso das diferentes categorias. Oliveira (2012) em sua análise sobre as ferramentas de avaliação de efetividade de gestão adotadas no Brasil ressalta a ausência de métodos que façam a diferenciação por categorias, havendo apenas algumas poucas metodologias com perguntas especificas para unidades de uso sustentável. A autora observa ainda o alto grau de subjetividade desses métodos, os quais, em sua maioria, refletem a percepção dos gestores de UCs em relação à realidade das unidades de conservação. Considera ainda que a predominante dependência de dados qualitativos justifica-se pela insuficiência de meios e recursos para o monitoramento.

As diversas metodologias de avaliação da efetividade de gestão não serão aprofundadas nesta Tese, uma vez que a eficiência destes métodos não foi objeto direto de estudo ${ }^{21}$.

No entanto, como os dados de participação social foram provenientes do RAPPAM, esta metodologia será descrita, como forma de contextualizá-la.

Vale ressaltar que a opção pela utilização do RAPPAM se deu pela diversidade de informações que a base detém, por ser hoje a mais abrangente ferramenta aplicada em âmbito nacional e internacional. Foi aplicado em aproximadamente de 40 países e mais de 1.000 áreas protegidas na Ásia, África, América Latina, Caribe e Europa (LEVERINGTON et al., 2010). Em 2012, apenas no Brasil o RAPPAM já havia sido implementado em 473 UCs, dentre unidades federais e estaduais (WWF-BRASIL \& ICMBIO, 2012). Ademais, a utilização dos dados o RAPPAM confere oficialidade às informações aqui tratadas, uma vez que é o método oficialmente adotado pelo Governo Federal para avaliação da efetividade de gestão das UCs federais.

\subsection{O RAPPAM}

No Brasil, o RAPPAM foi aplicado pela primeira vez no Estado de São Paulo, em 2004, visando à avaliação da gestão de unidades de conservação de proteção integral administradas pelo Instituto Florestal e Fundação Florestal. Durante os anos de 2005 a 2007, o método foi implementado junto a 246 unidades de conservação federais brasileiras, em uma iniciativa de parceria entre o WWF-Brasil e o Instituto Brasileiro do Meio Ambiente e dos Recursos Naturais Renováveis. Nos anos de 2008 a 2010, o RAPPAM foi aplicado em unidades de conservação sob gestão dos estados do Acre, Amapá, Mato Grosso, Amazonas, Pará, Rondônia e Mato Grosso do Sul. Como anteriormente mencionado, na primeira aplicação do RAPPAM nas UC federais foram avaliadas 246 áreas. No segundo período de avaliação, que ocorreu no ano de

\footnotetext{
${ }^{21}$ Para maior aprofundamento consulte (CIFUENTES et. al., 2000; HOCKINGS et. al. 2000 e 2006; FARIA, 2003; ERVING, 2003; ARAÚJO, 2007; LEVERINGTON et. al., 2010; OLIVEIRA, 2012; COAD, L. et. al., 2015)
} 
2010, o número de UC foi expandido para 292, abrangendo 94\% do número total de UC federais no Brasil (WWF-BRASIL \& ICMBIO, 2012).

O RAPPAM avalia a efetividade da gestão de APs com base na percepção dos gestores destas áreas, auferida por meio de questionários.

Os questionários estão estruturados segundo as orientações da CMAP/UICN, encerrando os cinco elementos do ciclo de gestão e avaliação: contexto, planejamento, insumos, processos e resultados da gestão, conforme representado na Figura 1. Cada um desses elementos é também chamado no RAPPAM de módulo.

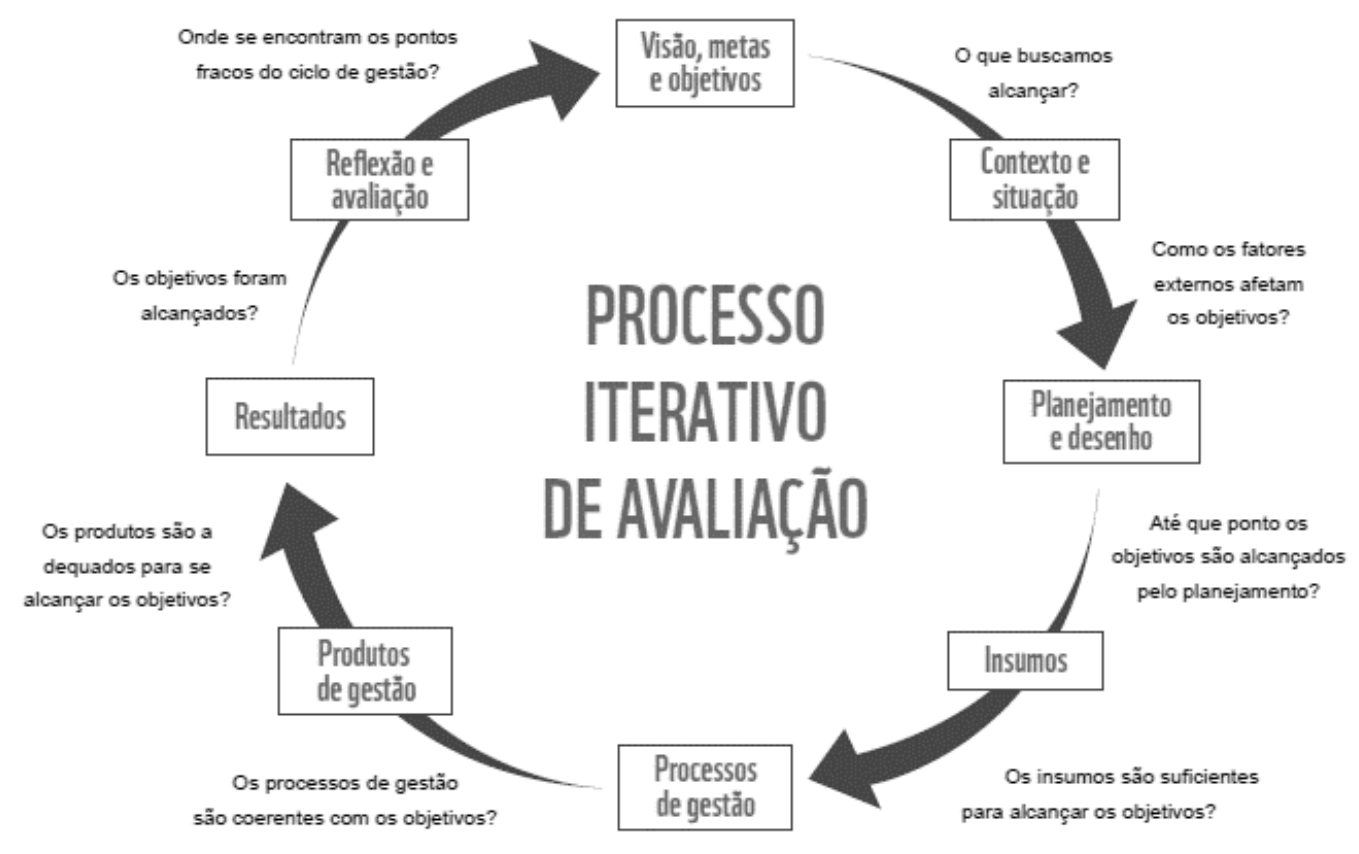

Fonte: Hockings et. al., 2000

Autoria: WWF\& ICMBio, 2012

Figura 1. Ciclo de gestão e avaliação proposto pela Comissão Mundial de Áreas Protegidas da União Internacional para a Conservação da Natureza.

O módulo contexto das unidades de conservação compreende a análise da importância biológica, importância socioeconômica, vulnerabilidades e pressões e ameaças sobre as unidades de conservação. O planejamento da unidade abrange a análise de objetivos, amparo legal e desenho e planejamento da área. O elemento insumos inclui a análise de recursos humanos, comunicação e informação, infraestrutura e recursos financeiros. Os processos contemplam o planejamento da gestão, a tomada de decisões e o desenvolvimento de pesquisas, avaliação e monitoramento. Os resultados são avaliados por meio da análise do nível de 
atendimento dos produtos e serviços gerados pelas ações relativas a diferentes temas desenvolvidas nos últimos dois anos na UC. A efetividade de gestão é analisada por meio dos elementos planejamento, insumos, processos e resultados (WWF-BRASIL \& ICMBIO, 2012). Cada gestor de UC deve responder ao questionário, atribuindo uma escala de valor com quatro categorias, em ordem crescente de atendimento da UC ao indicador avaliado, onde: $0=$ não, $1=$ predominantemente não, $3=$ predominantemente sim, $5=\operatorname{sim}$.

A efetividade é dada pela média dos indicadores avaliados, exceto indicadores de contexto.

O Governo Federal prevê a aplicação do RAPPAM em uma periodicidade de cinco anos. A primeira aplicação ocorreu em 2005, contemplou 103 indicadores e abrangeu 246 unidades de conservação federais. A segunda ocorreu em 2010 e contou com 140 indicadores e abarcou 292 UCs federais. O Anexo I contém os indicadores de cada módulo da avaliação do RAPPAM em 2010, exceto módulo perfil das UCs.

Dentre os pontos positivos do método RAPPAM está a perspectiva abrangente da gestão de UCs, além de produzir um resultado global que sintetiza o desempenho gerencial das UCs, o que facilita a comparação e discussão sobre o desempenho entre UCs (ARAÚJO, 2004).

A despeito da importância conferida ao RAPPAM e da grande disseminação do seu uso nas últimas décadas, a ferramenta possui limitações importantes que devem ser consideradas por aqueles que a adotam. Em primeiro lugar, é preciso se ter em mente que o RAPPAM resulta em um índice e, como tal é, via de regra, uma simplificação da realidade. Para tanto, há de se fazer opções de abordagem. Para cada metodologia observada, sempre haverá um conjunto de limitações. De tal modo que, mesmo à metodologia mais abrangente, em termos de indicadores considerados, recai o risco de que elementos cruciais para a efetividade da UC sejam diluídos em um conjunto de indicadores com muitos outros objetivos secundários, criando distorções da realidade em termos de eficiência das UCs.

Para Araújo (2004), ainda que o foco da ferramenta RAPPAM esteja voltado aos aspectos da gestão, mesmo este pode se apresentar carente de uma abordagem mais plena, pois trata-se de uma metodologia apoiada nos efeitos da gestão e não nas causas que os originaram. Assim, investiga-se a existência ou não de planos de manejo, conselho gestor, o conhecimento deficiente dos recursos naturais, dentre outros; mas não fornece uma visão sobre quais fatores são responsáveis por deficiências na gestão. $\mathrm{O}$ autor destaca que avaliações com esse cunho podem gerar um comportamento passivo por parte dos funcionários e gestores de UCs, uma vez que a baixa efetividade da gestão é atribuída a fatores que muitas vezes estão fora da governabilidade do gestor, só restando a ele o sentimento de impotência e o comportamento de 
lamúria. A avaliação gera a percepção equivocada de que ele pode fazer pouco para melhorar a gestão e que cabe ao órgão gestor a responsabilidade.

Outro ponto crítico no RAPPAM refere-se à subavaliação do impacto da gestão na conservação e na utilização dos recursos naturais pelas comunidades, ora pela ausência de indicadores, ora pela baixa contribuição dos mesmos em relação ao conjunto de indicadores de efetividade de gestão. Também não se avalia se estão sendo alcançados os objetivos das UCs de acordo com sua categoria. O RAPPAM, do mesmo modo que a maioria das outras ferramentas disponíveis, não dispõe de indicadores para fornecimento de uma visão sistêmica. Não avalia se a gestão está sendo integrada, se melhora a capacidade funcional do conjunto de UCs, se amplia a escala de conservação da natureza (o objetivo do conjunto deve ser maior do que a soma dos objetivos das áreas envolvidas), se promove a conectividade funcional e física, se garante a manutenção das funções ecossistêmicas, se contribui para o ordenamento territorial com base conservacionista, se estabelece espaços de articulação institucional e se fortalece a identidade territorial (OLIVEIRA, 2012).

Outro ponto negativo é a subjetividade existente não apenas na metodologia RAPPAM, mas na maioria das metodologias de efetividade de gestão disponíveis. Tal subjetividade é em grande parte atribuída a forma de mensuração, quase que unanimemente realizada com base na percepção de gestores. A respeito disso, Hockings (2003) pondera defendendo que, embora haja uma subjetividade nas respostas dos gestores das UCs, a grande experiência de campo faz com que suas respostas capturarem melhor a realidade e a complexidade envolvida com a gestão de UCs do que muitos programas de monitoramento baseados em dados quantitativos. Por outro lado, ainda que sejam reduzidos os erros de julgamento decorrentes do não entendimento dos conceitos arrolados, por trás da autoavaliação existe uma conveniência sustentada pelos valores pessoais e culturais de cada gestor e também do contexto político, os quais podem favorecer condições de efetividade super ou subestimadas. Ilustrando uma condição de autoavaliação superdimensionada, tem-se o profissional que demonstra mais do que na verdade existe para que seu conceito se eleve perante seus superiores e sua gestão colha melhores resultados (FARIA, 2007). Experiências com subdimensionamento podem estar relacionadas com uma postura modesta por parte do gestor, mas também há aqueles que consideram que valores demonstrar uma condição mais precária da gestão da UC do que de fato ela é, favorece uma maior chance de captação de recursos. Tal condição foi verificada no Programa Áreas 
Protegidas da Amazônia ${ }^{22}$ (ARPA), onde a postura de subvalorização de alguns fatores de avaliação foi adotada por parte de alguns gestores como forma de assegurar o fluxo de recursos para determinados programas de manejo (ARAÚJO et. al., 2009). Outra fonte de entendimentos equivocados é a substituição do entrevistado em função da troca de chefia na unidade - fato tão recorrente para as UCs brasileiras, sobretudo amazônicas, em função da alta rotatividade do seu corpo funcional

A despeito das críticas engendradas às metodologias apoiadas com base em percepções, e em específico, ao RAPPAM é extremamente relevante considerar os ganhos de escala decorrentes desses métodos, os quais permitem com um menor tempo, investimento de recursos humanos e financeiros levantar informações de âmbito nacional.

\subsubsection{STATUS E INFLUÊNCIAS SOBRE A EFETIVIDADE DE GESTÃO DE UNIDADES DE CONSERVAÇÃO FEDERAIS}

\subsubsection{Uma perspectiva com base nos dados do RAPPAM}

Apesar das diferentes abordagens metodológicas, todas as metodologias de avaliação, pelo menos até 2007, apontavam para uma baixa efetividade de gestão nas UCs federais brasileiras (ARAÚJO, 2007). Essa condição levou ao que ficou conhecido popularmente como "parques de papel" - unidades e conservação criadas legalmente, mas que, na prática em nada diferiam das demais áreas que não estavam sob regime especial de uso.

Entretanto, os diversos esforços de melhoria nos processos de gestão implementados na última década, parecem ter sido convertidos em ganhos de efetividade gerencial, pelo menos em relação às UCs federais brasileiras. Isso é o que diz a análise comparativa dos resultados de efetividade das UCs, decorrentes da aplicação do RAPPAM em 2005 e em 2010 (Tabela 1).

Tabela 1. Comparação dos índices de efetividade de gestão de unidades de conservação federais auferidos com base nos indicadores de efetividade do RAPPAM.

\begin{tabular}{|l|c|c|c|}
\hline Elemento/Módulo & $2005-2006$ & 2010 & Diferença percentual \\
\hline Importância biológica & 76,8 & 73,2 & $-3,6$ \\
\hline Importância socioeconômica & 61,4 & 59,5 & $-1,9$ \\
\hline Vulnerabilidade & 56,7 & 51,3 & $-5,4$ \\
\hline Planejamento & 56,2 & 60,5 & 4,3 \\
\hline Objetivos & 64,7 & 71,3 & 6,6 \\
\hline Amparo legal & 53,4 & 46,8 & $-6,6$ \\
\hline Desenho e planejamento da área & 51,4 & 61 & 9,6 \\
\hline Insumos & 32,3 & 38 & 5,7 \\
\hline Recursos humanos & 25,7 & 37,9 & 12,2 \\
\hline
\end{tabular}

${ }^{22}$ Programa voltado à consolidação e manutenção à longo prazo de UCs Amazônicas, considerado o maior programa de conservação de florestas tropicais do Planeta. O ARPA é conduzido pelo Governo Federal e implementado por uma parceria público-privada, onde o Fundo Brasileiro para Biodiversidade (uㅡbio $)$ é o gestor financeiro dos recursos provenientes de doação. 


\begin{tabular}{|l|c|c|c|}
\hline Comunicação e informação & 42,9 & 43,5 & 0,6 \\
\hline Infraestrutura & 28,5 & 38,4 & 9,9 \\
\hline Recursos financeiros & 30,4 & 32,3 & 1,9 \\
\hline Processos & 42 & 47,8 & 5,8 \\
\hline Planejamento da gestão & 32,6 & 37,7 & 5,1 \\
\hline Tomada de decisão & 59,3 & 60,5 & 1,2 \\
\hline Pesquisa, avaliação e monitoramento & 32,6 & 40,6 & 8 \\
\hline Resultados & 34,9 & 48,6 & 13,7 \\
\hline Efetividade de gestão & 41 & 48,1 & 7,1 \\
\hline
\end{tabular}

Fonte: WWF-BRASIL \& ICMBio, 2012
De 2005 para 2010 se observou um ganho de sete pontos percentuais em termos de efetividade de gestão dentre as UCs federais brasileiras.

O único elemento/módulo em que não houve incremento percentual foi o de contexto. Esse fato pode ser explicado pelo decréscimo da vulnerabilidade das unidades de conservação, o que é positivo. Por outro lado, observam-se também diferenças negativas na importância biológica e socioeconômica, as quais podem ser explicadas pelo declínio de alguns indicadores de avaliação relacionados, principalmente, ao desmatamento e degradação no entorno e, em alguns casos, no interior das (WWF-BRASIL \& ICMBIO, 2012).

Na avaliação de 2010 os módulos piores avaliados foram, em primeiro lugar, insumos e, em segundo, processos.

Embora não seja um objetivo específico da Tese, diante da necessidade de maior aprofundamento de algumas questões de base, realizou-se uma análise mais acurada da efetividade de gestão apontada pelo RAPPAM em 2010 e do avanço observado em relação a 2005. Os dados agregados das UCs contempladas por este estudo encontram-se no Anexo I. No módulo insumo, o ponto mais crítico observado foi o reduzido quadro de recursos humanos para a gestão da UC e a instabilidade da previsão financeira.

Apesar do número insuficiente de funcionários, houve um incremento considerável nas habilidades dos mesmos para realizarem a gestão - quase $25 \%$ em cinco anos. Tal condição pode ser reflexo do aumento registrado de cerca de $20 \%$ nas oportunidades de capacitação e desenvolvimento da equipe gestora da UC, entre 2005 e 2010.

Sobre os recursos financeiros para a implementação das UCs, embora os gestores apontem para um maior aporte nos últimos anos, a maioria considera que este aporte foi insuficiente para o atendimento dos objetivos de criação das unidades, corroborando o que vem apontando diversos estudos. No entanto, a alocação financeira parece estar sendo realizada de forma mais estratégica. É o que aponta o aumento de 15 pontos percentuais do indicador que indica a alocação com base nas prioridades e nos objetivos das UCs. No entanto, tão estratégico como 
essa alocação eficiente, está o aumento da capacidade de captação de recursos, sobretudo em períodos de retração econômica como o que o País atravessa atualmente. Justamente nesse ponto, foi registrada uma queda em relação ao ano de 2005. Na medida em que a crise econômica se agrava e se intensificam os cortes em setores considerados capazes de gerar menor rentabilidade líquida, a demanda pela captação de recursos aumenta. Dessa forma, devem ser empreendidos esforços urgentes para o desenvolvimento da capacidade de captação de recursos externos, sob o risco de descontinuidade das ações de implementação das UCs.

A gestão da informação também foi destacada como ponto crítico. Menos de $30 \%$ das UCs consideram possuir sistemas adequados para armazenamento, processamento e análise de dados. As instalações das unidades, sobretudo a infraestrutura voltada ao uso público, são consideradas inapropriadas na percepção da maioria dos gestores consultados. A comunicação entre a UC e outras instâncias administrativas foi o indicador melhor avaliado do módulo insumos (55\%), seguido das habilidades de gerenciamento da equipe gestora (53\%) e da comunicação efetiva com as comunidades locais (47\%).

No módulo planejamento, os itens piores avaliados foram os relacionados ao amparo legal, tanto em relação a baixa capacidade para se fazer cumprir as leis, quanto à reduzida conformidade da demarcação e sinalização dos limites das UCs. Em relação ao primeiro ponto, há uma grande lacuna no que tange à disponibilidade de recursos humanos e financeiros necessário às ações críticas de proteção (17\%).

A participação na definição do desenho e da categoria da UC, embora tenha sofrido um incremento de 13 pontos percentuais em cinco anos, ainda é considerada baixa (34\%).

Pontos do planejamento que colaboraram com o aumento da efetividade de gestão foram o conhecimento dos objetivos e políticas da UC por parte dos gestores, a localização da UC em coerência com seus objetivos e o amparo legal da UC e seus recursos naturais.

Avaliando-se os processos de gestão nas UCs um dos pontos mais críticos observados foi a falha no monitoramento dos impactos decorrentes de atividades legais e ilegais no interior das UCs. Essa deficiência, vinculada à outras condições também precárias como às lacunas nos inventários de fauna e flora e pesquisas socioeconômicas corroboram as dificuldades relatadas anteriormente de implementação de um sistema de monitoramento da biodiversidade e da sustentabilidade do seu uso.

Observou-se também que, a despeito do aumento das oportunidades de capacitação, percebido no módulo insumo, as UCs federais ainda carecem de processos de capacitação mais continuados. Esse ponto é crucial para que o conhecimento seja institucionalizado e não se 
perca em função da alta rotatividade de funcionários nas unidades de conservação, sobretudo no âmbito das UCs Amazônicas.

Igualmente preocupante é a situação de implementação dos dois principais instrumentos de gestão das unidades de conservação: o plano de manejo e os conselhos gestores. Embora o quesito adequação dos planos de manejo à realidade da $U C$ tenha dobrado em cinco anos, os valores do indicador ainda são muito baixos (30\%). Os conselhos gestores estão em situação um pouco mais favorável, no entanto, merecem rigorosa atenção, uma vez que sua efetividade média foi avaliada em cerca de $50 \%$.

O nível de participação das comunidades locais nos processos decisórios ainda é mediano, tendendo a estagnação nos últimos anos. Não foi observado qualquer incremento percentual nas médias do indicador para o ano de 2005 e 2010. O acesso das comunidades e equipe gestora aos conhecimentos decorrentes de pesquisas científicas na UC ainda é incipiente (32\%). Quase na mesma proporção em que são considerados os conhecimentos tradicionais no planejamento da UC (33\%). Isso significa que, de um modo geral, o investimento em produção do conhecimento científico ou tradicional não está sendo revertido em ações concretas em benefício da unidade de conservação.

Ainda no módulo processos, um grande destaque, desta vez positivo, foi atribuído à transparência no processo de tomada de decisões, que alcançou patamares superiores à $70 \%$. Também contribuem para o aumento da efetividade de gestão, a articulação efetiva da UC com órgãos e entidades relacionadas e o caráter colaborativo da unidade com as comunidades locais e outras organizações.

Em relação aos indicadores de resultado, de um modo geral, os gestores consideraram que o manejo de espécies e de habitats foi pouco adequado às suas necessidades nos dois anos que precederam a avaliação (2008 e 2009). Constatou-se também que, no mesmo período, o monitoramento de resultados da gestão ocorreu de forma deficiente. Aqui é importante destacar que o monitoramento da gestão via RAPPAM está previsto para ser realizado de cinco em cinco anos e que questão aborda mecanismos de monitoramento com um ciclo menor.

A temática de maior êxito no módulo resultado foi a prevenção de ameaças. Contudo, tal condição deve ser avaliada com cautela, uma vez que as grandes deficiências observadas no monitoramento de impacto não permitem que sejam traçadas ações preventivas mais estratégicas, pautadas pela realidade. Ao implementar ações preventivas não coordenadas com os impactos e ameaças prioritários para a UC, os parcos recursos financeiros e humanos podem estar sendo desperdiçados sem garantia de que as ameaças em potencial poderão ser evitadas. 
O indicador desenvolvimento de pesquisas alinhadas aos objetivos da UC nos últimos dois anos não só foi o indicador melhor avaliado como também apresentou um grande progresso entre as duas verificações do RAPPAM (25\% de incremento). O item planejamento da gestão foi o terceiro melhor pontuado em termos de fortalecimento da gestão.

\subsection{Efetividade de gestão $x$ desmatamento segundo o RAPPAM}

Como discutido nas seções anteriores, a avaliação de efetividade da UC com base no RAPPAM vem recebendo críticas por não explorar suficientemente os objetivos de conservação das UCs. No entanto, a importância dos instrumentos gerenciais (superestimados no RAPPAM) torna-se evidente ao observar como UCs em diferentes estágios de efetividade de gestão, se comportam de forma mais ou menos efetiva na contenção do desmatamento (Figura 2).

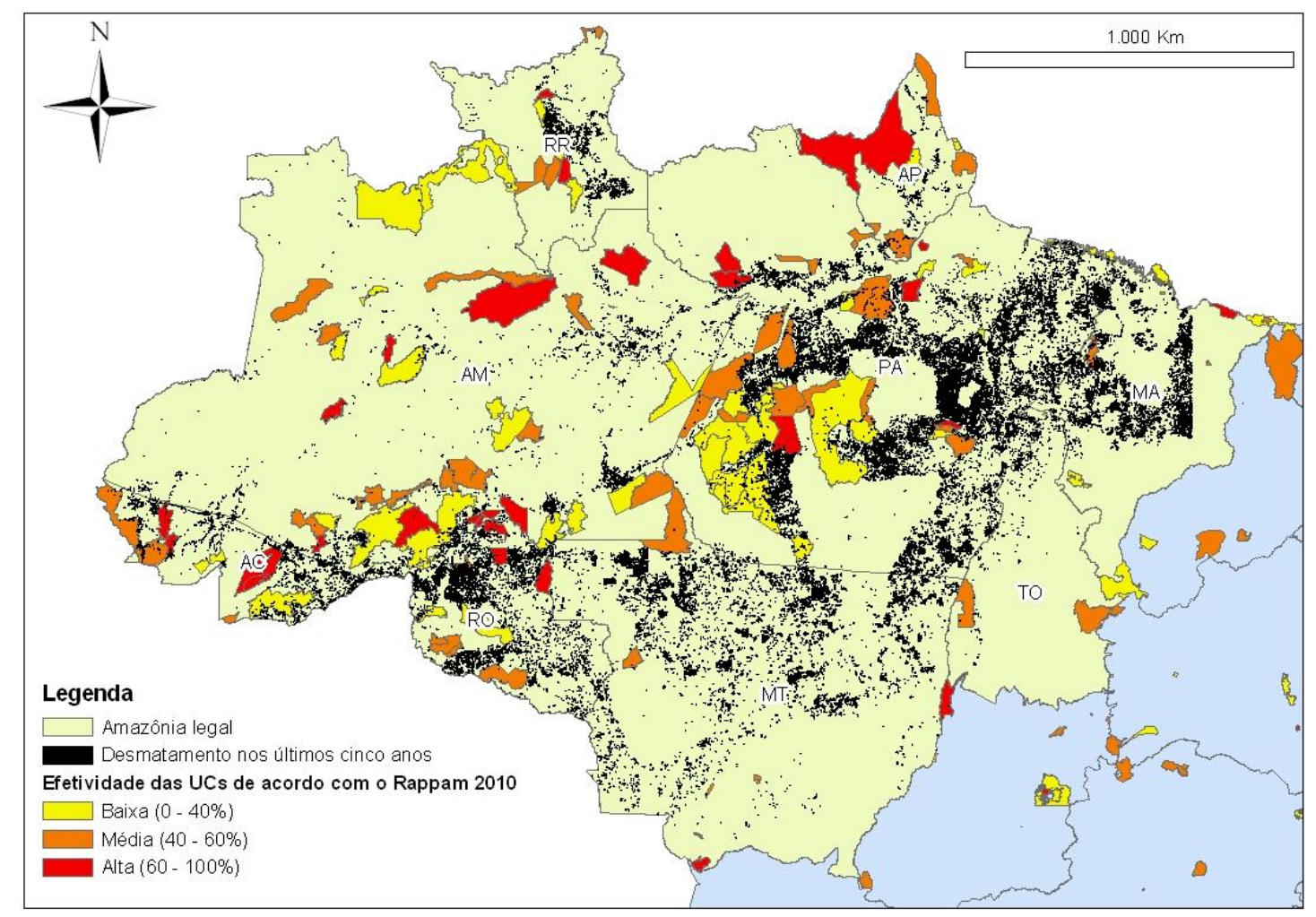

Autoria própria

Fonte: ICMBIO, INPE e IBGE

Figura 2. Mapa das unidades de conservação federais da Amazônia, categorizadas de acordo com a efetividade de gestão (segundo RAPPAM 2010) e desmatamento na região nos últimos cinco anos.

No mapa da Figura 2 estão representadas as unidades de conservação localizadas no bioma Amazônico, classificadas de acordo com sua efetividade de gestão, dada pelo RAPPAM. Uma avaliação visual do desmatamento nos cinco anos que antecederam a aplicação da ferramenta demonstra que as UCs como um todo estão cumprindo minimante o seu papel de proteção da biodiversidade. Observa-se, no entanto, que as unidades funcionam como barreira ao 
desmatamento, em uma relação diretamente proporcional à efetividade observada. Assim, UCs com alta efetividade tendem a atuar como uma barreira ao desmatamento mais eficiente do que as UCs menos eficientes (destacadas em amarelo).

\subsubsection{A efetividade de UCs sob a perspectiva administrativa}

Outros métodos de avaliação da gestão de UCs encerram abordagens distintas do método RAPPAM, resultando em outros indicadores, que, por vezes, conferem complementariedade e uma perspectiva mais ampla da temática.

Esse é o caso de uma abordagem com base nos preceitos da administração e pautada pelos princípios da gestão da excelência, difundida por Araújo (2007; ARAÚJO \& PINTOCOELHO, 2007 e ARAÚJO et. al., 2009). Nela, as UCs entendidas como espaços organizacionais necessitam, assim como qualquer organização, desenvolver três elementos básicos para obter êxito: liderança, conhecimento técnico e conhecimento gerencial. A ausência ou a fragilidade de qualquer um desses elementos na gestão da UC comprometeria a obtenção de bons resultados. Os autores consideram que o processo de formação e seleção dos gestores de UCs priorizam o conhecimento técnico, em detrimento do desenvolvimento da liderança e do conhecimento gerencial. O conhecimento gerencial relaciona-se ao uso de metodologias e ferramentas de gerenciamento para manter e melhorar os resultados da UC e vem sendo obtidos por esforço pessoal, de forma isolada e em uma profundidade muito aquém das exigências das funções. Para eles, a cultura organizacional ${ }^{23}$ vigente reflete a cultura burocrática e patrimonialista do setor público brasileiro. Não há foco em resultados ou preocupação em atender adequadamente aos usuários, em aumentar a produtividade e em reduzir os custos para a sociedade. Parte significativa dos cargos de chefia nos órgãos gestores são comissionados e preenchidos por critérios pessoais, e não em função a capacidade do profissional ou seu comprometimento com a obtenção de resultados. Não raro, os escolhidos não têm o preparo necessário à função e, para se manter no cargo, passam a priorizar o agrado ao padrinho político ou ao chefe imediato, em vez de se preocuparem com a eficiência e eficácia organizacional (ARAÚJO \& PINTO-COELHO, 2007).

Também é merecedora de destaque a perda de memória institucional em decorrência da alta rotatividade das equipes e a consequente descontinuidade administrativa. São priorizados projetos de curto prazo que podem ser relacionados mais facilmente com administração que o implantou. A perda de memória e do aprendizado organizacional impede que a instituição

${ }^{23}$ Conjunto de hábitos, crenças, valores e tradições, interações e relacionamentos sociais típicos de cada organização. 
promova a melhoria contínua de seus processos. Assim, boa parte da mudança na gestão das UCS brasileiras dependeria de uma mudança na cultura destas instituições (ARAÚJO, 2007; ARAÚJO \& PINTO-COELHO, 2007).

Nesse modelo, o monitoramento auxilia na identificação de causas gerenciais que podem estar agindo contra ou a favor do aumento da efetividade de UCs. Com isse intuito, Araújo et. al. (2009) propõem uma metodologia de avaliação da efetividade com base nos critérios de Excelência (MEG) da Gestão Pública: liderança, estratégias e planos, clientes e sociedade, informações e conhecimento, gestão de pessoas, gestão de processos e gestão de resultados. $\mathrm{Na}$ metodologia são identificados não apenas os efeitos da gestão (planos de manejo, regularização fundiária, inventários naturais, dentre outros), mas também as causas responsáveis pelos efeitos mensurados. Os autores consideram que com a aplicação do modelo de excelência em gestão, boa parte das análises é realizada sobre práticas de gestão sob governabilidade dos gestores, estimulando assim um comportamento proativo. Para eles, esse efeito é, ainda, potencializado considerando-se que na prática pequenas melhorias realizadas de forma contínua nas práticas de gestão das UCs podem trazer grandes resultados. Ademais muitas dessas melhorias não necessitariam de recursos humanos e financeiros adicionais e sim uma alocação orçamentária dos recursos já existentes mais eficiente.

As possibilidades de aplicação mais eficiente dos recursos financeiros com vista a maior efetividade de gestão são inúmeras, mas o investimento adequado em um conselho gestor mais atuante, certamente é um dos investimentos mais seguros. Um conselho gestor operante multiplica a capacidade de gestão da UC, além de representar uma instância potente de articulação e gestão de conflitos. Em função deste entendimento, a próxima seção caracteriza brevemente tais instâncias.

\subsection{CONSELHOS GESTORES DE UNIDADES DE CONSERVAÇÃO}

A participação efetiva das populações locais na criação, implantação e gestão das unidades de conservação é uma diretriz prevista na lei do SNUC, a qual determina a instituição de conselhos de UCs de modo a propiciar maior interação entre sociedade e poder público.

Os conselhos gestores (CGs) de UCs objetivam a formação de um espaço democrático de diálogo, negociação de interesses, participação e controle social, onde são debatidas questões ambientais, sociais, econômicas e culturais que tenham relação com a UC, sua zona de amortecimento e território de influência (ICMBIO, 2014).

De natureza deliberativa ou consultiva, a depender da exigência legal da sua categoria de manejo (Quadro 3), são compostos pelos principais atores de influência no contexto 
socioambiental da unidade - órgãos públicos, de organizações da sociedade civil, e, se for o caso, de populações tradicionais residentes e proprietários de terras. Via de regra, são presididos pelo órgão gestor responsável pela sua administração e instituídos por meio de Portaria do Presidente do Instituto Chico Mendes.

Quadro 3. Tipos de conselhos gestores por categoria de unidades de conservação.

\begin{tabular}{|c|l|c|}
\hline \multirow{4}{*}{ GRUPO } & \multicolumn{1}{|c|}{ CATEGORIA } & $\begin{array}{c}\text { TIPO DE CONSELHO } \\
\text { GESTOR } \\
\text { UCs federais* }\end{array}$ \\
\hline \multirow{5}{*}{ Proteção Integral } & Estação Ecológica & Consultivo \\
\cline { 2 - 3 } & Reserva Biológica & Consultivo \\
\cline { 2 - 3 } & Parque Nacional & Consultivo \\
\cline { 2 - 3 } & Refúgio da Vida Silvestre & Consultivo \\
\cline { 2 - 3 } & Monumento Natural & Consultivo \\
\hline \multirow{5}{*}{ Uso Sustentável } & Área de Preservação Ambiental & Consultivo \\
\cline { 2 - 3 } & Floresta Nacional & Deliberativo \\
\cline { 2 - 3 } & Reserva Extrativista & Deliberativo \\
\cline { 2 - 3 } & Reserva de Desenvolvimento Sustentável & Não exigido \\
\cline { 2 - 3 } & Reserva de Fauna & Não exigido \\
\cline { 2 - 3 } & Área de Relevante Interesse Ecológico & Não exigido \\
\cline { 2 - 3 } & Reserva Particular do Patrimônio Natural & \\
\hline
\end{tabular}

*A exigência do tipo de conselho por vezes é distinta entre as unidades de conservação federais e estaduais.

Os conselhos gestores de UCs são o principal elo de comunicação comunidade-sociedade e tem sido formalmente constituídos desde a institucionalização da obrigação legal destas instâncias na estrutura administrativa da UC.

Dentre as potencialidades decorrentes da ativa atuação destas instâncias, Palmieri \& Veríssimo (2009) destacam: (i) aumento do diálogo entre o órgão gestor, comunidade local, órgãos públicos e instituições da sociedade civil, na medida em que os conselheiros têm acesso a informações e compreendem as limitações e os desafios para gestão da UC; (ii) aumenta a governança e o apoio político da UC junto às comunidades locais, setor privado, ONGs, instituições de pesquisa, entre outros atores; (iii) amplia o conhecimento sobre a região e sobre o contexto político-institucional em que estão inseridas as UCs por meio da contribuição técnica dos conselheiros; (iv) aumenta o orçamento destinado às UCs, pois entidades que integram o conselho podem atrair recursos de doações para projetos da UC.

Para Abramovay (2001), um conselho que está aberto às variadas formas de participação pública, garantindo ampla difusão da pauta e estimulando a discussão prévia pela população 
sobre os temas que serão abordados, junto ao seu local de origem, contribui de forma decisiva para alterar as regras do jogo e fazer das organizações fonte de mudança social.

No entanto, o aumento da efetividade ${ }^{24}$ de gestão promovido pelos conselhos gestores, não se restringe a sua criação. É necessário envidar esforços para que eles, de fato, contribuam com o aprimoramento da gestão da UC.

Existe uma tendência a considerar que conselhos menos numerosos são mais efetivos, em função da dificuldade de mobilização dos membros (PALMIERI \& VERÍSSIMO, 2009).

Também se defende que, a princípio, quanto maior for o grupo, maior a diversidade de interesses dentro dele e mais fácil o aparecimento de "free riders", o que dificulta promover de forma igual interesses comuns e obter participação efetiva de todos (OLSON, 1991).

Palmieri e Veríssimo (2009) fazem um contraponto em relação aos conselhos muito pequenos, considerando o risco de nesses casos estes deixarem de expressar a diversidade das instituições, tornando-se pouco representativos. Os autores consideram que um conselho composto entre 12 e 24 conselheiros titulares seja o mais adequado.

No entanto, não se tem um número ideal de representantes no conselho. Ele não deve ser suficientemente grande, ao ponto de não inviabilizar a logística para reuniões, nem suficientemente pequeno, ao ponto de não contemplar os principais segmentos sociais que são afetados pela presença da unidade.

Mais adiante, o funcionamento dos conselhos gestores será abordado mais amiúde.

\section{CAPÍTULO 2. PARTICIPAÇÃO SOCIAL: CONCEITOS E LIMITES}

Este capítulo apresenta alguns caminhos conceituais para se definir o termo participação social em sentido mais amplo, com o objetivo de adquirir instrumental teórico para o delineamento conceitual adotado nesta tese.

\subsection{O QUE É PARTICIPAÇÃO SOCIAL?}

Participação social é um termo explorado nas mais variadas disciplinas e que agrega múltiplas perspectivas. Abrange desde ferramentas metodológicas até filosofias políticas, sendo utilizado para se referir a uma variedade de escalas de interação social e política e invocado para dar apoio a posições políticas e éticas diversas (MCGEE, 2003). Como resultado, verifica-se uma gama diversa de abordagens e significados, que devem ser claramente delimitados de modo a qualificar a discussão. A maioria delas, no entanto, possui, como denominador comum, o

\footnotetext{
24 Por conselho efetivo entende-se aquele conselho que se reúne regularmente, contribuindo com o
} amadurecimento de questões que envolvem a gestão da UC da gestão da UC 
próprio sentido etimológico da palavra (do latim participatio, participacionis, participatum) fazer parte, o que, dotado de significado político, equivale a fazer parte do processo decisório (PIZZORNO, 1966; MODESTO, 1999).

Para Demo (2001), a participação é um dos eixos fundamentais da política social, e como tal, deve ser caracteristicamente distributiva, de modo a reduzir as desigualdades sociais. Assim, mais que tomar parte do processo decisório, é necessário distribuir e disputar poder. Trata-se de reduzir a repressão, passar de objeto de manipulação para sujeito de seu próprio destino.

Mannigel (2008) atribui sentido similar ao ressaltar seu caráter facilitador de mudanças sociais em benefício de grupos marginalizados. Ambos ressaltam seu caráter dualístico: "Participação é meio e fim" (MANNIGEL, 2008 - p. 499, DEMO, 2001 p. 67). Meio, quando usada para aumentar a eficiência das intervenções na gestão e fim, quando vista como necessária para a equidade e o empoderamento de grupos suprimidos (MANNIGEL, 2008). Demo (2001) ressalta, no entanto, a preferência pelo sentido metodológico do termo, de modo a se evitar a participação pela participação, pois "miséria participada não interessa a ninguém” (DEMO, 2001, p.67).

Diversos autores qualificam o processo participativo recorrendo à categorização da participação segundo sua intensidade e/ou finalidade, ou outros padrões de ramificação (ARNSTEIN, 1969; AGARWAL, 2001; PERUZZO, 2002; MILANI, 2008), defendendo que não existe apenas uma forma de participação. Sinteticamente, as diferenças concentram-se, na sua maioria, na intensidade com que a voz ou controle dos participantes são incorporados. Variam, assim, de uma escala de não participação, participação passiva ou pouca participação, a uma escala onde o indivíduo ou o grupo participa ativamente do processo decisório.

Uma das categorizações mais difundidas é a proposta por Arnstein (1969), a escada da participação cidadã (Figura 3), onde níveis de participação são apresentados em um continuum. O nível de participação aumenta à medida que se sobe um degrau. Nos níveis manipulação e terapia, não existe participação. Os degraus, informação e consulta representam níveis de participação passiva. Na pacificação já item início algum grau de participação ativa. A partir do sexto degrau "parceria", o cidadão começa, de fato, a ter poder.

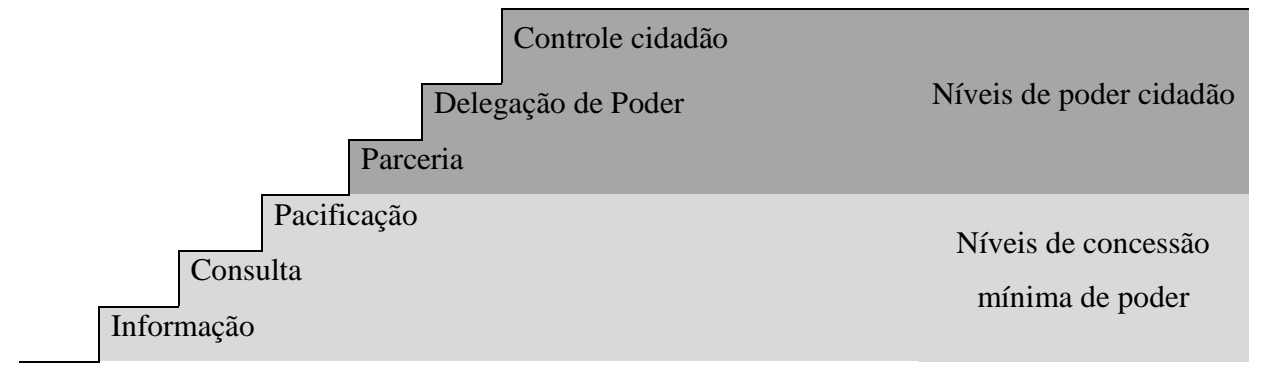




\begin{tabular}{l|l} 
Terapia & Não-participação
\end{tabular}

Adaptado de Arnstein, 1998

Figura 3. Níveis de participação propostos por Arnstein.

Mannigel (2008) propõe uma adaptação com base nas tipologias defendidas por quatro outros estudos: Borrini-Feyerabend (1996), Pimbert and Pretty (1997) e Mattes (1998). Nessa nova proposta, apresenta sete diferentes tipos de participação que variam do simples compartilhamento de informações à transferência de poderes e responsabilidades (Figura 4).

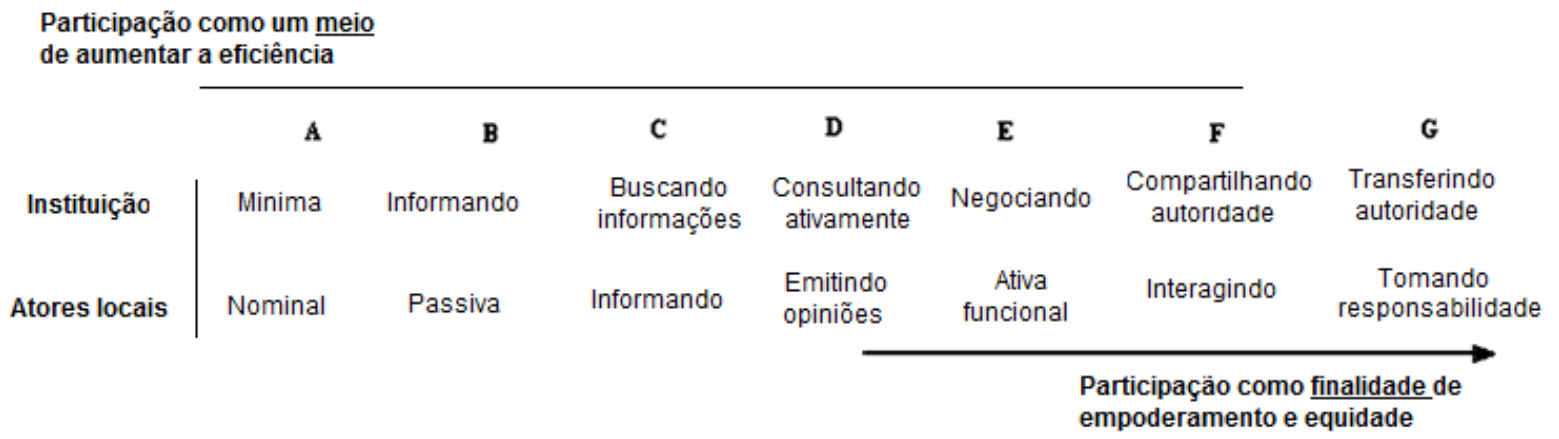

Tradução livre de Mannigel, 2008.

Figura 4. Diferentes tipos de participação propostos por Mannigel.

No primeiro nível, ocorre quase ou nenhuma interação entre atores as partes; no segundo participação passiva, a interação é unilateral; a partir do nível $\mathrm{C}$, os níveis de troca de participação aumentam gradativamente até se alcançar uma situação de transferência total de autoridade para os atores locais. Quando a participação é vista como um meio, as instituições normalmente não partilham a autoridade na tomada de decisão e os níveis $\mathrm{E}, \mathrm{F}$ e $\mathrm{G}$ são raramente usados. Considerando-se a participação como um fim para empoderar ou fortalecer grupos locais, os últimos níveis tornam-se preferíveis.

Mannigel (2008) enfatiza que se usando o sentido literal de "tomar parte" ou "agir junto" não apenas os níveis A e B não podem ser considerados participativos, mas também o último nível, porque novamente se tem um desequilíbrio na distribuição do poder. De fato, sabe-se que Participação não é ausência, superação, eliminação do poder, mas outras formas de poder (DEMO, $2001-$ p.20).

Outros autores que também se dedicaram a criação de tipologias de participação:

Sayago (2008), apesar de destacar que defende a existência da participação social nas mais variadas combinações, as divide para fins didáticos em quatro tipos: Participação individual, Participação coletiva, Participação passiva e Participação ativa. 
Pimbert e Pretty, (2000) propõem a seguinte divisão: participação passiva, participação como extração de informação, participação por consulta, participação por incentivos materiais, participação funcional, participação interativa e automobilização.

Gohn (2000) categorizou a participação a partir de cinco distintas abordagens: liberal, autoritária, democrática, revolucionária e democrático-radical. A autora ressalta a popularidade que o conceito alcançou, sendo uma das palavras mais utilizadas no vocabulário político, científico e popular da modernidade (GOHN, 2007).

A unanimidade da busca pela participação social também é destacada Montaño (2014), o qual apresenta duras críticas a vulgarização do conceito. Para ele, a participação amplamente disseminada é aquela desprovida de qualquer disputa de poder e concentrada em pequenas mudanças locais, com pouco potencial transformador.

Eguiluz (2011) aborda o risco da participação social como instrumento de manipulação. Para ele, se a participação não for trabalhada como facilitadora dos processos de mudança social, pode servir apenas como ferramenta para se alcançar objetivos escusos, um mecanismo proforma capaz de aliviar apenas momentaneamente a sensação de exclusão, sem atuar diretamente nas relações de poder desiguais e sem questionar a estrutura de poder vigente.

As prerrogativas para a promoção da participação social são tão diversas quanto a grande sorte de interpretações e tipologias existentes. Os atores políticos, ao decidirem pela participação, podem intencionar legitimar decisões previamente concebidas, atendendo a lógica da manipulação (YOUNG, 1990) ou dar legitimidade às ações genuinamente participativas e equilibrar as relações de poder entre instituições e atores que participam da dinâmica social (REDCLIFT, 1995), atendendo a anseios de descentralização, democratização do poder e o fortalecimento da cidadania ativa (JACOBI, 2002).

Young (1990) defende que a participação direta na política pública é rara e a política de implantação é, na maior parte, hierárquica impondo regras sobre os cidadãos. Assim, a maioria das pessoas não participa regularmente dos processos de tomada de decisão e carecem de poder significativo. A autora defende que, somente quando os grupos oprimidos são capazes de se expressar em condições de igualdade com outros grupos que o processo de tomada de decisão pode ser considerado ético.

Para muitos autores, participação e não participação são determinados quase que exclusivamente pelo exercício do poder e para se alcançar um modelo mais participativo, se deve estar disposto a ceder, pelo menos, algum poder (BERKES, 1995; GAVENTA, 1980; DEMO, 2001). A não observância das relações de poder e de desigualdade entre atores 
envolvidos e a heterogeneidade do acesso a informação qualificada nos processos participativos são apontadas como importantes falhas que devem ser observadas por aqueles que tem interesse em promover uma participação mais qualificada (ARNSTEIN, 1969; SIMMON, 1969; REDCLIFT, 1995). O acesso não equitativo às informações pode inibir a autoconfiança fazendo com que muitos participantes simplesmente não se manifestem (ARNSTEIN, 1969; AGARWAL, 2001).

Por vezes, as críticas aos processos participativos são mais centradas na atuação do Estado enquanto promotor e nos interesses que estariam por trás do compartilhamento dos processos decisórios. Montaño (2014) propõe que o empoderamento da sociedade como projeto ideológico procuraria desmobilizar a sociedade para as questões mais estruturais, desviando seu poder transformador para a gerência de conflitos. Para ele, a desresponsabilização do Estado nessas situações, seria reflexo natural da autoresponsabilização do indivíduo.

No entanto, são muitos os interesses por trás da participação social e, com frequência, a própria sociedade, via representação de determinados setores, realiza coligações advogando em prol de interesses próprios e em detrimento dos interesses da coletividade defendidos pelo Estado. $\mathrm{Na}$ prática, esta postura pode ser observada na maioria das reuniões de conselhos de meio ambiente, onde alguns representantes de setores sociais (como o madeireiro, do agronegócio, da indústria, dentre outros) realizam alianças de modo a dificultar o êxito de ações ambientais que poderiam representar alguma perda econômica.

Apesar das limitações de ordem política, diversos autores dedicam-se a demonstrar importantes ganhos associados a maior envolvimento social nas políticas públicas, além dos mencionados anteriormente, tais como:

- Redução de conflitos gerados a partir de restrições de uso dos recursos naturais (AGRAWAL \& GIBSON, 2001; BARROW \& MURPHREE, 2001; BRECHIN et. al. 2002; BERKES, 2007);

- Maior proteção ambiental (AGRAWAL \& GIBSON, 2001);

- Favorecimento da incorporação dos conhecimentos locais na implantação de projetos (JUNIOR \& SAMPAIO, 2008; BAQUERO, 2003);

- Maior sustentabilidade e a efetividade das ações (TOTH, 2012).

\subsection{A PARTICIPAÇÃO SOCIAL NA GESTÃO AMBIENTAL BRASILEIRA}

Até o início do seu processo de democratização, o Brasil foi considerado um País com baixa propensão associativa, com predominância de formas verticais de sociabilidade política, 
decorrentes de um processo de colonização que constituiu uma esfera pública fraca e ampliadora da desigualdade social (AVRITZER, 2006).

A explosão da participação social no Brasil ocorreu nos anos 1990 em decorrência da instalação da Assembleia Nacional Constituinte (ANC), após a derrubada da ditadura militar. Diante da possibilidade das emendas populares serem contempladas na nova constituição e na intenção de se colher assinaturas para muitas propostas ligadas às políticas públicas, foram organizadas diversas campanhas populares (AVRITZER, 2013). Para se ter uma ideia da força desse processo, em 2006 existiam cerca de 10.000 conselhos de políticas públicas que tiveram sua origem no processo Constituinte e na legislação ordinária que se seguiu, sobretudo nas áreas da saúde, assistência social e meio ambiente (AVRITZER, 2006). Nos últimos dois anos dessa década, dois outros poderosos canais de participação de grande impacto na relação Estado e sociedade foram instituídos: o orçamento participativo e as conferências nacionais.

Além dessas formas institucionais de participação, destacam-se audiências públicas, comitês de bacia, conferências, conselhos, mesas de negociação, ouvidorias, orçamentos participativos e planos diretores. Todas têm sido multiplicadas nas três esferas da Federação (IPEA, 2013).

No entanto, Pires (2013) defende que, a despeito da intensa disseminação e incorporação de mecanismos de participação social no Governo Federal, isso ainda seja um projeto inacabado, marcado por insuficiências, sobretudo pela falta ou deficiente abertura à participação de algumas áreas do Governo. Os programas governamentais dos diversos setores são desigualmente submetidos a processos participativos e em diferentes graus de intensidade. Isso é, enquanto as políticas sociais são debatidas em fóruns públicos, abertos e que propiciam aos atores sociais participar na definição de diretrizes para as políticas, na área de infraestrutura, adotam-se mecanismos que não contemplam a possibilidade de decisão compartilhada. Já na área de desenvolvimento econômico, não há sequer discussão pública e aberta, e essas se limitam à incorporação seletiva de atores, não sujeitos a requisitos de publicidade e transparência. Assim, os cidadãos e as organizações da sociedade civil encontram oportunidades desiguais de participação nas suas distintas áreas de atuação. A impossibilidade de atores sociais intervirem ou serem ouvidos em temas e áreas centrais da atuação do Estado, como desenvolvimento econômico e infraestrutura, impõe limites sérios à participação social e introduz lacunas na construção de uma gestão pública democrática.

Nesse sentido, faz-se necessária a ampliação de pontos de intersecção entre sociedade civil e governo que possibilitem a interação entre estes atores e regulem os termos de suas obrigações e orientem para ações conjuntas de governança onde os dois grupos possam agir juntos. Nesse 
sentido, marcos legais e políticos assumem relevância (MCGEE, 2003) enquanto instrumento ordenador e facilitador da participação social nas políticas públicas.

$\mathrm{Na}$ esfera ambiental, a participação social está prevista em diversos documentos, dentre os quais, destacam-se: Constituição Federal de 1988, Política Nacional de Meio Ambiente (PNMA), Agenda 21, Política Nacional de Gerenciamento de Recursos Hídricos, Política Nacional de Educação Ambiental, Sistema Nacional de Unidades de Conservação (SNUC), Plano Nacional Estratégico de Áreas Protegidas e Política Nacional de Participação Social (ICMBio, 2014).

A PNMA instituiu o maior colegiado participativo sobre meio ambiente, no qual interagem distintos setores da sociedade e do governo para regulamentar a política ambiental - o Conselho Nacional de Meio Ambiente (CONAMA). O Conselho Nacional de Meio Ambiente tem como atribuições principais propor diretrizes para as políticas de meio ambiente e recursos naturais e deliberar sobre normas e padrões relativos a área ambiental.

A Constituição Federal de 1988 prevê em seu artigo $1^{\circ}$ que "todo poder emana do povo, que o exerce indiretamente, através de seus representantes eleitos, ou diretamente, nos termos desta Constituição" e abre para a possibilidade de criação de meios de participação popular (plebiscito, referendo, iniciativa popular de lei, audiências públicas, conselhos, comitês, fóruns, orçamento participativo, ouvidorias). A participação da sociedade na defesa do meio ambiente ganhou importância a partir do artigo 225 da Constituição Federal, que assegura o direito a todos os cidadãos ao meio ambiente ecologicamente equilibrado, bem de uso comum do povo e essencial à sadia qualidade de vida, impondo-se ao poder público e à coletividade o dever de defendê-lo e preservá-lo para as presentes e futuras gerações.

Em 1992, o Brasil e outros 178 Países acordaram e assinaram a Agenda 21 global durante a Conferência da ONU sobre Meio Ambiente e Desenvolvimento (Eco 92), ocorrida no Rio de Janeiro - Brasil. A Agenda 21 faz parte de um processo participativo para sensibilização, mobilização, interação e pactuação entre diferentes setores da sociedade e do governo para políticas, planos e programas de desenvolvimento sustentável (ICMBio, 2014).

A Lei ${ }^{\circ}$ 9.985/2000 institui o Sistema Nacional de Unidades de Conservação - SNUC, um dos marcos regulatórios de maior importância na democratização dos espaços de gestão ambiental pública, ao tornar obrigatório o estabelecimento de processos de participação na gestão das unidades de conservação (MACEDO, 2008). O SNUC trouxe importantes contribuições na política de criação e gestão de unidades de conservação, favorecendo uma maior participação da sociedade nesses processos. Destas, destacam-se: a consulta pública para a criação de 
unidades de conservação e os conselhos de gestão das unidades criadas. A Lei obriga o Poder Público a consultar previamente a sociedade, com atenção especial à população local, sobre toda proposta de criação de unidade de conservação (exceto no caso de Estação Ecológica ou Reserva Biológica). Institui a obrigatoriedade de as unidades de conservação disporem de um conselho gestor (consultivo ou deliberativo, a depender da categoria da unidade), composto por representantes governamentais e da sociedade; estabelece diversas orientações para a gestão participativa em unidades de conservação, assegurando a participação efetiva das populações locais na criação, implantação e gestão das unidades de conservação e incentivando as populações locais e as organizações privadas a estabelecerem e administrarem as unidades de conservação.

Dentre os objetivos da Política Nacional de Educação Ambiental estão a garantia de democratização das informações ambientais, o estímulo e o fortalecimento de uma consciência crítica sobre a problemática ambiental e social e o incentivo à participação individual e coletiva, permanente e responsável, na preservação do equilíbrio do meio ambiente, entendendo-se a defesa da qualidade ambiental como um valor inseparável do exercício da cidadania.

O Plano Estratégico Nacional de Áreas Protegidas - 2006 - PNAP, constitui-se em uma das estratégias para implementar o SNUC e ampliar a participação da sociedade na gestão das áreas protegidas. Possui como princípio promover a participação, a inclusão social e o exercício da cidadania na gestão das áreas protegidas, buscando permanentemente o desenvolvimento social, especialmente para as populações do interior e do entorno das áreas protegidas. A participação social também aparece como bem marcada em suas diretrizes.

Os Congressos Mundiais de Parques ocorrem a cada dez anos e são organizados pela União Internacional para a Conservação da Natureza (UICN). Desde o $4^{\circ}$ Congresso, realizado em Caracas, em 1992, as recomendações emitidas pelos participantes destacam a participação da sociedade na gestão das áreas protegidas: "Recomenda o reconhecimento das relações entre populações locais e as áreas protegidas e a continuidade dos valores sociais e culturais". No $5^{\circ}$ Congresso, realizado na África do Sul em 2003, foi publicado o Acordo de Durban, que entre outras questões "reconhece a importância dos processos participativos e recomenda a adoção de mecanismos que permitam a representação e a participação de todos os atores locais envolvidos com a Unidade de Conservação”.

A Declaração de Bariloche, documento resultante do $2^{\circ}$ Congresso Latino-Americano de Parques Nacionais e outras Áreas Protegidas, realizado em 2007, estabelece que: “É essencial fortalecer e ampliar os processos de planejamento participativo das áreas protegidas como 
mecanismo que envolva ativamente os atores, gerando espaço de diálogo onde se analisem as preocupações e expectativas e se estabeleçam compromissos e responsabilidades".

Na COP 5 - CDB, a abordagem ecossistêmica, decisão dessa Conferência, estabelece em seus princípios que a gestão deve ser descentralizada e participativa, isto é, o manejo deve envolver todos os atores interessados, com uso do conhecimento local, visando a compatibilização de distintos interesses.

As metas de biodiversidade, definidas na COP 10 - CDB em 2010 (metas de Aichi) objetivam, além da redução da perda de biodiversidade, chamar a atenção de governos e da sociedade para a conservação ambiental.

Até este ponto, foram apresentados os principais fundamentos teóricos que servirão de alicerce ao desenvolvimento da tese. O capítulo seguinte descreve, pormenorizadamente, a metodologia de análise de cada um dos objetivos específicos perseguidos.

\section{Capítulo 3. Metodologia}

Neste capítulo será apresentada a metodologia adotada para se alcançar cada um dos objetivos específicos propostos, desde a seleção da fonte de dados secundários sobre participação social na gestão de UCs e o esforço de levantamento de dados primários, ao método de mensuração da participação e aquele utilizado para confrontar os dados sociais com os de conservação da biodiversidade.

O fluxograma da Figura 5 resume cada etapa, descrita pormenorizadamente mais à frente.

Para facilitar a compreensão, é apresentado no Quadro 4 o fluxo metodológico aplicado para cada objetivo específico, tendo como referência as etapas descritas na Figura 5.

Quadro 4. Fluxo metodológico representado na Figura 5 de acordo com cada objetivo específico.

\begin{tabular}{|l|l|}
\hline OBJETIVOS ESPECíFICOS & $\begin{array}{l}\text { ETAPAS DO FLUXO } \\
\text { METODOLÓGICO SEGUNDO } \\
\text { FIGURA 5 }\end{array}$ \\
\hline $\begin{array}{l}\text { Objetivo específico 1. Fornecer um panorama geral da } \\
\text { participação social na gestão de UCs brasileiras. }\end{array}$ & $\mathrm{A}-\mathrm{B}-\mathrm{C}-\mathrm{D}-\mathrm{F}$ \\
\hline $\begin{array}{l}\text { Objetivo específico 2. Estabelecer um parâmetro de } \\
\text { dimensionamento da participação social e de quantificação da } \\
\text { biodiversidade. }\end{array}$ & $\mathrm{A}-\mathrm{B}-\mathrm{C}-\mathrm{G}-\mathrm{H}-\mathrm{I}$ \\
\hline $\begin{array}{l}\text { Objetivo específico 3. Verificar a inter-relação entre } \\
\text { participação social na gestão de unidades de conservação } \\
\text { federais brasileiras e a conservação da biodiversidade. }\end{array}$ & $\mathrm{A}-\mathrm{B}-\mathrm{C}-\mathrm{G}-\mathrm{H}-\mathrm{I}-\mathrm{J}-\mathrm{K}$ \\
\hline $\begin{array}{l}\text { Objetivo específico 4. Analisar que fatores explicam as } \\
\text { variações na intensidade da participação social na gestão de } \\
\text { unidades conservação. }\end{array}$ & $\mathrm{A}-\mathrm{B}-\mathrm{C}-\mathrm{G}-\mathrm{H}-\mathrm{I}-\mathrm{L}-\mathrm{M}$ \\
\hline
\end{tabular}




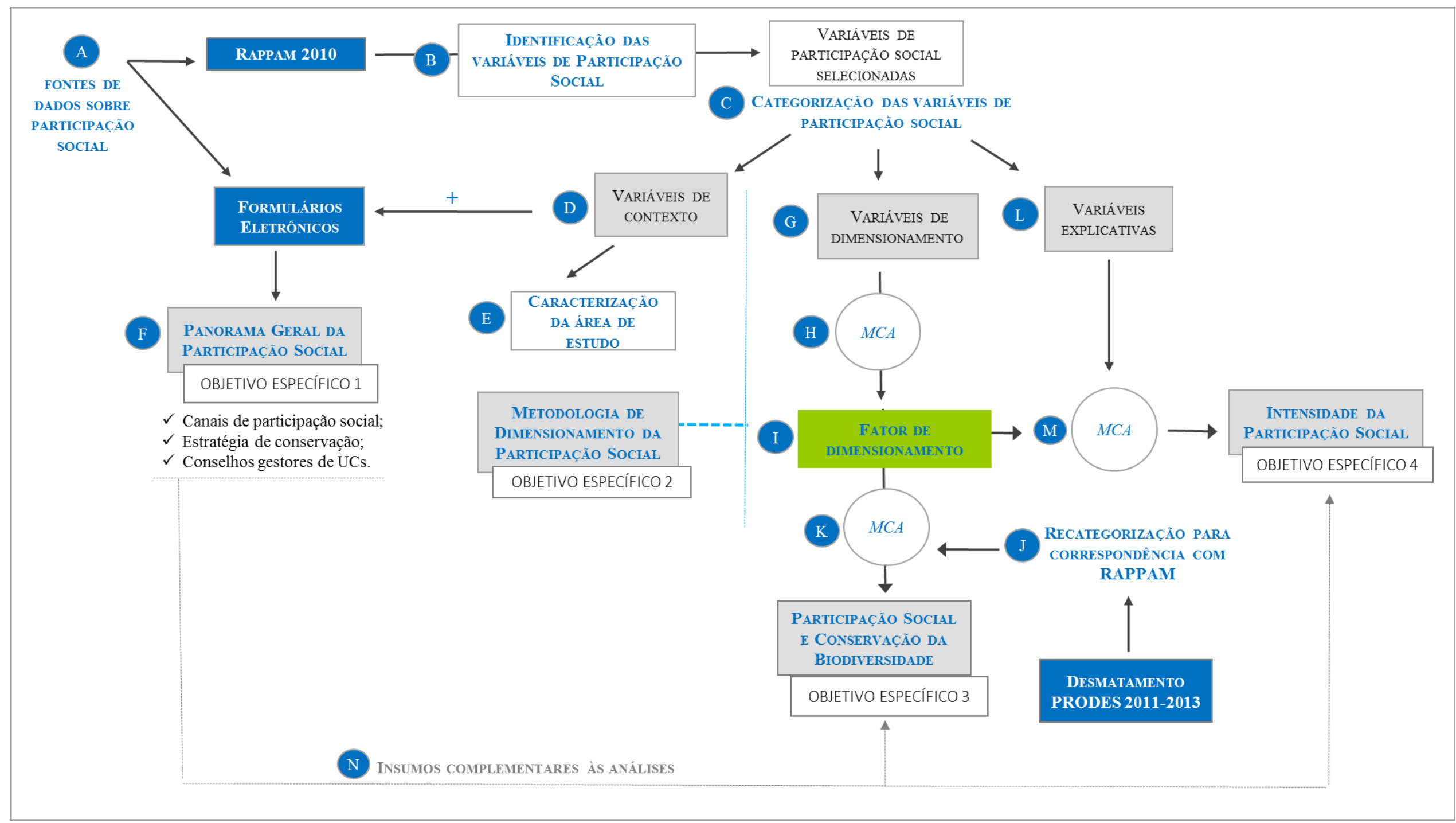

Figura 5. Fluxo metodológico adotado para consecução de cada objetivo específico. 


\subsubsection{Efetividade de unidades de conservação}

Esta Tese trata, em última instância, da efetividade das unidades de conservação, propriamente dita. A base conceitual adotada para o termo harmoniza-se com o proposto por Nogueira e Pereira (1999) no âmbito da temática da economia ambiental, sinônimo de um cenário no qual metas alcançadas ao menor custo cumprem seus objetivos mais amplos.

Entende-se como objetivo maior das UCs a conservação da biodiversidade, independentemente da categoria de manejo. No entanto, ao desconsiderar-se as questões socioculturais decorrentes da convivência das comunidades locais com as UCs, reconhece-se aqui a redução dos objetivos das unidades de conservação do grupo de uso sustentável. O intuito desta extrapolação conceitual foi possibilitar a utilização de um indicador capaz de encerrar a efetividade das unidades de conservação em uma medida quantitativa de fácil mensuração. Esse exercício foi necessário por dois motivos: redução da subjetividade da medida de conservação da biodiversidade, tendo em vista o alto grau de complexidade do conceito participação social que a ele seria associado, e a inexistência de métodos de avaliação da efetividade de unidades de conservação nacionais que contemplassem a dimensão de impacto (no caso a conservação da biodiversidade).

Por esse motivo, tais métodos não foram adotados, optando-se pela utilização de um proxy de conservação da biodiversidade: o desmatamento, como será detalhado na seção 3.10.

\subsubsection{Participação social}

O termo participação foi entendido aqui como sinônimo de interação social no processo de tomada de decisão.

Reconheceu-se que esta interação ocorre, ao longo de um continuum onde estágios iniciais estão mais associados a uma participação passiva e finais ao equilíbrio de poderes para a tomada de decisão.

Ademais, considerou-se o caráter dual do conceito - ao mesmo tempo meio e fim (DEMO, 2001; MANNIGEL, 2008), para orientar duas perspectivas de análise contempladas neste estudo, que conduzirão a diferentes caminhos que ora se bifurcam, ora se entrelaçam:

i. $\quad$ Finalidade, enquanto busca democrática, na missão de resgate da cidadania e/ou como pressuposto de diversas políticas sociais.

O capítulo 5 lança mão dessa ótica participativa ao apresentar o status quo da participação per si - tendo como pano de fundo as unidades de conservação. 
ii. Meio, no que se refere ao seu caráter instrumental, perspectiva utilizada quando se almeja alcançar objetivos específicos, que transcendem a participação.

Essa última abordagem será utilizada na seção 7.2, onde objetivou-se perceber a participação enquanto instrumento para se alcançar a conservação da biodiversidade.

\subsection{FONTE DE DADOS SOBRE PARTICIPAÇÃO SOCIAL}

As informações referentes às características gerais das unidades de conservação e ao status da participação social nas UCs foram obtidas a partir de dados secundários e primários (Figura 5, etapa A). Os primeiros, referentes ao ano de $2010^{25}$, foram disponibilizados pelo Instituto Chico Mendes de Conservação da Biodiversidade ${ }^{26}$ - ICMBio.

Desde 2005, o ICMBio utiliza o método “Avaliação Rápida e Priorização da Gestão de Unidades de Conservação" - RAPPAM ${ }^{27}$ (ERVIN, 2003) para o monitoramento quinquenal da efetividade de gestão das UCs federais, reunindo um expressivo acervo de informações. O método corresponde à mais abrangente ferramenta de medição da efetividade de gestão no quesito número de UCs do mundo (OLIVEIRA, 2012), abrangendo 94\% das UCs federais na sua última verificação, em 2010. Os resultados desse monitoramento são públicos e podem ser visualizados

em: http://observatorio.wwf.org.br/site_media/upload/gestao/documentos/Rappam_federal_2010.p df.

Adicionalmente, com intuito de dar complementaridade aos dados disponíveis, foi realizada a coleta de dados primários a partir da aplicação de um formulário eletrônico (Anexo III), direcionado à equipe gestora da UC em plataforma web, entre os meses de abril a outubro de 2013.

As perguntas não respondidas ou respostas nitidamente equivocadas foram complementadas com os dados secundários disponíveis. Foi o caso das variáveis "ano de criação do conselho gestor" e "número de conselheiros. A inadequação das respostas dessa última variável se deu, sobretudo, a interpretações heterogêneas sobre que número de conselheiros deveria ser considerado, somente titulares ou também os suplentes.

\footnotetext{
${ }^{25}$ Dados mais recentes durante a etapa de análise da Tese.

26 Autarquia vinculada ao Ministério do Meio Ambiente, criada em 2007 (Lei no 11.516 de 28/08/2007), quando passou a assumir a função de gerenciamento das unidades de conservação federais, até então realizada pelo Instituto Brasileiro do Meio Ambiente e dos Recursos Naturais Renováveis (IBAMA).
} 
De forma a sanar algumas destas lacunas, foram realizadas consultas às portarias de criação dos conselhos gestores a partir do site do ICMBio (http://www.icmbio.gov.br/portal/) e Instituto Socioambiental - ISA (http://uc.socioambiental.org/).

\subsection{SELEÇÃO DAS VARIÁVEIS DE PARTICIPAÇÃO SOCIAL}

As variáveis de participação social foram selecionadas dentro do conjunto de indicadores do método RAPPAM, considerando a capacidade de elucidar as seguintes questões:

i. $\quad \mathrm{O}$ ambiente político na UC favorece uma maior participação social? (Gestão transparente, comunicação eficiente com a comunidade, percepção positiva dos gestores da UC em relação às comunidades residentes ou de entorno)

ii. Que tipo de retorno a unidade de conservação traz para sociedade (fonte de emprego, valor recreativo, subsistência, valor espiritual, estético, dentre outros)?

iii. O perfil do conselho gestor influencia na intensidade da participação social - PS?

Como resultado desta primeira triagem, do total de 140 indicadores do RAPPAM, foram identificadas 24 variáveis, que, em conjunto com as informações levantadas no presente estudo, constituíram uma base com 51 variáveis, dentre descritivas do contexto da UC e potencialmente relacionadas à participação social na gestão de UCs (Figura 5, etapa B).

\subsection{CATEGORIZAÇÃO DAS VARIÁVEIS}

Com intuito de orientar a análise, foi realizado um esforço de categorização de todas as variáveis selecionadas em três diferentes grupos de acordo com sua função (Quadro 5 e Figura 5, etapa C), a saber:

i. Descritivas ou de contexto (Figura 5, etapa D) - resumem o contexto da unidade de conservação avaliada.

ii. Dimensionamento (Figura 5, etapa G) - potencialmente medidoras da participação social em si.

iii. Explicativas (Figura 5, etapa L) - exercem (ao menos potencialmente) alguma influência sobre o grau de participação social em determinada UC ou grupo de UCs.

Quadro 5. Categorização das variáveis de participação, por método utilizado (RAPPAM 2010 ou formulário eletrônico).

\begin{tabular}{|c|c|c|c|c|c|}
\hline \multicolumn{3}{|c|}{ VARIÁVEL } & \multicolumn{3}{|c|}{ FONTE } \\
\hline GRUPO & NOME & ABREVIAÇÃO & $\begin{array}{l}\text { RAPPAM } \\
2010\end{array}$ & $\begin{array}{c}\text { FORMULÁRIO } \\
\text { ELETRÔNICO }\end{array}$ & OUTROS* \\
\hline \multirow{4}{*}{ 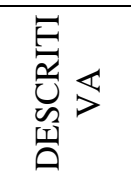 } & Nome da UC & $\mathrm{C} 1$ & $X$ & $\mathrm{X}$ & \\
\hline & Grupo da UC & $\mathrm{C} 2$ & $\mathrm{X}$ & $X$ & \\
\hline & Categoria & $\mathrm{c} 3$ & $X$ & $X$ & \\
\hline & Bioma & $\mathrm{c} 4$ & $\mathrm{X}$ & $\mathrm{X}$ & \\
\hline
\end{tabular}




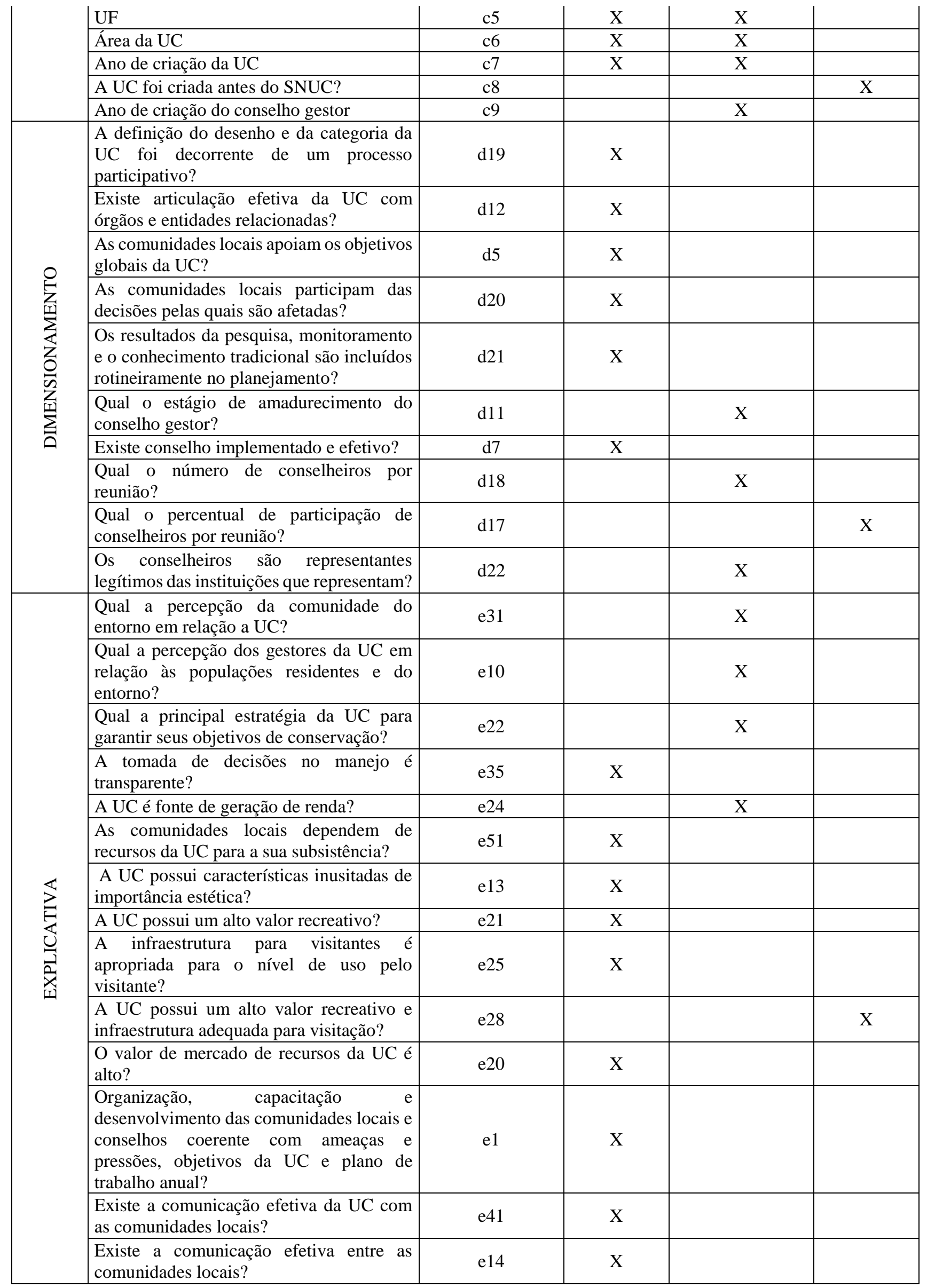




\begin{tabular}{|c|c|c|c|c|}
\hline $\begin{array}{l}\text { Os conflitos com a comunidade local são } \\
\text { resolvidos de forma justa e efetiva? }\end{array}$ & e7 & & & \\
\hline $\begin{array}{l}\text { Qual o canal de participação entre } \\
\text { comunidades e UC mais acessado pela } \\
\text { sociedade? }\end{array}$ & e 48 & & $X$ & \\
\hline $\begin{array}{l}\text { Qual a diversidade de canais de } \\
\text { participação social utilizados pela UC? }\end{array}$ & e2 & & $X$ & \\
\hline $\begin{array}{l}\text { Quantos anos se passaram da criação da } \\
\text { UC até a formação do conselho gestor? }\end{array}$ & e5 & & & $X$ \\
\hline $\begin{array}{l}\text { Qual o número de conselheiros que } \\
\text { compõem o conselho da UC? }\end{array}$ & e12 & & $X$ & \\
\hline $\begin{array}{l}\text { Qual o principal o principal entrave a } \\
\text { participação da comunidade nas reuniões } \\
\text { do conselho gestor da UC? }\end{array}$ & e29 & & $X$ & \\
\hline 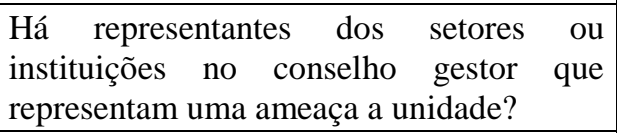 & e23 & & $X$ & \\
\hline $\begin{array}{l}\text { Os funcionários da } \text { UC colaboram } \\
\text { regularmente com os parceiros, } \\
\text { comunidades locais e outras organizações? }\end{array}$ & e49 & $X$ & & \\
\hline A UC é apoiada pelo Programa ARPA? & $\mathrm{e} 50$ & & & $\mathrm{X}$ \\
\hline $\begin{array}{l}\text { Qual a média anual de ações de fiscalização } \\
\text { nos últimos cinco anos? }\end{array}$ & e3 & & $X$ & \\
\hline $\begin{array}{l}\text { Quantas ações de fiscalização foram } \\
\text { realizadas no último ano (2013)? }\end{array}$ & e37 & & $X$ & \\
\hline
\end{tabular}

* Decorrente da combinação de variáveis do RAPPAM e/ou formulário, ou levantada em um dos seguintes sites: ISA/Unidades de conservação no Brasil (http://uc.socioambiental.org/), ICMBio (http://www.icmbio.gov.br/portal/biodiversidade/unidades-de-conservacao/biomas-brasileiros.html) e ARPA (http://programaarpa.gov.br/pt/)

A Tabela 2 resume o resultado do agrupamento de variáveis de cada método de acordo com a sua função.

Tabela 2. Categorização das variáveis analisadas em cada fonte de dados de acordo com a sua função.

\begin{tabular}{lcccc}
\hline TIPO DA & \multicolumn{3}{c}{ FONTE DE DADOS } & TOTAL \\
\cline { 2 - 4 } VARIÁVEL & RAPPAM 2010 & $\begin{array}{c}\text { Formulário } \\
\text { eletrônico }\end{array}$ & Outros* & \\
\hline Contexto & 7 & 8 & 1 & 16 \\
\hline Dimensionamento & 6 & 3 & 1 & 10 \\
\hline Explicativa & 11 & 11 & 3 & 25 \\
\hline Total & 24 & 22 & 5 & 51
\end{tabular}

* Decorrente da combinação de variáveis do RAPPAM e/ou formulário, ou levantada em um dos seguintes sites: ISA/Unidades de conservação no Brasil (http://uc.socioambiental.org/), ICMBio (http://www.icmbio.gov.br/portal/biodiversidade/unidadesde-conservacao/biomas-brasileiros.html) e ARPA (http://programaarpa.gov.br/pt/)

\subsection{CARACTERIZAÇÃO DA ÁREA DE ESTUDO}

A caracterização da área de estudo (Figura 5, etapa E) foi realizada a partir das variáveis do RAPPAM classificadas como de contexto e das informações obtidas pelo formulário eletrônico. 
Foi traçado um perfil da UC quanto a representatividade das categorias de manejo avaliadas, representatividade por bioma e Estados e momentos históricos mais favoráveis no Brasil para criação de UCs.

\subsection{ESTRATÉGIA DE CONSERVAÇÃO ADOTADA PELAS UCS}

Valendo-se da premissa que a propensão à participação social na gestão de UCs será tão maior quanto for a abertura de seus gestores ao diálogo com a comunidade afetada pelas restrições de uso da região da UC e entorno, categorizou-se as UCs de acordo com sua estratégia de conservação - se mais ou menos participativa.

Para tanto, foi levantado junto aos gestores qual seria a estratégia prioritária adotada pela UC para conservação da biodiversidade por ela abrigada. A pergunta, encaminhada via formulário eletrônico (pergunta número 1 do Anexo III), continha quatro possibilidades de enfoque prioritário: i. incentivos econômicos, ii. comando e controle, iii. educação ambiental e iv. engajamento social. O gestor também poderia optar por adicionar uma outra linha de ação voltada a conservação adotada prioritariamente pela UC que não estivesse contemplada dentre as quatro. $\mathrm{O}$ questionário restringiu o conceito de educação ambiental ao investimento no aprendizado, sem envolvimento ativo da comunidade, enquanto que o engajamento social foi considerado uma forma mais ativa de participação social na conservação da biodiversidade, na qual a comunidade não apenas recebe a informação sobre determinada realidade, mas busca construí-la. Assim, nesse estudo, esse último é considerado um nível onde ocorre uma maior de participação social.

A categorização do que convencionou-se chamar aqui de estratégias de conservação, reflete o conjunto de políticas adotadas pelos gestores de determinada unidade de conservação, às quais determinam diferentes de ação. A classificação estabelacida está de acordo com a lógica de divisão dos instrumentos políticos proposta por BEMELMANS-VIDEC et. al. (1998): instrumentos econômicos ou remunerativos, regulatórios ou coercitivos e persuasivos ou normativos.

\subsection{PANORAMA GERAL DA PARTICIPAÇÃO SOCIAL}

Os dados referentes à gestão de unidades de conservação federais brasileiras, obtidos pela aplicação do método RAPPAM, foram cedidos pelo ICMBio, já consolidados em planilha excel.

Os dados da tese que não estavam categorizados em padrão semelhante ao RAPPAM foram recategorizados de modo a refletir este comportamento. Esse foi o caso dos dados de desmatamento que será abordado mais adiante. 
Em relação aos dados primários, foi realizado esforço adicional de categorizar as respostas abertas do formulário eletrônico de modo a torná-las agrupáveis e permitir a sua consolidação e comparabilidade.

Os Anexos IV e V contém as informações necessárias para a compreensão de como foi feito este agrupamento para cada variável. O primeiro são os metadados e o segundo os dados do formulário eletrônico agrupados.

Essa base de dados foi utilizada para apresentar um panorama geral da participação social nas unidades e conservação selecionadas (Figura 5, etapa F).

É importante considerar que as respostas à todas as variáveis estudadas, tanto do RAPPAM quanto do formulário eletrônico, foram fornecidas pelos gestores das unidades de conservação, refletindo, portanto, a sua percepção individual. Isso representa uma limitação, uma vez que essa condição aumenta os níveis de subjetividade, mas permitiu que se fossem construídas linhas gerais sobre o tema participação social em UCs em escala nacional.

\subsection{DIMENSIONAMENTO DA PARTICIPAÇÃO SOCIAL}

Uma vez identificadas as variáveis potencialmente mensuradoras da participação social, dentre as variáveis selecionadas do RAPPAM, foi construído o desenho metodológico a partir do qual as mesmas interagiriam retornando medidas quantitativas de participação.

O método desenhado favoreceu duas condições consideradas relevantes neste trabalho: mínima perda de complexidade das inter-relações entre variáveis de participação social e possibilidade de replicação em estudos posteriores.

Esse último ponto foi considerado importante na medida em que possibilitaria uma avaliação continuada da participação social nas UCs. Com este intuito, convencionou-se que os dados de entrada do modelo de dimensionamento deveriam ser compostos, exclusivamente, por variáveis contempladas pelo método RAPPAM, dada sua oficialidade e ampla publicidade.

Os dados do RAPPAM são públicos, tem periodicidade definida (cinco anos), são oficialmente utilizados pelo Governo Federal na avaliação da efetividade de gestão das unidades de conservação brasileiras e adotados para o monitoramento de áreas protegidas em vários outros Países.

Para a definição da metodologia de dimensionamento buscou-se, ainda, a máxima preservação da complexidade das inter-relações entre variáveis de dimensionamento e explicativas da participação social. Fato esse considerando importante, tendo em vista que qualquer modelo que se propõe a explicar fenômenos de natureza complexa, tal como a participação, representaria uma simplificação e uma redução. 
Por esta razão, optou-se por um método que não estivesse apoiado sob modelos da estatística linear.

Pelo mesmo motivo, optou-se pela análise de correlação multivariada - MCA (Anexo VI) para verificar se as variáveis do RAPPAM, categorizadas nesta Tese como de dimensionamento, possuíam identidade ${ }^{28}$ entre si.

Essa identidade pode ser atestada visualmente, a partir da organização espacial dos dados. A análise de correspondência reproduz a distância entre as variáveis para uma tabela e gráfico de duas dimensões (STATSOFT, Inc, 2010), onde são criados diversos eixos (dimensões). Quando os eixos são criados e o gráfico é plotado em $2 \mathrm{D}$, as variáveis que estão próximas podem ser interpretadas como aquelas que 'caminham juntas'. Os eixos resultantes do $M C A$ demonstram quanto da variabilidade dos dados (ou inércia, ou dispersão dos dados) é explicável.

Ao demonstrarem identidade entre si, elas apresentam uma redundância de comportamento que representa um bom indicativo de que o conjunto pode ser utilizado como uma boa medida (no caso, de participação social), sem a necessidade de redução à um índice.

Diante do exposto, as variáveis de dimensionamento selecionadas dentre os indicadores do RAPPAM foram submetidas a análise de correlação multivariada (Figura 5, etapa $\mathrm{H}$ ).

A aplicação do $M C A$ nas variáveis de dimensionamento do RAPPAM resultou em um conjunto de variáveis que, juntas, resumiram a participação social. A esse conjunto convencionou-se chamar aqui de fator de dimensionamento (Figura 5, etapa I).

Assim, foi o fator de dimensionamento a medida de participação social utilizada para analisar os fatores que influenciaram na intensidade da participação social (seção 7.1) e o estudo da relação entre esta e as medidas de conservação da biodiversidade (capítulo 7.2).

A discussão em torno da adoção do método de dimensionamento proposto é apresentada no capítulo 6.

\subsection{IDENTIFICAÇÃO DOS FATORES DE MAIOR INFLUÊNCIA SOB A PARTICIPAÇÃO SOCIAL}

De forma semelhante e valendo-se dos mesmos argumentos apresentados na seção anterior, a análise da inter-relação entre variáveis para identificação daquelas que mais influenciam na participação social, foi realizada com apoio do $M C A$.

Foi realizada a análise de correlação multivariada entre as variáveis que compuseram ofator de dimensionamento (apresentadas mais adiante na seção 6.2) e as variáveis selecionadas como variáveis explicativas, dentre àquelas do RAPPAM (Figura 5, etapa M).

\footnotetext{
${ }^{28}$ Identidade é o nome atribuído ao padrão de resposta similar de uma determinada variável.
} 
Os metadados para essa análise são apresentados no Anexo VI e os resultados são descritos no próximo capítulo.

\subsection{DESENVOLVIMENTO DA MEDIDA DE CONSERVAÇÃO DA BIODIVERSIDADE}

\subsubsection{DESMATAMENTO COMO PROXY DE CONSERVAÇÃO DA BIODIVERSIDADE}

O método mais óbvio para se dimensionar o estado de conservação das UCs seria proceder com a avaliação a partir de medidas de índices de efetividade de gestão, talvez o próprio RAPPAM, já que este estudo o utilizou como base até este momento. No entanto, sabe-se que índices como esse estão muito mais empenhados em avaliar o desempenho dos processos de gestão do que os objetivos de conservação em si, e que o estado de conservação das áreas - objetivo fundamental de qualquer UC - frequentemente é subestimado (OLIVEIRA, 2012). Além disto, são muitas as dimensões avaliadas nestes índices, o que acaba por confundir a interpretação.

Em função dessas razões, optou-se por utilizar uma medida mais direta de perda da biodiversidade, o desmatamento florestal.

O desmatamento tem sido a principal causa de perda da biodiversidade no mundo (ALENCAR et al., 2004; BRANDÃO-JÚNIOR \& SOUZA-JÚNIOR, 2006; FEARNSIDE, 2005 e 2006; LAURANCE et al., 2001; MARGULIS, 2002; SOARES-FILHO et al., 2004; VIÉ et. al., 2009; RODRIGUES-FILHO et. al., 2015)

No Brasil, o Bioma Amazônia responde pelo maior impacto em termos de área desmatada. A escala na qual o desmatamento ocorre na região e o porte da cobertura vegetal amazônica favorecem o monitoramento remoto da sua evolução. Dada essas condições, a análise do desmatamento na Amazônia nos permite perceber variações espaciais da conservação da biodiversidade em grande escala, úteis no exercício de avaliação da gestão territorial. Esses argumentos contribuem para que o desmatamento possa ser considerado um bom proxy de conservação da biodiversidade.

Embora a utilização das medidas de desmatamento como inferência sobre o estado de conservação dos recursos naturais de determinadas regiões seja uma extrapolação e uma simplificação, ela se justifica em parte pelas grandes lacunas de conhecimento a respeito de nossa riqueza de espécies e diversidade genética.

Assim, a análise do efeito da participação social sobre a conservação da biodiversidade ocorreu tendo como base o fator de dimensionamento como medida de participação social (como apresentado anteriormente) e o desmatamento como medida de conservação das UCs. 


\subsubsection{LEVANTAMENTO DAS INFORMAÇ̃ES}

Os dados de base para cálculo do desmatamento no interior das UCs foram obtidos a partir do Programa de Cálculo do Desflorestamento da Amazônia $\left(\right.$ PRODES $^{29}$ ) do Instituto de Pesquisas Espaciais / Ministério da Ciência e Tecnologia (INPE/MCT).

Considerando que o reflexo da participação social no desmatamento pode ter, e é provável que tenha, consequências não imediatas, o desmatamento foi avaliado até três anos após a data de aplicação do RAPPAM utilizado (2010): 2011, 2012 e 2013.

\subsubsection{ADEQUAÇ̃̃O METODOLÓGICA DAS MEDIDAS DE DESMATAMENTO}

Como medida de desmatamento no interior de cada UC foi utilizada a média dos incrementos de desmatamento das áreas florestadas, contabilizadas a partir da criação da unidade. $\mathrm{O}$ valor utilizado nas análises foi a média dos três anos desse incremento.

Em função da natureza contínua da variável de desmatamento utilizada e, de modo a permitir a análise exploratória com a mesma técnica de correspondência multivariada, essas precisaram ser categorizadas dentro da mesma escala do fator de dimensionamento (0-5).

A categorização de dados contínuos é um artefato com consequências negativas por diminuir a precisão da informação. Por outro lado, é um artifício comum que permite a análise de dados de diferentes escalas, facilitando a interpretação (DOEY \& KURTA, 2011).

Após cálculo das médias dos incrementos da extensão do desmatamento e ordenação em sequência crescente de valores, a variável de desmatamento foi dividida em quatro categorias (Figura 5, etapa J), para garantir correspondência com as variáveis do RAPPAM (0, 1, 3 e 5). A intensidade atribuída a cada categoria foi crescente $(0=$ pouco desmatamento e $5=$ áreas muito desmatadas).

\subsubsection{ANÁLISE DE CORRELAÇÃO ENTRE AS VARIÁVEIS DE PARTICIPAÇÃO SOCIAL E DE CONSERVAÇÃO DA BIODIVERSIDADE}

No estudo da relação entre participação social e desmatamento foi processada a análise de correlação multivariada $(M C A)$ entre o fator de dimensionamento e as medidas de desmatamento em UCs (Figura 5, etapa $\mathrm{K}$ ). O MCA foi rodado três vezes, de modo a considerar: i) as UCs amazônicas como um todo, independente da sua categoria de manejo, ii) as UCs de proteção integral e iii) as unidades de uso sustentável. Assim, foi necessária a recategorização das variáveis de desmatamento em cada uma destas aplicações. Os Anexos VIII, IX e X contém a tabela de entrada para $o M C A$ entre desmatamento e fator de dimensionamento da participação

29 O PRODES realiza o monitoramento do desmatamento por corte raso na Amazônia Legal, via satélite e produz, desde 1988, as taxas anuais de desmatamento na região, utilizadas pelo governo brasileiro para o estabelecimento de políticas públicas. 
social, em todas as UC federais, nas UCs de uso sustentável e nas UCs de proteção integral, respectivamente.

\subsection{SELEÇÃO DAS UNIDADES DE CONSERVAÇÃO ANALISADAS}

O universo amostral de unidades de conservação avaliadas variou conforme o objetivo específico. Para todos esses, à exceção da análise do efeito da participação social sob a conservação da biodiversidade, foram consideradas todas unidades de conservação federais, independente do bioma, que responderam a pelo menos um dos instrumentos que compuseram a base de dados deste estudo (RAPPAM 2010 ou formulário eletrônico próprio da tese, como será detalhado mais adiante).

Isso retornou um total de 299 unidades de conservação, conforme presentado na Tabela 3.

Tabela 3. Número de unidades de conservação avaliadas por cada método e ano de aplicação considerado na análise.

\begin{tabular}{lllll}
\hline \multirow{2}{*}{ Método } & $\begin{array}{l}\text { Ano de aplicação } \\
\text { ferramenta/questionário }\end{array}$ & da & \multicolumn{3}{l}{ Número de UCs contempladas } \\
\cline { 4 - 5 } & PI & US & Total \\
\hline RAPPAM & 2005 e 2010 & 119 & 138 & 257 \\
\hline Projeto & 2013 & 75 & 54 & 129 \\
\hline $\begin{array}{l}\text { Total de UCs avaliadas por pelo menos um dos } \\
\text { dois métodos }\end{array}$ & 135 & 164 & 299 \\
\hline \hline
\end{tabular}

Para análise do desmatamento foram consideradas exclusivamente as unidades de conservação do bioma amazônico, cujo desmatamento foi monitorado pelo INPE entre 2011-2013.

A lista das unidades analisadas, dependendo da fonte de dados verificada, encontra-se no Anexo II.

A caracterização da área de estudo, apresentada na próxima seção, traz informações gerais sobre as UCs avaliadas.

\section{CAPÍtulo 4. CARACTERIZAÇÃo DA ÁREA DE ESTUdo E DA ESTRATÉGIA DE CONSERVAÇÃO} ADOTADAS

O presente capítulo, de cunho essencialmente descritivo, objetiva fornecer um panorama geral das unidades de conservação amostradas e as estratégias de conservação caracteristicamente adotadas pelas mesmas. 


\subsection{PERFIL GERAL DAS UCS}

Este estudo abarcou quase a totalidade de unidades de conservação federais brasileiras $(96,3 \%)^{30}-45 \%$ de proteção integral e $55 \%$ de uso sustentável, dentre nove categorias de manejo (Tabela 4).

Tabela 4. Grupos e categorias de manejo das UCs analisadas.

\begin{tabular}{lcc}
\hline \multirow{2}{*}{ Grupo de proteção / Categoria de manejo } & \multicolumn{2}{c}{ Unidades de conservação avaliadas } \\
\cline { 2 - 3 } & $\mathrm{n}$ & $\%$ \\
\hline \hline PI & 135 & 45 \\
\hline Estação Ecológica & 32 & 11 \\
Parque & 68 & 23 \\
Refúgio de Vida Silvestre & 65 & 22 \\
Reserva Biológica & 30 & 10 \\
\hline US & 164 & 55 \\
\hline Área de Proteção Ambiental & 29 & 10 \\
Área de Relevante Interesse Ecológico & 10 & 3 \\
Floresta & 65 & 22 \\
Reserva de Desenvolvimento Sustentável & 1 & 0 \\
Reserva Extrativista & 59 & 20 \\
\hline Total Geral & 299 & 100 \\
\hline
\end{tabular}

Em termos de representatividade por bioma, quase $70 \%$ das unidades estudadas localizam-se ou no bioma Amazônico ou na Mata Atlântica (Tabela 5). Esse último bioma, no entanto, abriga um maior número de unidades de conservação de proteção integral do que o Amazônico. Para as UCs de uso sustentável é observada uma tendência contrária.

Tabela 5. Distribuição percentual das UCs analisadas por bioma.

\begin{tabular}{l|rrrr|rrrrrrrr|r}
\hline \multirow{2}{*}{ BIOMA } & \multicolumn{9}{c|}{ PROTEÇÃO INTEGRAL } & Total & \multicolumn{4}{c}{ USO SUSTENTÁ VEL (US) } & \multicolumn{2}{c|}{ Total } & TOTAL \\
& ESEC & PARNA & RVS & REBIO & (PI) & APA & ARIE & FLONA & RESEX & RDS & (US) & (PI+US) \\
\hline \hline Amazonia & 3,68 & 6,02 & - & 3,01 & 12,71 & 0,67 & 1,00 & 10,70 & 13,04 & 0,33 & 25,75 & 38 \\
Caatinga & 1,34 & 2,01 & - & 0,33 & 3,68 & 0,33 & - & 2,01 & - & - & 2,34 & 6 \\
Cerrado & 1,67 & 4,35 & 0,33 & 0,33 & 6,69 & 3,34 & 0,67 & 1,34 & 2,68 & - & 8,03 & 15 \\
Marinho & 1,34 & 2,01 & 0,33 & 0,67 & 4,35 & 1,34 & 0,33 & - & 3,68 & - & 5,35 & 10 \\
Mata atlântica & 2,01 & 7,69 & 1,00 & 5,69 & 16,39 & 3,68 & 1,34 & 7,02 & 0,33 & - & 12,37 & 29 \\
Pampa & 0,33 & 0,33 & - & - & 0,67 & 0,33 & - & 0,67 & - & - & 1,00 & 2 \\
Pantanal & 0,33 & 0,33 & - & - & 0,67 & - & - & - & - & - & - & 1 \\
TOTAL & 10,70 & 22,74 & 1,67 & 10,03 & 45,15 & 9,70 & 3,34 & 21,74 & 19,73 & 0,33 & 54,85 & 100 \\
\hline
\end{tabular}

LEGENDA: ESEC - Estação Ecológica, PARNA - Parque Nacional, RVS - Refúgio da Vida Silvestre, REBIO - Reserva Biológica, PI - Proteção Integral, APA - Área de Proteção Ambiental, ARIE - Área de Relevante Interesse Ecológico, FLONA - Floresta Nacional, RESEX - Reserva Extrativista, RDS - Reserva de Desenvolvimento Sustentável, US - Uso Sustentável.

${ }^{30}$ Excetuando-se as RPPNs 
A significativa amostragem permitiu uma grande aproximação do padrão das UCs na sua totalidade de modo que as características gerais das UCs analisadas e aqui descritas podem facilmente ser extrapoladas para a realidade das unidades de conservação federais brasileiras como um todo.

Na história das unidades de conservação brasileiras podem ser observados dois picos de criação, tanto em termos de área destinada à UC (Figura 6), quanto em relação ao número de unidades de conservação criadas (Figura 7).

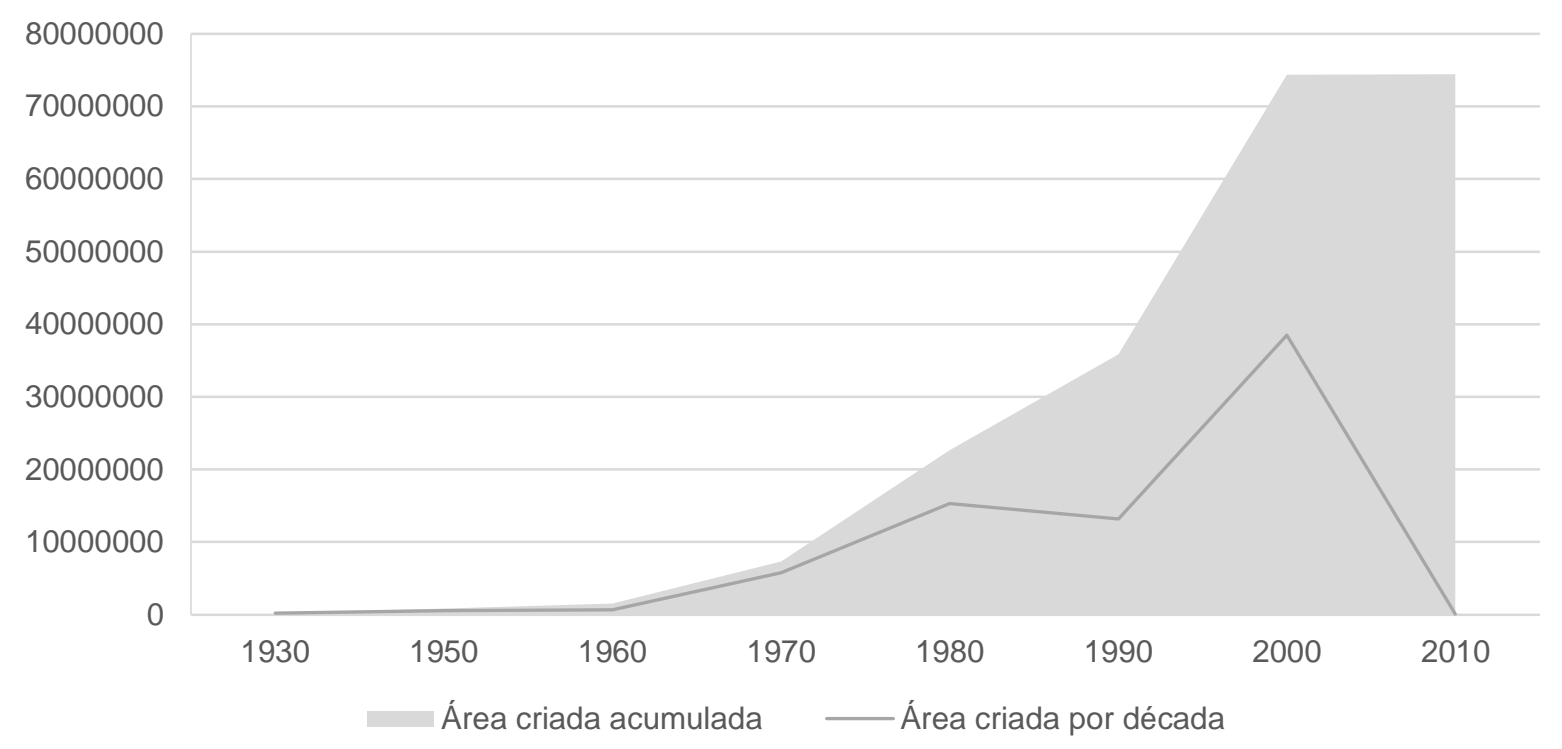

Fonte: RAPPAM, 2010

Autoria própria, 2015.

$(n=299)$

Figura 6. Área efetivamente destinada para criação unidades de conservação até 2014.

O primeiro pico de criação de unidades e conservação foi decorrente do posicionamento político do governo militar (1964-1985), que viu nas unidades de conservação uma oportunidade de aumentar o controle sob o território nacional (MEDEIROS et. al., 2004), bem como atender as salvaguardas ambientais exigidas nos projetos financiados por entidades multilaterais (DIEGUES, 2001). O segundo, e mais expressivo, foi registrado na primeira década do século atual, e é reflexo da combinação entre o estabelecimento de um aparato legal para criação e estabelecimento de UCs e ambiente político favorável. Como resultado, quase $87 \%$ das UCs federais brasileiras foram criadas entre os anos 1980 e a década atual. 


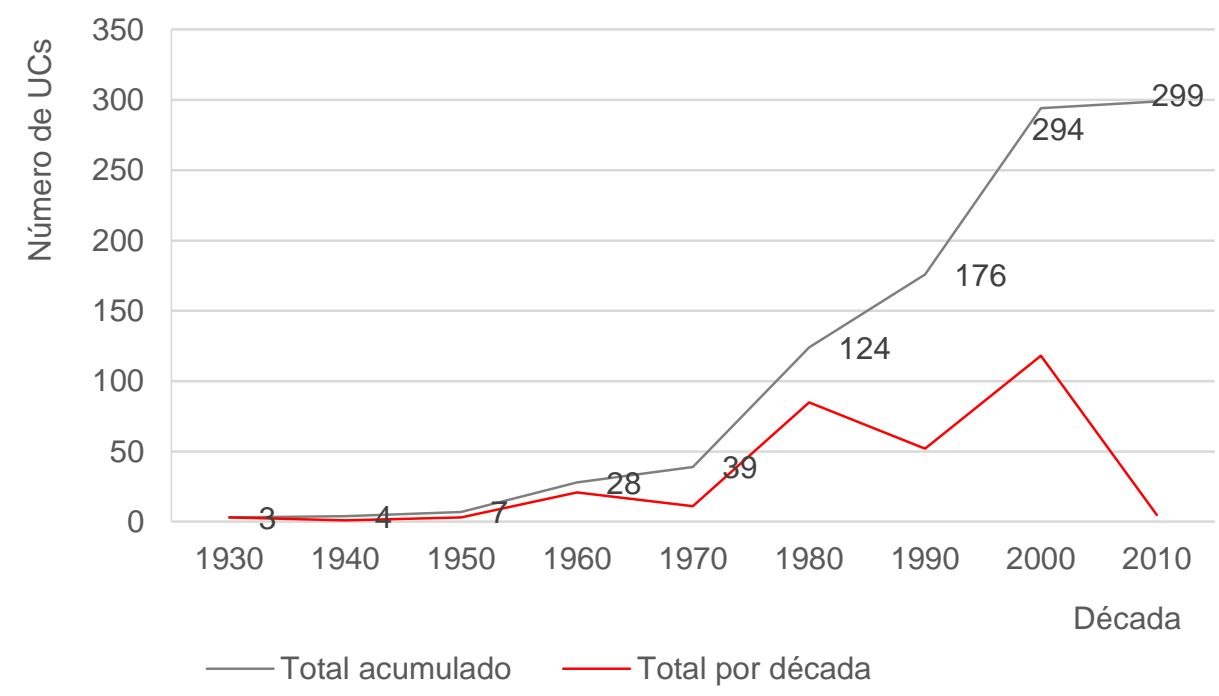

$(\mathrm{n}=299)$

Fonte: RAPPAM, 2010

Autoria própria, 2015.

Figura 7. Unidades de conservação federais criadas por década até 2014.

Ao avaliar especificamente a década de 2000, dois momentos fundamentais podem ser observados (Figura 8). O primeiro compreende os anos seguintes à instituição do Sistema Nacional de Unidades de Conservação da Natureza - SNUC, pela publicação da Lei que estabeleceu critérios e normas para a criação, implantação e gestão das unidades de conservação, em julho de 2000. Entre 2000-2002 foram criadas mais de 50\% de todas as unidades de conservação dessa década. O segundo período, entre 2005-2006, representou provavelmente o momento político nacional mais favorável para a criação de unidades de conservação, onde foram criados outros $40 \%$ do total da mesma década.

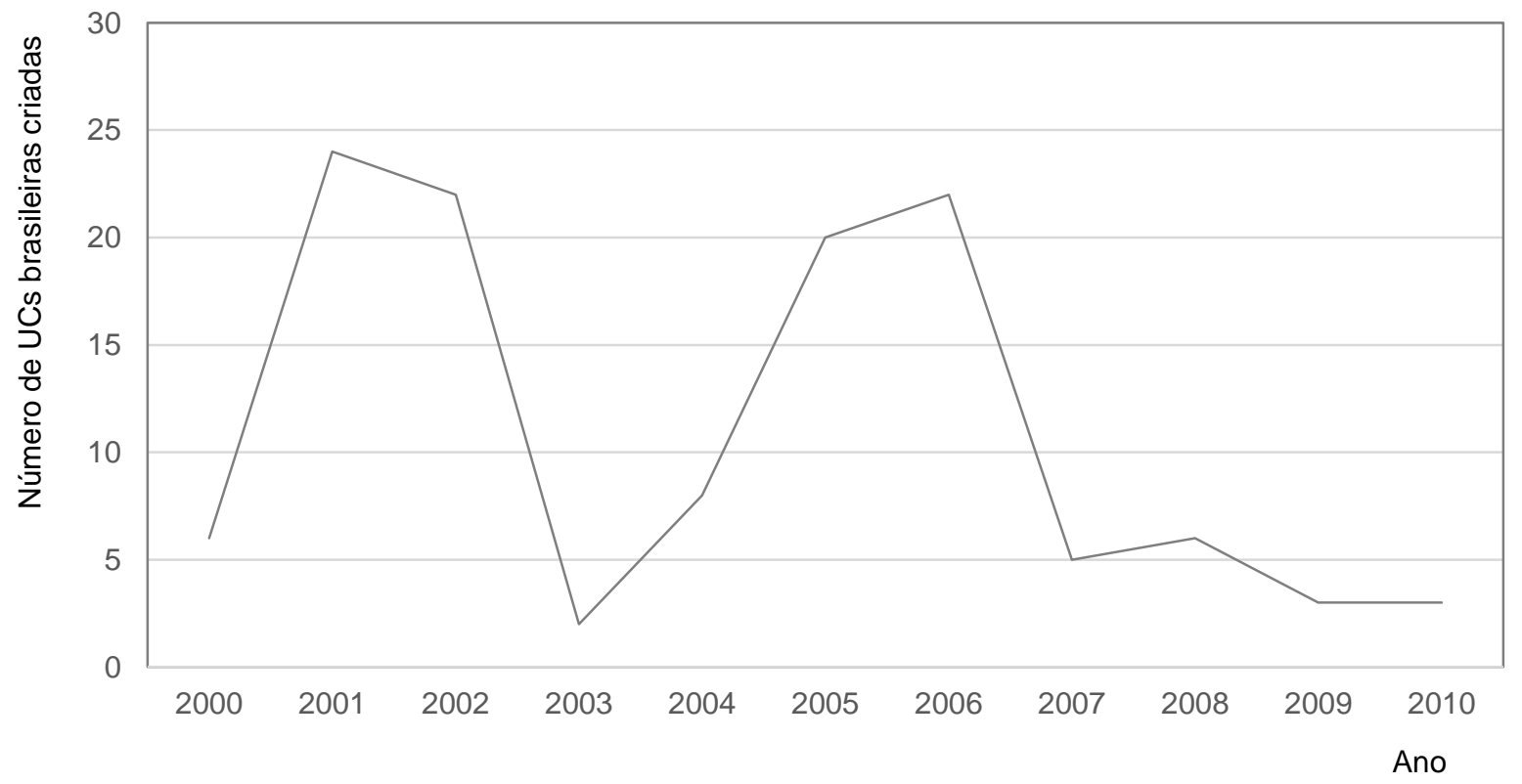


$(n=299)$

Fonte: RAPPAM, 2010

Autoria própria, 2015.

Figura 8. Unidades de conservação brasileiras criadas entre 2000-2010.

O contexto político internacional favoreceu a configuração deste segundo marco, uma vez que em 2006 pode ser observado um pico de criação de áreas protegidas no mundo (Figura 9).

A contribuição das unidades de conservação brasileiras no conjunto de áreas protegidas no mundo é notável. Como exemplo, entre 2003 e 2009, o País respondeu com 75\% das áreas protegidas criadas no mundo (JENKINS, 2009). No entanto, a criação de unidades de conservação brasileiras sofreu drástica redução na última década.

\section{Número de APs}

criadas no mundo

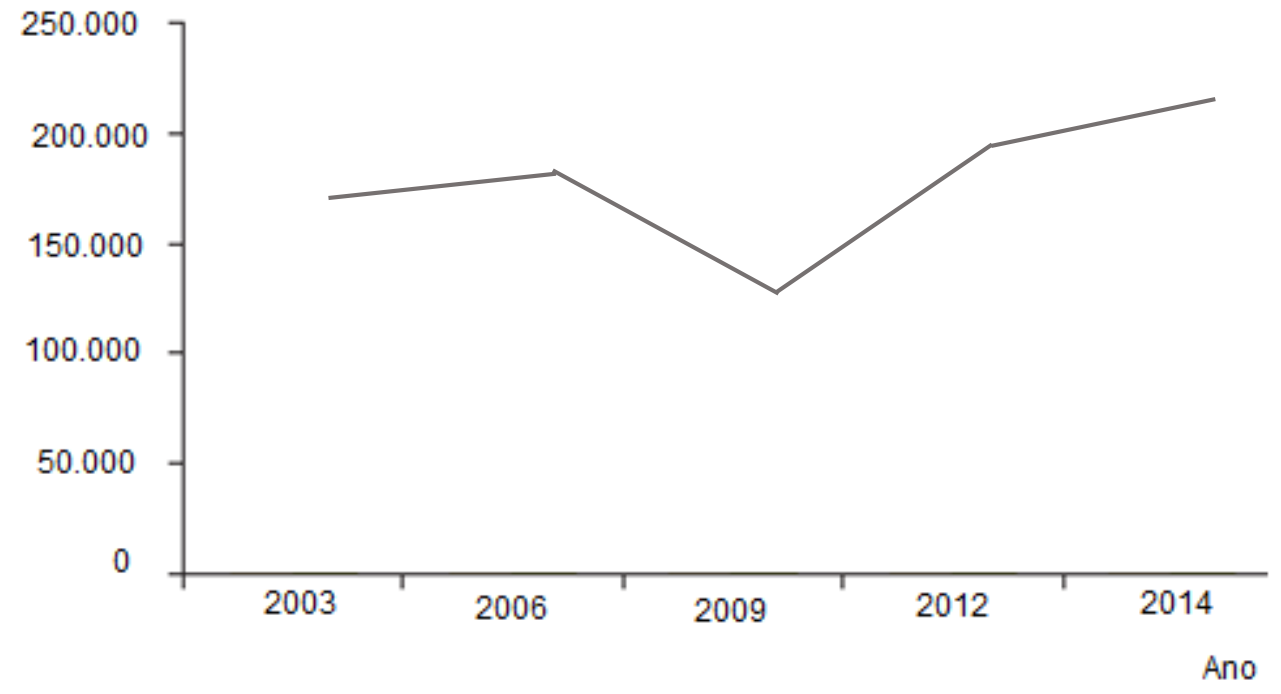

Fonte e Autoria: IUCN/WDPA, 2014

Figura 9. Áreas Protegidas criadas no mundo entre 2000-2014.

Em relação a área protegida por bioma sob forma de UC, a Amazônia é o melhor representado, com quase 15\% do seu território delimitado como unidade de conservação (Figura 10). A figura evidencia ainda o forte desequilíbrio na representação dos demais biomas. O bioma Cerrado, segundo melhor representado, não possui nem 5\% do seu território sob forma de UC. 


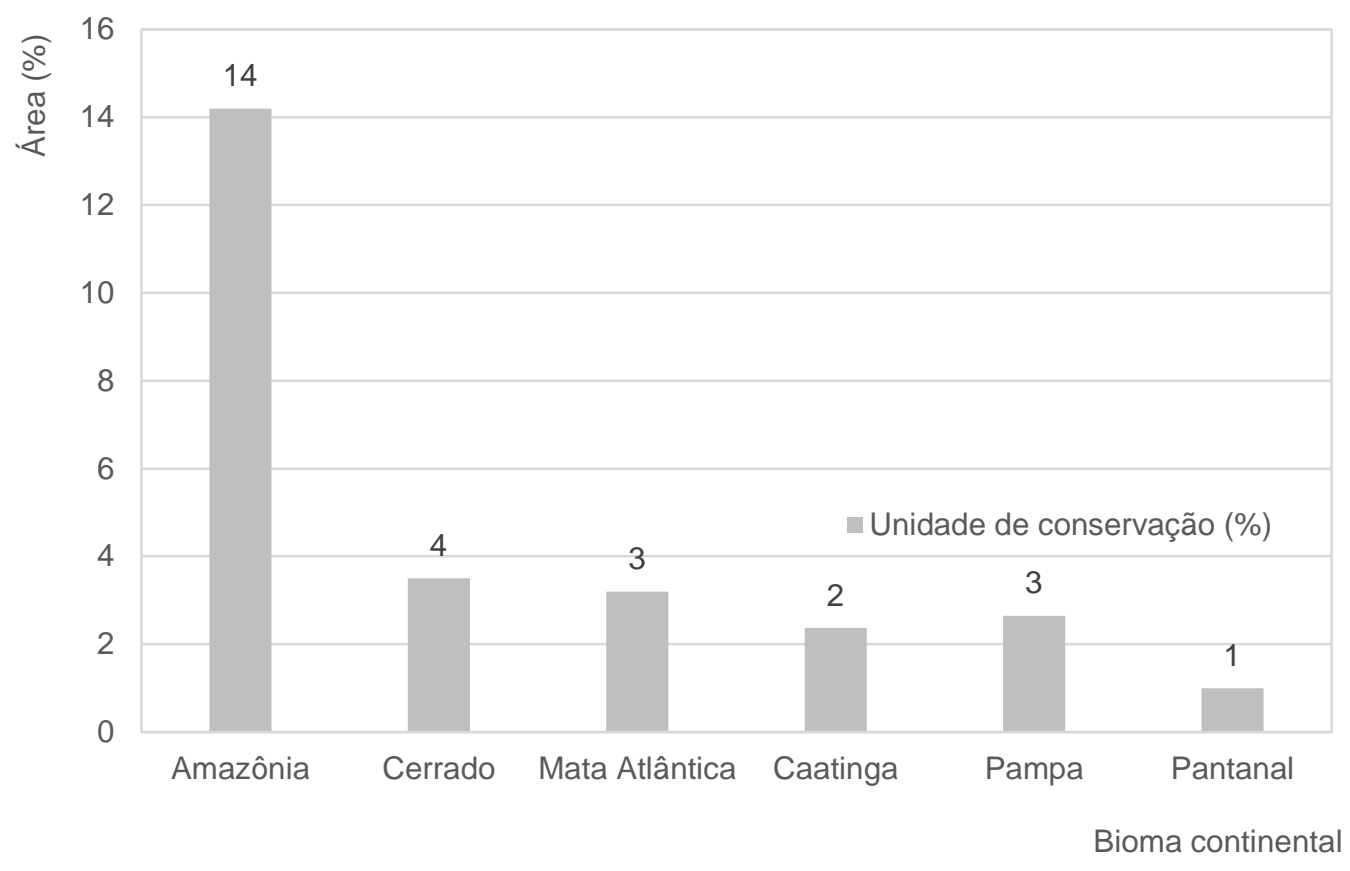

Fonte: RAPPAM 2010

Autoria própria, 2015.

Figura 10. Percentual de área destinado à unidade de conservação em cada bioma continental brasileiro.

Em relação ao tamanho, as UCs federais brasileiras são maiores do que as de outros Países (Figura 11). Enquanto que quase a metade das áreas protegidas do mundo abarcam territórios de até 100 hectares, as brasileiras concentram-se na classe de tamanho entre 1.000 e 100.000 hectares, sobretudo as Amazônicas (Figura 12).

Percentual de

áreas protegidas

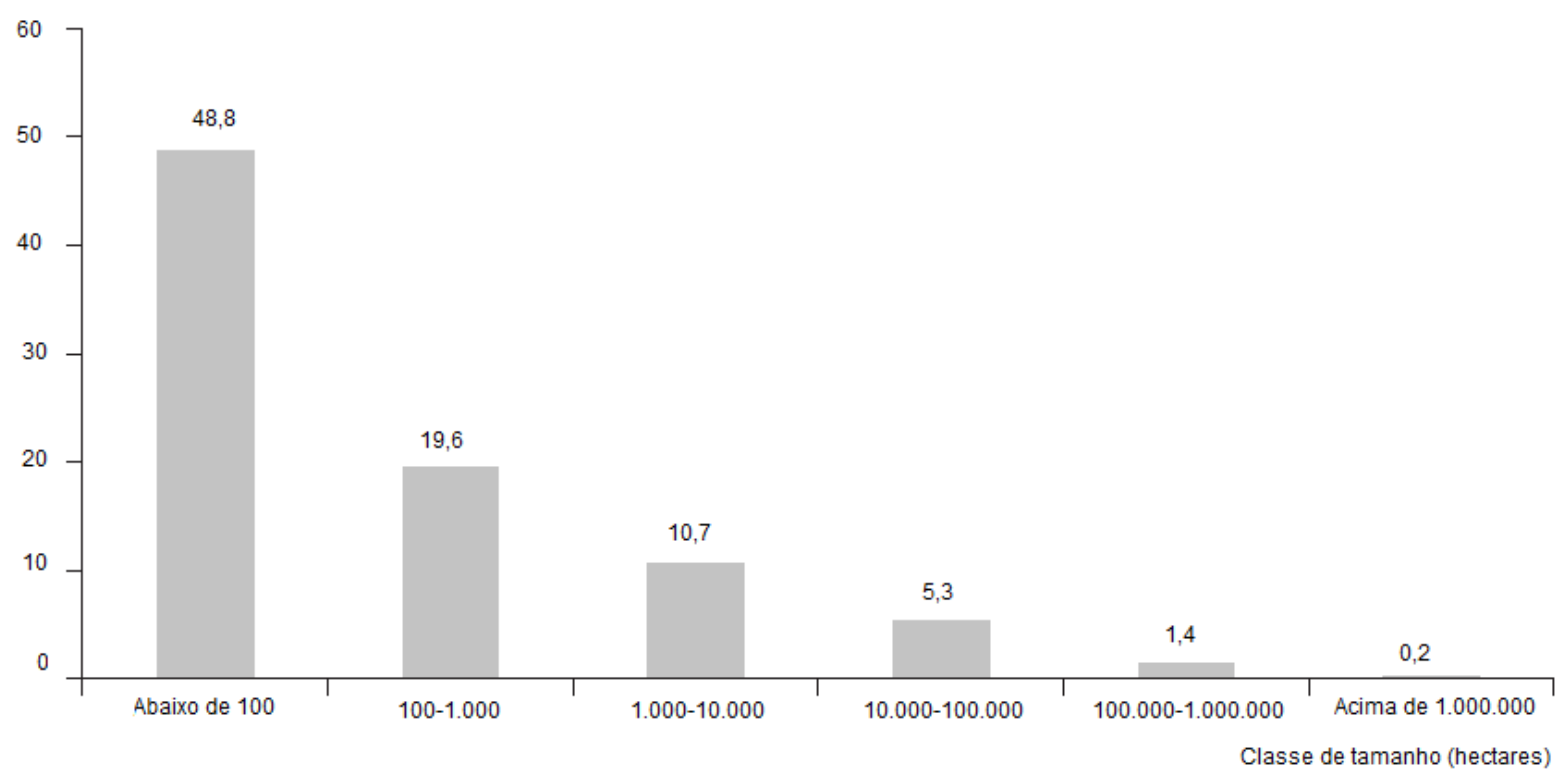

Fonte: IUCN/WDPA, 2014

Figura 11. Áreas protegidas no mundo por classe de tamanho. 


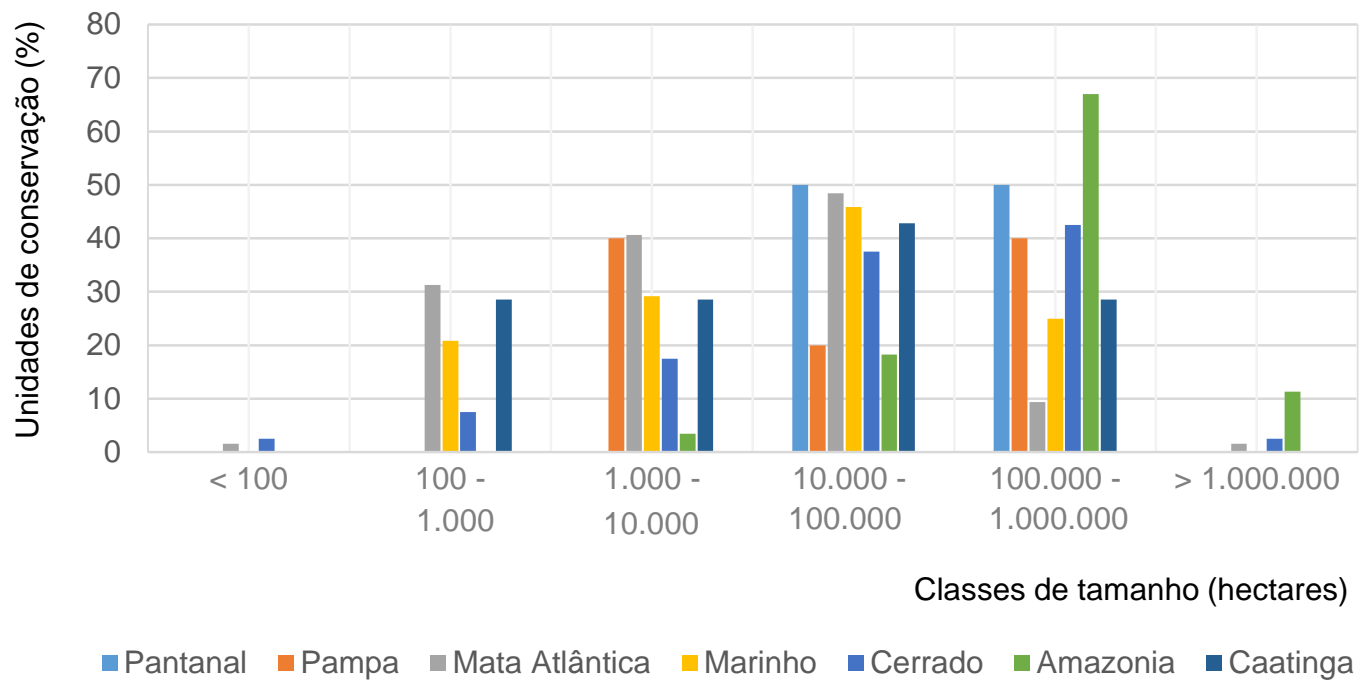

Fonte: RAPPAM 2010

Autoria própria, 2015.

Figura 12. Proporção de UCs em cada bioma por classe de tamanho.

Em relação ao número de UCs, a Amazônia e Mata Atlântica são os biomas mais expressivos.

O primeiro é composto caracteristicamente por unidades de conservação de grande extensão territorial e o segundo, por unidades de conservação de pequeno porte (Figura 13). Tal constatação pode ser observada também na Figura 14 (nomeadamente nas regiões norte e sudeste) que resume a extensão territorial média das unidades de conservação nas diferentes regiões brasileiras'.

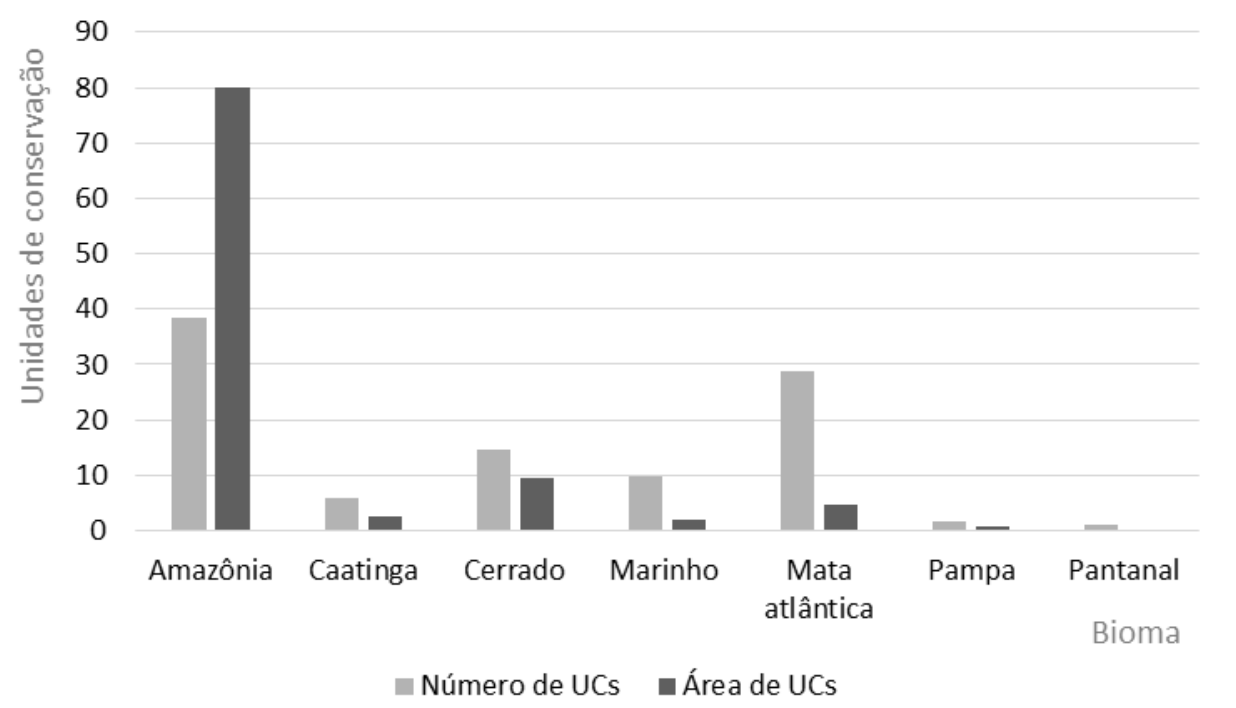

$(\mathrm{n}=299)$

Fonte: RAPPAM 2010

Autoria própria, 2015.

Figura 13. Distribuição percentual das unidades de conservação por bioma. 


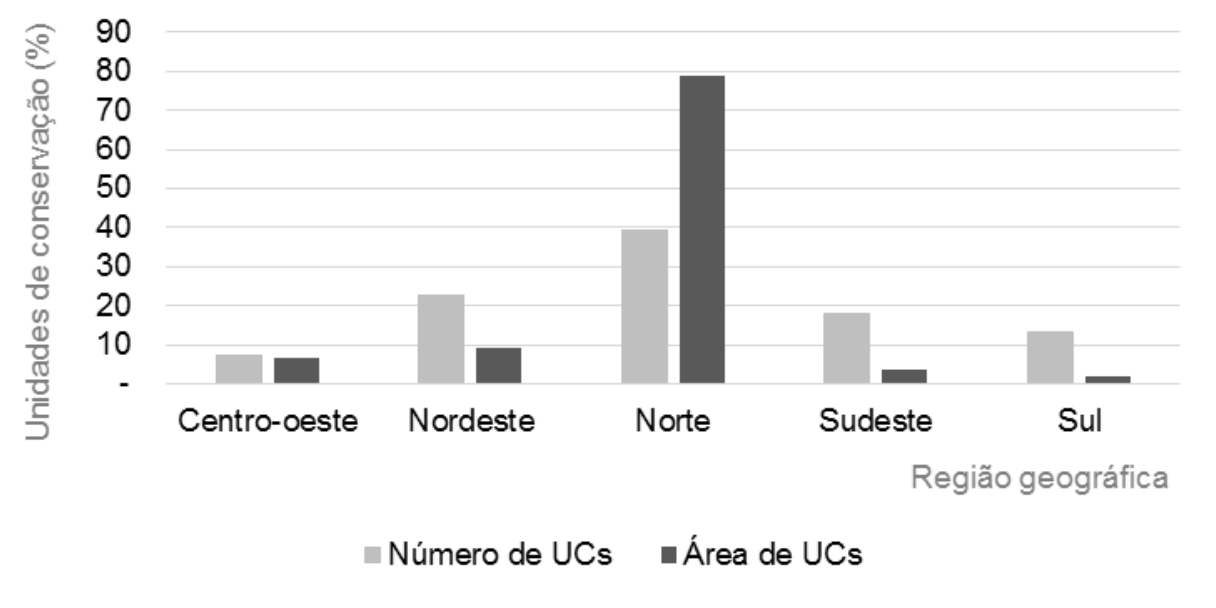

$(\mathrm{n}=299)$

Fonte: RAPPAM 2010

Autoria própria, 2015.

Figura 14. Localização das áreas protegidas federais por região geográfica.

Os estados do Pará e Amazonas, que seguem o mesmo padrão das UCs do norte do País, lideram o ranking em número de unidades de conservação (Figura 15).

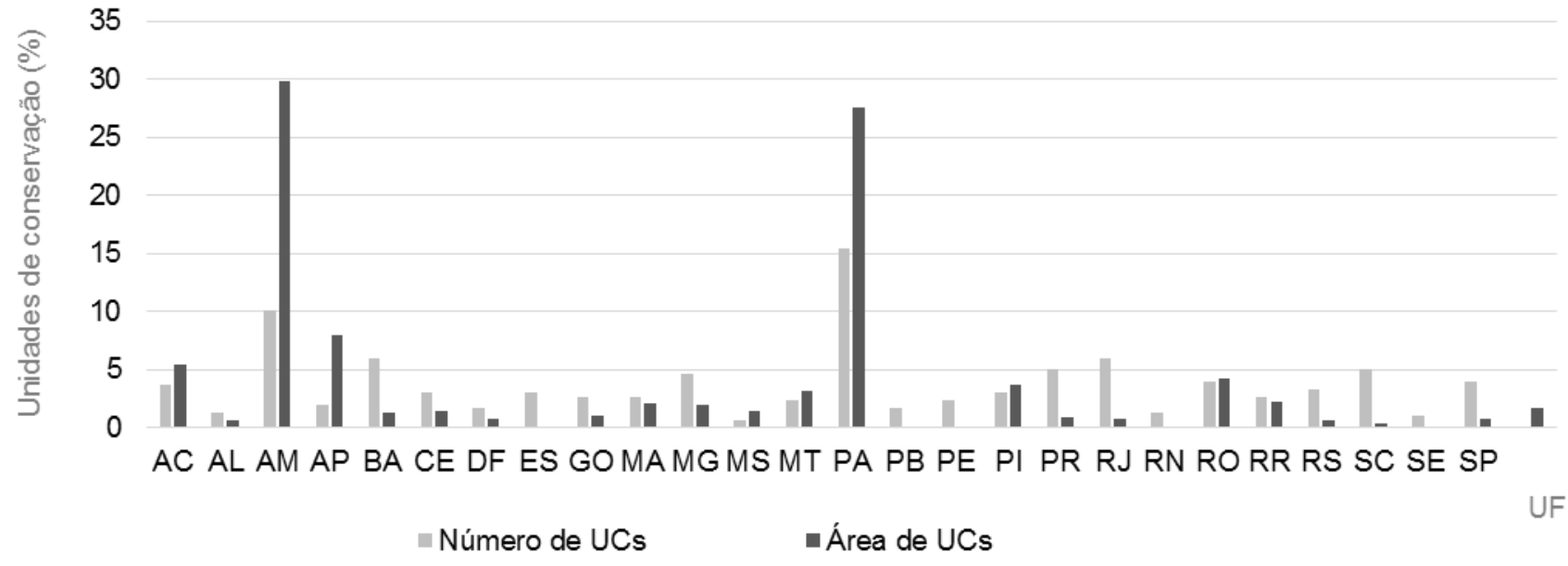

$(n=299)$

Fonte: RAPPAM 2010

Autoria própria, 2015.

Figura 15. Localização das Unidades de Conservação federais por unidade federativa.

A figura a seguir (Figura 16) apresenta a evolução da criação de UCs por categoria de manejo, na qual as unidades e conservação de uso sustentável assumem maior expressão do que as de proteção integral. 


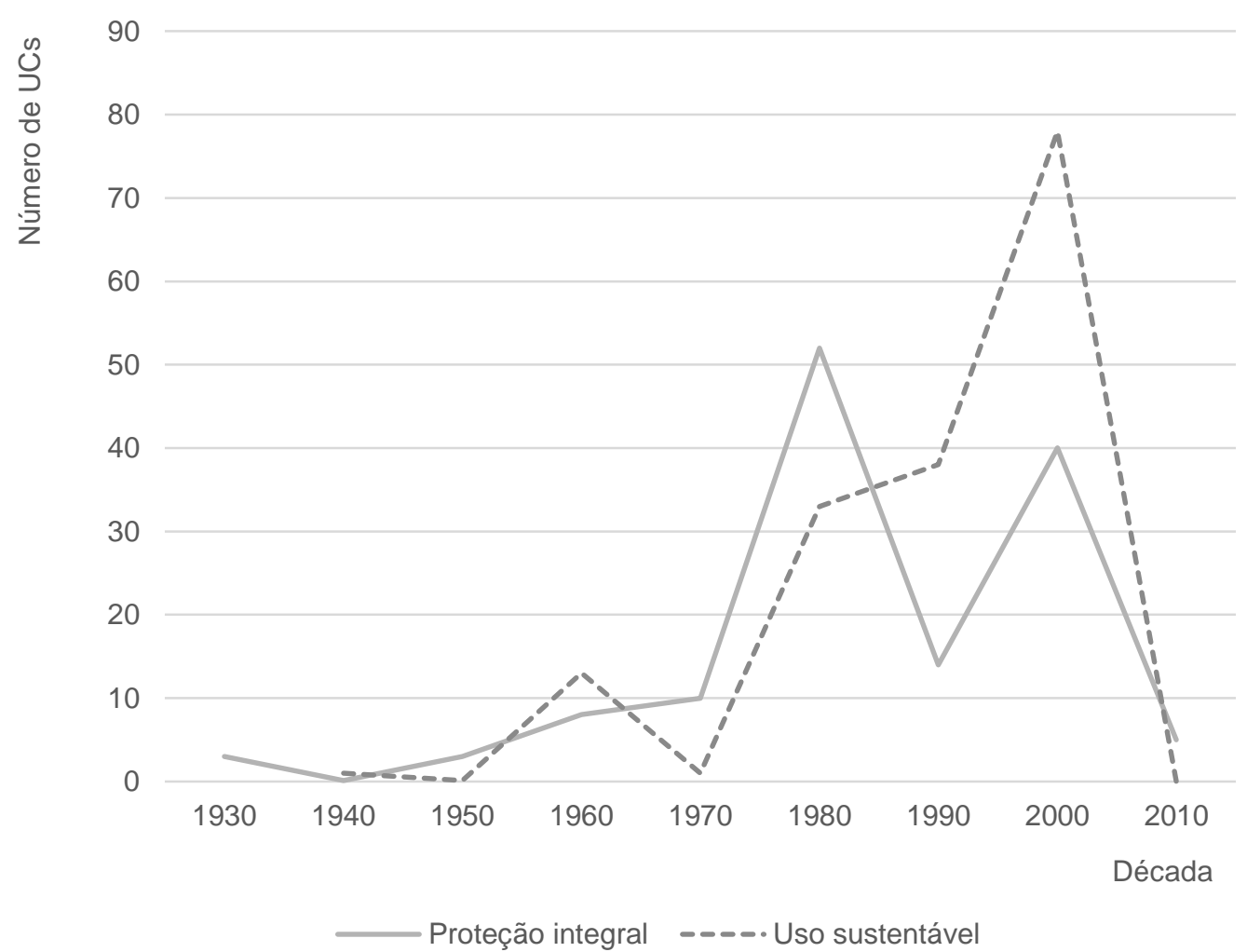

$(\mathrm{n}=299$, ano de corte $=2014)$

Fonte: RAPPAM, 2010

Autoria própria, 2015

Figura 16. Ano de criação das unidades de conservação federais avaliadas.

A partir da Figura 16 observa-se predominância de unidades de conservação de proteção integral até meados de 1980, quando a tendência de criação por grupo de manejo é invertida. Veríssimo (2011) observou que, em 1984, 92\% da área destinada às UCs era do grupo de proteção integral, enquanto o de uso sustentável contribuía com apenas $8 \%$ do total. $\mathrm{O}$ autor considera que os fatores determinantes para a inversão da predominância de UCs em função do modo de uso, a partir da década de 1990, sobretudo depois de 2002, foi estimulada por três diferentes motivos. Um deles é que a criação e implementação de UCs de uso sustentável é politicamente mais aceitável por setores econômicos que uma unidade de proteção integral, por permitir o uso econômico dos seus recursos. Em segundo lugar, o aumento da pressão de movimentos sociais organizados, com o apoio de organizações não governamentais, em defesa das populações locais tem favorecido a criação de RESEXs e RDSs, com o intuito de garantir a permanência de populações na área que ocupam. Por último, o fato de que a criação de Florestas Nacionais e Estaduais tem sido fomentada pelo governo para viabilizar a exploração madeireira ordenada em áreas regularizadas do ponto de vista fundiário.

Neste estudo foram observadas nove tipologias de unidades de conservação, dentre as quais, destacam-se como mais frequentes as categorias de manejo Parque Nacional e Floresta 
Nacional. Ambos compõem caracteristicamente grandes unidades territoriais (Figura 17) de modo análogo as Áreas de Proteção Ambiental.

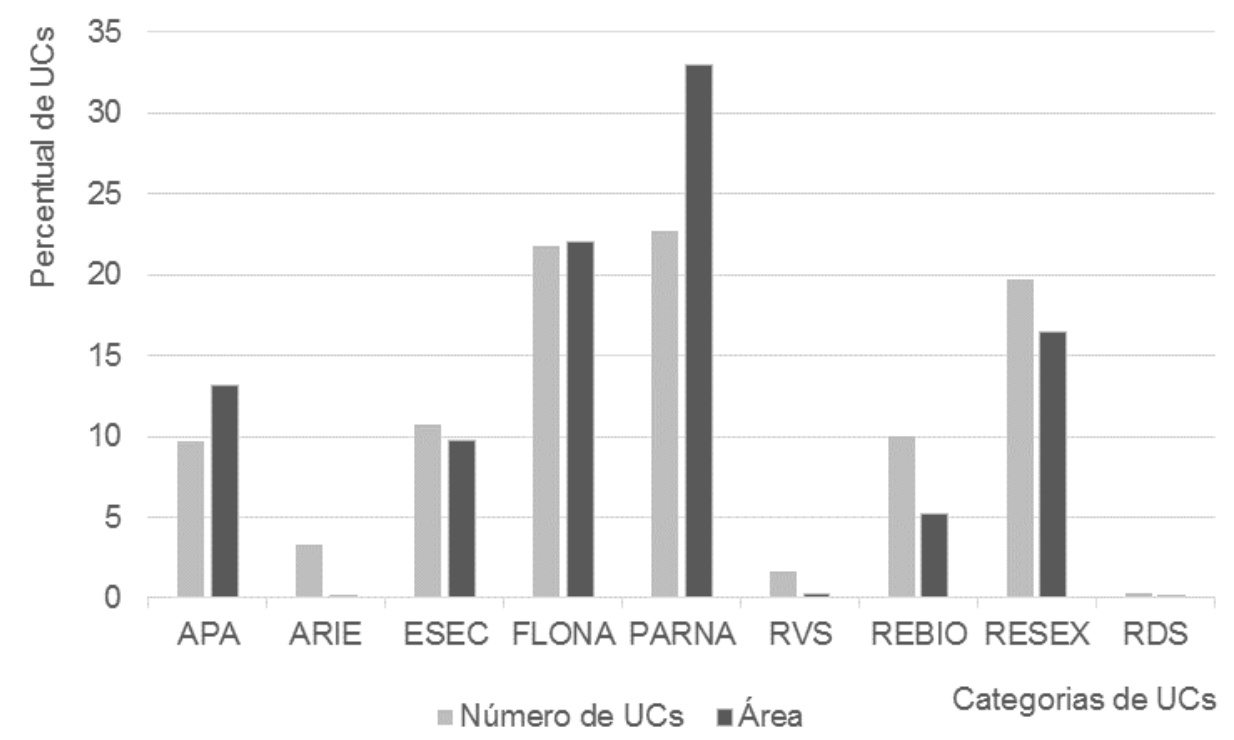

Fonte: RAPPAM 2010

Autoria própria, 2015.

Figura 17. Categorias de manejo das UCs analisadas.

Em resumo, pode-se dizer que o sistema nacional de UCs é caracterizado por uma variada tipologia de unidades de conservação, relativamente equilibrada entre as formas de uso direto e indireto (55 e $45 \%$ de UCs de uso sustentável e $55 \%$ de proteção integral, respectivamente dentro do universo avaliado). Há, no entanto, grande irregularidade na distribuição destas UCs entre os biomas, que tem a Amazônia como líder em representatividade e tamanho das áreas. Diferentes biomas revelam ainda expressões territoriais distintas. As maiores áreas estão concentradas na região Amazônica, dentro de uma estratégia de proteção do território nacional e serviços ambientais. Outros biomas, como a Mata Atlântica abrigam numerosas e pequenas UCs, seguindo a meta de proteger os poucos remanescentes existentes da ação do crescimento urbano desordenado.

O ambiente, segundo os gestores de unidades de conservação, é favorável ao envolvimento popular, uma vez que os mesmos são receptivos ao diálogo e ao acolhimento das reinvindicações populares e as comunidades locais, de uma forma geral, aceitam bem as limitações de uso da UC.

De um modo geral, os gestores de UCs acreditam ouvir e considerar as reinvindicações da sociedade na gestão da unidade (Figura 18), de forma basicamente análoga dentro dos dois grupos de manejo. 


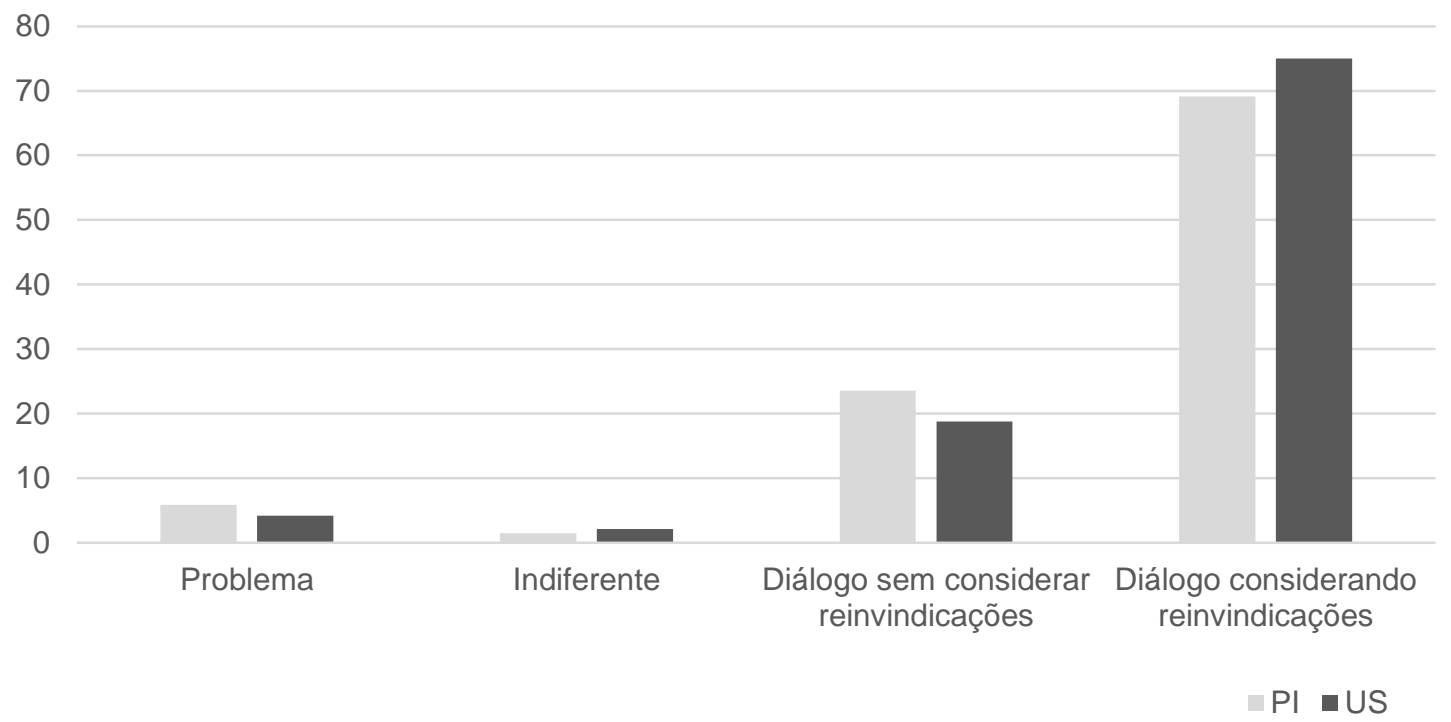

$(\mathrm{n}=116)$

Fonte e autoria própria, 2013.

Figura 18. Percepção dos gestores de unidades de conservação federais em relação a comunidade.

Em relação a percepção da comunidade sobre a UC, a maioria dos gestores considerou muito variada a percepção da comunidade. Observou-se, no entanto, que, de um modo geral, as unidades e suas limitações são bem aceitas pela comunidade (Figura 19).

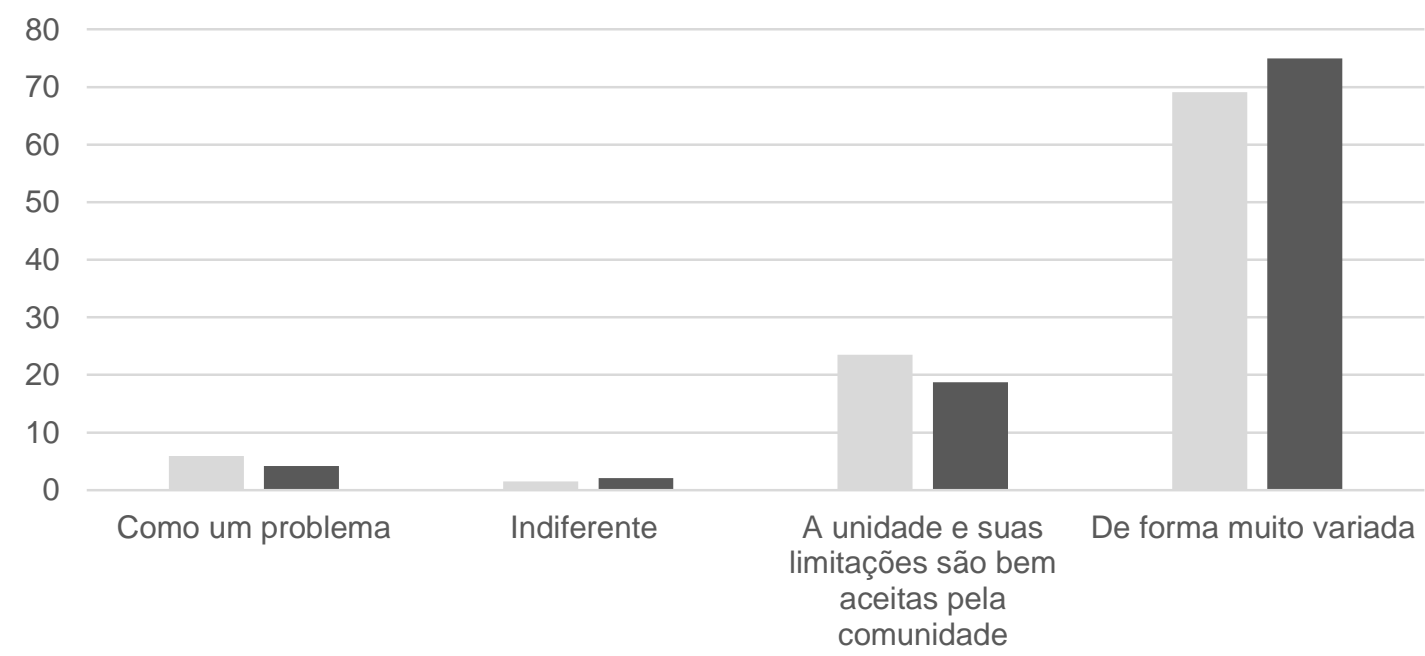

PI $\square$ US

$(n=116)$

Fonte e autoria própria, 2013.

Figura 19. Percepção da comunidade em relação à unidade de conservação.

Vale salientar, no entanto, que os dados primários referentes a percepção da comunidade se mostraram na maioria inconclusivos, visto que os gestores percebem variações dos diferentes atores sociais em relação a unidade de conservação. Há de se considerar aqui dois fatos: i. A subjetividade inerente à metodologia utilizada, onde os dados primários apoiam-se em 
percepções dos gestores, ii. Que essa fragilidade é agravada ao se avaliar a percepção da comunidade a partir da percepção dos gestores.

\subsection{ESTRATÉGIAS DE CONSERVAÇÃO DA BIODIVERSIDADE EM UNIDADES DE CONSERVAÇÃO}

De uma forma geral, as unidades de conservação apresentaram uma tendência maior à abordagem participativa de conservação da biodiversidade do que aquelas baseadas na coerção ou incentivos econômicos, independente do grupo de manejo (PI ou US). No entanto, quando isoladas por grupo de proteção, observou-se dois padrões de comportamento distintos, com predominância da estratégia coercitiva nas UCs de proteção integral e estratégias mais participativas de gestão nas unidades de conservação de uso sustentável.

Dentre as unidades de uso sustentável também foram observadas diferentes estratégias em subgrupos definidos pelo bioma onde encontra-se a UC (Figura 20).

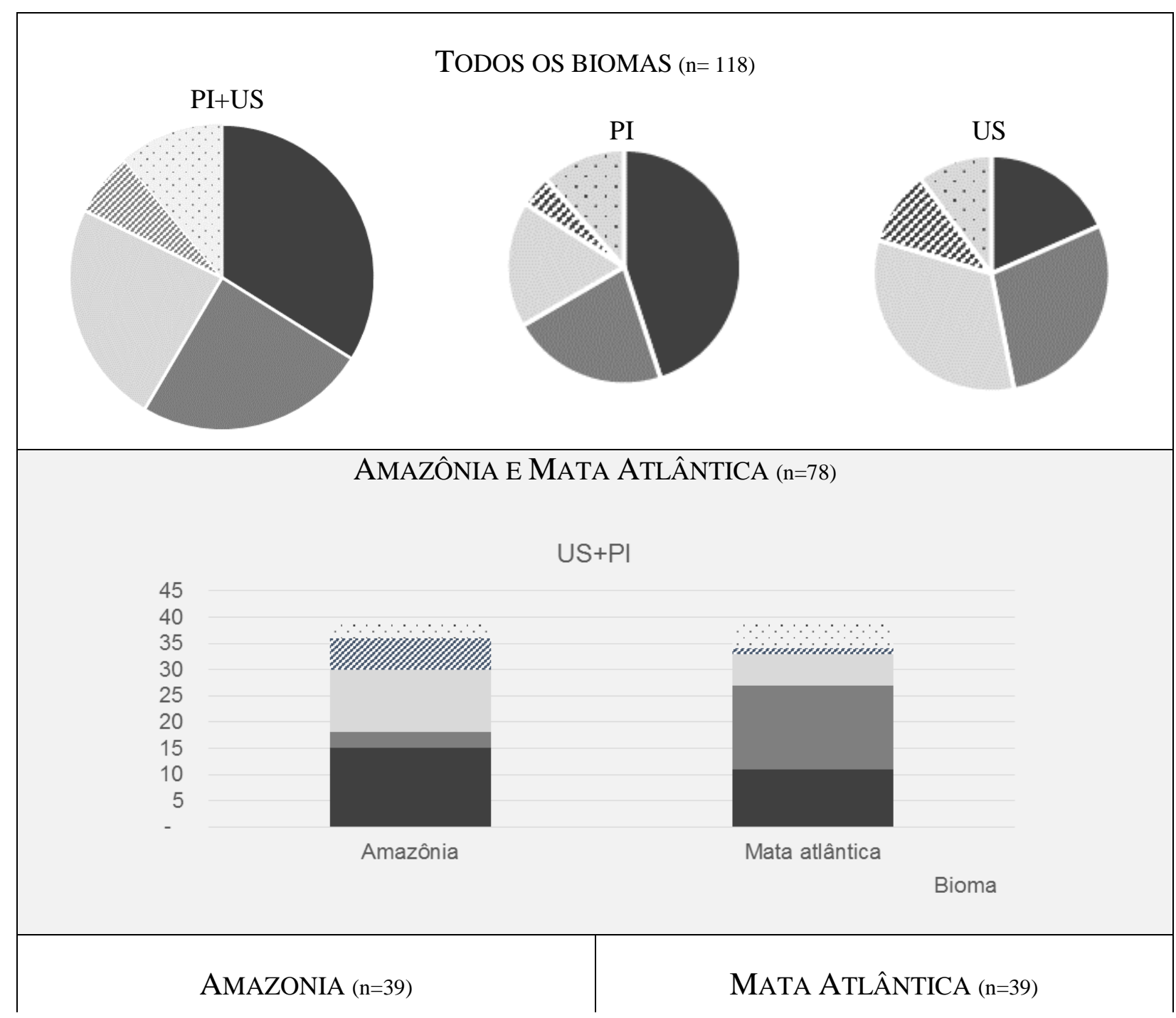




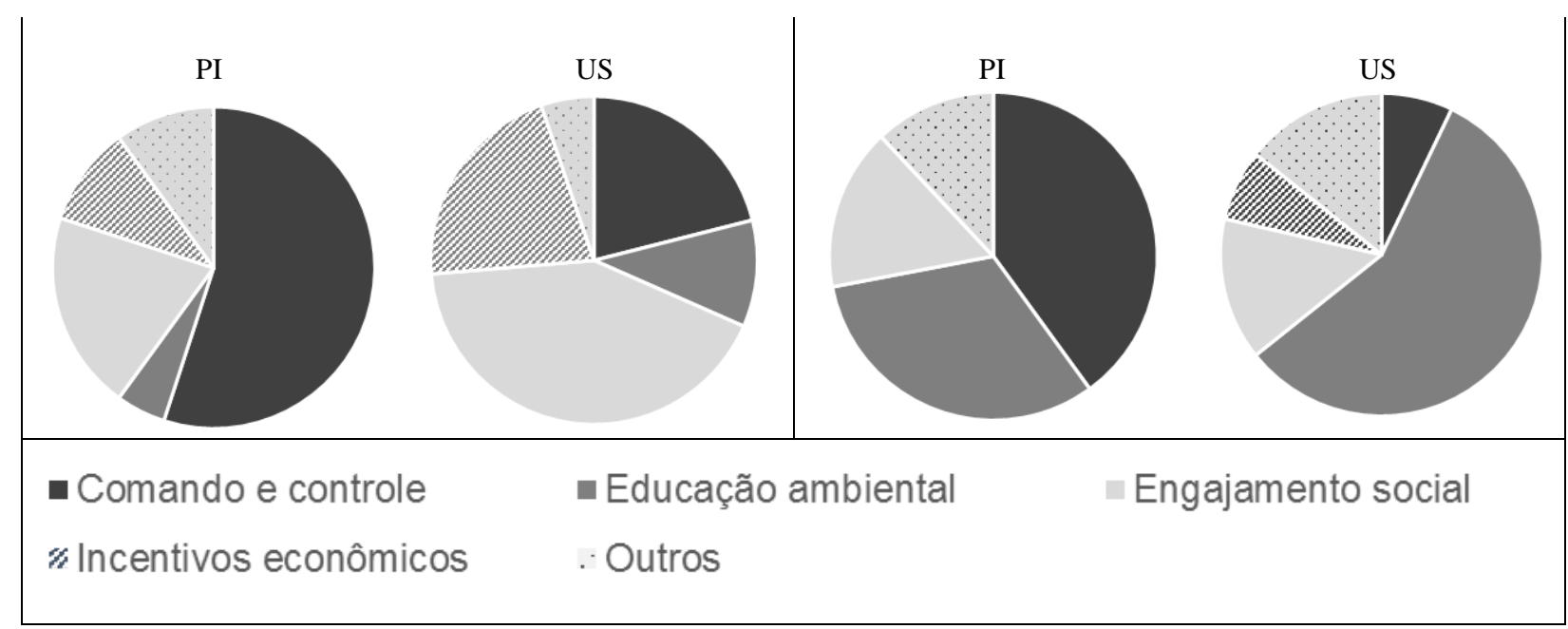

Fonte e autoria própria, 2013.

Figura 20. Estratégia de conservação prioritariamente adotada pelas UCs.

Nas UCs de uso sustentável, apenas uma pequena porção adotou a estratégia de comando e controle como a principal linha de ação. Nesse grupo, o engajamento social e a educação ambiental assumiram maior importância, demonstrando que essas UCs estão mais receptivas às formas mais participativas de gestão.

Resultados similares foram encontrados por Barreto e Cezar (2012) ao analisarem as categorias de instrumentos políticos ${ }^{31}$ predominantes no planejamento de oito planos de manejo de UCs federais do Rio de Janeiro. As autoras observaram predomínio dos instrumentos persuasivos sob os coercitivos, quando considerado todo o grupo das UCs. Quando analisadas por grupo de proteção, do mesmo modo, houve predomínio de ações coercitivas sobre as persuasivas.

A prevalência de uma estratégia mais participativa em relação às UCs de uso sustentável era esperada, considerando que a maioria de UCs desse grupo possui conselhos gestores deliberativos e que a participação social é uma condição básica para a implementação das mesmas. Barreto e Cezar (2012) ponderam que os diferentes interesses dos atores sociais envolvidos na gestão da UC podem contribuir com os padrões observados entre UCs de uso sustentável e de proteção integral. Em UCs de uso sustentável, a persuasão pode ser mais adotada, pois as ações gerenciais afetam mais diretamente seus residentes (ou proprietários, conforme o caso), em contraposição, caráter mais coercitivo pode estar mais vinculado às UCs de proteção integral, cujo objetivo principal é a proteção da natureza sem intervenção humana direta. $\mathrm{O}$ detalhamento das estratégias de conservação dentro dos biomas melhor representados em número de UCs - Amazônia e Mata Atlântica - evidenciou duas distintas tendências. As

\footnotetext{
${ }^{31}$ Econômicos, regulatórios ou coercitivos e persuasivos ou normativos
} 
UCs da Amazônia assumiram uma estratégia relativamente mais coercitiva quando comparadas com às UCs do bioma Mata Atlântica.

A predominância da estratégia de conservação coercitiva sob forma mais persuasivas nas unidades de proteção integral da Amazônia, possivelmente reflete a natureza das pressões sobre os recursos naturais da região, na maioria relacionadas ao desmatamento ou vinculadas as ações de proteção do território em regiões de fronteira.

Em relação à qualidade da participação social nas unidades de conservação amazônicas e da mata atlântica, observou-se um caráter mais ativo nas primeiras, as quais foram classificadas pela maioria dos gestores na tipologia engajamento social. Já na Mata Atlântica, há predominância da tipologia educação ambiental como forma de participação social.

A participação social mais ativa nas UCs do bioma amazônico pode ser fruto da influência do movimento socioambientalista, muito vinculado a presença de populações tradicionais nas unidades de conservação amazônicas, e que contribuem para que o engajamento social ocorra de forma mais natural.

Sobre os incentivos financeiros, além de representarem uma pequena parcela da estratégia de conservação observada para as UCs como um todo, pouca ou nenhuma variação foi verificada dentro do grupo grupos de manejo ou biomas (Mata Atlântica e Amazônia).

Provavelmente, a principal dificuldade na adoção de incentivos financeiros por parte das UCs decorre do desconhecimento de aspectos como legalidade, forma de aplicação e regulação, dos mecanismos financeiros para a conservação da biodiversidade. Diante do desconhecimento, essa abordagem, via de regra, assume um papel secundário.

Reconhece-se que dadas as especificidades dos mais variados cenários aos quais estão inseridas as UCs, ainda que a unidade opte por determinada abordagem de conservação, o desenvolvimento concomitante das três abordagens, nas mais variadas proporções é o que mais ocorre na prática, além de representar o ambiente mais favorável ao alcance dos resultados de conservação.

Como exemplo, ainda que não sejam utilizados como estratégia primordial de conservação, o conhecimento sobre os incentivos financeiros existentes, é condição fundamental para a construção de estratégias de sustentabilidade financeira para as UCs. Sem uma estratégia que forneça, minimamente, segurança sobre como o recurso será aplicado e os efeitos esperados, as chances de frustração dos esforços empreendidos com vista à captação de recursos são muito altas. Como agravante, e talvez em também em decorrência disto, os dados do RAPPAM 2010 
registram uma estagnação, com tendência à queda, na capacidade de captação de recursos por partes dos gestores.

Também é necessário considerar que a baixa implementação das UCs brasileiras faz com que elas não reflitam plenamente (e na verdade, muitas vezes quase nada) seus objetivos de criação. Caso ilustrativo é a permanência de população residente no interior de unidades de conservação de proteção integral, situação que, embora programada para ser transitória, pode perdurar gerações. Assim, embora, teoricamente, a UC devesse se ocupar da preservação em si, sem intervenção humana, a prática exige que os gestores tenham um grande preparo para lidar com sérios conflitos sociais. Nesses casos, a simples coerção pode resultar em agravamento dos conflitos, sendo mais desejável um equilíbrio entre ações de cunho persuasivo.

Assim, à despeito de padrões na estratégia de conservação e, consequentemente, nas ações e instrumentos políticos, de UCs de acordo com grupos de manejo ou biomas, a opção por determinada abordagem para a conservação reflete uma área complexa da política, na qual a adoção de um ou outro instrumento político depende de escolhas em um contexto complexo. Tais escolhas podem ser influenciadas também por outros fatores como custos operacionais, disponibilidade de recursos e conhecimento, conformidade com outras estratégias, contextos ou cenários políticos (BARRETO \& CEZAR, 2012).

\section{CAPÍTUlO 5. STATUS DA PARTICIPAÇÃO SOCIAL NA GESTÃo DE UCS}

\subsection{CANAIS DE PARTICIPAÇ̃̃O MAIS UTILIZADOS}

Para identificação dos principais canais que promovem a integração sociedade-unidade de conservação, foi realizada uma pergunta aberta aos gestores por meio do formulário eletrônico.

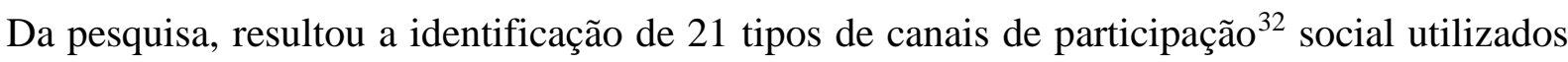
para aproximação com a UC, conforme apresentado na Figura 21.

\footnotetext{
${ }^{32}$ Considerou-se canais de participação social como todo e qualquer meio capaz de aproximar a sociedade da gestão da UC.
} 


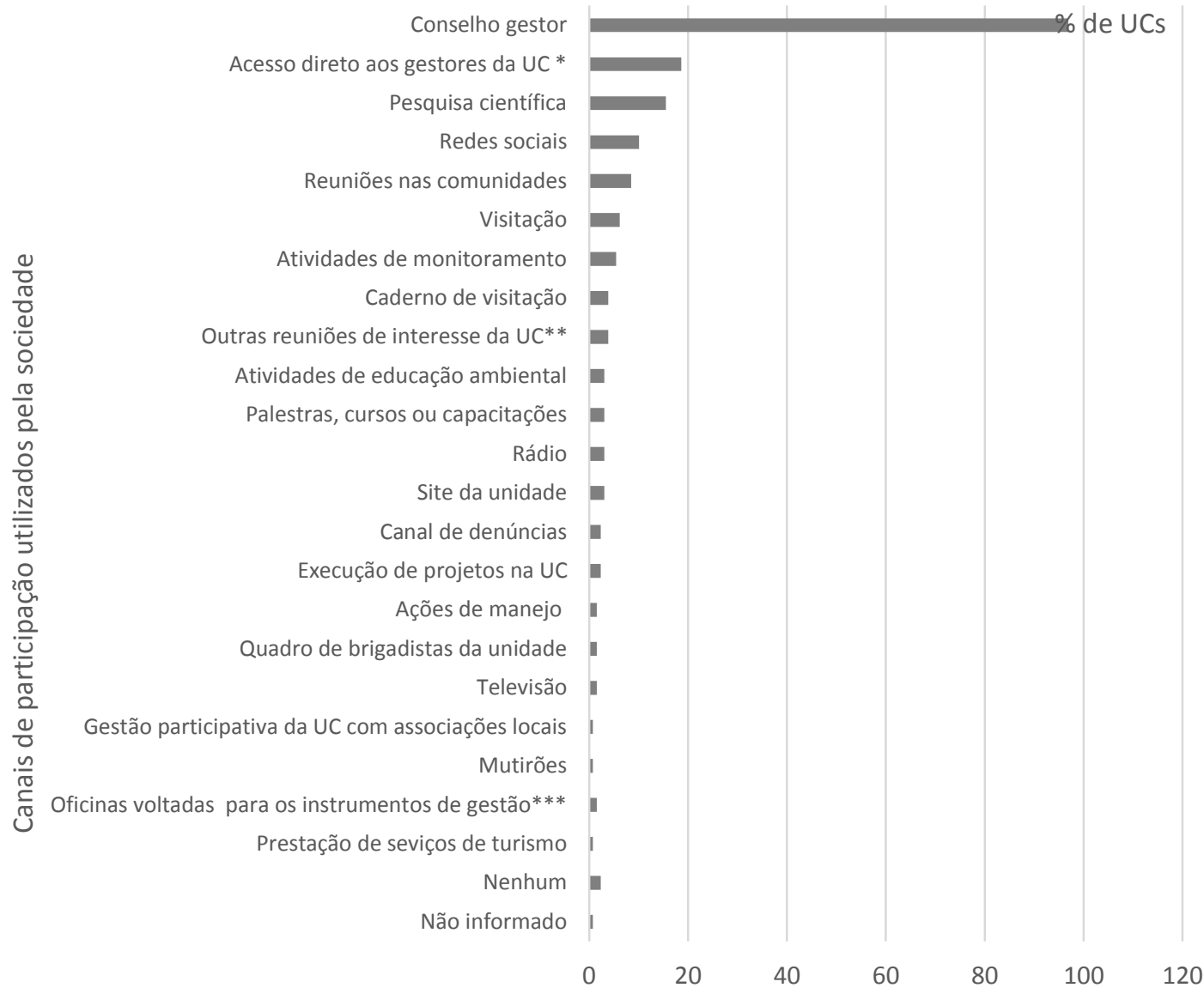

$(\mathrm{n}=129)$

Fonte e autoria própria, 2013.

Figura 21. Percentual de respostas para a questão "Quais os cinco canais de participação mais utilizados pela sociedade na gestão da sua unidade?", com base no formulário da tese.

Setenta por cento das unidades indicaram o conselho gestor como o principal canal de participação social na gestão das UCs e $97 \%$ consideraram que os mesmos estavam dentre os cinco principais canais, seguidos do acesso direto aos gestores da UC, pesquisa científica, redes sociais e reuniões da gestão da UC nas comunidades (Figura 21).

Cuidado especial deve ser conferido ao canal de participação identificado como "acesso direto aos gestores de UCs". Embora esta aproximação favoreça o estabelecimento de formas menos burocráticas de participação e, mesmo incentivo à outras formas mais institucionalizadas de participação, não deve substituir os processos de negociação conduzidos no âmbito do conselho gestor. O conselho deve ser entendida como a principal arena política, instância máxima de articulação entre objetivos da UC e os segmentos sociais vinculados. Posicionamentos frequentes por parte das equipes gestoras acerca de assuntos de interesse coletivo, sem a devida pactuação social via contatos diretos com os gestores, podem contribuir com o enfraquecimento desses espaços. 
O canal pesquisa científica embora tenha sido identificado como um dos canais mais importantes, tende a perder importância na próxima avaliação. Isso porque, embora o grau de alinhamento das pesquisas com os objetivos da UC tenha correspondido ao terceiro maior avanço observado dentre os resultados da UC, os dados do RAPPAM 2010 registraram criticidade no acesso aos dados científicos pela sociedade. O indicador "A equipe da UC $e$ comunidades locais têm acesso regular às informações geradas pelas pesquisas realizadas na $U C$ " que já vinha recebendo uma baixa pontuação, sofreu um decréscimo entre a avaliação de 2005 e 2010.

Os resultados da aplicação do formulário eletrônico demonstraram a importância que vem sendo conferida às redes sociais como um importante elo UC-sociedade. Dentre possibilidades de atuação social, Toth (2012) destaca o alto potencial das redes sociais de promoverem um maior engajamento das populações nas questões socioambientais, com base em relações mais horizontais. No entanto, a autora ressalta a necessidade de uma abordagem sistêmica sobre as relações que se formam dentro das redes, de modo a não as perceber como fenômenos livres da hierarquia de poder.

Com base nos formulários eletrônicos foram traçados perfis das UCs quanto à diversidade de canais acessados por elas. A Figura 22 resume os resultados encontrados, onde quase metade das unidades (40\%) entrevistadas declararam utilizar somente um canal de participação.

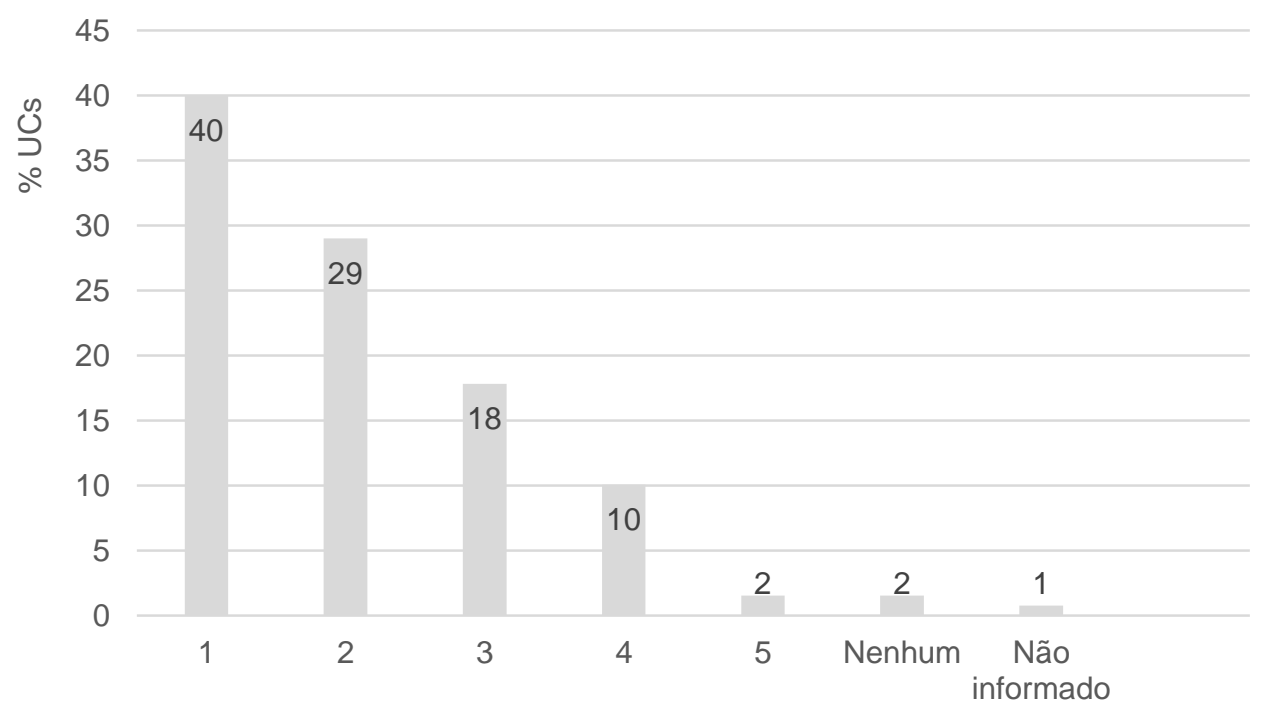

Número de canais de participação social identificados

$(n=129)$

Fonte e autoria própria, 2013.

Figura 22. Diversidade de canais de participação utilizados pelas unidades de conservação federais. 
Os dados evidenciaram uma baixa diversidade na utilização dos canais de participação. Quase a metade das unidades utiliza somente um tipo de canal de participação social (42\%) e quase $70 \%$ até dois canais de participação.

Dentre aquelas que utilizam apenas um canal, o conselho gestor foi o principal canal utilizado por $100 \%$ das unidades. Aquelas cujos conselhos não foram criados, indicaram que o processo de formação dos conselhos é o principal canal de participação social.

Foram observadas ainda duas unidades que não utilizam qualquer instrumento de participação, ambas de proteção integral e criadas na década de oitenta, sendo consideradas, pois, unidades de conservação relativamente antigas. Uma delas possui conselho gestor constituído, mas considera que este não pode ser considerado um canal de participação ativo.

A pequena diversidade de canais de participação utilizada pela maioria das UCs indica que novas frentes devem ser criadas para favorecer a aproximação da comunidade na gestão das UCs. Os processos de articulação interinstitucional seriam beneficiados com canais que pudessem contemplar as especificidades dos diversos grupos sociais.

Diante da constatada predileção, quase unânime, pelo conselho gestor como elo primordial da relação sociedade-UC, há de ser dar maior importância ao seu fortalecimento enquanto instância participativa.

Sabe-se que, no entanto, que a simples implantação dessas instâncias não é condição suficiente para cumprir sua função democrática. É necessário empreender esforços para aumentar a sua efetividade, contribuindo assim para uma maior capacidade de gerar respostas em benefício dos objetivos das unidades de conservação.

Assim, como forma de colaborar com essa temática, as seções seguintes se dedicarão a descrever um pouco sobre o funcionamento dessas instâncias.

\subsubsection{CONSELHOS GESTORES}




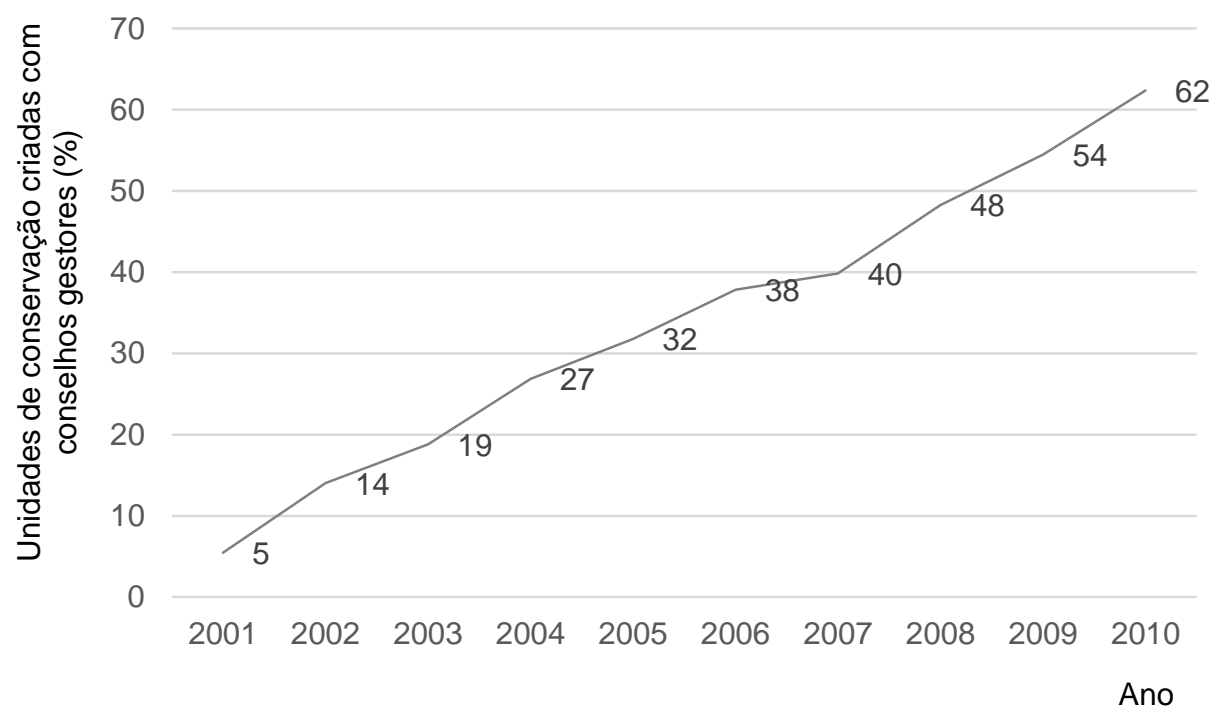

$(n=250)$

Fonte e autoria própria, 2013.

Figura 23. Proporção de unidades de conservação com conselhos gestores criados anualmente entre 2000-2010.

A análise das 129 UCs estudadas via formulário eletrônico revela que apenas uma porção pequena das unidades $(1,6 \%)$ não iniciaram movimento de sensibilização e mobilização de atores sociais para sua formação.

Ainda que o quantitativo de conselhos criados decorra, sobretudo, da obrigação legal de sua implantação e que uma série de dificuldades na sua operacionalização reduzam sua efetividade (como será abordado na seção 5.1.2), sua simples existência, por si só, amplia o círculo social em que se operam as discussões sobre o uso dos recursos públicos, conforme defendido por Abramovay (2001).

\subsubsection{Tamanho dos conselhos gestores e frequência dos conselheiros às reuniões}

Em uma amostra de 113 UCs, observou-se uma média de 23 conselheiros por conselho gestor, com pouca variação entre os grupos de manejo - 23 para os conselhos consultivos e 22 para os deliberativos.

No entanto, a avaliação por classes de tamanho demonstra uma maior ocorrência na faixa dos 21-25 conselheiros em conselhos deliberativos, ao passo que as unidades com conselho consultivo estão bem distribuídas entre a faixa de 16-30 conselheiros (Figura 24).

O menor conselho identificado apresentou sete conselheiros e o maior, 40 conselheiros.

Considerando o número de 12-24 conselheiros defendido por Palmieri \& Veríssimo (2009) como mais adequado, os conselhos deliberativos tenderiam a apresentar maiores dificuldades logísticas para se reunirem do que os consultivos sendo, portanto, mais propensos a uma menor efetividade. No entanto, isso não foi observado nem quando considerados os extremos de 
tamanho, nem quando considerado o conjunto de UCs (Figura 25). O conselho formado por sete conselheiros apresentou grau moderado de efetividade, enquanto que o formado por 40 conselheiros apresentou o grau máximo.

Em relação a presença nas reuniões, a frequência média dos conselheiros nas reuniões foi de $69 \%$, com variação de cinco pontos entre conselhos deliberativos e consultivos, sendo os primeiros mais frequentados. Também não foi verificada correlação estatística significativa entre a frequência dos conselheiros nas reuniões e a efetividade do conselho gestor.

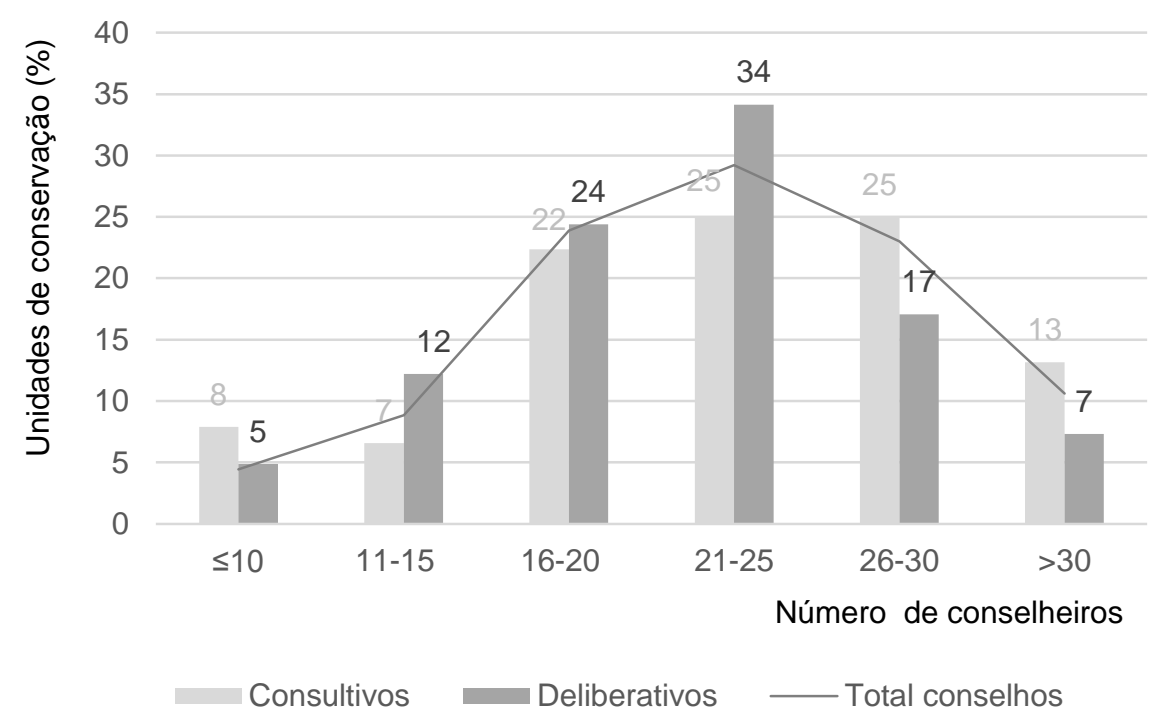

$(\mathrm{n}=113)$

Fonte e autoria própria, 2013.

Figura 24. Percentual de unidades de conservação dentro de cada classe de tamanho do conselho gestor.

\subsubsection{Fatores limitantes à operacionalização dos conselhos gestores}

A partir da análise das respostas à pergunta aberta "Qual o principal entrave à participação social nas reuniões de conselho" foi possível estabelecer três grupos de entraves principais e um geral com dificuldades diversificadas e relativamente pouco expressivas, citados, no máximo, por 3 UCs (Figura 25).

A seguir, são listados alguns exemplos verificados em cada uma das categorias.

i. Políticos: monopolização da pauta por setores específicos da sociedade, centralização do poder (em uma liderança ou setor); disputas internas para eleição dos representantes comunitários, sobrecarga de representação - conselheiros são também representantes em outros fóruns e não podem estar presentes em todas as reuniões, interesses pessoais prevalecem sobre os coletivos.

ii. Logístico: distância entre as comunidades, meios de comunicação deficientes ou inexistentes (telefone/internet), dificuldades no transporte dos comunitários até o local de reunião. 
iii. Financeiro: custos relativos ao transporte e alimentação dos conselheiros, recursos insuficientes para se implementar as ações planejadas, comunitários não podem perder dias de trabalho.

iv. Outros: falta de organização por parte da equipe gestora, baixa organização social, falta de tempo, desmotivação dos conselheiros, natureza consultiva do conselho, dispersão dos participantes que não ficam presentes durante toda a reunião, pouca divulgação das reuniões de conselho.

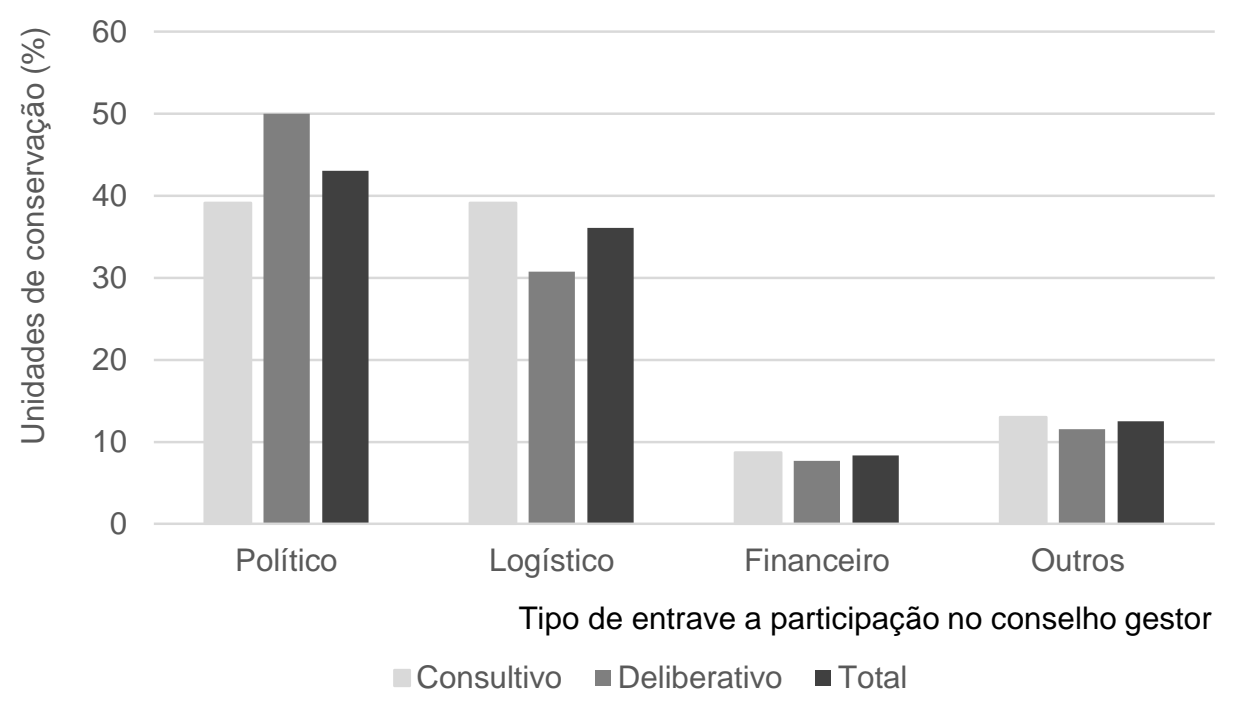

$(\mathrm{n}=113)$

Fonte e autoria própria, 2013.

Figura 25. Tipos de entraves à participação social por tipo de conselho gestor.

O acúmulo de funções também foi detectado pelo professor Sérgio Schneider, conforme expõe Abramovay (2001), como uma importante limitação à operacionalização das reuniões do conselho. Segundo o professor Schneider, onde há regras impeditivas do acúmulo da representação, o problema passa a ser o de localizar interessados para ocupar as vagas disponíveis.

Os custos que devem ser arcados por aquele que se dispõe a participar (transporte, alimentação, da hora não trabalhada que deixou de produzir alguma renda) foram destacados por Dombrowski e Parmigiani (2009) como importante impeditivo e recai com maior intensidade sobre os segmentos populares. Assim, tal investimento de tempo e recurso só será realizado se houver uma expectativa verossímil de retorno (ABRAMOVAY, 2001).

Esse quadro de insuficiência de recursos representa um importante obstáculo a implementação dos instrumentos básicos de gestão das unidades de conservação, tais como: planos de manejo, conselhos gestores, regularização fundiária, planos de proteção. 
Dentre deste contexto, o Programa Áreas Protegidas da Amazônia (ARPA) destaca-se pelo forte impacto na consolidação das áreas protegidas da Amazônia, o que inclui o apoio a organização comunitária para reuniões de criação e manutenção dos conselhos gestores (reuniões ordinárias e extraordinárias), bem como a capacitação dos seus membros.

Algumas unidades de conservação avaliadas nesse estudo recebem apoio do Programa ARPA, o que permitiu identificar dois subgrupos de análise: i. UCs com forte restrição orçamentária (UCs sem ARPA) e UCs com situação orçamentária favorável - UCs ARPA (Figura 26).

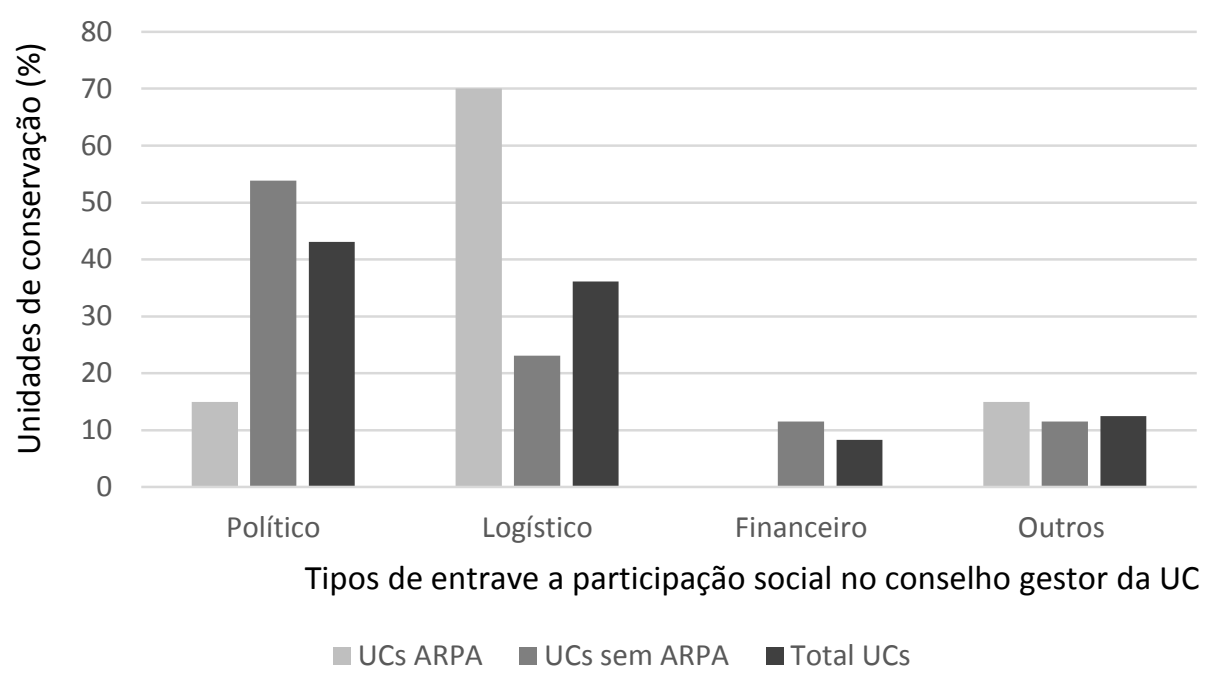

$(\mathrm{n}=113)$

Fonte e autoria própria, 2013.

Figura 26. Tipos de entraves à participação social em unidades que recebem apoio financeiro do Programa ARPA e UCs que não são apoiadas pelo programa.

Nos dois grupos foi verificado um padrão diferenciado dentre os obstáculos à participação social elencados pelos gestores. Para as unidades de conservação que não recebem apoio do ARPA, o principal entrave à PS foi de ordem política, sendo o financeiro o terceiro maior obstáculo a realização das reuniões. Já nas UCs ARPA, o aspecto financeiro não apenas não foi considerado como relevante como, mesmo o político perdeu expressão quando comparados ao de ordem logística.

É importante ressaltar que o fato das unidades ARPA não apontarem desafios de ordem financeira como importantes entraves à PS deve-se não tão somente pela quantidade de recursos aportado, mas também, e em grande parte, à um mecanismo de execução diferenciado, denominado conta vinculada, que favorece a execução de gastos locais.

Essa forma de execução é caracterizada pela disponibilização de quantias pré-aprovadas de em contas correntes conjuntas entre as unidades de conservação e o gestor financeiro do ARPA, o Fundo Brasileiro para Biodiversidade (FUNBIO). A partir desta conta, é possível executar pequenos gastos locais sem necessidade de seguir as diretrizes das leis de licitação 
governamentais (Lei $n^{0} 8.666$, de 21/06/1993) que tornam, em geral, a execução muito mais morosa.

A execução via conta vinculada permite que os gastos locais ocorram de acordo com o dinamismo requerido à operacionalização do conselho, sem a obrigatoriedade de aguardar o fluxo burocrático requerido pelos gastos governamentais. Isso é essencial, pois na maioria das vezes a rotina de reuniões dos conselhos é pautada pela necessidade de respostas emergenciais e a existência de limitações burocráticas para a convocação das reuniões pode reduzir a capacidade de retorno, induzindo a tomada de decisões sem o necessário envolvimento do conselho.

Esta condição pode ser reforçada pela figura a seguir (Figura 27) onde a efetividade dos conselhos gestores das unidades apoiadas pelo ARPA se revela maior do que a dos demais conselhos.

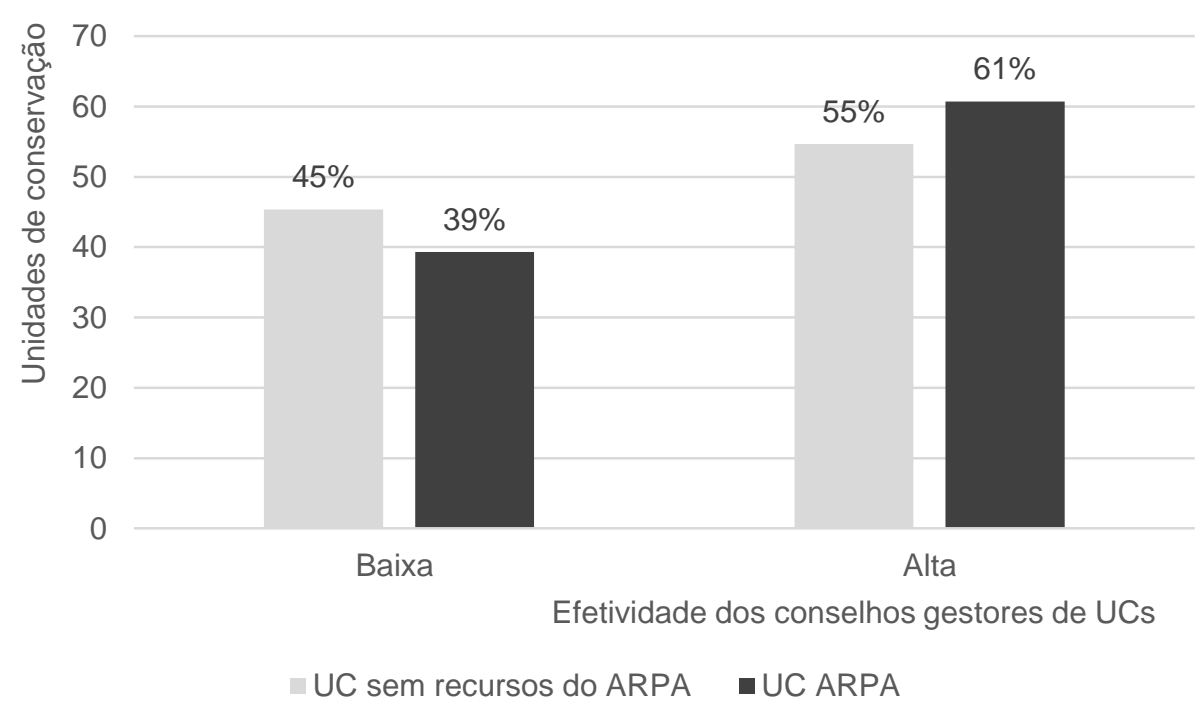

$(\mathrm{n}=292)$

Fonte: RAPPAM

Autoria própria, 2013.

Figura 27. Efetividade dos conselhos gestores de unidades de conservação em unidades apoiadas ou não pelo ARPA.

O fato, no entanto, das UCs ARPA apresentarem relativamente uma maior dificuldade logística quando comparadas as UCs que não recebem apoio desta fonte, deve-se, provavelmente, mais ao bioma ao qual estão inseridas essas UCs do que a fonte ou forma de execução dos recursos. Isso pode ser corroborado pela Figura 28, onde os desafios de ordem logística são predominantes nas UCs amazônicas e perdem expressão nos demais biomas. 


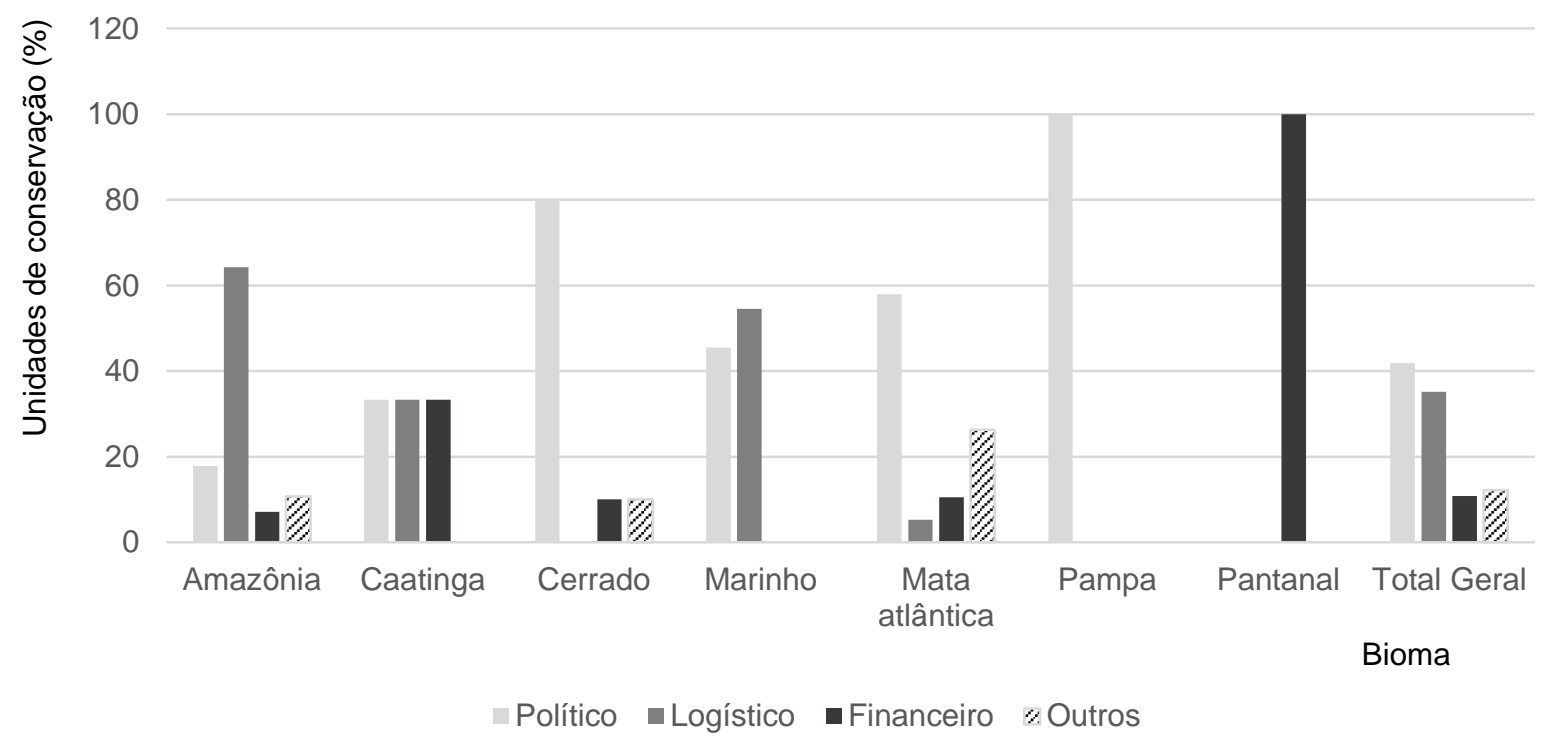

$(\mathrm{n}=113)$

Fonte e autoria própria, 2013.

Figura 28. Tipos de entraves à participação social nas reuniões dos conselhos gestores de unidades conservação por bioma brasileiro.

Os dois principais biomas brasileiros em termos de representatividade de unidades de conservação, Amazônia e Mata Atlântica, apresentaram cenários diferentes em relação aos entraves à participação social nos conselhos gestores.

Na Amazônia, os entraves logísticos prevaleceram, pois são agravados pelas grandes distâncias entre as comunidades amazônicas e pelas dificuldades de transporte e comunicação da região. Já na Mata Atlântica, as dificuldades políticas se sobressaíram.

Quanto à legitimidade dos representantes dos conselhos, as UCs de uso sustentável apresentaram conselheiros dotados de uma maior legitimidade que os representantes de unidades de proteção integral (Figura 29). 


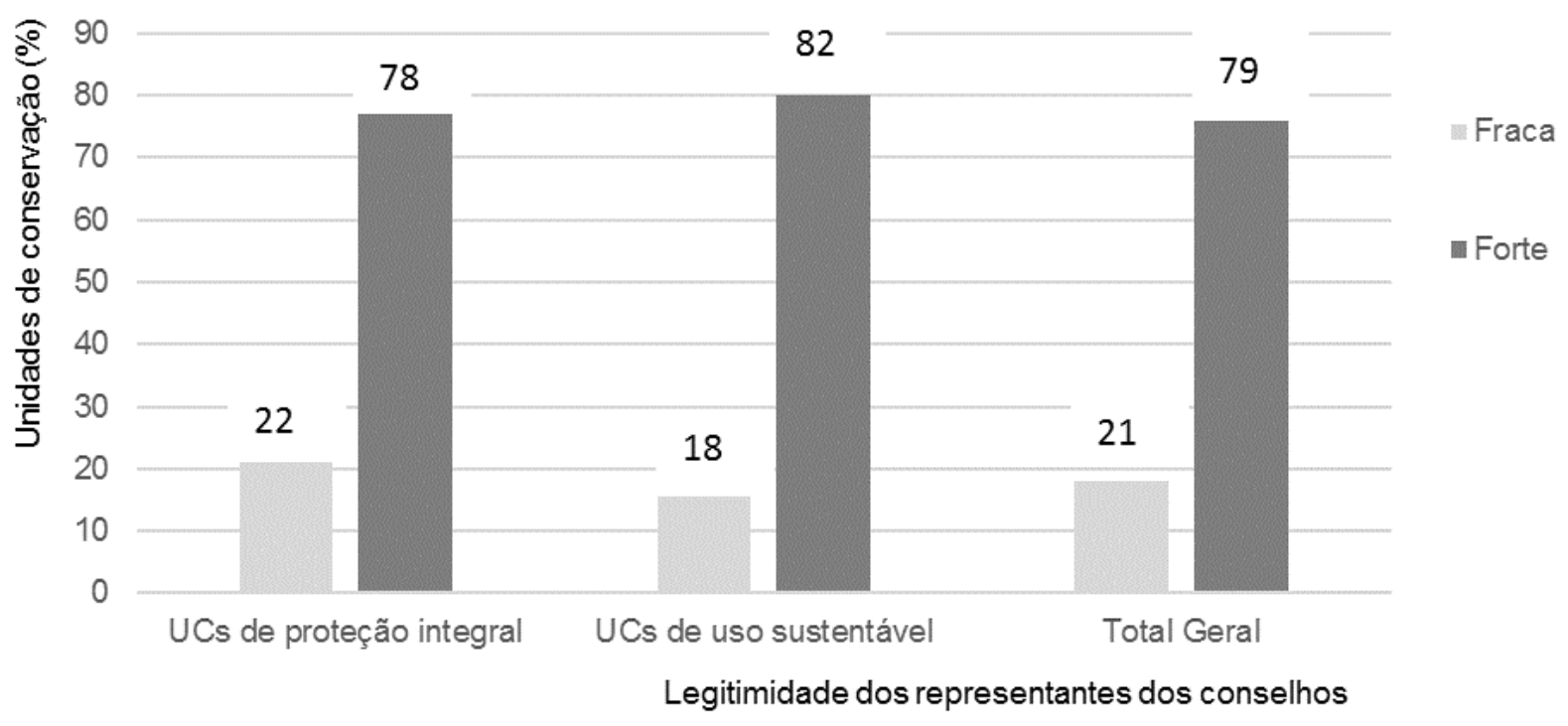

$(\mathrm{n}=129)$

Fonte e autoria própria, 2013.

Figura 29. Legitimidade da representação dos conselheiros por grupo de UC.

Nesta seção foram explorados os dados primários referentes a participação social e contexto das unidades de conservação, obtidos a partir da aplicação do formulário eletrônico e RAPPAM. O objetivo foi fornecer subsídios para a discussão desse e futuros estudos.

\subsubsection{Efetividade dos conselhos}

Considerando a amostra total deste estudo $(\mathrm{n}=299), 47 \%$ dos conselhos gestores criados foram considerados efetivos ${ }^{33}$.

Dentre os conselhos criados, aqueles das UCs amazônicas e da mata atlântica apresentaram o maior percentual de efetividade (Figura 30).

\footnotetext{
${ }^{33}$ Considerou-se como efetivos os conselhos que se reúnem regularmente, participando ativamente da gestão da
} UC. 


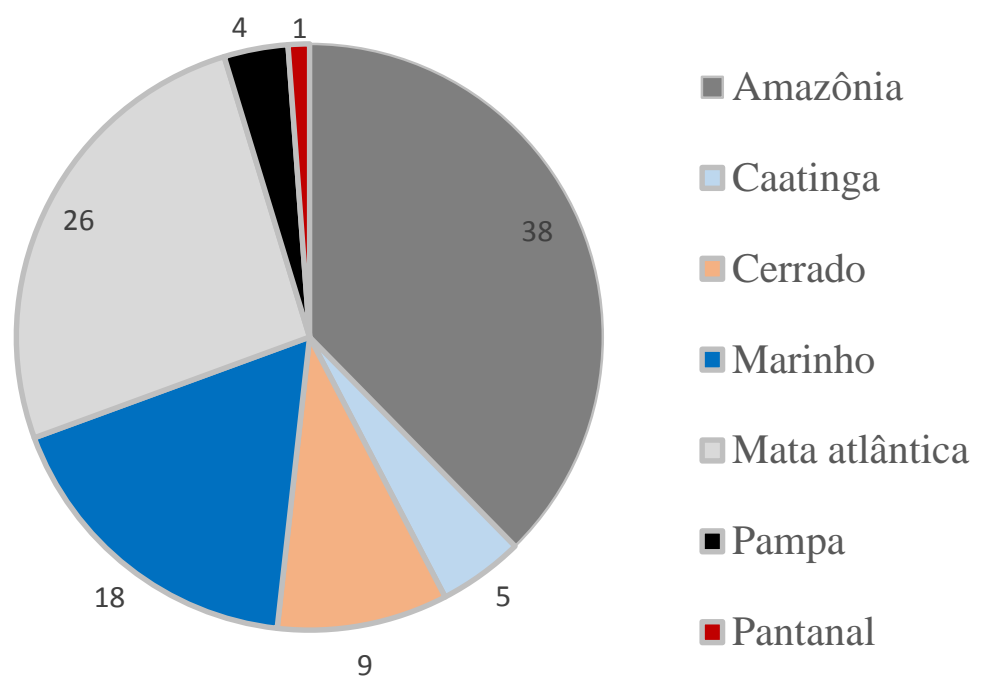

$(n=129)$

Fonte e autoria própria, 2013.

Figura 30. Percentual de unidades de conservação com conselhos gestores criados e operantes em cada bioma brasileiro.

Em relação ao grupo de UCs, as unidades de conservação de uso sustentável apresentaram conselhos gestores mais ativos do que as de proteção integral - 79 e $67 \%$, repectivamente, de acordo com as informações levantadas via formulário eletrônico.

Ao menos dois fatores analisados parecem contribuir para a maior efetividade dos conselhos gestores de unidades de conservação de proteção integral: i. a necessidade de validação popular dos instrumentos e ações de gestão, inerente à natureza deliberativa dos mesmos e ii. a adoção de uma estratégica de conservação mais participativa nas UCs de uso sustentável em contraposição à adotada nas UCs de PI, cuja estratégia de comando e controle prevalece.

Os resultados sugerem que o estabelecimento de algumas medidas poderia contribuir com o ganho da efetividade dos conselhos gestores, a saber: i. maior apoio financeiro para possibilitar o deslocamento dos conselheiros e favorecer a logística necessária para a realização das reuniões; ii. maior diversificação das representações nos diversos fóruns socioambientais e iii. divisão de poder mais equânime no que concerne a proposição da pauta das reuniões pelos diferentes atores sociais.

A velocidade de execução orçamentária para realização das reuniões dos conselhos provavelmente também influencia sua efetividade.

Essa crença deriva da constatação de ganho de efetividade destas instâncias em unidades de conservação apoiadas pelo programa ARPA. Nessas UCs, as reuniões de conselhos são realizadas a partir de gastos locais, utilizando-se um mecanismo de execução direta (conta vinculada) pelos gestores que confere maior agilidade. Mecanismos semelhantes deveriam ser 
desenvolvidos pelo Governo Federal para a operacionalização dos conselhos gestores, de modo a facilitar a execução dos recursos, pois as decisões próprias dessas instâncias precisam ser tomadas a uma velocidade normalmente bastante superior aos trâmites burocráticos demandados pelas formas de gastos governamentais.

\section{CAPÍTULO 6. DIMENSIONAMENTO DA PARTICIPAÇÃO SOCIAL}

\subsection{CONSIDERAÇÕES SOBRE O DELINEAMENTO CONCEITUAL PROPOSTO}

A literatura consultada evidenciou que a PS nas políticas públicas brasileiras ainda é incipiente. Fato este que, provavelmente, decorre da predominância de processos decisórios pouco participativos e de relacionamentos sociais e políticos verticais, tradicionalmente instituídos no País (SIQUEIRA, 2008; JUNIOR \& SAMPAIO, 2008). De acordo com Young (1990), mesmo quando as políticas públicas se declaram participativas, frequentemente elas são hierárquicas e implementadas dentro de uma lógica de manipulação, ou, como destacam Abramovay (2001) e Macedo (2008), de submissão aos poderes dominantes.

Ao mesmo tempo, observa-se que a avaliação da participação social em seu sentido mais pleno, envolve um olhar minucioso para a disputa de poder entre os atores sociais locais, nos mais diversos contextos políticos de cada unidade de conservação. Essa análise em uma perspectiva de escala nacional, tal qual a trabalhada neste estudo, representaria em si um objetivo à parte. Em função destas colocações, a participação social avaliada não carregou, necessariamente, pressupostos de distribuição de poder.

No lugar disto, optou-se por uma ampla abrangência do significado de participação social, conforme foi apresentado na seção 3.1.2, de modo a contemplar todas relações, mais fortes ou mais fracas de participação, sem distinção.

Assim, entendendo a PS enquanto interação social no processo de tomada de decisão, o capítulo 3 descreveu os critérios para a seleção das variáveis de dimensionamento e justificou a aplicação do $M C A$, com intuito de revelar a existência ou não de identidade entre elas. Atestando-se a identidade de todo o grupo, ou de determinado subgrupo de variáveis, a utilização do conjunto selecionado enquanto uma medida apropriada de dimensionamento da PS seria corroborada. O resultado deste exercício é apresentado e discutido na próxima seção.

\subsection{DEFINIÇÃO DO FATOR DE DIMENSIONAMENTO}

Dimensionar a PS não é das tarefas mais triviais. A primeira dificuldade decorre da possibilidade de análise sob duas diferentes perspectivas - participação enquanto finalidade e enquanto meio. 
As variáveis que definem a PS, a mensuram e a influenciam dependem do objetivo para o qual ela está se valendo e isso varia de acordo com a perspectiva analisada.

Não bastasse a multiplicidade de objetivos, o conceito de PS necessita de qualificação (participação cidadã, participação passiva, participação emancipadora, dentre muitos outros). Associe-se a isso, distintas percepções, pois, sim, "a tarefa de classificar e nomear os fenômenos do mundo social está diretamente relacionada com a forma como atribuímos sentido a ele" (BRANDY, 1999), e dificilmente será exitosa a tarefa de convertê-la a uma medida unidimensional, como um índice.

Frente aos desafios mencionados, não se buscou neste estudo a modelagem matemática ou a construção de um índice que remetesse a um valor numérico final de participação.

No lugar, foi identificado um grupo de variáveis a partir do qual seria possível traçar um padrão de comportamento que corroborasse sua função de dimensionamento.

$\mathrm{Na}$ seção 3.8 do capítulo anterior, foi defendida a opção metodológica adotada para dimensionamento da participação social, que resultou na escolha da análise de correlação multivariada (MCA) para seleção dos fatores de dimensionamento da PS.

Da inter-relação das variáveis de dimensionamento pelo método MCA (Anexo XI) resultou o padrão de associação apresentado no mapa de fatores a seguir (Figura 31), no qual as variáveis foram plotadas de acordo com a seguinte representação:

$\mathbf{d x} \_\mathbf{y}$, onde x é o número de identificação da variável de dimensionamento e y é a intensidade observada, com variação de 0 (menor intensidade) a 5 (maior intensidade) que espelha a medida utilizada no RAPPAM ( $0=$ não, $1=$ predominantemente não, $3=$ predominantemente sim, $5=\operatorname{sim})$.

Para facilitar a visualização do padrão de agrupamento das variáveis, os grupos com intensidade similar foram reunidos em um conjunto de mesma $\operatorname{cor}^{34}$.

Grupo A, azul, expressão mais fraca de todas as variáveis (zero);

Grupo B, vermelho, categoria de intensidade 1;

Grupo C, verde, intensidade 3 e

Grupo D, amarelo, intensidade 5.

\footnotetext{
${ }^{34}$ Apenas através da inspeção visual.
} 


\section{Dimensão $2(14,51 \%)$}

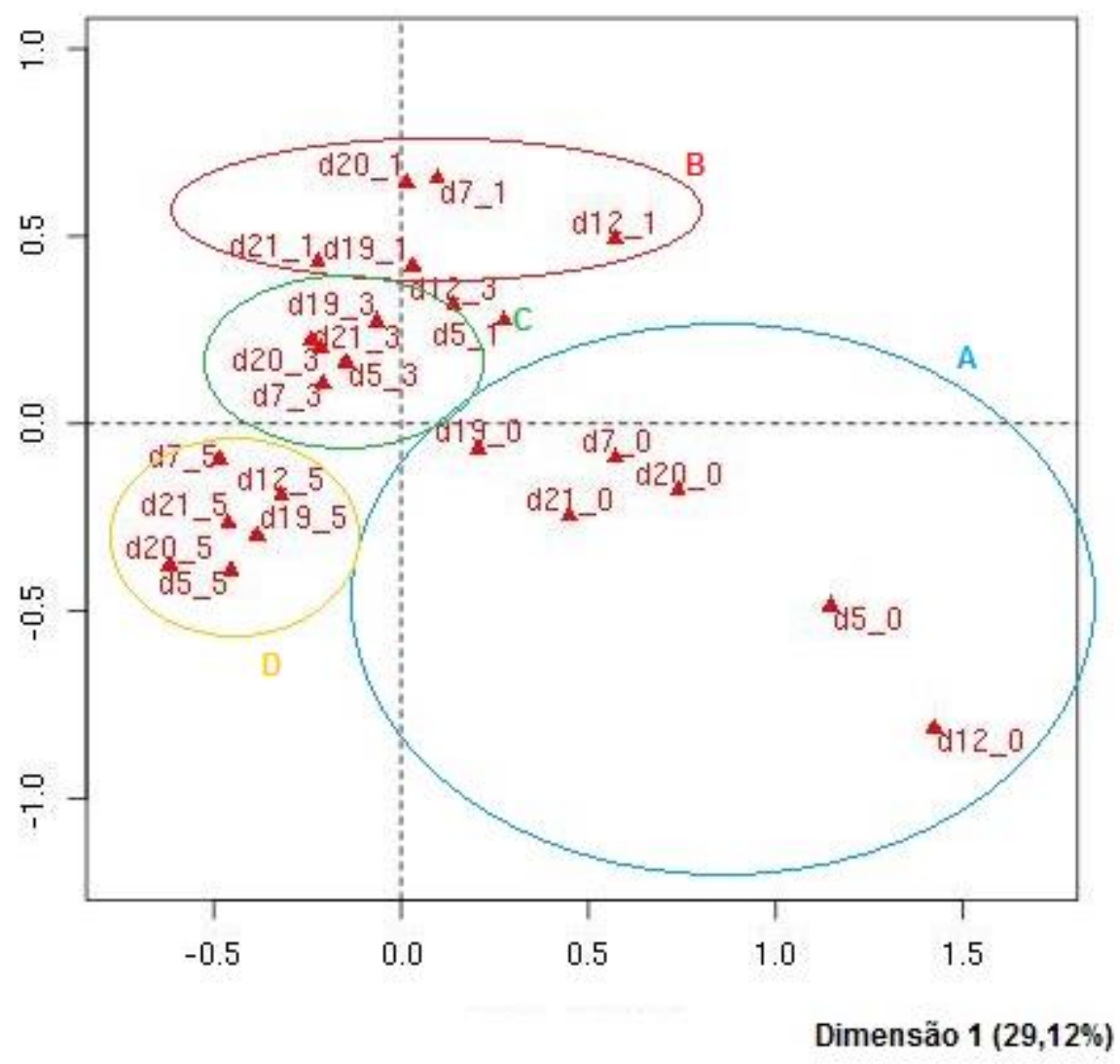

$(\mathrm{n}=292)$

Fonte: RAPPAM, 2010

Autoria própria

LEGENDA: dx_y, onde x é o número de identificação da variável de dimensionamento e y é a intensidade observada, com variação de 0 (menor intensidade) a 5 (maior intensidade). d20 = comunidades locais participam das decisões pelas quais são afetadas; $\mathrm{d} 21$ = resultados da pesquisa, monitoramento e o conhecimento tradicional são incluídos rotineiramente no planejamento; $\mathrm{d} 5$ = comunidades locais apoiam os objetivos globais da UC; $\mathrm{d} 7$ = efetividade do conselho; $\mathrm{d} 12=$ Articulação efetiva da UC com órgãos e entidades relacionadas, d19= A definição do desenho e da categoria da UC foi decorrente de um processo participativo.

Figura 31. Mapa de fatores da Análise de Correspondência Múltipla das variáveis de dimensionamento

A partir da análise da Figura 31, conclui-se que todas as variáveis, previamente identificadas como potencialmente medidoras de participação social (variáveis de dimensionamento), apresentaram o mesmo padrão de agrupamento espacial.

Isto significa dizer que elas apresentam uma redundância de comportamento e que o conjunto pode ser utilizado como uma boa medida de participação social, corroborando a seleção inicial. O Quadro 6 reúne todas as variáveis de dimensionamento que, juntas, compõem o que esse estudo convencionou chamar de fator de dimensionamento.

Quadro 6. Variáveis de dimensionamento selecionadas para compor o fator de dimensionamento.

\section{FATORES DE DIMENSIONAMENTO}

1. Efetividade do conselho gestor; 
2. Comunidades locais participam das decisões pelas quais são afetadas;

3. Resultados da pesquisa, monitoramento e o conhecimento tradicional são incluídos rotineiramente no planejamento;

4. Comunidades locais apoiam os objetivos globais da UC;

5. Articulação efetiva da UC com órgãos e entidades relacionadas;

6. Definição do desenho e da categoria da UC é decorrente de um processo participativo.

Essa será a medida utilizada como parâmetro de comparação entre os fatores que influenciam a participação social (seção 7.1) e as medidas de conservação da biodiversidade (seção 7.2).

Os resultados sugerem que os indicadores acima encerram em si o próprio conceito de participação. Ademais, orientam para ótica de que é desejável uma imersão no processo de gestão em todas as suas etapas, da criação da UC (criação participativa), a legitimação do espaço protegido (apoio aos objetivos globais da UC) até o estabelecimento de canais de participação (conselho efetivo, articulação com a sociedade), que propiciem a participação ativa da sociedade (comunidades participam das decisões pelas quais são afetadas) e a incorporação da sua identidade cultural (resultados de pesquisa, monitoramento $e$ o conhecimento tradicional são incluídos rotineiramente no planejamento) para que a comunidade se sinta parte do processo.

Os resultados obtidos neste estudo demonstraram um elevado grau de importância na participação da sociedade via conselhos gestores. Importância percebida, tanto em termos de frequência de acesso a este canal, considerado o mais utilizado pela grande maioria, como em relação ao crescente número de conselhos criados, desde a instituição da obrigação legal de instituí-los, em 2001.

Como será apresentado mais adiante, considerado o principal elo entre sociedade e gestão da UC pela imensa maioria das UCs analisadas (90\%), corrobora a grande expressão dos mesmos, evidenciada por Gohn (2007) no movimento de democratização da sociedade. Os CGs são considerados por Abramovay (2001) como a mais importante inovação institucional das políticas públicas no Brasil após a redemocratização. Arendt (1973) os entende como a única forma possível de um governo horizontal que tenha como condição de existência a participação e a cidadania. Propiciam a entrada de temas até então ausentes na sociedade, na vida dos indivíduos, contribuindo com a atribuição explícita de poder àqueles que não fazem parte do corpo político eleito ou da administração pública profissionalizada. Apesar da precariedade da participação social nestas instâncias e da frequente submissão a poderes locais dominantes, encerram grande potencial de transformação política (ABRAMOVAY, 2001). Por contemplar 
a participação da sociedade e não apenas do poder público, possibilitam a consolidação da participação democrática na tomada de decisões (DE SOUZA, 2015).

Ainda sobre o fator de dimensionamento, é interessante observar que ele encerra conceitos capazes de estabelecer um gradiente de intensidade entre um continum de PS que liga um extremo da manipulação, a outro do poder cidadão, conforme conceituação definida por (ARNSTEIN (1969); BORRINI-FEYERABEND (1996), MANNIGEL (2008); PIMBERT \& PRETTY (1997) e MATTES (1998)).Os resultados demonstram que a metodologia construída conferiu a possibilidade de comparação com outras medidas mais lineares, como a conservação da biodiversidade, sem maiores reduções (restrições a outras variáveis).

Dada a importância desses colegiados, a seção 5.1.2 abordará especificamente a organização dos mesmos dentro da perspectiva de aproximação sociedade-unidade de conservação.

Após breve conceituação, serão discutidos elementos que podem influenciar na sua efetividade.

\subsubsection{CONSIDERAÇÕES SOBRE O MÉTODO PROPOSTO}

O estabelecimento do fator de dimensionamento resumiu uma redundância de comportamento que ratificou a ideia de semelhança das variáveis selecionadas, corroborando a escolha das mesmas como bons medidores de participação social.

Dessa forma, a medida de participação utilizada para efeitos comparativos neste estudo está resumida nas características das variáveis do fator de dimensionamento. Abriga uma visão de participação enquanto processo, ao contemplar na análise distintos momentos, desde a definição do desenho e da categoria da UC até uma medida de consolidação do conselho gestor (variável conselho gestor efetivo). O fator contempla ainda importantes características para qualificação da participação social, como a participação na tomada de decisões, incorporação do conhecimento tradicional na gestão da UC e articulação entre UCs e demais segmentos envolvidos na sua gestão.

É importante ressaltar que, dependendo da escala de análise ou mesmo da disponibilidade de informações, outros elementos podem ser agregados para compor o fator de dimensionamento, sendo suficiente que, seguidos os mesmos passos de categorização dos dados e aplicação do $M C A$, a nova variável siga a mesma orientação espacial.

CAPÍTUlO 7. PARTICIPAÇÃO SOCIAL NA GESTÃo DE UCS: UMA ANÁLISE DE INTENSIDADE PARA DUAS DIMENSÕES

Este capítulo analisa a participação social sob duas perspectivas. A primeira, abordada na seção 7.1, concentra-se em um olhar para dentro da participação, sobre a determinação de fatores de 
maior influência sob sua intensidade. Na segunda, são avaliados os efeitos decorrentes de sua expressão no que concerne, especificamente, a conservação da biodiversidade.

\subsection{ALGUNS CAMINHOS PARA POTENCIALIZAR A PARTICIPAÇÃO SOCIAL}

Nas seções anteriores foram apresentados os dados de base e descrita a metodologia adotada para selecionar as variáveis de maior influência sob a participação social. Neste capítulo serão apresentados os resultados desta análise, com o objetivo de explorar possíveis caminhos para se potencializar a PS na gestão de unidades de conservação.

O mapa de fatores decorrente da análise do $M C A$ entre fator de dimensionamento e variáveis explicativas (tabela de saída da aplicação deste $M C A$ no (Anexo XII) é apresentado na Figura 32.

Nela, são realizados destaques com diferentes cores de modo a evidenciar os agrupamentos espaciais de mesma intensidade.

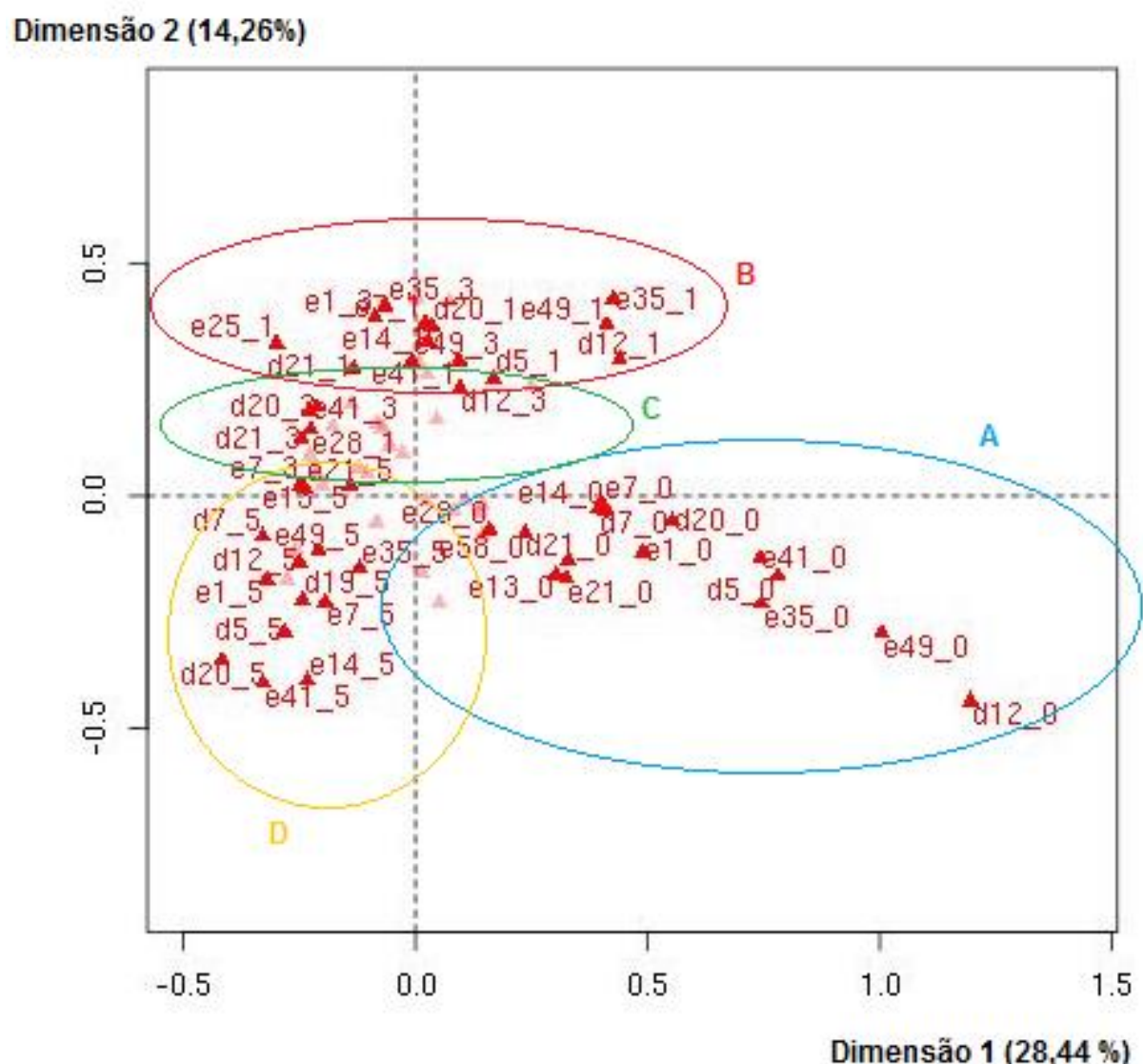

LEGENDA: dx_y, onde x é o número de identificação da variável de dimensionamento e y é a intensidade observada, com variação de 0 (menor intensidade) a 5 (maior intensidade). d5. As comunidades locais apoiam os objetivos globais da UC, d7. Conselho implementado e efetivo, d12. Articulação efetiva da UC com órgãos e entidades relacionadas, d19. A definição do desenho e da categoria da UC foi decorrente de um processo participativo, d20. As comunidades locais participam das decisões pelas quais são afetadas, d21. Os resultados da pesquisa, monitoramento e o conhecimento tradicional são incluídos rotineiramente no planejamento, e1. Organização, capacitação e desenvolvimento das comunidades locais e conselhos coerente com ameaças e pressões, objetivos da UC e plano de trabalho anual, e13. A UC possui características inusitadas de importância estética, e14. Existe a comunicação efetiva entre as comunidades locais, e20. O valor de mercado de recursos da UC é alto, e21. A UC possui um alto valor recreativo, e25. A infraestrutura para visitantes é apropriada para o nível de uso pelo visitante, e28. A UC possui um alto valor recreativo e infraestrutura adequada para visitação, e35. A tomada de decisões no manejo é 
transparente, e41. Existe a comunicação efetiva da UC com as comunidades locais, e49. Os funcionários da UC colaboram regularmente com os parceiros, comunidades locais e outras organizações, e7. Os conflitos com a comunidade local são resolvidos de forma justa e efetiva.

Figura 32. Mapa de fatores da Análise de Correspondência Múltipla entre variáveis de dimensionamento e variáveis explicativas $(n=292)$.

Como se pode observar, algumas variáveis explicativas se reuniram em torno da mesma intensidade de outras explicativas e das que compõe o fator de dimensionamento. Esta similaridade foi determinante para a priorização de um grupo de variáveis (Quadro 7) como o de mais forte influência sobre o fator de dimensionamento da participação social em unidades de conservação federais.

Ou seja, o resultado prático da aplicação desta metodologia permite inferir que a participação social nas UCs será tão expressiva quanto for a expressão das variáveis explicativas selecionadas. Assim, ao objetivar dar prioridade às ações com maior capacidade de potencializar a participação social, àquelas vinculadas às variáveis identificadas no quadro abaixo devem ser priorizadas.

Quadro 7. Variáveis explicativas selecionadas por proximidade no agrupamento espacial decorrente da análise multivariada, dentre o grupo de onze variáveis explicativas do RAPPAM consideradas no estudo.

VARIÁVEIS EXPLICATIVAS - PARTICIPAÇÃO SOCIAL

1. Capacitação e desenvolvimento das comunidades locais e conselhos coerente com ameaças e pressões, objetivos da UC e plano de trabalho anual;

2. Existe a comunicação efetiva entre as comunidades locais;

3. Existe a comunicação efetiva com as comunidades locais;

4. Os conflitos com a comunidade local são resolvidos de forma justa e efetiva;

5. A UC possui características inusitadas de importância estética;

6. A UC possui um alto valor recreativo;

7. A infraestrutura para visitantes é apropriada para o nível de uso pelo visitante;

8. Tomada de decisões no manejo é transparente;

9. Funcionários da UC colaboram regularmente com os parceiros, comunidades locais e outras organizações.

A análise das variáveis selecionadas conduz a reflexão de alguns pontos.

Em primeiro lugar, o grau e a qualidade de participação social não ocorrem em um vazio social e cultural, mas em uma rede de poder e forças. A comunicação é entendida como uma variável política fundamental, para a efetivação da ideia de democracia, mas muitas vezes não significa que o conhecimento foi transmitido. Muitas vezes, o tecnicismo exagerado no repasse de informações pode desfavorecer a assimilação das informações debatidas nos espaços sociais de 
diálogo (DOMBROWSKI \& PARMIGIANI, 2009) e/culminando, eventualmente, em formas de dominação política e de inibição do controle social (OLIVEIRA, 2004). É necessário verificar se a informação alcança a compreensão do público pretendido de modo que o processo decisório ocorra de forma consciente. Isso é oportuno dizer, uma vez que se trata de um risco iminente que deve ser mitigado por aqueles que pretendem fortalecer processos participativos. No entanto, os dados do RAPPAM mostram que a comunicação e o indicador capacitação e desenvolvimento das comunidades locais e conselhos são dos três indicadores melhor pontuados no módulo insumos e indicam níveis medianos e bem próximos de atendimento por parte das UCs. Ademais, foi registrado um grande avanço quanto ao atendimento da UCs ao indicador de desenvolvimento das comunidades, quase 20 pontos percentuais em cinco anos.

Iniciativas de capacitação continuada para conselheiros em temas como legislação, negociação de conflitos e mobilização social, como forma de renovação dos conselhos e de se corrigir assimetrias de informação entre atores sociais tem sido sugeridas (PALMIERI \& VERÍSSIMO, 2009). Loureiro (2004) ressalta que também as assimetrias de poder entre os atores que formam o espaço público podem ser harmonizadas investindo-se no caráter educativo destes espaços e que as diferenças devem ser percebidas como condição para que ele exista como espaço de manifestação, compartilhamento de poder e de decisão. Dombrowski e Parmigiani (2009) relativizam esse tipo de iniciativa alertando que, se por um lado, o conhecimento técnico hierarquiza as relações, se o povo precisa ser preparado para participar de uma instância política, é porque ela não trata das coisas que motivam sua participação.

Tão importante quanto o nivelamento das informações técnicas é a disseminação do conhecimento tradicionalmente acumulado pela sociedade, de modo a permitir a interação e, quiçá complementariedade, de ambas as visões na definição das ações planejadas. Assim, parece adequado que esta última medida tenha sido indicada como uma das variáveis que compõem o fator de dimensionamento da participação social (variável "resultados da pesquisa, monitoramento e o conhecimento tradicional são incluídos rotineiramente no planejamento"). Dito isso, é importante ressaltar que a comunicação é um pressuposto fundamental para a transparência da gestão da UC. Uma comunicação insuficiente pode acarretar em um ambiente de desconfiança, onde os envolvidos podem ter a sensação de que informações estão sendo omitidas propositadamente, mesmo que essa não tenha sido a intenção, como ressaltado por (PALMIERI \& VERÍSSIMO, 2009). Os gestores tem investido em processos mais transparentes nos últimos anos, de modo que a transparência nos processos de tomada de decisão correspondeu a um dos poucos indicadores com mais de $70 \%$ de atendimento na última 
verificação. Patamares semelhantes de atendimento indicam uma postura colaborativa com os parceiros, comunidades locais e outras organizações.

Por fim, ressalta-se ainda a importância que o turismo assume no caminho para práticas mais participativas de gestão. Fato que pode ser evidenciado a partir do agrupamento de três variáveis vinculadas à visitação com o fator de dimensionamento, a saber: "A UC possui características inusitadas de importância estética", "A UC possui um alto valor recreativo" e "a infraestrutura para visitantes é apropriada para o nivel de uso pelo visitante”.

Ou seja, unidades de conservação com maior potencial estético e infraestrutura para visitação, estiveram bem associadas com as variáveis de dimensionamento.

Dada a precariedade das condições de visitação da maioria das unidades brasileiras, parece claro que o mínimo esforço para melhor estruturar esta função social pode trazer grandes retornos para a conservação da biodiversidade, além de reduzir as distâncias entre sociedade e UCs de proteção integral.

Outras práticas de uso direto e indireto do espaço avaliadas no RAPPAM foram consideradas neste estudo, mas somente a visitação parece influenciar a intensidade da participação social nas UCs analisadas.

\subsection{INFLUÊNCIA DA PARTICIPAÇÃO SOCIAL NA CONSERVAÇÃO DA BIODIVERSIDADE BRASILEIRA DE UCS BRASILEIRAS}

Esta seção objetiva inferir sobre o objetivo central da tese: qual a influência da participação social na conservação da biodiversidade?

Embora tenham aumentado significativamente os estudos sobre participação social em espaços colegiados de discussão e deliberação, são ainda recentes aqueles relacionados à utilização desses mecanismos voltados à conservação da biodiversidade (SOUZA, 2012). Conforme pormenorizado no capítulo 3, para análise dessa influência, foi criado um fator de dimensionamento e categorizadas as médias incrementais de desmatamento dos três anos seguintes a verificação das medidas de participação. A partir do $M C A$ procedeu-se, então a análise da inter-relação das variáveis de PS e conservação da biodiversidade (desmatamento). Na Figura 33 é apresentado o mapa de fatores decorrente da análise de múltipla correspondência entre as medidas de desmatamento categorizadas (vide seção metodológica para maiores detalhes) e o fator de dimensionamento (Anexo XIII). 


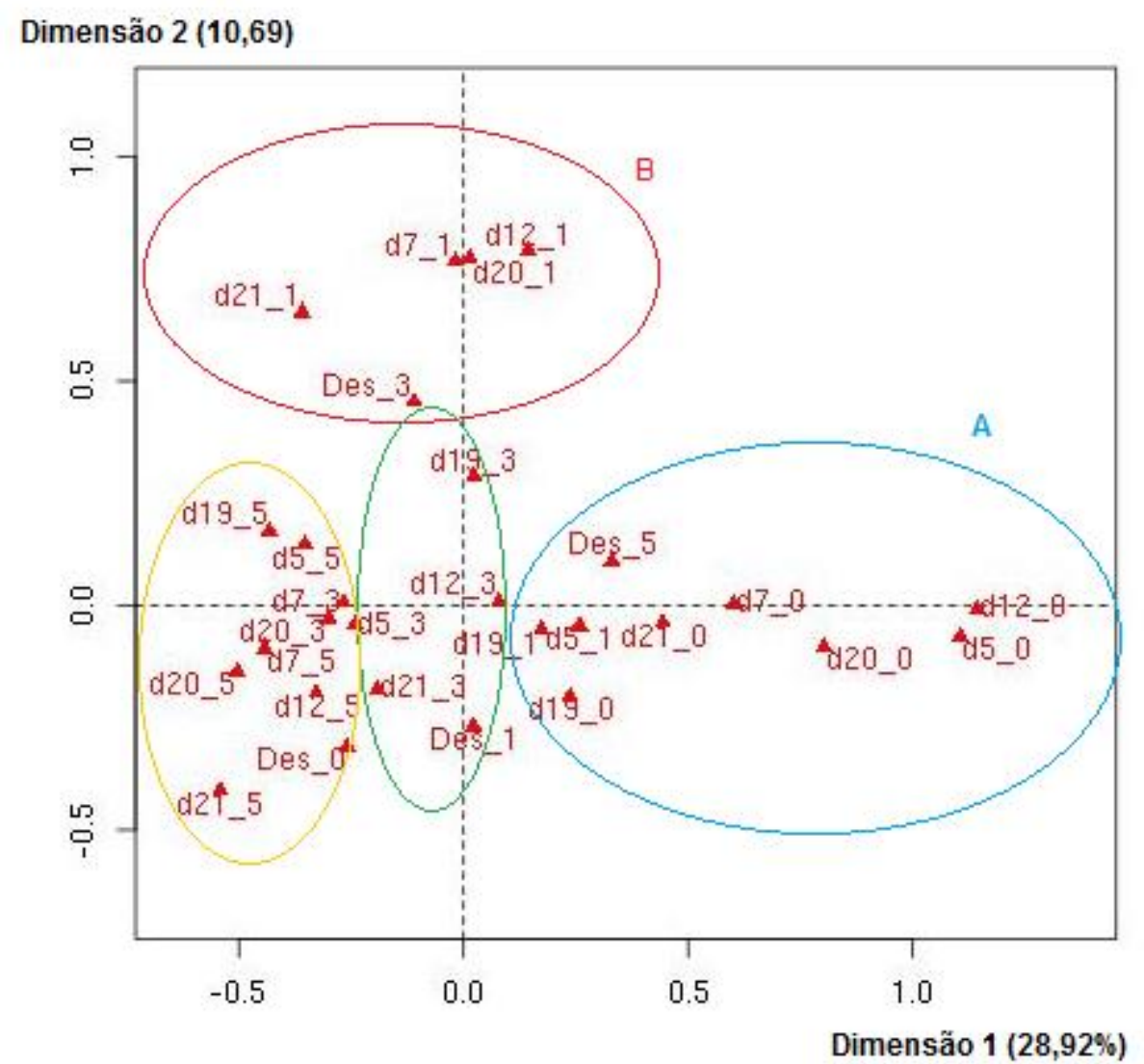

$(\mathrm{n}=113)$

Fonte: RAPPAM 2010 e INPE: 2010-2013

Autoria própria, 2013

LEGENDA: Des_x, onde "Des" é o prefixo da variável desmatamento e x, a sua intensidade; dx_y, onde x é o número de identificação da variável de dimensionamento e y é a intensidade observada, com variação de 0 (menor intensidade) a 5 (maior intensidade). $\mathrm{d} 20=$ comunidades locais participam das decisões pelas quais são afetadas; $\mathrm{d} 21=$ resultados da pesquisa, monitoramento e o conhecimento tradicional são incluídos rotineiramente no planejamento; d5 = comunidades locais apoiam os objetivos globais da UC; $\mathrm{d} 7$ = efetividade do conselho; $\mathrm{d} 12$ = Articulação efetiva da UC com órgãos e entidades relacionadas; d19 = A definição do desenho e da categoria da UC foi decorrente de um processo participativo

Figura 33. Mapa de fatores do MCA para fator de dimensionamento e desmatamento das unidades de conservação da Amazônia (proteção e integral e uso sustentável).

É possível observar a conformação de quatro distintos conjuntos. No grupo destacado em amarelo (D), observa-se claramente um padrão de agrupamento entre fator de dimensionamento da participação social de maior intensidade (“dX_5") e medidas de desmatamento de menor intensidade ("Des_0"). De modo similar, no quadrante onde os fator de dimensionamento com menor intensidade (dx_0) estiveram agrupados (conjunto A) também foram agrupados os maiores valores de desmatamento (Des_5).

Isto evidencia uma tendência de redução do desmatamento em unidades de conservação onde a participação social foi trabalhada mais intensamente.

Tendência similar não foi verificada, no entanto, para as unidades de conservação de proteção integral (Anexo XIV), como indicado na análise do MCA corrrespondente (Figura 34). 


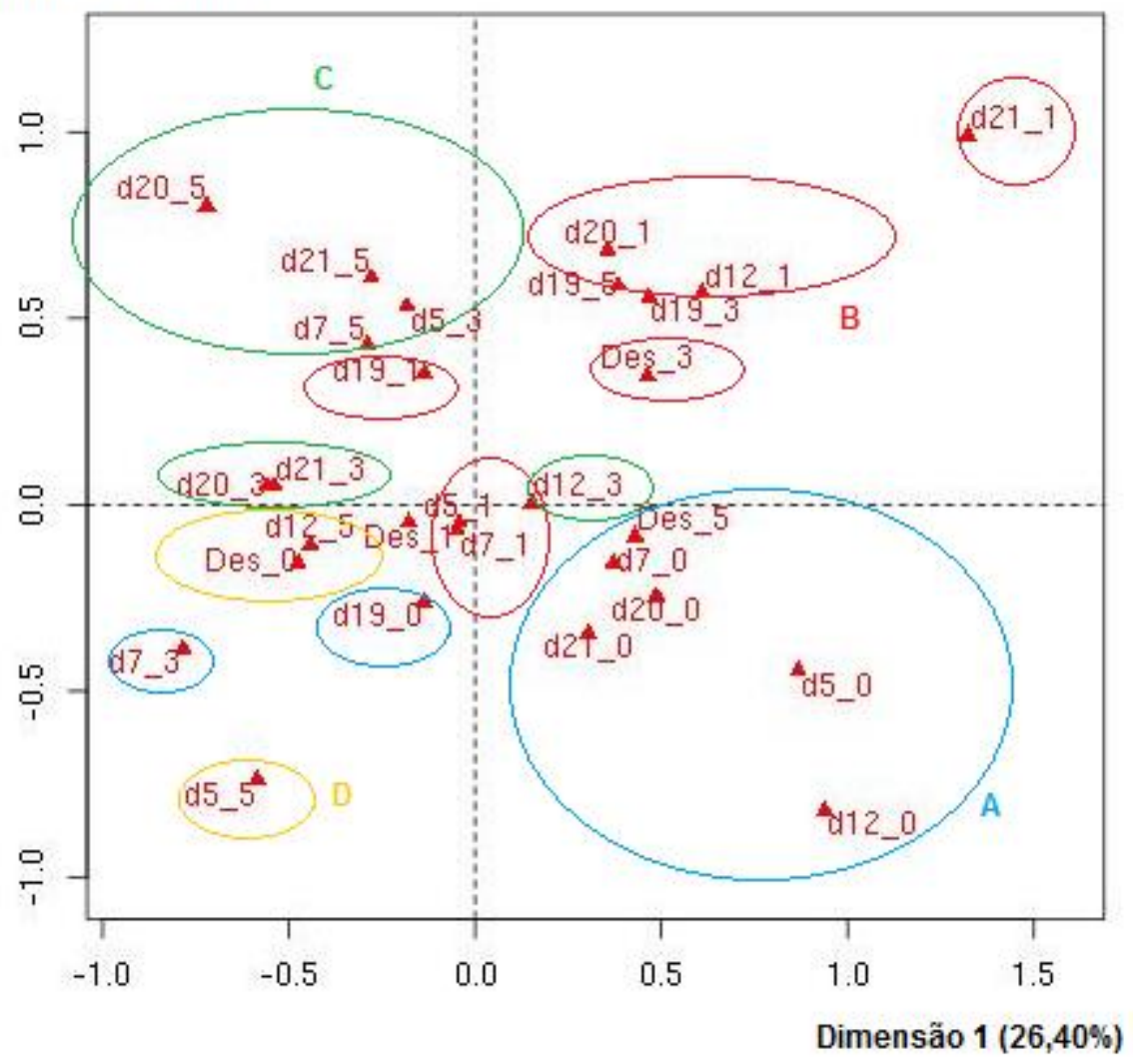

$(\mathrm{n}=38)$

Fonte: RAPPAM 2010 e INPE: 2010-20132

Autoria própria, 2013

Figura 34. Mapa de fatores do MCA entre fator de dimensionamento e desmatamento das unidades de conservação da Amazônia para unidades de proteção integral.

LEGENDA: Des_x, onde "Des" é o prefixo da variável desmatamento e $\mathrm{x}$, a sua intensidade; dx_y, onde x é o número de identificação da variável de dimensionamento e y é a intensidade observada, com variação de 0 (menor intensidade) a 5 (maior intensidade). $\mathrm{d} 20=$ comunidades locais participam das decisões pelas quais são afetadas; $\mathrm{d} 21$ = resultados da pesquisa, monitoramento e o conhecimento tradicional são incluídos rotineiramente no planejamento; d5 = comunidades locais apoiam os objetivos globais da UC; $\mathrm{d} 7$ = efetividade do conselho; d12 = Articulação efetiva da UC com órgãos e entidades relacionadas.

Embora os mais altos índices de desmatamento coincidam com uma baixa intensidade de participação (conjunto verde), pela dispersão das cores ao longo dos quadrantes, evidencia-se que não há um padrão de agrupamento entre estas variáveis e, portanto, elas não revelam identidade entre si.

Essa condição pode ser decorrente de múltiplos de fatores e não significa dizer que para as unidades de proteção integral que o engajamento social não interfira na conservação da biodiversidade. Os benefícios decorrentes da conservação stricto sensu demandam uma percepção mais refinada que não foi ainda absorvida pela maior parte da sociedade. Eles relacionam-se, sobretudo, a "serviços invisíveis", como os serviços ambientais, cuja conexão causal com a UC raramente é estabelecida pela comunidade, ao ponto de motivar um maior 
engajamento social ou de estimular mudanças de hábitos. Esse é um típico exemplo da racionalidade de Olson (1991), a qual postula que onde existirem free riders em excesso, o bem coletivo não poderá ser absolutamente alcançado. Talvez por isso o engajamento social na gestão de unidades de conservação de proteção integral seja mais raro e ocorra em uma dimensão que não pode ser capturada por esse estudo. Assim, pode se concluir tão somente que o engajamento social na gestão de unidades de conservação de proteção integral não foi suficientemente potente ao ponto de refletir em uma menor perda da biodiversidade.

Por outro lado, o engajamento social na gestão das UCs de uso sustentável tende a potencializar a conservação da biodiversidade nestas áreas. A partir da análise das estratégias de conservação adotadas pelas UCs de proteção integral e uso sustentável da Amazônia, discutidas no capítulo 4 (Figura 20), percebe-se que as de proteção integral utilizam uma estratégia muito mais coercitiva do que as de uso sustentável. Assim, o fato da participação social não ter apresentado um padrão de relacionamento bem definido com o desmatamento nas UC de proteção integral pode ser apenas reflexo da abordagem utilizada por este grupo, refletindo o tipo de gestão que está atuando, onde a PS não é a principal estratégia utilizada.

Tendo em vista que a ótica preservacionista tradicionalmente exclui as populações locais das arenas de discussão, ou as colocam em papel secundário, a participação efetiva nas UCs pode ser freada ou ocorrer de forma parcial ou distorcida (GONÇALVES et. al., 2011).

Assim, considerando a abordagem preservacionista defendida por alguns estudiosos ${ }^{35}$ como precursora das unidades de conservação de proteção integral e, que a população local tradicionalmente as percebe como obstáculo ao seu desenvolvimento, pode-se inferir que os resultados decorrentes da participação social nestas áreas demandem um trabalho mais árduo do que o que vem sendo engendrado.

O investimento no aprimoramento da participação social nestas áreas pode ser de grande valia como fator incremental na estratégia de conservação da biodiversidade também neste grupo de UCs.

Ademais, de acordo com os resultados observados na seção que resume o status atual da participação federal na gestão das UCs federais, as UCs de uso sustentável reúnem elementos capazes de propiciar uma participação social de maior qualidade. A começar pelo próprio caráter deliberativo dos seus conselhos gestores, tais UCs adotam prioritariamente uma

\footnotetext{
${ }^{35}$ P. ex. HUTTON et. al, 2005; OATES, 1999; SOULÉ \& TERBOGH, 1999; TERBOGH, 2004; KRAMER et. al., 1997.
} 
estratégia de conservação com maior envolvimento popular, apresentam conselheiros com maior legitimidade e conselhos gestores mais efetivos.

Assim, é o grupo de UCs de uso sustentável que está influenciando na tendência geral do desmatamento nas unidades de conservação (Figura 35) se agrupar por similaridade com o fator de dimensionamento da participação social (Anexo XV).

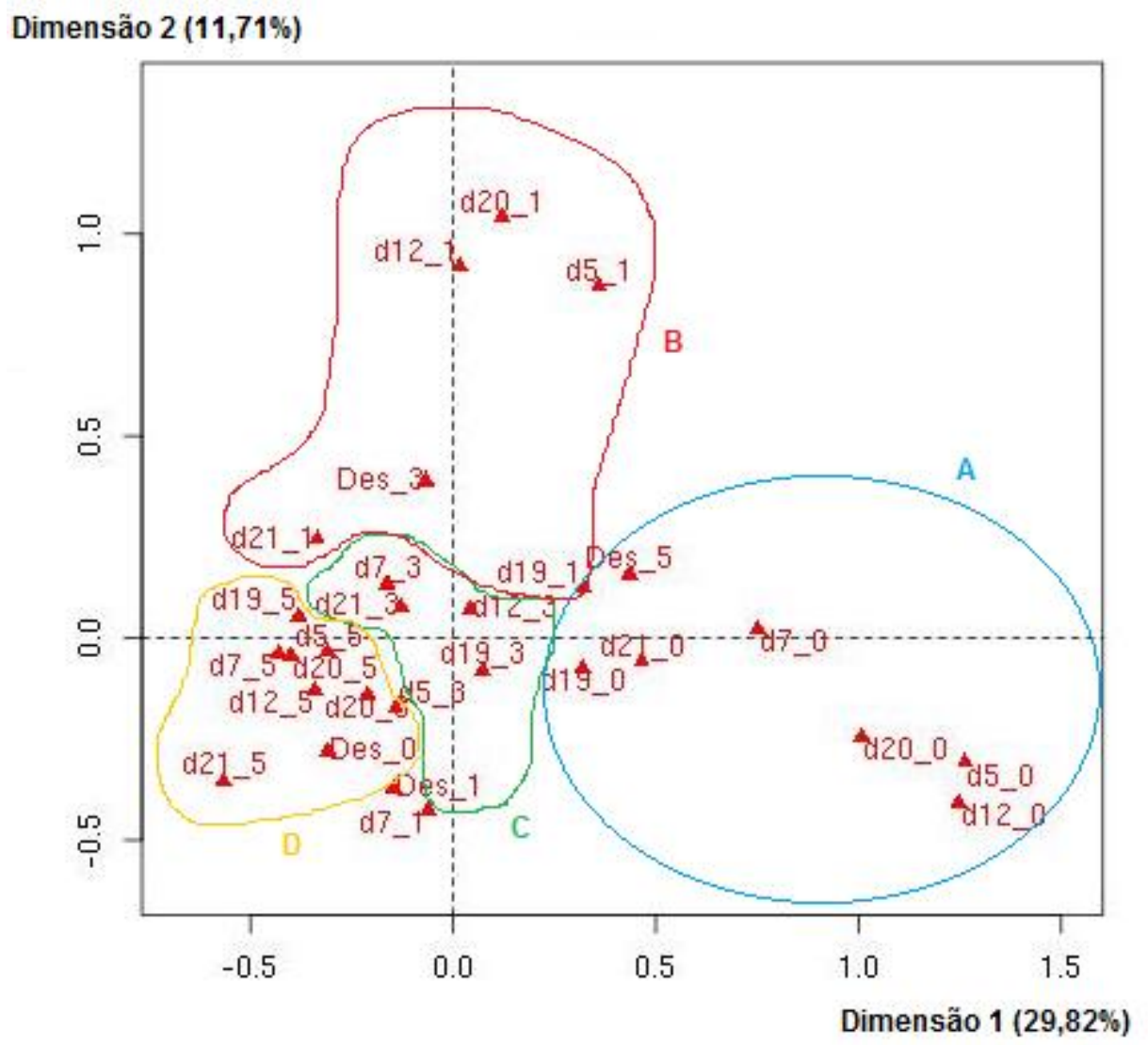

$(\mathrm{n}=75)$

Fonte: PRODES 2010-2013, RAPPAM 2010

Autoria própria, 2013.

LEGENDA: Des x, onde "Des" é o prefixo da variável desmatamento e $\mathrm{x}$, a sua intensidade; $\mathrm{dx}$ y, onde $\mathrm{x}$ é o número de identificação da variável de dimensionamento e y é a intensidade observada, com variação de 0 (menor intensidade) a 5 (maior intensidade). $\mathrm{d} 20=$ comunidades locais participam das decisões pelas quais são afetadas; $\mathrm{d} 21$ = resultados da pesquisa, monitoramento e o conhecimento tradicional são incluídos rotineiramente no planejamento; d5 = comunidades locais apoiam os objetivos globais da UC; d7 = efetividade do conselho; d12 = Articulação efetiva da UC com órgãos e entidades relacionadas.

Figura 35. Mapa de fatores do MCA para fator de dimensionamento e desmatamento das unidades de conservação da Amazônia para unidades de uso sustentável.

Observa-se na Figura 35 o padrão de distribuição de intensidade das medidas de participação social na gestão de UCs e o desmatamento. Observa-se também, que esta é uma relação inversamente proporcional. Pela análise do grupo com destaque em azul, percebe-se que as unidades e conservação de uso sustentável da Amazônia brasileira mais desmatadas são as mesmas onde há, predominantemente, níveis muito baixos de participação social. 
Os resultados apontam para a compreensão de que estratégias mais participativas de gestão de unidades de conservação, que promovam uma maior aproximação entre sociedade e estes espaços, favorecem a conservação da biodiversidade.

Considerando que as UCs apresentam características dos chamados recursos comuns ${ }^{36}$, a intenção de maximizar os benefícios individuais às custas do ônus coletivo resultaria, segundo Hardin (1968) em uma tragédia coletiva, ou "tragédia dos comuns 37 ". Assim, no regime de propriedade comum, haveria uma consequente degradação dos recursos naturais, pois cada usuário tenderia a sobreexplotá-los. Em outras palavras, os indivíduos defenderiam preferencialmente os seus próprios interesses sendo impossível a ação coletiva para regular o uso apropriado dos recursos naturais. As únicas alternativas seriam a regulação central (por meio da ação coercitiva do Estado) ou a privatização. Os resultados aqui observados, no entanto, se contrapõem às argumentações de Hardin, uma vez que, ao contrário do que por ele postulado, nas áreas onde houve menor regulação estatal e a sociedade se fez mais presente na gestão, houve menor evidência de degradação ambiental.

Diversos outros estudos apontam com base em dados concretos que é possível a gestão de bens comuns, sobretudo de recursos naturais de longa duração, (OSTROM, 1990; FEENY et. al., 2001) em bases alternativas as propostas por Hardin.

Ostrom discutindo o modelo de Hardin apresenta uma nova leitura dos commons, ao demonstrar que o que ele define como commons não são recursos comuns, mas sim recursos em livre acesso. Os commons, entendidos como espaços e recursos naturais coletivos, apropriados e gerenciados por grupos definidos, segundo modalidades e regras definidas, são na verdade a terceira via (propriedade comum), e justamente uma potencial solução à problemática exposta por Hardin (LAURIOLA, 2009).

Para Ostrom (1990), pequenos grupos locais e populações maiores são capazes de criar instituições ${ }^{38}$ e a partir delas garantir o respeito dos envolvidos em relação ao uso de bens comuns.

Em outras palavras, existe uma terceira via para evitar a "tragédia dos comuns": a gestão comunitária. Com grande diversidade institucional interna, a gestão comunitária articula-se com a diversidade das reais situações locais, culturais e históricas (LAURIOLA, 2009).

\footnotetext{
${ }^{36}$ São utilizados por múltiplos usuários, há grande dificuldade de controle do acesso e o uso compartilhado permite a cada usuário subtrair daquilo que pertencem também a outros usuários (OSTRON, 1990).

${ }^{37}$ Tradução livre de The Tragedy of the Commons.

${ }^{38}$ Definidas pela autora como o conjunto de regras e normas efetivamente aplicadas por um grupo de indivíduos para organizar as suas atividades. As normas correspondem a valores internos ao grupo e as regras são representações compartilhadas com o exterior.
} 
Para Ostrom (1990) a ação coletiva depende da capacidade de elaboração e adaptação de regras comuns e sua institucionalização depende de cooperação e compartilhamento. Vincula-se, portanto, à capacidade de inovação dos atores, a qual lhes permite, evoluir as regras, aprender juntos e reduzir as assimetrias.

Por fim, entendemos que os resultados obtidos por este estudo estão de acordo com o entendimento apresentado por Ostron e que a participação social, ao favorecer a redistribuição de poder e contribuir com a disseminação e absorção do aprendizado colabora com a redução das desigualdades, favorecendo a conservação dos recursos naturais em regimes de propriedade comum.

\section{CONCLUSÕES}

O perfil geral das unidades de conservação brasileiras e da participação social traçados neste estudo forneceram subsídios importantes às inferências sobre as inter-relações entre participação social e conservação da biodiversidade, podendo servir à outras pesquisas em escala nacional, tamanha a representatividade amostral do estudo.

Diante da indicação, quase que unânime, do conselho gestor, enquanto instância articuladora primordial entre unidade de conservação e sociedade, e o percentual, ainda insatisfatório, de conselhos gestores efetivos, recomenda-se que sejam envidados maiores esforços para aumento da funcionalidade dos mesmos. Devem ser trabalhadas relações mais horizontais entre os membros do conselho, de modo a reduzir os entraves políticos. Com mesmo intuito, recomendase e uma maior diversificação de representantes, minimizando a sobrecarga de agenda dos representantes. Como forma de suprir a demanda financeira dos conselhos é recomendado o desenvolvimento de mecanismos financeiros que favoreçam a desburocratização da execução financeira local. Estudos futuros sobre a relação entre a efetividade de conselhos gestores e a velocidade e complexidade de execução financeira podem favorecer caminhos para maior operacionalização dessas instâncias.

A metodologia proposta para dimensionamento da participação, a partir da técnica de análise de correlação multivariada, foi exitosa enquanto medida capaz de garantir a comparabilidade entre variáveis de dimensionamento, explicativas e de conservação da biodiversidade (desmatamento), com a mínima perda de complexidade das inter-relações. O método se apresentou coerente com o conceito de participação social adotado, representando, sobretudo, uma boa possibilidade metodológica, replicável a conceitos multifacetados nas mais diversas realidades. 
A reprodução dos métodos aplicados deve ser adotada com grande cautela. Por mais aproximadas que sejam as realidades, é fundamental uma análise acurada do delineamento conceitual que se pretende dar ao estudo, de modo a selecionar as variáveis que, de fato, resumem o conceito, para que o exercício de agrupamento, não seja invalidado por interpretações equivocadas.

Assim, a análise estatística é importante, mas é essencial que haja uma cuidadosa e responsável avaliação empírica que a fundamente no momento da escolha das possíveis variáveis de dimensionamento. Uma boa bagagem teórica e prática podem reduzir, e reduziram, sobremaneira esse risco.

Deve ser realizado um esforço de redução da subjetividade, não apenas no momento de se definir os conceitos de inclusão das variáveis, mas também no modo de dimensionamento dos indicadores selecionados. Esse foi um risco presente nesta avaliação, uma vez que as respostas obtidas pelo método RAPPAM e pelo formulário da tese são decorrentes da percepção do gestor em um determinado momento temporal. À despeito dos diversos argumentos apresentados pro e contra a utilização de respostas com base em percepções, é imperativo o ganho de escala quanto se pretende ter uma visão de âmbito nacional. Essa condição acaba por determinar uma boa relação custo-benefício na adoção de metodologias um pouco mais subjetivas, mas de largo alcance.

Analisar que fatores explicam as variações na intensidade da participação social na gestão de unidades conservação;

Os resultados apontam na direção que, ao enxergar a sociedade como aliada na conservação, mitigando conflitos, dentro de uma lógica de comunicação e integração da realidade local com a gestão destes espaços e dotando-a de ferramentas para compreensão e participação consciente na tomada de decisão potencializam-se as chances de que a participação social na gestão das UCs ocorra de forma mais fluida. Em outras palavras, ao desenvolver os elementos acima elencados, a UC caminha para uma prática mais participativa, pois aumentam-se as chances de que o fator de dimensionamento, que empresta intensidade ao conceito, alcance maiores expressões.

Tendo em vista a alta demanda por recursos humanos e financeiros, inerentes aos processos participativos, a alocação orçamentária insuficiente para as UCs, a queda da sua capacidade de captação de recursos e a crise econômica pela qual atravessa o país nesse momento, não há dúvidas que devem ser buscados mecanismos alternativos para assegurar minimamente a condução participativa dos processos de gestão. Mais do que nunca deve ser empreendidos 
esforços no estabelecimento de parcerias e no fortalecimento da representatividade e alinhamento da atuação dos conselhos com os objetivos da UC.

Finalmente, no que tange o objetivo fundamental desta tese, constatou-se haver uma relação de causa e efeito entre o aumento da participação social nas unidades de conservação federais da Amazônia e o desmatamento. Na medida em que a participação social foi trabalhada mais intensamente houve uma tendência de redução do desmatamento no interior dessas UCs. Em outras palavras, o trabalho mais intenso das variáveis de maior influência na participação social existiu uma tendência de aumento da efetividade da UC no que tange a conservação da sua biodiversidade. $\mathrm{O}$ fato de essa relação ser mais restrita às unidades de conservação de uso sustentável do que às de UCs de proteção integral, provavelmente, reflete a natureza mais participativa da estratégia de conservação adotada na gestão destas UCs e também a própria natureza deliberativa de seus conselhos gestores.

Esses resultados são importantes na medida em que permitem estabelecer uma relação causal entre participação social e controle do desmatamento, orientando políticas públicas e futuros estudos. Além disto, colocam em evidência os elementos que devem ser prioritariamente trabalhados para potencializar o efeito do engajamento social na conservação da biodiversidade. À despeito da essencialidade das ações coercitivas, elas não têm caracteristicamente o mesmo potencial de multiplicação que as ações persuasivas, pois uma vez engajada, a sociedade atua como aliada na gestão da UC contribuindo com o aumento de sua efetividade.

Acredita-se, assim que o caminho para se contornar a grande lacuna financeira e de pessoal para gestão de UCs seja uma combinação de estratégias de efeito mais imediato com outras que ajam mais estrategicamente sobre as causas da perda da biodiversidade.

Recomenda-se buscar soluções alternativas viáveis, dentro do restritivo contexto atual, com intuito de multiplicar a capacidade de gestão destas áreas, a partir de um maior envolvimento da sociedade nesses processos. No entanto, empreender esforços que resultem em ganhos de eficiência dos processos participativos, agir mais estrategicamente, priorizando aquelas ações capazes de resultar em uma participação mais qualificada e impactante no que tange às metas de conservação da biodiversidade.

Apesar da relação aqui defendida entre participação social na gestão de UCs e redução da perda da biodiversidade, aparentemente, tender para uma abordagem mais conservacionista da proteção da natureza, defende-se uma opção por múltiplas perspectivas. Esse posicionamento decorre do entendimento que o sistema nacional de unidades de conservação deve refletir a 
multiplicidade de respostas possíveis de serem formuladas para mitigar pressões e ameaças correntes ou potenciais.

\section{REFERÊNCIAS BIBLIOGRÁFICAS}

ABRAMOVAY, R. Conselhos além dos limites. Estudos avançados, v. 15, n. 43, p. 121-140, 2001.

ADAMS, W.M. \& HULME, D. If community conservation is the answer in Africa, what is the question? Oryx 35: 193-200. 2001

AGARWAL, B. 2001. Participatory exclusions, community forestry, and gender: An analysis for South Asia and a conceptual framework. World Dev. 29(10):1623-1648.

AGRAWAL, A.; GIBSON, C. C. (Ed.). Communities and the environment: ethnicity, gender, and the state in community-based conservation. Rutgers University Press, 2001.

ALENCAR, A. et al. O desenvolvimento que queremos: ordenamento territorial da BR-163, Baixo Amazonas, Transamazônica e Xingu. Meeting report. 29-31 mar. (IPAM, ISA, FVPP, Fetagri BAM, FORMAD, FVPP, CEFTBAM, Forum BR-163, GTA), Santarém, PA, 2004. ANDAM, K. S., FERRARO, P. J., PFAFF, A., SANCHEZ-AZOFEIFA, G. A., \& ROBALINO, J. A. Measuring the effectiveness of protected area networks in reducing deforestation. Proceedings of the National Academy of Sciences,105(42), 16089-16094. 2008 ANDRADE, J.T.; STEIN, F.F.G. \& MEDEIROS, R. Avaliando a consolidação da gestão participativa na APA Petrópolis/RJ a partir das propostas do conselho de gestão. Floresta e Ambiente. v.14, n.2, p.14 - 21, 2007.

ARAÚJO, M. A. R; MARQUES, C. P. \& CABRAL, R. F. B. Melhorando a efetividade da gestão de unidades de conservação: a experiência do Programa de Gestão para Resultados PGR. Cadernos ARPA, v. 3, Brasília, DF: Ministério do Meio Ambiente, 2009, 56 p. BBC. 2009.

Unidades de Conservação no Brasil: da república à gestão de classe mundial. Belo Horizonte, MG, 2007, 272 p. WEIGAND, R. \& PEREIRA, T.E.B. Transformando o Tracking Tool em instrumento de planejamento plurianual para as unidades de conservação. In: ARAÚJO, M. A. R. Unidades de Conservação no Brasil: da república à gestão de classe mundial. Belo Horizonte, MG, 2007. 272 p.

\& PINTO-COELHO. In: ARAÚJO, M. A. R. Unidades de Conservação no Brasil: da república à gestão de classe mundial. Belo Horizonte, MG, 2007, 272 p. 
Subsídios ao planejamento do Sistema Estadual de Unidades de Conservação: tamanho, representatividade, e gestão de parques em Minas Gerais. 2004. Tese de Doutorado. Tese de Doutoramento. Universidade Federal de Minas Gerais. Instituto de Ciências Biológicas. Belo Horizonte, MG, 300p.

ARENDT, H. Desobediência civil. Crises da república, v. 2, 1973.

ARNSTEIN, S.R. Partnerships online. Reino Unido, 1998. Disponível em: http://www.partnerships.org.uk/part/arn.htm. Acesso em: 15 mar. 2014.

A ladder of citizen participation. Journal of the American Planning Association, v. 35, n. 4, p. 216-224, July 1969.

AUBERTIN, C., et al. Sustainable Development, a New Age for Conservation? In: AUBERTIN, C.; RODARY, E. Protected Areas, Sustainable Land? (Orgs.). Ashgate, England, 2011.

AVRITZER, L. Um balanço da participação social no Brasil pós-constituição de 1988. In: AVRITZER. Experiência democrática, sistema político e participação popular / São Paulo : Editora Fundação Perseu Abramo, 2013. 128 p

- Sociedade civil e participação social no Brasil. DCE/UFMG. Belo Horizonte. 2006.2 Disponível em: http://ligiatavares.com/gerencia/uploads/arquivos/1b1f265f82523b57537f1cfac0b66dee.pdf. Acesso em: 16/06/2015.

BARBOSA, L. N. de H. \& DRUMMOND, J. A. L. Os direitos da natureza numa sociedade relacional: reflexões sobre uma nova ética ambiental. Estudos Históricos, 14. 1994.

BAQUERO, M. Building another society: social capital in the structuring of participatory political culture in Brazil. Revista de Sociologia e Política, n. 21, p. 83-108, 2003.

BARRETO, C. G; VEZAR, K. G. Cenoura, chicote ou sermão? Mecanismos de implementação de políticas públicas em unidades de conservação. Raízes, v.32, n.1, jan-jun. 2012

BARROW, E.; MURPHREE, M. 3Community Conservation from Concept to Practice. 2001.

BEMELMANS-VIDEC, M.L., RIST, R.C. \& VEDUNG, E. Carrots, Sticks and Sermons: Policy Instruments and Their Evaluation. New Brunswick, N.J., U.S.A.: Transaction Publishers, 1998, 280 pp.

BENATTI, J. H. Unidades de conservação e as populações tradicionais: uma análise jurídica da realidade brasileira. 1999. 
BENSUSAN, N. Conservação da biodiversidade em áreas protegidas. Rio de Janeiro: Editora FGV, 2006.

BERKES, F.; FOLKE, C. \& GADGIL, M. 1995. Traditional ecological knowledge, biodiversity, resilience and sustainability. Pp. 281-300. In: C.S. PERRINGS; K.G. MALLER; C. FOLKE; C.S. HOLLING \& B.O. JANSSON (eds.). Biodiversity conservation. Problems and policies. Dordrecht, Kluwer Academic Press. . Community-based conservation in a globalized world.Proceedings of the National academy of sciences, v. 104, n. 39, p. 15188-15193, 2007.

BONAR, S. A. The conservation professional's guide to working with people. Island Press, 2012.

BORRINI-FEYERABEND, G. Collaborative management of protected areas: tailoring the approach to the context. IUCN-The World Conservation Union, 1996.

BRANDÃO-JÚNIOR., A.; SOUZA-JÚNIOR., C. Desmatamento nos assentamentos de reforma agrária na Amazônia. O Estado da Amazônia, n .4, p.1-4, 2006.

BRANDY, H.E. Political participation. In: Robinson, J. P. (eds.). Measures of political attitudes. San Diego, CA: Academic Press, p. 737-801, 1999.

BRASIL. Decreto n ${ }^{\circ} 23.672$ de 02 de janeiro de 1934. . Decreto n ${ }^{\mathrm{o}} 23.793$ de janeiro de 1934. . Decreto $n^{0} 24.643$ de 10 de julho de 1934. . Lei $\mathrm{n}^{0} 4.771$ de 15 de setembro 1965. . Decreto-Lei Federal n²89 de 28 de fevereiro de 1967. . Decreto $n^{\circ} 73.030$ de 30 de outubro de 1973. . Lei $\mathrm{n}^{\circ} 6.938$ de 31 de agosto de 1981. . Lei $\mathrm{n}^{\circ} 6.902$ de abril de 1981 . Decreto $\mathrm{n}^{\mathrm{o}} 89.336$, de janeiro de 1984 . Decreto 98.897, de 30 de janeiro de 1990. . Lei n ${ }^{0} 8.666$, de 21 de junho de 1993. . Lei $\mathrm{n}^{\circ} 9985$ de 18 de julho de 2000. . Decreto $\mathrm{n}^{0} 4.340$ de 22 de agosto de 2002. . Decreto $\mathrm{n}^{0} 5.758$ de 13 de abril de 2006. . Lei $\mathrm{n}^{\circ} 12.651$ de 25 de maio de 2012. 
BRECHIN, S. R. et al. Beyond the square wheel: toward a more comprehensive understanding of biodiversity conservation as social and political process. Society \&Natural Resources, v. 15, n. 1, p. 41-64, 2002.

BURSZTYN, M.; PERSEGONA, M. A grande transformação ambiental: uma cronologia da dialética homem-natureza. Editora Garamond, 2008.

COP. Secretariado da CDB. 2010. Panorama da Biodiversidade Global 3. Montreal, Canadá.

CHAPE, S. et. al. Measuring the extent and effectiveness of protected areas as an indicator for meeting global biodiversity targets. Philosophical Transactions of the Royal Society B: Biological Sciences, v. 360, n. 1454, p. 443-455, 2005.

CHRISTOFFERSEN, L. E. IUCN: A bridge-builder for nature conservation.Green globe yearbook, p. 59-70, 1997.

CIFUENTES, M.A; IZURIETA, A. \& FARIA, H.H. 2000. Medición de la efectividad del manejo de areas protegidas. Turrialba, Costa Rica: WWF, UICN \& GTZ. 89 p.

COAD, L. et al. Measuring impact of protected area management interventions: current and future use of the Global Database of Protected Area Management Effectiveness. Phil. Trans. R. Soc. B, v. 370, n. 1681, p. 20140281, 2015.

COSTA, F. R. C.; MAGNUSSON, W. E. The need for large-scale, integrated studies of biodiversity-the experience of the Program for Biodiversity Research in Brazilian Amazonia. Natureza \& Conservação, v. 8, n. 1, p. 3-12, 2010.

CYSNE, M. \& AMADOR, T. Direito do ambiente e redacção normativa: teoria e prática nos Países lusófonos. IUCN, 2000.

DAVENPORT, L.; RAO, M. A História da Proteção: Paradoxos do passado e Desafios do Futuro. In: TERBORGH, J; SCHAIK, C. DAVENPORT, L.; RAO, M. (Orgs). Tornando os Parques Eficientes: Estratégias para a conservação da Natureza nos trópicos. Curitiba, Editora da UFPR/Fundação O Boticário, 2002.

DEAN, W. A ferro e fogo: a história e a devastação da Mata Atlântica brasileira. Companhia das Letras, 1996.

DEARDEN, P., BENNET, M. \& JOHNSTON, J. Trends in global protected area governance, 1992-2002. Environmental Management 36: 89-100.2005

DEMO, P. Participação Social e conquista: noções de política social participativa. 5. ed. São Paulo: Cortez, 2001.

DE SOUZA, J. et al. Democracia participativa, pluralismo e constitucionalismo latino americano: o caso dos conselhos gestores das unidades de conservação ambiental no Brasil. 
(Participatory democracy, legal pluralism and new constitutionalism in Latin America). Revista Eletrônica do Mestrado em Direito da UFAL, v. 5, n. 2, p. 51-72, 2015. DIEGUES, A. C. Desenvolvimento sustentável ou sociedades sustentáveis: da crítica dos modelos aos novos paradigmas. São Paulo em perspectiva, v. 6, n. 1-2, p. 22-29, 1992. O mito moderno da natureza intocada. v. 3. São Paulo: Hucitec, 2001.

DOEY, L.; KURTA, J. Correspondence analysis applied to psychological research. Tutorials in Quantitative Methods for Psychology, v. 7, n. 1, p. 5-14, 2011.

DOMBROWSKI, O. \& PARMIGIANI, J. Não Quero Saber dos seus Conselhos: considerações sobre a nossa democracia participativa.Seminário Nacional Estado e Políticas Sociais, v. 4, 2009.

DRUMMOND, J. A. L.; FRANCO, J. L. A \& OLIVEIRA, D. Uma análise sobre a história e a situação das Unidades de Conservação no Brasil. In: GANEM, Roseli Senna (Org.), Conservação da Biodiversidade: Legislação e Políticas Públicas. Brasília: Câmara dos Deputados, 2010.

; FRANCO, J. L. A.; NINIS, A. B. O estado das áreas protegidas do Brasil - 2005. Brasília, DF, Universidade de Brasília: Observatório de Unidades de Conservação, 2006, 200 p.

EGUILUZ, Unai Villalba. Desarrollo humano local y calidad participativa. Experiencias en Ecuador. In: La cooperación y el desarrollo humano local: retos desde la equidad de género y la participación social. Universidad del País Vasco, 2011. p. 155-170.

ERVIN, J. Metodologia para Avaliação Rápida e Priorização do Manejo de Unidades de Conservação (RAPPAM). Gland, WWF, 2003. 70 p.

FARIA, H. H. Elaboracion de um procedimento para medir La efectividad de manejo de áreas silvestres y su aplication em dos áreas protegidas de Costa Rica. Tesis (Mag. Scientiae). Catie, Turrialba, Costa Rica, 2003, 167 p.

FEARNSIDE, P. O valor de áreas protegidas para evitar mudança climática na Amazônia. In: ALBERNAZ, A. L. K. M. \& WEIGAND, R. (Orgs.). Atualização das Áreas Prioritárias para a Conservação e Repartição dos Benefícios da Biodiversidade - Bioma Amazônia. Brasília, DF: Ministério do Meio Ambiente, 2008.

FEARNSIDE, P. Desmatamento na Amazônia: dinâmica, impactos e controle. Acta Amazônica, v. 36, n. 3, p. 395-400, 2006.

FEARNSIDE, P. Desmatamento na Amazônia brasileira: história, índices e consequências. Megadiversidade, v.1, n.1, p.113-123, 2005. 
FEENY, D.; BERKES, F., MCCAY, B. J., \& ACHESON, J. M. A tragédia dos comuns: vinte e dois anos depois. Espaços e recursos naturais de uso comum. São Paulo: NUPAUB-USP, 17-42. 2001

FERREIRA, L. V.; VENTICINQUE, E. \& ALMEIDA, S. O Desmatamento na Amazônia e a importância das áreas protegidas. Estudos Avançados, [online], 2005, v. 19, n.53, p. 157-166. FRANCA, N. Gestão participativa em unidades de conservação. Ibase. 2006.

FRANCO, J. L. A; SCHITTINI, G. M.; BRAZ, V. da S. História da Conservação da Natureza e das Áreas Protegidas: Panorama Geral. Historiae, Rio Grande, Volume 6, número 2, 2015 (No prelo).

O conceito de biodiversidade e a história da biologia da conservação: da preservação da wilderness à concervação da biodiversidade. In: História (São Paulo) v.32, n.2, jul./dez. 2013, pp. 21-48.

\& DRUMMOND, José Augusto. História das preocupações com o mundo natural no Brasil: da proteção à natureza à conservação da biodiversidade. In: FRANCO, José Luiz de Andrade; SILVA, Sandro Dutra e; DRUMMOND, José Augusto; e TAVARES, Giovana Galvão (Orgs.). História Ambiental: fronteiras, recursos naturais e conservação da natureza. Rio de Janeiro: Garamond, 2012, pp. 333-366.

\& DRUMMOND, José Augusto. Proteção à Natureza e Identidade Nacional no Brasil: anos 1920-1940. Rio de Janeiro: FIOCRUZ, 2009.

A primeira conferência brasileira de proteção à natureza e a questão da identidade nacional. Revista Varia História, n. 26, p. 77-96, 2002.

GAVENTA, J. 1980. Power and powerlessness: Quiescence and rebellion in an Appalachian valley. Urbana: University of Illinois Press.

GELUDA, L. Desvendando a compensação ambiental: aspectos jurídicos, operacionais e financeiros / Leonardo Geluda... [et al.] - Rio de Janeiro: Funbio, 2015. 270

\& SERRÃO, M.S. A compensação ambiental para as unidades de conservação. In: Incentivos Econômicos para Serviços Ecossistêmicos no Brasil. Rio de Janeiro: Forest Trends, 2015.

GOHN, M. G. Teoria dos movimentos sociais. 2 ed., São Paulo, Loyola. 2000. Conselhos gestores e participação sociopolítica. In: Questões da nossa época. Cortez, 2007.

GONÇALVES, M. P; BRANQUINHO, F. T. B.; FELZENSZWALB, I. Uma análise contextual do funcionamento efetivo e participação popular em uma unidade de conservação: o caso da 
área de proteção ambiental de Petrópolis (Rio de Janeiro: Brasil). Sociedade \& Natureza, v. 23, n. 2, p. 323-334, 2011.

GRAU, N. C. A rearticulação das relações Estado-sociedade: em busca de novos significados. In: Revista do Serviço Público, ano 47, vol. 120, nº 1. ENAP: Brasília, DF, 1996.

HARDIN, G. The tragedy of the commons. Science, v. 162, p. 1244-1248, 1968.

HOCKINGS, M. Evaluating Effectiveness: A framework for assessing management effectiveness of protected areas. IUCN, 2006.

, M.; STOLTON, S.; LEVERINGTON, DUDLEY, N. \& COURRAU, J. Evaluating Effectiveness: a framework for assessing management effectiveness of protected areas. $2^{\mathrm{a}}$ edition. Ed. Peter Valentine. Gland, Switzerland: IUCN. 121p. 2006

; DUDLEY, N. \& STOLTON, S. The WCPA Management effectiveness

framework - where to from here? A Paper for the Beyond the Trees conference, Bangkok, 2000

HUTTON, J.; ADAMS, W. M.; MUROMBEDZI, J. C. Back to the barriers? Changing narratives in biodiversity conservation. In: Forum for development studies. Taylor \& Francis Group, 2005. p. 341-370.

IBDF/FBCN. Plano do sistema de unidades de conservação do Brasil: II Etapa. Brasília: Min.da Agricultura. 1982, 173p.

ICMBio \& WWF-Brasil. Avaliação comparada das aplicações do método Rappam nas unidades de conservação federais, nos ciclos 2005-06 e 2010. Instituto Chico Mendes de Conservação da Biodiversidade, WWF-Brasil. Brasília: ICMBio, 2011.

ICMBio. Conselhos gestores de unidades de conservação federais: um guia para gestores e conselheiros. 2014, 76 p.

IPEA, 2013. Ampliação da Participação na Gestão Pública um estudo sobre conferências nacionais realizadas entre 2003 e 2011. Relatório de Pesquisa. 75p.

JACOBI, P. R. Políticas sociais locais e os desafios da participação citadina. Ciência \& Saúde Coletiva, v. 7, n. 3, p. 443-54, 2002.

JENKINS, C. N.; JOPPA, L. Expansion of the global terrestrial protected area system Biological Conservation, p. 2166-2174, 2009.

JUNIOR, A.P.B \& SAMPAIO, J.J.C. Participação social em saúde em áreas rurais do Nordeste do Brasil. Revista Panamericana de Salud, v.23. n. p.403-409, 2008.

KEMF, E. The law of the mother: protecting indigenous peoples in protected areas. Sierra Club Books, 1993. 
KRAMER, R. et al. Last stand: protected areas and the defense of tropical biodiversity. Oxford University Press, 1997.

LAURANCE, W. F.; COCHRANE, M. A.; BERGEN, S.; FEARNSIDE, P. M.;

DELAMÔNICA, P.; BARBER, C.; D'ANGELO, S. e FERNANDES, T. The future of the brazilian Amazon. Science, n. 291, pp. 438-439, 2001.

LAURIOLA, V. Elinor Ostrom: um nobel heterodoxo e rosa-verde. Sinal de esperança. Boletim da Sociedade Econômica de Economia Ecológica, n. 21, p. 03-08, 2009. LEMOS DE SÁ, R. M. \& FERREIRA, L. V. Áreas protegidas ou espaços ameaçados: o grau de implementação e a vulnerabilidade das Unidades de Conservação federais brasileiras de Uso Indireto. Série Técnica III. WWF-Brasil, 1999.

Unidades de conservação como instrumento de proteção da biodiversidade. In: BENSUSAN, N. Seria melhor ladrilhar? Biodiversidade: como, para que e por quê. 2. ed. Brasília, DF: Universidade de Brasília, 2008. p. 81-92.

LEVERINGTON, F. et. al. Protected Area Management Effectiveness Assessments in EuropeSupplementary Report. Nature, 2010.

LOPES, T.E., Schietti J, Nelson B, Desmoulière SJM, Espírito Santo HM \& Costa FRC, 2010. Assessing the relationship between forest types and canopy tree beta diversity. Ecography (Copenhagen).

LOUREIRO, C.B. et al. Educação ambiental e conselho em unidades de conservação: Aspectos técnicos e metodológicos. Ibase, Parque Nacional da Tijuca, 2007.

Educação Ambiental e gestão participativa na explicitação e resolução de conflitos. Gestão em ação, Salvador, v. 7, n. 01, p. 37-50, jan/abr. 2004.

MACEDO, H. S. et. al. Processos Participativos na gestão de áreas protegidas: estudo de caso em unidades de conservação de uso sustentável da zona costeira do Sul do Brasil. 2008.

MACÊDO, J.A.C. Avaliação da gestão participativa dos parques estaduais da Bahia. 2008. Dissertação (Mestrado em Desenvolvimento Sustentável) - Centro de Desenvolvimento Sustentável, Universidade de Brasília. 188 p.

MACIEL, B. A. Mosaico de Unidades de Conservação: uma estratégia de conservação para a Mata Atlântica. 2007. Dissertação (Mestrado em Desenvolvimento Sustentável) Centro de Desenvolvimento Sustentável, Universidade de Brasília. 182 p. 
MANNIGEL, E. Integrating Parks and People: How Does Participation Work in Protected Area Management?, Society \& Natural Resources: An International Journal, 21:6, 498-511, 2008 .

MARGULIS, S. Quem são os agentes dos desmatamentos na Amazônia e por que eles desmatam? Word Bank internal paper, 2002. Disponível em: http://www.obancomundial.org /index.php/content/view_folder/87.html. Acesso em: 15.12.2014.

MATTES, A. 1998. Partizipation der Bevo“" lkerung am Management von zwei ausgewa“ hlten Schutzgebieten in Minas Gerais, Brasilien. Der PRA-Ansatz als Beginn einer Zusammenarbeit zwischen Schutzgebietsverwaltung und Bevo“ lkerung in der Pufferzone. Diplomarbeit, Faculty f Forestry, Albert-Ludwigs-University Freiburg, Freiburg, Germany. MCCORMICK, John. Rumo ao paraíso: a história do movimento ambientalista. Rio de Janeiro: Relume-Dumará, p. 111, 1992.

MCGEE, Rosemary et al. Marcos legais para participação cidadã: relatório síntese. São Paulo: Instituto Pólis, 2003.

MEDEIROS, R. "Evolução das tipologias e categorias de áreas protegidas no Brasil." Ambiente \& Sociedade 9.1 (2006): 41-64. .; Irving, M; GARAY, I. A proteção da natureza no Brasil: evolução e conflitos de um modelo em construção. Revista de Desenvolvimento Econômico, v. 6, n. 9, 2004. MENZIES, N.K. Our Forest, Your Ecosystem, Their Timber: Communities, Conservation, and the State in Community-Based Forest Management. New York, NY, USA: Columbia University Press. 2007

MERCADANTE, M. Uma década de debate e negociação: a história da elaboração da Lei do SNUC. In: BENJAMIN, A.H. (org.) Direito Ambiental das Áreas Protegidas. Rio de Janeiro: Ed. Forense Universitária, 2001, p. 190-231.

MILANI, C. RS. O princípio da participação social na gestão de políticas públicas locais: uma análise de experiências latino-americanas e europeias. Revista de Administração Pública, v. 42, n. 3, p. 551-579, 2008.

MILANO, M. S. Unidades de conservação - técnica, lei e ética para a conservação da biodiversidade. In: Direito ambiental das áreas protegidas - o regime jurídico das unidades de conservação. Coord. Antônio Herman Benjamin. Rio de Janeiro: Forense Universitária, 2001. p. 3 a 41.

MINISTÉRIO DO MEIO AMBIENTE. Gestão Participativa do SNUC 2. Série Áreas Protegidas do Brasil. Brasília, DF. 2004. 205p. 
Sistema Nacional de Unidades de Conservação. Brasília: Ministério do Meio Ambiente, 72p. (Áreas Protegidas do Brasil, 7), 2a ed., 2009.

MITTERMEIER, R. A. et. al. Uma breve história da conservação da biodiversidade no Brasil. Megadiversidade, v. 1, n. 1, p. 14-21, 2005.

MODESTO, P. Participação popular na administração pública: mecanismos de speracionalização.JusVigilantibus. Vitória, 1999.

MONTAÑ, C. O canto da sereia: críticas à ideologia e aos projetos do "terceiro setor". São Paulo: Cortez, 2014. 2014

MORSELLO, C. Áreas protegidas públicas e privadas: seleção e manejo. São Paulo, Annablume: FAPESP. p.66-200. 2001.

MUANIS, M. M.; SERRÃO, M.; GELUDA, L. Quanto custa uma unidade de conservação federal? Uma visão estratégica para o financiamento do Sistema Nacional de Unidades de Conservação (Snuc). Rio de Janeiro: Funbio, 52 p., 2009.

NASH, R. Wilderness and the American Mind (Fifith ed.). New Haven: Yale University Press, 2014.

Wilderness and theAmerican mind. New Haven und Lon, 1982.

NOGUEIRA, J. M.; PEREIRA, R. R. Critérios de análise econômica de políticas ambientais. NEPAMA. Departamento de Economia. Universidade de Brasília - UnB. Brasília, 1999.

OLIVEIRA, D. Avaliação de Efetividade de Gestão de Unidades de Conservação: O Mosaico do Apuí - Amazonas/AM. Dissertação (Mestrado) - Universidade de Brasília, 2012. OLIVEIRA, V. C. Comunicação, Controle Público e Participação Popular no sistema Único de Saúde. Rev Acad Grupo Comun São Bernardo, v. 1, n. 2, p. 1-21, 2004.

OATES, J. F. Myth and reality in the rain forest: How conservation strategies are failing in West Africa. Univ of California Press, 1999.

OLSON, D. M.; MEZEY, M. L. Legislatures in the policy process: The dilemmas of economic policy. Cambridge University Press, 1991.

OSTROM, E. Governing the commons: The evolution of institutions for collective action. Cambridge university press, 1990.

PÁDUA, J. A. Um sopro de destruição: pensamento político e crítica ambiental no Brasil escravista, 1786-1888. Zahar, 2002.

PÁDUA, M. T. J. Do Sistema Nacional de Unidades de Conservação. In: MEDEIROS, R.; ARAÚJO, F. F. S. (Org.). Dez anos do Sistema Nacional de Unidades de Conservação da 
Natureza: lições do passado, realizações presentes e perspectivas para o futuro. Brasília: MMA, 2011.

PALMIERI, R. \& VERÍSSIMO, A. Conselhos de Unidades de Conservação: Guia sobre sua criação e seu funcionamento. Imaflora e Imazon, Piracicaba e Belém, 2009.

PERUZZO, C. M. K. Em busca dos objetos de pesquisa em comunicação no Brasil. Tensões e objetos da comunicação. Porto Alegre: Sulina, 2002.

PIMBERT, M.P. \& PRETTY, J.N. 2000. Parques, comunidades e profissionais: incluindo 'participação' no manejo de áreas protegidas. Pp. 183- 224. In: A.C. Diegues (org.). Etnoconservação: novos rumos para a proteção da natureza nos trópicos. São Paulo, Hucitec. N. Parks, people and professionals: putting 'participation'into protected area management. Social change and conservation, p. 297-330, 1997.

PETERS, E. L. Meio ambiente \& propriedade rural. Curitiba: Juruá, 2003.

PIRES, R. R. C. A participação social no nível nacional: desafios a um projeto inacabado. In: AVRITZER. Experiência democrática, sistema político e participação popular / São Paulo : Editora Fundação Perseu Abramo, 2013. 128 p.

PIZZORNO, A. Introduzione allo studio della partecipazione politica. Quaderni di sociologia 15.3-4 (1966): 235-287.

PORTER-BOLLAND, L., ELLIS, E. A., GUARIGUATA, M. R., Ruiz-Mallén, I., NEGRETEYANKELEVICH; REYES-GARCÍA, V. Community managed forests and forest protected areas: An assessment of their conservation effectiveness across the tropics. Forest Ecology and Management, 268, 6-17. 2012.

PORTO, M. F; MILANEZ, B. Eixos de desenvolvimento econômico e geração de conflitos socioambientais no Brasil: desafios para a sustentabilidade e a justiça ambiental. Ciência \& Saúde Coletiva, v. 14, n. 6, p. 1983-1994, 2009.

REDCLIFT, M. Sustainable development and popular participation: a framework for analysis. In: GHAI, D.; VIVIAN, J.M., ed. Grassroots-environmental action: people participation in sustainable development. London: Routledge, p.23-77, 1995.

RIBEIRO, B. VERÍSSIMO, A. \& PEREIRA, K. O Desmatamento em Áreas Protegidas na Amazônia brasileira: o caso de Rondônia. O Estado da Amazônia, n. 6, Belém: Imazon, 2006. RIBEIRO, W. C. A Ordem Ambiental Internacional. São Paulo: Editora Contexto, 2001, 176p RIBEIRO, W. C. Geografia política e gestão internacional dos recursos naturais. Estudos Avançados, v. 24, n. 68, p. 69-80, 2010. 
RODARY, E.; MILIAN, J. Expansion and Diversification of Protected Areas: Rupture or Continuity? Protected Areas, Sustainable Land? 2011.

RODRIGUES, A. S. et. al. Effectiveness of the global protected area network in representing species diversity. Nature, v. 428, n. 6983, p. 640-643, 2004.

RODRIGUES-FILHO, S.; VERBURG, R.; BURSZTYN, M.; LINDOSOA, D.; DEBORTOLI, N.; VILHENA, A. M. G. Election-driven weakening of deforestation control in the Brazilian Amazon. Land Use Policy, n. 43, p. 111-118, 2015.

RUNTE, A. National Parks: The American Experience (Fourth ed.). Lanham: Taylor, 2010. SACHS, I. Primeiras intervenções. NASCIMENTO, EP; VIANNA, JN Dilemas e desafios do desenvolvimento sustentável no Brasil. Rio de Janeiro: Garamond, 2007.

SANTILLI, J. Unidades de conservação da natureza, territórios indígenas e de quilombolas: aspectos jurídicos. In: RIOS, A.V. V. \& IRIGARAY, C.T.H. (orgs.) O direito ambiental e o desenvolvimento sustentável. Curso de direito ambiental. Brasília, DF: Instituto Internacional de Educação do Brasil, 2005, p. 167-203

SAYAGO, D. Participação: Olhar para fora ou olhar para dentro? Ra Ximhai. v. 4, 2008 SCHITTINI, G. de M. Políticas públicas, conservação e movimentos sociais em uma área de expansão de fronteira: a criação de unidades de conservação no âmbito do Plano Br 163 Sustentável. 2009. Dissertação de Mestrado. 225p

SIMMONS, W. M. Participation and power: civic discourse in environmental policy decisions. 1969.

SIQUEIRA, L. Política ambiental para quem? Ambiente e Sociedade, Campinas, v. 11 n. 2, 2008 .

SIRKIS, A.; TRIGUEIRO, A. Meio ambiente no século 2121 especialistas falam da questão ambiental nas suas áreas de conhecimento. Autores Associados, 2005.

SOARES-FILHO, B. et al. Cenários de desmatamento para Amazônia. Estudos Avançados, São Paulo, 2005, v. 19, n· 54, p. 138-152.

; ALENCAR, A.; NEPSTAD, D.; CERQUEIRA, G.C.; VERA DIAZ, M.; RIVERO, S.; SOLÓRZANO, L.; VOLL, E. Simulating the response of land-cover changes to road paving and governance along a major Amazon highway: the Santarém-Cuiabá corredor. Global Change Biology, v.10, n.7, p. 745-764, 2004.

SOULÉ, M. E.; TERBORGH, J. The policy and science of regional conservation. Continental conservation: scientific foundations of regional reserve networks. Island Press, Washington, DC, p. 1-17, 1999. 
SOUZA, F. A. Z. Desafios e perspectivas da participação social nos conselhos gestores de duas Unidades de Conservação na baixada santista do estado de São Paulo. Tese de Doutorado. Universidade de São Paulo. 2012.

SOUZA, J. V. C. Congressos mundiais de parques nacionais da UICN (1962-2003): registros e reflexões sobre o surgimento de um novo paradigma para a conservação da natureza. Dissertação de mestrado. 2013. UnB Brasília. 214 p.

SOUZA, P.R.P. Além do Estado: os papéis da iniciativa privada e d terceiro setor na implementação e manejo de unidades de conservação. In: MILANO, M.S. (Org.) Unidades de conservação: atualidades e tendências. Fundação O Boticário, 2002.

STATSOFT, Inc. 2010. Correspondence Analysis, from Electronic Statistics Textbook. Retrieved 04/01/2010 from http://www.statsoft.com/textbook/

TERBORGH, J. Requiem for nature. Island Press, 2004. SUNY Press, NY, 1969.

TRIBUNAL DE CONTAS DA UNIÃO (TCU). Relatório de auditoria operacional TC034.496/2012-2. Brasília: TCU, 2013.

TÓTH, M. Desafios da participação social no contexto do desenvolvimento sustentável: as contribuições da educomunicação e da atuação em redes sociais. 2012. Dissertação de Mestrado CDS, 102.

TRIBUNAL DE CONTAS DA UNIÃO (TCU). Relatório de auditoria operacional TC034.496/2012-2. Brasília: TCU, 2013.

UICN, WWF-BRASIL e IPÊ. Metas de Aichi: Situação atual no Brasil. Ronaldo Weigand Jr; Danielle Calandino da Silva; Daniela de Oliveira e Silva. Brasília, DF: UICN, WWF-Brasil e IPÊ, 2011.

VERÍSSIMO, A. Áreas protegidas na Amazônia Brasileira-avanços e desafios. 2011.VIÉ et. al., 2009. Wildlife in A Changing World - An Analysis of the 2008 IUCN Red List of Threatened Species. IUCN, Gland, Switzerland, pp. 180.

YOUNG, I. M. Justice and the politics of difference. Princeton: Princeton University Press, 1990.

WATSON, J. E.M. et al. The performance and potential of protected areas. Nature, v. 515, n. 7525, p. 67-73, 2014.

WWF-BRASIL \& ICMBio. Efetividade de gestão das unidades de conservação federais do Brasil. Resultados de 2010. ONAGA, C.A.; DRUMOND, M.A. \& FERREIRA, M.N. (Orgs). 43p. 2012 
ANEXOS

ANEXO I. LISTA DE INDICADORES DE EFETIVIDADE DE GESTÃo AVALIADOS NO RAPPAM 2010 POR ELEMENTO E MÓDULO.

\begin{tabular}{|c|c|c|c|c|c|c|}
\hline ELEMENTO & & MÓDULO & INDICADORES & $\begin{array}{c}\text { Média } \\
\text { Percentual no } \\
\text { RAPPAM } 2010 \\
\end{array}$ & $\begin{array}{c}\text { Média } \\
\text { Percentual no } \\
\text { RAPPAM 2005 } \\
\end{array}$ & $\begin{array}{l}\text { A VANÇO \% } \\
\text { (período de 2005 } \\
\text { a 2010) } \\
\end{array}$ \\
\hline CONTEXTO & ESPÉCIES AMEAÇADAS & $\begin{array}{l}\text { Importância } \\
\text { biológica }\end{array}$ & $\begin{array}{l}\text { A UC contém um número } \\
\text { significativo de espécies que } \\
\text { constam da lista brasileira e ou } \\
\text { das listas estaduais de espécies } \\
\text { ameaçadas de extinção. }\end{array}$ & 70 & 60 & 11 \\
\hline CONTEXTO & $\begin{array}{l}\text { ESPÉCIES } \\
\text { SOBREEXPLOTADAS }\end{array}$ & $\begin{array}{l}\text { Importância } \\
\text { biológica }\end{array}$ & $\begin{array}{l}\text { A UC contém um número } \\
\text { significativo de espécies cujas } \\
\text { populações estão } \\
\text { sobrexplotadas, ameaçadas de } \\
\text { sobrexplotação e ou reduzidas } \\
\text { por pressões diversas. }\end{array}$ & 65 & 60 & 5 \\
\hline CONTEXTO & BIODIVERSIDADE & $\begin{array}{l}\text { Importância } \\
\text { biológica }\end{array}$ & $\begin{array}{l}\text { A UC tem níveis significativos } \\
\text { de biodiversidade. }\end{array}$ & 82 & 71 & 11 \\
\hline CONTEXTO & ENDEMISMO & $\begin{array}{l}\text { Importância } \\
\text { biológica }\end{array}$ & $\begin{array}{l}\text { A UC possui níveis } \\
\text { significativos de endemismo. }\end{array}$ & 52 & 44 & 9 \\
\hline CONTEXTO & FUNÇÃO NA PAISAGEM & $\begin{array}{l}\text { Importância } \\
\text { biológica }\end{array}$ & $\begin{array}{l}\text { A UC exerce uma função } \\
\text { crítica na paisagem. }\end{array}$ & 76 & 65 & 11 \\
\hline CONTEXTO & REPRESENTATIVIDADE & $\begin{array}{l}\text { Importância } \\
\text { biológica }\end{array}$ & $\begin{array}{l}\text { A UC contribui } \\
\text { significativamente para a } \\
\text { representatividade do sistema } \\
\text { de UCs. }\end{array}$ & 75 & 68 & 7 \\
\hline CONTEXTO & ESPÉCIES-CHAVE & $\begin{array}{l}\text { Importância } \\
\text { biológica }\end{array}$ & $\begin{array}{l}\text { A UC sustenta populações } \\
\text { mínimas viáveis de espécies- } \\
\text { chave. }\end{array}$ & 62 & 55 & 7 \\
\hline CONTEXTO & PADRÃES HISTÓRICOS & $\begin{array}{l}\text { Importância } \\
\text { biológica }\end{array}$ & $\begin{array}{l}\text { A UC mantém os padrões } \\
\text { históricos de diversidade } \\
\text { estrutural. }\end{array}$ & 65 & 58 & 7 \\
\hline CONTEXTO & $\begin{array}{l}\text { ECOSSISTEMAS } \\
\text { REDUZIDOS }\end{array}$ & $\begin{array}{l}\text { Importância } \\
\text { biológica }\end{array}$ & $\begin{array}{l}\text { A UC protege ecossistemas } \\
\text { cuja abrangência tem } \\
\text { diminuído significativamente. }\end{array}$ & 73 & 64 & 9 \\
\hline
\end{tabular}




\begin{tabular}{|c|c|c|c|c|c|c|}
\hline ELEMENTO & & MÓDULO & INDICADORES & $\begin{array}{c}\text { Média } \\
\text { Percentual no } \\
\text { RAPPAM } 2010 \\
\end{array}$ & $\begin{array}{c}\text { Média } \\
\text { Percentual no } \\
\text { RAPPAM 2005 } \\
\end{array}$ & $\begin{array}{c}\text { A VANÇO \% } \\
\text { (período de 2005 } \\
\text { a 2010) } \\
\end{array}$ \\
\hline CONTEXTO & EMPREGO & $\begin{array}{l}\text { Importância } \\
\text { socioeconômica }\end{array}$ & $\begin{array}{l}\text { A UC é uma fonte importante } \\
\text { de emprego para as } \\
\text { comunidades locais. }\end{array}$ & 43 & 39 & 4 \\
\hline CONTEXTO & SUBSISTÊNCIA & $\begin{array}{l}\text { Importância } \\
\text { socioeconômica }\end{array}$ & $\begin{array}{l}\text { As comunidades locais } \\
\text { subsistem do uso dos recursos } \\
\text { da UC. }\end{array}$ & 53 & 44 & 8 \\
\hline CONTEXTO & USO SUSTENTÁ・ VEL & $\begin{array}{l}\text { Importância } \\
\text { socioeconômica }\end{array}$ & $\begin{array}{l}\text { A UC oferece oportunidades de } \\
\text { desenvolvimento da } \\
\text { comunidade mediante o uso } \\
\text { sustentável de recursos. }\end{array}$ & 51 & 43 & 8 \\
\hline CONTEXTO & IMPORTÂNCIA RELIGIOSA & $\begin{array}{l}\text { Importância } \\
\text { socioeconômica }\end{array}$ & $\begin{array}{l}\text { A UC tem importância } \\
\text { religiosa ou espiritual. }\end{array}$ & 18 & 16 & 2 \\
\hline CONTEXTO & ATRIBUTOS RELEVANTES & $\begin{array}{l}\text { Importância } \\
\text { socioeconômica }\end{array}$ & $\begin{array}{l}\text { A UC possui atributos de } \\
\text { relevante importância estética, } \\
\text { histórica e ou cultural. }\end{array}$ & 63 & 46 & 17 \\
\hline CONTEXTO & $\begin{array}{l}\text { ESPÉCIES DE INTERESSE } \\
\text { SOCIOECONÔMICO }\end{array}$ & $\begin{array}{l}\text { Importância } \\
\text { socioeconômica }\end{array}$ & $\begin{array}{l}\text { A UC possui espécies de } \\
\text { plantas e animais de alta } \\
\text { importância social, cultural ou } \\
\text { econômica. }\end{array}$ & 75 & 59 & 16 \\
\hline CONTEXTO & VALOR RECREATIVO & $\begin{array}{l}\text { Importância } \\
\text { socioeconômica }\end{array}$ & $\begin{array}{l}\text { A UC possui um alto valor } \\
\text { recreativo. }\end{array}$ & 50 & 48 & 2 \\
\hline CONTEXTO & SERVIÇOS AMBIENTAIS & $\begin{array}{l}\text { Importância } \\
\text { socioeconômica }\end{array}$ & $\begin{array}{l}\text { A UC contribui } \\
\text { significativamente com } \\
\text { serviços e benefícios } \\
\text { ambientais. }\end{array}$ & 79 & 62 & 17 \\
\hline CONTEXTO & $\begin{array}{l}\text { VALOR EDUCACIONAL E } \\
\text { CIENTIIFICO }\end{array}$ & $\begin{array}{l}\text { Importância } \\
\text { socioeconômica }\end{array}$ & $\begin{array}{l}\text { A UC possui um alto valor } \\
\text { educacional e }\end{array}$ & 73 & 71 & 3 \\
\hline CONTEXTO & $\begin{array}{l}\text { MONITORAMENTO DE } \\
\text { ATIVIDADES ILEGAIS } \\
\end{array}$ & Vulnerabilidade & $\begin{array}{l}\text { As atividades ilegais na UC são } \\
\text { difíceis para monitorar. }\end{array}$ & 59 & 50 & 9 \\
\hline CONTEXTO & $\begin{array}{l}\text { APLICAÇÃO DOS } \\
\text { INSTRUMENTOS LEGAIS }\end{array}$ & Vulnerabilidade & $\begin{array}{l}\text { A aplicação dos instrumentos } \\
\text { legais é baixa na região. }\end{array}$ & 45 & 46 & 0 \\
\hline CONTEXTO & INSTABILIDADE POLÍTICA & Vulnerabilidade & $\begin{array}{l}\text { A UC está sofrendo distúrbios } \\
\text { civis e ou instabilidade política. }\end{array}$ & 19 & 17 & 3 \\
\hline
\end{tabular}




\begin{tabular}{|c|c|c|c|c|c|c|}
\hline ELEMENTO & & MÓDULO & INDICADORES & $\begin{array}{c}\text { Média } \\
\text { Percentual no } \\
\text { RAPPAM } 2010 \\
\end{array}$ & $\begin{array}{c}\text { Média } \\
\text { Percentual no } \\
\text { RAPPAM 2005 } \\
\end{array}$ & $\begin{array}{l}\text { AVANÇO \% } \\
\text { (período de 2005 } \\
\text { a 2010) } \\
\end{array}$ \\
\hline CONTEXTO & $\begin{array}{l}\text { USOS TRADICIONAIS } \\
\text { CONFLITANTES }\end{array}$ & Vulnerabilidade & $\begin{array}{l}\text { As práticas culturais, as crenças } \\
\text { e os usos tradicionais estão em } \\
\text { conflito com a categoria e os } \\
\text { objetivos da UC. }\end{array}$ & 31 & 28 & 3 \\
\hline CONTEXTO & VALOR DE MERCADO & Vulnerabilidade & $\begin{array}{l}\text { O valor de mercado de recursos } \\
\text { da UC é alto. }\end{array}$ & 62 & 56 & 6 \\
\hline CONTEXTO & ACESSIBILIDADE & Vulnerabilidade & $\begin{array}{l}\text { A UC é de fácil acesso para } \\
\text { atividades ilegais. }\end{array}$ & 74 & 65 & 8 \\
\hline CONTEXTO & DEMANDA POR RECURSOS & Vulnerabilidade & $\begin{array}{l}\text { Existe uma grande demanda } \\
\text { por recursos naturais da UC. }\end{array}$ & 62 & 53 & 9 \\
\hline CONTEXTO & $\begin{array}{l}\text { PRESSÕES POLÍTICAS E } \\
\text { ECONÔMICAS }\end{array}$ & Vulnerabilidade & $\begin{array}{l}\text { A gestão da UC sofre pressão } \\
\text { para desenvolver ações em } \\
\text { desacordo com os objetivos da } \\
\text { UC. } \\
\end{array}$ & 38 & 28 & 10 \\
\hline CONTEXTO & $\begin{array}{l}\text { CONTRATAÇÃO DE } \\
\text { FUNCIONÁRIOS } \\
\end{array}$ & Vulnerabilidade & $\begin{array}{l}\text { A contratação de funcionários é } \\
\text { difícil. }\end{array}$ & 45 & 63 & -18 \\
\hline CONTEXTO & PERMANÊNCIA DA EQUIPE & Vulnerabilidade & $\begin{array}{l}\text { A permanência da equipe na } \\
\text { UC é difícil } * * \text {. }\end{array}$ & 48 & - & - \\
\hline PLANEJAMENTO & OBJETIVOS GERAIS & Objetivos & $\begin{array}{l}\text { Os objetivos da UC incluem a } \\
\text { proteção e a conservação da } \\
\text { biodiversidade. }\end{array}$ & 88 & 77 & 11 \\
\hline PLANEJAMENTO & OBJETIVOS ESPECÍFICOS & Objetivos & $\begin{array}{l}\text { Os objetivos específicos } \\
\text { relacionados à biodiversidade } \\
\text { são claramente expressos nos } \\
\text { instrumentos de planejamento } \\
\text { da UC. }\end{array}$ & 60 & 23 & 37 \\
\hline PLANEJAMENTO & COERÊNCIA & Objetivos & $\begin{array}{l}\text { Os planos e projetos são } \\
\text { coerentes com os objetivos da } \\
\text { UC. }\end{array}$ & 74 & 47 & 27 \\
\hline PLANEJAMENTO & $\begin{array}{l}\text { COMPREENSÃO PELO } \\
\text { FUNCIONÁRIO }\end{array}$ & Objetivos & $\begin{array}{l}\text { Os funcionários e gestores da } \\
\text { UC entendem os objetivos e as } \\
\text { políticas da UC. }\end{array}$ & 82 & 64 & 18 \\
\hline PLANEJAMENTO & APOIO DA COMUNIDADE & Objetivos & $\begin{array}{l}\text { As comunidades locais apoiam } \\
\text { os objetivos da UC. }\end{array}$ & 51 & 46 & 5 \\
\hline
\end{tabular}




\begin{tabular}{|c|c|c|c|c|c|c|}
\hline \multicolumn{2}{|l|}{ ELEMENTO } & \multirow{2}{*}{$\begin{array}{l}\text { MÓDULO } \\
\text { Objetivos }\end{array}$} & \multirow{2}{*}{$\begin{array}{l}\text { Os membros do conselho } \\
\text { gestor da UC entendem os } \\
\text { objetivos e as políticas da } \\
\text { UC***. }\end{array}$} & \multirow{2}{*}{$\begin{array}{c}\text { Média } \\
\text { Percentual no } \\
\text { RAPPAM } 2010 \\
48 \\
\end{array}$} & \multirow{2}{*}{$\begin{array}{c}\text { Média } \\
\text { Percentual no } \\
\text { RAPPAM 2005 } \\
\\
\text { - }\end{array}$} & \multirow{2}{*}{$\begin{array}{c}\text { A VANÇO \% } \\
\text { (período de 2005 } \\
\text { a 2010) } \\
\\
\text { - }\end{array}$} \\
\hline PLANEJAMENTO & $\begin{array}{l}\text { COMPREENSÃO PELO } \\
\text { CONSELHEIRO }\end{array}$ & & & & & \\
\hline PLANEJAMENTO & AMPARO LEGAL & Amparo legal & $\begin{array}{l}\text { A UC e seus recursos naturais } \\
\text { possuem amparo legal. }\end{array}$ & 85 & 74 & 11 \\
\hline PLANEJAMENTO & SITUAÇÃO FUNDIÁ• RIA & Amparo legal & $\begin{array}{l}\text { A situação fundiária está } \\
\text { regularizada. }\end{array}$ & 41 & 39 & 3 \\
\hline PLANEJAMENTO & $\begin{array}{l}\text { DEMARCAÇÃO DOS } \\
\text { LIMITES }\end{array}$ & Amparo legal & $\begin{array}{l}\text { A demarcação e sinalização dos } \\
\text { limites da UC é adequada. }\end{array}$ & 32 & 38 & -6 \\
\hline PLANEJAMENTO & APLICAÇÃO DAS LEIS & Amparo legal & $\begin{array}{l}\text { Os recursos humanos e } \\
\text { financeiros são adequados para } \\
\text { realizar as ações críticas de } \\
\text { proteção. }\end{array}$ & 17 & 10 & 7 \\
\hline PLANEJAMENTO & GESTÃO DE CONFLITOS & Amparo legal & $\begin{array}{l}\text { Há amparo legal para a gestão } \\
\text { de conflitos. }\end{array}$ & 44 & 50 & -6 \\
\hline PLANEJAMENTO & LOCALIZAÇÃO & $\begin{array}{l}\text { Desenho e } \\
\text { planejamento da } \\
\text { área }\end{array}$ & $\begin{array}{l}\text { A localização da UC é coerente } \\
\text { com os seus objetivos. }\end{array}$ & 77 & 66 & 11 \\
\hline PLANEJAMENTO & DESENHO & $\begin{array}{l}\text { Desenho e } \\
\text { planejamento da } \\
\text { área }\end{array}$ & $\begin{array}{l}\text { O desenho da UC favorece a } \\
\text { conservação da biodiversidade } \\
\text { e ou aspectos socioculturais e } \\
\text { econômicos. }\end{array}$ & 64 & 51 & 13 \\
\hline PLANEJAMENTO & ZONEAMENTO & $\begin{array}{l}\text { Desenho e } \\
\text { planejamento da } \\
\text { área }\end{array}$ & $\begin{array}{l}\text { O zoneamento da UC é } \\
\text { adequado para alcançar os } \\
\text { objetivos da UC. }\end{array}$ & 41 & 25 & 16 \\
\hline PLANEJAMENTO & USOS NO ENTORNO & $\begin{array}{l}\text { Desenho e } \\
\text { planejamento da } \\
\text { área }\end{array}$ & $\begin{array}{l}\text { Os usos no entorno propiciam a } \\
\text { gestão efetiva da UC. }\end{array}$ & 38 & 24 & 14 \\
\hline PLANEJAMENTO & CONECTIVIDADE & $\begin{array}{l}\text { Desenho e } \\
\text { planejamento da } \\
\text { área }\end{array}$ & $\begin{array}{l}\text { A UC é ligada à outra unidade } \\
\text { de conservação ou a outra área } \\
\text { protegida. }\end{array}$ & 70 & 57 & 14 \\
\hline
\end{tabular}




\begin{tabular}{|c|c|c|c|c|c|c|}
\hline \multicolumn{2}{|l|}{ ELEMENTO } & \multirow{2}{*}{\begin{tabular}{l}
\multicolumn{1}{c|}{ MÓDULO } \\
$\begin{array}{l}\text { Desenho e } \\
\text { planejamento da } \\
\text { área }\end{array}$
\end{tabular}} & \multirow{2}{*}{$\begin{array}{l}\text { INDICADORES } \\
\text { A definição do desenho e da } \\
\text { categoria da UC foi decorrente } \\
\text { de um processo participativo. }\end{array}$} & \multirow{2}{*}{$\begin{array}{c}\text { Média } \\
\text { Percentual no } \\
\text { RAPPAM 2010 } \\
34\end{array}$} & \multirow{2}{*}{$\begin{array}{c}\text { Média } \\
\text { Percentual no } \\
\text { RAPPAM 2005 } \\
22\end{array}$} & \multirow{2}{*}{$\begin{array}{c}\text { A VANÇO \% } \\
\text { (período de 2005 } \\
\text { a 2010) } \\
13 \\
\end{array}$} \\
\hline PLANEJAMENTO & PROCESSO PARTICIPATIVO & & & & & \\
\hline PLANEJAMENTO & $\begin{array}{l}\text { ADEQUAÇÃO DA } \\
\text { CATEGORIA }\end{array}$ & $\begin{array}{l}\text { Desenho e } \\
\text { planejamento da } \\
\text { área }\end{array}$ & $\begin{array}{l}\text { A categoria da UC é adequada } \\
\text { às características naturais e de } \\
\text { uso da área***. }\end{array}$ & 77 & - & - \\
\hline INSUMOS & RECURSOS HUMANOS & Recursos humanos & $\begin{array}{l}\text { Há recursos humanos em } \\
\text { número suficiente para a gestão } \\
\text { efetiva da UC. }\end{array}$ & 12 & 6 & 6 \\
\hline INSUMOS & HABILIDADES & Recursos humanos & $\begin{array}{l}\text { Os funcionários possuem } \\
\text { habilidades adequadas para } \\
\text { realizar as ações de gestão. }\end{array}$ & 53 & 29 & 24 \\
\hline INSUMOS & CAPACITAÇÃO & Recursos humanos & $\begin{array}{l}\text { Há oportunidades de } \\
\text { capacitação e desenvolvimento } \\
\text { da equipe, apropriadas às } \\
\text { necessidades da UC. } \\
\end{array}$ & 43 & 23 & 19 \\
\hline INSUMOS & $\begin{array}{l}\text { AVALIAÇÃO DE } \\
\text { DESEMPENHO }\end{array}$ & Recursos humanos & $\begin{array}{l}\text { Há avaliação periódica do } \\
\text { desempenho e do progresso dos } \\
\text { funcionários. }\end{array}$ & 36 & 23 & 13 \\
\hline INSUMOS & CONDIÇÃES DE TRABALHO & Recursos humanos & $\begin{array}{l}\text { As condições de trabalho são } \\
\text { suficientes para manter uma } \\
\text { equipe adequada aos objetivos } \\
\text { da UC. }\end{array}$ & 33 & 20 & 13 \\
\hline INSUMOS & $\begin{array}{l}\text { ESTRUTURA DE } \\
\text { COMUNICAÇÃO }\end{array}$ & $\begin{array}{l}\text { Comunicação e } \\
\text { informação }\end{array}$ & $\begin{array}{l}\text { Há estrutura de comunicação } \\
\text { adequada entre a UC e outras } \\
\text { instâncias administrativas. }\end{array}$ & 55 & 40 & 15 \\
\hline INSUMOS & $\begin{array}{l}\text { DISPONIBILIDADE DE } \\
\text { INFORMAÇÃO }\end{array}$ & $\begin{array}{l}\text { Comunicação e } \\
\text { informação }\end{array}$ & $\begin{array}{l}\text { As informações ecológicas e } \\
\text { socioeconômicas existentes são } \\
\text { adequadas ao planejamento da } \\
\text { gestão. }\end{array}$ & 41 & 30 & 11 \\
\hline INSUMOS & MEIOS DE COLETA & $\begin{array}{l}\text { Comunicação e } \\
\text { informação }\end{array}$ & $\begin{array}{l}\text { Há meios adequados para a } \\
\text { coleta de dados. }\end{array}$ & 33 & 27 & 6 \\
\hline
\end{tabular}




\begin{tabular}{|c|c|c|c|c|c|c|}
\hline \multicolumn{2}{|c|}{ ELEMENTO } & \multirow{2}{*}{$\begin{array}{l}\text { MÓDULO } \\
\begin{array}{l}\text { Comunicação e } \\
\text { informação }\end{array}\end{array}$} & \multirow{2}{*}{$\begin{array}{l}\text { INDICADORES } \\
\begin{array}{l}\text { Há sistemas adequados para o } \\
\text { armazenamento, processamento } \\
\text { e análise de dados. }\end{array} \\
\end{array}$} & \multirow{2}{*}{$\begin{array}{c}\text { Média } \\
\text { Percentual no } \\
\text { RAPPAM } 2010 \\
28\end{array}$} & \multirow{2}{*}{$\begin{array}{c}\text { Média } \\
\text { Percentual no } \\
\text { RAPPAM 2005 } \\
21\end{array}$} & \multirow{2}{*}{$\begin{array}{c}\text { AVANÇO \% } \\
\text { (período de 2005 } \\
\text { a 2010) } \\
7\end{array}$} \\
\hline INSUMOS & $\begin{array}{l}\text { MEIOS DE } \\
\text { PROCESSAMENTO }\end{array}$ & & & & & \\
\hline INSUMOS & $\begin{array}{l}\text { COMUNICAÇÃO COM } \\
\text { COMUNIDADE }\end{array}$ & $\begin{array}{l}\text { Comunicação e } \\
\text { informação }\end{array}$ & $\begin{array}{l}\text { Existe comunicação efetiva da } \\
\text { UC com as comunidades } \\
\text { locais. }\end{array}$ & 47 & 47 & 0 \\
\hline INSUMOS & $\begin{array}{l}\text { COMUNICAÇÃO ENTRE } \\
\text { COMUNIDADES }\end{array}$ & $\begin{array}{l}\text { Comunicação e } \\
\text { informação }\end{array}$ & $\begin{array}{l}\text { Existe comunicação efetiva } \\
\text { entre as comunidades locais. }\end{array}$ & 42 & 39 & 3 \\
\hline INSUMOS & TRANSPORTE & Infraestrutura & $\begin{array}{l}\text { A infraestrutura de transporte é } \\
\text { adequada para o atendimento } \\
\text { dos objetivos da UC. }\end{array}$ & 39 & 22 & 17 \\
\hline INSUMOS & $\begin{array}{l}\text { EQUIPAMENTO DE } \\
\text { TRABALHO }\end{array}$ & Infraestrutura & $\begin{array}{l}\text { O equipamento de trabalho é } \\
\text { adequado para o atendimento } \\
\text { dos objetivos da UC. }\end{array}$ & 40 & 19 & 21 \\
\hline INSUMOS & $\begin{array}{l}\text { INSTALAÇÃES PARA } \\
\text { EQUIPES }\end{array}$ & Infraestrutura & $\begin{array}{l}\text { As instalações da UC são } \\
\text { adequadas para o atendimento } \\
\text { dos seus objetivos. }\end{array}$ & 30 & 24 & 7 \\
\hline INSUMOS & $\begin{array}{l}\text { INSTALAÇÃES PARA } \\
\text { VISITANTES }\end{array}$ & Infraestrutura & $\begin{array}{l}\text { A infraestrutura para visitantes } \\
\text { é apropriada para o nível de } \\
\text { uso. }\end{array}$ & 30 & 17 & 13 \\
\hline INSUMOS & MANUTENÇÃO & Infraestrutura & $\begin{array}{l}\text { A manutenção e cuidados com } \\
\text { os equipamentos e instalações } \\
\text { são adequados para garantir seu } \\
\text { uso a longo prazo. }\end{array}$ & 42 & 32 & 10 \\
\hline INSUMOS & HISTÓRICO DE RECURSOS & $\begin{array}{l}\text { Recursos } \\
\text { financeiros }\end{array}$ & $\begin{array}{l}\text { Os recursos financeiros dos } \\
\text { últimos } 5 \text { anos foram } \\
\text { adequados para atendimento } \\
\text { dos objetivos da UC. }\end{array}$ & 21 & 9 & 12 \\
\hline INSUMOS & PREVISÃO DE RECURSOS & $\begin{array}{l}\text { Recursos } \\
\text { financeiros }\end{array}$ & $\begin{array}{l}\text { Estão previstos recursos } \\
\text { financeiros para os próximos } 5 \\
\text { anos para atendimento dos } \\
\text { objetivos da UC. }\end{array}$ & 36 & 31 & 5 \\
\hline
\end{tabular}




\begin{tabular}{|c|c|c|c|c|c|c|}
\hline \multicolumn{2}{|l|}{ ELEMENTO } & \multirow{2}{*}{$\begin{array}{l}\qquad \text { MÓDULO } \\
\begin{array}{l}\text { Recursos } \\
\text { financeiros }\end{array}\end{array}$} & \multirow{2}{*}{$\begin{array}{l}\text { INDICADORES } \\
\text { As práticas de administração } \\
\text { financeira propiciam a gestão } \\
\text { eficiente da UC. }\end{array}$} & \multirow{2}{*}{$\begin{array}{c}\text { Média } \\
\text { Percentual no } \\
\text { RAPPAM 2010 } \\
29\end{array}$} & \multirow{2}{*}{$\begin{array}{c}\text { Média } \\
\text { Percentual no } \\
\text { RAPPAM 2005 } \\
25\end{array}$} & \multirow{2}{*}{$\begin{array}{c}\text { A VANÇO \% } \\
\text { (período de 2005 } \\
\text { a 2010) } \\
4 \\
4\end{array}$} \\
\hline INSUMOS & $\begin{array}{l}\text { PRÁTICAS DE } \\
\text { ADMINISTRAÇÃO }\end{array}$ & & & & & \\
\hline INSUMOS & ALOCAÇÃO DE RECURSOS & $\begin{array}{l}\text { Recursos } \\
\text { financeiros }\end{array}$ & $\begin{array}{l}\text { A alocação de recursos está de } \\
\text { acordo com as prioridades e os } \\
\text { objetivos da UC. }\end{array}$ & 43 & 28 & 15 \\
\hline INSUMOS & PERSPECTIVA FINANCEIRA & $\begin{array}{l}\text { Recursos } \\
\text { financeiros }\end{array}$ & $\begin{array}{l}\text { A previsão financeira a longo } \\
\text { prazo para a UC é estável. }\end{array}$ & 14 & 8 & 6 \\
\hline INSUMOS & $\begin{array}{l}\text { CAPACIDADE DE } \\
\text { CAPTAÇÃO }\end{array}$ & $\begin{array}{l}\text { Recursos } \\
\text { financeiros }\end{array}$ & $\begin{array}{l}\text { A UC possui capacidade para a } \\
\text { captação de recursos externos. }\end{array}$ & 39 & 43 & -4 \\
\hline PROCESSOS & PLANO DE MANEJO & $\begin{array}{l}\text { Planejamento e } \\
\text { gestão }\end{array}$ & $\begin{array}{l}\text { Existe um plano de manejo } \\
\text { adequado à gestão. }\end{array}$ & 32 & 16 & 16 \\
\hline PROCESSOS & INVENTÁRIO & $\begin{array}{l}\text { Planejamento e } \\
\text { gestão }\end{array}$ & $\begin{array}{l}\text { Existe um inventário dos } \\
\text { recursos naturais e culturais } \\
\text { adequados à gestão da UC. }\end{array}$ & 35 & 26 & 9 \\
\hline PROCESSOS & $\begin{array}{l}\text { ESTRATÉGIA PARA } \\
\text { PRESSÕS E AMEAÇAS }\end{array}$ & $\begin{array}{l}\text { Planejamento e } \\
\text { gestão }\end{array}$ & $\begin{array}{l}\text { Existe uma análise e também } \\
\text { uma estratégia para enfrentar as } \\
\text { ameaças e as pressões na UC. }\end{array}$ & 43 & 33 & 10 \\
\hline PROCESSOS & $\begin{array}{l}\text { INSTRUMENTO DE } \\
\text { PLANEJAMENTO } \\
\text { OPERACIONAL }\end{array}$ & $\begin{array}{l}\text { Planejamento e } \\
\text { gestão }\end{array}$ & $\begin{array}{l}\text { Existe um instrumento de } \\
\text { planejamento operacional que } \\
\text { identifica as atividades para } \\
\text { alcançar as metas e os objetivos } \\
\text { de gestão da UC. }\end{array}$ & 35 & 25 & 9 \\
\hline PROCESSOS & APRENDIZADO & $\begin{array}{l}\text { Planejamento e } \\
\text { gestão }\end{array}$ & $\begin{array}{l}\text { Os resultados da pesquisa, } \\
\text { monitoramento e o } \\
\text { conhecimento tradicional são } \\
\text { incluídos rotineiramente no } \\
\text { planejamento. }\end{array}$ & 33 & 29 & 3 \\
\hline PROCESSOS & ORGANIZAÇÃO INTERNA & Tomada de decisão & $\begin{array}{l}\text { Existe uma organização interna } \\
\text { nítida da UC. }\end{array}$ & 54 & 38 & 16 \\
\hline PROCESSOS & TRANSPARÊNCIA & Tomada de decisão & $\begin{array}{l}\text { A tomada de decisões na gestão } \\
\text { é transparente. }\end{array}$ & 73 & 55 & 19 \\
\hline
\end{tabular}




\begin{tabular}{|c|c|c|c|c|c|c|}
\hline ELEMENTO & & MÓDULO & INDICADORES & \begin{tabular}{|c|c|} 
Média \\
Percentual no \\
RAPPAM 2010 \\
\end{tabular} & \begin{tabular}{|c|c|} 
Média \\
Percentual no \\
RAPPAM 2005 \\
\end{tabular} & $\begin{array}{c}\text { A VANÇO \% } \\
\text { (período de 2005 } \\
\text { a 2010) } \\
\end{array}$ \\
\hline PROCESSOS & PARCERIAS & Tomada de decisão & $\begin{array}{l}\text { A UC colabora regularmente } \\
\text { com os parceiros, comunidades } \\
\text { locais e outras organizações. }\end{array}$ & 71 & 60 & 11 \\
\hline PROCESSOS & $\begin{array}{l}\text { PARTICIPAÇÃO } \\
\text { COMUNITÁ・RIA }\end{array}$ & Tomada de decisão & $\begin{array}{l}\text { As comunidades locais } \\
\text { participam efetivamente da } \\
\text { gestão da UC, contribuindo na } \\
\text { tomada de decisão. }\end{array}$ & 44 & 44 & 0 \\
\hline PROCESSOS & FLUXO DE COMUNICAÇÃO & Tomada de decisão & $\begin{array}{l}\text { Existe a comunicação efetiva } \\
\text { entre os funcionários da UC e } \\
\text { Administração. }\end{array}$ & 66 & 57 & 9 \\
\hline PROCESSOS & CONSELHO EFETIVO & Tomada de decisão & $\begin{array}{l}\text { Existe conselho implementado } \\
\text { e efetivo. }\end{array}$ & 47 & 29 & 18 \\
\hline PROCESSOS & $\begin{array}{l}\text { ARTICULAÇÃO } \\
\text { INTERINSTITUCIONAL }\end{array}$ & Tomada de decisão & $\begin{array}{l}\text { Existe articulação efetiva da } \\
\text { UC com órgãos e entidades } \\
\text { relacionadas***. }\end{array}$ & 70 & - & - \\
\hline PROCESSOS & EDUCAÇÃO AMBIENTAL & Tomada de decisão & $\begin{array}{l}\text { Há implementação de ações } \\
\text { educativas contínuas e } \\
\text { consistentes que contribuem } \\
\text { com a gestão e atingimento dos } \\
\text { objetivos da UC.*** }\end{array}$ & 30 & - & - \\
\hline PROCESSOS & IMPACTOS LEGAIS & $\begin{array}{l}\text { Pesquisa, avaliação } \\
\text { e monitoramento }\end{array}$ & $\begin{array}{l}\text { O impacto das atividades legais } \\
\text { na UC é monitorado e } \\
\text { registrado de forma precisa. }\end{array}$ & 32 & 23 & 9 \\
\hline PROCESSOS & IMPACTOS ILEGAIS & $\begin{array}{l}\text { Pesquisa, avaliação } \\
\text { e monitoramento }\end{array}$ & $\begin{array}{l}\text { O impacto das atividades } \\
\text { ilegais na UC é monitorado e } \\
\text { registrado de forma precisa. }\end{array}$ & 29 & 22 & 7 \\
\hline PROCESSOS & PESQUISA ECOLÓGICA & $\begin{array}{l}\text { Pesquisa, avaliação } \\
\text { e monitoramento }\end{array}$ & $\begin{array}{l}\text { As pesquisas sobre questões } \\
\text { ecológicas são coerentes com } \\
\text { as necessidades da UC. }\end{array}$ & 45 & 24 & 21 \\
\hline PROCESSOS & PESQUISA SOCIOECÔMICA & $\begin{array}{l}\text { Pesquisa, avaliação } \\
\text { e monitoramento }\end{array}$ & $\begin{array}{l}\text { As pesquisas sobre questões } \\
\text { socioeconômicas são coerentes } \\
\text { com as necessidades da UC. }\end{array}$ & 36 & 21 & 15 \\
\hline
\end{tabular}




\begin{tabular}{|c|c|c|c|c|c|c|}
\hline ELEMENTO & & MÓDULO & INDICADORES & $\begin{array}{c}\text { Média } \\
\text { Percentual no } \\
\text { RAPPAM } 2010 \\
\end{array}$ & $\begin{array}{c}\text { Média } \\
\text { Percentual no } \\
\text { RAPPAM 2005 } \\
\end{array}$ & $\begin{array}{l}\text { AVANÇO \% } \\
\text { (período de 2005 } \\
\text { a 2010) } \\
\end{array}$ \\
\hline PROCESSOS & $\begin{array}{l}\text { ACESSO A RESULTADOS DE } \\
\text { PESQUISAS CIENTIIFICAS }\end{array}$ & $\begin{array}{l}\text { Pesquisa, avaliação } \\
\text { e monitoramento }\end{array}$ & $\begin{array}{l}\text { A equipe da UC e comunidades } \\
\text { locais têm acesso regular às } \\
\text { informações geradas pelas } \\
\text { pesquisas realizadas na UC. }\end{array}$ & 32 & 35 & -2 \\
\hline PROCESSOS & $\begin{array}{l}\text { IDENTIFICAÇÃO DE } \\
\text { NECESSIDADES }\end{array}$ & $\begin{array}{l}\text { Pesquisa, avaliação } \\
\text { e monitoramento }\end{array}$ & $\begin{array}{l}\text { As necessidades críticas de } \\
\text { pesquisa e monitoramento são } \\
\text { identificadas e priorizadas. }\end{array}$ & 38 & 31 & 7 \\
\hline PROCESSOS & $\begin{array}{l}\text { ACESSO AO } \\
\text { CONHECIMENTO } \\
\text { CIENTÍFICO }\end{array}$ & $\begin{array}{l}\text { Pesquisa, avaliação } \\
\text { e monitoramento }\end{array}$ & $\begin{array}{l}\text { A equipe da UC tem acesso a } \\
\text { conhecimentos científicos } \\
\text { recentes***. }\end{array}$ & 55 & - & - \\
\hline RESULTADOS & $\begin{array}{l}\text { PLANEJAMENTO DA } \\
\text { GESTÃO }\end{array}$ & Resultados & $\begin{array}{l}\text { A UC realizou o planejamento } \\
\text { da gestão nos últimos dois } \\
\text { anos. }\end{array}$ & 57 & 31 & 26 \\
\hline RESULTADOS & RECUPERAÇÃO & Resultados & $\begin{array}{l}\text { A UC realizou a recuperação } \\
\text { de áreas e ações mitigatórias } \\
\text { adequadas às suas necessidades } \\
\text { nos últimos dois anos. }\end{array}$ & 39 & 20 & 19 \\
\hline RESULTADOS & MANEJO & Resultados & $\begin{array}{l}\text { A UC realizou o manejo da } \\
\text { vida silvestre, de habitat ou } \\
\text { recursos naturais adequado às } \\
\text { suas necessidades nos últimos } \\
\text { dois anos. }\end{array}$ & 30 & 19 & 11 \\
\hline RESULTADOS & DIVULGAÇÃO & Resultados & $\begin{array}{l}\text { A UC realizou ações de } \\
\text { divulgação e informação à } \\
\text { sociedade nos últimos dois } \\
\text { anos. } \\
\end{array}$ & 56 & 41 & 15 \\
\hline RESULTADOS & CONTROLE DE VISITANTES & Resultados & $\begin{array}{l}\text { A UC realizou o controle de } \\
\text { visitantes adequado às suas } \\
\text { necessidades nos últimos dois } \\
\text { anos. }\end{array}$ & 45 & 27 & 19 \\
\hline RESULTADOS & INFRAESTRUTURA & Resultados & $\begin{array}{l}\text { A UC realizou a Implantação e } \\
\text { manutenção da infraestrutura } \\
\text { nos últimos dois anos. }\end{array}$ & 33 & 21 & 12 \\
\hline RESULTADOS & PREVENÇÃO DE AMEAÇAS & Resultados & $\begin{array}{l}\text { A UC realizou a prevenção, } \\
\text { detecção de ameaças e }\end{array}$ & 62 & 39 & 23 \\
\hline
\end{tabular}




\begin{tabular}{|c|c|c|c|c|c|c|}
\hline \multicolumn{2}{|l|}{ ELEMENTO } & \multirow[t]{2}{*}{ MÓDULO } & \multirow{2}{*}{$\begin{array}{l}\text { INDICADORES } \\
\text { aplicação da lei nos últimos } \\
\text { dois anos. }\end{array}$} & \multirow{2}{*}{$\begin{array}{c}\text { Média } \\
\text { Percentual no } \\
\text { RAPPAM } 2010 \\
\end{array}$} & \multirow{2}{*}{$\begin{array}{c}\text { Média } \\
\text { Percentual no } \\
\text { RAPPAM 2005 } \\
\end{array}$} & \multirow{2}{*}{$\begin{array}{l}\text { A VANÇO \% } \\
\text { (período de 2005 } \\
\text { a 2010) }\end{array}$} \\
\hline & & & & & & \\
\hline RESULTADOS & GESTÃO DE PESSOAL & Resultados & $\begin{array}{l}\text { A UC realizou a supervisão e } \\
\text { avaliação de desempenho de } \\
\text { funcionários nos últimos dois } \\
\text { anos. }\end{array}$ & 38 & 28 & 10 \\
\hline RESULTADOS & CAPACITAÇÃO & Resultados & $\begin{array}{l}\text { A UC realizou capacitação e } \\
\text { desenvolvimento de recursos } \\
\text { humanos nos últimos dois anos. }\end{array}$ & 45 & 21 & 24 \\
\hline RESULTADOS & $\begin{array}{l}\text { RELAÇÃO COM } \\
\text { COMUNIDADES LOCAIS }\end{array}$ & Resultados & $\begin{array}{l}\text { A UC apoiou a organização, } \\
\text { capacitação e desenvolvimento } \\
\text { das comunidades locais e } \\
\text { conselho nos últimos dois anos. }\end{array}$ & 53 & 33 & 19 \\
\hline RESULTADOS & $\begin{array}{l}\text { DESENVOLVIMENTO DE } \\
\text { PESQUISAS }\end{array}$ & Resultados & $\begin{array}{l}\text { Houve o desenvolvimento de } \\
\text { pesquisas na UC nos últimos } \\
\text { dois anos, alinhadas aos seus } \\
\text { objetivos. }\end{array}$ & 58 & 33 & 25 \\
\hline RESULTADOS & $\begin{array}{l}\text { MONITORAMENTO DE } \\
\text { RESULTADOS }\end{array}$ & Resultados & $\begin{array}{l}\text { Os resultados da gestão foram } \\
\text { monitorados nos últimos dois } \\
\text { anos. }\end{array}$ & 30 & 20 & 9 \\
\hline RESULTADOS & EDUCAÇÃO AMBIENTAL & Resultados & $\begin{array}{l}\text { A UC desenvolveu ações de } \\
\text { educação ambiental nos } \\
\text { últimos dois anos.*** }\end{array}$ & 49 & - & - \\
\hline
\end{tabular}

*Houve algumas alterações em relação aos indicadores nas versões 2005 e 2010 do RAPPAM. Para os ajustes menos estruturais, mais voltados à redação, privilegiou-se a redação de 2020. A inserção e exclusão de indicadores estão sinalizadas na tabela.

**Em 2005 essa questão não existia de forma isolada. Estava contemplada no indicador que trata da dificuldade de contratação (localizado nesta tabela imediatamente acima)

***Nova questão. Não existia em 2005. 
ANEXo II. LISTA DE UNIDADES DE CONSERVAÇÃO ESTUDADAS DE ACORDO COM O MÉTODO UTILIZADO.

\begin{tabular}{|c|c|c|c|}
\hline & UNIDADE DE CONSERVAÇÃO & $\begin{array}{c}\text { BANCO DA } \\
\text { TESE }\end{array}$ & RAPPAM \\
\hline 1 & ARIE SERINGAL NOVA ESPERANCA & - & $\mathrm{X}$ \\
\hline 2 & FLONA DE MACAUÃ & - & $\mathrm{X}$ \\
\hline 3 & FLONA DE SANTA ROSA DO PURUS & - & $\mathrm{X}$ \\
\hline 4 & RESEX ALTO JURUA & - & $\mathrm{X}$ \\
\hline 5 & FLONA DE SÃO FRANCISCO & - & $\mathrm{X}$ \\
\hline 6 & PARNA DA SERRA DO DIVISOR & $\mathrm{X}$ & $\mathrm{X}$ \\
\hline 7 & RESEX ALTO TARAUACA & $\mathrm{X}$ & $\mathrm{X}$ \\
\hline 8 & RESEX RIOZINHO DA LIBERDADE & $\mathrm{X}$ & $\mathrm{X}$ \\
\hline 9 & ESEC RIO ACRE & - & $\mathrm{X}$ \\
\hline 10 & RESEX CAZUMBA-IRACEMA & $\mathrm{X}$ & $\mathrm{X}$ \\
\hline 11 & RESEX CHICO MENDES & $\mathrm{X}$ & $\mathrm{X}$ \\
\hline 12 & APA DE PIACABUCU & - & $\mathrm{X}$ \\
\hline 13 & ESEC DE MURICI & - & $\mathrm{X}$ \\
\hline 14 & RESEX MARINHA DA LAGOA DO JEQUIA & - & $\mathrm{X}$ \\
\hline 15 & APA COSTA DOS CORAIS & $\mathrm{X}$ & $\mathrm{X}$ \\
\hline 16 & $\begin{array}{l}\text { ARIE PROJETO DINÂMICA BIOLÓGICA DE } \\
\text { FRAGMENTOS FLORESTAIS }\end{array}$ & - & $\mathrm{X}$ \\
\hline 17 & ESEC DE JUTAI-SOLIMÕES & - & $\mathrm{X}$ \\
\hline 18 & FLONA DE BALATA-TUFARI & - & $\mathrm{X}$ \\
\hline 19 & FLONA DE HUMAITA & - & $\mathrm{X}$ \\
\hline 20 & FLONA DE JATUARANA & - & $\mathrm{X}$ \\
\hline 21 & FLONA DE MAPIA-INAUINI & - & $\mathrm{X}$ \\
\hline 22 & FLONA DE PURUS & - & $\mathrm{X}$ \\
\hline 23 & FLONA DE TEFE & - & $\mathrm{X}$ \\
\hline 24 & FLONA DO AMAZONAS & - & $\mathrm{X}$ \\
\hline 25 & REBIO DO ABUFARI & - & $\mathrm{X}$ \\
\hline 26 & ARIE JAVARI BURITI & - & $\mathrm{X}$ \\
\hline 27 & FLONA DE PAU-ROSA & - & $\mathrm{X}$ \\
\hline 28 & FLONA DO IQUIRI & - & $\mathrm{X}$ \\
\hline 29 & PARNA MAPINGUARI & - & $\mathrm{X}$ \\
\hline 30 & PARNA DO PICO DA NEBLINA & $\mathrm{X}$ & $\mathrm{X}$ \\
\hline 31 & RESEX DO RIO JUTAI & $\mathrm{X}$ & $\mathrm{X}$ \\
\hline 32 & PARNA NASCENTES DO LAGO JARI & - & $\mathrm{X}$ \\
\hline 33 & RESEX ARAPIXI & - & $\mathrm{X}$ \\
\hline 34 & RESEX DO MEDIO PURÚS & - & $\mathrm{X}$ \\
\hline 35 & RESEX ITUXI & - & $\mathrm{X}$ \\
\hline 36 & RESEX MEDIO JURUA & $\mathrm{X}$ & $\mathrm{X}$ \\
\hline 37 & RESEX RIO UNINI & $\mathrm{X}$ & $\mathrm{X}$ \\
\hline
\end{tabular}




\begin{tabular}{|c|c|c|c|}
\hline & UNIDADE DE CONSERVAÇÃO & $\begin{array}{c}\text { BANCO DA } \\
\text { TESE }\end{array}$ & RAPPAM \\
\hline 38 & REBIO DO UATUMÃ & - & $\mathrm{X}$ \\
\hline 39 & RESEX AUATI-PARANA & - & $\mathrm{X}$ \\
\hline 40 & RESEX DO LAGO DO CAPANÃ GRANDE & - & $\mathrm{X}$ \\
\hline 41 & PARNA DOS CAMPOS AMAZÔNICOS & - & $\mathrm{X}$ \\
\hline 42 & ESEC DE ANAVILHANAS & $\mathrm{X}$ & $\mathrm{X}$ \\
\hline 43 & ESEC JUAMI-JAPURA & $\bar{X}$ & $\mathrm{X}$ \\
\hline 44 & PARNA DO JAÚ & $\mathrm{X}$ & $\mathrm{X}$ \\
\hline 45 & RESEX BAIXO JURUA & $\mathrm{X}$ & $\mathrm{X}$ \\
\hline 46 & FLONA DE AMAPA & - & $\mathrm{X}$ \\
\hline 47 & RESEX RIO CAJARI & - & $\mathrm{X}$ \\
\hline 48 & ESEC DE MARACA JIPIOCA & $\mathrm{X}$ & $\mathrm{X}$ \\
\hline 49 & PARNA DO CABO ORANGE & $\mathrm{X}$ & $\mathrm{X}$ \\
\hline 50 & PARNA MONTANHAS DO TUMUCUMAQUE & $\mathrm{X}$ & $\mathrm{X}$ \\
\hline 51 & REBIO DO LAGO PIRATUBA & $\mathrm{X}$ & $\mathrm{X}$ \\
\hline 52 & ESEC RASO DA CATARINA & - & $\mathrm{X}$ \\
\hline 53 & FLONA DE CONTENDAS DO SINCORA & - & $\mathrm{X}$ \\
\hline 54 & PARNA DESCOBRIMENTO & - & $\mathrm{X}$ \\
\hline 55 & RESEX CORUMBAU & - & $\mathrm{X}$ \\
\hline 56 & REVIS VEREDAS DO OESTE BAIANO & - & $\mathrm{X}$ \\
\hline 57 & RESEX DE CASSURUBA & - & $\mathrm{X}$ \\
\hline 58 & REVIS DO RIO DOS FRADES & - & $\mathrm{X}$ \\
\hline 59 & PARNA DA CHAPADA DIAMANTINA & $\mathrm{X}$ & $\mathrm{X}$ \\
\hline 60 & PARNA DO MONTE PASCOAL & $\mathrm{X}$ & $\mathrm{X}$ \\
\hline 61 & PARNA MARINHO DOS ABROLHOS & $\mathrm{X}$ & $\mathrm{X}$ \\
\hline 62 & PARNA PAU BRASIL & $\mathrm{X}$ & $\mathrm{X}$ \\
\hline 63 & REBIO DE UNA & $\mathrm{X}$ & $\mathrm{X}$ \\
\hline 64 & RESEX MARINHA DA BAIA DE IGUAPE & $\mathrm{X}$ & $\mathrm{X}$ \\
\hline 65 & PARNA DE BOA NOVA & $\mathrm{X}$ & - \\
\hline 66 & PARNA DE SERRA DAS LONTRAS & $\mathrm{X}$ & - \\
\hline 67 & PARNA DO ALTO CARIRI & $\mathrm{X}$ & - \\
\hline 68 & RESEX DE CANAVIEIRAS & $\mathrm{X}$ & $\mathrm{X}$ \\
\hline 69 & REVIS DE UNA & $\mathrm{X}$ & $\mathrm{X}$ \\
\hline 70 & ESEC DE AIUABA & - & $\mathrm{X}$ \\
\hline 71 & ESEC DO CASTANHÃO & - & $\mathrm{X}$ \\
\hline 72 & FLONA DE SOBRAL & - & $\mathrm{X}$ \\
\hline 73 & FLONA DO ARARIPE-APODI & - & $\mathrm{X}$ \\
\hline 74 & PARNA DE UBAJARA & - & $\mathrm{X}$ \\
\hline 75 & RESEX DO BATOQUE & - & $\mathrm{X}$ \\
\hline 76 & RESEX PRAINHA DO CANTO VERDE & - & $\mathrm{X}$ \\
\hline 77 & APA CHAPADA DO ARARIPE & $\mathrm{X}$ & $\mathrm{X}$ \\
\hline 78 & PARNA DE JERICOACOARA & $\mathrm{X}$ & $\mathrm{X}$ \\
\hline
\end{tabular}




\begin{tabular}{|c|c|c|c|}
\hline & UNIDADE DE CONSERVAÇÃO & $\begin{array}{c}\text { BANCO DA } \\
\text { TESE }\end{array}$ & RAPPAM \\
\hline 79 & APA DA BACIA DO RIO DESCOBERTO & - & $\mathrm{X}$ \\
\hline 80 & FLONA DE BRASILIA & - & $\mathrm{X}$ \\
\hline 81 & REBIO DA CONTAGEM & - & $\mathrm{X}$ \\
\hline 82 & APA DO PLANALTO CENTRAL & $\mathrm{X}$ & $\mathrm{X}$ \\
\hline 83 & PARNA DE BRASILIA & $\mathrm{X}$ & $\mathrm{X}$ \\
\hline 84 & FLONA DE PACOTUBA & - & $\mathrm{X}$ \\
\hline 85 & PARNA DOS PONTÕES CAPIXABAS & - & $\mathrm{X}$ \\
\hline 86 & REBIO DE COMBOIOS & - & $\mathrm{X}$ \\
\hline 87 & FLONA DE GOYTACAZES & $\mathrm{X}$ & $\mathrm{X}$ \\
\hline 88 & FLONA DE RIO PRETO & $\mathrm{X}$ & $\mathrm{X}$ \\
\hline 89 & REBIO AUGUSTO RUSCHI & $\mathrm{X}$ & $\mathrm{X}$ \\
\hline 90 & REBIO DE SOORETAMA & $\mathrm{X}$ & $\mathrm{X}$ \\
\hline 91 & REBIO DO CORREGO DO VEADO & $\mathrm{X}$ & $\mathrm{X}$ \\
\hline 92 & REBIO DO CORREGO GRANDE & $\mathrm{X}$ & $\mathrm{X}$ \\
\hline 93 & FLONA DA MATA GRANDE & - & $\mathrm{X}$ \\
\hline 94 & PARNA DA CHAPADA DOS VEADEIROS & - & $\mathrm{X}$ \\
\hline 95 & RESEX DO RECANTO DAS ARARAS DE TERRA RONCA & - & $\mathrm{X}$ \\
\hline 96 & APA MEANDROS DO ARAGUAIA & - & $\mathrm{X}$ \\
\hline 97 & APA DAS NASCENTES DO RIO VERMELHO & $\mathrm{X}$ & $\mathrm{X}$ \\
\hline 98 & FLONA DE SILVÂNIA & $\mathrm{X}$ & $\mathrm{X}$ \\
\hline 99 & PARNA DAS EMAS & $\mathrm{X}$ & $\mathrm{X}$ \\
\hline 100 & RESEX LAGO DO CEDRO & $\mathrm{X}$ & $\mathrm{X}$ \\
\hline 101 & PARNA DA CHAPADA DAS MESAS & - & $\mathrm{X}$ \\
\hline 102 & RESEX DO CIRIACO & - & $\mathrm{X}$ \\
\hline 103 & RESEX QUILOMBO DO FREXAL & - & $\mathrm{X}$ \\
\hline 104 & PARNA DOS LENCOIS MARANHENSES & $\mathrm{X}$ & $\mathrm{X}$ \\
\hline 105 & PARNA DAS NASCENTES DO RIO PARNAIBA & $\mathrm{X}$ & $\mathrm{X}$ \\
\hline 106 & RESEX MATA GRANDE & $\mathrm{X}$ & $\mathrm{X}$ \\
\hline 107 & RESEX DE CURURUPU & $\mathrm{X}$ & $\mathrm{X}$ \\
\hline 108 & REBIO DO GURUPI & $\mathrm{X}$ & $\mathrm{X}$ \\
\hline 109 & APA CAVERNAS DO PERUACU & - & $\mathrm{X}$ \\
\hline 110 & APA MORRO DA PEDREIRA & - & $\mathrm{X}$ \\
\hline 111 & APA SERRA DA MANTIQUEIRA & - & $\mathrm{X}$ \\
\hline 112 & FLONA DE PASSA QUATRO & - & $\mathrm{X}$ \\
\hline 113 & FLONA DE RITAPOLIS & - & $\mathrm{X}$ \\
\hline 114 & PARNA CAVERNAS DO PERUACU & - & $\mathrm{X}$ \\
\hline 115 & PARNA DA SERRA DA CIPO & - & $\mathrm{X}$ \\
\hline 116 & PARNA DAS SEMPRE VIVAS & - & $\mathrm{X}$ \\
\hline 117 & PARNA DE CAPARAO & - & $\mathrm{X}$ \\
\hline 118 & PARNA GRANDE SERTÃO VEREDAS & - & $\mathrm{X}$ \\
\hline 119 & REBIO DA MATA ESCURA & - & $\mathrm{X}$ \\
\hline
\end{tabular}




\begin{tabular}{|c|c|c|c|}
\hline & UNIDADE DE CONSERVAÇÃO & $\begin{array}{c}\text { BANCO DA } \\
\text { TESE }\end{array}$ & RAPPAM \\
\hline 120 & APA CARSTE DA LAGOA SANTA & $\mathrm{X}$ & $\mathrm{X}$ \\
\hline 121 & FLONA DE PARAOPEBA & $\mathrm{X}$ & $\mathrm{X}$ \\
\hline 122 & PARNA DA SERRA DA CANASTRA & $\mathrm{X}$ & $\mathrm{X}$ \\
\hline 123 & APA ILHAS E VARZEAS DO RIO PARANA & - & $\mathrm{X}$ \\
\hline 124 & PARNA DA SERRA DA BODOQUENA & $\mathrm{X}$ & $\mathrm{X}$ \\
\hline 125 & ESEC DE IQUE & - & $\mathrm{X}$ \\
\hline 126 & ESEC DE PIRAPITINGA & $\mathrm{X}$ & $\mathrm{X}$ \\
\hline 127 & ESEC DA SERRA DAS ARARAS & $\mathrm{X}$ & $\mathrm{X}$ \\
\hline 128 & ESEC DE TAIAMÃ & $\mathrm{X}$ & $\mathrm{X}$ \\
\hline 129 & PARNA DA CHAPADA DOS GUIMARÃES & $\mathrm{X}$ & $\mathrm{X}$ \\
\hline 130 & PARNA DO PANTANAL MATOGROSSENSE & $\mathrm{X}$ & $\mathrm{X}$ \\
\hline 131 & PARNA DO JURUENA & - & $\mathrm{X}$ \\
\hline 132 & APA DO IGARAPE GELADO & - & $\mathrm{X}$ \\
\hline 133 & FLONA DE CAXIUANÃ & - & $\mathrm{X}$ \\
\hline 134 & FLONA DE ITACAIUNAS & - & $\mathrm{X}$ \\
\hline 135 & FLONA DE TAPIRAPE-AQUIRI & - & $\mathrm{X}$ \\
\hline 136 & PARNA DA AMAZÔNIA & - & $\mathrm{X}$ \\
\hline 137 & REBIO NASCENTES SERRA DO CACHIMBO & - & $\mathrm{X}$ \\
\hline 138 & RESEX MAE GRANDE DE CURUCA & - & $\mathrm{X}$ \\
\hline 139 & RESEX MARINHA ARAI-PEROBA & - & $\mathrm{X}$ \\
\hline 140 & RESEX MARINHA CAETE-TAPERACU & - & $\mathrm{X}$ \\
\hline 141 & RESEX MARINHA DE SOURE & - & $\mathrm{X}$ \\
\hline 142 & RESEX MARINHA TRACUATEUA & - & $\mathrm{X}$ \\
\hline 143 & FLONA DE ITAITUBA I & - & $\mathrm{X}$ \\
\hline 144 & FLONA DE ITAITUBA II & - & $\mathrm{X}$ \\
\hline 145 & FLONA DE MULATA & - & $\mathrm{X}$ \\
\hline 146 & APA DO TAPAJOS & - & $\mathrm{X}$ \\
\hline 147 & FLONA DO AMANA & - & $\mathrm{X}$ \\
\hline 148 & FLONA DO CREPORI & - & $\mathrm{X}$ \\
\hline 149 & FLONA DO JAMANXIM & - & $\mathrm{X}$ \\
\hline 150 & FLONA DO TRAIRÃO & - & $\mathrm{X}$ \\
\hline 151 & RESEX GURUPA-MELGACO & - & $\mathrm{X}$ \\
\hline 152 & FLONA DE CARAJAS & $\mathrm{X}$ & $\mathrm{X}$ \\
\hline 153 & FLONA DE SARACA-TAQUERA & $\mathrm{X}$ & $\mathrm{X}$ \\
\hline 154 & FLONA DE TAPAJOS & $\mathrm{X}$ & $\mathrm{X}$ \\
\hline 155 & RESEX CHOCOARE-MATO GROSSO & $\mathrm{X}$ & $X$ \\
\hline 156 & RESEX MARINHA DE GURUPI-PIRIA & $\mathrm{X}$ & $\mathrm{X}$ \\
\hline 157 & RESEX SÃO JOÃO DA PONTA & $\mathrm{X}$ & $\mathrm{X}$ \\
\hline 158 & RESEX TAPAJOS ARAPIUNS & $\mathrm{X}$ & $\mathrm{X}$ \\
\hline 159 & FLONA ALTAMIRA & $\mathrm{X}$ & $\mathrm{X}$ \\
\hline 160 & PARNA DO JAMANXIM & $\mathrm{X}$ & $\mathrm{X}$ \\
\hline
\end{tabular}




\begin{tabular}{|c|c|c|c|}
\hline & UNIDADE DE CONSERVAÇÃO & $\begin{array}{l}\text { BANCO DA } \\
\text { TESE }\end{array}$ & RAPPAM \\
\hline 161 & RDS ITATUPÃ-BAQUIA & - & $\mathrm{X}$ \\
\hline 162 & RESEX ARIOCA PRUANÃ & - & $\mathrm{X}$ \\
\hline 163 & RESEX IPAÚ-ANILZINHO & - & $\mathrm{X}$ \\
\hline 164 & RESEX MAPUA & - & $\mathrm{X}$ \\
\hline 165 & RESEX MARACANÃ & - & $\mathrm{X}$ \\
\hline 166 & PARNA DO RIO NOVO & - & $\mathrm{X}$ \\
\hline 167 & RESEX RENASCER & - & $\mathrm{X}$ \\
\hline 168 & RESEX RIO XINGU & - & $\mathrm{X}$ \\
\hline 169 & RESEX TERRA GRANDE PRACUUBA & - & $\mathrm{X}$ \\
\hline 170 & ESEC DO JARI & $\mathrm{X}$ & $\mathrm{X}$ \\
\hline 171 & ESEC DA TERRA DO MEIO & - & $\mathrm{X}$ \\
\hline 172 & PARNA DA SERRA DO PARDO & - & $\mathrm{X}$ \\
\hline 173 & RESEX RIOZINHO DO ANFRISIO & - & $\mathrm{X}$ \\
\hline 174 & RESEX VERDE PARA SEMPRE & - & $\mathrm{X}$ \\
\hline 175 & RESEX RIO IRIRI & - & $\mathrm{X}$ \\
\hline 176 & REBIO DO RIO TROMBETAS & $\mathrm{X}$ & $\mathrm{X}$ \\
\hline 177 & REBIO DO TAPIRAPE & $\mathrm{X}$ & $\mathrm{X}$ \\
\hline 178 & ARIE MANGUEZAIS DA FOZ DO RIO MAMANGUAPE & - & $\mathrm{X}$ \\
\hline 179 & REBIO GUARIBAS & - & $\mathrm{X}$ \\
\hline 180 & APA BARRA DO RIO MAMANGUAPE & $\bar{X}$ & $\mathrm{X}$ \\
\hline 181 & FLONA DA RESTINGA DE CABEDELO & $\mathrm{X}$ & $\mathrm{X}$ \\
\hline 182 & RESEX ACAÚ-GOIANA & $\mathrm{X}$ & $\mathrm{X}$ \\
\hline 183 & REBIO DE PEDRA TALHADA & - & $\mathrm{X}$ \\
\hline 184 & REBIO DE SERRA NEGRA & - & $\mathrm{X}$ \\
\hline 185 & PARNA DO CATIMBAU & - & $\mathrm{X}$ \\
\hline 186 & FLONA DE NEGREIROS & - & $\mathrm{X}$ \\
\hline 187 & APA DE FERNANDO DE NORONHA & $\mathrm{X}$ & $\mathrm{X}$ \\
\hline 188 & PARNA MARINHO DE FERNANDO DE NORONHA & $\mathrm{X}$ & $\mathrm{X}$ \\
\hline 189 & REBIO DE SALTINHO & $\mathrm{X}$ & $\mathrm{X}$ \\
\hline 190 & APA DELTA DO PARNAIBA & - & $\mathrm{X}$ \\
\hline 191 & APA SERRA DA IBIAPABA & - & $\mathrm{X}$ \\
\hline 192 & PARNA DA SERRA DA CAPIVARA & - & $\mathrm{X}$ \\
\hline 193 & PARNA SERRA DAS CONFUSÕES & - & $\mathrm{X}$ \\
\hline 194 & RESEX MARINHA DO DELTA DO PARNAIBA & - & $\mathrm{X}$ \\
\hline 195 & RESEX CHAPADA LIMPA & - & $\mathrm{X}$ \\
\hline 196 & ESEC DE URUCUI-UNA & $\mathrm{X}$ & $\mathrm{X}$ \\
\hline 197 & FLONA DE PALMARES & $\mathrm{X}$ & $\mathrm{X}$ \\
\hline 198 & PARNA DE SETE CIDADES & $\mathrm{X}$ & $\mathrm{X}$ \\
\hline 199 & APA DE GUARAQUECABA & - & $\mathrm{X}$ \\
\hline 200 & ESEC DE GUARAQUECABA & - & $\mathrm{X}$ \\
\hline 201 & FLONA DE ACUNGUI & - & $\mathrm{X}$ \\
\hline
\end{tabular}




\begin{tabular}{|c|c|c|c|}
\hline & UNIDADE DE CONSERVAÇÃO & $\begin{array}{l}\text { BANCO DA } \\
\text { TESE }\end{array}$ & RAPPAM \\
\hline 202 & PARNA DE ILHA GRANDE & - & $\mathrm{X}$ \\
\hline 203 & PARNA DE SAINT-HILAIRE/LANGE & - & $\mathrm{X}$ \\
\hline 204 & PARNA DO IGUACU & - & $\mathrm{X}$ \\
\hline 205 & REVIS DOS CAMPOS DE PALMAS & - & $\mathrm{X}$ \\
\hline 206 & REBIO DAS ARAUCARIAS & - & $\mathrm{X}$ \\
\hline 207 & FLONA DE IRATI & $\mathrm{X}$ & $\mathrm{X}$ \\
\hline 208 & PARNA DO SUPERAGUI & $\mathrm{X}$ & $\mathrm{X}$ \\
\hline 209 & REBIO DAS PEROBAS & $\mathrm{X}$ & $\mathrm{X}$ \\
\hline 210 & ESEC DE MATA PRETA & $\mathrm{X}$ & $\mathrm{X}$ \\
\hline 211 & PARNA DOS CAMPOS GERAIS & $\mathrm{X}$ & $\mathrm{X}$ \\
\hline 212 & FLONA do Assungui & $\mathrm{X}$ & - \\
\hline 213 & REBIO Bom Jesus & $\mathrm{X}$ & - \\
\hline 214 & APA DA BACIA DO RIO SÃO JOÃO - MICO LEÃO & - & $\mathrm{X}$ \\
\hline 215 & APA DE PETROPOLIS & - & $\mathrm{X}$ \\
\hline 216 & FLONA DE MARIO XAVIER & - & $\mathrm{X}$ \\
\hline 217 & PARNA DA SERRA DOS ORGÃOS & - & $\mathrm{X}$ \\
\hline 218 & PARNA DA TIJUCA & - & $\mathrm{X}$ \\
\hline 219 & REBIO DE POCO DAS ANTAS & - & $\mathrm{X}$ \\
\hline 220 & REBIO DO TINGUA & - & $\mathrm{X}$ \\
\hline 221 & RESEX MARINHA ARRAIAL DO CABO & - & $\mathrm{X}$ \\
\hline 222 & ARIE MATÃO DE COSMOPOLIS & - & $\mathrm{X}$ \\
\hline 223 & APA DE CAIRUCU & $\mathrm{X}$ & $\mathrm{X}$ \\
\hline 224 & APA DE GUAPI-MIRIM & $\mathrm{X}$ & $\mathrm{X}$ \\
\hline 225 & ARIE FLORESTA DA CICUTA & $\mathrm{X}$ & $\mathrm{X}$ \\
\hline 226 & ESEC DE TAMOIOS & $\mathrm{X}$ & $\mathrm{X}$ \\
\hline 227 & PARNA DA SERRA DA BOCAINA & $\mathrm{X}$ & $\mathrm{X}$ \\
\hline 228 & PARNA ITATIAIA & $\mathrm{X}$ & $\mathrm{X}$ \\
\hline 229 & PARNA RESTINGA DE JURUBATIBA & $\mathrm{X}$ & $\mathrm{X}$ \\
\hline 230 & REBIO UNIÃO & $\mathrm{X}$ & $\mathrm{X}$ \\
\hline 231 & ESEC DA GUANABARA & $\mathrm{X}$ & $\mathrm{X}$ \\
\hline 232 & FLONA DE ACU & - & $\mathrm{X}$ \\
\hline 233 & FLONA DE NISIA FLORESTA & - & $\mathrm{X}$ \\
\hline 234 & ESEC DO SERIDO & $\mathrm{X}$ & $\mathrm{X}$ \\
\hline 235 & REBIO ATOL DAS ROCAS & $\mathrm{X}$ & $\mathrm{X}$ \\
\hline 236 & FLONA DE BOM FUTURO & - & $\mathrm{X}$ \\
\hline 237 & FLONA DE JACUNDA & - & $\mathrm{X}$ \\
\hline 238 & FLONA DO JAMARI & - & $\mathrm{X}$ \\
\hline 239 & PARNA DE PACAAS NOVOS & - & $\mathrm{X}$ \\
\hline 240 & REBIO DO GUAPORE & - & $\mathrm{X}$ \\
\hline 241 & ESEC DE CUNIÃ & $\mathrm{X}$ & $\mathrm{X}$ \\
\hline 242 & RESEX LAGO DO CUNIÃ & $\mathrm{X}$ & $\mathrm{X}$ \\
\hline
\end{tabular}




\begin{tabular}{|c|c|c|c|}
\hline & UNIDADE DE CONSERVAÇÃO & $\begin{array}{l}\text { BANCO DA } \\
\text { TESE }\end{array}$ & RAPPAM \\
\hline 243 & PARNA DA SERRA DA CUTIA & - & $\mathrm{X}$ \\
\hline 244 & RESEX DO RIO CAUTARIO & $\mathrm{X}$ & $\mathrm{X}$ \\
\hline 245 & RESEX BARREIRO DAS ANTAS & $\mathrm{X}$ & $\mathrm{X}$ \\
\hline 246 & RESEX RIO OURO PRETO & - & $\mathrm{X}$ \\
\hline 247 & REBIO DO JARU & $\mathrm{X}$ & $\mathrm{X}$ \\
\hline 248 & FLONA DE ANAUA & - & $\mathrm{X}$ \\
\hline 249 & FLONA DE RORAIMA & - & $\mathrm{X}$ \\
\hline 250 & PARNA DO MONTE RORAIMA & - & $\mathrm{X}$ \\
\hline 251 & ESEC DE CARACARAI & $\mathrm{X}$ & $\mathrm{X}$ \\
\hline 252 & ESEC DE NIQUIA & $\mathrm{X}$ & $\mathrm{X}$ \\
\hline 253 & PARNA SERRA DA MOCIDADE & $\mathrm{X}$ & $\mathrm{X}$ \\
\hline 254 & ESEC DE MARACA & $\mathrm{X}$ & $\mathrm{X}$ \\
\hline 255 & PARNA VIRUA & $\mathrm{X}$ & $\mathrm{X}$ \\
\hline 256 & APA IBIRAPUITÃ & - & $\mathrm{X}$ \\
\hline 257 & PARNA DA LAGOA DO PEIXE & - & $\mathrm{X}$ \\
\hline 258 & REVIS ILHA DOS LOBOS & - & $\mathrm{X}$ \\
\hline 259 & ESEC DE ARACURI-ESMERALDA & $\mathrm{X}$ & $\mathrm{X}$ \\
\hline 260 & ESEC DO TAIM & $\mathrm{X}$ & $\mathrm{X}$ \\
\hline 261 & FLONA DE CANELA & $\mathrm{X}$ & $\mathrm{X}$ \\
\hline 262 & FLONA DE PASSO FUNDO & $\mathrm{X}$ & $\mathrm{X}$ \\
\hline 263 & FLONA DE SÃO FRANCISCO DE PAULA & $\mathrm{X}$ & $\mathrm{X}$ \\
\hline 264 & PARNA DA SERRA GERAL & $\mathrm{X}$ & $\mathrm{X}$ \\
\hline 265 & PARNA DE APARADOS DA SERRA & $\mathrm{X}$ & $\mathrm{X}$ \\
\hline 266 & APA ANHATOMIRIM & - & $\mathrm{X}$ \\
\hline 267 & APA DA BALEIA FRANCA & - & $\mathrm{X}$ \\
\hline 268 & ARIE SERRA DAS ABELHAS E RIO DA PRATA & - & - \\
\hline 269 & FLONA DE CACADOR & - & $\mathrm{X}$ \\
\hline 270 & PARNA DA SERRA DO ITAJAI & - & $\mathrm{X}$ \\
\hline 271 & RESEX MARINHA PIRAJUBAE & - & $\mathrm{X}$ \\
\hline 272 & PARNA DAS ARAUCARIAS & - & $\mathrm{X}$ \\
\hline 273 & ESEC DE CARIJOS & $\mathrm{X}$ & $\mathrm{X}$ \\
\hline 274 & FLONA DE CHAPECO & $\mathrm{X}$ & $\mathrm{X}$ \\
\hline 275 & FLONA DE IBIRAMA & $\mathrm{X}$ & $\mathrm{X}$ \\
\hline 276 & FLONA DE PIRAI DO SUL & $\mathrm{X}$ & $\mathrm{X}$ \\
\hline 277 & FLONA DE TRES BARRAS & $\mathrm{X}$ & $\mathrm{X}$ \\
\hline 278 & PARNA DE SÃO JOAQUIM & $\mathrm{X}$ & $\mathrm{X}$ \\
\hline 279 & REBIO MARINHA DO ARVOREDO & $\mathrm{X}$ & $\mathrm{X}$ \\
\hline 280 & PARNA MARINHO DAS ILHAS DOS CURRAIS & $\mathrm{X}$ & - \\
\hline 281 & FLONA DO IBURA & - & $\mathrm{X}$ \\
\hline 282 & PARNA DA SERRA DE ITABAIANA & - & $\mathrm{X}$ \\
\hline & REBIO DE SANTA ISABEL & $\mathrm{X}$ & $\mathrm{X}$ \\
\hline
\end{tabular}




\begin{tabular}{|c|c|c|c|}
\hline & UNIDADE DE CONSERVAÇÃO & $\begin{array}{l}\text { BANCO DA } \\
\text { TESE }\end{array}$ & RAPPAM \\
\hline 284 & APA BACIA DO PARAIBA DO SUL & - & $\mathrm{X}$ \\
\hline 285 & ARIE ILHA AMEIXAL & - & $\mathrm{X}$ \\
\hline 286 & FLONA DE CAPÃO BONITO & - & $\mathrm{X}$ \\
\hline 287 & FLONA DE LORENA & - & $\mathrm{X}$ \\
\hline 288 & ARIE MATA DE SANTA GENEBRA & - & $\mathrm{X}$ \\
\hline 289 & APA DE CANANEIA-IGUAPE-PERUIBE & $\mathrm{X}$ & $\mathrm{X}$ \\
\hline 290 & ESEC DE TUPINAMBAS & $\mathrm{X}$ & $\mathrm{X}$ \\
\hline 291 & ESEC DOS TUPINIQUINS & $\mathrm{X}$ & $\mathrm{X}$ \\
\hline 292 & ESEC MICO LEÃO PRETO & $\mathrm{X}$ & $\mathrm{X}$ \\
\hline 293 & FLONA DE IPANEMA & $\mathrm{X}$ & $\mathrm{X}$ \\
\hline 294 & RESEX MANDIRA & $\mathrm{X}$ & $\mathrm{X}$ \\
\hline 295 & $\begin{array}{l}\text { ARIE ILHAS QUEIMADA GRANDE E QUEIMADA } \\
\text { PEQUENA }\end{array}$ & $\mathrm{X}$ & $\mathrm{X}$ \\
\hline 296 & APA SERRA DA TABATINGA & - & $\mathrm{X}$ \\
\hline 297 & ESEC SERRA GERAL DO TOCANTINS & - & $\mathrm{X}$ \\
\hline 298 & PARNA DO ARAGUAIA & - & $\mathrm{X}$ \\
\hline 299 & RESEX EXTREMO NORTE DO TOCANTINS & - & $\mathrm{X}$ \\
\hline
\end{tabular}




\section{PESQUISA SOBRE O EFEITO DA PARTICIPAÇÃO SOCIAL NA GESTÃO DAS UNIDADES DE CONSERVAÇÃO BRASILEIRAS}

Esta é uma pesquisa acadêmica que, em linhas gerais, pretende aprofundar na relação entre participação social e a conservação da biodiversidade. Não há respostas certas ou erradas, fique à vontade para expressar o seu ponto de vista. Os nomes dos entrevistados não serão divulgados.

Pesquisadora: Danielle Calandino

Aluna de doutorado da Universidade de Brasília - UnB Centro de Desenvolvimento Sustentável - CDS

Orientador: Fernando Scardua

Em caso de dúvidas no preenchimento, entre em contato.dcalandino@ gmail.com Skype: dcalandino

\section{NOME DA UNIDADE}

Indique o nome completo da unidade, incluindo a categoria e o órgão gestor. Ex.: Reserva Extrativista Cazumbá-Iracema ICMBio

\section{DADOS DO ENTREVISTADO}

Nome do entrevistado

Telefone com DDD

E-mail

Cargo

É o chefe da unidade?

\section{INFORMAÇÕES GERAIS DA UNIDADE}

Resuma o contexto socioambiental e socioeconômico da unidade e seu entorno, com ênfase pressões e ameaças aos objetivos da unidade. Quais as atividades geradoras de renda, a relação da sociedade com meio ambiente e como isto impacta a unidade.

1. Qual a principal estratégia adotada pela UC para garantir a conservação de seus recursos naturais?

* Engajamento social refere-se aqui à participação ativa da comunidade na conservação da biodiversidade, enquanto educação ambiental é o investimento no aprendizado, sem que a a comunidade se envolva de forma ativa em atividades de conservação

$\begin{array}{lllll}\text { Incen } & \text { Com } & \text { Educ } & \text { Engaja } & \\ \text { tivos } & \text { ando } & \text { ação } & \text { mento } & \text { Outro } \\ \text { econ } & \text { e } & \text { ambi } & \text { social* } & \\ \text { ômic } & \text { contr } & \text { ental } & & \\ \text { os } & \text { ole } & & & \end{array}$

\begin{tabular}{|c|c|c|c|c|c|}
\hline $\begin{array}{l}\text { Principal estratégia da } \\
\text { UC }\end{array}$ & $C$ & 0 & $C$ & $C$ & $C$ \\
\hline $\begin{array}{l}\text { Estratégia adotada de } \\
\text { forma relevante, mas não } \\
\text { é a principal }\end{array}$ & $C$ & $C$ & $C$ & $C$ & $C$ \\
\hline $\begin{array}{l}\text { Estratégia adotada de } \\
\text { forma insipiente }\end{array}$ & $C$ & 0 & $C$ & 0 & 0 \\
\hline Estratégia não utilizada & 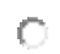 & $\mathrm{C}$ & $\mathrm{C}$ & $\mathrm{C}$ & $\mathrm{C}$ \\
\hline
\end{tabular}

2. Caso tenha optado por "outro" dentre as estratégias adotadas pela UC na questão anterior. Especifique.

FORMULÁRIO SOBRE PARTICIPAÇÃO SOCIAL 
3. Indique as instituições parceiras da UC.

4. Indique as instituições que representam um entrave ao alcance dos objetivos de conservação da biodiversidade ou uso sustentável dos recursos.

5. Como a comunidade do entorno percebe a unidade?

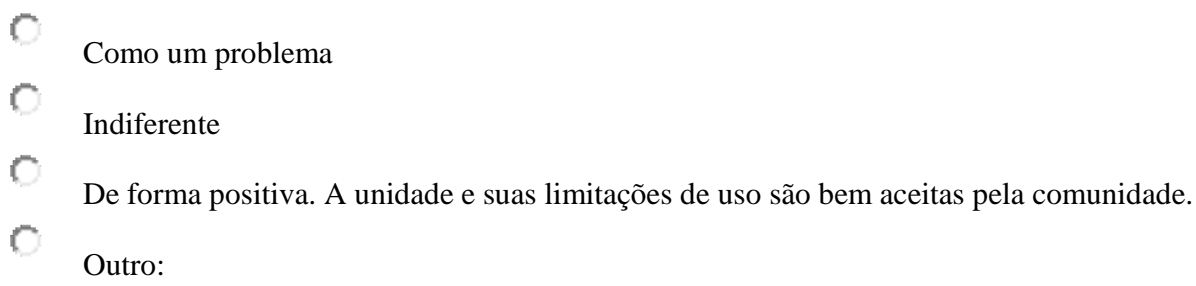

6. Como os gestores da unidade historicamente percebem as populações residentes e/ou do entorno da UC?

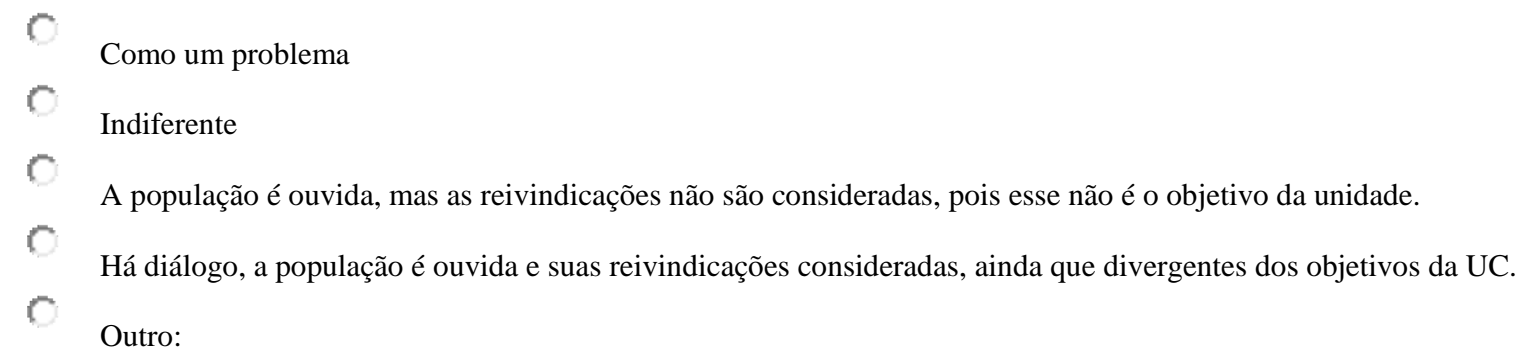

7. Quais os canais de participação mais utilizados pela sociedade na gestão da sua unidade?

Cite-os em ordem de acesso (do mais acessado para o menos acessado). Algumas possibilidades são: reuniões de conselho gestor, monitoramento, site, cartas, pesquisa, caderno de visitação, dentre outros. A lista não é exaustiva, fique à vontade para citar outras possibilidades.

8. Na sua percepção, qual a importância que a sociedade confere para a sua unidade de conservação? Exemplo: há uma importância significativa do ponto de vista cultural, espiritual, econômico, político ou alguma outra não mencionada?

9. A unidade é uma fonte de geração de renda para a comunidade do entorno? Se sim, especifique como e quanto aproximadamente ao ano.

10. Qual o estágio de amadurecimento do seu conselho gestor?

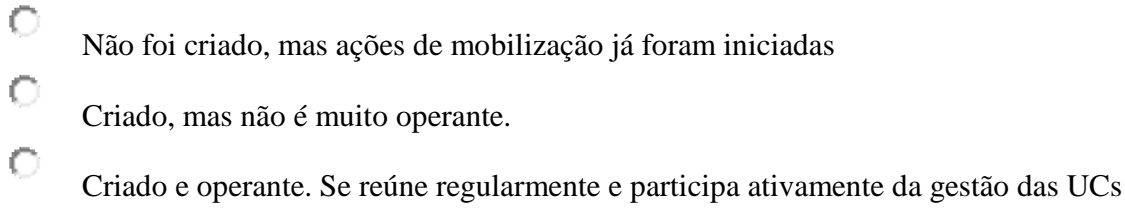

11. Qual a o ano de criação do conselho gestor da UC?

12. Quantos conselheiros compõem o conselho gestor de sua unidade?

13. Quais instituições estes conselheiros representam?

14. Que critérios foram utilizados para identificação de quais conselheiros deveriam compor o conselho da unidade?

15. O conselho gestor da UC tem participação ativa na gestão da UC? Ou seja, as questões relativas à gestão da unidade são debatidas neste espaço e levadas em consideração no momento de deliberar?

16. Quais instituições participam com maior frequência e mais ativamente as reuniões de conselho. Na sua opinião, o que as leva a participar mais das reuniões?

17. Há representantes dos setores/instituições que representam uma ameaça à unidade em seu conselho gestor?

18. De uma forma geral, no seu ponto de vista, os conselheiros são representantes legítimos das instituições que representam? Disserte sobre esta representação. 
Consideramos aqui "representantes legítimos" aqueles que atuam em nome da instituição e em detrimento das vontades pessoais, caso haja algum conflito entre estas. Fazem chegar os anseios e visões do grupo que representam e retornam ao grupo o que foi discutido e decidido nas reuniões de conselho.

19. Qual o principal entrave à participação da comunidade nas reuniões de conselho?

20. Qual o número médio de conselheiros em cada reunião?

21. Quais as instituições que mais frequentam as reuniões? Quais as ausências mais recorrentes?

22. Há algum ponto sobre participação social na gestão de sua unidade que não foi abordado por este formulário e você gostaria de acrescentar? Caso positivo, fique à vontade.

\section{DADOS SOBRE ATIVIDADES DE COMANDO E CONTROLE}

23. Quais ações de comando e controle sua unidade implementa e com qual frequência elas ocorrem?

24. Quantas ações de fiscalização foram realizadas em 2013 ?

25. Qual a média anual de ações de fiscalização na unidade nos últimos 5 anos (2009-2013)?

C. Não houve atividades de fiscalização nos últimos cinco anos

$C$ 1 a 3 ações de fiscalização ao ano

C 3 a 5 ações de fiscalização por ano

(C) Mais de 5 ações ao ano

(C) Desconheço esta informação 
ANEXO IV. METADADOS DO FORMULÁRIO DE PARTICIPAÇÃO SOCIAL.

\begin{tabular}{|c|c|}
\hline PERGUNTA & $\begin{array}{lll}\text { LEGENDA DAS } & \text { CATEGORIAS } & \text { DE } \\
\text { AGRUPAMENTO } & & \\
\end{array}$ \\
\hline \multirow{2}{*}{ Grupo da UC } & Proteção integral \\
\hline & Uso Sustentável \\
\hline \multirow{9}{*}{ Categoria } & Área de Proteção Ambiental \\
\hline & $2=\quad \begin{array}{ccc}\text { Área de } & \text { Relevante } & \text { Interesse } \\
\text { Ecológico } & & \end{array}$ \\
\hline & Estação Ecológica \\
\hline & Floresta Nacional \\
\hline & Parque Nacional \\
\hline & Refúgio de Vida Silvestre \\
\hline & Reserva Biológica \\
\hline & Reserva Extrativista \\
\hline & $\begin{array}{l}\text { Reserva de Desenvolvimento } \\
\text { Sustentável }\end{array}$ \\
\hline \multirow{7}{*}{ Bioma } & Amazônia \\
\hline & Caatinga \\
\hline & Cerrado \\
\hline & Marinho \\
\hline & Mata atlântica \\
\hline & Pampa \\
\hline & Pantanal \\
\hline Área da UC & Não se aplica / Variável contínua \\
\hline Qual o ano de criação da UC? & Não se aplica / Variável contínua \\
\hline \multirow{2}{*}{ A UC foi criada antes do SNUC?* } & $0=$ \\
\hline & $1=$ \\
\hline Qual o ano de criação do conselho gestor? & Não se aplica / Variável contínua \\
\hline \multirow[b]{4}{*}{ Qual o estágio de amadurecimento do conselho gestor? } & Não criado \\
\hline & $\begin{array}{l}\text { Não foi criado, mas ações de } \\
\text { mobilização já foram iniciadas }\end{array}$ \\
\hline & Criado, mas não é operante \\
\hline & $\begin{array}{l}\text { Criado e operante. Se reúne } \\
\text { regularmente e participa ativamente } \\
\text { da gestão das UCs }\end{array}$ \\
\hline \multirow{4}{*}{$\begin{array}{l}\text { Qual a principal estratégia da UC para garantir seus objetivos de } \\
\text { conservação? }\end{array}$} & $\begin{array}{l}\text { Comando e controle, fiscalização/ } \\
\text { cadastro socioeconomico de } \\
\text { moradores }\end{array}$ \\
\hline & Educação ambiental \\
\hline & Engajamento social \\
\hline & Incentivos econômicos \\
\hline
\end{tabular}




\begin{tabular}{|c|c|c|}
\hline & $5=$ & Outros \\
\hline \multirow{2}{*}{ A UC é fonte de geração de renda? } & $0=$ & Não \\
\hline & $1=$ & Sim \\
\hline \multirow{24}{*}{$\begin{array}{l}\text { Qual o canal de participação entre comunidades e UC mais acessado } \\
\text { pela sociedade? }\end{array}$} & $0=$ & Nenhum \\
\hline & $1=$ & $\begin{array}{l}\text { Acesso direto aos gestores da UC } \\
\text { (pessoalmente - na unidade } \\
\text { administrativa, por telefone ou e- } \\
\text { mail) }\end{array}$ \\
\hline & $2=$ & Ações de manejo \\
\hline & $3=$ & Atividades de monitoramento \\
\hline & $4=$ & Conselho gestor \\
\hline & $5=$ & Execução de projetos na UC \\
\hline & $6=$ & $\begin{array}{l}\text { Outras reuniões de interesse da UC } \\
\text { (conselhos municipais de meio } \\
\text { ambiente, reuniões setoriais, comitês } \\
\text { de bacia, etc) }\end{array}$ \\
\hline & $7=$ & $\begin{array}{l}\text { Oficinas voltadas para } \\
\text { construção/aperfeiçoamento dos } \\
\text { instrumentos de gestão (planos de } \\
\text { manejo, planos de uso público) }\end{array}$ \\
\hline & $8=$ & $\begin{array}{l}\text { Participação no quadro de brigadistas } \\
\text { da unidade }\end{array}$ \\
\hline & $9=$ & Pesquisa científica \\
\hline & $10=$ & Redes sociais \\
\hline & $11=$ & Reuniões nas comunidades \\
\hline & $12=$ & Televisão \\
\hline & $13=$ & Visitação \\
\hline & $14=$ & Caderno de visitação \\
\hline & $15=$ & Atividades de educação ambiental \\
\hline & $16=$ & Palestras, cursos ou capacitações \\
\hline & $17=$ & Rádio \\
\hline & $18=$ & Site da unidade \\
\hline & $19=$ & Canal de denúncias \\
\hline & $20=$ & Gestão participtiva da UC com ONG \\
\hline & $21=$ & Mutirões \\
\hline & $22=$ & Prestação de serviço de turismo \\
\hline & $23=$ & Não informado \\
\hline \multirow{4}{*}{$\begin{array}{l}\text { Qual a diversidade de canais de participação social utilizados pela } \\
\text { UC?* }\end{array}$} & $0=$ & Nenhum \\
\hline & $1=$ & 1 \\
\hline & $2=$ & 2 \\
\hline & $3=$ & 3 ou mais \\
\hline Idade do conselho gestor?* & \multicolumn{2}{|c|}{ Não se aplica / Variável contínua } \\
\hline Qual o número de conselheiros que compõem o conselho da UC? & \multicolumn{2}{|c|}{ Não se aplica / Variável contínua } \\
\hline
\end{tabular}




\begin{tabular}{|c|c|c|}
\hline Qual o número de conselheiros por reunião? & \multicolumn{2}{|c|}{ Não se aplica / Variável contínua } \\
\hline Qual o percentual de participação de conselheiros por reunião?* & \multicolumn{2}{|c|}{ Não se aplica / Variável contínua } \\
\hline \multirow{5}{*}{$\begin{array}{l}\text { Qual o principal o principal entrave a participação da comunidade nas } \\
\text { reuniões do conselho gestor da UC? }\end{array}$} & $0=$ & Nenhum \\
\hline & $1=$ & Político \\
\hline & $2=$ & Logístico \\
\hline & $3=$ & Financeiro \\
\hline & $4=$ & Outros \\
\hline \multirow{3}{*}{$\begin{array}{l}\text { Há representantes dos setores ou instituicoes no conselho gestor que } \\
\text { representam uma ameaça a unidade? }\end{array}$} & $0=$ & Não \\
\hline & $1=$ & Sim \\
\hline & Nulo - & Variado \\
\hline Quantas ações de fiscalização foram realizadas no último ano (2013)? & Não se aplica / & ável contínua \\
\hline \multirow{3}{*}{ Qual a média anual de ações de fiscalização nos últimos cinco anos? } & $1=$ & 1 a 3 \\
\hline & $2=$ & 3 a 5 \\
\hline & $3=$ & Mais de 5 \\
\hline \multirow{2}{*}{ Unidade apoiada pelo ARPA? } & $0=$ & Não \\
\hline & $1=$ & Sim \\
\hline \multirow{3}{*}{$\begin{array}{l}\text { Os conselheiros são representantes legítimos das instituições que } \\
\text { representam? }\end{array}$} & $0=$ & Não ou tendendo a não \\
\hline & $1=$ & Sim ou tendendo a sim \\
\hline & $2=$ & Variado \\
\hline \multirow{4}{*}{ Qual a percepção da comunidade do entorno em relação a UC? } & $0=$ & De forma negativa \\
\hline & $1=$ & Indiferente \\
\hline & $2=$ & Tendendo ao positivo ou positivo \\
\hline & $3=$ & De forma variada \\
\hline \multirow{5}{*}{$\begin{array}{l}\text { Percepção dos gestores da UC em relação às populações residentes e } \\
\text { do entorno }\end{array}$} & $0=$ & Como um problema \\
\hline & $1=$ & Indiferente \\
\hline & $2=$ & $\begin{array}{l}\text { A população é ouvida, mas as } \\
\text { reivindicações não são consideradas, } \\
\text { pois esse não é o objetivo da unidade. }\end{array}$ \\
\hline & $3=$ & $\begin{array}{l}\text { Há diálogo, a população é ouvida e } \\
\text { suas reivindicações consideradas, } \\
\text { ainda que divergentes dos objetivos } \\
\text { da UC }\end{array}$ \\
\hline & Nulo - & $\begin{array}{l}\text { variado. Seja por muitos gestores } \\
\text { diferentes ao longo da história ou } \\
\text { outros fatores como divergências na } \\
\text { mesma gestão }\end{array}$ \\
\hline
\end{tabular}


ANEXO V. DADOS CONSOLIDADOS PROVENIENTES DO FORMULÁRIO ELETRÔNICO.

\begin{tabular}{|c|c|c|c|c|c|c|c|c|c|c|c|c|c|c|c|c|c|c|c|c|c|c|}
\hline c2 & c3 & c4 & c7 & c8 & c9 & e2 & e3 & e5 & e9 & e10 & e12 & e22 & e23 & e24 & e29 & e31 & e37 & e48 & d11 & d17 & d18 & $\mathrm{d} 22$ \\
\hline 2 & 1 & 4 & 1992 & NA & 2008 & NA & NA & NA & NA & NA & NA & NA & NA & NA & NA & NA & NA & NA & NA & NA & NA & NA \\
\hline 2 & 1 & 3 & 1989 & NA & 2004 & NA & NA & NA & NA & NA & NA & NA & NA & NA & $\mathrm{NA}$ & NA & NA & NA & NA & NA & NA & NA \\
\hline 2 & 1 & 3 & 1983 & NA & 2014 & NA & NA & NA & NA & $\mathrm{NA}$ & NA & NA & NA & NA & $\mathrm{NA}$ & NA & NA & NA & NA & NA & NA & NA \\
\hline 2 & 1 & 5 & 2002 & NA & 2005 & NA & NA & NA & NA & NA & NA & NA & NA & NA & NA & NA & NA & NA & NA & NA & NA & NA \\
\hline 2 & 1 & 4 & 2000 & NA & 2006 & NA & NA & NA & NA & NA & NA & NA & NA & NA & NA & NA & NA & NA & NA & NA & NA & NA \\
\hline 2 & 1 & 5 & 1993 & 1 & 2005 & 2 & 10 & 12 & 1 & 3 & 26 & 3 & 1 & NA & 10 & NA & 13 & 2 & 2 & 58 & 15 & 1 \\
\hline 2 & 1 & 2 & 1997 & 1 & 2008 & 3 & NA & 11 & 3 & NA & 33 & 5 & 1 & NA & 8 & NA & NA & 1 & 3 & NA & NA & 1 \\
\hline 2 & 1 & 4 & 1997 & 1 & 2011 & 3 & NA & 14 & 2 & 3 & 27 & 3 & 1 & 1 & 4 & NA & 12 & 2 & 3 & 70 & 19 & 1 \\
\hline 2 & 1 & 5 & 1982 & NA & 2001 & NA & NA & NA & NA & NA & NA & NA & NA & NA & NA & NA & NA & NA & NA & NA & NA & NA \\
\hline 2 & 1 & 5 & 1985 & NA & 2004 & NA & NA & NA & NA & NA & NA & NA & NA & NA & $\mathrm{NA}$ & NA & NA & NA & NA & NA & NA & NA \\
\hline 2 & 1 & 3 & 1990 & NA & NA & NA & NA & NA & NA & NA & NA & NA & NA & NA & $\mathrm{NA}$ & NA & NA & NA & NA & NA & NA & NA \\
\hline 2 & 1 & 5 & 1983 & 1 & 2001 & 3 & NA & 18 & 1 & 3 & 23 & 5 & 1 & 1 & 10 & 2 & 3 & 2 & 3 & 57 & 13 & 0 \\
\hline 2 & 1 & 5 & 1984 & NA & 2002 & NA & NA & NA & NA & NA & 15 & 6 & 0 & NA & 0 & NA & NA & NA & NA & NA & NA & NA \\
\hline 2 & 1 & 4 & 1986 & 1 & 2001 & 2 & NA & 15 & NA & NA & 24 & 6 & NA & NA & NA & NA & NA & 1 & 3 & NA & NA & NA \\
\hline 2 & 1 & 5 & 1984 & NA & 2001 & 2 & NA & 17 & 1 & 3 & 19 & 2 & 1 & 1 & 6 & 1 & NA & 1 & 3 & 184 & 35 & 0 \\
\hline 2 & 1 & 5 & 1985 & NA & 2002 & NA & NA & NA & NA & NA & NA & NA & NA & NA & NA & NA & NA & NA & NA & NA & NA & NA \\
\hline 2 & 1 & 5 & 1983 & NA & 2003 & NA & NA & NA & NA & NA & NA & NA & NA & NA & NA & NA & NA & NA & NA & NA & NA & NA \\
\hline 2 & 1 & 3 & 1996 & NA & 2007 & NA & NA & NA & NA & NA & NA & NA & NA & NA & NA & NA & NA & NA & NA & NA & NA & NA \\
\hline 2 & 1 & 3 & 1996 & 1 & 2005 & 2 & NA & 9 & 1 & 3 & 24 & 1 & 0 & 1 & 5 & NA & NA & 1 & 3 & 67 & 16 & 1 \\
\hline 2 & 1 & 6 & 1992 & NA & 2008 & NA & NA & NA & NA & NA & NA & NA & NA & NA & $\mathrm{NA}$ & NA & NA & NA & NA & NA & NA & NA \\
\hline 2 & 1 & 1 & 1989 & NA & 2014 & NA & NA & NA & NA & NA & NA & NA & NA & NA & $\mathrm{NA}$ & NA & NA & NA & NA & NA & NA & NA \\
\hline 2 & 1 & 3 & 2002 & 0 & 2003 & 1 & NA & 1 & 1 & 2 & 32 & 5 & 1 & 0 & 10 & 0 & 30 & 1 & 3 & 50 & 16 & 0 \\
\hline 2 & 1 & 3 & 1998 & NA & 2007 & NA & NA & NA & NA & NA & NA & NA & NA & NA & NA & NA & NA & NA & NA & NA & NA & NA \\
\hline 2 & 1 & 5 & 1997 & NA & 2009 & NA & NA & NA & NA & NA & NA & NA & NA & NA & NA & NA & NA & NA & NA & NA & NA & NA \\
\hline
\end{tabular}




\begin{tabular}{|c|c|c|c|c|c|c|c|c|c|c|c|c|c|c|c|c|c|c|c|c|c|c|}
\hline 2 & 1 & 3 & 1990 & NA & 2004 & NA & NA & NA & NA & NA & NA & NA & NA & NA & NA & NA & NA & NA & NA & NA & NA & NA \\
\hline 2 & 1 & 3 & 2001 & 0 & 2006 & 2 & NA & NA & NA & 3 & NA & 1 & $\mathrm{NA}$ & NA & NA & 1 & 8 & 2 & 1 & NA & $\mathrm{NA}$ & NA \\
\hline 2 & 1 & 3 & 1996 & NA & 2012 & $\mathrm{NA}$ & NA & NA & NA & NA & NA & NA & $\mathrm{NA}$ & NA & NA & NA & $\mathrm{NA}$ & NA & NA & NA & $\mathrm{NA}$ & NA \\
\hline 2 & 2 & 5 & 1985 & 1 & 2007 & 3 & NA & 22 & NA & NA & 21 & 6 & NA & 0 & NA & 1 & NA & 1 & 3 & 62 & 13 & $\mathrm{NA}$ \\
\hline 2 & 2 & 5 & 1984 & NA & NA & NA & NA & NA & NA & NA & NA & NA & NA & NA & NA & NA & NA & NA & NA & NA & NA & $\mathrm{NA}$ \\
\hline 2 & 2 & 4 & 1985 & 1 & 2012 & 1 & NA & 27 & NA & 3 & 25 & 2 & 0 & 0 & 0 & 1 & 18 & 1 & 3 & 60 & 15 & 1 \\
\hline 2 & 2 & 1 & 1985 & NA & NA & NA & NA & NA & NA & NA & NA & NA & NA & NA & NA & NA & NA & NA & NA & NA & NA & NA \\
\hline 2 & 2 & 3 & 1985 & NA & 2014 & NA & $\mathrm{NA}$ & NA & NA & NA & NA & NA & NA & NA & NA & NA & NA & $\mathrm{NA}$ & NA & NA & NA & NA \\
\hline 2 & 2 & 3 & 1985 & NA & 2012 & NA & NA & NA & NA & NA & NA & NA & NA & NA & NA & NA & NA & NA & NA & NA & NA & NA \\
\hline 2 & 2 & 1 & 1985 & NA & NA & NA & NA & NA & NA & NA & NA & NA & NA & NA & NA & NA & NA & NA & NA & NA & NA & NA \\
\hline 2 & 2 & 1 & 1999 & NA & NA & NA & NA & NA & NA & NA & NA & NA & NA & NA & NA & NA & NA & NA & NA & NA & NA & NA \\
\hline 2 & 2 & 5 & 1990 & $\mathrm{NA}$ & NA & NA & $\mathrm{NA}$ & NA & NA & NA & NA & NA & NA & NA & NA & NA & NA & NA & NA & NA & NA & NA \\
\hline 1 & 3 & 1 & 2005 & NA & 2012 & $\mathrm{NA}$ & NA & NA & NA & NA & NA & NA & $\mathrm{NA}$ & NA & NA & NA & $\mathrm{NA}$ & NA & NA & NA & $\mathrm{NA}$ & NA \\
\hline 1 & 3 & 1 & 1981 & 1 & 2006 & 3 & 3 & 25 & 2 & 3 & 24 & 4 & 0 & 1 & 9 & 2 & 60 & 2 & 3 & 63 & 15 & 1 \\
\hline 1 & 3 & 5 & 1981 & 1 & NA & 2 & NA & NA & NA & 3 & NA & 2 & $\mathrm{NA}$ & 0 & NA & NA & NA & 2 & 1 & NA & NA & NA \\
\hline 1 & 3 & 1 & 1982 & 1 & NA & 1 & NA & NA & NA & 3 & NA & 1 & 0 & 0 & NA & 2 & NA & 0 & 1 & NA & NA & NA \\
\hline 1 & 3 & 5 & 1987 & 1 & 2001 & 3 & NA & 14 & NA & 3 & 21 & 1 & 1 & 1 & NA & 1 & 50 & 2 & 2 & NA & NA & 1 \\
\hline 1 & 3 & 1 & 2001 & 0 & 2006 & 1 & NA & 5 & 2 & 3 & 20 & 1 & 1 & 0 & 4 & 2 & 18 & 1 & 3 & 100 & 20 & 1 \\
\hline 1 & 3 & 4 & 1982 & NA & 2012 & NA & NA & NA & NA & NA & NA & NA & NA & NA & NA & NA & NA & NA & NA & NA & NA & NA \\
\hline 1 & 3 & 3 & 1981 & NA & 2011 & NA & NA & NA & NA & NA & NA & NA & NA & NA & NA & NA & NA & NA & NA & NA & NA & NA \\
\hline 1 & 3 & 1 & 1983 & NA & 2011 & NA & NA & NA & NA & NA & NA & NA & NA & NA & NA & NA & NA & NA & NA & NA & NA & NA \\
\hline 1 & 3 & 1 & 1981 & 1 & 2009 & 2 & 2 & 28 & 2 & 3 & 24 & 1 & 0 & 1 & 9 & NA & 3 & 2 & 3 & 71 & 17 & 1 \\
\hline 1 & 3 & 1 & 1981 & 1 & 2003 & 1 & NA & 22 & 4 & 3 & 24 & 5 & 1 & 0 & 12 & 2 & NA & 1 & 3 & 63 & 15 & 0 \\
\hline 1 & 3 & 5 & 2001 & NA & 2002 & $\mathrm{NA}$ & NA & NA & NA & NA & NA & NA & NA & NA & NA & NA & NA & NA & NA & NA & NA & $\mathrm{NA}$ \\
\hline 1 & 3 & 1 & 1985 & 1 & 2010 & 1 & 3 & 25 & NA & 3 & 18 & 5 & NA & 1 & NA & 1 & 6 & 1 & 3 & NA & NA & NA \\
\hline
\end{tabular}




\begin{tabular}{|c|c|c|c|c|c|c|c|c|c|c|c|c|c|c|c|c|c|c|c|c|c|c|}
\hline 1 & 3 & 3 & 1987 & 1 & 2005 & 3 & NA & 18 & NA & 3 & 12 & 2 & 0 & 1 & 0 & 2 & 78 & 1 & 3 & 75 & 9 & 1 \\
\hline 1 & 3 & 7 & 1981 & 1 & 2004 & 1 & NA & 23 & NA & 3 & 18 & 1 & 0 & 1 & NA & 1 & 23 & 1 & 3 & 50 & 9 & 1 \\
\hline 1 & 3 & 4 & 1990 & 1 & 2002 & 1 & NA & 12 & 1 & NA & 28 & 5 & 0 & 0 & 10 & NA & NA & 1 & 3 & 54 & 15 & NA \\
\hline 1 & 3 & 4 & 1987 & 1 & 2005 & 3 & NA & 18 & NA & 3 & 24 & 1 & 1 & 0 & 0 & 1 & 88 & 1 & 3 & 67 & 16 & 1 \\
\hline 1 & 3 & 3 & 1981 & 1 & NA & 2 & NA & NA & NA & 3 & NA & 2 & NA & 0 & NA & 1 & NA & 2 & 1 & NA & NA & NA \\
\hline 1 & 3 & 2 & 2001 & NA & NA & NA & NA & NA & NA & NA & NA & NA & NA & NA & NA & NA & NA & NA & NA & NA & NA & NA \\
\hline 1 & 3 & 1 & 1982 & 1 & 2014 & 2 & 1 & 32 & NA & 2 & 23 & 3 & 1 & 0 & NA & 2 & 0 & 1 & 3 & 87 & 20 & 1 \\
\hline 1 & 3 & 1 & 1981 & NA & 2008 & NA & NA & NA & NA & NA & NA & NA & NA & NA & NA & NA & NA & NA & NA & NA & NA & NA \\
\hline 1 & 3 & 2 & 1982 & 1 & 2006 & 1 & NA & 24 & NA & 3 & 20 & 2 & NA & NA & NA & 1 & 4 & 1 & 3 & NA & NA & NA \\
\hline 1 & 3 & 6 & 1986 & 1 & 2003 & 3 & NA & 17 & 1 & 3 & 26 & 3 & 0 & 1 & 2 & 1 & 15 & 1 & 3 & 96 & 25 & NA \\
\hline 1 & 3 & 4 & 1986 & 1 & 2012 & 2 & NA & 26 & 2 & 3 & 38 & 5 & 0 & 1 & 4 & 1 & 16 & 1 & 3 & 53 & 20 & 1 \\
\hline 1 & 3 & 1 & 2001 & 0 & 2009 & 1 & 1 & 8 & 2 & 2 & 15 & 1 & 1 & 0 & 9 & 0 & 4 & 1 & 2 & 60 & 9 & 0 \\
\hline 1 & 3 & 5 & 2002 & 0 & 2012 & 2 & 1 & 10 & 2 & 3 & 29 & 5 & 0 & 1 & 4 & NA & 2 & 2 & 2 & 52 & 15 & 0 \\
\hline 1 & 3 & 2 & 1984 & NA & 2014 & NA & NA & NA & NA & NA & NA & NA & NA & NA & NA & NA & NA & NA & NA & NA & NA & NA \\
\hline 1 & 3 & 3 & 1982 & 1 & 2011 & 2 & NA & 29 & 1 & 2 & 22 & 5 & 0 & 0 & 2 & 2 & 4 & 2 & 2 & 59 & 13 & 1 \\
\hline 1 & 3 & 3 & 2001 & NA & 2012 & NA & NA & NA & NA & NA & NA & NA & NA & NA & NA & NA & NA & NA & NA & NA & NA & NA \\
\hline 2 & 4 & 5 & 1968 & NA & 2010 & NA & NA & NA & NA & NA & NA & NA & NA & NA & NA & NA & NA & NA & NA & NA & NA & NA \\
\hline 2 & 4 & 5 & 1968 & NA & 2014 & NA & NA & NA & NA & NA & NA & NA & NA & NA & NA & NA & NA & NA & NA & NA & NA & NA \\
\hline 2 & 4 & 5 & 1968 & NA & 2009 & NA & NA & NA & NA & NA & NA & NA & NA & NA & NA & NA & NA & NA & NA & NA & NA & NA \\
\hline 2 & 4 & 5 & 1968 & 1 & 2004 & 3 & 1 & 36 & 4 & 0 & 23 & 2 & 1 & 0 & 12 & NA & 1 & 2 & 2 & 52 & 12 & 1 \\
\hline 2 & 4 & 2 & 1999 & NA & 2005 & NA & NA & NA & NA & NA & NA & NA & NA & NA & NA & NA & NA & NA & NA & NA & NA & NA \\
\hline 2 & 4 & 2 & 2001 & NA & 2008 & NA & NA & NA & NA & NA & NA & NA & NA & NA & NA & NA & NA & NA & NA & NA & NA & NA \\
\hline 2 & 4 & 1 & 1998 & 1 & 2011 & 1 & 1 & 13 & NA & 3 & 21 & 1 & 1 & 0 & NA & 2 & 1 & 1 & 2 & 71 & 15 & NA \\
\hline 2 & 4 & 1 & 2005 & NA & 2006 & NA & NA & NA & NA & NA & NA & NA & NA & NA & NA & NA & NA & NA & NA & NA & NA & NA \\
\hline 2 & 4 & 1 & 2002 & NA & 2010 & NA & NA & NA & NA & NA & NA & NA & NA & NA & NA & NA & NA & NA & NA & NA & NA & NA \\
\hline 2 & 4 & 3 & 1999 & NA & 2001 & NA & NA & NA & NA & NA & NA & NA & NA & NA & NA & NA & NA & NA & NA & NA & NA & NA \\
\hline 2 & 4 & 5 & 1968 & 1 & 2004 & 2 & NA & 36 & 4 & 2 & 24 & 2 & 0 & 1 & 12 & 0 & 36 & 1 & 3 & 50 & 12 & 1 \\
\hline
\end{tabular}




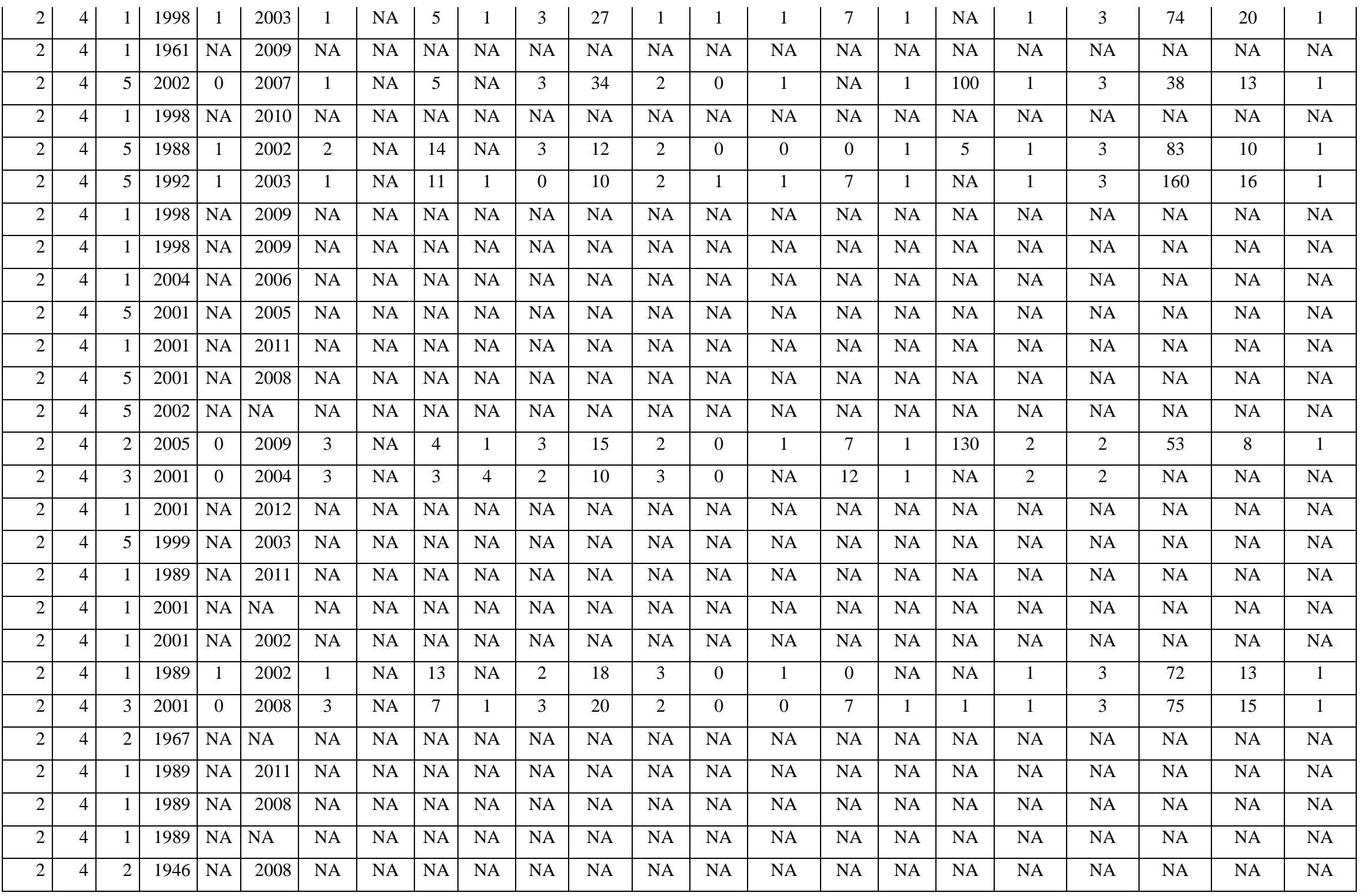




\begin{tabular}{|c|c|c|c|c|c|c|c|c|c|c|c|c|c|c|c|c|c|c|c|c|c|c|}
\hline 2 & 4 & 1 & 1988 & NA & 2014 & NA & NA & NA & NA & NA & NA & NA & NA & NA & NA & NA & NA & NA & NA & NA & NA & NA \\
\hline 2 & 4 & 1 & 1998 & $\mathrm{NA}$ & NA & NA & $\mathrm{NA}$ & $\mathrm{NA}$ & NA & NA & NA & NA & $\mathrm{NA}$ & NA & NA & NA & NA & NA & NA & $\mathrm{NA}$ & NA & NA \\
\hline 2 & 4 & 1 & 1984 & NA & 2003 & NA & $\mathrm{NA}$ & NA & NA & NA & NA & NA & NA & NA & NA & NA & NA & NA & NA & NA & NA & NA \\
\hline 2 & 4 & 1 & 2002 & NA & 2011 & NA & $\mathrm{NA}$ & NA & NA & NA & NA & NA & $\mathrm{NA}$ & NA & NA & NA & NA & NA & NA & NA & NA & NA \\
\hline 2 & 4 & 1 & 1988 & NA & 2002 & NA & NA & NA & NA & NA & NA & NA & NA & NA & NA & NA & NA & NA & NA & NA & NA & NA \\
\hline 2 & 4 & 1 & 1988 & NA & 2010 & NA & NA & NA & NA & NA & NA & NA & NA & NA & NA & NA & NA & NA & NA & NA & NA & NA \\
\hline 2 & 4 & 5 & 1990 & 1 & NA & 1 & NA & NA & NA & 3 & NA & 4 & NA & 1 & NA & 1 & 4 & 1 & 1 & NA & NA & NA \\
\hline 2 & 4 & 1 & 1974 & 1 & 2001 & 3 & NA & 27 & 2 & 2 & 27 & 5 & 0 & 0 & 9 & 2 & 56 & 2 & 3 & 85 & 23 & 1 \\
\hline 2 & 4 & 1 & 1989 & NA & 2005 & NA & NA & NA & NA & NA & NA & NA & NA & NA & NA & NA & NA & NA & NA & NA & NA & NA \\
\hline 2 & 4 & 5 & 1968 & 1 & 2002 & 1 & 1 & 34 & NA & 3 & 23 & 2 & 0 & NA & 0 & 0 & NA & 1 & 2 & 52 & 12 & 0 \\
\hline 2 & 4 & 1 & 1989 & NA & 2010 & NA & NA & NA & NA & NA & NA & NA & NA & NA & NA & NA & NA & NA & NA & NA & NA & NA \\
\hline 2 & 4 & 5 & 1986 & NA & 2013 & NA & NA & NA & NA & NA & NA & NA & NA & NA & NA & NA & NA & NA & NA & NA & NA & NA \\
\hline 2 & 4 & 3 & 2003 & NA & NA & NA & NA & NA & NA & NA & NA & NA & NA & NA & NA & NA & NA & NA & NA & NA & NA & NA \\
\hline 2 & 4 & 5 & 1968 & $\mathrm{NA}$ & 2003 & NA & NA & $\mathrm{NA}$ & NA & $\mathrm{NA}$ & NA & NA & NA & NA & NA & NA & NA & NA & NA & NA & NA & NA \\
\hline 2 & 4 & 5 & 2004 & 0 & 2011 & 1 & NA & 7 & 1 & 1 & 21 & 1 & NA & 0 & 5 & 0 & 110 & 1 & 3 & 57 & 12 & 1 \\
\hline 2 & 4 & 5 & 2004 & 0 & 2009 & 1 & NA & 5 & 1 & 2 & 16 & 2 & 1 & 0 & 2 & 2 & NA & 1 & 3 & 63 & 10 & 1 \\
\hline 2 & 4 & 6 & 1968 & 1 & 2003 & 3 & NA & 35 & NA & NA & 16 & 6 & NA & NA & NA & NA & NA & 2 & 3 & NA & NA & NA \\
\hline 2 & 4 & 5 & 1968 & 1 & 2005 & 2 & NA & 37 & NA & 2 & 23 & 5 & 0 & 1 & 0 & 1 & 40 & 1 & 3 & 100 & 23 & 1 \\
\hline 1 & 5 & 3 & 1999 & NA & 2004 & NA & NA & NA & NA & NA & NA & NA & NA & NA & NA & NA & NA & NA & NA & NA & NA & NA \\
\hline 1 & 5 & 1 & 1974 & NA & 2004 & NA & NA & NA & NA & NA & NA & NA & NA & NA & NA & NA & NA & NA & NA & $\mathrm{NA}$ & NA & NA \\
\hline 1 & 5 & 2 & 1985 & 1 & 2001 & 2 & 1 & 16 & 2 & 3 & 40 & 3 & 1 & 1 & 9 & 2 & 2 & 1 & 3 & 50 & 20 & 1 \\
\hline 1 & 5 & 3 & 1989 & 1 & 2008 & 2 & NA & 19 & NA & NA & 21 & 6 & NA & NA & NA & NA & NA & 1 & 3 & NA & NA & NA \\
\hline 1 & 5 & 3 & 1961 & NA & 2004 & NA & NA & NA & NA & NA & NA & NA & NA & NA & NA & NA & NA & NA & NA & NA & NA & NA \\
\hline 1 & 5 & 6 & 1986 & NA & 2006 & NA & $\mathrm{NA}$ & NA & NA & NA & NA & NA & NA & NA & NA & NA & NA & NA & NA & NA & NA & NA \\
\hline 1 & 5 & 4 & 1998 & 1 & 2004 & 1 & NA & 6 & NA & 3 & 36 & 2 & 0 & 1 & 0 & NA & 48 & 1 & 3 & 56 & 20 & 1 \\
\hline 1 & 5 & 5 & 1971 & 1 & 2010 & 3 & NA & 39 & NA & 0 & 34 & 1 & 1 & 1 & 5 & NA & 12 & 2 & 2 & 59 & 20 & NA \\
\hline
\end{tabular}




\begin{tabular}{|c|c|c|c|c|c|c|c|c|c|c|c|c|c|c|c|c|c|c|c|c|c|c|}
\hline 1 & 5 & 3 & 2000 & 0 & 2010 & 2 & 1 & 10 & 1 & 3 & 28 & 2 & 1 & 1 & 5 & 0 & 3 & 2 & 2 & 43 & 12 & 0 \\
\hline 1 & 5 & 3 & 1972 & 1 & 2004 & 3 & NA & 32 & 1 & 2 & 18 & 4 & 1 & 1 & 5 & 2 & 90 & 2 & 3 & 56 & 10 & 1 \\
\hline 1 & 5 & 2 & 1979 & NA & 2010 & NA & NA & NA & NA & NA & NA & NA & NA & NA & NA & NA & NA & NA & NA & NA & NA & NA \\
\hline 1 & 5 & 2 & 1998 & NA & 2010 & NA & NA & NA & $\mathrm{NA}$ & $\mathrm{NA}$ & NA & NA & NA & $\mathrm{NA}$ & $\mathrm{NA}$ & NA & NA & NA & NA & NA & NA & NA \\
\hline 1 & 5 & 5 & 2005 & NA & NA & NA & NA & NA & NA & NA & NA & NA & NA & NA & NA & NA & NA & NA & NA & NA & NA & NA \\
\hline 1 & 5 & 3 & 1984 & NA & 2004 & NA & NA & NA & NA & NA & NA & NA & NA & NA & NA & NA & NA & NA & NA & NA & NA & NA \\
\hline 1 & 5 & 1 & 1989 & 1 & 2002 & 3 & 3 & 13 & 2 & 3 & 33 & 3 & 0 & 1 & 9 & 2 & 17 & 1 & 2 & 91 & 30 & 0 \\
\hline 1 & 5 & 5 & 2004 & NA & 2005 & NA & NA & NA & NA & NA & NA & NA & NA & NA & NA & NA & NA & NA & NA & NA & NA & NA \\
\hline 1 & 5 & 1 & 2005 & NA & 2012 & NA & NA & NA & NA & NA & NA & NA & NA & NA & NA & NA & NA & NA & NA & NA & NA & NA \\
\hline 1 & 5 & 5 & 1984 & NA & 2002 & NA & NA & NA & NA & NA & NA & NA & NA & NA & NA & NA & NA & NA & NA & NA & NA & NA \\
\hline 1 & 5 & 5 & 1992 & 1 & 2003 & 3 & 1 & 11 & 3 & 2 & 26 & 1 & 1 & 1 & 8 & 2 & 2 & 1 & 3 & 58 & 15 & 1 \\
\hline 1 & 5 & 5 & 1961 & NA & 2002 & NA & NA & NA & NA & NA & NA & NA & NA & NA & NA & NA & NA & NA & NA & NA & NA & NA \\
\hline 1 & 5 & 3 & 1961 & 1 & 2002 & 1 & $\mathrm{NA}$ & 41 & 1 & 2 & 22 & 1 & 1 & 1 & 5 & 0 & 56 & 1 & 2 & 59 & 13 & 1 \\
\hline 1 & 5 & 3 & 2002 & 0 & 2014 & 3 & 1 & NA & NA & 2 & NA & 2 & NA & NA & NA & NA & 3 & 2 & 1 & NA & NA & NA \\
\hline 1 & 5 & 5 & 1959 & 1 & 2003 & 3 & 1 & 44 & 3 & 2 & 26 & 1 & 1 & 1 & 8 & 2 & 2 & 1 & 3 & 58 & 15 & 1 \\
\hline 1 & 5 & 3 & 1961 & 1 & 2001 & 1 & NA & 40 & NA & NA & 11 & 6 & NA & NA & NA & $\mathrm{NA}$ & NA & 1 & 3 & NA & NA & NA \\
\hline 1 & 5 & 5 & 1961 & NA & 2002 & NA & NA & NA & NA & NA & NA & NA & NA & NA & NA & NA & NA & NA & NA & NA & NA & NA \\
\hline 1 & 5 & 5 & 1997 & NA & NA & $\mathrm{NA}$ & NA & NA & $\mathrm{NA}$ & NA & NA & NA & NA & $\mathrm{NA}$ & $\mathrm{NA}$ & NA & NA & NA & NA & NA & NA & NA \\
\hline 1 & 5 & 4 & 2002 & 1 & 2002 & 2 & NA & NA & 2 & 3 & 20 & 1 & NA & 1 & 9 & NA & 130 & 1 & 3 & 70 & 14 & 1 \\
\hline 1 & 5 & 1 & 1979 & NA & NA & NA & NA & NA & NA & NA & NA & NA & NA & NA & NA & NA & NA & NA & NA & NA & NA & NA \\
\hline 1 & 5 & 5 & 2001 & NA & 2008 & NA & NA & NA & NA & NA & NA & NA & NA & NA & NA & NA & NA & NA & NA & NA & NA & NA \\
\hline 1 & 5 & 5 & 1961 & 1 & 2011 & 3 & 1 & 50 & NA & 3 & 16 & 5 & 0 & 1 & 0 & 2 & 0 & 2 & 3 & 69 & 11 & 1 \\
\hline 1 & 5 & 2 & 1961 & 1 & 2010 & 1 & NA & 49 & NA & 3 & 14 & 1 & 0 & 1 & 0 & 1 & 10 & 1 & 3 & 71 & 10 & 1 \\
\hline 1 & 5 & 2 & 1959 & NA & 2008 & NA & NA & NA & NA & NA & NA & NA & NA & NA & $\mathrm{NA}$ & NA & NA & NA & NA & NA & NA & NA \\
\hline 1 & 5 & 3 & 1959 & NA & 2011 & NA & NA & NA & NA & $\mathrm{NA}$ & NA & NA & NA & $\mathrm{NA}$ & NA & NA & NA & NA & NA & NA & NA & NA \\
\hline 1 & 5 & 1 & 1980 & 1 & 2006 & 1 & 3 & 26 & 1 & 3 & 27 & 1 & 0 & 1 & 5 & NA & 6 & 1 & 2 & 56 & 15 & 0 \\
\hline
\end{tabular}




\begin{tabular}{|c|c|c|c|c|c|c|c|c|c|c|c|c|c|c|c|c|c|c|c|c|c|c|}
\hline 1 & 5 & 2 & 2002 & NA & NA & NA & NA & NA & NA & NA & NA & NA & NA & NA & NA & NA & NA & NA & NA & NA & NA & NA \\
\hline 1 & 5 & 5 & 1999 & NA & 2008 & $\mathrm{NA}$ & $\mathrm{NA}$ & NA & NA & NA & NA & NA & NA & NA & NA & NA & NA & NA & NA & NA & NA & NA \\
\hline 1 & 5 & 5 & 1939 & NA & 2009 & NA & NA & NA & NA & NA & NA & NA & NA & NA & NA & NA & NA & NA & NA & NA & NA & NA \\
\hline 1 & 5 & 1 & 1980 & 1 & 2008 & 3 & 2 & 28 & 2 & 3 & 26 & 3 & 1 & 1 & 9 & 2 & 5 & 1 & 3 & 46 & 12 & 1 \\
\hline 1 & 5 & 1 & 1989 & NA & 2012 & NA & NA & NA & NA & NA & NA & NA & NA & NA & NA & NA & NA & NA & NA & NA & NA & NA \\
\hline 1 & 5 & 7 & 1981 & 1 & 2008 & 2 & NA & 27 & NA & 2 & 36 & 1 & 0 & 0 & NA & 2 & NA & 2 & 2 & NA & NA & 1 \\
\hline 1 & 5 & 5 & 1999 & 1 & 2005 & 1 & NA & 6 & NA & 3 & 21 & 1 & 0 & 1 & NA & 1 & NA & 1 & 3 & 86 & 18 & 1 \\
\hline 1 & 5 & 1 & 1979 & 1 & 2012 & 1 & 1 & 33 & 3 & 2 & 28 & 3 & 1 & 0 & 8 & 0 & 6 & 1 & 2 & 89 & 25 & 1 \\
\hline 1 & 5 & 4 & 1989 & 1 & 2006 & 3 & 1 & 17 & 2 & 3 & 16 & 3 & NA & 1 & 9 & 2 & 1 & 2 & 3 & 75 & 12 & 1 \\
\hline 1 & 5 & 1 & 1998 & 1 & 2012 & 1 & 3 & 14 & NA & 3 & 26 & 4 & 0 & 1 & 0 & 1 & 8 & 1 & 3 & 96 & 25 & 1 \\
\hline 1 & 5 & 4 & 1981 & 1 & 2014 & 1 & NA & 33 & NA & 2 & 28 & 3 & NA & NA & NA & 2 & 50 & 1 & 2 & 93 & 26 & 1 \\
\hline 1 & 5 & 5 & 2002 & NA & NA & NA & NA & NA & NA & NA & NA & NA & NA & NA & NA & NA & NA & NA & NA & NA & NA & NA \\
\hline 1 & 5 & 5 & 1961 & 1 & 2010 & 2 & NA & 49 & 1 & 3 & 18 & 3 & 1 & 1 & 7 & NA & 5 & 2 & 2 & 83 & 15 & 0 \\
\hline 1 & 5 & 3 & 1989 & NA & 2004 & NA & NA & NA & NA & NA & NA & NA & NA & NA & NA & NA & NA & NA & NA & NA & NA & NA \\
\hline 1 & 5 & 5 & 1937 & 1 & 2001 & 1 & NA & 64 & NA & 3 & 28 & 6 & NA & 1 & NA & 1 & NA & 1 & 3 & 57 & 16 & NA \\
\hline 1 & 5 & 4 & 1983 & 1 & 2002 & 3 & NA & 19 & 2 & 3 & 18 & 1 & 1 & 1 & 9 & 1 & 12 & 1 & 3 & 67 & 12 & 1 \\
\hline 1 & 5 & 4 & 1988 & 1 & 2002 & 1 & NA & 14 & 1 & 3 & 24 & 1 & 1 & 1 & 5 & 2 & 256 & 1 & 3 & 83 & 20 & NA \\
\hline 1 & 5 & 1 & 2002 & 0 & 2005 & 3 & 2 & 3 & 2 & 3 & 30 & 2 & 1 & 1 & 9 & 2 & 4 & 2 & 3 & 67 & 20 & 0 \\
\hline 1 & 5 & 1 & 2001 & NA & 2007 & $\mathrm{NA}$ & NA & NA & NA & NA & NA & NA & NA & NA & NA & NA & NA & NA & NA & NA & NA & NA \\
\hline 1 & 5 & 1 & 1998 & 1 & 2010 & 1 & 2 & 12 & 2 & 3 & 18 & 1 & 0 & 0 & 9 & NA & 4 & 1 & 3 & 67 & 12 & 1 \\
\hline 1 & 6 & 4 & 1983 & NA & NA & NA & NA & NA & NA & NA & NA & NA & NA & NA & NA & NA & NA & NA & NA & NA & NA & NA \\
\hline 1 & 7 & 5 & 1982 & 1 & 2006 & 1 & NA & 24 & NA & 3 & 16 & 3 & 0 & 1 & 0 & 1 & 256 & 1 & 2 & 38 & 6 & 1 \\
\hline 1 & 7 & 3 & 2002 & NA & 2014 & NA & NA & NA & NA & NA & NA & NA & NA & NA & NA & NA & NA & NA & NA & NA & NA & NA \\
\hline 1 & 7 & 5 & 2003 & NA & 2014 & NA & NA & NA & NA & NA & NA & NA & NA & NA & NA & NA & NA & NA & NA & NA & NA & NA \\
\hline 1 & 7 & 1 & 1982 & NA & 2011 & NA & NA & NA & NA & NA & NA & NA & NA & NA & NA & NA & NA & NA & NA & NA & NA & NA \\
\hline 1 & 7 & 5 & 1984 & NA & 2013 & NA & NA & NA & NA & NA & NA & NA & NA & NA & NA & NA & NA & NA & NA & NA & NA & NA \\
\hline 1 & 7 & 5 & 1990 & NA & 2008 & NA & NA & NA & NA & NA & NA & NA & NA & NA & NA & NA & NA & NA & NA & NA & NA & NA \\
\hline
\end{tabular}




\begin{tabular}{|c|c|c|c|c|c|c|c|c|c|c|c|c|c|c|c|c|c|c|c|c|c|c|}
\hline 1 & 7 & 5 & 1989 & NA & 2004 & NA & NA & NA & NA & NA & NA & NA & NA & NA & NA & NA & NA & NA & NA & NA & NA & NA \\
\hline 1 & 7 & 5 & 1983 & 1 & 2007 & 1 & 1 & 24 & NA & 2 & 23 & 2 & 1 & 0 & NA & 1 & 3 & 1 & 3 & 78 & 18 & 1 \\
\hline 1 & 7 & 5 & 1988 & 1 & 2015 & 0 & NA & NA & NA & 1 & NA & 2 & NA & 1 & NA & 2 & 4 & 0 & 1 & NA & NA & NA \\
\hline 1 & 7 & 2 & 1982 & NA & 2012 & NA & NA & NA & NA & NA & NA & NA & NA & $\mathrm{NA}$ & $\mathrm{NA}$ & NA & NA & NA & NA & NA & NA & NA \\
\hline 1 & 7 & 5 & 1982 & 1 & 2007 & 0 & NA & 25 & 4 & 2 & 20 & 1 & NA & NA & 12 & 2 & 300 & 0 & 2 & 60 & 12 & 1 \\
\hline 1 & 7 & 5 & 1980 & 1 & 2005 & 2 & 1 & 25 & 1 & 3 & 26 & 1 & 1 & 1 & 7 & 2 & 1 & 2 & 2 & NA & NA & 0 \\
\hline 1 & 7 & 4 & 1979 & 1 & 2013 & 3 & NA & 34 & NA & 2 & 9 & 1 & 1 & 0 & NA & 1 & 256 & 2 & 2 & 100 & 9 & 1 \\
\hline 1 & 7 & 5 & 1982 & 1 & NA & 3 & 1 & NA & NA & 0 & NA & 2 & NA & 1 & NA & NA & 1 & 2 & 1 & NA & NA & NA \\
\hline 1 & 7 & 5 & 1989 & 1 & 2008 & 1 & 1 & 19 & NA & 3 & 9 & 2 & 0 & NA & 0 & 1 & 2 & 1 & 2 & 78 & 7 & 1 \\
\hline 1 & 7 & 1 & 1982 & NA & 2013 & NA & NA & NA & NA & NA & NA & NA & NA & NA & NA & NA & NA & NA & NA & NA & NA & NA \\
\hline 1 & 7 & 1 & 1988 & 1 & 2013 & 1 & 3 & 25 & 2 & 0 & 27 & 1 & 1 & 1 & 9 & 2 & 15 & 1 & 3 & 74 & 20 & 1 \\
\hline 1 & 7 & 1 & 1979 & 1 & 2006 & 3 & 3 & 27 & 4 & 2 & 17 & 1 & 0 & 0 & 12 & 2 & 12 & 1 & 3 & 88 & 15 & 0 \\
\hline 1 & 7 & 1 & 1980 & 1 & 2006 & 3 & $\mathrm{NA}$ & 26 & NA & NA & 30 & 6 & NA & 1 & $\mathrm{NA}$ & $\mathrm{NA}$ & $\mathrm{NA}$ & 1 & 3 & 67 & 20 & NA \\
\hline 1 & 7 & 1 & 1979 & 1 & 2006 & 2 & 3 & 27 & 2 & 3 & 7 & 1 & 0 & 1 & 9 & 2 & 18 & 1 & 3 & 86 & 6 & 1 \\
\hline 1 & 7 & 1 & 1989 & 1 & 2008 & 1 & 3 & 19 & 2 & 3 & 25 & 1 & 0 & 0 & 9 & 1 & 6 & 1 & 3 & 72 & 18 & 1 \\
\hline 1 & 7 & 5 & 1989 & NA & 2011 & NA & NA & NA & NA & NA & NA & NA & NA & NA & NA & NA & NA & NA & NA & NA & NA & NA \\
\hline 1 & 7 & 1 & 1990 & NA & 2008 & NA & NA & NA & NA & NA & NA & NA & NA & NA & NA & $\mathrm{NA}$ & NA & NA & NA & NA & NA & NA \\
\hline 1 & 7 & 4 & 1990 & 1 & 2004 & 3 & NA & 14 & 1 & 3 & 23 & 1 & 1 & 1 & 2 & 2 & 21 & 1 & 3 & 87 & 20 & 1 \\
\hline 1 & 7 & 5 & 1974 & NA & 2002 & NA & NA & NA & NA & NA & NA & NA & NA & $\mathrm{NA}$ & $\mathrm{NA}$ & NA & NA & NA & NA & NA & NA & NA \\
\hline 1 & 7 & 1 & 2005 & NA & 2011 & NA & NA & NA & NA & NA & NA & NA & NA & NA & $\mathrm{NA}$ & NA & NA & NA & NA & NA & $\mathrm{NA}$ & NA \\
\hline 1 & 7 & 5 & 1998 & 1 & 2002 & 3 & NA & 4 & NA & NA & 16 & 6 & NA & NA & NA & NA & NA & 1 & 3 & NA & NA & NA \\
\hline 2 & 9 & 1 & 2005 & NA & 2009 & NA & NA & NA & NA & $\overline{\mathrm{NA}}$ & NA & NA & NA & NA & NA & NA & NA & NA & NA & NA & NA & NA \\
\hline 1 & 6 & 3 & 2002 & NA & NA & NA & NA & NA & NA & NA & NA & NA & NA & NA & NA & NA & NA & NA & NA & NA & NA & NA \\
\hline 2 & 8 & 1 & 2001 & NA & 2008 & NA & NA & NA & NA & NA & NA & NA & NA & NA & NA & NA & NA & NA & NA & NA & NA & NA \\
\hline 2 & 8 & 1 & 2001 & 0 & 2008 & 1 & 1 & 7 & NA & 2 & 23 & 4 & NA & 0 & $\mathrm{NA}$ & 1 & 1 & 1 & 3 & 52 & 12 & 1 \\
\hline 2 & 8 & 1 & 1990 & 1 & 2003 & 1 & 3 & 13 & 2 & 3 & 24 & 4 & 0 & $\mathrm{NA}$ & 9 & 2 & 11 & 1 & 3 & 79 & 19 & 1 \\
\hline 2 & 8 & 1 & 2002 & 0 & 2007 & 1 & NA & 5 & 2 & 3 & 15 & 3 & 0 & 1 & 9 & 1 & NA & 1 & 3 & 67 & 10 & 1 \\
\hline
\end{tabular}




\begin{tabular}{|c|c|c|c|c|c|c|c|c|c|c|c|c|c|c|c|c|c|c|c|c|c|c|}
\hline 2 & 8 & 3 & 2000 & NA & NA & NA & NA & NA & NA & NA & NA & NA & NA & NA & NA & NA & NA & NA & NA & NA & NA & NA \\
\hline 2 & 8 & 3 & 1992 & 1 & 2012 & 1 & NA & 20 & 3 & 3 & 31 & 3 & 1 & 1 & 8 & 2 & 3 & 1 & 2 & 58 & 18 & 1 \\
\hline 2 & 8 & 1 & 2002 & NA & 2009 & NA & NA & NA & NA & NA & NA & NA & NA & NA & NA & NA & NA & NA & NA & NA & NA & NA \\
\hline 2 & 8 & 1 & 2002 & 0 & 2007 & 2 & NA & 5 & 2 & 2 & 21 & 3 & 0 & 1 & 9 & 1 & NA & 1 & 3 & 76 & 16 & 0 \\
\hline 2 & 8 & 1 & 2001 & 0 & 2009 & 2 & 2 & 8 & NA & 3 & 16 & 3 & $\mathrm{NA}$ & 1 & NA & NA & 3 & 1 & 3 & NA & NA & NA \\
\hline 2 & 8 & 4 & 2005 & NA & 2012 & NA & NA & NA & NA & NA & NA & NA & NA & NA & NA & NA & NA & NA & NA & NA & NA & NA \\
\hline 2 & 8 & 1 & 2002 & 0 & 2006 & 2 & 1 & 4 & 1 & 3 & 17 & 3 & 0 & 1 & 5 & 0 & 2 & 1 & 3 & 88 & 15 & 1 \\
\hline 2 & 8 & 1 & 1999 & 1 & 2006 & 1 & NA & 7 & 1 & 3 & 24 & 3 & 0 & 1 & 5 & 2 & 5 & 1 & 3 & 83 & 20 & 1 \\
\hline 2 & 8 & 5 & 2002 & 0 & 2005 & 2 & NA & 3 & 1 & 3 & 16 & 3 & 0 & 1 & 11 & NA & 5 & 1 & 3 & 81 & 13 & 1 \\
\hline 2 & 8 & 1 & 1997 & 1 & 2007 & 1 & 1 & 10 & 2 & 3 & 27 & 4 & 0 & 1 & 9 & 1 & 1 & 1 & 3 & NA & NA & 1 \\
\hline 2 & 8 & 1 & 2001 & 0 & 2010 & 3 & 3 & 9 & 2 & 3 & 16 & 2 & 0 & NA & 9 & 1 & 10 & 1 & 3 & 63 & 10 & 1 \\
\hline 2 & 8 & 1 & 2002 & 0 & 2006 & 1 & NA & 4 & NA & 3 & 30 & 1 & 0 & 0 & 0 & 1 & 9 & 1 & 3 & 100 & 30 & 1 \\
\hline 2 & 8 & 3 & 1992 & NA & 2011 & NA & $\mathrm{NA}$ & $\mathrm{NA}$ & NA & NA & NA & NA & NA & NA & NA & NA & NA & NA & NA & NA & NA & NA \\
\hline 2 & 8 & 1 & 2005 & NA & 2010 & NA & NA & $\mathrm{NA}$ & NA & NA & NA & NA & NA & NA & NA & NA & NA & NA & NA & NA & NA & NA \\
\hline 2 & 8 & 1 & 2002 & NA & 2006 & NA & NA & NA & NA & NA & NA & NA & NA & NA & NA & NA & NA & NA & NA & NA & NA & NA \\
\hline 2 & 8 & 1 & 2005 & NA & 2008 & $\mathrm{NA}$ & NA & NA & NA & NA & NA & $\mathrm{NA}$ & NA & NA & $\mathrm{NA}$ & NA & NA & NA & NA & NA & NA & $\mathrm{NA}$ \\
\hline 2 & 8 & 4 & 2000 & 0 & 2006 & 1 & NA & 6 & 1 & 3 & 36 & 3 & 0 & 1 & 7 & 0 & 80 & 1 & 3 & 83 & 30 & NA \\
\hline 2 & 8 & 4 & 2001 & NA & 2011 & $\mathrm{NA}$ & NA & NA & NA & NA & NA & $\mathrm{NA}$ & NA & NA & $\mathrm{NA}$ & NA & NA & NA & NA & NA & NA & $\mathrm{NA}$ \\
\hline 2 & 8 & 1 & 2005 & NA & 2007 & NA & NA & NA & NA & NA & NA & NA & NA & NA & NA & NA & NA & NA & NA & NA & NA & NA \\
\hline 2 & 8 & 1 & 2005 & NA & 2007 & NA & $\mathrm{NA}$ & $\mathrm{NA}$ & NA & NA & NA & NA & NA & NA & NA & NA & NA & NA & NA & NA & NA & NA \\
\hline 2 & 8 & 1 & 2005 & 0 & 2008 & 2 & 1 & 3 & 2 & 3 & 22 & 3 & 0 & 1 & 9 & 1 & 2 & 2 & 3 & 82 & 18 & 1 \\
\hline 2 & 8 & 1 & 2005 & NA & 2007 & NA & NA & NA & NA & NA & NA & NA & NA & NA & NA & NA & NA & NA & NA & NA & NA & NA \\
\hline 2 & 8 & 4 & 1997 & NA & 2010 & NA & NA & NA & NA & NA & NA & NA & NA & NA & NA & NA & NA & NA & NA & NA & NA & NA \\
\hline 2 & 8 & 4 & 2000 & NA & 2006 & NA & $\mathrm{NA}$ & NA & NA & NA & NA & NA & NA & NA & NA & NA & NA & NA & NA & NA & NA & NA \\
\hline 2 & 8 & 4 & 2006 & 0 & 2009 & 2 & NA & 3 & 1 & 3 & 25 & 3 & 1 & 0 & 3 & 2 & 5 & 1 & 3 & 80 & 20 & 1 \\
\hline 2 & 8 & 1 & 2001 & NA & 2003 & NA & NA & NA & NA & NA & NA & NA & NA & NA & NA & NA & NA & NA & NA & NA & NA & NA \\
\hline
\end{tabular}




\begin{tabular}{|c|c|c|c|c|c|c|c|c|c|c|c|c|c|c|c|c|c|c|c|c|c|c|}
\hline 2 & 8 & 4 & 1992 & NA & 2011 & NA & NA & NA & NA & NA & NA & NA & NA & NA & NA & NA & NA & NA & NA & NA & NA & NA \\
\hline 2 & 8 & 1 & 1990 & $\mathrm{NA}$ & 2006 & NA & $\mathrm{NA}$ & $\mathrm{NA}$ & NA & NA & NA & NA & $\mathrm{NA}$ & NA & NA & NA & NA & $\mathrm{NA}$ & $\mathrm{NA}$ & $\mathrm{NA}$ & NA & NA \\
\hline 2 & 8 & 1 & 2005 & 0 & 2012 & 1 & $\mathrm{NA}$ & 7 & 1 & 3 & 17 & 3 & 0 & 0 & 7 & 1 & 0 & 1 & 2 & 65 & 11 & NA \\
\hline 2 & 8 & 1 & 2004 & NA & 2008 & NA & $\mathrm{NA}$ & NA & NA & NA & NA & NA & $\mathrm{NA}$ & NA & NA & NA & NA & $\mathrm{NA}$ & $\mathrm{NA}$ & NA & NA & NA \\
\hline 2 & 8 & 1 & 1998 & 1 & 2004 & 1 & 1 & 6 & 3 & 3 & 28 & 4 & 0 & 0 & 8 & NA & 3 & 1 & 3 & 82 & 23 & 1 \\
\hline 2 & 8 & 1 & 2004 & NA & 2008 & NA & NA & NA & NA & NA & NA & NA & NA & NA & NA & NA & NA & NA & NA & NA & NA & NA \\
\hline 1 & 3 & 5 & 2005 & 0 & 2010 & 2 & NA & 5 & 4 & 3 & 16 & 1 & 1 & 0 & 12 & NA & 50 & 1 & 3 & NA & NA & NA \\
\hline 1 & 5 & 5 & 2005 & NA & 2010 & NA & NA & NA & NA & NA & NA & NA & NA & NA & NA & NA & NA & NA & NA & NA & NA & NA \\
\hline 1 & 3 & 5 & 2006 & NA & 2011 & 2 & NA & 5 & 1 & 3 & 39 & 2 & 1 & 1 & 6 & 1 & NA & 1 & 3 & 90 & 35 & 0 \\
\hline 1 & 5 & 1 & 2006 & NA & 2011 & NA & NA & NA & NA & NA & NA & NA & NA & NA & NA & NA & NA & NA & NA & NA & NA & NA \\
\hline 2 & 4 & 1 & 2006 & NA & 2009 & NA & NA & $\mathrm{NA}$ & NA & NA & NA & NA & NA & NA & NA & NA & NA & NA & NA & NA & NA & NA \\
\hline 2 & 4 & 1 & 2006 & NA & 2009 & NA & NA & NA & NA & NA & NA & NA & NA & NA & NA & NA & NA & NA & NA & NA & NA & NA \\
\hline 1 & 5 & 1 & 2006 & 0 & NA & 2 & 1 & NA & 4 & 3 & NA & 1 & 1 & 0 & 12 & 2 & 2 & 2 & 1 & NA & NA & 1 \\
\hline 2 & 1 & 1 & 2006 & $\mathrm{NA}$ & 2011 & NA & NA & $\mathrm{NA}$ & NA & NA & NA & NA & NA & NA & NA & NA & NA & NA & NA & NA & NA & NA \\
\hline 2 & 4 & 1 & 2006 & NA & 2009 & NA & NA & NA & NA & NA & NA & NA & NA & NA & NA & NA & NA & NA & NA & NA & NA & NA \\
\hline 2 & 4 & 1 & 2006 & NA & 2009 & NA & NA & NA & NA & NA & NA & NA & NA & NA & NA & NA & NA & NA & NA & NA & NA & NA \\
\hline 1 & 5 & 3 & 2005 & NA & 2012 & NA & NA & NA & NA & NA & NA & NA & NA & NA & NA & NA & NA & NA & NA & NA & NA & NA \\
\hline 2 & 8 & 1 & 2005 & NA & 2012 & NA & NA & NA & NA & NA & NA & NA & NA & NA & NA & NA & NA & NA & NA & NA & NA & NA \\
\hline 2 & 8 & 1 & 2000 & 0 & 2011 & 2 & 1 & 11 & NA & 3 & 15 & 2 & 0 & 0 & NA & 1 & 3 & 1 & 3 & 67 & 10 & 1 \\
\hline 1 & 7 & 5 & 2006 & 0 & 2010 & 3 & 1 & 4 & 1 & 3 & 28 & 1 & 1 & 0 & 7 & 1 & 3 & 1 & 3 & 61 & 17 & 1 \\
\hline 1 & 7 & 5 & 2006 & NA & 2010 & NA & $\mathrm{NA}$ & NA & NA & NA & NA & NA & NA & NA & NA & NA & NA & NA & $\mathrm{NA}$ & NA & NA & NA \\
\hline 1 & 5 & 5 & 2006 & 0 & NA & 2 & NA & NA & NA & 3 & NA & 2 & NA & 1 & NA & NA & NA & 1 & 1 & NA & NA & NA \\
\hline 1 & 6 & 5 & 2006 & NA & 2011 & NA & NA & NA & NA & NA & NA & NA & NA & NA & NA & NA & NA & NA & NA & NA & NA & NA \\
\hline 2 & 8 & 4 & 2004 & 0 & 2011 & 1 & 2 & 7 & 2 & 3 & 23 & 1 & NA & 1 & 9 & 1 & 5 & 1 & 2 & 70 & 16 & 1 \\
\hline 2 & 8 & 1 & 2006 & NA & 2008 & NA & NA & NA & NA & NA & NA & NA & NA & NA & NA & NA & NA & NA & NA & NA & NA & NA \\
\hline 1 & 5 & 1 & 2006 & NA & 2011 & NA & NA & NA & NA & NA & NA & NA & NA & NA & NA & NA & NA & NA & NA & NA & NA & NA \\
\hline
\end{tabular}




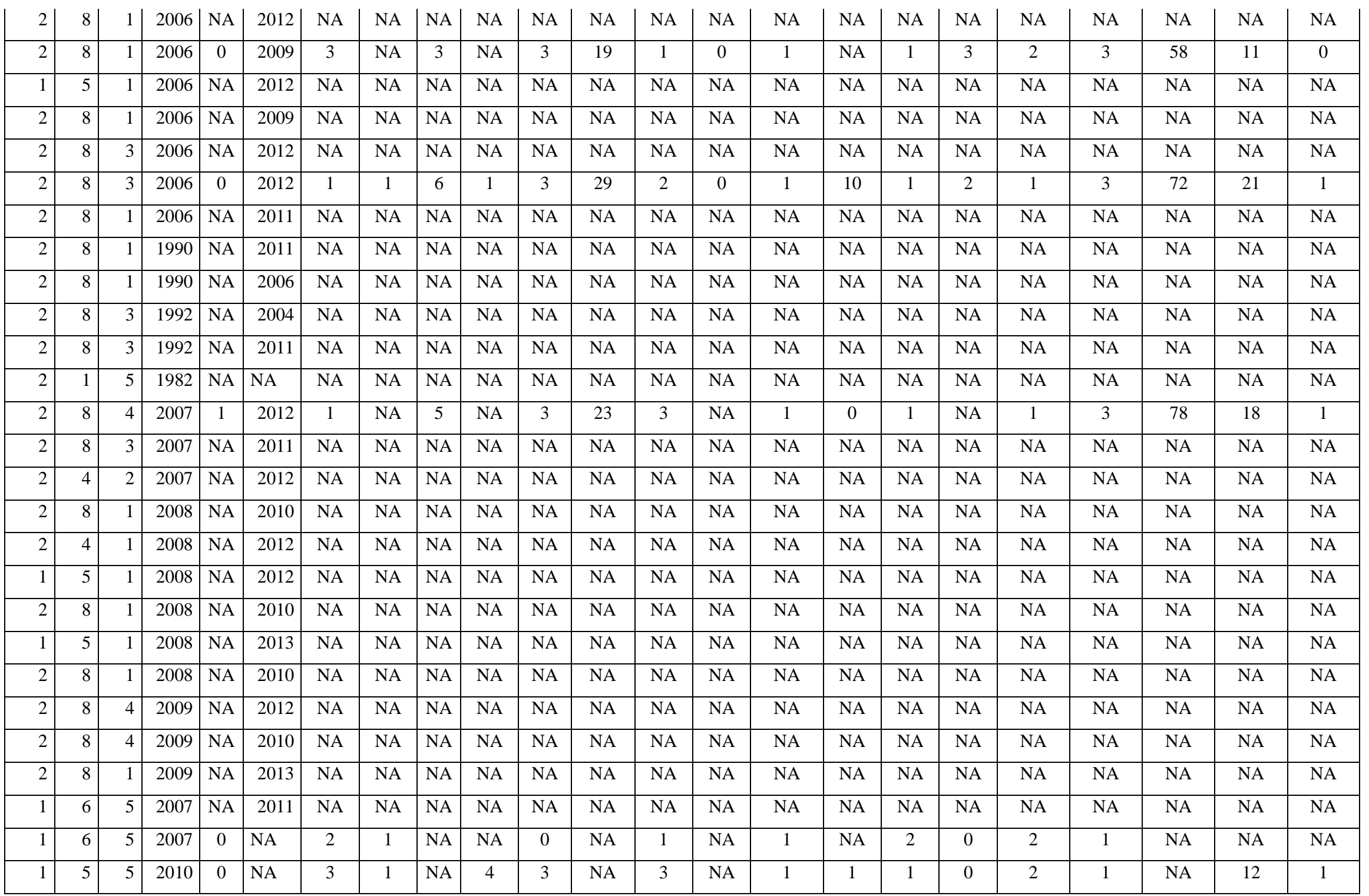




\begin{tabular}{|c|c|c|c|c|c|c|c|c|c|c|c|c|c|c|c|c|c|c|c|c|c|c|}
\hline 1 & 5 & 5 & 2010 & 0 & NA & 3 & 0 & NA & NA & 3 & NA & 5 & NA & 1 & NA & NA & 0 & 2 & 1 & NA & NA & NA \\
\hline 1 & \begin{tabular}{|l|}
5 \\
\end{tabular} & 5 & 2010 & 0 & NA & 1 & 1 & NA & NA & 2 & NA & 6 & NA & 1 & NA & 2 & NA & 1 & 0 & NA & $\mathrm{NA}$ & NA \\
\hline 2 & 4 & 5 & 1968 & 1 & 2010 & 2 & 1 & 42 & NA & NA & 15 & 0 & 0 & 0 & NA & NA & 1 & 1 & 3 & 53 & 8 & 0 \\
\hline 1 & 7 & 5 & 2012 & 0 & NA & 3 & 2 & NA & NA & NA & NA & 2 & NA & NA & NA & NA & 2 & NA & 1 & NA & NA & NA \\
\hline 1 & 5 & 5 & 2013 & 0 & NA & 3 & 2 & NA & NA & NA & NA & 3 & NA & 1 & NA & NA & 2 & NA & 1 & NA & NA & NA \\
\hline
\end{tabular}


ANEXO VI. DADOS UTILIZADOS NA ANÁLISE DE CORRESPONDÊNCIA MULTIVARIADA (MCA) PARA DETERMINAÇÃO DO FATOR DE DIMENSIONAMENTO DA PARTICIPAÇÃO SOCIAL.

\begin{tabular}{|c|c|c|c|c|c|}
\hline $\begin{array}{c}\text { As comunidades } \\
\text { locais apoiam os } \\
\text { objetivos globais da } \\
\text { UC? }\end{array}$ & $\begin{array}{l}\text { Existe conselho } \\
\text { implementado e } \\
\text { efetivo? }\end{array}$ & $\begin{array}{l}\text { Existe articulação } \\
\text { efetiva da UC com } \\
\text { órgãos e entidades } \\
\text { relacionadas? }\end{array}$ & $\begin{array}{l}\text { A definição do desenho } \\
\text { e da categoria da UC } \\
\text { foi decorrente de um } \\
\text { processo participativo? }\end{array}$ & $\begin{array}{c}\text { As comunidades } \\
\text { locais participam das } \\
\text { decisões pelas quais } \\
\text { são afetadas? }\end{array}$ & $\begin{array}{l}\text { Os resultados da } \\
\text { pesquisa, } \\
\text { monitoramento e o } \\
\text { conhecimento } \\
\text { tradicional são } \\
\text { incluídos } \\
\text { rotineiramente no } \\
\text { planejamento? }\end{array}$ \\
\hline $\mathrm{d} 5$ & $\mathrm{~d} 7$ & $\mathrm{~d} 12$ & d19 & $\mathrm{d} 20$ & $\mathrm{~d} 21$ \\
\hline s1 & 5 & 3 & 0 & 5 & 5 \\
\hline 5 & 1 & 3 & 1 & 3 & 1 \\
\hline 1 & 0 & 3 & 0 & 1 & 0 \\
\hline 5 & 5 & 5 & 3 & 3 & 1 \\
\hline 1 & 5 & 5 & 0 & 5 & 3 \\
\hline 1 & 5 & 5 & 5 & 3 & 0 \\
\hline 3 & 5 & 5 & 5 & 5 & 0 \\
\hline 3 & 0 & 5 & 5 & 1 & 5 \\
\hline 1 & 1 & 1 & 0 & 0 & 1 \\
\hline 3 & 5 & 5 & 5 & 5 & 3 \\
\hline 1 & 0 & 0 & 0 & 0 & 0 \\
\hline 3 & 5 & 5 & 0 & 1 & 0 \\
\hline 5 & 3 & 5 & 0 & 1 & 5 \\
\hline 0 & 5 & 5 & 3 & 3 & 0 \\
\hline 3 & 5 & 5 & 3 & 5 & 3 \\
\hline 1 & 3 & 3 & 0 & 3 & 0 \\
\hline 3 & 1 & 3 & 0 & 1 & 3 \\
\hline 1 & 5 & 3 & 1 & 1 & 3 \\
\hline 1 & 5 & 3 & 3 & 0 & 0 \\
\hline 3 & 0 & 5 & 0 & 1 & 5 \\
\hline 3 & 3 & 5 & 0 & 5 & 0 \\
\hline 1 & 5 & 1 & 1 & 3 & 0 \\
\hline 5 & 5 & 5 & 5 & 5 & 5 \\
\hline 3 & 3 & 3 & 3 & 1 & 3 \\
\hline 3 & 1 & 5 & 5 & 1 & 0 \\
\hline 3 & 3 & 5 & 3 & 3 & 1 \\
\hline 3 & 0 & 5 & 5 & 5 & 3 \\
\hline 5 & 5 & 5 & 0 & 5 & 0 \\
\hline 1 & 0 & 3 & 0 & 0 & 0 \\
\hline 3 & 1 & 3 & 0 & 1 & 1 \\
\hline
\end{tabular}




\begin{tabular}{|c|c|c|c|c|c|}
\hline $\begin{array}{c}\text { As comunidades } \\
\text { locais apoiam os } \\
\text { objetivos globais da } \\
\text { UC? }\end{array}$ & $\begin{array}{l}\text { Existe conselho } \\
\text { implementado e } \\
\text { efetivo? }\end{array}$ & $\begin{array}{l}\text { Existe articulação } \\
\text { efetiva da UC com } \\
\text { órgãos e entidades } \\
\text { relacionadas? }\end{array}$ & $\begin{array}{l}\text { A definição do desenho } \\
\text { e da categoria da UC } \\
\text { foi decorrente de um } \\
\text { processo participativo? }\end{array}$ & $\begin{array}{c}\text { As comunidades } \\
\text { locais participam das } \\
\text { decisões pelas quais } \\
\text { são afetadas? }\end{array}$ & $\begin{array}{l}\text { Os resultados da } \\
\text { pesquisa, } \\
\text { monitoramento e o } \\
\text { conhecimento } \\
\text { tradicional são } \\
\text { incluídos } \\
\text { rotineiramente no } \\
\text { planejamento? }\end{array}$ \\
\hline 3 & 0 & 0 & 0 & 0 & 0 \\
\hline 1 & 5 & 5 & 5 & 3 & 0 \\
\hline 1 & 5 & 3 & 0 & 3 & 3 \\
\hline 0 & 0 & 3 & 0 & 0 & 0 \\
\hline 3 & 0 & 3 & 3 & 1 & 1 \\
\hline 0 & 0 & 0 & 0 & 0 & 0 \\
\hline 0 & 0 & 0 & 0 & 0 & 0 \\
\hline 3 & 0 & 1 & 3 & 1 & 1 \\
\hline 1 & 0 & 3 & 0 & 3 & 0 \\
\hline 1 & 5 & 3 & 0 & 3 & 3 \\
\hline 3 & 0 & 5 & 0 & 0 & 0 \\
\hline 0 & 0 & 5 & 0 & 0 & 0 \\
\hline 3 & 5 & 5 & 0 & 5 & 3 \\
\hline 3 & 5 & 5 & 1 & 5 & 3 \\
\hline 0 & 0 & 1 & 0 & 0 & 0 \\
\hline 5 & 0 & 3 & 0 & 0 & 0 \\
\hline 3 & 0 & 5 & 1 & 3 & 3 \\
\hline 3 & 3 & 3 & 0 & 3 & 3 \\
\hline 1 & 1 & 1 & 0 & 0 & 3 \\
\hline 1 & 3 & 5 & 0 & 0 & 3 \\
\hline 3 & 3 & 5 & 0 & 3 & 0 \\
\hline 5 & 5 & 5 & 0 & 5 & 1 \\
\hline 1 & 3 & 1 & 0 & 3 & 1 \\
\hline 1 & 5 & 5 & 0 & 3 & 5 \\
\hline 1 & 1 & 5 & 0 & 1 & 1 \\
\hline 1 & 0 & 0 & 0 & 0 & 0 \\
\hline 0 & 0 & 0 & 0 & 0 & 0 \\
\hline 5 & 0 & 5 & 0 & 3 & 3 \\
\hline 5 & 3 & 5 & 0 & 0 & 0 \\
\hline 1 & 5 & 5 & 3 & 5 & 1 \\
\hline 5 & 5 & 5 & 0 & 1 & 3 \\
\hline 3 & 0 & 3 & 0 & 0 & 0 \\
\hline 1 & 5 & 3 & 0 & 0 & 0 \\
\hline 3 & 0 & 3 & 3 & 0 & 3 \\
\hline 1 & 0 & 5 & 0 & 0 & 0 \\
\hline 1 & 0 & 1 & 0 & 0 & 5 \\
\hline
\end{tabular}




\begin{tabular}{|c|c|c|c|c|c|}
\hline $\begin{array}{c}\text { As comunidades } \\
\text { locais apoiam os } \\
\text { objetivos globais da } \\
\text { UC? }\end{array}$ & $\begin{array}{l}\text { Existe conselho } \\
\text { implementado e } \\
\text { efetivo? }\end{array}$ & $\begin{array}{l}\text { Existe articulação } \\
\text { efetiva da UC com } \\
\text { órgãos e entidades } \\
\text { relacionadas? }\end{array}$ & $\begin{array}{l}\text { A definição do desenho } \\
\text { e da categoria da UC } \\
\text { foi decorrente de um } \\
\text { processo participativo? }\end{array}$ & $\begin{array}{c}\text { As comunidades } \\
\text { locais participam das } \\
\text { decisões pelas quais } \\
\text { são afetadas? }\end{array}$ & $\begin{array}{l}\text { Os resultados da } \\
\text { pesquisa, } \\
\text { monitoramento e o } \\
\text { conhecimento } \\
\text { tradicional são } \\
\text { incluídos } \\
\text { rotineiramente no } \\
\text { planejamento? }\end{array}$ \\
\hline 1 & 0 & 5 & 0 & 0 & 5 \\
\hline 1 & 5 & 5 & 0 & 1 & 0 \\
\hline 1 & 0 & 1 & 0 & 1 & 0 \\
\hline 5 & 5 & 5 & 3 & 5 & 0 \\
\hline 0 & 3 & 3 & 1 & 0 & 0 \\
\hline 5 & 5 & 5 & 0 & 5 & 3 \\
\hline 5 & 3 & 5 & 5 & 5 & 5 \\
\hline 5 & 5 & 5 & 5 & 5 & 1 \\
\hline 5 & 3 & 0 & 5 & 0 & 0 \\
\hline 3 & 0 & 5 & 1 & 3 & 3 \\
\hline 3 & 3 & 5 & 0 & 3 & 0 \\
\hline 3 & 5 & 5 & 3 & 5 & 3 \\
\hline 3 & 3 & 5 & 0 & 5 & 0 \\
\hline 5 & 5 & 5 & 0 & 5 & 3 \\
\hline 3 & 5 & 5 & 3 & 3 & 0 \\
\hline 3 & 3 & 5 & 5 & 5 & 3 \\
\hline 3 & 5 & 3 & 0 & 5 & 3 \\
\hline 1 & 5 & 5 & 0 & 5 & 1 \\
\hline 3 & 5 & 3 & 0 & 5 & 0 \\
\hline 0 & 5 & 5 & 1 & 5 & 0 \\
\hline 5 & 5 & 5 & 5 & 5 & 5 \\
\hline 3 & 5 & 5 & 0 & 3 & 1 \\
\hline 3 & 1 & 3 & 3 & 3 & 0 \\
\hline 5 & 5 & 5 & 0 & 0 & 5 \\
\hline 5 & 5 & 5 & 5 & 5 & 0 \\
\hline 3 & 3 & 5 & 5 & 3 & 0 \\
\hline 5 & 5 & 5 & 0 & 5 & 0 \\
\hline 3 & 0 & 3 & 0 & 0 & 0 \\
\hline 5 & 5 & 5 & 0 & 5 & 5 \\
\hline 1 & 0 & 3 & 5 & 0 & 0 \\
\hline 1 & 0 & 0 & 0 & 0 & 0 \\
\hline 5 & 5 & 5 & 0 & 5 & 5 \\
\hline 3 & 3 & 5 & 0 & 3 & 3 \\
\hline 5 & 5 & 5 & 0 & 3 & 1 \\
\hline 3 & 0 & 0 & 0 & 0 & 0 \\
\hline 5 & 1 & 0 & 0 & 3 & 0 \\
\hline
\end{tabular}




\begin{tabular}{|c|c|c|c|c|c|}
\hline $\begin{array}{c}\text { As comunidades } \\
\text { locais apoiam os } \\
\text { objetivos globais da } \\
\text { UC? }\end{array}$ & $\begin{array}{l}\text { Existe conselho } \\
\text { implementado e } \\
\text { efetivo? }\end{array}$ & $\begin{array}{l}\text { Existe articulação } \\
\text { efetiva da UC com } \\
\text { órgãos e entidades } \\
\text { relacionadas? }\end{array}$ & $\begin{array}{l}\text { A definição do desenho } \\
\text { e da categoria da UC } \\
\text { foi decorrente de um } \\
\text { processo participativo? }\end{array}$ & $\begin{array}{c}\text { As comunidades } \\
\text { locais participam das } \\
\text { decisões pelas quais } \\
\text { são afetadas? }\end{array}$ & $\begin{array}{l}\text { Os resultados da } \\
\text { pesquisa, } \\
\text { monitoramento e o } \\
\text { conhecimento } \\
\text { tradicional são } \\
\text { incluídos } \\
\text { rotineiramente no } \\
\text { planejamento? }\end{array}$ \\
\hline 3 & 3 & 5 & 0 & 0 & 1 \\
\hline 3 & 0 & 3 & 0 & 0 & 0 \\
\hline 5 & 5 & 5 & 0 & 5 & 0 \\
\hline 0 & 0 & 3 & 0 & 0 & 0 \\
\hline 1 & 0 & 3 & 0 & 1 & 0 \\
\hline 5 & 5 & 3 & 0 & 5 & 5 \\
\hline 0 & 0 & 3 & 1 & 0 & 3 \\
\hline 5 & 5 & 5 & 0 & 5 & 5 \\
\hline 5 & 3 & 3 & 0 & 3 & 1 \\
\hline 5 & 0 & 5 & 0 & 0 & 0 \\
\hline 3 & 5 & 5 & 5 & 5 & 1 \\
\hline 1 & 5 & 3 & 0 & 5 & 0 \\
\hline 3 & 3 & 3 & 0 & 0 & 0 \\
\hline 3 & 0 & 5 & 0 & 3 & 5 \\
\hline 0 & 0 & 1 & 0 & 0 & 0 \\
\hline 5 & 0 & 3 & 5 & 3 & 0 \\
\hline 5 & 5 & 5 & 0 & 5 & 3 \\
\hline 1 & 3 & 3 & 0 & 1 & 3 \\
\hline 3 & 0 & 5 & 0 & 0 & 3 \\
\hline 1 & 1 & 1 & 0 & 0 & 3 \\
\hline 5 & 3 & 3 & 0 & 1 & 3 \\
\hline 3 & 3 & 5 & 0 & 5 & 5 \\
\hline 5 & 1 & 5 & 1 & 3 & 3 \\
\hline 1 & 5 & 5 & 0 & 3 & 3 \\
\hline 1 & 5 & 3 & 1 & 1 & 1 \\
\hline 1 & 3 & 3 & 1 & 5 & 5 \\
\hline 5 & 5 & 5 & 1 & 3 & 1 \\
\hline 0 & 3 & 5 & 0 & 0 & 3 \\
\hline 5 & 5 & 5 & 5 & 5 & 1 \\
\hline 1 & 1 & 3 & 0 & 3 & 3 \\
\hline 3 & 0 & 5 & 3 & 0 & 0 \\
\hline 1 & 5 & 5 & 0 & 3 & 3 \\
\hline 3 & 1 & 3 & 0 & 0 & 0 \\
\hline 5 & 3 & 3 & 3 & 3 & 1 \\
\hline 5 & 0 & 5 & 5 & 0 & 5 \\
\hline 3 & 3 & 5 & 0 & 3 & 0 \\
\hline
\end{tabular}




\begin{tabular}{|c|c|c|c|c|c|}
\hline $\begin{array}{c}\text { As comunidades } \\
\text { locais apoiam os } \\
\text { objetivos globais da } \\
\text { UC? }\end{array}$ & $\begin{array}{l}\text { Existe conselho } \\
\text { implementado e } \\
\text { efetivo? }\end{array}$ & $\begin{array}{l}\text { Existe articulação } \\
\text { efetiva da UC com } \\
\text { órgãos e entidades } \\
\text { relacionadas? }\end{array}$ & $\begin{array}{l}\text { A definição do desenho } \\
\text { e da categoria da UC } \\
\text { foi decorrente de um } \\
\text { processo participativo? }\end{array}$ & $\begin{array}{c}\text { As comunidades } \\
\text { locais participam das } \\
\text { decisões pelas quais } \\
\text { são afetadas? }\end{array}$ & $\begin{array}{l}\text { Os resultados da } \\
\text { pesquisa, } \\
\text { monitoramento e o } \\
\text { conhecimento } \\
\text { tradicional são } \\
\text { incluídos } \\
\text { rotineiramente no } \\
\text { planejamento? }\end{array}$ \\
\hline 1 & 5 & 5 & 0 & 0 & 5 \\
\hline 5 & 5 & 5 & 5 & 5 & 5 \\
\hline 3 & 0 & 1 & 5 & 0 & 0 \\
\hline 3 & 5 & 5 & 3 & 5 & 5 \\
\hline 1 & 5 & 3 & 0 & 0 & 0 \\
\hline 3 & 5 & 5 & 1 & 1 & 1 \\
\hline 3 & 5 & 3 & 0 & 5 & 1 \\
\hline 5 & 0 & 5 & 5 & 0 & 0 \\
\hline 1 & 5 & 5 & 1 & 5 & 3 \\
\hline 1 & 5 & 3 & 0 & 0 & 0 \\
\hline 5 & 5 & 5 & 5 & 3 & 5 \\
\hline 3 & 1 & 3 & 1 & 0 & 5 \\
\hline 1 & 0 & 3 & 3 & 1 & 3 \\
\hline 3 & 0 & 5 & 3 & 3 & 0 \\
\hline 1 & 0 & 3 & 0 & 0 & 0 \\
\hline 1 & 5 & 5 & 1 & 5 & 1 \\
\hline 1 & 0 & 3 & 0 & 0 & 1 \\
\hline 5 & 3 & 5 & 0 & 5 & 0 \\
\hline 3 & 3 & 3 & 1 & 3 & 1 \\
\hline 3 & 0 & 5 & 0 & 3 & 1 \\
\hline 1 & 3 & 5 & 0 & 3 & 3 \\
\hline 1 & 1 & 3 & 5 & 0 & 1 \\
\hline 3 & 5 & 3 & 0 & 5 & 1 \\
\hline 1 & 5 & 5 & 0 & 1 & 3 \\
\hline 3 & 5 & 5 & 0 & 5 & 3 \\
\hline 5 & 0 & 5 & 0 & 3 & 0 \\
\hline 3 & 1 & 5 & 1 & 1 & 3 \\
\hline 5 & 5 & 5 & 1 & 3 & 1 \\
\hline 0 & 0 & 3 & 0 & 0 & 0 \\
\hline 5 & 5 & 5 & 0 & 5 & 5 \\
\hline 3 & 0 & 5 & 0 & 1 & 5 \\
\hline 5 & 0 & 5 & 5 & 0 & 3 \\
\hline 3 & 0 & 5 & 0 & 5 & 0 \\
\hline 5 & 0 & 5 & 0 & 5 & 0 \\
\hline 3 & 1 & 5 & 1 & 1 & 5 \\
\hline 1 & 5 & 5 & 0 & 3 & 1 \\
\hline
\end{tabular}




\begin{tabular}{|c|c|c|c|c|c|}
\hline $\begin{array}{c}\text { As comunidades } \\
\text { locais apoiam os } \\
\text { objetivos globais da } \\
\text { UC? }\end{array}$ & $\begin{array}{l}\text { Existe conselho } \\
\text { implementado e } \\
\text { efetivo? }\end{array}$ & $\begin{array}{l}\text { Existe articulação } \\
\text { efetiva da UC com } \\
\text { órgãos e entidades } \\
\text { relacionadas? }\end{array}$ & $\begin{array}{l}\text { A definição do desenho } \\
\text { e da categoria da UC } \\
\text { foi decorrente de um } \\
\text { processo participativo? }\end{array}$ & $\begin{array}{c}\text { As comunidades } \\
\text { locais participam das } \\
\text { decisões pelas quais } \\
\text { são afetadas? }\end{array}$ & $\begin{array}{c}\text { Os resultados da } \\
\text { pesquisa, } \\
\text { monitoramento e o } \\
\text { conhecimento } \\
\text { tradicional são } \\
\text { incluídos } \\
\text { rotineiramente no } \\
\text { planejamento? }\end{array}$ \\
\hline 3 & 5 & 5 & 1 & 3 & 1 \\
\hline 1 & 5 & 3 & 3 & 3 & 3 \\
\hline 1 & 5 & 5 & 3 & 3 & 5 \\
\hline 3 & 5 & 5 & 3 & 3 & 0 \\
\hline 5 & 0 & 5 & 0 & 3 & 0 \\
\hline 5 & 0 & 5 & 5 & 0 & 5 \\
\hline 5 & 1 & 5 & 0 & 0 & 5 \\
\hline 1 & 0 & 1 & 0 & 0 & 0 \\
\hline 1 & 0 & 1 & 0 & 0 & 1 \\
\hline 1 & 0 & 3 & 0 & 0 & 0 \\
\hline 3 & 0 & 5 & 0 & 3 & 0 \\
\hline 3 & 3 & 5 & 0 & 5 & 3 \\
\hline 1 & 0 & 5 & 3 & 0 & 0 \\
\hline 3 & 3 & 3 & 0 & 3 & 1 \\
\hline 3 & 0 & 5 & 0 & 0 & 1 \\
\hline 5 & 3 & 5 & 0 & 0 & 5 \\
\hline 3 & 5 & 3 & 0 & 1 & 3 \\
\hline 1 & 3 & 5 & 5 & 0 & 0 \\
\hline 1 & 0 & 5 & 0 & 0 & 5 \\
\hline 3 & 0 & 5 & 1 & 0 & 0 \\
\hline 3 & 5 & 5 & 0 & 5 & 1 \\
\hline 1 & 0 & 3 & 1 & 0 & 3 \\
\hline 0 & 0 & 5 & 0 & 0 & 0 \\
\hline 1 & 5 & 3 & 0 & 0 & 0 \\
\hline 3 & 5 & 1 & 0 & 3 & 5 \\
\hline 1 & 3 & 5 & 0 & 3 & 3 \\
\hline 3 & 5 & 3 & 5 & 3 & 5 \\
\hline 1 & 1 & 1 & 5 & 0 & 0 \\
\hline 1 & 5 & 3 & 3 & 3 & 5 \\
\hline 5 & 3 & 5 & 3 & 3 & 3 \\
\hline 3 & 0 & 5 & 0 & 0 & 1 \\
\hline 1 & 0 & 0 & 0 & 0 & 0 \\
\hline 3 & 5 & 3 & 0 & 3 & 3 \\
\hline 5 & 5 & 5 & 5 & 5 & 5 \\
\hline 1 & 0 & 1 & 1 & 1 & 1 \\
\hline 5 & 1 & 3 & 5 & 1 & 1 \\
\hline
\end{tabular}




\begin{tabular}{|c|c|c|c|c|c|}
\hline $\begin{array}{c}\text { As comunidades } \\
\text { locais apoiam os } \\
\text { objetivos globais da } \\
\text { UC? }\end{array}$ & $\begin{array}{l}\text { Existe conselho } \\
\text { implementado e } \\
\text { efetivo? }\end{array}$ & $\begin{array}{l}\text { Existe articulação } \\
\text { efetiva da UC com } \\
\text { órgãos e entidades } \\
\text { relacionadas? }\end{array}$ & $\begin{array}{l}\text { A definição do desenho } \\
\text { e da categoria da UC } \\
\text { foi decorrente de um } \\
\text { processo participativo? }\end{array}$ & $\begin{array}{c}\text { As comunidades } \\
\text { locais participam das } \\
\text { decisões pelas quais } \\
\text { são afetadas? }\end{array}$ & $\begin{array}{l}\text { Os resultados da } \\
\text { pesquisa, } \\
\text { monitoramento e o } \\
\text { conhecimento } \\
\text { tradicional são } \\
\text { incluídos } \\
\text { rotineiramente no } \\
\text { planejamento? }\end{array}$ \\
\hline 3 & 3 & 3 & 0 & 3 & 1 \\
\hline 3 & 5 & 5 & 1 & 3 & 0 \\
\hline 3 & 5 & 5 & 5 & 5 & 1 \\
\hline 3 & 0 & 5 & 3 & 3 & 3 \\
\hline 3 & 0 & 3 & 1 & 5 & 5 \\
\hline 1 & 5 & 3 & 5 & 5 & 3 \\
\hline 3 & 3 & 3 & 5 & 3 & 5 \\
\hline 3 & 5 & 3 & 3 & 5 & 5 \\
\hline 1 & 0 & 5 & 5 & 1 & 3 \\
\hline 3 & 5 & 5 & 5 & 5 & 3 \\
\hline 3 & 5 & 5 & 3 & 3 & 5 \\
\hline 5 & 5 & 5 & 5 & 5 & 3 \\
\hline 5 & 5 & 5 & 5 & 5 & 5 \\
\hline 5 & 5 & 5 & 5 & 5 & 0 \\
\hline 5 & 3 & 3 & 5 & 3 & 3 \\
\hline 3 & 0 & 5 & 1 & 0 & 0 \\
\hline 3 & 0 & 5 & 1 & 3 & 0 \\
\hline 5 & 3 & 5 & 5 & 0 & 0 \\
\hline 3 & 5 & 3 & 3 & 3 & 1 \\
\hline 5 & 5 & 3 & 1 & 5 & 0 \\
\hline 5 & 5 & 5 & 3 & 3 & 1 \\
\hline 3 & 0 & 5 & 5 & 1 & 1 \\
\hline 5 & 3 & 3 & 3 & 3 & 3 \\
\hline 1 & 3 & 3 & 1 & 1 & 5 \\
\hline 3 & 3 & 1 & 5 & 3 & 1 \\
\hline 3 & 5 & 5 & 5 & 5 & 0 \\
\hline 5 & 3 & 5 & 5 & 5 & 0 \\
\hline 3 & 3 & 1 & 3 & 3 & 3 \\
\hline 1 & 5 & 5 & 3 & 5 & 3 \\
\hline 3 & 5 & 5 & 5 & 5 & 1 \\
\hline 3 & 0 & 1 & 3 & 1 & 1 \\
\hline 1 & 3 & 3 & 3 & 5 & 1 \\
\hline 5 & 0 & 3 & 5 & 5 & 3 \\
\hline 3 & 5 & 5 & 5 & 3 & 5 \\
\hline 5 & 5 & 1 & 5 & 3 & 1 \\
\hline
\end{tabular}




\begin{tabular}{|c|c|c|c|c|c|}
\hline $\begin{array}{c}\text { As comunidades } \\
\text { locais apoiam os } \\
\text { objetivos globais da } \\
\text { UC? }\end{array}$ & $\begin{array}{l}\text { Existe conselho } \\
\text { implementado e } \\
\text { efetivo? }\end{array}$ & $\begin{array}{l}\text { Existe articulação } \\
\text { efetiva da UC com } \\
\text { órgãos e entidades } \\
\text { relacionadas? }\end{array}$ & $\begin{array}{l}\text { A definição do desenho } \\
\text { e da categoria da UC } \\
\text { foi decorrente de um } \\
\text { processo participativo? }\end{array}$ & $\begin{array}{c}\text { As comunidades } \\
\text { locais participam das } \\
\text { decisões pelas quais } \\
\text { são afetadas? }\end{array}$ & $\begin{array}{l}\text { Os resultados da } \\
\text { pesquisa, } \\
\text { monitoramento e o } \\
\text { conhecimento } \\
\text { tradicional são } \\
\text { incluídos } \\
\text { rotineiramente no } \\
\text { planejamento? }\end{array}$ \\
\hline 5 & 5 & 3 & 3 & 1 & 0 \\
\hline 1 & 3 & 5 & 1 & 1 & 0 \\
\hline 3 & 3 & 3 & 3 & 1 & 5 \\
\hline 3 & 5 & 5 & 5 & 5 & 3 \\
\hline 0 & 0 & 0 & 0 & 0 & 0 \\
\hline 5 & 5 & 1 & 1 & 1 & 1 \\
\hline 0 & 0 & 0 & 3 & 0 & 0 \\
\hline 0 & 0 & 1 & 3 & 0 & 1 \\
\hline 0 & 0 & 3 & 3 & 3 & 3 \\
\hline 0 & 0 & 5 & 5 & 3 & 0 \\
\hline 3 & 5 & 3 & 3 & 3 & 1 \\
\hline 3 & 3 & 1 & 0 & 3 & 0 \\
\hline 3 & 0 & 1 & 3 & 0 & 3 \\
\hline 3 & 0 & 1 & 3 & 0 & 1 \\
\hline 5 & 3 & 5 & 3 & 5 & 3 \\
\hline 3 & 5 & 5 & 3 & 5 & 5 \\
\hline 0 & 0 & 1 & 5 & 0 & 0 \\
\hline 1 & 0 & 1 & 1 & 0 & 1 \\
\hline 1 & 0 & 1 & 0 & 1 & 0 \\
\hline 3 & 0 & 5 & 5 & 3 & 0 \\
\hline 3 & 5 & 5 & 5 & 3 & 3 \\
\hline 1 & 0 & 1 & 1 & 0 & 0 \\
\hline 1 & 0 & 1 & 0 & 1 & 0 \\
\hline 3 & 5 & 3 & 5 & 3 & 1 \\
\hline 1 & 0 & 3 & 0 & 1 & 3 \\
\hline 5 & 5 & 5 & 5 & 5 & 0 \\
\hline 5 & 0 & 5 & 5 & 3 & 0 \\
\hline 0 & 0 & 3 & 1 & 3 & 0 \\
\hline 1 & 0 & 5 & 5 & 1 & 3 \\
\hline 1 & 3 & 5 & 5 & 1 & 1 \\
\hline 3 & 5 & 3 & 5 & 3 & 1 \\
\hline 3 & 5 & 5 & 0 & 5 & 3 \\
\hline 3 & 0 & 3 & 0 & 5 & 0 \\
\hline 1 & 0 & 3 & 3 & 0 & 0 \\
\hline 3 & 0 & 3 & 5 & 1 & 3 \\
\hline 5 & 3 & 5 & 5 & 5 & 5 \\
\hline
\end{tabular}




\begin{tabular}{|c|c|c|c|c|c|}
\hline $\begin{array}{c}\text { As comunidades } \\
\text { locais apoiam os } \\
\text { objetivos globais da } \\
\text { UC? }\end{array}$ & $\begin{array}{c}\text { Existe conselho } \\
\text { implementado e } \\
\text { efetivo? }\end{array}$ & $\begin{array}{l}\text { Existe articulação } \\
\text { efetiva da UC com } \\
\text { órgãos e entidades } \\
\text { relacionadas? }\end{array}$ & $\begin{array}{l}\text { A definição do desenho } \\
\text { e da categoria da UC } \\
\text { foi decorrente de um } \\
\text { processo participativo? }\end{array}$ & $\begin{array}{c}\text { As comunidades } \\
\text { locais participam das } \\
\text { decisões pelas quais } \\
\text { são afetadas? }\end{array}$ & $\begin{array}{l}\text { Os resultados da } \\
\text { pesquisa, } \\
\text { monitoramento e o } \\
\text { conhecimento } \\
\text { tradicional são } \\
\text { incluídos } \\
\text { rotineiramente no } \\
\text { planejamento? }\end{array}$ \\
\hline 5 & 0 & 5 & 3 & 3 & 5 \\
\hline 5 & 0 & 5 & 5 & 3 & 0 \\
\hline 0 & 0 & 0 & 0 & 0 & 0 \\
\hline 3 & 0 & 3 & 5 & 0 & 0 \\
\hline 5 & 0 & 5 & 5 & 5 & 1 \\
\hline 0 & 0 & 3 & 3 & 0 & 0 \\
\hline 5 & 1 & 5 & 5 & 3 & 0 \\
\hline 3 & 1 & 5 & 3 & 3 & 1 \\
\hline 5 & 3 & 5 & 5 & 5 & 5 \\
\hline 3 & 0 & 0 & 1 & 0 & 0 \\
\hline 1 & 0 & 3 & 3 & 0 & 0 \\
\hline 1 & 0 & 5 & 3 & 0 & 0 \\
\hline NA & NA & 0 & 0 & NA & 0 \\
\hline NA & NA & 0 & 0 & NA & 0 \\
\hline NA & NA & 0 & 0 & NA & 0 \\
\hline NA & NA & NA & NA & NA & NA \\
\hline NA & NA & NA & NA & NA & NA \\
\hline NA & NA & NA & NA & NA & NA \\
\hline
\end{tabular}

LEGENDA: c2. Grupo da UC, c3. Categoria, c4. Bioma, c7. Ano de criação da UC, c8. UC criada antes do SNUC, c9. Ano de criação do conselho gestor, e2. Diversidade de canais de participação social utilizados pela UC, e3. Média anual de ações de fiscalização nos últimos cinco anos, e5. Idade do conselho gestor, e9. Principal entrave à participação da sociedade (variável e.29 categorizada), e10. Percepção dos gestores da UC em relação às populações residentes e do entorno, e12. Número de conselheiros que compõem o conselho da UC, e22. Principal estratégia da UC para garantir seus objetivos de conservação, e23. Conselho contempla segmentos que representam uma ameaça aos objetivos da UC, e24. A UC é fonte de geração de renda, e29. Principal entrave a participação da comunidade nas reuniões do conselho gestor da UC, e31. Percepção da comunidade do entorno em relação a UC, e37. Ações de fiscalização realizadas no último ano (2013), e48. Canal de participação entre comunidades e UC mais acessado pela sociedade? d11. Estágio de amadurecimento do conselho gestor? d7.Conselho implementado e efetivo, d17. Percentual de participação de conselheiros por reunião, NA. Nulo. 
ANEXO VII. DADOS UTILIZADOS NA ANÁLISE DE CORRESPONDÊNCIA MULTIVARIADA (MCA) PARA DETERMINAÇÃO DAS VARIÁVEIS DE MAIOR INFLUÊNCIA SOB A PARTICIPAÇÃO SOCIAL.

\begin{tabular}{|c|c|c|c|c|c|c|c|c|c|c|c|c|c|c|c|}
\hline e1 & e7 & e13 & e14 & e20 & e21 & e25 & e28 & e35 & e41 & e49 & d5 & d7 & d12 & d20 & d21 \\
\hline 5 & 3 & 5 & 0 & 5 & 5 & 0 & 0 & 5 & 3 & 5 & 1 & 5 & 3 & 5 & 5 \\
\hline 3 & 3 & 5 & 3 & 3 & 5 & 1 & NA & 3 & 5 & 5 & 5 & 1 & 3 & 3 & 1 \\
\hline 0 & 3 & 0 & 3 & 5 & 0 & 3 & 0 & 1 & 1 & 3 & 1 & 0 & 3 & 1 & 0 \\
\hline 5 & 3 & 5 & 0 & 5 & 5 & 0 & 0 & 5 & 1 & 5 & 5 & 5 & 5 & 3 & 1 \\
\hline 5 & 5 & 5 & 1 & 5 & 5 & 5 & 1 & 5 & 3 & 5 & 1 & 5 & 5 & 5 & 3 \\
\hline 3 & 5 & 5 & 3 & 3 & 5 & 1 & 1 & 3 & 3 & 5 & 1 & 5 & 5 & 3 & 0 \\
\hline 5 & 5 & 5 & 5 & 5 & 5 & 5 & 1 & 5 & 5 & 5 & 3 & 5 & 5 & 5 & 0 \\
\hline 5 & 3 & 5 & 1 & 5 & 5 & 1 & 1 & 5 & 3 & 5 & 3 & 0 & 5 & 1 & 5 \\
\hline 3 & 1 & 5 & 1 & 5 & 5 & 1 & 1 & 3 & 3 & 1 & 1 & 1 & 1 & 0 & 1 \\
\hline 5 & 3 & 5 & 3 & 5 & 5 & 3 & 1 & 5 & 3 & 5 & 3 & 5 & 5 & 5 & 3 \\
\hline 0 & 0 & 5 & 5 & 5 & 0 & 0 & 0 & 5 & 0 & 0 & 1 & 0 & 0 & 0 & 0 \\
\hline 0 & 0 & 5 & 0 & 0 & 5 & 0 & 0 & 0 & 5 & 0 & 3 & 5 & 5 & 1 & 0 \\
\hline 5 & 5 & 5 & 3 & 5 & 5 & 1 & 1 & 5 & 1 & 5 & 5 & 3 & 5 & 1 & 5 \\
\hline 3 & 3 & 5 & 5 & 3 & 5 & 0 & 0 & 0 & 1 & 3 & 0 & 5 & 5 & 3 & 0 \\
\hline 5 & 5 & 5 & 3 & 3 & 3 & 3 & 1 & 5 & 5 & 5 & 3 & 5 & 5 & 5 & 3 \\
\hline 3 & 0 & 5 & 1 & 3 & 3 & 0 & 0 & 3 & 1 & 3 & 1 & 3 & 3 & 3 & 0 \\
\hline 0 & 5 & 5 & 5 & 5 & 3 & 0 & 0 & 1 & 3 & 3 & 3 & 1 & 3 & 1 & 3 \\
\hline 5 & 1 & 1 & 0 & 3 & 3 & 1 & 1 & 3 & 1 & 5 & 1 & 5 & 3 & 1 & 3 \\
\hline 0 & 3 & 5 & 0 & 3 & 3 & 5 & 1 & 3 & 0 & 5 & 1 & 5 & 3 & 0 & 0 \\
\hline 3 & 3 & 5 & 1 & 5 & 3 & 3 & 1 & 1 & 1 & 5 & 3 & 0 & 5 & 1 & 5 \\
\hline 5 & 3 & 5 & 5 & 0 & 3 & 0 & 0 & 5 & 5 & 5 & 3 & 3 & 5 & 5 & 0 \\
\hline 3 & 0 & 5 & 0 & 5 & 0 & 5 & 0 & 1 & 0 & 1 & 1 & 5 & 1 & 3 & 0 \\
\hline 5 & 5 & 0 & 0 & 3 & 5 & 5 & 1 & 5 & 0 & 5 & 5 & 5 & 5 & 5 & 5 \\
\hline 3 & 1 & 1 & 1 & 3 & 3 & 1 & 1 & 3 & 1 & 3 & 3 & 3 & 3 & 1 & 3 \\
\hline 5 & 3 & 5 & 1 & 1 & 5 & 5 & 1 & 5 & 1 & 5 & 3 & 1 & 5 & 1 & 0 \\
\hline 3 & 5 & 5 & 1 & 5 & 5 & 3 & 1 & 5 & 5 & 5 & 3 & 3 & 5 & 3 & 1 \\
\hline 5 & 5 & 5 & 3 & 5 & 5 & 1 & 1 & 5 & 5 & 5 & 3 & 0 & 5 & 5 & 3 \\
\hline 0 & 3 & 0 & 5 & 0 & 5 & 1 & 1 & 5 & 5 & 5 & 5 & 5 & 5 & 5 & 0 \\
\hline 5 & 0 & 5 & 5 & 0 & 3 & 5 & 1 & 0 & 0 & 5 & 1 & 0 & 3 & 0 & 0 \\
\hline 1 & 1 & 5 & 3 & 1 & 1 & 0 & 1 & 3 & 3 & 3 & 3 & 1 & 3 & 1 & 1 \\
\hline 0 & 0 & 5 & 0 & 1 & 0 & 5 & 0 & 0 & 0 & 0 & 3 & 0 & 0 & 0 & 0 \\
\hline 3 & 5 & 5 & 3 & 3 & 5 & 1 & 1 & 3 & 3 & 5 & 1 & 5 & 5 & 3 & 0 \\
\hline 5 & 5 & 0 & 0 & 0 & 3 & 3 & 1 & 5 & 1 & 5 & 1 & 5 & 3 & 3 & 3 \\
\hline 0 & 0 & 0 & 0 & 5 & 3 & 0 & 1 & 3 & 0 & 5 & 0 & 0 & 3 & 0 & 0 \\
\hline 0 & 0 & 0 & 1 & 1 & 0 & 3 & 0 & 3 & 1 & 5 & 3 & 0 & 3 & 1 & 1 \\
\hline 0 & 0 & 0 & 3 & 1 & 0 & 0 & 0 & 0 & 0 & 0 & 0 & 0 & 0 & 0 & 0 \\
\hline 0 & 0 & 0 & 0 & 0 & 0 & 0 & 0 & 0 & 0 & 0 & 0 & 0 & 0 & 0 & 0 \\
\hline 0 & 1 & 5 & 1 & 3 & 5 & 0 & 0 & 3 & 3 & 5 & 3 & 0 & 1 & 1 & 1 \\
\hline 0 & 1 & 0 & 3 & 3 & 0 & 3 & 0 & 5 & 3 & 3 & 1 & 0 & 3 & 3 & 0 \\
\hline
\end{tabular}




\begin{tabular}{|c|c|c|c|c|c|c|c|c|c|c|c|c|c|c|c|}
\hline 3 & 0 & 5 & 1 & 5 & 5 & 0 & 0 & 5 & 0 & 3 & 1 & 5 & 3 & & 3 \\
\hline 5 & 5 & 0 & 0 & 0 & 0 & 5 & 0 & 5 & 0 & 5 & 3 & 0 & 5 & & 0 \\
\hline 0 & 3 & 0 & 0 & 5 & 0 & 0 & 0 & 5 & 0 & 5 & 0 & 0 & 5 & & 0 \\
\hline 5 & 5 & 0 & 5 & 0 & 0 & 5 & 0 & 5 & 3 & 3 & 3 & 5 & 5 & & 3 \\
\hline 5 & 1 & 5 & 3 & 5 & 0 & 3 & 0 & 5 & 5 & 5 & 3 & 5 & 5 & & 3 \\
\hline 1 & 0 & 1 & 0 & 1 & 1 & 0 & 0 & 0 & 0 & 1 & 0 & 0 & 1 & & 0 \\
\hline 0 & 1 & 0 & 1 & 5 & 0 & 5 & 0 & 5 & 1 & 1 & 5 & 0 & 3 & & 0 \\
\hline 3 & 1 & 0 & 5 & 5 & 0 & 0 & 0 & 3 & 3 & 5 & 3 & 0 & 5 & & 3 \\
\hline 3 & 3 & 3 & 1 & 3 & 3 & 1 & 1 & 5 & 3 & 3 & 3 & 3 & 3 & & 3 \\
\hline 0 & 0 & 1 & 0 & 5 & 0 & 0 & 0 & 5 & 0 & 5 & 1 & 1 & 1 & & 3 \\
\hline 0 & 0 & 3 & 0 & 5 & 0 & 0 & 0 & 5 & 1 & 3 & 1 & 3 & 5 & & 3 \\
\hline 3 & 3 & 0 & 0 & 0 & 3 & 0 & 0 & 5 & 3 & 5 & 3 & 3 & 5 & & 0 \\
\hline 0 & 0 & 5 & 0 & 0 & 0 & 5 & 0 & 5 & 0 & 5 & 5 & 5 & 5 & & 1 \\
\hline 1 & 3 & 5 & 1 & 3 & 5 & 0 & 0 & 3 & 1 & 0 & 1 & 3 & 1 & & 1 \\
\hline 5 & 1 & 5 & 3 & 5 & 5 & 1 & 1 & 5 & 3 & 3 & 1 & 5 & 5 & & 5 \\
\hline 3 & 3 & 5 & 5 & 5 & 0 & 1 & 0 & 3 & 3 & 3 & 1 & 1 & 5 & & 1 \\
\hline 0 & 0 & 0 & 0 & 0 & 0 & 0 & 0 & 0 & 0 & 0 & 1 & 0 & 0 & & 0 \\
\hline 0 & 0 & 0 & 3 & 0 & 0 & 0 & 0 & 1 & 1 & 0 & 0 & 0 & 0 & & 0 \\
\hline 5 & 3 & 5 & 5 & 3 & 5 & 5 & 2 & 5 & 5 & 5 & 5 & 0 & 5 & & 3 \\
\hline 3 & 1 & 0 & 1 & 3 & 0 & 1 & 0 & 0 & 1 & 3 & 5 & 3 & 5 & 7 & 0 \\
\hline 5 & 5 & 3 & 3 & 1 & 3 & 5 & 1 & 5 & 5 & 5 & 1 & 5 & 5 & & 1 \\
\hline 5 & 0 & 5 & 1 & 5 & 3 & 1 & 1 & 5 & 1 & 5 & 5 & 5 & 5 & & 3 \\
\hline 3 & 3 & 3 & 0 & 0 & 5 & 0 & 0 & 5 & 1 & 5 & 3 & 0 & 3 & 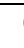 & 0 \\
\hline 3 & 0 & 0 & 3 & 5 & 0 & 5 & 0 & 5 & 3 & 3 & 1 & 5 & 3 & & 0 \\
\hline 1 & 1 & 3 & 1 & 5 & 0 & 0 & 0 & 3 & 3 & 3 & 3 & 0 & 3 & & 3 \\
\hline 5 & 0 & 5 & 0 & 0 & 0 & 5 & 0 & 5 & 0 & 5 & 1 & 0 & 5 & & 0 \\
\hline 0 & 3 & 5 & 0 & 5 & 5 & 3 & 2 & 3 & 1 & 3 & 1 & 0 & 1 & & 5 \\
\hline 0 & 1 & 1 & 3 & 3 & 3 & 1 & 1 & 5 & 1 & 5 & 1 & 0 & 5 & & 5 \\
\hline 5 & 5 & 5 & 1 & 5 & 0 & 3 & 0 & 3 & 0 & 5 & 1 & 5 & 5 & & 0 \\
\hline 0 & 5 & 3 & 0 & 5 & 0 & 3 & 0 & 3 & 0 & 1 & 1 & 0 & 1 & & 0 \\
\hline 5 & 3 & 3 & 3 & 5 & 5 & 3 & 1 & 3 & 3 & 3 & 5 & 5 & 5 & & 0 \\
\hline 1 & 1 & 3 & 1 & 5 & 5 & 0 & 0 & 5 & 0 & 5 & 0 & 3 & 3 & & 0 \\
\hline 5 & 5 & 5 & 5 & 5 & 3 & 5 & 1 & 5 & 5 & 5 & 5 & 5 & 5 & & 3 \\
\hline 0 & 0 & 0 & 5 & 3 & 3 & 0 & 0 & 5 & 5 & 3 & 5 & 3 & 5 & & 5 \\
\hline 5 & 5 & 5 & 5 & 5 & 0 & 0 & 0 & 5 & 5 & 5 & 5 & 5 & 5 & & 1 \\
\hline 0 & 5 & 0 & 5 & 3 & 0 & 0 & 0 & 5 & 5 & 0 & 5 & 3 & 0 & & 0 \\
\hline 5 & 3 & 3 & 1 & 5 & 3 & 1 & 1 & 3 & 5 & 5 & 3 & 0 & 5 & & 3 \\
\hline 3 & 1 & 0 & 1 & 5 & 3 & 3 & 1 & 1 & 3 & 5 & 3 & 3 & 5 & & 0 \\
\hline 3 & 5 & 5 & 3 & 5 & 5 & 3 & 2 & 5 & 3 & 3 & 3 & 5 & 5 & & 3 \\
\hline 5 & 3 & 5 & 5 & 0 & 3 & 0 & 0 & 5 & 5 & 5 & 3 & 3 & 5 & 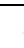 & 0 \\
\hline 5 & 3 & 5 & 5 & 5 & 3 & 0 & 0 & 5 & 5 & 5 & 5 & 5 & 5 & & 3 \\
\hline 5 & 5 & 0 & 0 & 3 & 5 & 0 & 0 & 5 & 5 & 3 & 3 & 5 & 5 & & 0 \\
\hline 5 & 3 & 5 & 5 & 5 & 5 & 0 & 0 & 5 & 1 & 5 & 3 & 3 & 5 & & 3 \\
\hline
\end{tabular}




\begin{tabular}{|c|c|c|c|c|c|c|c|c|c|c|c|c|c|c|c|}
\hline 0 & 0 & 0 & 0 & 0 & 1 & 3 & 1 & 5 & 3 & 5 & 3 & 5 & 3 & 5 & 3 \\
\hline 3 & 3 & 5 & 3 & 5 & 5 & 1 & 1 & 3 & 0 & 5 & 1 & 5 & 5 & 5 & 1 \\
\hline 5 & 5 & 0 & 5 & 5 & 0 & 0 & 0 & 5 & 5 & 5 & 3 & 5 & 3 & 5 & 0 \\
\hline 5 & 0 & 1 & 5 & 5 & 1 & 0 & 1 & 3 & 5 & 5 & 0 & 5 & 5 & 5 & 0 \\
\hline 5 & 3 & 3 & 3 & 5 & 5 & 5 & 1 & 5 & 5 & 5 & 5 & 5 & 5 & 5 & 5 \\
\hline 1 & 1 & 5 & 1 & 0 & 3 & 0 & 0 & 5 & 3 & 5 & 3 & 5 & 5 & 3 & 1 \\
\hline 3 & 0 & 5 & 5 & 5 & 1 & 0 & 1 & 5 & 3 & 0 & 3 & 1 & 3 & 3 & 0 \\
\hline 5 & 5 & 3 & 5 & 5 & 5 & 3 & 1 & 5 & 5 & 3 & 5 & 5 & 5 & 0 & 5 \\
\hline 5 & 5 & 3 & 5 & 3 & 5 & 0 & 0 & 5 & 5 & 5 & 5 & 5 & 5 & 5 & 0 \\
\hline 5 & 5 & 3 & 5 & 3 & 5 & 1 & 1 & 5 & 5 & 5 & 3 & 3 & 5 & 3 & 0 \\
\hline 0 & 3 & 1 & 5 & 5 & 3 & 1 & 1 & 5 & 3 & 5 & 5 & 5 & 5 & 5 & 0 \\
\hline 0 & 0 & 5 & 5 & 5 & 0 & 0 & 0 & 0 & 0 & 0 & 3 & 0 & 3 & 0 & 0 \\
\hline 5 & 0 & 5 & 5 & 3 & 5 & 0 & 0 & 5 & 5 & 5 & 5 & 5 & 5 & 5 & 5 \\
\hline 0 & 0 & 3 & 0 & 3 & 3 & 0 & 0 & 5 & 1 & 0 & 1 & 0 & 3 & 0 & 0 \\
\hline 3 & 0 & 1 & 0 & 1 & 1 & 0 & 0 & 0 & 0 & 1 & 1 & 0 & 0 & 0 & 0 \\
\hline 5 & 3 & 5 & 3 & 3 & 0 & 5 & 0 & 5 & 3 & 5 & 5 & 5 & 5 & 5 & 5 \\
\hline 5 & 1 & 0 & 3 & 5 & 1 & 1 & 1 & 5 & 3 & 5 & 3 & 3 & 5 & 3 & 3 \\
\hline 3 & 1 & 0 & 1 & 3 & 5 & 0 & 0 & 3 & 3 & 5 & 5 & 5 & 5 & 3 & 1 \\
\hline 0 & 0 & 5 & 0 & 0 & 0 & 0 & 0 & 0 & 0 & 0 & 3 & 0 & 0 & 0 & 0 \\
\hline 3 & 3 & 1 & 3 & 3 & 3 & 0 & 0 & 5 & 1 & 5 & 5 & 1 & 0 & 3 & 0 \\
\hline 5 & 0 & 1 & 0 & 3 & 3 & 3 & 1 & 5 & 1 & 3 & 3 & 3 & 5 & 0 & 1 \\
\hline 0 & 0 & 5 & 0 & 3 & 3 & 0 & 0 & 5 & 0 & 0 & 3 & 0 & 3 & 0 & 0 \\
\hline 5 & 5 & 5 & 5 & 0 & 5 & 3 & 1 & 5 & 5 & 5 & 5 & 5 & 5 & 5 & 0 \\
\hline 0 & 1 & 0 & 1 & 5 & 0 & 3 & 0 & 5 & 5 & 5 & 0 & 0 & 3 & 0 & 0 \\
\hline 1 & 0 & 0 & 0 & 5 & 0 & 5 & 0 & 1 & 1 & 1 & 1 & 0 & 3 & 1 & 0 \\
\hline 5 & 5 & 3 & 0 & 5 & 1 & 1 & 1 & 5 & 3 & 5 & 5 & 5 & 3 & 5 & 5 \\
\hline 0 & 5 & 5 & 0 & 5 & 0 & 0 & 0 & 5 & 3 & 5 & 0 & 0 & 3 & 0 & 3 \\
\hline 5 & 3 & 5 & 3 & 3 & 0 & 5 & 0 & 5 & 3 & 5 & 5 & 5 & 5 & 5 & 5 \\
\hline 5 & 5 & 0 & 1 & 0 & 3 & 0 & 0 & 0 & 1 & 3 & 5 & 3 & 3 & 3 & 1 \\
\hline 1 & 5 & 0 & 5 & 5 & 3 & 5 & 2 & 5 & 1 & 5 & 5 & 0 & 5 & 0 & 0 \\
\hline 0 & 5 & 5 & 3 & 5 & 5 & 1 & 1 & 5 & 3 & 5 & 3 & 5 & 5 & 5 & 1 \\
\hline 5 & 5 & 5 & 0 & 5 & 5 & 0 & 0 & 5 & 3 & 5 & 1 & 5 & 3 & 5 & 0 \\
\hline 0 & 5 & 0 & 0 & 5 & 0 & 5 & 0 & 5 & 0 & 3 & 3 & 3 & 3 & 0 & 0 \\
\hline 0 & 0 & 0 & 0 & 0 & 0 & 0 & 0 & 5 & 3 & 5 & 3 & 0 & 5 & 3 & 5 \\
\hline 0 & 0 & 3 & 0 & 5 & 3 & 0 & 0 & 0 & 1 & 0 & 0 & 0 & 1 & 0 & 0 \\
\hline 3 & 5 & 0 & 3 & 0 & 0 & 5 & 0 & 5 & 5 & 3 & 5 & 0 & 3 & 3 & 0 \\
\hline 5 & 5 & 5 & 5 & 3 & 5 & 3 & 1 & 5 & 3 & 5 & 5 & 5 & 5 & 5 & 3 \\
\hline 3 & 0 & 0 & 1 & 5 & 0 & 1 & 0 & 3 & 1 & 1 & 1 & 3 & 3 & 1 & 3 \\
\hline 1 & 3 & 3 & 0 & 3 & 0 & 5 & 0 & 3 & 0 & 1 & 3 & 0 & 5 & 0 & 3 \\
\hline 5 & 3 & 3 & 0 & 0 & 3 & 0 & 0 & 3 & 0 & 3 & 1 & 1 & 1 & 0 & 3 \\
\hline 0 & 5 & 5 & 0 & 5 & 5 & 3 & 2 & 5 & 5 & 3 & 5 & 3 & 3 & 1 & 3 \\
\hline 5 & 3 & 1 & 3 & 5 & 1 & 5 & 1 & 5 & 3 & 5 & 3 & 3 & 5 & 5 & 5 \\
\hline 1 & 1 & 5 & 3 & 5 & 5 & 1 & 1 & 3 & 5 & 3 & 5 & 1 & 5 & 3 & 3 \\
\hline
\end{tabular}




\begin{tabular}{|c|c|c|c|c|c|c|c|c|c|c|c|c|c|c|c|}
\hline 3 & 3 & 5 & 5 & 5 & 5 & 0 & 0 & 5 & 3 & 5 & 1 & 5 & 5 & & 3 \\
\hline 0 & 1 & 5 & 0 & 5 & 5 & 0 & 0 & 1 & 1 & 1 & 1 & 5 & 3 & & 1 \\
\hline 3 & 1 & 5 & 1 & 1 & 5 & 0 & 0 & 5 & 5 & 5 & 1 & 3 & 3 & & 5 \\
\hline 1 & 3 & 5 & 0 & 5 & 5 & 3 & 1 & 5 & 3 & 5 & 5 & 5 & 5 & & 1 \\
\hline 5 & 3 & 5 & 3 & 3 & 0 & 0 & 0 & 3 & 3 & 5 & 0 & 3 & 5 & & 3 \\
\hline 5 & 5 & 5 & 5 & 0 & 5 & 0 & 0 & 5 & 5 & 5 & 5 & 5 & 5 & & 1 \\
\hline 3 & 0 & 5 & 3 & 5 & 3 & 1 & 1 & 5 & 3 & 3 & 1 & 1 & 3 & & 3 \\
\hline 5 & 0 & 5 & 0 & 1 & 1 & 0 & 0 & 0 & 1 & 5 & 3 & 0 & 5 & & 0 \\
\hline 3 & 3 & 3 & 5 & 3 & 5 & 3 & 2 & 5 & 5 & 5 & 1 & 5 & 5 & & 3 \\
\hline 3 & 3 & 5 & 1 & 1 & 5 & 5 & 1 & 1 & 3 & 3 & 3 & 1 & 3 & 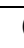 & 0 \\
\hline 0 & 5 & 5 & 3 & 0 & 5 & 0 & 0 & 5 & 5 & 5 & 5 & 3 & 3 & & 1 \\
\hline 0 & 1 & 5 & 5 & 5 & 5 & 0 & 0 & 5 & 3 & 5 & 5 & 0 & 5 & & 5 \\
\hline 5 & 0 & 5 & 3 & 0 & 5 & 3 & 1 & 5 & 5 & 5 & 3 & 3 & 5 & 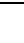 & 0 \\
\hline 5 & 0 & 5 & 0 & 5 & 3 & 0 & 0 & 5 & 1 & 5 & 1 & 5 & 5 & & 5 \\
\hline 0 & 0 & 5 & 0 & 5 & 5 & 0 & 0 & 5 & 5 & 5 & 5 & 5 & 5 & & 5 \\
\hline 1 & 0 & 5 & 0 & 5 & 3 & 0 & 0 & 3 & 0 & 5 & 3 & 0 & 1 & & 0 \\
\hline 0 & 3 & 5 & 5 & 5 & 5 & 5 & 1 & 3 & 5 & 5 & 3 & 5 & 5 & & 5 \\
\hline 3 & 1 & 5 & 1 & 0 & 5 & 0 & 0 & 5 & 1 & 3 & 1 & 5 & 3 & & 0 \\
\hline 3 & 3 & 5 & 1 & 5 & 5 & 3 & 1 & 3 & 1 & 3 & 3 & 5 & 5 & & 1 \\
\hline 3 & 5 & 1 & 5 & 1 & 3 & 1 & 1 & 3 & 3 & 3 & 3 & 5 & 3 & & 1 \\
\hline 0 & 5 & 0 & 0 & 5 & 0 & 0 & 0 & 5 & 0 & 5 & 5 & 0 & 5 & & 0 \\
\hline 5 & 5 & 5 & 1 & 5 & 3 & 0 & 0 & 5 & 3 & 1 & 1 & 5 & 5 & & 3 \\
\hline 3 & 1 & 5 & 1 & 0 & 5 & 0 & 0 & 5 & 1 & 3 & 1 & 5 & 3 & & 0 \\
\hline 0 & 5 & 5 & 1 & 3 & 5 & 5 & 2 & 5 & 5 & 5 & 5 & 5 & 5 & & 5 \\
\hline 5 & 5 & 5 & 3 & 0 & 5 & 3 & 1 & 5 & 3 & 5 & 3 & 1 & 3 & & 5 \\
\hline 1 & 3 & 3 & 1 & 3 & 5 & 1 & 1 & 3 & 1 & 3 & 1 & 0 & 3 & & 3 \\
\hline 5 & 5 & 5 & 5 & 1 & 5 & 5 & 2 & 5 & 5 & 5 & 3 & 0 & 5 & & 0 \\
\hline 0 & 1 & 5 & 0 & 5 & 0 & 1 & 0 & 1 & 0 & 3 & 1 & 0 & 3 & & 0 \\
\hline 3 & 1 & 5 & 0 & 5 & 5 & 1 & 1 & 5 & 1 & 3 & 1 & 5 & 5 & & 1 \\
\hline 3 & 0 & 5 & 1 & 3 & 3 & 3 & 2 & 1 & 1 & 5 & 1 & 0 & 3 & & 1 \\
\hline 5 & 5 & 5 & 5 & 0 & 5 & 5 & 2 & 5 & 5 & 5 & 5 & 3 & 5 & & 0 \\
\hline 5 & 1 & 5 & 1 & 1 & 5 & 3 & 1 & 3 & 1 & 1 & 3 & 3 & 3 & & 1 \\
\hline 5 & 1 & 5 & 3 & 5 & 5 & 0 & 0 & 5 & 3 & 5 & 3 & 0 & 5 & & 1 \\
\hline 3 & 3 & 3 & 0 & 5 & 1 & 3 & 1 & 3 & 1 & 5 & 1 & 3 & 5 & & 3 \\
\hline 5 & 0 & 5 & 1 & 3 & 5 & 0 & 1 & 1 & 1 & 3 & 1 & 1 & 3 & & 1 \\
\hline 3 & 3 & 0 & 1 & 3 & 1 & 0 & 0 & 3 & 3 & 5 & 3 & 5 & 3 & & 1 \\
\hline 5 & 5 & 5 & 0 & 5 & 5 & 5 & 1 & 5 & 3 & 5 & 1 & 5 & 5 & & 3 \\
\hline 5 & 5 & 5 & 5 & 5 & 5 & 3 & 2 & 5 & 5 & 5 & 3 & 5 & 5 & & 3 \\
\hline 3 & 5 & 5 & 3 & 5 & 3 & 5 & 1 & 3 & 3 & 3 & 5 & 0 & 5 & & 0 \\
\hline 3 & 3 & 5 & 3 & 3 & 3 & 0 & 0 & 5 & 3 & 5 & 3 & 1 & 5 & & 3 \\
\hline 3 & 5 & 5 & 1 & 5 & 3 & 0 & 0 & 5 & 3 & 5 & 5 & 5 & 5 & & 1 \\
\hline 0 & 0 & 5 & 0 & 5 & 3 & 0 & 0 & 3 & 3 & 5 & 0 & 0 & 3 & & 0 \\
\hline 5 & 3 & 5 & 3 & 3 & 5 & 0 & 0 & 5 & 5 & 5 & 5 & 5 & 5 & & 5 \\
\hline
\end{tabular}




\begin{tabular}{|c|c|c|c|c|c|c|c|c|c|c|c|c|c|c|c|}
\hline 5 & 3 & 5 & 1 & 1 & 5 & 0 & 0 & 5 & 3 & 5 & 3 & 0 & 5 & 1 & 5 \\
\hline 0 & 5 & 5 & 5 & 5 & 5 & 1 & 1 & 5 & 3 & 5 & 5 & 0 & 5 & 0 & 3 \\
\hline 0 & 3 & 5 & 5 & 5 & 5 & 0 & 0 & 5 & 5 & 5 & 3 & 0 & 5 & 5 & 0 \\
\hline 5 & 0 & 5 & 5 & 5 & 5 & 5 & 2 & 5 & 5 & 3 & 5 & 0 & 5 & 5 & 0 \\
\hline 3 & 1 & 5 & 0 & 0 & 3 & 5 & 1 & 0 & 0 & 5 & 3 & 1 & 5 & 1 & 5 \\
\hline 1 & 5 & 5 & 0 & 3 & 5 & 1 & 1 & 3 & 1 & 3 & 1 & 5 & 5 & 3 & 1 \\
\hline 3 & 0 & 5 & 1 & 5 & 5 & 5 & 2 & 3 & 3 & 5 & 3 & 5 & 5 & 3 & 1 \\
\hline 5 & 3 & 5 & 3 & 0 & 5 & 1 & 1 & 3 & 3 & 5 & 1 & 5 & 3 & 3 & 3 \\
\hline 5 & 3 & 3 & 1 & 5 & 1 & 5 & 1 & 5 & 1 & 5 & 1 & 5 & 5 & 3 & 5 \\
\hline 5 & 5 & 3 & 3 & 5 & 1 & 0 & 0 & 3 & 1 & 5 & 3 & 5 & 5 & 3 & 0 \\
\hline 5 & 3 & 5 & 1 & 5 & 5 & 0 & 0 & 5 & 3 & 5 & 5 & 0 & 5 & 3 & 0 \\
\hline 5 & 5 & 3 & 5 & 1 & 5 & 3 & 1 & 0 & 5 & 5 & 5 & 0 & 5 & 0 & 5 \\
\hline 0 & 0 & 0 & 0 & 0 & 0 & 5 & 0 & 5 & 0 & 5 & 5 & 1 & 5 & 0 & 5 \\
\hline 0 & 0 & 5 & 0 & 5 & 5 & 0 & 0 & 5 & 1 & 3 & 1 & 0 & 1 & 0 & 0 \\
\hline 1 & 0 & 1 & 3 & 3 & 1 & 5 & 1 & 1 & 1 & 1 & 1 & 0 & 1 & 0 & 1 \\
\hline 0 & 1 & 0 & 1 & 5 & 0 & 1 & 0 & 1 & 0 & 0 & 1 & 0 & 3 & 0 & 0 \\
\hline 0 & 0 & 0 & 1 & 5 & 5 & 3 & 1 & 0 & 1 & 5 & 3 & 0 & 5 & 3 & 0 \\
\hline 5 & 5 & 0 & 5 & 5 & 0 & 5 & 0 & 5 & 1 & 5 & 3 & 3 & 5 & 5 & 3 \\
\hline 0 & 5 & 5 & 5 & 5 & 5 & 0 & 0 & 5 & 5 & 5 & 1 & 0 & 5 & 0 & 0 \\
\hline 0 & 3 & 0 & 1 & 5 & 0 & 5 & 0 & 5 & 3 & 3 & 3 & 3 & 3 & 3 & 1 \\
\hline 5 & 3 & 3 & 3 & 5 & 3 & 5 & 2 & 5 & 1 & 5 & 3 & 0 & 5 & 0 & 1 \\
\hline 0 & 5 & 5 & 0 & 5 & 0 & 0 & 0 & 5 & 5 & 5 & 5 & 3 & 5 & 0 & 5 \\
\hline 1 & 5 & 0 & 0 & 5 & 0 & 5 & 0 & 5 & 1 & 5 & 3 & 5 & 3 & 1 & 3 \\
\hline 0 & 5 & 0 & 0 & 5 & 0 & 0 & 0 & 5 & 1 & 5 & 1 & 3 & 5 & 0 & 0 \\
\hline 0 & 0 & 0 & 0 & 0 & 0 & 0 & 0 & 5 & 0 & 3 & 1 & 0 & 5 & 0 & 5 \\
\hline 0 & 5 & 0 & 0 & 1 & 3 & 5 & 2 & 5 & 0 & 5 & 3 & 0 & 5 & 0 & 0 \\
\hline 0 & 0 & 0 & 3 & 5 & 0 & 3 & 0 & 5 & 5 & 5 & 3 & 5 & 5 & 5 & 1 \\
\hline 1 & 5 & 3 & 1 & 3 & 1 & 0 & 0 & 5 & 3 & 3 & 1 & 0 & 3 & 0 & 3 \\
\hline 0 & 0 & 0 & 0 & 5 & 0 & 5 & 0 & 5 & 0 & 0 & 0 & 0 & 5 & 0 & 0 \\
\hline 5 & 1 & 5 & 5 & 5 & 0 & 3 & 0 & 0 & 5 & 3 & 1 & 5 & 3 & 0 & 0 \\
\hline 3 & 3 & 5 & 1 & 5 & 3 & 0 & 0 & 5 & 3 & 5 & 3 & 5 & 1 & 3 & 5 \\
\hline 5 & 1 & 0 & 3 & 0 & 0 & 3 & 0 & 5 & 3 & 5 & 1 & 3 & 5 & 3 & 3 \\
\hline 5 & 0 & 5 & 3 & 5 & 0 & 5 & 0 & 5 & 5 & 5 & 3 & 5 & 3 & 3 & 5 \\
\hline 0 & 3 & 5 & 0 & 5 & 0 & 0 & 0 & 1 & 0 & 0 & 1 & 1 & 1 & 0 & 0 \\
\hline 5 & 3 & 5 & 1 & 5 & 0 & 3 & 0 & 5 & 1 & 5 & 1 & 5 & 3 & 3 & 5 \\
\hline 5 & 5 & 5 & 1 & 3 & 3 & 0 & 0 & 5 & 3 & 5 & 5 & 3 & 5 & 3 & 3 \\
\hline 1 & 5 & 0 & 0 & 5 & 0 & 3 & 0 & 5 & 5 & 5 & 3 & 0 & 5 & 0 & 1 \\
\hline 0 & 0 & 5 & 3 & 5 & 5 & 0 & 0 & 5 & 0 & 1 & 1 & 0 & 0 & 0 & 0 \\
\hline 3 & 5 & 0 & 1 & 5 & 0 & 3 & 0 & 5 & 3 & 5 & 3 & 5 & 3 & 3 & 3 \\
\hline 5 & 3 & 0 & 5 & 1 & 0 & 5 & 0 & 5 & 5 & 5 & 5 & 5 & 5 & 5 & 5 \\
\hline 0 & 0 & 1 & 1 & 3 & 1 & 0 & 0 & 5 & 1 & 0 & 1 & 0 & 1 & 1 & 1 \\
\hline 3 & 1 & 3 & 3 & 3 & 1 & 0 & 0 & 1 & 1 & 3 & 5 & 1 & 3 & 1 & 1 \\
\hline 5 & 0 & 0 & 1 & 3 & 1 & 1 & 1 & 3 & 3 & 3 & 3 & 3 & 3 & 3 & 1 \\
\hline
\end{tabular}




\begin{tabular}{|c|c|c|c|c|c|c|c|c|c|c|c|c|c|c|c|}
\hline 1 & 1 & 5 & 3 & 3 & 0 & 0 & 0 & 5 & 1 & 5 & 3 & 5 & 5 & 3 & 0 \\
\hline 5 & 0 & 5 & 3 & 0 & 5 & 0 & 0 & 5 & 5 & 5 & 3 & 5 & 5 & 5 & 1 \\
\hline 3 & 3 & 5 & 5 & 3 & 5 & 1 & 1 & 3 & 3 & 3 & 3 & 0 & 5 & 3 & 3 \\
\hline 5 & 0 & 0 & 1 & 5 & 0 & 5 & 0 & 5 & 5 & 5 & 3 & 0 & 3 & 5 & 5 \\
\hline 1 & 3 & 5 & 3 & 3 & 5 & 1 & 1 & 5 & 3 & 5 & 1 & 5 & 3 & 5 & 3 \\
\hline 5 & 5 & 5 & 3 & 0 & 5 & 1 & 1 & 5 & 3 & 3 & 3 & 3 & 3 & 3 & 5 \\
\hline 5 & 3 & 5 & 3 & 1 & 3 & 0 & 0 & 5 & 3 & 5 & 3 & 5 & 3 & 5 & 5 \\
\hline 3 & 3 & 5 & 3 & 3 & 5 & 0 & 0 & 3 & 3 & 5 & 1 & 0 & 5 & 1 & 3 \\
\hline 5 & 5 & 3 & 1 & 1 & 0 & 0 & 0 & 5 & 1 & 5 & 3 & 5 & 5 & 5 & 3 \\
\hline 5 & 5 & 5 & 3 & 5 & 5 & 3 & 2 & 5 & 3 & 5 & 3 & 5 & 5 & 3 & 5 \\
\hline 5 & 3 & 5 & 5 & 3 & 5 & 1 & 1 & 5 & 5 & 5 & 5 & 5 & 5 & 5 & 3 \\
\hline 5 & 5 & 5 & 3 & 5 & 3 & 0 & 0 & 5 & 5 & 5 & 5 & 5 & 5 & 5 & 5 \\
\hline 5 & 1 & 3 & 5 & 3 & 0 & 0 & 0 & 5 & 5 & 5 & 5 & 5 & 5 & 5 & 0 \\
\hline 5 & 0 & 5 & 5 & 5 & 1 & 3 & 1 & 0 & 3 & 3 & 5 & 3 & 3 & 3 & 3 \\
\hline 5 & 0 & 5 & 3 & 3 & 0 & 0 & 0 & 1 & 3 & 5 & 3 & 0 & 5 & 0 & 0 \\
\hline 3 & 1 & 5 & 1 & 5 & 3 & 0 & 0 & 5 & 3 & 5 & 3 & 0 & 5 & 3 & 0 \\
\hline 0 & 5 & 0 & 5 & 1 & 0 & 0 & 0 & 0 & 5 & 0 & 5 & 3 & 5 & 0 & 0 \\
\hline 0 & 3 & 3 & 1 & 3 & 1 & 0 & 0 & 5 & 3 & 1 & 3 & 5 & 3 & 3 & 1 \\
\hline 5 & 3 & 0 & 5 & 1 & 0 & 5 & 0 & 5 & 1 & 3 & 5 & 5 & 3 & 5 & 0 \\
\hline 5 & 1 & 5 & 1 & 1 & 5 & 0 & 0 & 5 & 1 & 5 & 5 & 5 & 5 & 3 & 1 \\
\hline 3 & 3 & 5 & 5 & 0 & 3 & 0 & 0 & 3 & 3 & 5 & 3 & 0 & 5 & 1 & 1 \\
\hline 3 & 1 & 3 & 3 & 1 & 0 & 5 & 0 & 3 & 1 & 3 & 5 & 3 & 3 & 3 & 3 \\
\hline 1 & 1 & 5 & 1 & 1 & 3 & 0 & 0 & 3 & 1 & 5 & 1 & 3 & 3 & 1 & 5 \\
\hline 3 & 3 & 5 & 5 & 1 & 1 & 0 & 0 & 3 & 3 & 1 & 3 & 3 & 1 & 3 & 1 \\
\hline 5 & 3 & 5 & 5 & 0 & 3 & 0 & 0 & 3 & 5 & 5 & 3 & 5 & 5 & 5 & 0 \\
\hline 5 & 3 & 5 & 5 & 0 & 5 & 0 & 0 & 5 & 5 & 5 & 5 & 3 & 5 & 5 & 0 \\
\hline 1 & 1 & 5 & 0 & 3 & 5 & 0 & 0 & 3 & 1 & 3 & 3 & 3 & 1 & 3 & 3 \\
\hline 5 & 1 & 3 & 3 & 3 & 5 & 0 & 1 & 5 & 5 & 5 & 1 & 5 & 5 & 5 & 3 \\
\hline 5 & 1 & 5 & 3 & 0 & 5 & 3 & 1 & 5 & 3 & 3 & 3 & 5 & 5 & 5 & 1 \\
\hline 3 & 1 & 0 & 3 & 0 & 0 & 0 & 0 & 5 & 5 & 1 & 3 & 0 & 1 & 1 & 1 \\
\hline 5 & 0 & 5 & 1 & 5 & 3 & 0 & 0 & 3 & 1 & 5 & 1 & 3 & 3 & 5 & 1 \\
\hline 5 & 0 & 0 & 5 & 1 & 0 & 0 & 0 & 5 & 5 & 5 & 5 & 0 & 3 & 5 & 3 \\
\hline 5 & 3 & 5 & 3 & 3 & 5 & 0 & 0 & 3 & 1 & 5 & 3 & 5 & 5 & 3 & 5 \\
\hline 5 & 5 & 5 & 5 & 5 & 5 & 1 & 1 & 5 & 5 & 1 & 5 & 5 & 1 & 3 & 1 \\
\hline 5 & 3 & 0 & 5 & 5 & 0 & 5 & 0 & 5 & 5 & 5 & 5 & 5 & 3 & 1 & 0 \\
\hline 3 & 0 & 3 & 1 & 5 & 0 & 5 & 0 & 3 & 1 & 1 & 1 & 3 & 5 & 1 & 0 \\
\hline 5 & 0 & 0 & 3 & 3 & 0 & 5 & 0 & 3 & 1 & 1 & 3 & 3 & 3 & 1 & 5 \\
\hline 5 & 3 & 5 & 3 & 3 & 0 & 3 & 0 & 5 & 5 & 5 & 3 & 5 & 5 & 5 & 3 \\
\hline 0 & 0 & 5 & 0 & 5 & 5 & 0 & 1 & 5 & 0 & 0 & 0 & 0 & 0 & 0 & 0 \\
\hline 0 & 5 & 5 & 1 & 5 & 5 & 0 & 1 & 5 & 1 & 3 & 5 & 5 & 1 & 1 & 1 \\
\hline 0 & 5 & 0 & 5 & 5 & 0 & 0 & 0 & 0 & 0 & 0 & 0 & 0 & 0 & 0 & 0 \\
\hline 0 & 0 & 5 & 3 & 5 & 5 & 0 & 1 & 5 & 0 & 5 & 0 & 0 & 1 & 0 & 1 \\
\hline 0 & 1 & 5 & 1 & 5 & 5 & 0 & 1 & 3 & 1 & 5 & 0 & 0 & 3 & 3 & 3 \\
\hline
\end{tabular}




\begin{tabular}{|c|c|c|c|c|c|c|c|c|c|c|c|c|c|c|c|}
\hline 0 & 5 & 5 & 1 & 0 & 3 & 0 & 0 & 5 & 1 & 3 & 0 & 0 & 5 & 3 & 0 \\
\hline 5 & 0 & 5 & 3 & 5 & 0 & 0 & 0 & 5 & 1 & 3 & 3 & 5 & 3 & 3 & 1 \\
\hline 1 & 3 & 3 & 0 & 5 & 0 & 5 & 0 & 5 & 1 & 5 & 3 & 3 & 1 & 3 & 0 \\
\hline 0 & 0 & 5 & 1 & 1 & 5 & 0 & 0 & 5 & 1 & 3 & 3 & 0 & 1 & 0 & 3 \\
\hline 0 & 0 & 0 & 1 & 3 & 3 & 5 & 2 & 0 & 1 & 1 & 3 & 0 & 1 & 0 & 1 \\
\hline 5 & 5 & 5 & 5 & 0 & 3 & 0 & 0 & 5 & 5 & 5 & 5 & 3 & 5 & 5 & 3 \\
\hline 5 & 5 & 3 & 5 & 5 & 0 & 0 & 0 & 5 & 5 & 5 & 3 & 5 & 5 & 5 & 5 \\
\hline 0 & 5 & 1 & 1 & 1 & 0 & 5 & 0 & 5 & 0 & 1 & 0 & 0 & 1 & 0 & 0 \\
\hline 0 & 5 & 5 & 3 & 5 & 5 & 0 & 1 & 5 & 0 & 0 & 1 & 0 & 1 & 0 & 1 \\
\hline 5 & 1 & 5 & 1 & 5 & 1 & 0 & 0 & 5 & 0 & 1 & 1 & 0 & 1 & 1 & 0 \\
\hline 5 & 0 & 5 & 3 & 1 & 3 & 0 & 0 & 3 & 3 & 1 & 3 & 0 & 5 & 3 & 0 \\
\hline 5 & 3 & 5 & 3 & 5 & 3 & 5 & 2 & 3 & 1 & 5 & 3 & 5 & 5 & 3 & 3 \\
\hline 3 & 0 & 5 & 0 & 5 & 5 & 0 & 1 & 5 & 1 & 3 & 1 & 0 & 1 & 0 & 0 \\
\hline 0 & 0 & 0 & 0 & 5 & 0 & 0 & 0 & 0 & 3 & 5 & 1 & 0 & 1 & 1 & 0 \\
\hline 5 & 3 & 5 & 1 & 3 & 3 & 0 & 1 & 3 & 5 & 5 & 3 & 5 & 3 & 3 & 1 \\
\hline 0 & 1 & 5 & 1 & 5 & 5 & 0 & 1 & 3 & 0 & 1 & 1 & 0 & 3 & 1 & 3 \\
\hline 5 & 3 & 1 & 5 & 1 & 1 & 0 & 1 & 5 & 5 & 5 & 5 & 5 & 5 & 5 & 0 \\
\hline 0 & 5 & 0 & 5 & 0 & 0 & 5 & 0 & 5 & 5 & 5 & 5 & 0 & 5 & 3 & 0 \\
\hline 5 & 0 & 5 & 0 & 0 & 5 & 0 & 1 & 3 & 1 & 3 & 0 & 0 & 3 & 3 & 0 \\
\hline 0 & 0 & 3 & 3 & 5 & 5 & 0 & 1 & 5 & 3 & 5 & 1 & 0 & 5 & 1 & 3 \\
\hline 5 & 5 & 5 & 3 & 3 & 0 & 0 & 0 & 5 & 3 & 5 & 1 & 3 & 5 & 1 & 1 \\
\hline 5 & 1 & 5 & 0 & 5 & 0 & 0 & 0 & 3 & 3 & 3 & 3 & 5 & 3 & 3 & 1 \\
\hline 5 & 5 & 5 & 5 & 5 & 5 & 0 & 0 & 5 & 5 & 5 & 3 & 5 & 5 & 5 & 3 \\
\hline 5 & 5 & 5 & 5 & 0 & 0 & 5 & 0 & 5 & 5 & 5 & 3 & 0 & 3 & 5 & 0 \\
\hline 0 & 1 & 5 & 0 & 5 & 3 & 0 & 0 & 3 & 0 & 5 & 1 & 0 & 3 & 0 & 0 \\
\hline 1 & 0 & 5 & 3 & 3 & 3 & 0 & 1 & 5 & 3 & 5 & 3 & 0 & 3 & 1 & 3 \\
\hline 5 & 3 & 3 & 5 & 0 & 0 & 0 & 0 & 5 & 5 & 5 & 5 & 3 & 5 & 5 & 5 \\
\hline 3 & 0 & 5 & 0 & 5 & 1 & 1 & 1 & 5 & 1 & 5 & 5 & 0 & 5 & 3 & 5 \\
\hline 5 & 3 & 0 & 5 & 5 & 1 & 0 & 1 & 5 & 5 & 5 & 5 & 0 & 5 & 3 & 0 \\
\hline 0 & 0 & 3 & 0 & 5 & 0 & 0 & 0 & 5 & 0 & 0 & 0 & 0 & 0 & 0 & 0 \\
\hline 0 & 0 & 1 & 0 & 3 & 3 & 0 & 1 & 3 & 0 & 1 & 3 & 0 & 3 & 0 & 0 \\
\hline 5 & 0 & 5 & 5 & 5 & 3 & 0 & 1 & 5 & 5 & 5 & 5 & 0 & 5 & 5 & 1 \\
\hline 0 & 0 & 3 & 1 & 5 & 5 & 0 & 1 & 5 & 0 & 0 & 0 & 0 & 3 & 0 & 0 \\
\hline 5 & 0 & 3 & 3 & 5 & 3 & 0 & 1 & 5 & 3 & 5 & 5 & 1 & 5 & 3 & 0 \\
\hline 1 & 0 & 3 & 3 & 0 & 3 & 1 & 1 & 3 & 3 & 5 & 3 & 1 & 5 & 3 & 1 \\
\hline 5 & 5 & 5 & 5 & 5 & 3 & 0 & 1 & 5 & 5 & 5 & 5 & 3 & 5 & 5 & 5 \\
\hline 0 & 0 & 0 & 1 & 5 & 0 & 0 & 0 & 0 & 0 & 0 & 3 & 0 & 0 & 0 & 0 \\
\hline 0 & 1 & 3 & 1 & 3 & 3 & 0 & 1 & 1 & 1 & 1 & 1 & 0 & 3 & 0 & 0 \\
\hline 0 & 3 & 0 & 0 & 5 & 0 & 0 & 0 & 5 & 1 & 3 & 1 & 0 & 5 & 0 & 0 \\
\hline NA & NA & NA & NA & NA & NA & NA & NA & 0 & NA & 0 & NA & NA & 0 & NA & 0 \\
\hline NA & NA & NA & NA & NA & NA & NA & NA & 0 & NA & 0 & NA & NA & 0 & NA & 0 \\
\hline NA & NA & NA & NA & NA & NA & NA & NA & 0 & NA & 0 & NA & NA & 0 & NA & 0 \\
\hline NA & NA & NA & NA & NA & NA & NA & NA & NA & NA & NA & NA & NA & NA & NA & $\mathrm{NA}$ \\
\hline
\end{tabular}




\begin{tabular}{|l|l|l|l|l|l|l|l|l|l|l|l|l|l|l|l|} 
NA & NA & NA & NA & NA & NA & NA & NA & NA & NA & NA & NA & NA & NA & NA & NA \\
\hline NA & NA & NA & NA & NA & NA & NA & NA & NA & NA & NA & NA & NA & NA & NA & NA \\
\hline
\end{tabular}

LEGENDA: d5. As comunidades locais apoiam os objetivos globais da UC, d7. Conselho implementado e efetivo, d12. Articulação efetiva da UC com órgãos e entidades relacionadas, d20. As comunidades locais participam das decisões pelas quais são afetadas, d21. Os resultados da pesquisa, monitoramento e o conhecimento tradicional são incluídos rotineiramente no planejamento, e1. Organização, capacitação e desenvolvimento das comunidades locais e conselhos coerente com ameaças e pressões, objetivos da UC e plano de trabalho anual, e13. A UC possui características inusitadas de importância estética, e14.

Existe a comunicação efetiva entre as comunidades locais, e20. O valor de mercado de recursos da UC é alto, e21. A UC possui um alto valor recreativo, e25. A infraestrutura para visitantes é apropriada para o nível de uso pelo visitante, e28. A UC possui um alto valor recreativo e infraestrutura adequada para visitação, e35. A tomada de decisões no manejo é transparente, e41. Existe a comunicação efetiva da UC com as comunidades locais , e49.

Os funcionários da UC colaboram regularmente com os parceiros, comunidades locais e outras organizações, e7. Os conflitos com a comunidade local são resolvidos de forma justa e efetiva, NA. Valor nulo 
ANEXO VIII. TABELA DE ENTRADA DE DADOS PARA $M C A$ ENTRE DESMATAMENTO EM UCS FEDERAIS (TODAS AS UCS - PROTEÇÃO INTEGRAL E USO SUSTENTÁVEL).

\begin{tabular}{|c|c|c|c|c|c|}
\hline \multicolumn{5}{|c|}{ FATOR DE DIMENSIONAMENTO DA PARTICIPAÇÃO SOCIAL } & \multirow{2}{*}{$\begin{array}{l}\text { CATEGORIAS DE } \\
\text { DESMATAMENTO } \\
\text { (todas as UCs) }\end{array}$} \\
\hline $\begin{array}{c}\text { As comunidades } \\
\text { locais apoiam os } \\
\text { objetivos globais } \\
\text { da UC? }\end{array}$ & $\begin{array}{l}\text { Existe conselho } \\
\text { implementado e } \\
\text { efetivo? }\end{array}$ & $\begin{array}{l}\text { Existe articulação } \\
\text { efetiva da UC com } \\
\text { órgãos e entidades } \\
\text { relacionadas? }\end{array}$ & $\begin{array}{c}\text { As comunidades } \\
\text { locais participam } \\
\text { das decisões pelas } \\
\text { quais são afetadas? }\end{array}$ & $\begin{array}{l}\text { Os resultados da } \\
\text { pesquisa, } \\
\text { monitoramento e o } \\
\text { conhecimento } \\
\text { tradicional são } \\
\text { incluídos no } \\
\text { planejamento? }\end{array}$ & \\
\hline (d5) & (d7) & (d12) & $\left(\mathrm{d} 20_{-}\right.$ & $(\mathrm{d} 21)$ & (Des) \\
\hline 3 & 0 & 5 & 3 & 3 & Des_0 \\
\hline 5 & 3 & 0 & 0 & 0 & Des_0 \\
\hline 3 & 3 & 5 & 5 & 3 & Des_0 \\
\hline 3 & 0 & 5 & 3 & 5 & Des_0 \\
\hline 5 & 5 & 3 & 5 & 5 & Des_0 \\
\hline 5 & 0 & 5 & 3 & 0 & Des_0 \\
\hline 5 & 3 & 3 & 3 & 3 & Des_0 \\
\hline 1 & 3 & 3 & 1 & 5 & Des_0 \\
\hline 3 & 5 & 5 & 5 & 1 & Des_0 \\
\hline 3 & 5 & 5 & 5 & 0 & Des_0 \\
\hline 3 & 0 & 0 & 0 & 0 & Des_0 \\
\hline 5 & 5 & 5 & 5 & 5 & Des_0 \\
\hline 0 & 0 & 5 & 0 & 0 & Des_0 \\
\hline 3 & 5 & 5 & 5 & 1 & Des_0 \\
\hline 3 & 5 & 5 & 3 & 5 & Des_0 \\
\hline 3 & 3 & 3 & 3 & 5 & Des_0 \\
\hline 1 & 1 & 1 & 0 & 3 & Des_0 \\
\hline 3 & 3 & 5 & 3 & 0 & $\begin{array}{l}\text { Des_0 } \\
\end{array}$ \\
\hline 5 & 0 & 5 & 3 & 3 & Des_0 \\
\hline 5 & 0 & 5 & 3 & 0 & Des_0 \\
\hline 3 & 3 & 3 & 3 & 1 & Des_0 \\
\hline 5 & 3 & 5 & 0 & 0 & Des_0 \\
\hline 1 & 5 & 3 & 3 & 3 & Des_0 \\
\hline 3 & 3 & 3 & 3 & 3 & Des_0 \\
\hline 1 & 5 & 5 & 3 & 5 & Des_0 \\
\hline 3 & 0 & 5 & 1 & 5 & Des_0 \\
\hline 3 & 5 & 1 & 3 & 5 & Des_0 \\
\hline 1 & 5 & 3 & 3 & 5 & Des_1 \\
\hline 1 & 0 & 3 & 0 & 0 & Des_1 \\
\hline 3 & 3 & 5 & 0 & 1 & Des_1 \\
\hline 3 & 0 & 3 & 0 & 0 & Des_1 \\
\hline 1 & 3 & 5 & 3 & 3 & Des_1 \\
\hline 1 & 0 & 3 & 0 & 3 & Des_1 \\
\hline 3 & 5 & 5 & 5 & 3 & Des_1 \\
\hline 0 & 0 & 3 & 0 & 3 & Des_1 \\
\hline 3 & 5 & 3 & 3 & 1 & Des_1 \\
\hline 0 & 0 & 3 & 0 & 0 & Des_1 \\
\hline 3 & 0 & 3 & 0 & 0 & Des_1 \\
\hline 1 & 3 & 5 & 3 & 3 & Des_1 \\
\hline 3 & 5 & 5 & 3 & 3 & Des_1 \\
\hline 1 & 5 & 3 & 0 & 0 & Des_1 \\
\hline 1 & 0 & 1 & 0 & 0 & Des_1 \\
\hline 3 & 0 & 3 & 0 & 0 & Des_1 \\
\hline
\end{tabular}




\begin{tabular}{|c|c|c|c|c|c|}
\hline \multicolumn{5}{|c|}{ FATOR DE DIMENSIONAMENTO DA PARTICIPAÇÃO SOCIAL } & \multirow{2}{*}{$\begin{array}{l}\text { CATEGORIAS DE } \\
\text { DESMATAMENTO } \\
\text { (todas as UCs) }\end{array}$} \\
\hline $\begin{array}{c}\text { As comunidades } \\
\text { locais apoiam os } \\
\text { objetivos globais } \\
\text { da UC? }\end{array}$ & $\begin{array}{l}\text { Existe conselho } \\
\text { implementado e } \\
\text { efetivo? }\end{array}$ & $\begin{array}{l}\text { Existe articulação } \\
\text { efetiva da UC com } \\
\text { órgãos e entidades } \\
\text { relacionadas? }\end{array}$ & $\begin{array}{c}\text { As comunidades } \\
\text { locais participam } \\
\text { das decisões pelas } \\
\text { quais são afetadas? }\end{array}$ & $\begin{array}{l}\text { Os resultados da } \\
\text { pesquisa, } \\
\text { monitoramento e o } \\
\text { conhecimento } \\
\text { tradicional são } \\
\text { incluídos no } \\
\text { planejamento? }\end{array}$ & \\
\hline 3 & 5 & 3 & 3 & 1 & Des_1 \\
\hline 5 & 5 & 5 & 5 & 5 & Des_1 \\
\hline 5 & 5 & 5 & 5 & 5 & Des_1 \\
\hline 3 & 0 & 5 & 3 & 3 & Des_1 \\
\hline 3 & 0 & 1 & 0 & 0 & Des_1 \\
\hline 5 & 5 & 5 & 5 & 5 & Des_1 \\
\hline 3 & 5 & 3 & 3 & 5 & Des_1 \\
\hline 5 & 1 & 5 & 3 & 0 & Des_1 \\
\hline 3 & 5 & 5 & 5 & 1 & Des_1 \\
\hline 1 & 5 & 3 & 0 & 0 & Des_1 \\
\hline 3 & 5 & 3 & 5 & 5 & Des_1 \\
\hline 1 & 0 & 3 & 0 & 0 & Des_1 \\
\hline 5 & 3 & 5 & 0 & 0 & Des_3 \\
\hline 3 & 1 & 3 & 3 & 0 & Des_3 \\
\hline 3 & 0 & 1 & 1 & 1 & Des_3 \\
\hline 5 & 1 & 3 & 1 & 1 & Des_3 \\
\hline 5 & 3 & 3 & 3 & 1 & Des_3 \\
\hline 5 & 1 & 0 & 3 & 0 & Des_3 \\
\hline 5 & 0 & 5 & 3 & 0 & Des_3 \\
\hline 3 & 3 & 1 & 3 & 1 & Des_3 \\
\hline 0 & 0 & 0 & 0 & 0 & Des_3 \\
\hline 5 & 5 & 1 & 1 & 1 & Des_3 \\
\hline 5 & 5 & 5 & 5 & 3 & Des_3 \\
\hline 3 & 5 & 5 & 5 & 3 & Des_3 \\
\hline 3 & 5 & 3 & 5 & 0 & Des_3 \\
\hline 1 & 0 & 3 & 1 & 3 & Des_3 \\
\hline 3 & 3 & 5 & 5 & 0 & Des_3 \\
\hline 3 & 5 & 5 & 3 & 5 & Des_3 \\
\hline 1 & 0 & 1 & 1 & 0 & Des_3 \\
\hline 0 & 0 & 0 & 0 & 0 & Des_3 \\
\hline 3 & 5 & 5 & 3 & 0 & Des_3 \\
\hline 5 & 5 & 3 & 5 & 0 & Des_3 \\
\hline 5 & 3 & 3 & 3 & 3 & Des_3 \\
\hline 1 & 5 & 5 & 3 & 3 & Des_3 \\
\hline 1 & 0 & 5 & 1 & 3 & Des_3 \\
\hline 5 & 5 & 1 & 3 & 1 & Des_3 \\
\hline 5 & 5 & 5 & 5 & 0 & Des_3 \\
\hline 3 & 3 & 5 & 5 & 0 & Des_3 \\
\hline 5 & 0 & 5 & 5 & 1 & Des_3 \\
\hline 3 & 5 & 3 & 3 & 1 & Des_3 \\
\hline 1 & 0 & 0 & 0 & 0 & Des_3 \\
\hline 1 & 5 & 3 & 5 & 0 & Des_5 \\
\hline 0 & 0 & 3 & 0 & 0 & Des_5 \\
\hline 5 & 0 & 3 & 5 & 3 & Des_5 \\
\hline 1 & 5 & 5 & 0 & 5 & Des_5 \\
\hline 3 & 5 & 5 & 5 & 3 & Des_5 \\
\hline 3 & 3 & 1 & 3 & 0 & Des_5 \\
\hline 1 & 5 & 3 & 5 & 3 & Des_5 \\
\hline
\end{tabular}




\begin{tabular}{|c|c|c|c|c|c|}
\hline \multicolumn{5}{|c|}{ FATOR DE DIMENSIONAMENTO DA PARTICIPAÇÃO SOCIAL } & \multirow{2}{*}{$\begin{array}{c}\text { CATEGORIAS DE } \\
\text { DESMATAMENTO } \\
\text { (todas as UCs) }\end{array}$} \\
\hline $\begin{array}{c}\text { As comunidades } \\
\text { locais apoiam os } \\
\text { objetivos globais } \\
\text { da UC? }\end{array}$ & $\begin{array}{l}\text { Existe conselho } \\
\text { implementado e } \\
\quad \text { efetivo? }\end{array}$ & $\begin{array}{l}\text { Existe articulação } \\
\text { efetiva da UC com } \\
\text { órgãos e entidades } \\
\text { relacionadas? }\end{array}$ & $\begin{array}{c}\text { As comunidades } \\
\text { locais participam } \\
\text { das decisões pelas } \\
\text { quais são afetadas? }\end{array}$ & $\begin{array}{l}\text { Os resultados da } \\
\text { pesquisa, } \\
\text { monitoramento e o } \\
\text { conhecimento } \\
\text { tradicional são } \\
\text { incluídos no } \\
\text { planejamento? }\end{array}$ & \\
\hline 0 & 0 & 1 & 0 & 1 & Des_5 \\
\hline 1 & 0 & 0 & 0 & 0 & Des_5 \\
\hline 5 & 5 & 3 & 1 & 0 & Des_5 \\
\hline 3 & 3 & 5 & 3 & 3 & Des_5 \\
\hline 5 & 3 & 5 & 5 & 3 & Des_5 \\
\hline 3 & 0 & 1 & 0 & 1 & Des_5 \\
\hline 1 & 3 & 5 & 1 & 1 & Des_5 \\
\hline 3 & 0 & 0 & 0 & 0 & Des_5 \\
\hline 3 & 5 & 3 & 3 & 1 & Des_5 \\
\hline 0 & 0 & 3 & 3 & 3 & Des_5 \\
\hline 1 & 3 & 3 & 5 & 1 & Des_5 \\
\hline 3 & 0 & 5 & 3 & 0 & Des_5 \\
\hline 3 & 5 & 5 & 3 & 0 & Des_5 \\
\hline 1 & 0 & 3 & 1 & 0 & Des_5 \\
\hline 0 & 5 & 5 & 5 & 0 & Des_5 \\
\hline 5 & 5 & 5 & 5 & 0 & Des_5 \\
\hline 0 & 0 & 5 & 0 & 0 & Des_5 \\
\hline 0 & 0 & 0 & 0 & 0 & Des_5 \\
\hline 5 & 5 & 5 & 5 & 1 & Des_5 \\
\hline 1 & 0 & 3 & 0 & 0 & Des_5 \\
\hline 0 & 0 & 0 & 0 & 0 & Des_5 \\
\hline 0 & 0 & 3 & 0 & 0 & Des_5 \\
\hline
\end{tabular}


ANEXo IX. TABEla DE ENTRADA DE DAdOS PARA $M C A$ ENTRE DESMATAMENTO EM UCS FEDERAIS DE USO SUSTENTÁVEL.

\begin{tabular}{|c|c|c|c|c|c|}
\hline \multicolumn{5}{|c|}{ FATOR DE DIMENSIONAMENTO DA PARTICIPAÇÃO SOCIAL } & \multirow{2}{*}{\begin{tabular}{|c} 
CATEGORIAS DE \\
DESMATAMENTO \\
(UCs de uso \\
sustentável)
\end{tabular}} \\
\hline $\begin{array}{c}\text { As comunidades } \\
\text { locais apoiam os } \\
\text { objetivos globais da } \\
\text { UC? }\end{array}$ & $\begin{array}{l}\text { Existe conselho } \\
\text { implementado e } \\
\text { efetivo? }\end{array}$ & $\begin{array}{c}\text { Existe a } \\
\text { articulação } \\
\text { efetiva da UC } \\
\text { com órgãos e } \\
\text { entidades } \\
\text { relacionadas? }\end{array}$ & $\begin{array}{c}\text { As comunidades } \\
\text { locais participam } \\
\text { das decisões pelas } \\
\text { quais são } \\
\text { afetadas? }\end{array}$ & $\begin{array}{l}\text { Os resultados da } \\
\text { pesquisa, monitoramento } \\
\text { e o conhecimento } \\
\text { tradicional são incluídos } \\
\text { no planejamento? }\end{array}$ & \\
\hline$(\mathrm{d} 5)$ & $(\mathrm{d} 7)$ & $(\mathrm{d} 12)$ & $(\mathrm{d} 20)$ & $(\mathrm{d} 21)$ & (Des) \\
\hline 5 & 3 & 0 & 0 & 0 & Des_0 \\
\hline 3 & 3 & 5 & 5 & 3 & Des_0 \\
\hline 3 & 0 & 5 & 3 & 5 & Des_0 \\
\hline 5 & 5 & 3 & 5 & 5 & Des_0 \\
\hline 5 & 3 & 3 & 3 & 3 & Des_0 \\
\hline 1 & 3 & 3 & 1 & 5 & Des_0 \\
\hline 3 & 5 & 5 & 5 & 1 & Des_0 \\
\hline 3 & 5 & 5 & 5 & 0 & Des_0 \\
\hline 3 & 0 & 0 & 0 & 0 & Des_0 \\
\hline 5 & 5 & 5 & 5 & 5 & Des_0 \\
\hline 3 & 5 & 5 & 5 & 1 & Des_0 \\
\hline 3 & 5 & 5 & 3 & 5 & Des_0 \\
\hline 3 & 3 & 3 & 3 & 5 & Des_0 \\
\hline 3 & 3 & 3 & 3 & 1 & Des_0 \\
\hline 3 & 3 & 5 & 0 & 1 & Des_1 \\
\hline 0 & 0 & 3 & 0 & 3 & Des_1 \\
\hline 3 & 5 & 3 & 3 & 1 & Des_1 \\
\hline 3 & 0 & 3 & 0 & 0 & Des_1 \\
\hline 3 & 5 & 5 & 3 & 3 & Des_1 \\
\hline 3 & 0 & 3 & 0 & 0 & Des_1 \\
\hline 3 & 5 & 3 & 3 & 1 & Des_1 \\
\hline 5 & 5 & 5 & 5 & 5 & Des_1 \\
\hline 5 & 5 & 5 & 5 & 5 & Des_1 \\
\hline 3 & 0 & 5 & 3 & 3 & Des_1 \\
\hline 5 & 5 & 5 & 5 & 5 & Des_1 \\
\hline 5 & 1 & 5 & 3 & 0 & Des_1 \\
\hline 3 & 5 & 5 & 5 & 1 & Des_1 \\
\hline 3 & 5 & 3 & 5 & 5 & Des_1 \\
\hline 5 & 3 & 5 & 0 & 0 & Des_1 \\
\hline 3 & 1 & 3 & 3 & 0 & Des_1 \\
\hline 5 & 1 & 3 & 1 & 1 & Des_1 \\
\hline 5 & 3 & 3 & 3 & 1 & Des_1 \\
\hline
\end{tabular}




\begin{tabular}{|c|c|c|c|c|c|}
\hline 5 & 1 & 0 & 3 & 0 & Des_1 \\
\hline 5 & 0 & 5 & 3 & 0 & Des_1 \\
\hline 3 & 3 & 1 & 3 & 1 & Des_3 \\
\hline 5 & 5 & 1 & 1 & 1 & Des_3 \\
\hline 5 & 5 & 5 & 5 & 3 & Des_3 \\
\hline 3 & 5 & 3 & 5 & 0 & Des_3 \\
\hline 3 & 3 & 5 & 5 & 0 & Des_3 \\
\hline 3 & 5 & 5 & 3 & 5 & Des_3 \\
\hline 1 & 0 & 1 & 1 & 0 & Des_3 \\
\hline 0 & 0 & 0 & 0 & 0 & Des_3 \\
\hline 5 & 5 & 3 & 5 & 0 & Des_3 \\
\hline 5 & 3 & 3 & 3 & 3 & Des_3 \\
\hline 1 & 0 & 5 & 1 & 3 & Des_3 \\
\hline 5 & 5 & 1 & 3 & 1 & Des_3 \\
\hline 5 & 5 & 5 & 5 & 0 & Des_3 \\
\hline 3 & 3 & 5 & 5 & 0 & Des_3 \\
\hline 5 & 0 & 5 & 5 & 1 & Des_3 \\
\hline 3 & 5 & 3 & 3 & 1 & Des_3 \\
\hline 1 & 0 & 0 & 0 & 0 & Des_3 \\
\hline 1 & 5 & 3 & 5 & 0 & Des_3 \\
\hline 5 & 0 & 3 & 5 & 3 & Des_3 \\
\hline 3 & 5 & 5 & 5 & 3 & Des_3 \\
\hline 3 & 3 & 1 & 3 & 0 & Des_3 \\
\hline 1 & 5 & 3 & 5 & 3 & Des_5 \\
\hline 5 & 5 & 3 & 1 & 0 & Des_5 \\
\hline 3 & 3 & 5 & 3 & 3 & Des_5 \\
\hline 5 & 3 & 5 & 5 & 3 & Des_5 \\
\hline 3 & 0 & 1 & 0 & 1 & Des_5 \\
\hline 1 & 3 & 5 & 1 & 1 & Des_5 \\
\hline 3 & 0 & 0 & 0 & 0 & Des_5 \\
\hline 3 & 5 & 3 & 3 & 1 & Des_5 \\
\hline 0 & 0 & 3 & 3 & 3 & Des_5 \\
\hline 1 & 3 & 3 & 5 & 1 & Des_5 \\
\hline 3 & 0 & 5 & 3 & 0 & Des_5 \\
\hline 3 & 5 & 5 & 3 & 0 & Des_5 \\
\hline 1 & 0 & 3 & 1 & 0 & Des_5 \\
\hline 0 & 5 & 5 & 5 & 0 & Des_5 \\
\hline 5 & 5 & 5 & 5 & 0 & Des_5 \\
\hline 0 & 0 & 0 & 0 & 0 & Des_5 \\
\hline 5 & 5 & 5 & 5 & 1 & Des_5 \\
\hline 1 & 0 & 3 & 0 & 0 & Des_5 \\
\hline 0 & 0 & 0 & 0 & 0 & Des_5 \\
\hline 0 & 0 & 3 & 0 & 0 & Des_5 \\
\hline
\end{tabular}


ANEXo X. TABELA DE ENTRADA DE DADOS PARA MCA ENTRE DESMATAMENTO EM UCS FEDERAIS DE PROTEÇÃo INTEGRAL.

\begin{tabular}{|c|c|c|c|c|c|}
\hline \multicolumn{5}{|c|}{ FATOR DE DIMENSIONAMENTO DA PARTICIPAÇÃO SOCIAL } & \multirow[b]{2}{*}{$\begin{array}{c}\text { CATEGORIAS DE } \\
\text { DESMATAMENTO (UCs } \\
\text { de proteção integral) }\end{array}$} \\
\hline $\begin{array}{c}\text { As comunidades } \\
\text { locais apoiam os } \\
\text { objetivos globais da } \\
\text { UC? }\end{array}$ & $\begin{array}{l}\text { Existe conselho } \\
\text { implementado e } \\
\quad \text { efetivo? }\end{array}$ & $\begin{array}{c}\text { Existe articulação } \\
\text { efetiva da UC com } \\
\text { órgãos e entidades } \\
\text { relacionadas? }\end{array}$ & $\begin{array}{c}\text { As comunidades } \\
\text { locais participam das } \\
\text { decisões pelas quais } \\
\text { são afetadas? }\end{array}$ & $\begin{array}{l}\text { Os resultados da } \\
\text { pesquisa, } \\
\text { monitoramento e o } \\
\text { conhecimento } \\
\text { tradicional são } \\
\text { inclúdos no } \\
\text { planejamento? }\end{array}$ & \\
\hline (d5) & (d7) & (d12) & $\begin{array}{l}(\mathrm{d} 20) \\
\end{array}$ & (d21) & (Des) \\
\hline 3 & 0 & 5 & 3 & 3 & Des_0 \\
\hline 5 & 0 & 5 & 3 & 0 & Des_0 \\
\hline 0 & 0 & 5 & 0 & 0 & Des_0 \\
\hline 1 & 1 & 1 & 0 & 3 & Des_0 \\
\hline 3 & 3 & 5 & 3 & 0 & Des_0 \\
\hline 5 & 0 & 5 & 3 & 3 & Des_0 \\
\hline 5 & 0 & 5 & 3 & 0 & Des_0 \\
\hline 5 & 3 & 5 & 0 & 0 & Des_0 \\
\hline 1 & 5 & 3 & 3 & 3 & Des_0 \\
\hline 3 & 3 & 3 & 3 & 3 & Des_0 \\
\hline 1 & 5 & 5 & 3 & 5 & Des_0 \\
\hline 3 & 0 & 5 & 1 & 5 & Des_0 \\
\hline 3 & 5 & 1 & 3 & 5 & Des_0 \\
\hline 1 & 5 & 3 & 3 & 5 & Des_1 \\
\hline 1 & 0 & 3 & 0 & 0 & Des_1 \\
\hline
\end{tabular}




\begin{tabular}{|c|c|c|c|c|c|}
\hline 3 & 0 & 3 & 0 & 0 & Des_1 \\
\hline 1 & 3 & 5 & 3 & 3 & Des_1 \\
\hline 1 & 0 & 3 & 0 & 3 & Des_1 \\
\hline 3 & 5 & 5 & 5 & 3 & Des_1 \\
\hline 0 & 0 & 3 & 0 & 0 & Des_1 \\
\hline 1 & 3 & 5 & 3 & 3 & Des_1 \\
\hline 1 & 5 & 3 & 0 & 0 & Des_3 \\
\hline 1 & 0 & 1 & 0 & 0 & Des_3 \\
\hline 3 & 0 & 1 & 0 & 0 & Des_3 \\
\hline 3 & 5 & 3 & 3 & 5 & Des_3 \\
\hline 1 & 5 & 3 & 0 & 0 & Des_3 \\
\hline 1 & 0 & 3 & 0 & 0 & Des_3 \\
\hline 3 & 0 & 1 & 1 & 1 & Des_3 \\
\hline 0 & 0 & 0 & 0 & 0 & Des_3 \\
\hline 3 & 5 & 5 & 5 & 3 & Des_3 \\
\hline 1 & 0 & 3 & 1 & 3 & Des_5 \\
\hline 3 & 5 & 5 & 3 & 0 & Des_5 \\
\hline 1 & 5 & 5 & 3 & 3 & Des_5 \\
\hline 0 & 0 & 3 & 0 & 0 & Des_5 \\
\hline 1 & 5 & 5 & 0 & 5 & Des_5 \\
\hline 0 & 0 & 1 & 0 & 1 & Des_5 \\
\hline 1 & 0 & 0 & 0 & 0 & Des_5 \\
\hline 0 & 0 & 5 & 0 & 0 & Des_5 \\
\hline
\end{tabular}


ANEXO XI. TABELA DE SAÍDA DO MCA ENTRE VARIÁVEIS DE DIMENSIONAMENTO.

\begin{tabular}{|c|c|c|c|c|c|}
\hline \multicolumn{6}{|l|}{ Eig } \\
\hline & \multicolumn{5}{|c|}{ percentagem da } \\
\hline & & percentagem da & variância & & \\
\hline & autovalores & variância & cumulativa & & \\
\hline $\operatorname{dim} 1$ & 0,1793559 & 29,120225 & 29,12022 & & \\
\hline $\operatorname{dim} 2$ & 0,08360403 & 13,57395 & 42,69418 & & \\
\hline $\operatorname{dim} 3$ & 0,04543678 & 7,377116 & 50,07129 & & \\
\hline $\operatorname{dim} 4$ & 0,04147166 & 6,733339 & 56,80463 & & \\
\hline $\operatorname{dim} 5$ & 0,03452716 & 5,60583 & 62,41046 & & \\
\hline $\operatorname{dim} 6$ & 0,02966618 & 4,8166 & 67,22706 & & \\
\hline $\operatorname{dim} 7$ & 0,02693305 & 4,372851 & 71,59991 & & \\
\hline $\operatorname{dim} 8$ & 0,02556037 & 4,149982 & 75,74989 & & \\
\hline $\operatorname{dim} 9$ & 0,02346932 & 3,81048 & 79,56037 & & \\
\hline $\operatorname{dim} 10$ & 0,02297252 & 3,729818 & 83,29019 & & \\
\hline $\operatorname{dim} 11$ & 0,0206537 & 3,353335 & 86,64353 & & \\
\hline $\operatorname{dim} 12$ & 0,01829858 & 2,970957 & 89,61448 & & \\
\hline $\operatorname{dim} 13$ & 0,0166834 & 2,708716 & 92,3232 & & \\
\hline $\operatorname{dim} 14$ & 0,01324253 & 2,150057 & 94,47326 & & \\
\hline $\operatorname{dim} 15$ & 0,01173524 & 1,905333 & 96,37859 & & \\
\hline $\operatorname{dim} 16$ & 0,01051226 & 1,706771 & 98,08536 & & \\
\hline $\operatorname{dim} 17$ & 0,00847581 & 1,376133 & 99,46149 & & \\
\hline $\operatorname{dim} 18$ & 0,00331675 & 0,538507 & 100 & & \\
\hline \multicolumn{6}{|l|}{ coord } \\
\hline & Dim 1 & $\operatorname{Dim} 2$ & Dim 3 & $\operatorname{Dim} 4$ & $\operatorname{Dim} 5$ \\
\hline d5_0 & 1,14665051 & $-0,48519748$ & $-0,416574572$ & 0,04842572 & $-0,19881335$ \\
\hline d5_1 & 0,27458994 & 0,27475864 & 0,36297162 & $-0,19885859$ & $-0,11244524$ \\
\hline d5_3 & $-0,14677385$ & 0,16424936 & $-0,258348774$ & 0,01054528 & $-0,00722082$ \\
\hline d5_5 & $-0,4535824$ & $-0,39189209$ & 0,113971456 & 0,18896693 & 0,19874648 \\
\hline d7_0 & 0,57224746 & $-0,09142931$ & $-0,028380147$ & 0,07373162 & $-0,07439276$ \\
\hline d7_1 & 0,09708248 & 0,65266667 & 0,450299244 & 0,4455911 & 0,50090706 \\
\hline d7_3 & $-0,20785941$ & 0,10694507 & $-0,222717592$ & $-0,19225$ & 0,60956267 \\
\hline d7_5 & $-0,48361589$ & $-0,09412234$ & 0,047570849 & $-0,06774788$ & $-0,32937543$ \\
\hline d12_0 & 1,42282892 & $-0,81091253$ & $-0,135225983$ & $-0,00717655$ & 0,10734248 \\
\hline d12_1 & 0,57142889 & 0,49136216 & 0,183303697 & 0,61889008 & $-0,17046315$ \\
\hline d12_3 & 0,1396694 & 0,31401971 & $-0,032625877$ & $-0,28218021$ & 0,03434051 \\
\hline d12_5 & $-0,32022564$ & $-0,1919807$ & $-0,003566151$ & 0,04185525 & 0,00281416 \\
\hline d19_0 & 0,2064539 & $-0,06780809$ & 0,136041063 & $-0,19879584$ & 0,07670311 \\
\hline
\end{tabular}




\begin{tabular}{|c|c|c|c|c|c|}
\hline d19_1 & 0,03121718 & 0,42156663 & 0,111079807 & 0,25262061 & $-0,21979962$ \\
\hline d19_3 & $-0,06434064$ & 0,27180178 & $-0,544603208$ & $-0,06980165$ & $-0,26883647$ \\
\hline d19_5 & $-0,38467423$ & $-0,29661982$ & 0,073929193 & 0,31541104 & 0,16669001 \\
\hline $\mathrm{d} 20 \_0$ & 0,73995699 & $-0,17923412$ & 0,072877676 & 0,04485138 & 0,00400839 \\
\hline d20_1 & 0,01499111 & 0,64271408 & 0,436973826 & $-0,00116271$ & 0,07943908 \\
\hline d20_3 & $-0,21408232$ & 0,20258597 & $-0,414961236$ & 0,04762082 & 0,16173621 \\
\hline $\mathrm{d} 20 \_5$ & $-0,61771216$ & $-0,37771312$ & 0,130760974 & $-0,10317785$ & $-0,22748308$ \\
\hline d21_0 & 0,44833742 & $-0,24552213$ & $-0,047201875$ & 0,0047569 & 0,03280727 \\
\hline d21_1 & $-0,22193855$ & 0,43105748 & $-0,137895664$ & 0,43569705 & $-0,14861716$ \\
\hline d21_3 & $-0,23997454$ & 0,22236446 & 0,026053752 & $-0,43374239$ & 0,00506147 \\
\hline $\mathrm{d} 21 \_5$ & $-0,4610955$ & $-0,2651256$ & 0,248988511 & 0,06738751 & 0,09921134 \\
\hline \multicolumn{6}{|l|}{ contrib } \\
\hline & Dim 1 & Dim 2 & Dim 3 & $\operatorname{Dim} 4$ & $\operatorname{Dim} 5$ \\
\hline d5_0 & 10,0078051 & 3,844167 & 5,213991932 & $7,72 \mathrm{E}-002$ & 1,56286902 \\
\hline d5_1 & 1,98478197 & 4,2631906 & 13,68979773 & $4,50 \mathrm{E}+000$ & 1,72894227 \\
\hline d5_3 & 0,75837817 & 2,0374374 & 9,27490325 & 1,69E-002 & 0,00953489 \\
\hline d5_5 & 4,89371996 & 7,8369701 & 1,219627065 & $3,67 \mathrm{E}+000$ & 4,88068077 \\
\hline d7_0 & 11,2164897 & 0,6142548 & 0,108899688 & $8,05 \mathrm{E}-001$ & 0,98470319 \\
\hline d7__1 & 0,06576121 & 6,3761641 & 5,584685431 & $5,99 \mathrm{E}+000$ & 9,09404816 \\
\hline d7_3 & 0,73994353 & 0,4202127 & 3,353330863 & $2,74 \mathrm{E}+000$ & 33,0560338 \\
\hline d7_5 & 8,08524313 & 0,6570007 & 0,308803273 & $6,86 \mathrm{E}-001$ & 19,4818031 \\
\hline d12_0 & 9,63079383 & 6,7110923 & 0,34338803 & $1,06 \mathrm{E}-003$ & 0,28474413 \\
\hline d12_1 & 3,10678427 & 4,9280898 & 1,261935917 & $1,58 \mathrm{E}+001$ & 1,43615908 \\
\hline d12_3 & 0,55062764 & 5,9711469 & 0,118600905 & $9,72 \mathrm{E}+000$ & 0,17291145 \\
\hline d12_5 & 5,17100306 & 3,9871832 & 0,002531455 & $3,82 \mathrm{E}-001$ & 0,00207451 \\
\hline d19_0 & 1,85196265 & 0,4285855 & 3,174199345 & $7,43 \mathrm{E}+000$ & 1,32790412 \\
\hline d19_1 & 0,01143548 & 4,473919 & 0,571538591 & $3,24 \mathrm{E}+000$ & 2,944936 \\
\hline d19_3 & 0,06695859 & 2,5634726 & 18,9366942 & $3,41 \mathrm{E}-001$ & 6,07248974 \\
\hline d19_5 & 3,19124809 & 4,0706445 & 0,465280068 & $9,28 \mathrm{E}+000$ & 3,112779 \\
\hline d20_0 & 15,2813276 & 1,9234371 & 0,585120489 & $2,43 \mathrm{E}-001$ & 0,0023294 \\
\hline d20_1 & 0,00306479 & 12,0853162 & 10,27904821 & $7,97 \mathrm{E}-005$ & 0,44705104 \\
\hline d20_3 & 1,23550917 & 2,3735129 & 18,32346409 & 2,64E-001 & 3,66314165 \\
\hline $\mathrm{d} 20 \_5$ & 9,31812386 & 7,4742703 & 1,648240639 & $1,12 \mathrm{E}+000$ & 6,56461363 \\
\hline d21_0 & 7,39491895 & 4,757658 & 0,323556477 & $3,60 \mathrm{E}-003$ & 0,2056925 \\
\hline $\mathrm{d} 21 \_1$ & 0,93730774 & 7,5853487 & 1,428321827 & $1,56 \mathrm{E}+001$ & 2,18327986 \\
\hline d21_3 & 1,26021571 & 2,3213134 & 0,058635851 & $1,78 \mathrm{E}+001$ & 0,00291221 \\
\hline $\mathrm{d} 21 \_5$ & 3,23659577 & 2,2956121 & 3,725404665 & 2,99E-001 & 0,7783665 \\
\hline
\end{tabular}




\begin{tabular}{|c|c|c|c|c|c|}
\hline & Dim 1 & $\operatorname{Dim} 2$ & Dim 3 & $\operatorname{Dim} 4$ & $\operatorname{Dim} 5$ \\
\hline d5_0 & 5,17E-001 & 0,09252268 & $6,82 \mathrm{E}-002$ & $9,22 \mathrm{E}-004$ & $1,55 \mathrm{E}-002$ \\
\hline d5_1 & $1,51 \mathrm{E}-001$ & 0,15125699 & 2,64E-001 & 7,92E-002 & $2,53 \mathrm{E}-002$ \\
\hline d5_3 & $7,30 \mathrm{E}-002$ & 0,09136035 & $2,26 \mathrm{E}-001$ & $3,77 \mathrm{E}-004$ & $1,77 \mathrm{E}-004$ \\
\hline d5_5 & $3,28 \mathrm{E}-001$ & 0,24493462 & 2,07E-002 & 5,69E-002 & $6,30 \mathrm{E}-002$ \\
\hline d7_0 & 7,28E-001 & 0,01858133 & $1,79 \mathrm{E}-003$ & $1,21 \mathrm{E}-002$ & $1,23 \mathrm{E}-002$ \\
\hline d7_1 & 4,26E-003 & 0,19249543 & $9,16 \mathrm{E}-002$ & $8,97 \mathrm{E}-002$ & $1,13 \mathrm{E}-001$ \\
\hline d7_3 & $5,54 \mathrm{E}-002$ & 0,01467494 & $6,36 \mathrm{E}-002$ & 4,74E-002 & 4,77E-001 \\
\hline d7_5 & 5,69E-001 & 0,02154338 & $5,50 \mathrm{E}-003$ & $1,12 \mathrm{E}-002$ & 2,64E-001 \\
\hline d12_0 & 4,87E-001 & 0,1583002 & $4,40 \mathrm{E}-003$ & $1,24 \mathrm{E}-005$ & $2,77 \mathrm{E}-003$ \\
\hline d12_1 & 1,90E-001 & 0,14053517 & $1,96 \mathrm{E}-002$ & 2,23E-001 & 1,69E-002 \\
\hline d12_3 & 4,65E-002 & 0,23504513 & $2,54 \mathrm{E}-003$ & $1,90 \mathrm{E}-001$ & $2,81 \mathrm{E}-003$ \\
\hline d12_5 & $5,18 \mathrm{E}-001$ & 0,18624072 & $6,43 \mathrm{E}-005$ & $8,85 \mathrm{E}-003$ & $4,00 \mathrm{E}-005$ \\
\hline d19_0 & 1,99E-001 & 0,0214904 & $8,65 \mathrm{E}-002$ & $1,85 \mathrm{E}-001$ & $2,75 \mathrm{E}-002$ \\
\hline d19_1 & 8,09E-004 & 0,14757265 & $1,02 \mathrm{E}-002$ & $5,30 \mathrm{E}-002$ & 4,01E-002 \\
\hline d19_3 & 4,92E-003 & 0,08777794 & $3,52 \mathrm{E}-001$ & $5,79 \mathrm{E}-003$ & $8,59 \mathrm{E}-002$ \\
\hline d19_5 & 2,29E-001 & 0,13632752 & $8,47 \mathrm{E}-003$ & $1,54 \mathrm{E}-001$ & $4,31 \mathrm{E}-002$ \\
\hline d20_0 & $8,13 \mathrm{E}-001$ & 0,0477081 & $7,89 \mathrm{E}-003$ & 2,99E-003 & $2,39 \mathrm{E}-005$ \\
\hline d20_1 & 2,06E-004 & 0,37801462 & $1,75 \mathrm{E}-001$ & $1,24 \mathrm{E}-006$ & $5,77 \mathrm{E}-003$ \\
\hline d20_3 & $1,00 \mathrm{E}-001$ & 0,08965817 & $3,76 \mathrm{E}-001$ & $4,95 \mathrm{E}-003$ & $5,71 \mathrm{E}-002$ \\
\hline $\mathrm{d} 20 \_5$ & 5,37E-001 & 0,20081604 & $2,41 \mathrm{E}-002$ & $1,50 \mathrm{E}-002$ & $7,28 \mathrm{E}-002$ \\
\hline $\mathrm{d} 21 \_0$ & 5,57E-001 & 0,16701627 & $6,17 \mathrm{E}-003$ & $6,27 \mathrm{E}-005$ & $2,98 \mathrm{E}-003$ \\
\hline d21_1 & 6,69E-002 & 0,25248897 & $2,58 \mathrm{E}-002$ & $2,58 \mathrm{E}-001$ & $3,00 \mathrm{E}-002$ \\
\hline d21_3 & $9,72 \mathrm{E}-002$ & 0,08345892 & $1,15 \mathrm{E}-003$ & $3,18 \mathrm{E}-001$ & $4,32 \mathrm{E}-005$ \\
\hline $\mathrm{d} 21 \_5$ & 2,21E-001 & 0,07301048 & $6,44 \mathrm{E}-002$ & $4,72 \mathrm{E}-003$ & $1,02 \mathrm{E}-002$ \\
\hline \multicolumn{6}{|l|}{ test $\mathrm{V}$} \\
\hline & Dim 1 & $\operatorname{Dim} 2$ & Dim 3 & $\operatorname{Dim} 4$ & $\operatorname{Dim} 5$ \\
\hline d5_0 & 5,8526422 & $-2,4765063$ & $-2,12624675$ & 0,2471707 & $-1,01476726$ \\
\hline d5_1 & 2,9498875 & 2,9516998 & 3,89936145 & $-2,13631446$ & $-1,20798598$ \\
\hline d5_3 & $-1,9586909$ & 2,1919009 & $-3,44765362$ & 0,14072634 & $-0,09636149$ \\
\hline d5_5 & $-4,5462154$ & $-3,927899$ & 1,14232559 & 1,89399841 & 1,99201797 \\
\hline d7_0 & 7,4713884 & $-1,1937211$ & $-0,37053742$ & 0,96265621 & $-0,97128818$ \\
\hline d7_1 & 0,472671 & 3,1776756 & 2,1923977 & 2,16947489 & 2,43879489 \\
\hline d7_3 & $-1,6883366$ & 0,8686606 & $-1,80902213$ & $-1,56154929$ & 4,95116863 \\
\hline d7_5 & $-6,3605743$ & $-1,2379083$ & 0,62565751 & $-0,89102829$ & $-4,33198515$ \\
\hline d12_0 & 5,6476444 & $-3,2187605$ & $-0,5367534$ & $-0,02848593$ & 0,42607523 \\
\hline d12_1 & 3,2978916 & 2,8358019 & 1,05790191 & 3,57180467 & $-0,98379519$ \\
\hline d12_3 & 1,5764225 & 3,5442819 & $-0,36824219$ & $-3,18491542$ & 0,38759493 \\
\hline d12_5 & $-5,960651$ & $-3,5735113$ & $-0,06638002$ & 0,77908984 & 0,05238258 \\
\hline
\end{tabular}




\begin{tabular}{|c|c|c|c|c|c|}
\hline d19_0 & 3,3060735 & $-1,0858527$ & 2,17850934 & $-3,18344017$ & 1,22829407 \\
\hline d19_1 & 0,2027991 & 2,7386626 & 0,72161811 & 1,64112282 & $-1,42790477$ \\
\hline d19_3 & $-0,5047243$ & 2,1321665 & $-4,27217492$ & $-0,5475635$ & $-2,10890496$ \\
\hline d19_5 & $-3,6136636$ & $-2,7864727$ & 0,69449735 & 2,96299906 & 1,56590057 \\
\hline d20_0 & 8,2844238 & $-2,0066726$ & 0,8159252 & 0,50214789 & 0,04487724 \\
\hline d20_1 & 0,1062403 & 4,5548435 & 3,09678513 & $-0,00824002$ & 0,56297596 \\
\hline d20_3 & $-2,3385681$ & 2,2129856 & $-4,53290638$ & 0,52019485 & 1,76675563 \\
\hline d20_5 & $-6,3022563$ & $-3,8536475$ & 1,334099 & $-1,05267999$ & $-2,32091377$ \\
\hline d21_0 & 6,2021001 & $-3,3964438$ & $-0,65296972$ & 0,06580489 & 0,45384117 \\
\hline $\mathrm{d} 21 \_1$ & $-1,9245174$ & 3,7378707 & $-1,19574811$ & 3,77810231 & $-1,28871843$ \\
\hline d21_3 & $-2,2759207$ & 2,1089066 & 0,24709402 & $-4,11361673$ & 0,04800305 \\
\hline $\mathrm{d} 21 \_5$ & $-3,4875455$ & $-2,0053061$ & 1,88325145 & 0,5096927 & 0,75039568 \\
\hline \multicolumn{6}{|l|}{ eta2 } \\
\hline & Dim 1 & $\operatorname{Dim} 2$ & Dim 3 & $\operatorname{Dim} 4$ & $\operatorname{Dim} 5$ \\
\hline d5 & 0,448356 & 0,3119587 & 0,37599107 & 0,1010416 & 0,09122053 \\
\hline d7 & 0,5109352 & 0,1399623 & 0,11965537 & 0,12488025 & 0,69810554 \\
\hline $\mathrm{d} 12$ & 0,4690533 & 0,374687 & 0,02208059 & 0,31602654 & 0,02113706 \\
\hline d19 & 0,1301413 & 0,2001444 & 0,29604865 & 0,24785127 & 0,15004299 \\
\hline $\mathrm{d} 20$ & 0,6565509 & 0,4138779 & 0,39437672 & 0,01993619 & 0,11903823 \\
\hline $\mathrm{d} 21$ & 0,3259892 & 0,2942314 & 0,07080187 & 0,41213963 & 0,03534478 \\
\hline
\end{tabular}

LEGENDA: eig = Autovalores, percentagem da variância e percentagem da variância cumulativa; coord $=$ valores das coordenadas das categorias em relação ao eixo (dimensão); contrib = Contribuição da variável para o eixo (ou dimensão); v.test $=($ teste $\mathrm{V})$ indica se o valor é significativo. (acima de 2 ou abaixo de -2 ); Eta2 = (variáveis categóricas) contém o quadrado da relação entre cada variável e as dimensões; $\cos 2$ = quadrado do cosseno. 
Anexo XII. TABela de SAÍdA do MCA ENTRE VARIÁVEIS EXPliCATIVAS E FATOR DE DIMENSIONAMENTO.

eig

\begin{tabular}{|c|c|c|c|}
\hline & $\begin{array}{l}\text { Autovalore } \\
\text { s }\end{array}$ & $\begin{array}{l}\text { Percentage } \\
\text { m da } \\
\text { variância } \\
28,4413955\end{array}$ & $\begin{array}{l}\mathrm{m} \text { d } \\
\text { variância } \\
\text { cumulativa }\end{array}$ \\
\hline $\operatorname{dim} 1$ & $7,23 \mathrm{E}-002$ & $\begin{array}{l}2 \\
14,2581010\end{array}$ & 28,4414 \\
\hline $\operatorname{dim} 2$ & $3,63 \mathrm{E}-002$ & 3 & 42,6995 \\
\hline $\operatorname{dim} 3$ & $1,26 \mathrm{E}-002$ & 4,96462099 & 47,66412 \\
\hline $\operatorname{dim} 4$ & $9,60 \mathrm{E}-003$ & 3,77398505 & 51,4381 \\
\hline $\operatorname{dim} 5$ & $8,42 \mathrm{E}-003$ & 3,31109301 & 54,7492 \\
\hline $\operatorname{dim} 6$ & $7,63 \mathrm{E}-003$ & 3,00091154 & 57,75011 \\
\hline $\operatorname{dim} 7$ & 7,04E-003 & 2,76734202 & 60,51745 \\
\hline $\operatorname{dim} 8$ & $6,37 \mathrm{E}-003$ & 2,50337594 & 63,02083 \\
\hline $\begin{array}{l}\operatorname{dim} 9 \\
\operatorname{dim}\end{array}$ & $5,72 \mathrm{E}-003$ & 2,24821915 & 65,26904 \\
\hline $\begin{array}{l}10 \\
\text { dim }\end{array}$ & $5,16 \mathrm{E}-003$ & 2,02718897 & 67,29623 \\
\hline $\begin{array}{l}11 \\
\operatorname{dim}\end{array}$ & $5,09 \mathrm{E}-003$ & 2,00221929 & 69,29845 \\
\hline $\begin{array}{l}12 \\
\operatorname{dim}\end{array}$ & 4,71E-003 & 1,85111105 & 71,14956 \\
\hline $\begin{array}{l}13 \\
\text { dim }\end{array}$ & $4,60 \mathrm{E}-003$ & 1,80966098 & 72,95922 \\
\hline $\begin{array}{l}14 \\
\text { dim }\end{array}$ & $4,42 \mathrm{E}-003$ & 1,73976302 & 74,69899 \\
\hline $\begin{array}{l}15 \\
\text { dim }\end{array}$ & $4,21 \mathrm{E}-003$ & 1,65498114 & 76,35397 \\
\hline $\begin{array}{l}16 \\
\operatorname{dim}\end{array}$ & $3,89 \mathrm{E}-003$ & 1,52981154 & 77,88378 \\
\hline $\begin{array}{l}17 \\
\operatorname{dim}\end{array}$ & $3,75 \mathrm{E}-003$ & 1,47443904 & 79,35822 \\
\hline $\begin{array}{l}18 \\
\operatorname{dim}\end{array}$ & $3,56 \mathrm{E}-003$ & 1,40117461 & 80,75939 \\
\hline $\begin{array}{l}19 \\
\operatorname{dim}\end{array}$ & $3,33 \mathrm{E}-003$ & 1,30956212 & 82,06896 \\
\hline $\begin{array}{l}20 \\
\operatorname{dim}\end{array}$ & $3,19 \mathrm{E}-003$ & 1,25367089 & 83,32263 \\
\hline $\begin{array}{l}21 \\
\operatorname{dim}\end{array}$ & $3,04 \mathrm{E}-003$ & 1,19408482 & 84,51671 \\
\hline $\begin{array}{l}22 \\
\operatorname{dim}\end{array}$ & $2,96 \mathrm{E}-003$ & 1,16389247 & 85,6806 \\
\hline $\begin{array}{l}23 \\
\operatorname{dim}\end{array}$ & $2,76 \mathrm{E}-003$ & 1,08640466 & 86,76701 \\
\hline $\begin{array}{l}24 \\
\operatorname{dim}\end{array}$ & $2,54 \mathrm{E}-003$ & 0,99815414 & 87,76516 \\
\hline $\begin{array}{l}25 \\
\operatorname{dim}\end{array}$ & $2,12 \mathrm{E}-003$ & 0,83324221 & 88,59841 \\
\hline $\begin{array}{l}26 \\
\operatorname{dim}\end{array}$ & $2,05 \mathrm{E}-003$ & 0,80715855 & 89,40556 \\
\hline $\begin{array}{l}27 \\
\operatorname{dim}\end{array}$ & $1,91 \mathrm{E}-003$ & 0,74961531 & 90,15518 \\
\hline $\begin{array}{l}28 \\
\operatorname{dim}\end{array}$ & $1,86 \mathrm{E}-003$ & 0,73309723 & 90,88828 \\
\hline 29 & $1,82 \mathrm{E}-003$ & 0,7147971 & 91,60307 \\
\hline
\end{tabular}




\begin{tabular}{|c|c|c|c|}
\hline $\operatorname{dim}$ & & & \\
\hline $\begin{array}{l}30 \\
\operatorname{dim}\end{array}$ & $1,70 \mathrm{E}-003$ & 0,66721066 & 92,27028 \\
\hline $\begin{array}{l}31 \\
\operatorname{dim}\end{array}$ & $1,63 \mathrm{E}-003$ & 0,64152335 & 92,91181 \\
\hline $\begin{array}{l}32 \\
\operatorname{dim}\end{array}$ & $1,49 \mathrm{E}-003$ & 0,58584587 & 93,49765 \\
\hline $\begin{array}{l}33 \\
\text { dim }\end{array}$ & $1,42 \mathrm{E}-003$ & 0,55666405 & 94,05432 \\
\hline $\begin{array}{l}34 \\
\operatorname{dim}\end{array}$ & $1,35 \mathrm{E}-003$ & 0,53124245 & 94,58556 \\
\hline $\begin{array}{l}35 \\
\operatorname{dim}\end{array}$ & $1,28 \mathrm{E}-003$ & 0,50395086 & 95,08951 \\
\hline $\begin{array}{l}36 \\
\operatorname{dim}\end{array}$ & $1,22 \mathrm{E}-003$ & 0,48033665 & 95,56985 \\
\hline $\begin{array}{l}37 \\
\operatorname{dim}\end{array}$ & $1,11 \mathrm{E}-003$ & 0,43718473 & 96,00703 \\
\hline $\begin{array}{l}38 \\
\operatorname{dim}\end{array}$ & $1,05 \mathrm{E}-003$ & 0,4136837 & 96,42072 \\
\hline $\begin{array}{l}39 \\
\operatorname{dim}\end{array}$ & 9,64E-004 & 0,37924437 & 96,79996 \\
\hline $\begin{array}{l}40 \\
\operatorname{dim}\end{array}$ & $9,38 \mathrm{E}-004$ & 0,36889158 & 97,16885 \\
\hline $\begin{array}{l}41 \\
\operatorname{dim}\end{array}$ & $8,44 \mathrm{E}-004$ & 0,33205081 & 97,5009 \\
\hline $\begin{array}{l}42 \\
\operatorname{dim}\end{array}$ & 7,74E-004 & 0,30456504 & 97,80547 \\
\hline $\begin{array}{l}43 \\
\operatorname{dim}\end{array}$ & 7,34E-004 & 0,28869642 & 98,09416 \\
\hline $\begin{array}{l}44 \\
\operatorname{dim}\end{array}$ & $6,87 \mathrm{E}-004$ & 0,26997156 & 98,36414 \\
\hline $\begin{array}{l}45 \\
\operatorname{dim}\end{array}$ & $6,42 \mathrm{E}-004$ & 0,25257214 & 98,61671 \\
\hline $\begin{array}{l}46 \\
\operatorname{dim}\end{array}$ & $5,71 \mathrm{E}-004$ & 0,22441102 & 98,84112 \\
\hline $\begin{array}{l}47 \\
\operatorname{dim}\end{array}$ & $4,78 \mathrm{E}-004$ & 0,18794171 & 99,02906 \\
\hline $\begin{array}{l}48 \\
\operatorname{dim}\end{array}$ & $4,53 \mathrm{E}-004$ & 0,17810449 & 99,20716 \\
\hline $\begin{array}{l}49 \\
\operatorname{dim}\end{array}$ & $4,14 \mathrm{E}-004$ & 0,16270203 & 99,36987 \\
\hline $\begin{array}{l}50 \\
\text { dim }\end{array}$ & $3,54 \mathrm{E}-004$ & 0,13902386 & 99,50889 \\
\hline $\begin{array}{l}51 \\
\operatorname{dim}\end{array}$ & $3,37 \mathrm{E}-004$ & 0,13261342 & 99,6415 \\
\hline $\begin{array}{l}52 \\
\operatorname{dim}\end{array}$ & $2,78 \mathrm{E}-004$ & 0,10920173 & 99,75071 \\
\hline $\begin{array}{l}53 \\
\operatorname{dim}\end{array}$ & $2,40 \mathrm{E}-004$ & 0,09426044 & 99,84497 \\
\hline $\begin{array}{l}54 \\
\operatorname{dim}\end{array}$ & $1,86 \mathrm{E}-004$ & 0,07323799 & 99,9182 \\
\hline $\begin{array}{l}55 \\
\operatorname{dim}\end{array}$ & $1,58 \mathrm{E}-004$ & 0,06211635 & 99,98032 \\
\hline 56 & $5,00 \mathrm{E}-005$ & 0,01967936 & 100 \\
\hline
\end{tabular}

Dim 1

Dim 2

Dim 3

Dim 4

Dim 5 


\begin{tabular}{|c|c|c|c|c|c|}
\hline \multirow[b]{2}{*}{ d5_0 } & \multirow[b]{2}{*}{ 7,81E-001 } & \multicolumn{2}{|l|}{-} & \multirow{2}{*}{$\begin{array}{l}- \\
0,0757347 \\
1 \\
-\end{array}$} & \multirow{2}{*}{$\begin{array}{l}- \\
0,0717178 \\
8\end{array}$} \\
\hline & & 6 & 4 & & \\
\hline & & 0,25182139 & $\overline{-}, 03643067$ & 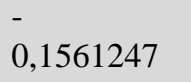 & 0,0695123 \\
\hline d5_1 & $1,68 \mathrm{E}-001$ & 9 & 5 & 4 & 1 \\
\hline & & 0,04641470 & 0,03842185 & 0,0926971 & 0,0601101 \\
\hline d5_3 & $-1,04 \mathrm{E}-001$ & 6 & 2 & 9 & 2 \\
\hline & & 0,29189545 & 0,01766447 & 0,0597873 & 0,0347430 \\
\hline d5_5 & $-2,83 \mathrm{E}-001$ & 7 & 6 & $\begin{array}{l}7 \\
-\end{array}$ & 7 \\
\hline & & 0,02779376 & & 0,0345458 & 0,0384098 \\
\hline d7_0 & 3,93E-001 & 1 & 0,05590877 & $\begin{array}{l}7 \\
-\end{array}$ & $\begin{array}{l}1 \\
-\end{array}$ \\
\hline d7_1 & 1,39E-003 & $\begin{array}{l}0,42517847 \\
5\end{array}$ & $\begin{array}{l}0,11994283 \\
6\end{array}$ & $\begin{array}{l}0,0846727 \\
8\end{array}$ & $\begin{array}{l}0,0753013 \\
2\end{array}$ \\
\hline & & 0,05979103 & 0,11869690 & 0,2059423 & 0,1142676 \\
\hline d7_3 & $-1,23 \mathrm{E}-001$ & $\begin{array}{l}4 \\
-\end{array}$ & 8 & $\begin{array}{l}2 \\
-\end{array}$ & 8 \\
\hline & & 0,08759516 & 0,02062716 & 0,0507309 & \\
\hline & & 0,44147583 & 0,37619593 & 0,0860286 & 0,2653692 \\
\hline d12_0 & $1,20 \mathrm{E}+000$ & $\begin{array}{l}4 \\
0,29308980\end{array}$ & $\begin{array}{l}1 \\
0,15026236\end{array}$ & $\begin{array}{l}1 \\
0,0211510\end{array}$ & 7 \\
\hline d12_1 & $4,40 \mathrm{E}-001$ & 1 & 9 & 8 & $\begin{array}{l}0,3563065 \\
-\end{array}$ \\
\hline d12_3 & $9,62 \mathrm{E}-002$ & 0,23161037 & $\begin{array}{l}0,09969440 \\
2\end{array}$ & $\begin{array}{l}0,0669456 \\
5\end{array}$ & $\begin{array}{l}0,1003044 \\
7\end{array}$ \\
\hline & & & $\overline{-}, 00791894$ & & \\
\hline d12_5 & $-2,50 \mathrm{E}-001$ & $\begin{array}{l}-0,14308702 \\
-\end{array}$ & $\begin{array}{l}9 \\
-\end{array}$ & $\begin{array}{l}-0,0333636 \\
-\end{array}$ & $\begin{array}{l}0,013838 \\
-\end{array}$ \\
\hline d19_0 & $1,44 \mathrm{E}-001$ & $\begin{array}{l}0,02052607 \\
8\end{array}$ & $\begin{array}{l}0,11731749 \\
6 \\
-\end{array}$ & $\begin{array}{l}0,0942070 \\
7 \\
-\end{array}$ & $\begin{array}{l}0,0175471 \\
6\end{array}$ \\
\hline d19_1 & 7,18E-003 & $\begin{array}{l}0,28593794 \\
4 \\
0,14693875\end{array}$ & $\begin{array}{l}0,01964143 \\
3 \\
0,03599249\end{array}$ & $\begin{array}{l}0,0205894 \\
3 \\
0,1375608\end{array}$ & $\begin{array}{l}0,0307339 \\
3 \\
0,0004502\end{array}$ \\
\hline d19_3 & $-7,00 \mathrm{E}-002$ & 5 & 2 & 4 & 3 \\
\hline d19_5 & $-2,43 \mathrm{E}-001$ & $\begin{array}{l}0,22394800 \\
7 \\
-\end{array}$ & $\begin{array}{l}0,22033100 \\
4 \\
-\end{array}$ & $\begin{array}{l}0,0977945 \\
5\end{array}$ & $\begin{array}{l}0,0180241 \\
6\end{array}$ \\
\hline d20_0 & $5,53 \mathrm{E}-001$ & $\begin{array}{l}0,05461044 \\
9\end{array}$ & $\begin{array}{l}0,00743639 \\
4 \\
-\end{array}$ & $-0,1052011$ & $\begin{array}{l}0,0699529 \\
2\end{array}$ \\
\hline $\mathrm{d} 20 \_1$ & $3,56 \mathrm{E}-002$ & $\begin{array}{l}0,36541301 \\
2\end{array}$ & $\begin{array}{l}0,04313746 \\
6\end{array}$ & $\begin{array}{l}0,0683678 \\
9\end{array}$ & $\begin{array}{l}0,0369756 \\
1\end{array}$ \\
\hline d20_3 & $-2,14 \mathrm{E}-001$ & $\begin{array}{l}0,19204349 \\
5 \\
-\end{array}$ & $\begin{array}{l}0,00019297 \\
4\end{array}$ & $\begin{array}{l}0,0326453 \\
7\end{array}$ & $\begin{array}{l}0,1377723 \\
1\end{array}$ \\
\hline d20_5 & $-4,17 \mathrm{E}-001$ & $\begin{array}{l}0,35321680 \\
2\end{array}$ & $\begin{array}{l}0,03262086 \\
2\end{array}$ & 0,0459802 & $\begin{array}{l}0,0512550 \\
4\end{array}$ \\
\hline
\end{tabular}




\begin{tabular}{|c|c|c|c|c|c|}
\hline & & $\begin{array}{l}- \\
0,13929177\end{array}$ & 0,02079366 & 0,0060392 & $\overline{0}, 0266256$ \\
\hline \multirow{2}{*}{$\mathrm{d} 21 \_0$} & 3,29E-001 & 3 & 7 & 6 & 9 \\
\hline & & 0,27328913 & 0,03926364 & 0,0824699 & 0,0164637 \\
\hline d21_1 & $-1,33 \mathrm{E}-001$ & 2 & 5 & 1 & 8 \\
\hline \multirow{3}{*}{ d21_3 } & & 0,12238085 & 0,05012272 & 0,0623461 & \\
\hline & $-2,46 \mathrm{E}-001$ & 2 & 9 & 3 & $-0,0431745$ \\
\hline & & $\overline{-}-18022370$ & $\overline{-}, 02688584$ & $\overline{0}, 0281127$ & 0,1054498 \\
\hline d21_5 & $-2,76 \mathrm{E}-001$ & $\begin{array}{l}2 \\
-\end{array}$ & 1 & $\begin{array}{l}3 \\
-\end{array}$ & 7 \\
\hline \multirow[b]{2}{*}{ e1_0 } & & 0,12085928 & 0,00109927 & 0,0946703 & \\
\hline & $4,90 \mathrm{E}-001$ & 3 & 5 & 1 & 0,0043502 \\
\hline \multirow[b]{2}{*}{ e1_1 } & & 0,41746400 & 0,06949444 & 0,0720948 & 0,1793322 \\
\hline & $7,33 \mathrm{E}-002$ & 6 & 8 & $\begin{array}{l}6 \\
-\end{array}$ & $\begin{array}{l}7 \\
-\end{array}$ \\
\hline \multirow[b]{2}{*}{ e1_3 } & & 0,38394507 & & 0,0050681 & 0,1454230 \\
\hline & $-8,72 \mathrm{E}-002$ & 6 & $\begin{array}{l}-0,03651277 \\
0,03071837\end{array}$ & $\begin{array}{l}1 \\
0,0546776\end{array}$ & $\begin{array}{l}3 \\
0,0288988\end{array}$ \\
\hline e1_5 & $-3,20 \mathrm{E}-001$ & $\begin{array}{l}-0,1801432 \\
-\end{array}$ & 7 & 4 & 8 \\
\hline e7_0 & $4,05 \mathrm{E}-001$ & $\begin{array}{l}0,02152676 \\
5\end{array}$ & $\begin{array}{l}0,08818684 \\
-\end{array}$ & $-0,0080362$ & $\begin{array}{l}0,0330277 \\
1 \\
-\end{array}$ \\
\hline e7_1 & $2,05 \mathrm{E}-002$ & $\begin{array}{l}0,37167902 \\
9\end{array}$ & $\begin{array}{l}0,05400747 \\
7\end{array}$ & 0,0574023 & $\begin{array}{l}0,1414120 \\
1 \\
-\end{array}$ \\
\hline e7_3 & $-2,48 \mathrm{E}-001$ & $\begin{array}{l}0,02272413 \\
7 \\
-\end{array}$ & $\begin{array}{l}0,06755774 \\
3 \\
-\end{array}$ & $\begin{array}{l}0,0285442 \\
4 \\
-\end{array}$ & $\begin{array}{l}0,0068961 \\
7\end{array}$ \\
\hline e7_5 & -1,94E-001 & $\begin{array}{l}0,22858200 \\
8 \\
-\end{array}$ & $\begin{array}{l}0,12293739 \\
8 \\
-\end{array}$ & $\begin{array}{l}0,0546181 \\
7\end{array}$ & $\begin{array}{l}0,0594564 \\
7 \\
-\end{array}$ \\
\hline e13_0 & $3,03 \mathrm{E}-001$ & $\begin{array}{l}0,17018647 \\
7 \\
0,23583540\end{array}$ & $\begin{array}{l}0,28063760 \\
3 \\
0,30837633\end{array}$ & $\begin{array}{l}0,1210639 \\
1 \\
0,2522202\end{array}$ & $\begin{array}{l}0,1433858 \\
7 \\
0,5203809\end{array}$ \\
\hline e13_1 & $2,50 \mathrm{E}-001$ & 4 & $\begin{array}{l}2 \\
-\end{array}$ & 8 & 2 \\
\hline e13_3 & $-2,74 \mathrm{E}-002$ & $\begin{array}{l}0,09101074 \\
9\end{array}$ & $\begin{array}{l}0,01125258 \\
2\end{array}$ & $\begin{array}{l}0,1126727 \\
6 \\
-\end{array}$ & $\begin{array}{l}0,1425342 \\
4 \\
-\end{array}$ \\
\hline e13_5 & $-1,40 \mathrm{E}-001$ & $\begin{array}{l}0,02158014 \\
3 \\
-\end{array}$ & $\begin{array}{l}0,08414266 \\
8\end{array}$ & $\begin{array}{l}0,1025977 \\
8 \\
-\end{array}$ & $\begin{array}{l}0,0314027 \\
6\end{array}$ \\
\hline e14_0 & 4,09E-001 & $\begin{array}{l}0,03166253 \\
7\end{array}$ & $-0,08802791$ & $\begin{array}{l}0,1368095 \\
2\end{array}$ & $\begin{array}{l}0,0991227 \\
5 \\
-\end{array}$ \\
\hline e14_1 & $2,75 \mathrm{E}-002$ & $\begin{array}{l}0,33287046 \\
7\end{array}$ & $-0,07697604$ & $\begin{array}{l}0,0953474 \\
3 \\
-\end{array}$ & $\begin{array}{l}0,0324021 \\
1 \\
-\end{array}$ \\
\hline e14_3 & $-2,27 \mathrm{E}-001$ & $\begin{array}{l}0,08769270 \\
2\end{array}$ & $\begin{array}{l}0,10274322 \\
3\end{array}$ & $\begin{array}{l}0,0503525 \\
5\end{array}$ & $\begin{array}{l}0,0743769 \\
5\end{array}$ \\
\hline \multirow[t]{2}{*}{ e14_5 } & $-2,33 \mathrm{E}-001$ & $\begin{array}{l}0,39805232 \\
8 \\
-\end{array}$ & $\begin{array}{l}0,06800017 \\
3 \\
-\end{array}$ & $\begin{array}{l}0,1001457 \\
9\end{array}$ & $\begin{array}{l}0,0034273 \\
6 \\
-\end{array}$ \\
\hline & $5,13 \mathrm{E}-002$ & $\begin{array}{l}0,23028777 \\
9\end{array}$ & $\begin{array}{l}0,09065923 \\
3\end{array}$ & $\begin{array}{l}0,0134751 \\
3\end{array}$ & $\begin{array}{l}0,2043533 \\
5\end{array}$ \\
\hline
\end{tabular}




\begin{tabular}{|c|c|c|c|c|c|}
\hline \multirow{3}{*}{ e20_1 } & \multirow{3}{*}{ 1,07E-001 } & 0,00991394 & 0,07312336 & 0,3959252 & 0,1799729 \\
\hline & & 5 & 8 & 9 & 9 \\
\hline & & 0,19755145 & 0,11526610 & 0,0827733 & 0,0074663 \\
\hline \multirow{2}{*}{ e20_3 } & $-1,38 \mathrm{E}-001$ & 8 & 8 & 2 & 8 \\
\hline & & - & - & - & \\
\hline \multirow[b]{2}{*}{ e20_5 } & & 0,01103747 & 0,03786613 & 0,1265912 & 0,0268198 \\
\hline & $2,30 \mathrm{E}-002$ & 2 & 6 & 6 & 9 \\
\hline \multirow{3}{*}{ e21_0 } & & 0,17850598 & & 0,0922989 & 0,1014547 \\
\hline & $3,25 \mathrm{E}-001$ & 5 & $-0,21120671$ & 3 & 7 \\
\hline & & 0,26092071 & 0,20362596 & & 0,2475247 \\
\hline e21_1 & $2,49 \mathrm{E}-002$ & 9 & 4 & 0,330048 & 3 \\
\hline \multirow[b]{2}{*}{ e21_3 } & & 0,10925118 & 0,05865541 & 0,0542204 & 0,0031703 \\
\hline & $-5,63 \mathrm{E}-002$ & 3 & 6 & 5 & 6 \\
\hline \multirow[b]{2}{*}{ e21_5 } & & 0,01729874 & 0,08940051 & 0,1887861 & 0,0265382 \\
\hline & $-2,39 \mathrm{E}-001$ & 1 & 4 & 3 & 6 \\
\hline \multirow{3}{*}{ e25_0 } & & $\overline{0}, 03915080$ & & 0,0694950 & 0,0755750 \\
\hline & $1,40 \mathrm{E}-001$ & 7 & 0,1365363 & 7 & 4 \\
\hline & & & & - & - \\
\hline \multirow{3}{*}{ e25_1 } & & 0,32798399 & 0,14463455 & 0,1889459 & 0,0264141 \\
\hline & $-3,00 \mathrm{E}-001$ & 7 & 7 & 2 & 6 \\
\hline & & & - & - & \\
\hline \multirow{3}{*}{ e25_3 } & & 0,04489561 & 0,24054746 & 0,1588768 & 0,0039067 \\
\hline & $-2,11 \mathrm{E}-001$ & 7 & 3 & 5 & 3 \\
\hline & & - & - & & \\
\hline \multirow{3}{*}{ e25_5 } & & 0,16676823 & 0,27213769 & 0,0747478 & 0,2122010 \\
\hline & 1,40E-002 & 6 & 1 & 4 & 9 \\
\hline & & - & & & - \\
\hline \multirow{3}{*}{ e35_0 } & & 0,23101015 & 0,15295140 & 0,1165574 & 0,0746998 \\
\hline & $7,45 \mathrm{E}-001$ & 4 & 9 & 8 & 5 \\
\hline & & & $\overline{0} 07892684$ & & \\
\hline \multirow{2}{*}{ e35_1 } & $4,26 \mathrm{E}-001$ & $\begin{array}{l}0,4<\angle \angle 30 \angle 4 \\
2\end{array}$ & $\begin{array}{l}0,0 / 892684 \\
1\end{array}$ & $-0,035862$ & $\begin{array}{l}0,0403498 \\
3\end{array}$ \\
\hline & & 0,40652846 & 0,09892536 & 0,0572908 & \\
\hline \multirow[t]{2}{*}{ e35_3 } & $-6,34 \mathrm{E}-002$ & 6 & 6 & 9 & $-0,024738$ \\
\hline & & - & - & & \\
\hline \multirow[b]{2}{*}{ e35_5 } & & 0,15555829 & 0,04844174 & & 0,0149766 \\
\hline & $-1,20 \mathrm{E}-001$ & 3 & 4 & $\begin{array}{l}-0,0328922 \\
-\end{array}$ & 7 \\
\hline \multirow[b]{2}{*}{ e41_0 } & & & 0,07112248 & 0,1506054 & 0,0781115 \\
\hline & 0,74300465 & $-0,13396239$ & 5 & 8 & 1 \\
\hline \multirow[b]{2}{*}{ e41_1 } & & 0,29075795 & 0,09269076 & 0,0866879 & 0,0806652 \\
\hline & 0,09385651 & 1 & 8 & 6 & 2 \\
\hline \multirow{3}{*}{ e41_3 } & & 0,18175332 & 0,03812343 & 0,0646783 & 0,1490708 \\
\hline & $-0,2282691$ & 9 & 3 & 9 & 2 \\
\hline & & - & & & \\
\hline \multirow[b]{2}{*}{ e41_5 } & - & 0,40313822 & 0,00439632 & 0,0830642 & 0,0323886 \\
\hline & 0,32837156 & 2 & 4 & 9 & 6 \\
\hline \multirow{3}{*}{ e49_0 } & & & 0,27167882 & 0,0845068 & 0,1654741 \\
\hline & 1,00415925 & $-0,29642523$ & 1 & & \\
\hline & & 0,368635887 & 0,05519022 & 0,2531910 & 0,3566921 \\
\hline e49_1 & 0,41147433 & & & 7 & 3 \\
\hline
\end{tabular}




\begin{tabular}{|c|c|c|c|c|c|}
\hline \multirow{4}{*}{ e49_3 } & \multirow{4}{*}{$-0,0075481$} & \multirow{4}{*}{$\begin{array}{l}0,28985694 \\
4 \\
-\end{array}$} & \multicolumn{2}{|l|}{-} & \multirow{3}{*}{$\begin{array}{l}- \\
0,1114538 \\
4\end{array}$} \\
\hline & & & \multicolumn{2}{|l|}{0,13540453} & \\
\hline & & & 4 & $-0,0403623$ & \\
\hline & & & & $\begin{array}{l}- \\
0,0116951\end{array}$ & \\
\hline \multirow[t]{3}{*}{ e49_5 } & \multirow[t]{3}{*}{0,20889175} & 3 & 0,00074432 & 2 & 9 \\
\hline & & - & & & - \\
\hline & & 0,07319036 & 0,05773098 & 0,0929226 & 0,0830322 \\
\hline \multirow[t]{3}{*}{ e28_0 } & \multirow[t]{2}{*}{0,15910674} & 2 & 3 & 8 & 1 \\
\hline & & & & - & \\
\hline & - & 0,14235707 & 0,15136946 & 0,1210785 & 0,0847467 \\
\hline \multirow[t]{2}{*}{ e28_1 } & 0,22504257 & $\begin{array}{l}3 \\
-\end{array}$ & $\begin{array}{l}8 \\
-\end{array}$ & 6 & 5 \\
\hline & - & 0,11640906 & 0,30177073 & & \\
\hline \multirow[t]{2}{*}{ e28_2 } & \multirow[t]{2}{*}{0,25771638} & 9 & 7 & $-0,2230481$ & 0,3500297 \\
\hline & & 0,08413258 & $\overline{0}, 24202336$ & 0,0258240 & 0,0759973 \\
\hline \multirow[t]{2}{*}{ e57_0 } & \multirow[t]{2}{*}{0,1424299} & 3 & 8 & 2 & 9 \\
\hline & & 015514129 & $\overline{-} .17650131$ & $\overline{0} .0744330$ & 0.1136668 \\
\hline \multirow{3}{*}{ e57_1 } & \multirow{3}{*}{0,08190232} & $\begin{array}{l}0,15314129 \\
5\end{array}$ & 6 & 8 & 6 \\
\hline & & & - & - & - \\
\hline & & 0,16434186 & 0,00363856 & 0,0181141 & 0,0355457 \\
\hline \multirow[t]{2}{*}{ e57_3 } & \multirow[t]{2}{*}{0,04561764} & 4 & 8 & 7 & 6 \\
\hline & & $\begin{array}{l}- \\
0,05701960\end{array}$ & 0,20846114 & 0,0458684 & $\overline{0}, 0688538$ \\
\hline \multirow[t]{3}{*}{ e57_5 } & \multirow[t]{3}{*}{$-0,0837099$} & 8 & 9 & 7 & 9 \\
\hline & & - & & & - \\
\hline & & 0,08146878 & 0,08957791 & 0,0812501 & 0,0397436 \\
\hline \multirow[t]{3}{*}{ e58_0 } & 0,23658735 & 9 & 9 & 4 & 2 \\
\hline & & - & - & & \\
\hline & & 0,03293422 & 0,11394810 & 0,1042145 & 0,1262960 \\
\hline e58_1 & 0,08398396 & 8 & 5 & 6 & 2 \\
\hline & - & 0,14850636 & 0,21138868 & 0,0280246 & 0,0381650 \\
\hline e58_3 & 0,17765975 & 2 & 1 & 8 & 1 \\
\hline & - & 0,02107024 & 0,08185528 & $\overline{-}, 1586108$ & 0,0008993 \\
\hline e58_5 & 0,20061609 & 5 & 9 & 9 & 3 \\
\hline contri & & & & & \\
\hline & Dim 1 & _ $\quad \operatorname{Dim} 2$ & Dim 3 & _ $\quad \operatorname{Dim} 4$ & _ $\quad \operatorname{Dim} 5$ \\
\hline & & 0,17200024 & 0,24927630 & 0,0757347 & 0,0717178 \\
\hline d5_0 & 0,78065164 & 6 & 4 & 1 & 8 \\
\hline & & 0,25182139 & 0,03643067 & 0,1561247 & 0,0695123 \\
\hline d5_1 & 0,16837096 & 9 & 5 & 4 & 1 \\
\hline & - & 0,04641470 & 0,03842185 & 0,0926971 & 0,0601101 \\
\hline d5_3 & 0,10404422 & 6 & 2 & 9 & 2 \\
\hline & - & $\overline{-} 29189545$ & & 00507873 & \\
\hline d5 5 & $\overline{0}, 28255466$ & $\begin{array}{l}0,29189545 \\
7\end{array}$ & $\begin{array}{l}0,01766447 \\
6\end{array}$ & $\begin{array}{l}0,0597873 \\
7\end{array}$ & $\begin{array}{l}0,0347430 \\
7\end{array}$ \\
\hline & & - & & r & \\
\hline & & 0,02779376 & & 0,0345458 & 0,0384098 \\
\hline d7_0 & 0,39319073 & 1 & 0,05590877 & 7 & 1 \\
\hline
\end{tabular}




\begin{tabular}{|c|c|c|c|c|c|}
\hline d7_1 & 0,00138896 & $\begin{array}{l}0,42517847 \\
5\end{array}$ & $\begin{array}{l}0,11994283 \\
6 \\
-\end{array}$ & $\begin{array}{l}- \\
0,0846727 \\
8\end{array}$ & $\begin{array}{l}- \\
0,0753013 \\
2 \\
-\end{array}$ \\
\hline & - & 0,05979103 & 0,11869690 & 0,2059423 & 0,1142676 \\
\hline d7_3 & 0,12270741 & $\begin{array}{l}4 \\
-\end{array}$ & $\begin{array}{l}8 \\
-\end{array}$ & $\begin{array}{l}2 \\
-\end{array}$ & 8 \\
\hline d7_5 & $\begin{array}{l}- \\
0,32934894\end{array}$ & $\begin{array}{l}0,08759516 \\
3 \\
-\end{array}$ & $\begin{array}{l}0,02062716 \\
6\end{array}$ & $\begin{array}{l}0,0507309 \\
7 \\
-\end{array}$ & $\begin{array}{l}0,0335837 \\
-\end{array}$ \\
\hline d12_0 & 1,19547302 & $\begin{array}{l}0,44147583 \\
4 \\
0,29308980\end{array}$ & $\begin{array}{l}0,37619593 \\
1 \\
0,15026236\end{array}$ & $\begin{array}{l}0,0860286 \\
1 \\
0,0211510\end{array}$ & $\begin{array}{l}0,2653692 \\
7\end{array}$ \\
\hline d12_1 & 0,43971596 & 1 & $\begin{array}{l}9 \\
-\end{array}$ & 8 & $\begin{array}{l}0,3563065 \\
-\end{array}$ \\
\hline d12_3 & 0,09622195 & 0,23161037 & $\begin{array}{l}0,09969440 \\
2 \\
-\end{array}$ & $\begin{array}{l}0,0669456 \\
5\end{array}$ & $\begin{array}{l}0,1003044 \\
7\end{array}$ \\
\hline d12_5 & $\begin{array}{l}- \\
0,24979501\end{array}$ & $\begin{array}{l}-0,14308702 \\
-\end{array}$ & $\begin{array}{l}0,00791894 \\
9 \\
-\end{array}$ & $\begin{array}{l}-0,0333636 \\
-\end{array}$ & $\begin{array}{l}0,013838 \\
-\end{array}$ \\
\hline d19_0 & 0,1443705 & $\begin{array}{l}0,02052607 \\
8\end{array}$ & $\begin{array}{l}0,11731749 \\
6 \\
-\end{array}$ & $\begin{array}{l}0,0942070 \\
7 \\
-\end{array}$ & $\begin{array}{l}0,0175471 \\
6\end{array}$ \\
\hline d19_1 & $\begin{array}{l}0,00717987 \\
-\end{array}$ & $\begin{array}{l}0,28593794 \\
4 \\
0,14693875\end{array}$ & $\begin{array}{l}0,01964143 \\
3 \\
0,03599249\end{array}$ & $\begin{array}{l}0,0205894 \\
3 \\
0,1375608\end{array}$ & $\begin{array}{l}0,0307339 \\
3 \\
0,0004502\end{array}$ \\
\hline d19_3 & 0,07004928 & $\begin{array}{l}5 \\
-\end{array}$ & 2 & 4 & 3 \\
\hline d19_5 & $\begin{array}{l}- \\
0,24267617\end{array}$ & $\begin{array}{l}0,22394800 \\
7 \\
-\end{array}$ & $\begin{array}{l}0,22033100 \\
4 \\
-\end{array}$ & $\begin{array}{l}0,0977945 \\
5\end{array}$ & $\begin{array}{l}0,0180241 \\
6\end{array}$ \\
\hline d20_0 & 0,55337724 & $\begin{array}{l}0,05461044 \\
9\end{array}$ & $\begin{array}{l}0,00743639 \\
4 \\
-\end{array}$ & $-0,1052011$ & $\begin{array}{l}0,0699529 \\
2\end{array}$ \\
\hline d20_1 & 0,03555494 & $\begin{array}{l}0,36541301 \\
2\end{array}$ & $\begin{array}{l}0,04313746 \\
6\end{array}$ & $\begin{array}{l}0,0683678 \\
9\end{array}$ & $\begin{array}{l}0,0369756 \\
1 \\
-\end{array}$ \\
\hline $\mathrm{d} 20 \_3$ & $\begin{array}{l}- \\
0,21364815\end{array}$ & $\begin{array}{l}0,19204349 \\
5 \\
-\end{array}$ & $\begin{array}{l}0,00019297 \\
4\end{array}$ & $\begin{array}{l}0,0326453 \\
7\end{array}$ & $\begin{array}{l}0,1377723 \\
1\end{array}$ \\
\hline $\mathrm{d} 20 \_5$ & - & $\begin{array}{l}0,35321680 \\
2 \\
-\end{array}$ & $\begin{array}{l}0,03262086 \\
2\end{array}$ & 0,0459802 & $\begin{array}{l}0,0512550 \\
4 \\
-\end{array}$ \\
\hline d21_0 & $\begin{array}{l}0,32915064 \\
-\end{array}$ & $\begin{array}{l}0,13929177 \\
3 \\
0,27328913\end{array}$ & $\begin{array}{l}0,02079366 \\
7 \\
0,03926364\end{array}$ & $\begin{array}{l}0,0060392 \\
6 \\
0,0824699\end{array}$ & $\begin{array}{l}0,0266256 \\
9 \\
0,0164637\end{array}$ \\
\hline $\mathrm{d} 21 \_1$ & 0,13320839 & 2 & $\begin{array}{l}5 \\
-\end{array}$ & $\begin{array}{l}1 \\
-\end{array}$ & 8 \\
\hline d21_3 & $\begin{array}{l}- \\
0,24591294\end{array}$ & $\begin{array}{l}0,12238085 \\
2 \\
-\end{array}$ & $\begin{array}{l}0,05012272 \\
9 \\
-\end{array}$ & $\begin{array}{l}0,0623461 \\
3 \\
-\end{array}$ & $-0,0431745$ \\
\hline d21_5 & - & $\begin{array}{l}0,18022370 \\
2 \\
-\end{array}$ & $\begin{array}{l}0,02688584 \\
1\end{array}$ & $\begin{array}{l}0,0281127 \\
3 \\
-\end{array}$ & $\begin{array}{l}0,1054498 \\
7\end{array}$ \\
\hline e1_0 & 0,48957428 & $\begin{array}{l}0,12085928 \\
3\end{array}$ & $\begin{array}{l}0,00109927 \\
5 \\
-\end{array}$ & $\begin{array}{l}0,0946703 \\
1\end{array}$ & 0,0043502 \\
\hline e1_1 & 0,07330404 & $\begin{array}{l}0,41746400 \\
6\end{array}$ & $\begin{array}{l}0,06949444 \\
8\end{array}$ & $\begin{array}{l}0,0720948 \\
6\end{array}$ & $\begin{array}{l}0,1793322 \\
7\end{array}$ \\
\hline
\end{tabular}




\begin{tabular}{|c|c|c|c|c|c|}
\hline & - & 0,38394507 & & $\overline{0}, 0050681$ & $\overline{0}, 1454230$ \\
\hline e1_3 & 0,08717723 & 6 & $-0,03651277$ & 1 & 3 \\
\hline e1_5 & $\begin{array}{l}- \\
0,32032002\end{array}$ & $-0,1801432$ & $\begin{array}{l}0,03071837 \\
7\end{array}$ & $\begin{array}{l}0,0546776 \\
4\end{array}$ & $\begin{array}{l}0,0288988 \\
8\end{array}$ \\
\hline e7_0 & 0,40513232 & $\begin{array}{l}0,02152676 \\
5\end{array}$ & $\begin{array}{l}0,08818684 \\
-\end{array}$ & $-0,0080362$ & $\begin{array}{l}0,0330277 \\
1 \\
-\end{array}$ \\
\hline e7_1 & 0,02052683 & $\begin{array}{l}0,37167902 \\
9\end{array}$ & $\begin{array}{l}0,05400747 \\
7\end{array}$ & 0,0574023 & $\begin{array}{l}0,1414120 \\
1 \\
-\end{array}$ \\
\hline e7_3 & $\begin{array}{l}- \\
0,24836226\end{array}$ & $\begin{array}{l}0,02272413 \\
7 \\
-\end{array}$ & $\begin{array}{l}0,06755774 \\
3 \\
-\end{array}$ & $\begin{array}{l}0,0285442 \\
4 \\
-\end{array}$ & $\begin{array}{l}0,0068961 \\
7\end{array}$ \\
\hline e7_5 & 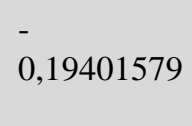 & $\begin{array}{l}0,22858200 \\
8 \\
-\end{array}$ & $\begin{array}{l}0,12293739 \\
8 \\
-\end{array}$ & $\begin{array}{l}0,0546181 \\
7\end{array}$ & $\begin{array}{l}0,0594564 \\
7 \\
-\end{array}$ \\
\hline e13_0 & 0,30267074 & $\begin{array}{l}0,17018647 \\
7 \\
0,23583540\end{array}$ & $\begin{array}{l}0,28063760 \\
3 \\
0,30837633\end{array}$ & $\begin{array}{l}0,1210639 \\
1 \\
0,2522202\end{array}$ & $\begin{array}{l}0,1433858 \\
7 \\
0,5203809\end{array}$ \\
\hline e13_1 & 0,25041855 & 4 & 2 & 8 & 2 \\
\hline e13_3 & 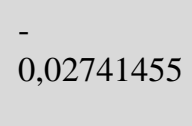 & $\begin{array}{l}0,09101074 \\
9\end{array}$ & $\begin{array}{l}0,01125258 \\
2\end{array}$ & $\begin{array}{l}0,1126727 \\
6 \\
-\end{array}$ & $\begin{array}{l}0,1425342 \\
4 \\
-\end{array}$ \\
\hline e13_5 & $\begin{array}{l}- \\
0,14020792\end{array}$ & $\begin{array}{l}0,02158014 \\
3 \\
-\end{array}$ & $\begin{array}{l}0,08414266 \\
8\end{array}$ & $\begin{array}{l}0,1025977 \\
8 \\
-\end{array}$ & $\begin{array}{l}0,0314027 \\
6\end{array}$ \\
\hline e14_0 & 0,40925972 & $\begin{array}{l}0,03166253 \\
7\end{array}$ & $-0,08802791$ & $\begin{array}{l}0,1368095 \\
2\end{array}$ & $\begin{array}{l}0,0991227 \\
5 \\
-\end{array}$ \\
\hline e14_1 & 0,02749324 & $\begin{array}{l}0,33287046 \\
7\end{array}$ & $-0,07697604$ & $\begin{array}{l}0,0953474 \\
3 \\
-\end{array}$ & $\begin{array}{l}0,0324021 \\
1 \\
-\end{array}$ \\
\hline e14_3 & $-\overline{0,22743356}$ & $\begin{array}{l}0,08769270 \\
2 \\
-\end{array}$ & $\begin{array}{l}0,10274322 \\
3\end{array}$ & $\begin{array}{l}0,0503525 \\
5\end{array}$ & $\begin{array}{l}0,0743769 \\
5\end{array}$ \\
\hline e14_5 & $\begin{array}{l}- \\
0,23293203\end{array}$ & $\begin{array}{l}0,39805232 \\
8 \\
-\end{array}$ & $\begin{array}{l}0,06800017 \\
3 \\
-\end{array}$ & $\begin{array}{l}0,1001457 \\
9\end{array}$ & $\begin{array}{l}0,0034273 \\
6 \\
-\end{array}$ \\
\hline e20_0 & 0,05128966 & $\begin{array}{l}0,23028777 \\
9 \\
-\end{array}$ & $\begin{array}{l}0,09065923 \\
3\end{array}$ & $\begin{array}{l}0,0134751 \\
3\end{array}$ & $\begin{array}{l}0,2043533 \\
5\end{array}$ \\
\hline e20_1 & $\begin{array}{l}0,10717906 \\
-\end{array}$ & $\begin{array}{l}0,00991394 \\
5 \\
0,19755145\end{array}$ & $\begin{array}{l}0,07312336 \\
8 \\
0,11526610\end{array}$ & $\begin{array}{l}0,3959252 \\
9 \\
0,0827733\end{array}$ & $\begin{array}{l}0,1799729 \\
9 \\
0,0074663\end{array}$ \\
\hline e20_3 & 0,13757709 & $\begin{array}{l}8 \\
-\end{array}$ & $\begin{array}{l}8 \\
-\end{array}$ & $\begin{array}{l}2 \\
-\end{array}$ & 8 \\
\hline e20_5 & 0,02295782 & $\begin{array}{l}0,01103747 \\
2 \\
-\end{array}$ & $\begin{array}{l}0,03786613 \\
6\end{array}$ & $\begin{array}{l}0,1265912 \\
6\end{array}$ & $\begin{array}{l}0,0268198 \\
9 \\
-\end{array}$ \\
\hline e21_0 & 0,32504541 & $\begin{array}{l}0,17850598 \\
5 \\
0,26092071\end{array}$ & $\begin{array}{l}-0,21120671 \\
0,20362596\end{array}$ & $\begin{array}{l}0,0922989 \\
3\end{array}$ & $\begin{array}{l}0,1014547 \\
7 \\
0,2475247\end{array}$ \\
\hline e21_1 & 0,02487034 & 9 & 4 & 0,330048 & 3 \\
\hline e21_3 & $\begin{array}{l}- \\
0,05626694\end{array}$ & $\begin{array}{l}0,10925118 \\
3\end{array}$ & $\begin{array}{l}0,05865541 \\
6\end{array}$ & $\begin{array}{l}0,0542204 \\
5\end{array}$ & $\begin{array}{l}0,0031703 \\
6\end{array}$ \\
\hline
\end{tabular}




\begin{tabular}{|c|c|c|c|c|c|}
\hline \multirow[b]{2}{*}{ e21_5 } & - & 0,01729874 & 0,08940051 & $\overline{0}, 1887861$ & 0,0265382 \\
\hline & 0,23949214 & 1 & 4 & 3 & 6 \\
\hline \multirow[b]{2}{*}{ e25_0 } & & 0,03915080 & & 0,0694950 & 0,0755750 \\
\hline & 0,13962256 & 7 & 0,1365363 & 7 & $\begin{array}{l}4 \\
-\end{array}$ \\
\hline \multirow[b]{2}{*}{ e25_1 } & - & 0,32798399 & 0,14463455 & 0,1889459 & 0,0264141 \\
\hline & 0,29963303 & 7 & 7 & 2 & 6 \\
\hline \multirow{3}{*}{ e25_3 } & - & 0,04489561 & $\begin{array}{l}- \\
0,24054746\end{array}$ & $\begin{array}{l}- \\
0,1588768\end{array}$ & $\begin{array}{l}- \\
0,0039067\end{array}$ \\
\hline & 0,21104568 & 7 & 3 & 5 & 3 \\
\hline & & $\overline{-}-16676823$ & $\begin{array}{l}- \\
0,27213769\end{array}$ & 0,0747478 & 0,2122010 \\
\hline e25_5 & 0,01399511 & 6 & 1 & 4 & 9 \\
\hline \multirow[b]{2}{*}{ e35_0 } & & 0,23101015 & 0,15295140 & 0,1165574 & 0,0746998 \\
\hline & 0,7453311 & 4 & $\begin{array}{l}9 \\
-\end{array}$ & 8 & 5 \\
\hline \multirow[t]{2}{*}{ e35_1 } & 0,42557872 & $\begin{array}{l}0,42223024 \\
2\end{array}$ & $\begin{array}{l}0,07892684 \\
1\end{array}$ & $-0,035862$ & $\begin{array}{l}0,0403498 \\
3\end{array}$ \\
\hline & - & 0,40652846 & 0,09892536 & 0,0572908 & \\
\hline e35_3 & 0,06338776 & 6 & 6 & 9 & $-0,024738$ \\
\hline \multirow[b]{2}{*}{ e35_5 } & - & 0,15555829 & 0,04844174 & & 0,0149766 \\
\hline & 0,12032707 & 3 & 4 & $\begin{array}{l}-0,0328922 \\
-\end{array}$ & 7 \\
\hline e41_0 & 0,74300465 & $-0,13396239$ & $\begin{array}{l}0,07112248 \\
5\end{array}$ & $\begin{array}{l}0,1506054 \\
8\end{array}$ & $\begin{array}{l}0,0781115 \\
1\end{array}$ \\
\hline \multirow{2}{*}{ e41_1 } & & 0,29075795 & 0,09269076 & 0,0866879 & 0,0806652 \\
\hline & 0,09385651 & 1 & 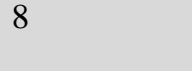 & $\begin{array}{l}6 \\
-\end{array}$ & $\begin{array}{l}2 \\
-\end{array}$ \\
\hline \multirow[b]{2}{*}{ e41_3 } & & 0,18175332 & 0,03812343 & 0,0646783 & 0,1490708 \\
\hline & $-0,2282691$ & $\begin{array}{l}9 \\
-\end{array}$ & 3 & 9 & 2 \\
\hline \multirow[b]{2}{*}{ e41_5 } & - & 0,40313822 & 0,00439632 & 0,0830642 & 0,0323886 \\
\hline & 0,32837156 & 2 & 4 & 9 & 6 \\
\hline \multirow{3}{*}{ e49_0 } & & & 0,27167882 & $\overline{0}, 0845068$ & $\overline{0}, 1654741$ \\
\hline & 1,00415925 & $-0,29642523$ & 1 & 2 & 4 \\
\hline & & 0,36863587 & 0,05519022 & 0,2531910 & 0,3566921 \\
\hline e49_1 & 0,41147433 & 8 & 2 & 7 & $\begin{array}{l}3 \\
-\end{array}$ \\
\hline \multirow[b]{2}{*}{ e49_3 } & & 0,28985694 & 0,13540453 & & 0,1114538 \\
\hline & $-0,0075481$ & $\begin{array}{l}4 \\
-\end{array}$ & 4 & $\begin{array}{l}-0,0403623 \\
-\end{array}$ & 4 \\
\hline \multirow{3}{*}{ e49_5 } & - & 0,11797678 & & 0,0116951 & 0,0101504 \\
\hline & 0,20889175 & 3 & 0,00074432 & 2 & 9 \\
\hline & & $\overline{-}, 07319036$ & $\begin{array}{l}- \\
0,05773098\end{array}$ & 0,0929226 & $\begin{array}{l}- \\
0,0830322\end{array}$ \\
\hline e28_0 & 0,15910674 & 2 & 3 & 8 & $\begin{array}{l}1 \\
1\end{array}$ \\
\hline \multirow{3}{*}{ e28_1 } & - & 0,14235707 & 0,15136946 & 0,1210785 & 0,0847467 \\
\hline & 0,22504257 & 3 & 8 & 6 & 5 \\
\hline & - & $\begin{array}{l}- \\
0,11640906\end{array}$ & $\overline{-}-30177073$ & & \\
\hline e28_2 & 0,25771638 & 9 & 7 & $-0,2230481$ & 0,3500297 \\
\hline
\end{tabular}




\begin{tabular}{|c|c|c|c|c|c|}
\hline \multirow[b]{3}{*}{ e57_0 } & \multirow[b]{3}{*}{0,1424299} & \multirow{3}{*}{$\begin{array}{l}- \\
0,08413258 \\
3\end{array}$} & \multirow{3}{*}{$\begin{array}{l}- \\
0,24202336 \\
8 \\
-\end{array}$} & \multirow{3}{*}{$\begin{array}{l}- \\
0,0258240 \\
2 \\
-\end{array}$} & \multirow{3}{*}{$\begin{array}{l}0,0759973 \\
9\end{array}$} \\
\hline & & & & & \\
\hline & & & & & \\
\hline & - & 0,15514129 & 0,17650131 & 0,0744330 & 0,1136668 \\
\hline \multirow[t]{3}{*}{ e57_1 } & 0,08190232 & 5 & 6 & 8 & 6 \\
\hline & & & - & - & - \\
\hline & & 0,16434186 & 0,00363856 & 0,0181141 & 0,0355457 \\
\hline \multirow[t]{2}{*}{ e57_3 } & 0,04561764 & $\begin{array}{l}4 \\
-\end{array}$ & 8 & 7 & 6 \\
\hline & & 0,05701960 & 0,20846114 & 0,0458684 & 0,0688538 \\
\hline \multirow[t]{2}{*}{ e57_5 } & $-0,0837099$ & $\begin{array}{l}8 \\
-\end{array}$ & 9 & 7 & $\begin{array}{l}9 \\
-\end{array}$ \\
\hline & & 0,08146878 & 0,08957791 & 0,0812501 & 0,0397436 \\
\hline \multirow[t]{2}{*}{ e58_0 } & 0,23658735 & $\begin{array}{l}9 \\
-\end{array}$ & $\begin{array}{l}9 \\
-\end{array}$ & 4 & 2 \\
\hline & & 0,03293422 & 0,11394810 & 0,1042145 & 0,1262960 \\
\hline \multirow[t]{2}{*}{ e58_1 } & 0,08398396 & 8 & $\begin{array}{l}5 \\
-\end{array}$ & 6 & $\begin{array}{l}2 \\
-\end{array}$ \\
\hline & - & 0,14850636 & 0,211388688 & 0,0280246 & 0,0381650 \\
\hline \multirow[t]{2}{*}{ e58_3 } & 0,17765975 & 2 & 1 & 8 & 1 \\
\hline & - & 0,02107024 & 0,08185528 & 0,1586108 & 0,0008993 \\
\hline e58_5 & 0,20061609 & 5 & 9 & 9 & 3 \\
\hline \multicolumn{6}{|l|}{$\cos 2$} \\
\hline & Dim 1 & $\operatorname{Dim} 2$ & $\operatorname{Dim} 3$ & $\operatorname{Dim} 4$ & $\operatorname{Dim} 5$ \\
\hline d5_0 & $5,55 \mathrm{E}-001$ & $\begin{array}{l}0,02693267 \\
0,29639504\end{array}$ & $5,66 \mathrm{E}-002$ & $5,22 \mathrm{E}-003$ & $4,68 \mathrm{E}-003$ \\
\hline d5_1 & $1,33 \mathrm{E}-001$ & 1 & $6,20 \mathrm{E}-003$ & $1,14 \mathrm{E}-001$ & 2,26E-002 \\
\hline d5_3 & $9,91 \mathrm{E}-002$ & $\begin{array}{l}0,01971489 \\
0,30687845\end{array}$ & $1,35 \mathrm{E}-002$ & $7,86 \mathrm{E}-002$ & $3,31 \mathrm{E}-002$ \\
\hline d5_5 & $2,88 \mathrm{E}-001$ & 8 & $1,12 \mathrm{E}-003$ & $1,29 \mathrm{E}-002$ & $4,35 \mathrm{E}-003$ \\
\hline d7_0 & 7,33E-001 & $\begin{array}{l}0,0036634 \\
0,20717906\end{array}$ & $1,48 \mathrm{E}-002$ & $5,66 \mathrm{E}-003$ & $7,00 \mathrm{E}-003$ \\
\hline d7_1 & $2,21 \mathrm{E}-006$ & 6 & $1,65 \mathrm{E}-002$ & $8,22 \mathrm{E}-003$ & $6,50 \mathrm{E}-003$ \\
\hline d7_3 & $5,38 \mathrm{E}-002$ & $\begin{array}{l}0,01278309 \\
0,04237317\end{array}$ & $5,04 \mathrm{E}-002$ & $1,52 \mathrm{E}-001$ & 4,67E-002 \\
\hline d7_5 & $5,99 \mathrm{E}-001$ & $\begin{array}{l}1 \\
0,08464441\end{array}$ & $2,35 \mathrm{E}-003$ & $1,42 \mathrm{E}-002$ & $6,23 \mathrm{E}-003$ \\
\hline d12_0 & $6,21 \mathrm{E}-001$ & $\begin{array}{l}7 \\
0,11728186\end{array}$ & $6,15 \mathrm{E}-002$ & $3,21 \mathrm{E}-003$ & $3,06 \mathrm{E}-002$ \\
\hline d12_1 & 2,64E-001 & $\begin{array}{l}8 \\
0,30622394\end{array}$ & $3,08 \mathrm{E}-002$ & $6,11 \mathrm{E}-004$ & $1,73 \mathrm{E}-001$ \\
\hline d12_3 & $5,29 \mathrm{E}-002$ & $\begin{array}{l}4 \\
0,19612326\end{array}$ & $5,67 \mathrm{E}-002$ & $2,56 \mathrm{E}-002$ & $5,74 \mathrm{E}-002$ \\
\hline d12_5 & $5,98 \mathrm{E}-001$ & $\begin{array}{l}2 \\
0,00470212\end{array}$ & $6,01 \mathrm{E}-004$ & $1,07 \mathrm{E}-002$ & $1,83 \mathrm{E}-003$ \\
\hline d19_0 & $2,33 \mathrm{E}-001$ & $\begin{array}{l}4 \\
0,18322597\end{array}$ & $1,54 \mathrm{E}-001$ & $9,90 \mathrm{E}-002$ & $3,44 \mathrm{E}-003$ \\
\hline d19_1 & $1,16 \mathrm{E}-004$ & $\begin{array}{l}7 \\
0,07119043\end{array}$ & $8,65 \mathrm{E}-004$ & $9,50 \mathrm{E}-004$ & $2,12 \mathrm{E}-003$ \\
\hline d19_3 & $1,62 \mathrm{E}-002$ & $\begin{array}{l}1 \\
0,18025042\end{array}$ & $4,27 \mathrm{E}-003$ & $6,24 \mathrm{E}-002$ & $6,68 \mathrm{E}-007$ \\
\hline d19_5 & $2,12 \mathrm{E}-001$ & $\begin{array}{l}9 \\
0,00817964\end{array}$ & $1,74 \mathrm{E}-001$ & $3,44 \mathrm{E}-002$ & $1,17 \mathrm{E}-003$ \\
\hline d20_0 & $8,40 \mathrm{E}-001$ & $\begin{array}{l}1 \\
0,32075444\end{array}$ & $1,52 \mathrm{E}-004$ & $3,04 \mathrm{E}-002$ & $1,34 \mathrm{E}-002$ \\
\hline d20_1 & $3,04 \mathrm{E}-003$ & 1 & $4,47 \mathrm{E}-003$ & $1,12 \mathrm{E}-002$ & $3,28 \mathrm{E}-003$ \\
\hline
\end{tabular}




\begin{tabular}{|c|c|c|c|c|c|}
\hline d20_3 & $2,25 \mathrm{E}-001$ & $\begin{array}{l}0,18171831 \\
7 \\
0,33849412\end{array}$ & $1,83 \mathrm{E}-007$ & $5,25 \mathrm{E}-003$ & $9,35 \mathrm{E}-002$ \\
\hline d20_5 & $4,71 \mathrm{E}-001$ & $\begin{array}{l}6 \\
0,11237933\end{array}$ & $2,89 \mathrm{E}-003$ & $5,74 \mathrm{E}-003$ & $7,13 \mathrm{E}-003$ \\
\hline d21_0 & $6,28 \mathrm{E}-001$ & $\begin{array}{l}5 \\
0,26274717\end{array}$ & $2,50 \mathrm{E}-003$ & $2,11 \mathrm{E}-004$ & $4,11 \mathrm{E}-003$ \\
\hline d21_1 & $6,24 \mathrm{E}-002$ & 2 & $5,42 \mathrm{E}-003$ & $2,39 \mathrm{E}-002$ & $9,54 \mathrm{E}-004$ \\
\hline d21_3 & $2,52 \mathrm{E}-001$ & 0,06248036 & $1,05 \mathrm{E}-002$ & 1,62E-002 & $7,78 \mathrm{E}-003$ \\
\hline d21_5 & $2,10 \mathrm{E}-001$ & $\begin{array}{l}0,08941733 \\
0,04597589\end{array}$ & $1,99 \mathrm{E}-003$ & $2,18 \mathrm{E}-003$ & $3,06 \mathrm{E}-002$ \\
\hline e1_0 & $7,54 \mathrm{E}-001$ & $\begin{array}{l}1 \\
0,24047350\end{array}$ & $3,80 \mathrm{E}-006$ & $2,82 \mathrm{E}-002$ & $5,96 \mathrm{E}-005$ \\
\hline e1_1 & $7,41 \mathrm{E}-003$ & $\begin{array}{l}6 \\
0,44266311\end{array}$ & $6,66 \mathrm{E}-003$ & 7,17E-003 & $4,44 \mathrm{E}-002$ \\
\hline e1_3 & $2,28 \mathrm{E}-002$ & $\begin{array}{l}1 \\
0,18817653\end{array}$ & $4,00 \mathrm{E}-003$ & $7,71 \mathrm{E}-005$ & $6,35 \mathrm{E}-002$ \\
\hline e1_5 & $5,95 \mathrm{E}-001$ & $\begin{array}{l}2 \\
0,00180844\end{array}$ & $5,47 \mathrm{E}-003$ & $1,73 \mathrm{E}-002$ & 4,84E-003 \\
\hline e7_0 & $6,41 \mathrm{E}-001$ & $\begin{array}{l}5 \\
0,37857392\end{array}$ & $3,03 \mathrm{E}-002$ & $2,52 \mathrm{E}-004$ & $4,26 \mathrm{E}-003$ \\
\hline e7_1 & $1,15 \mathrm{E}-003$ & $\begin{array}{l}1 \\
0,00253960\end{array}$ & 7,99E-003 & $9,03 \mathrm{E}-003$ & $5,48 \mathrm{E}-002$ \\
\hline e7_3 & $3,03 \mathrm{E}-001$ & $\begin{array}{l}6 \\
0,24869832\end{array}$ & $2,24 \mathrm{E}-002$ & 4,01E-003 & 2,34E-004 \\
\hline e7_5 & $1,79 \mathrm{E}-001$ & $\begin{array}{l}9 \\
0,09198948\end{array}$ & $7,19 \mathrm{E}-002$ & $1,42 \mathrm{E}-002$ & $1,68 \mathrm{E}-002$ \\
\hline e13_0 & $2,91 \mathrm{E}-001$ & $\begin{array}{l}6 \\
0,04754112\end{array}$ & $2,50 \mathrm{E}-001$ & $4,65 \mathrm{E}-002$ & $6,53 \mathrm{E}-002$ \\
\hline e13_1 & $5,36 \mathrm{E}-002$ & $\begin{array}{l}8 \\
0,02260001\end{array}$ & $8,13 \mathrm{E}-002$ & $5,44 \mathrm{E}-002$ & 2,31E-001 \\
\hline e13_3 & $2,05 \mathrm{E}-003$ & $\begin{array}{l}4 \\
0,00702911\end{array}$ & $3,45 \mathrm{E}-004$ & $3,46 \mathrm{E}-002$ & $5,54 \mathrm{E}-002$ \\
\hline e13_5 & $2,97 \mathrm{E}-001$ & $\begin{array}{l}3 \\
0,00341910\end{array}$ & $1,07 \mathrm{E}-001$ & $1,59 \mathrm{E}-001$ & $1,49 \mathrm{E}-002$ \\
\hline e14_0 & $5,71 \mathrm{E}-001$ & $\begin{array}{l}3 \\
0,45059228\end{array}$ & $2,64 \mathrm{E}-002$ & $6,38 \mathrm{E}-002$ & $3,35 \mathrm{E}-002$ \\
\hline e14_1 & $3,07 \mathrm{E}-003$ & 3 & $2,41 \mathrm{E}-002$ & 3,70E-002 & $4,27 \mathrm{E}-003$ \\
\hline e14_3 & $2,30 \mathrm{E}-001$ & $\begin{array}{l}0,03422776 \\
0,48674459\end{array}$ & $4,70 \mathrm{E}-002$ & $1,13 \mathrm{E}-002$ & $2,46 \mathrm{E}-002$ \\
\hline e14_5 & $1,67 \mathrm{E}-001$ & $\begin{array}{l}5 \\
0,16102946\end{array}$ & $1,42 \mathrm{E}-002$ & $3,08 \mathrm{E}-002$ & $3,61 \mathrm{E}-005$ \\
\hline e20_0 & $7,99 \mathrm{E}-003$ & $\begin{array}{l}4 \\
0,00018227\end{array}$ & $2,50 \mathrm{E}-002$ & $5,51 \mathrm{E}-004$ & $1,27 \mathrm{E}-001$ \\
\hline e20_1 & $2,13 \mathrm{E}-002$ & $\begin{array}{l}4 \\
0,16637586\end{array}$ & $9,92 \mathrm{E}-003$ & 2,91E-001 & $6,01 \mathrm{E}-002$ \\
\hline e20_3 & $8,07 \mathrm{E}-002$ & $\begin{array}{l}7 \\
0,00193593\end{array}$ & $5,66 \mathrm{E}-002$ & 2,92E-002 & 2,38E-004 \\
\hline e20_5 & $8,38 \mathrm{E}-003$ & $\begin{array}{l}4 \\
0,12335894\end{array}$ & 2,28E-002 & $2,55 \mathrm{E}-001$ & $1,14 \mathrm{E}-002$ \\
\hline e21_0 & $4,09 \mathrm{E}-001$ & $\begin{array}{l}1 \\
0,09612575\end{array}$ & $1,73 \mathrm{E}-001$ & $3,30 \mathrm{E}-002$ & $3,98 \mathrm{E}-002$ \\
\hline e21_1 & 8,73E-004 & $\begin{array}{l}9 \\
0,05745744\end{array}$ & $5,85 \mathrm{E}-002$ & $1,54 \mathrm{E}-001$ & $8,65 \mathrm{E}-002$ \\
\hline e21_3 & $1,52 \mathrm{E}-002$ & $\begin{array}{l}9 \\
0,00190087\end{array}$ & $1,66 \mathrm{E}-002$ & $1,42 \mathrm{E}-002$ & $4,84 \mathrm{E}-005$ \\
\hline e21_5 & 3,64E-001 & $\begin{array}{l}8 \\
0,01741531\end{array}$ & $5,08 \mathrm{E}-002$ & 2,26E-001 & 4,47E-003 \\
\hline e25_0 & $2,21 \mathrm{E}-001$ & 8 & $2,12 \mathrm{E}-001$ & $5,49 \mathrm{E}-002$ & $6,49 \mathrm{E}-002$ \\
\hline
\end{tabular}




\begin{tabular}{|c|c|c|c|c|c|}
\hline e25_1 & $1,76 \mathrm{E}-001$ & $\begin{array}{l}0,21053210 \\
8 \\
0,00505989\end{array}$ & $4,09 \mathrm{E}-002$ & $6,99 \mathrm{E}-002$ & $1,37 \mathrm{E}-003$ \\
\hline e25_3 & $1,12 \mathrm{E}-001$ & $\begin{array}{l}9 \\
0,09508808\end{array}$ & $1,45 \mathrm{E}-001$ & 6,34E-002 & $3,83 \mathrm{E}-005$ \\
\hline e25_5 & $6,70 \mathrm{E}-004$ & $\begin{array}{l}3 \\
0,04973494\end{array}$ & $2,53 \mathrm{E}-001$ & 1,91E-002 & $1,54 \mathrm{E}-001$ \\
\hline e35_0 & $5,18 \mathrm{E}-001$ & 1 & $2,18 \mathrm{E}-002$ & 1,27E-002 & $5,20 \mathrm{E}-003$ \\
\hline e35_1 & $1,59 \mathrm{E}-001$ & $\begin{array}{l}0,15668199 \\
0,55048433\end{array}$ & $5,47 \mathrm{E}-003$ & $1,13 \mathrm{E}-003$ & $1,43 \mathrm{E}-003$ \\
\hline e35_3 & $1,34 \mathrm{E}-002$ & $\begin{array}{l}5 \\
0,40740414\end{array}$ & $3,26 \mathrm{E}-002$ & $1,09 \mathrm{E}-002$ & $2,04 \mathrm{E}-003$ \\
\hline e35_5 & $2,44 \mathrm{E}-001$ & $\begin{array}{l}8 \\
0,02607250\end{array}$ & $3,95 \mathrm{E}-002$ & $1,82 \mathrm{E}-002$ & $3,78 \mathrm{E}-003$ \\
\hline e41_0 & 8,02E-001 & $\begin{array}{l}4 \\
0,37847251\end{array}$ & 7,35E-003 & $3,30 \mathrm{E}-002$ & $8,86 \mathrm{E}-003$ \\
\hline e41_1 & $3,94 \mathrm{E}-002$ & 2 & $3,85 \mathrm{E}-002$ & 3,36E-002 & 2,91E-002 \\
\hline e41_3 & $2,55 \mathrm{E}-001$ & $\begin{array}{l}0,16184588 \\
0,48037044\end{array}$ & $7,12 \mathrm{E}-003$ & $2,05 \mathrm{E}-002$ & $1,09 \mathrm{E}-001$ \\
\hline e41_5 & $3,19 \mathrm{E}-001$ & $\begin{array}{l}3 \\
0,06217038\end{array}$ & $5,71 \mathrm{E}-005$ & 2,04E-002 & $3,10 \mathrm{E}-003$ \\
\hline e49_0 & $7,13 \mathrm{E}-001$ & $\begin{array}{l}6 \\
0,16532861\end{array}$ & $5,22 \mathrm{E}-002$ & $5,05 \mathrm{E}-003$ & 1,94E-002 \\
\hline e49_1 & $2,06 \mathrm{E}-001$ & $\begin{array}{l}7 \\
0,31760965\end{array}$ & $3,71 \mathrm{E}-003$ & $7,80 \mathrm{E}-002$ & $1,55 \mathrm{E}-001$ \\
\hline e49_3 & $2,15 \mathrm{E}-004$ & 1 & 6,93E-002 & $6,16 \mathrm{E}-003$ & 4,70E-002 \\
\hline e49_5 & $5,56 \mathrm{E}-001$ & $\begin{array}{l}0,1774737 \\
0,07376727\end{array}$ & $7,06 \mathrm{E}-006$ & 1,74E-003 & $1,31 \mathrm{E}-003$ \\
\hline e28_0 & $3,49 \mathrm{E}-001$ & $\begin{array}{l}7 \\
0,10827039\end{array}$ & $4,59 \mathrm{E}-002$ & $1,19 \mathrm{E}-001$ & $9,49 \mathrm{E}-002$ \\
\hline e28_1 & 2,71E-001 & $\begin{array}{l}8 \\
0,01265721\end{array}$ & $1,22 \mathrm{E}-001$ & $7,83 \mathrm{E}-002$ & $3,84 \mathrm{E}-002$ \\
\hline e28_2 & $6,20 \mathrm{E}-002$ & $\begin{array}{l}3 \\
0,03649011\end{array}$ & $8,51 \mathrm{E}-002$ & $4,65 \mathrm{E}-002$ & $1,14 \mathrm{E}-001$ \\
\hline e57_0 & $1,05 \mathrm{E}-001$ & $\begin{array}{l}6 \\
0,05536818\end{array}$ & $3,02 \mathrm{E}-001$ & 3,44E-003 & 2,98E-002 \\
\hline e57_1 & $1,54 \mathrm{E}-002$ & $\begin{array}{l}8 \\
0,08913219\end{array}$ & $7,17 \mathrm{E}-002$ & $1,27 \mathrm{E}-002$ & 2,97E-002 \\
\hline e57_3 & $6,87 \mathrm{E}-003$ & $\begin{array}{l}1 \\
0,03234018\end{array}$ & 4,37E-005 & $1,08 \mathrm{E}-003$ & $4,17 \mathrm{E}-003$ \\
\hline e57_5 & $6,97 \mathrm{E}-002$ & $\begin{array}{l}8 \\
0,04137632\end{array}$ & $4,32 \mathrm{E}-001$ & 2,09E-002 & $4,72 \mathrm{E}-002$ \\
\hline e58_0 & $3,49 \mathrm{E}-001$ & $\begin{array}{l}1 \\
0,00337917\end{array}$ & $5,00 \mathrm{E}-002$ & $4,12 \mathrm{E}-002$ & $9,85 \mathrm{E}-003$ \\
\hline e58_1 & $2,20 \mathrm{E}-002$ & $\begin{array}{l}3 \\
0,07028061\end{array}$ & $4,05 \mathrm{E}-002$ & $3,38 \mathrm{E}-002$ & 4,97E-002 \\
\hline e58_3 & $1,01 \mathrm{E}-001$ & $\begin{array}{l}1 \\
0,00273972\end{array}$ & $1,42 \mathrm{E}-001$ & $2,50 \mathrm{E}-003$ & 4,64E-003 \\
\hline e58_5 & $2,48 \mathrm{E}-001$ & 2 & $4,13 \mathrm{E}-002$ & $1,55 \mathrm{E}-001$ & 4,99E-006 \\
\hline v.test & Dim 1 & $\operatorname{Dim} 2$ & Dim 3 & $\begin{array}{l}\quad \operatorname{Dim} 4 \\
-\end{array}$ & 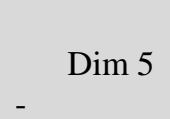 \\
\hline d5_0 & 3,98457064 & $-0,8779167$ & $\begin{array}{l}1,27234606 \\
2 \\
-\end{array}$ & $\begin{array}{l}0,3865620 \\
4 \\
-\end{array}$ & $\begin{array}{l}0,3660594 \\
9\end{array}$ \\
\hline d5_1 & 1,80885315 & 2,7053829 & $\begin{array}{l}0,39138423 \\
4\end{array}$ & $\begin{array}{l}1,6772887 \\
8\end{array}$ & $\begin{array}{l}0,7467889 \\
1\end{array}$ \\
\hline
\end{tabular}




\begin{tabular}{|c|c|c|c|c|c|}
\hline & - & & $\begin{array}{l}- \\
0,51276594\end{array}$ & 1,2371075 & $\begin{array}{l}- \\
0,8022107\end{array}$ \\
\hline d5_3 & 1,38854148 & 0,6194361 & 3 & 2 & 6 \\
\hline d5_5 & $\begin{array}{l}- \\
2,83210645\end{array}$ & $-2,9257313$ & $\begin{array}{l}0,17705485 \\
7\end{array}$ & $\begin{array}{l}0,5992617 \\
4\end{array}$ & $\begin{array}{l}0,3482372 \\
7\end{array}$ \\
\hline d7_0 & 5,13385206 & $-0,3629004$ & $\begin{array}{l}0,72999522 \\
6\end{array}$ & $\begin{array}{l}- \\
0,4510620 \\
2 \\
-\end{array}$ & $\begin{array}{l}0,5015131 \\
-\end{array}$ \\
\hline d7_1 & 0,00676253 & 2,0701052 & $\begin{array}{l}0,58397663 \\
1\end{array}$ & $\begin{array}{l}0,4122540 \\
9\end{array}$ & $\begin{array}{l}0,3666263 \\
9 \\
-\end{array}$ \\
\hline d7_3 & $-0,99671$ & 0,485662 & $\begin{array}{l}-0,9641341 \\
-\end{array}$ & $\begin{array}{l}1,6727985 \\
2 \\
-\end{array}$ & $\begin{array}{l}0,9281570 \\
1\end{array}$ \\
\hline d7_5 & $-4,331866$ & $-1,1521231$ & $\begin{array}{l}0,27130531 \\
7\end{array}$ & $\begin{array}{l}0,6672550 \\
8 \\
-\end{array}$ & $\begin{array}{l}0,4417202 \\
5\end{array}$ \\
\hline d12_0 & 4,7452206 & $-1,7523609$ & $\begin{array}{l}1,49324380 \\
8 \\
0,86721888\end{array}$ & $\begin{array}{l}0,3414754 \\
8 \\
0,1220705\end{array}$ & $\begin{array}{c}-1,0533368 \\
2,0563746\end{array}$ \\
\hline d12_1 & 2,53776105 & 1,691528 & $\begin{array}{l}6 \\
-\end{array}$ & 6 & $\begin{array}{l}2 \\
-\end{array}$ \\
\hline d12_3 & 1,08608147 & 2,6142447 & $\begin{array}{l}1,12527587 \\
2 \\
-\end{array}$ & $\begin{array}{l}0,7556324 \\
2 \\
-\end{array}$ & $\begin{array}{l}1,1321618 \\
3\end{array}$ \\
\hline d12_5 & $-\overline{4,65015592}$ & $-2,6636919$ & $\begin{array}{l}0,14741825 \\
7 \\
-\end{array}$ & $\begin{array}{l}0,6210929 \\
4 \\
-\end{array}$ & $\begin{array}{l}0,2576065 \\
9 \\
-\end{array}$ \\
\hline d19_0 & 2,31207541 & $-0,3287226$ & $\begin{array}{l}1,87882497 \\
4 \\
-\end{array}$ & $\begin{array}{l}1,5087144 \\
5 \\
-\end{array}$ & $\begin{array}{l}0,2810154 \\
9\end{array}$ \\
\hline d19_1 & $\begin{array}{l}0,04664385 \\
-\end{array}$ & 1,8575889 & $\begin{array}{l}0,12760008 \\
9 \\
0,28235067\end{array}$ & $\begin{array}{l}0,1337587 \\
4 \\
1,0791249\end{array}$ & $\begin{array}{l}0,1996622 \\
2 \\
0,0035319\end{array}$ \\
\hline d19_3 & $\begin{array}{l}0,54951629 \\
-\end{array}$ & 1,152692 & 7 & $\begin{array}{l}6 \\
0,9187152\end{array}$ & 1 \\
\hline d19_5 & 2,27978244 & $-2,1038437$ & $\begin{array}{l}2,06986439 \\
-\end{array}$ & 5 & 0,1693251 \\
\hline d20_0 & 6,19574794 & $-0,611432$ & $\begin{array}{l}0,08325970 \\
4 \\
-\end{array}$ & $-1,1778574$ & $\begin{array}{l}0,7832101 \\
7\end{array}$ \\
\hline d20_1 & 0,25197772 & 2,5896808 & $\begin{array}{l}0,30571507 \\
3\end{array}$ & 0,484523 & $\begin{array}{l}0,2620460 \\
2\end{array}$ \\
\hline d20_3 & $\begin{array}{l}- \\
2,33391038 \\
-\end{array}$ & 2,0978993 & $\begin{array}{l}0,00210806 \\
4 \\
0,33282743\end{array}$ & $\begin{array}{l}0,3566207 \\
4 \\
0,4691314\end{array}$ & $\begin{array}{l}1,5050363 \\
2 \\
0,5229500\end{array}$ \\
\hline $\mathrm{d} 20 \_5$ & 4,25289333 & $-3,6038362$ & 3 & 4 & $\begin{array}{l}8 \\
-\end{array}$ \\
\hline $\mathrm{d} 21 \_0$ & $\begin{array}{l}4,55358999 \\
-\end{array}$ & $-1,9270132$ & $\begin{array}{l}0,28766718 \\
0,34047843\end{array}$ & $\begin{array}{l}0,0835492 \\
5 \\
0,7151457\end{array}$ & $\begin{array}{l}0,3683495 \\
2 \\
0,1427672\end{array}$ \\
\hline d21_1 & 1,15512929 & 2,3698528 & $\begin{array}{l}7 \\
-\end{array}$ & $\begin{array}{l}2 \\
-\end{array}$ & $\begin{array}{l}3 \\
-\end{array}$ \\
\hline $\mathrm{d} 21 \_3$ & - 2,33230435 & 1,1606929 & $\begin{array}{l}0,47537742 \\
8 \\
-\end{array}$ & $\begin{array}{l}0,5913074 \\
5 \\
-\end{array}$ & $\begin{array}{l}0,4094785 \\
8\end{array}$ \\
\hline d21_5 & $\begin{array}{l}- \\
2,08807352\end{array}$ & $-1,363165$ & $\begin{array}{l}0,20335747 \\
1\end{array}$ & $\begin{array}{l}0,2126373 \\
7\end{array}$ & $\begin{array}{l}0,7975952 \\
6\end{array}$ \\
\hline
\end{tabular}




\begin{tabular}{|c|c|c|c|c|c|}
\hline e1_0 & 5,43691296 & $-1,3421894$ & $\begin{array}{l}0,01220787 \\
8 \\
-\end{array}$ & $\begin{array}{l}- \\
1,0513506 \\
4\end{array}$ & $\begin{array}{l}0,0483106 \\
4\end{array}$ \\
\hline e1_1 & 0,38258283 & 2,178796 & $\begin{array}{l}0,36270007 \\
7 \\
-\end{array}$ & $\begin{array}{l}0,3762719 \\
4 \\
-\end{array}$ & $\begin{array}{l}0,9359571 \\
8 \\
-\end{array}$ \\
\hline e1_3 & $\begin{array}{l}- \\
0,74008921 \\
-\end{array}$ & 3,2594933 & $\begin{array}{l}0,30997435 \\
4 \\
0,44652509\end{array}$ & $\begin{array}{l}0,0430256 \\
2 \\
0,7947991\end{array}$ & $\begin{array}{l}1,2345656 \\
4 \\
0,4200766\end{array}$ \\
\hline e1_5 & 4,65620084 & $-2,6185779$ & 9 & $\begin{array}{l}8 \\
-\end{array}$ & 7 \\
\hline e7_0 & 4,38904829 & $-0,2332127$ & 0,95538244 & $\begin{array}{l}0,0870610 \\
7\end{array}$ & $\begin{array}{l}0,3578095 \\
4 \\
-\end{array}$ \\
\hline e7_1 & 0,15911206 & 2,8810397 & $-0,41863456$ & $\begin{array}{l}0,4449492 \\
6\end{array}$ & $\begin{array}{l}1,0961436 \\
7 \\
-\end{array}$ \\
\hline e7_3 & $\begin{array}{l}- \\
2,55634299\end{array}$ & 0,233895 & $\begin{array}{l}0,69535831 \\
-\end{array}$ & $\begin{array}{l}0,2938001 \\
8 \\
-\end{array}$ & $\begin{array}{l}0,0709809 \\
1\end{array}$ \\
\hline e7_5 & $\begin{array}{l}- \\
2,04935806\end{array}$ & $-2,4144756$ & $\begin{array}{l}1,29856829 \\
5\end{array}$ & $\begin{array}{l}0,5769230 \\
4\end{array}$ & $\begin{array}{l}0,6280292 \\
9 \\
-\end{array}$ \\
\hline e13_0 & 2,8161545 & $-1,5834745$ & $\begin{array}{c}-2,61115049 \\
1,30780999\end{array}$ & $\begin{array}{l}1,1264209 \\
6 \\
1,0696547\end{array}$ & $\begin{array}{l}1,3341123 \\
3 \\
2,2069118\end{array}$ \\
\hline e13_1 & 1,06201368 & 1,0001672 & $\begin{array}{l}6 \\
-\end{array}$ & 5 & 1 \\
\hline e13_3 & 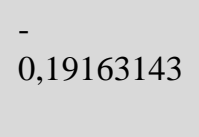 & 0,6361775 & $\begin{array}{l}0,07865707 \\
3\end{array}$ & $\begin{array}{l}0,7875979 \\
-\end{array}$ & $\begin{array}{l}0,9963337 \\
1 \\
-\end{array}$ \\
\hline e13_5 & $\begin{array}{l}- \\
2,75859863\end{array}$ & 0,4245905 & $\begin{array}{l}1,65551168 \\
3 \\
-\end{array}$ & $\begin{array}{l}2,0186169 \\
2 \\
-\end{array}$ & $\begin{array}{l}0,6178510 \\
5\end{array}$ \\
\hline e14_0 & 4,13886143 & $-0,3202046$ & $\begin{array}{l}0,89023010 \\
8 \\
- \\
0,75772198\end{array}$ & $\begin{array}{l}1,3835606 \\
2 \\
0,9385627\end{array}$ & $\begin{array}{l}1,0024326 \\
9\end{array}$ \\
\hline e14_1 & 0,27063266 & 3,2766465 & 9 & $\begin{array}{l}0,9385021 \\
6\end{array}$ & $\begin{array}{l}-0,3189537 \\
-\end{array}$ \\
\hline e14_3 & $\begin{array}{l}- \\
2,23876691 \\
-\end{array}$ & 0,8632126 & $\begin{array}{l}1,01136404 \\
7 \\
0,65715296\end{array}$ & $\begin{array}{l}-0,4956508 \\
0,9678079\end{array}$ & $\begin{array}{l}0,7321375 \\
6 \\
0,0331219\end{array}$ \\
\hline e14_5 & 2,25105271 & $-3,8467736$ & $\begin{array}{l}5 \\
-\end{array}$ & 2 & $\begin{array}{l}4 \\
-\end{array}$ \\
\hline e20_0 & 0,39276432 & $-1,7634906$ & $\begin{array}{l}0,69424744 \\
8 \\
0,42981572\end{array}$ & $\begin{array}{l}0,1031894 \\
5 \\
2,3272302\end{array}$ & $\begin{array}{l}1,5648907 \\
1 \\
1,0578727\end{array}$ \\
\hline e20_1 & $\begin{array}{l}0,62999347 \\
-\end{array}$ & $-0,0582737$ & $\begin{array}{l}2 \\
1,07247621\end{array}$ & $\begin{array}{l}4 \\
0,7701519\end{array}$ & $\begin{array}{l}8 \\
0,0694698\end{array}$ \\
\hline e20_3 & 1,28006539 & 1,8380879 & 7 & $\begin{array}{l}4 \\
-\end{array}$ & 2 \\
\hline e20_5 & 0,39100156 & $-0,1879825$ & $\begin{array}{l}-0,64490953 \\
-\end{array}$ & $\begin{array}{l}2,1560137 \\
2\end{array}$ & $\begin{array}{l}0,4567775 \\
5 \\
-\end{array}$ \\
\hline e21_0 & 3,69850206 & $-2,0311154$ & $\begin{array}{l}2,40319790 \\
8 \\
1,08582362\end{array}$ & $\begin{array}{l}1,0502156 \\
6 \\
1,7599617\end{array}$ & $\begin{array}{l}1,1543946 \\
2 \\
1,3199112\end{array}$ \\
\hline e21_1 & 0,13261966 & 1,3913446 & 9 & 9 & 5 \\
\hline
\end{tabular}




\begin{tabular}{|c|c|c|c|c|c|}
\hline & - & & 0,55102892 & 0,5093653 & $\overline{-}, 0297834$ \\
\hline e21_3 & 0,52859075 & 1,0263428 & 9 & $\begin{array}{l}9 \\
-\end{array}$ & 1 \\
\hline e21_5 & $\begin{array}{l}- \\
3,14999602\end{array}$ & 0,2275272 & $\begin{array}{l}1,17586849 \\
9 \\
2.37351336\end{array}$ & $\begin{array}{l}2,4830692 \\
4 \\
1,2080850\end{array}$ & $\begin{array}{l}0,3490528 \\
3\end{array}$ \\
\hline e25_0 & 2,42716414 & $-0,680588$ & 5 & 9 & $\begin{array}{l}-1,3137778 \\
-\end{array}$ \\
\hline e25_1 & $\begin{array}{l}- \\
2,09447553\end{array}$ & 2,2926526 & $\begin{array}{l}1,01101517 \\
8 \\
-\end{array}$ & $\begin{array}{l}-1,3207576 \\
-\end{array}$ & $\begin{array}{l}0,1846385 \\
4 \\
-\end{array}$ \\
\hline e25_3 & $\overline{-}$ & 0,3181751 & $\begin{array}{l}1,70475906 \\
1\end{array}$ & $\begin{array}{l}1,1259597 \\
1\end{array}$ & $\begin{array}{l}0,0276870 \\
1\end{array}$ \\
\hline e25_5 & 0,12008684 & $-1,4309766$ & $\begin{array}{l}2,33511300 \\
1\end{array}$ & $\begin{array}{l}0,6413835 \\
9\end{array}$ & $\begin{array}{l}1,8208191 \\
6 \\
-\end{array}$ \\
\hline e35_0 & 3,88997475 & $-1,2056704$ & $\begin{array}{l}0,79827222 \\
9 \\
-\end{array}$ & $\begin{array}{l}0,6083278 \\
1 \\
-\end{array}$ & $\begin{array}{l}0,3898676 \\
9\end{array}$ \\
\hline e35_1 & 1,8605599 & 1,8459209 & $\begin{array}{l}0,34505511 \\
6\end{array}$ & $\begin{array}{l}0,1567827 \\
2\end{array}$ & $\begin{array}{l}0,1764027 \\
9 \\
-\end{array}$ \\
\hline e35_3 & $\begin{array}{l}- \\
0,58407296\end{array}$ & 3,7458694 & $\begin{array}{l}0,91152658 \\
3 \\
- \\
1,07565397\end{array}$ & $\begin{array}{l}0,5278946 \\
- \\
0,7303747\end{array}$ & $\begin{array}{l}0,2279430 \\
3\end{array}$ \\
\hline e35_5 & $-2,6718752$ & $-3,4541882$ & 8 & $\begin{array}{l}9 \\
-\end{array}$ & 0,3325585 \\
\hline e41_0 & 5,82865637 & $-1,0508962$ & $\begin{array}{l}0,55793530 \\
4 \\
-\end{array}$ & $\begin{array}{l}1,1814564 \\
2\end{array}$ & $\begin{array}{l}0,6127622 \\
2\end{array}$ \\
\hline e41_1 & 0,9660463 & 2,9927133 & $\begin{array}{l}0,95404749 \\
7\end{array}$ & $\begin{array}{l}0,8922618 \\
3 \\
-\end{array}$ & $\begin{array}{l}0,8302709 \\
7 \\
-\end{array}$ \\
\hline e41_3 & $\begin{array}{l}- \\
2,51430921 \\
-\end{array}$ & 2,0019532 & $\begin{array}{l}0,41991709 \\
7 \\
0,04525048\end{array}$ & $\begin{array}{l}0,7124112 \\
2 \\
0,8549640\end{array}$ & $\begin{array}{l}1,6419661 \\
2 \\
0,3333699\end{array}$ \\
\hline e41_5 & 3,37986264 & $-4,1494209$ & 5 & $\begin{array}{l}5 \\
-\end{array}$ & $\begin{array}{l}9 \\
-\end{array}$ \\
\hline e49_0 & 5,35462086 & $-1,5806703$ & $\begin{array}{l}1,44871153 \\
8\end{array}$ & $\begin{array}{l}0,4506277 \\
2 \\
1,3784299\end{array}$ & $\begin{array}{l}0,8823812 \\
6 \\
1,9419133\end{array}$ \\
\hline e49_1 & 2,24016012 & 2,0069378 & $\begin{array}{l}0,30046816 \\
-\end{array}$ & $\begin{array}{l}7 \\
-\end{array}$ & $\begin{array}{l}4 \\
-\end{array}$ \\
\hline e49_3 & $\overline{-}, 06818865$ & 2,6185336 & $\begin{array}{l}1,22322866 \\
4\end{array}$ & $\begin{array}{l}0,3646282 \\
3 \\
-\end{array}$ & $\begin{array}{l}1,0068608 \\
7\end{array}$ \\
\hline e49_5 & $-\overline{4,37859397}$ & $-2,4729193$ & $\begin{array}{l}0,01560173 \\
4 \\
-\end{array}$ & $\begin{array}{l}0,2451421 \\
2\end{array}$ & $\begin{array}{l}0,2127650 \\
1 \\
-\end{array}$ \\
\hline e28_0 & 3,28804744 & $-1,5125279$ & $\begin{array}{l}1,19304942 \\
8\end{array}$ & $\begin{array}{l}1,9203094 \\
1 \\
-\end{array}$ & $\begin{array}{l}1,7159161 \\
6\end{array}$ \\
\hline e28_1 & - & 1,7511038 & $\begin{array}{l}1,86196338 \\
6 \\
-\end{array}$ & $\begin{array}{l}1,4893614 \\
6 \\
-\end{array}$ & $\begin{array}{l}1,0424515 \\
8\end{array}$ \\
\hline e28_2 & $\begin{array}{l}- \\
1,12669346\end{array}$ & $-0,5089212$ & $\begin{array}{l}1,31929183 \\
5\end{array}$ & $\begin{array}{l}0,9751294 \\
6\end{array}$ & $\begin{array}{l}1,5302720 \\
5\end{array}$ \\
\hline
\end{tabular}




\begin{tabular}{|c|c|c|c|c|c|}
\hline \multirow{3}{*}{ e57_0 } & & & & $\begin{array}{l}- \\
0,2704487\end{array}$ & 0,7959024 \\
\hline & 1,4916341 & $-0,8811003$ & $-2,53465257$ & $\begin{array}{l}1 \\
-\end{array}$ & 4 \\
\hline & - & & 1,16430499 & 0,4910037 & 0,7498125 \\
\hline e57_1 & 0,54027518 & 1,0234019 & $\begin{array}{l}6 \\
-\end{array}$ & $\begin{array}{l}4 \\
-\end{array}$ & $\begin{array}{l}1 \\
-\end{array}$ \\
\hline e57_3 & 0,34932931 & 1,258492 & $\begin{array}{l}0,02786331 \\
3\end{array}$ & $\begin{array}{l}0,1387141 \\
5\end{array}$ & $\begin{array}{l}0,2722012 \\
2 \\
-\end{array}$ \\
\hline e57_5 & $\begin{array}{l}- \\
1,24258059\end{array}$ & $-0,8463929$ & $\begin{array}{l}3,09437463 \\
4\end{array}$ & $\begin{array}{l}0,6808665 \\
6\end{array}$ & $\begin{array}{l}1,0220596 \\
8 \\
-\end{array}$ \\
\hline e58_0 & 2,93233375 & $-1,0097483$ & $\begin{array}{l}1,11025530 \\
7 \\
-\end{array}$ & $\begin{array}{l}1,0070383 \\
3\end{array}$ & $\begin{array}{l}0,4925942 \\
7\end{array}$ \\
\hline e58_1 & 0,62730171 & $-0,2459958$ & $\begin{array}{l}0,85111300 \\
7 \\
-\end{array}$ & $\begin{array}{l}0,7784101 \\
9\end{array}$ & $\begin{array}{l}0,9433433 \\
3 \\
-\end{array}$ \\
\hline e58_3 & $-\overline{1,42666256}$ & 1,1925519 & $\begin{array}{l}1,69751628 \\
9\end{array}$ & $\begin{array}{l}0,2250468 \\
2 \\
-\end{array}$ & $\begin{array}{l}0,3064768 \\
3\end{array}$ \\
\hline e58_5 & 2,31937406 & 0,2435985 & $\begin{array}{l}0,94634998 \\
8\end{array}$ & $\begin{array}{l}1,8337411 \\
9\end{array}$ & $\begin{array}{l}0,0103974 \\
2\end{array}$ \\
\hline eta2 & Dim 1 & $\operatorname{Dim} 2$ & $\operatorname{Dim} 3$ & Dim 4 & Dim 5 \\
\hline d5 & 0,30676917 & 0,22593018 & $\begin{array}{l}0,05434342 \\
8 \\
0,04439419\end{array}$ & $\begin{array}{l}0,1178688 \\
9 \\
0,0995662\end{array}$ & $\begin{array}{l}0,0377997 \\
5 \\
0,0413712\end{array}$ \\
\hline d7 & 0,37232585 & 0,09124727 & $\begin{array}{l}2 \\
0,11224907\end{array}$ & $\begin{array}{l}1 \\
0,0244017\end{array}$ & $\begin{array}{l}8 \\
0,2154242\end{array}$ \\
\hline $\mathrm{d} 12$ & 0,48211981 & 0,24255644 & $\begin{array}{l}8 \\
0,16001614\end{array}$ & $\begin{array}{l}9 \\
0,0992024\end{array}$ & $\begin{array}{l}1 \\
0,0036915\end{array}$ \\
\hline d19 & 0,09027612 & 0,13614513 & $\begin{array}{l}8 \\
0,00506819\end{array}$ & $\begin{array}{l}6 \\
0,0497686\end{array}$ & $\begin{array}{l}8 \\
0,0857519\end{array}$ \\
\hline $\mathrm{d} 20$ & 0,56180315 & 0,3360544 & $\begin{array}{l}4 \\
0,01065444\end{array}$ & $\begin{array}{l}4 \\
0,0250343\end{array}$ & $\begin{array}{l}4 \\
0,0283048\end{array}$ \\
\hline $\mathrm{d} 21$ & 0,2724291 & 0,16715849 & 9 & $\begin{array}{l}6 \\
0,0445629\end{array}$ & $\begin{array}{l}3 \\
0,0794221\end{array}$ \\
\hline e1 & 0,43217129 & 0,32572167 & $\begin{array}{l}0,00954657 \\
0,07228469\end{array}$ & $\begin{array}{l}9 \\
0,0165640\end{array}$ & $\begin{array}{l}6 \\
0,0513949\end{array}$ \\
\hline e7 & 0,27503894 & 0,20111846 & 9 & $\begin{array}{l}2 \\
0,1517334\end{array}$ & $\begin{array}{l}7 \\
0,2603691\end{array}$ \\
\hline e13 & 0,13351021 & 0,05936944 & $\begin{array}{l}0,24550792 \\
0,06441828\end{array}$ & 8 & $\begin{array}{l}2 \\
0,0456840\end{array}$ \\
\hline e14 & 0,25910203 & 0,3581078 & $\begin{array}{l}9 \\
0,05067541\end{array}$ & $\begin{array}{l}0,1039526 \\
0,2671601\end{array}$ & $\begin{array}{l}1 \\
0,1175219\end{array}$ \\
\hline e20 & 0,02322948 & 0,093834 & $\begin{array}{l}7 \\
0,18829709\end{array}$ & $\begin{array}{l}5 \\
0,2677361\end{array}$ & $\begin{array}{l}4 \\
0,0966038\end{array}$ \\
\hline e21 & 0,20298841 & 0,09827837 & $\begin{array}{l}4 \\
0,31941855\end{array}$ & 2 & $\begin{array}{l}3 \\
0,1316065\end{array}$ \\
\hline e25 & 0,10918814 & 0,11606045 & $\begin{array}{l}1 \\
0,05391502\end{array}$ & 0,1266293 & $\begin{array}{l}6 \\
0,0093176\end{array}$ \\
\hline e35 & 0,25484183 & 0,35680571 & $\begin{array}{l}9 \\
0,03204010\end{array}$ & $\begin{array}{l}0,0271264 \\
0,0920212\end{array}$ & 9 \\
\hline e41 & 0,5297268 & 0,41280534 & $\begin{array}{l}6 \\
0,09645203\end{array}$ & $\begin{array}{l}5 \\
0,0712533\end{array}$ & $\begin{array}{l}0,1045956 \\
0,1845264\end{array}$ \\
\hline e49 & 0,48832162 & 0,24704252 & 1 & 5 & 1 \\
\hline
\end{tabular}




$\begin{array}{llllll} & & & 0,13702807 & 0,1346387 & 0,1533868 \\ \text { e28 } & 0,13536771 & 0,05741256 & 1 & 4 & 7 \\ & & & 0,34469719 & 0,0189923 & 0,0599782 \\ \text { e57 } & 0,03633629 & 0,05761652 & 7 & 5 & 1 \\ & & & 0,13384024 & 0,1231184 & 0,0366984 \\ \text { e58 } & 0,14419753 & 0,03461801 & 6 & 5 & 1\end{array}$

LEGENDA: eig = Autovalores, percentagem da variância e percentagem da variância cumulativa; coord $=$ valores das coordenadas das categorias em relação ao eixo (dimensão); contrib = Contribuição da variável para o eixo (ou dimensão); v.test $=($ teste $\mathrm{V})$ indica se o valor é significativo. (acima de 2 ou abaixo de -2$) ; E t a 2=($ variáveis categóricas) contém o quadrado da relação entre cada variável e as dimensões; $\cos 2=$ quadrado do cosseno. 


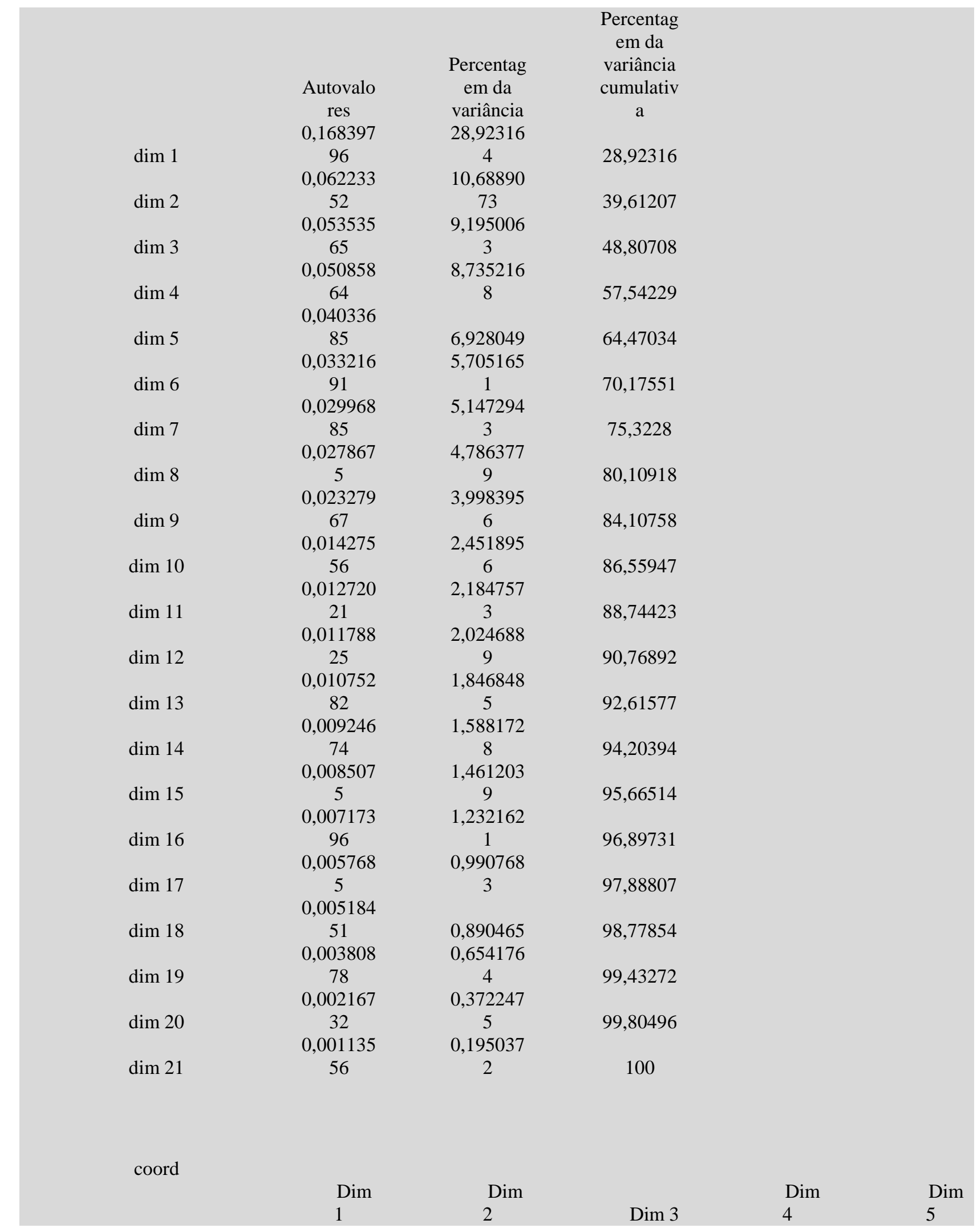




\begin{tabular}{|c|c|c|c|c|c|}
\hline d5_0 & $\begin{array}{c}1,105686 \\
64\end{array}$ & $\begin{array}{c}0,069398 \\
614 \\
-\end{array}$ & $\begin{array}{c}0,141772 \\
842\end{array}$ & $\begin{array}{c}0,39063 \\
305\end{array}$ & $\begin{array}{c}0,32586 \\
725\end{array}$ \\
\hline d5_1 & $\begin{array}{c}0,258258 \\
02 \\
-\end{array}$ & $\begin{array}{c}0,044425 \\
396 \\
-\end{array}$ & $\begin{array}{c}0,355784 \\
542\end{array}$ & $\begin{array}{c}0,16084 \\
042 \\
-\end{array}$ & $\begin{array}{c}0,49745 \\
26 \\
-\end{array}$ \\
\hline d5_3 & $\begin{array}{c}0,241306 \\
96 \\
-\end{array}$ & $\begin{array}{c}0,042043 \\
228\end{array}$ & $\begin{array}{c}0,130208 \\
551 \\
-\end{array}$ & $\begin{array}{c}0,00625 \\
013\end{array}$ & $\begin{array}{c}0,27048 \\
006\end{array}$ \\
\hline d5_5 & $\begin{array}{c}0,352752 \\
46\end{array}$ & $\begin{array}{c}0,136178 \\
88\end{array}$ & $\begin{array}{c}0,457473 \\
654\end{array}$ & $\begin{array}{c}0,04060 \\
808 \\
-\end{array}$ & $\begin{array}{c}0,11979 \\
688\end{array}$ \\
\hline d7_0 & $\begin{array}{c}0,601152 \\
61 \\
-\end{array}$ & $\begin{array}{c}0,003237 \\
713\end{array}$ & $\begin{array}{c}0,020634 \\
217 \\
-\end{array}$ & $\begin{array}{c}0,00131 \\
109\end{array}$ & $\begin{array}{c}0,00497 \\
69\end{array}$ \\
\hline d7_1 & $\begin{array}{c}0,017866 \\
9 \\
-\end{array}$ & $\begin{array}{c}0,767246 \\
022\end{array}$ & $\begin{array}{c}0,358848 \\
657\end{array}$ & $\begin{array}{c}0,70657 \\
085\end{array}$ & $\begin{array}{c}0,19709 \\
179 \\
-\end{array}$ \\
\hline d7_3 & $\begin{array}{c}0,266637 \\
8 \\
-\end{array}$ & $\begin{array}{c}0,006190 \\
77 \\
-\end{array}$ & $\begin{array}{c}0,023074 \\
787\end{array}$ & $\begin{array}{c}0,42126 \\
879 \\
-\end{array}$ & $\begin{array}{c}0,20072 \\
019\end{array}$ \\
\hline d7_5 & $\begin{array}{c}0,442474 \\
55\end{array}$ & $\begin{array}{c}0,095688 \\
413 \\
-\end{array}$ & $\begin{array}{c}0,009229 \\
909 \\
-\end{array}$ & $\begin{array}{c}0,30620 \\
862\end{array}$ & $\begin{array}{c}0,07958 \\
315 \\
-\end{array}$ \\
\hline d12_0 & $\begin{array}{c}1,143512 \\
41\end{array}$ & $\begin{array}{c}0,008254 \\
43\end{array}$ & $\begin{array}{c}0,628798 \\
619\end{array}$ & $\begin{array}{c}0,14843 \\
464\end{array}$ & $\begin{array}{c}0,26483 \\
437 \\
-\end{array}$ \\
\hline d12_1 & $\begin{array}{c}0,143511 \\
07\end{array}$ & $\begin{array}{c}0,790520 \\
713\end{array}$ & $\begin{array}{c}0,305060 \\
936\end{array}$ & $\begin{array}{c}0,11176 \\
621 \\
-\end{array}$ & $\begin{array}{c}0,18036 \\
292\end{array}$ \\
\hline d12_3 & $\begin{array}{c}0,079028 \\
25 \\
-\end{array}$ & $\begin{array}{c}0,008540 \\
032 \\
-\end{array}$ & $\begin{array}{c}0,312599 \\
12 \\
-\end{array}$ & $\begin{array}{c}0,06541 \\
428 \\
-\end{array}$ & $\begin{array}{c}0,14733 \\
139 \\
-\end{array}$ \\
\hline d12_5 & $\begin{array}{c}0,327948 \\
3\end{array}$ & $\begin{array}{c}0,195076 \\
911 \\
-\end{array}$ & $\begin{array}{c}0,203786 \\
18 \\
-\end{array}$ & $\begin{array}{c}0,00287 \\
111\end{array}$ & $\begin{array}{c}0,02455 \\
776\end{array}$ \\
\hline d19_0 & $\begin{array}{c}0,236753 \\
44\end{array}$ & $\begin{array}{c}0,203343 \\
797 \\
-\end{array}$ & $\begin{array}{c}0,048995 \\
963\end{array}$ & $\begin{array}{c}0,26873 \\
676 \\
-\end{array}$ & $\begin{array}{c}0,04257 \\
699\end{array}$ \\
\hline d19_1 & $\begin{array}{c}0,173600 \\
42\end{array}$ & $\begin{array}{c}0,053487 \\
861\end{array}$ & $\begin{array}{c}0,151492 \\
696\end{array}$ & $\begin{array}{c}0,16888 \\
877 \\
-\end{array}$ & $\begin{array}{c}0,21272 \\
932 \\
-\end{array}$ \\
\hline d19_3 & $\begin{array}{c}0,023225 \\
9 \\
-\end{array}$ & $\begin{array}{c}0,287193 \\
552\end{array}$ & $\begin{array}{c}0,447457 \\
066 \\
-\end{array}$ & $\begin{array}{c}0,31994 \\
404 \\
-\end{array}$ & $\begin{array}{c}0,42616 \\
114\end{array}$ \\
\hline d19_5 & $\begin{array}{c}0,432599 \\
7\end{array}$ & $\begin{array}{c}0,166354 \\
676 \\
-\end{array}$ & $\begin{array}{c}0,230994 \\
85 \\
-\end{array}$ & $\begin{array}{c}0,15798 \\
651 \\
-\end{array}$ & $\begin{array}{c}0,08542 \\
87 \\
-\end{array}$ \\
\hline d20_0 & $\begin{array}{c}0,802309 \\
4 \\
0,014705\end{array}$ & $\begin{array}{c}0,091732 \\
754 \\
0,772574\end{array}$ & $\begin{array}{c}0,016213 \\
697 \\
0,276474\end{array}$ & $\begin{array}{c}0,05424 \\
572 \\
0,27902\end{array}$ & $\begin{array}{c}0,00521 \\
633 \\
0,51276\end{array}$ \\
\hline d20_1 & $\begin{array}{l}92 \\
-\end{array}$ & 304 & 12 & 685 & $\begin{array}{c}811 \\
-\end{array}$ \\
\hline d20_3 & $\begin{array}{c}0,301016 \\
88 \\
-\end{array}$ & $\begin{array}{c}0,029561 \\
939 \\
-\end{array}$ & $\begin{array}{c}0,173061 \\
863 \\
-\end{array}$ & $\begin{array}{c}0,25218 \\
6 \\
-\end{array}$ & $\begin{array}{c}0,24355 \\
686\end{array}$ \\
\hline d20_5 & $\begin{array}{c}0,503355 \\
19\end{array}$ & $\begin{array}{c}0,147884 \\
79\end{array}$ & $\begin{array}{c}0,325125 \\
444\end{array}$ & $\begin{array}{c}0,39195 \\
264\end{array}$ & $\begin{array}{c}0,14737 \\
806\end{array}$ \\
\hline
\end{tabular}




\begin{tabular}{|c|c|c|c|c|c|}
\hline \multirow[t]{2}{*}{ d21_0 } & $\begin{array}{c}0,443436 \\
08 \\
-\end{array}$ & $\begin{array}{c}0,038498 \\
989\end{array}$ & $\begin{array}{c}0,212041 \\
445\end{array}$ & $\begin{array}{c}0,00063 \\
072 \\
-\end{array}$ & $\begin{array}{c}0,00723 \\
83 \\
-\end{array}$ \\
\hline & 0,359030 & 0,653688 & 0,133337 & 0,19689 & 0,21645 \\
\hline \multirow[t]{2}{*}{ d21_1 } & $\begin{array}{l}72 \\
-\end{array}$ & $\begin{array}{c}747 \\
-\end{array}$ & 989 & 424 & 075 \\
\hline & 0,192004 & 0,186264 & 0,140362 & 0,18850 & 0,19624 \\
\hline \multirow[t]{2}{*}{ d21_3 } & $\begin{array}{l}4 \\
-\end{array}$ & 993 & 994 & 417 & $\begin{array}{l}91 \\
-\end{array}$ \\
\hline & 0,540976 & 0,411654 & 0,231793 & 0,04689 & 0,05362 \\
\hline \multirow[t]{2}{*}{ d21_5 } & $\begin{array}{c}96 \\
-\end{array}$ & $\begin{array}{c}317 \\
-\end{array}$ & 836 & 616 & $\begin{array}{c}867 \\
-\end{array}$ \\
\hline & 0,259079 & 0,313990 & 0,000801 & 0,38853 & 0,28793 \\
\hline Des_0 & 01 & $\begin{array}{c}809 \\
-\end{array}$ & 889 & $\begin{array}{c}441 \\
-\end{array}$ & 062 \\
\hline Des_1 & $\begin{array}{c}0,022118 \\
19 \\
-\end{array}$ & $\begin{array}{c}0,269121 \\
26\end{array}$ & $\begin{array}{c}0,296702 \\
398 \\
-\end{array}$ & $\begin{array}{c}0,14990 \\
392\end{array}$ & $\begin{array}{c}0,24585 \\
788\end{array}$ \\
\hline Des_3 & $\begin{array}{c}0,110306 \\
11\end{array}$ & $\begin{array}{c}0,454107 \\
322\end{array}$ & $\begin{array}{c}0,308347 \\
003\end{array}$ & $\begin{array}{c}0,17542 \\
405 \\
-\end{array}$ & $\begin{array}{c}0,14084 \\
591 \\
-\end{array}$ \\
\hline Des_5 & $\begin{array}{c}0,330162 \\
11\end{array}$ & $\begin{array}{c}0,098070 \\
165\end{array}$ & $\begin{array}{c}0,021129 \\
136\end{array}$ & $\begin{array}{c}0,39242 \\
816\end{array}$ & $\begin{array}{c}0,11015 \\
26\end{array}$ \\
\hline \multicolumn{6}{|l|}{ contrib } \\
\hline & 1 & 2 & Dim 3 & $4^{\text {Dim }}$ & $\begin{array}{l}\text { Dim } \\
5\end{array}$ \\
\hline d5_0 & $\begin{array}{c}11,93147 \\
58\end{array}$ & $\begin{array}{c}1,27 \mathrm{E}- \\
001\end{array}$ & $\begin{array}{c}6,17 \mathrm{E}- \\
001\end{array}$ & $\begin{array}{c}4,93 \mathrm{E}+0 \\
00\end{array}$ & $\begin{array}{c}4,32659 \\
576\end{array}$ \\
\hline & 1,301870 & $1,04 \mathrm{E}-$ & $7,77 \mathrm{E}+00$ & $1,67 \mathrm{E}+0$ & 20,1650 \\
\hline d5_1 & $\begin{array}{c}12 \\
1,967156\end{array}$ & $\begin{array}{c}001 \\
1,62 \mathrm{E}-\end{array}$ & $\begin{array}{c}0 \\
1,80 \mathrm{E}+00\end{array}$ & $\begin{array}{c}00 \\
4,37 \mathrm{E}-\end{array}$ & $\begin{array}{c}034 \\
10,3182\end{array}$ \\
\hline d5_3 & $\begin{array}{c}48 \\
2709098\end{array}$ & $\begin{array}{c}001 \\
109 \mathrm{E}+00\end{array}$ & $\begin{array}{c}0 \\
143 \mathrm{~F}+00\end{array}$ & 003 & 15 \\
\hline d5_5 & $\begin{array}{c}2,709098 \\
51 \\
11\end{array}$ & $\begin{array}{c}1,09 \mathrm{E}+00 \\
0 \\
0\end{array}$ & $\begin{array}{c}1,43 \mathrm{E}+00 \\
1\end{array}$ & $\begin{array}{c}1,19 \mathrm{E}- \\
001 \\
170 \mathrm{E}\end{array}$ & $\begin{array}{c}1,30439 \\
924\end{array}$ \\
\hline d7_0 & $\begin{array}{c}11,394 / 6 \\
72 \\
0,001198\end{array}$ & $\begin{array}{c}8,94 \mathrm{E}- \\
004 \\
5,98 \mathrm{E}+00\end{array}$ & $\begin{array}{c}4,22 \mathrm{E}- \\
002 \\
1,52 \mathrm{E}+00\end{array}$ & $\begin{array}{c}1,79 \mathrm{E}- \\
004 \\
6,20 \mathrm{E}+0\end{array}$ & $\begin{array}{c}0,00326 \\
053 \\
0,60873\end{array}$ \\
\hline d7_1 & 27 & 0 & 0 & 00 & 547 \\
\hline d7_3 & $\begin{array}{c}1,227603 \\
09\end{array}$ & $\begin{array}{c}1,79 \mathrm{E}- \\
003\end{array}$ & $\begin{array}{c}2,89 \mathrm{E}- \\
002\end{array}$ & $\begin{array}{c}1,01 \mathrm{E}+0 \\
01\end{array}$ & $\begin{array}{c}2,90423 \\
312\end{array}$ \\
\hline d7 5 & $\begin{array}{c}6,320213 \\
39\end{array}$ & 8,00E- & $\begin{array}{c}8,65 \mathrm{E}- \\
003\end{array}$ & $1,00 \mathrm{E}+0$ & $\begin{array}{c}0,85355 \\
653\end{array}$ \\
\hline al_J & 9,816766 & $1,38 \mathrm{E}-$ & $9,34 \mathrm{E}+00$ & $5,48 \mathrm{E}-$ & 2,19821 \\
\hline d12_0 & 33 & 003 & 0 & 001 & 538 \\
\hline & 0,185540 & $1,52 \mathrm{E}+00$ & $2,64 \mathrm{E}+00$ & $3,73 \mathrm{E}-$ & 1,22348 \\
\hline d12_1 & 5 & 1 & 0 & 001 & 118 \\
\hline & 0,192236 & $6,07 \mathrm{E}-$ & $9,46 \mathrm{E}+00$ & $4,36 \mathrm{E}-$ & 2,78930 \\
\hline d12_3 & 23 & 003 & 0 & 001 & 456 \\
\hline & 4,037080 & $3,87 \mathrm{E}+00$ & $4,90 \mathrm{E}+00$ & $1,02 \mathrm{E}-$ & 0,09450 \\
\hline d12_5 & 98 & 0 & 0 & 003 & 811 \\
\hline & 2,061936 & $4,12 \mathrm{E}+00$ & $2,78 \mathrm{E}-$ & $8,80 \mathrm{E}+0$ & 0,27839 \\
\hline d19_0 & 88 & 0 & 001 & 00 & 886 \\
\hline & 0,294124 & $7,56 \mathrm{E}-$ & $7,05 \mathrm{E}-$ & $9,22 \mathrm{E}-$ & 1,84382 \\
\hline d19_1 & 77 & 002 & 001 & 001 & 462 \\
\hline & 0,007289 & $3,02 \mathrm{E}+00$ & $8,51 \mathrm{E}+00$ & $4,58 \mathrm{E}+0$ & 10,2457 \\
\hline d19_3 & 61 & 0 & 0 & 00 & 024 \\
\hline & 4,636316 & $1,86 \mathrm{E}+00$ & $4,16 \mathrm{E}+00$ & $2,05 \mathrm{E}+0$ & 0,75481 \\
\hline d19_5 & 37 & 0 & 0 & 00 & 94 \\
\hline
\end{tabular}




\begin{tabular}{|c|c|c|c|c|c|}
\hline \multirow{3}{*}{ d20_0 } & 15,94719 & $5,64 \mathrm{E}-$ & $2,05 \mathrm{E}-$ & 2,41E- & $\begin{array}{c}0,00281 \\
426\end{array}$ \\
\hline & 83 & 001 & 002 & 001 & 426 \\
\hline & 0,001785 & $1,33 \mathrm{E}+00$ & $1,99 \mathrm{E}+00$ & $2,13 \mathrm{E}+0$ & 9,06475 \\
\hline \multirow[t]{2}{*}{ d20_1 } & 93 & 1 & 0 & 00 & 855 \\
\hline & 2,720998 & $7,10 \mathrm{E}-$ & $2,83 \mathrm{E}+00$ & $6,32 \mathrm{E}+0$ & 7,43673 \\
\hline \multirow[t]{2}{*}{ d20_3 } & 92 & 002 & 0 & 00 & 416 \\
\hline & 5,516120 & $1,29 \mathrm{E}+00$ & $7,24 \mathrm{E}+00$ & $1,11 \mathrm{E}+0$ & 1,97417 \\
\hline \multirow{2}{*}{ d20_5 } & 97 & 0 & 0 & 01 & 309 \\
\hline & 7,233438 & $1,48 \mathrm{E}-$ & $5,20 \mathrm{E}+00$ & $4,85 \mathrm{E}-$ & 0,00804 \\
\hline \multirow{2}{*}{$\mathrm{d} 21 \_0$} & 91 & 001 & 0 & 005 & 619 \\
\hline & 2,032212 & $1,82 \mathrm{E}+00$ & $8,82 \mathrm{E}-$ & $2,02 \mathrm{E}+0$ & 3,08360 \\
\hline \multirow[t]{2}{*}{ d21_1 } & 92 & 1 & 001 & 00 & 692 \\
\hline & 0,719585 & $1,83 \mathrm{E}+00$ & $1,21 \mathrm{E}+00$ & $2,30 \mathrm{E}+0$ & 3,13841 \\
\hline \multirow[t]{2}{*}{ d21_3 } & 49 & 0 & 0 & 00 & 384 \\
\hline & 3,735021 & $5,85 \mathrm{E}+00$ & $2,16 \mathrm{E}+00$ & $9,29 \mathrm{E}-$ & 0,15323 \\
\hline \multirow{2}{*}{$\mathrm{d} 21 \_5$} & 81 & 0 & 0 & 002 & 728 \\
\hline & 1,360551 & $5,41 \mathrm{E}+00$ & $4,10 \mathrm{E}-$ & $1,01 \mathrm{E}+0$ & 7,01553 \\
\hline \multirow[t]{2}{*}{ Des_0 } & 27 & 0 & 005 & 01 & 855 \\
\hline & 0,010283 & $4,12 \mathrm{E}+00$ & $5,82 \mathrm{E}+00$ & $1,56 \mathrm{E}+0$ & 5,30454 \\
\hline \multirow[t]{2}{*}{ Des_1 } & 57 & 0 & 0 & 00 & 144 \\
\hline & 0,264901 & $1,21 \mathrm{E}+00$ & $6,51 \mathrm{E}+00$ & $2,22 \mathrm{E}+0$ & 1,80305 \\
\hline \multirow[t]{2}{*}{ Des_3 } & 12 & 1 & 0 & 00 & 103 \\
\hline & 2,373226 & $5,67 \mathrm{E}-$ & $3,06 \mathrm{E}-$ & $1,11 \mathrm{E}+0$ & 1,10283 \\
\hline Des_5 & 24 & 001 & 002 & 01 & 114 \\
\hline \multicolumn{6}{|l|}{$\cos 2$} \\
\hline & Dim & Dim & Dim & & \\
\hline & 1 & 2 & 3 & $\operatorname{Dim} 4$ & $\operatorname{Dim} 5$ \\
\hline \multirow[b]{2}{*}{ d5_0 } & 0,668499 & $2,63 \mathrm{E}-$ & $1,10 \mathrm{E}-$ & $8,34 \mathrm{E}-$ & $5,81 \mathrm{E}-$ \\
\hline & 21 & 003 & $\begin{array}{c}002 \\
2.09 \mathrm{E}-\end{array}$ & $\begin{array}{c}002 \\
426 \mathrm{E}-\end{array}$ & $\begin{array}{c}002 \\
408 \mathrm{E}-\end{array}$ \\
\hline \multirow[t]{2}{*}{ d5_1 } & $\begin{array}{c}0,109925 \\
74\end{array}$ & $\begin{array}{c}3,25 \mathrm{E}- \\
003\end{array}$ & $\begin{array}{c}2,09 \mathrm{E}- \\
001\end{array}$ & $\begin{array}{c}4,26 \mathrm{E}- \\
002\end{array}$ & $\begin{array}{c}4,08 \mathrm{E}- \\
001\end{array}$ \\
\hline & 0,215609 & $6,55 \mathrm{E}-$ & $6,28 \mathrm{E}-$ & $1,45 \mathrm{E}-$ & $2,71 \mathrm{E}-$ \\
\hline \multirow{2}{*}{ d5_3 } & 55 & 003 & 002 & 004 & 001 \\
\hline & 0,230055 & $3,43 \mathrm{E}-$ & 3,87E- & $3,05 \mathrm{E}-$ & $\begin{array}{c}2,65 \mathrm{E}- \\
002\end{array}$ \\
\hline d5_5 & 0.814874 & $2.36 \mathrm{E}-$ & $9.60 \mathrm{E}-$ & $3.88 \mathrm{E}-$ & $5,59 \mathrm{E}-$ \\
\hline \multirow[t]{2}{*}{ d7_0 } & 43 & 005 & 004 & 006 & 005 \\
\hline & $9,1879 \mathrm{E}-$ & $1,69 \mathrm{E}-$ & $3,71 \mathrm{E}-$ & $1,44 \mathrm{E}-$ & $1,12 \mathrm{E}-$ \\
\hline d7_1 & 05 & 001 & 002 & 001 & 002 \\
\hline d7 3 & $\begin{array}{c}0,107903 \\
21\end{array}$ & $\begin{array}{c}5,82 \mathrm{E}- \\
005\end{array}$ & $\begin{array}{c}8,08 \mathrm{E}- \\
004\end{array}$ & $\begin{array}{c}2,69 \mathrm{E}- \\
001\end{array}$ & $\begin{array}{c}6,11 \mathrm{E}- \\
002\end{array}$ \\
\hline d I ${ }^{3}$ & 0,520859 & $2,44 \mathrm{E}-$ & $2,27 \mathrm{E}-$ & $2,49 \mathrm{E}-$ & $1,68 \mathrm{E}-$ \\
\hline d7_5 & 91 & 002 & 004 & 001 & 002 \\
\hline & 0,573725 & 2,99E- & $1,73 \mathrm{E}-$ & $9,67 \mathrm{E}-$ & $3,08 \mathrm{E}-$ \\
\hline d12_0 & 84 & 005 & 001 & 003 & 002 \\
\hline & 0,014280 & $4,33 \mathrm{E}-$ & $6,45 \mathrm{E}-$ & 8,66E- & $2,26 \mathrm{E}-$ \\
\hline d12_1 & 22 & 001 & 002 & 003 & 002 \\
\hline & 0,021777 & $2,54 \mathrm{E}-$ & $3,41 \mathrm{E}-$ & 1,49E- & 7,57E- \\
\hline d12_3 & 21 & 004 & 001 & 002 & 002 \\
\hline & 0,411798 & $1,46 \mathrm{E}-$ & $1,59 \mathrm{E}-$ & $3,16 \mathrm{E}-$ & $2,31 \mathrm{E}-$ \\
\hline d12_5 & 99 & 001 & 001 & 005 & 003 \\
\hline & 0,226844 & 1,67E- & $9,72 \mathrm{E}-$ & 2,92E- & $7,34 \mathrm{E}-$ \\
\hline d19_0 & 1 & 001 & 003 & 001 & 003 \\
\hline & 0,025441 & $2,42 \mathrm{E}-$ & $1,94 \mathrm{E}-$ & 2,41E- & $3,82 \mathrm{E}-$ \\
\hline d19_1 & 96 & 003 & 002 & 002 & 002 \\
\hline & 0,000593 & $9,08 \mathrm{E}-$ & $2,20 \mathrm{E}-$ & $1,13 \mathrm{E}-$ & $2,00 \mathrm{E}-$ \\
\hline d19_3 & 64 & 002 & 001 & 001 & 001 \\
\hline & 0,396423 & $5,86 \mathrm{E}-$ & $1,13 \mathrm{E}-$ & $5,29 \mathrm{E}-$ & $1,55 \mathrm{E}-$ \\
\hline d19_5 & 08 & 002 & 001 & 002 & 002 \\
\hline
\end{tabular}




\begin{tabular}{|c|c|c|c|c|c|}
\hline & 0,875471 & $1,14 \mathrm{E}-$ & $3,58 \mathrm{E}-$ & $4,00 \mathrm{E}-$ & $\begin{array}{l}3,70 \mathrm{E}- \\
005\end{array}$ \\
\hline d20_0 & $\begin{array}{c}47 \\
000131\end{array}$ & $\begin{array}{c}002 \\
363 \mathrm{~F}-\end{array}$ & 004 & 003 & $\begin{array}{c}005 \\
1.60 \mathrm{E}-\end{array}$ \\
\hline d20_1 & 62 & $\begin{array}{c}3,63 \mathrm{E}- \\
001\end{array}$ & $\begin{array}{c}4,65 \mathrm{E}- \\
002\end{array}$ & $\begin{array}{c}4,74 \mathrm{E}- \\
002\end{array}$ & $\begin{array}{c}1,60 \mathrm{E}- \\
001\end{array}$ \\
\hline d20_3 & $\begin{array}{c}0,261195 \\
45\end{array}$ & $\begin{array}{c}2,52 \mathrm{E}- \\
003\end{array}$ & $\begin{array}{c}8,63 \mathrm{E}- \\
002\end{array}$ & $\begin{array}{c}1,83 \mathrm{E}- \\
001\end{array}$ & $\begin{array}{c}1,71 \mathrm{E}- \\
001\end{array}$ \\
\hline $\mathrm{d} 20 \_5$ & $\begin{array}{c}0,393755 \\
3\end{array}$ & $\begin{array}{c}3,40 \mathrm{E}- \\
002\end{array}$ & $\begin{array}{c}1,64 \mathrm{E}- \\
001\end{array}$ & $\begin{array}{c}2,39 \mathrm{E}- \\
001\end{array}$ & $\begin{array}{c}3,38 \mathrm{E}- \\
002\end{array}$ \\
\hline$a<v_{-}$ & 0,644875 & 4,86E- & $1,47 \mathrm{E}-$ & $1,30 \mathrm{E}-$ & $1,72 \mathrm{E}-$ \\
\hline d21_0 & 75 & 003 & 001 & 006 & 004 \\
\hline d21_1 & $\begin{array}{c}0,151686 \\
93\end{array}$ & $\begin{array}{c}5,03 \mathrm{E}- \\
001\end{array}$ & $\begin{array}{c}2,09 \mathrm{E}- \\
002\end{array}$ & $\begin{array}{c}4,56 \mathrm{E}- \\
002\end{array}$ & $\begin{array}{c}5,51 \mathrm{E}- \\
002\end{array}$ \\
\hline d21_3 & $\begin{array}{c}0,065683 \\
73\end{array}$ & $\begin{array}{c}6,18 \mathrm{E}- \\
002\end{array}$ & $\begin{array}{c}3,51 \mathrm{E}- \\
002\end{array}$ & $\begin{array}{c}6,33 \mathrm{E}- \\
002\end{array}$ & $\begin{array}{c}6,86 \mathrm{E}- \\
002\end{array}$ \\
\hline d21_5 & $\begin{array}{c}0,269080 \\
89\end{array}$ & $\begin{array}{c}1,56 \mathrm{E}- \\
001\end{array}$ & $\begin{array}{c}4,94 \mathrm{E}- \\
002\end{array}$ & $\begin{array}{c}2,02 \mathrm{E}- \\
003\end{array}$ & $\begin{array}{c}2,64 \mathrm{E}- \\
003\end{array}$ \\
\hline Des_0 & $\begin{array}{c}0,116391 \\
8\end{array}$ & $\begin{array}{c}1,71 \mathrm{E}- \\
001\end{array}$ & $\begin{array}{c}1,12 \mathrm{E}- \\
006\end{array}$ & $\begin{array}{c}2,62 \mathrm{E}- \\
001\end{array}$ & $\begin{array}{c}1,44 \mathrm{E}- \\
001\end{array}$ \\
\hline & 0,000929 & $1,38 \mathrm{E}-$ & $1,67 \mathrm{E}-$ & $4,27 \mathrm{E}-$ & $1,15 \mathrm{E}-$ \\
\hline Des_1 & 81 & 001 & 001 & 002 & 001 \\
\hline Des_3 & $\begin{array}{c}0,023591 \\
08\end{array}$ & $\begin{array}{c}4,00 \mathrm{E}- \\
001\end{array}$ & $\begin{array}{c}1,84 \mathrm{E}- \\
001\end{array}$ & $\begin{array}{c}5,97 \mathrm{E}- \\
002\end{array}$ & $\begin{array}{c}3,85 \mathrm{E}- \\
002\end{array}$ \\
\hline Des_5 & $\begin{array}{c}0,204273 \\
61\end{array}$ & $\begin{array}{c}1,80 \mathrm{E}- \\
002\end{array}$ & $\begin{array}{c}8,37 \mathrm{E}- \\
004\end{array}$ & $\begin{array}{c}2,89 \mathrm{E}- \\
001\end{array}$ & $\begin{array}{c}2,27 \mathrm{E}- \\
002\end{array}$ \\
\hline v.test & & & & & \\
\hline & Dim & & & Dim & Dim \\
\hline & 1 & $\operatorname{Dim} 2$ & Dim 3 & 4 & 5 \\
\hline & 4,219031 & 0,264808 & 0,540970 & 1,49056 & 1,24343 \\
\hline d5_0 & 32 & 23 & 685 & 071 & 017 \\
\hline & 1,494135 & 0,257020 & 2,058368 & 0,93053 & 2,87797 \\
\hline d5_1 & 11 & 26 & 534 & 191 & 996 \\
\hline & - & - & & - & - \\
\hline & 2,077450 & 0,361956 & 1,120986 & 0,05380 & 2,32860 \\
\hline d5_3 & 4 & 9 & 336 & 837 & 632 \\
\hline & $\begin{array}{c}- \\
2,193503\end{array}$ & 0,846794 & $\begin{array}{c}- \\
2,844686\end{array}$ & 0,25251 & 0,74492 \\
\hline d5_5 & 96 & 69 & 785 & 133 & 726 \\
\hline & 4,893157 & 0,026353 & 0,167954 & 0,01067 & 0,04051 \\
\hline d7_0 & 79 & 77 & 817 & 18 & 009 \\
\hline & - & & - & & \\
\hline & 0,040684 & 1,747096 & 0,817134 & 1,60893 & 0,44879 \\
\hline d7_1 & 72 & 05 & 339 & 26 & 775 \\
\hline & 1,426505 & 0,033120 & 0,123449 & 2,25377 & 1,07384 \\
\hline d7_3 & 33 & 46 & 511 & 712 & 778 \\
\hline & - & - & & 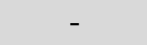 & \\
\hline & 3,670139 & 0,793694 & 0,076558 & 2,53987 & 0,66010 \\
\hline d7_5 & 04 & 87 & 188 & 084 & 856 \\
\hline & 3,770780 & 0,027219 & 2,073490 & 0,48946 & 0,87330 \\
\hline d12_0 & 75 & 33 & 156 & 954 & 26 \\
\hline & 0,523509 & 2,883714 & 1,112821 & 0,40770 & 0,65793 \\
\hline d12_1 & 22 & 1 & 598 & 824 & 986 \\
\hline
\end{tabular}




\begin{tabular}{|c|c|c|c|c|c|}
\hline & 0,631127 & 0,068201 & 2,496447 & 0,52240 & 1,17660 \\
\hline \multirow[t]{3}{*}{ d12_3 } & 4 & 54 & 533 & 492 & 303 \\
\hline & - & - & - & - & - \\
\hline & 3,091926 & 1,839202 & 1,921314 & 0,02706 & 0,23153 \\
\hline \multirow[t]{3}{*}{ d12_5 } & 22 & 76 & 527 & 908 & 279 \\
\hline & & - & - & & \\
\hline & 2,192367 & 1,882989 & 0,453708 & 2,48853 & 0,39426 \\
\hline \multirow[t]{3}{*}{ d19_0 } & 54 & 91 & 965 & 726 & 841 \\
\hline & & - & & - & \\
\hline & & 0,204096 & 0,578059 & 0,64443 & 0,81172 \\
\hline \multirow[t]{3}{*}{ d19_1 } & 0,662417 & 67 & 287 & 847 & 336 \\
\hline & & & & - & - \\
\hline & 0,106993 & 1,322994 & 2,061269 & 1,47386 & 1,96316 \\
\hline \multirow[t]{3}{*}{ d19_3 } & 14 & 83 & 758 & 424 & 728 \\
\hline & - & & - & - & \\
\hline & 2,940405 & 1,130722 & 1,570085 & 1,07384 & 0,58066 \\
\hline \multirow[t]{3}{*}{ d19_5 } & 35 & 41 & 438 & 349 & 383 \\
\hline & & - & - & - & - \\
\hline & 5,453343 & 0,623512 & 0,110205 & 0,36871 & 0,03545 \\
\hline \multirow[t]{2}{*}{ d20_0 } & 71 & 86 & 439 & 129 & 566 \\
\hline & & 2,685007 & 0,960859 & 0,96973 & 1,78207 \\
\hline \multirow[t]{3}{*}{ d20_1 } & 0,051109 & 65 & 199 & 095 & 623 \\
\hline & - & - & & & - \\
\hline & 2,358133 & 0,231585 & 1,355747 & 1,97559 & 1,90799 \\
\hline \multirow{3}{*}{ d20_3 } & 68 & 04 & 936 & 784 & 811 \\
\hline & - & - & - & - & \\
\hline & 3,129989 & 0,919584 & 2,021712 & 2,43726 & 0,91643 \\
\hline \multirow[t]{3}{*}{ d20_5 } & 74 & 99 & 168 & 054 & 404 \\
\hline & & - & - & & \\
\hline & 4,106275 & 0,356505 & 1,963531 & 0,00584 & 0,06702 \\
\hline \multirow[t]{3}{*}{ d21_0 } & 54 & 63 & 259 & 055 & 756 \\
\hline & - & & & - & - \\
\hline & 1,815333 & 3,305184 & 0,674184 & 0,99553 & 1,09441 \\
\hline \multirow[t]{3}{*}{ d21_1 } & 23 & 85 & 315 & 781 & 953 \\
\hline & - & - & & & \\
\hline & 1,110829 & 1,077624 & 0,812061 & 1,09057 & 1,13538 \\
\hline \multirow[t]{3}{*}{ d21_3 } & 08 & 11 & 051 & 875 & 649 \\
\hline & - & - & & - & - \\
\hline & 2,409220 & 1,833287 & 1,032285 & 0,20885 & 0,23883 \\
\hline \multirow[t]{3}{*}{ d21_5 } & 9 & 3 & 29 & 033 & 328 \\
\hline & - & - & & & - \\
\hline & 1,536292 & 1,861909 & 0,004755 & 2,30393 & 1,70737 \\
\hline \multirow[t]{3}{*}{ Des_0 } & 45 & 65 & 057 & 995 & 738 \\
\hline & & - & & - & \\
\hline & 0,134347 & 1,634656 & 1,802186 & 0,91052 & 1,49335 \\
\hline \multirow[t]{3}{*}{ Des_1 } & 04 & 75 & 036 & 432 & 377 \\
\hline & - & & - & & \\
\hline & 0,685911 & 2,823754 & 1,917379 & 1,09083 & 0,87581 \\
\hline \multirow[t]{3}{*}{ Des_3 } & 25 & 08 & 583 & 106 & 546 \\
\hline & & & & - & - \\
\hline & 2,053031 & 0,609825 & 0,131386 & 2,44021 & 0,68495 \\
\hline \multirow[t]{5}{*}{ Des_5 } & 41 & 07 & 307 & 748 & 669 \\
\hline & & & & & \\
\hline & & & & Dim & Dim \\
\hline & Dim 1 & Dim 2 & Dim 3 & 4 & 5 \\
\hline & 0.514460 & 0,025940 & 0,397180 & 0,10618 & 0,50772 \\
\hline d5 & 90 & 8 & 95 & 257 & 341 \\
\hline
\end{tabular}




\begin{tabular}{|c|c|c|c|c|c|}
\hline $\mathrm{d} 7$ & $\begin{array}{c}0.544168 \\
20\end{array}$ & $\begin{array}{c}0,118425 \\
3\end{array}$ & $\begin{array}{c}0,025918 \\
38\end{array}$ & $\begin{array}{c}0,41634 \\
124\end{array}$ & $\begin{array}{c}0,06143 \\
405\end{array}$ \\
\hline d12 & $\begin{array}{c}0.408809 \\
40\end{array}$ & 0,33365 & $\begin{array}{c}0,426590 \\
9\end{array}$ & $\begin{array}{c}0,02142 \\
872\end{array}$ & $\begin{array}{c}0,08864 \\
805\end{array}$ \\
\hline d19 & $\begin{array}{c}0.201068 \\
40\end{array}$ & $\begin{array}{c}0,158254 \\
9\end{array}$ & $\begin{array}{c}0,221097 \\
14\end{array}$ & $\begin{array}{c}0,25803 \\
983\end{array}$ & $\begin{array}{c}0,18449 \\
038\end{array}$ \\
\hline $\mathrm{d} 20$ & $\begin{array}{c}0.694756 \\
10\end{array}$ & $\begin{array}{c}0,266496 \\
4\end{array}$ & $\begin{array}{c}0,195558 \\
06\end{array}$ & $\begin{array}{c}0,31206 \\
781\end{array}$ & $\begin{array}{c}0,25978 \\
572\end{array}$ \\
\hline $\mathrm{d} 21$ & $\begin{array}{c}0.394120 \\
30\end{array}$ & $\begin{array}{c}0,455094 \\
6\end{array}$ & $\begin{array}{c}0,153069 \\
45\end{array}$ & $\begin{array}{c}0,06966 \\
835\end{array}$ & $\begin{array}{c}0,08974 \\
176\end{array}$ \\
\hline des10c & $\begin{array}{c}0.115159 \\
10\end{array}$ & $\begin{array}{c}0,388403 \\
3\end{array}$ & $\begin{array}{c}0,200229 \\
13\end{array}$ & $\begin{array}{c}0,39490 \\
165\end{array}$ & $\begin{array}{c}0,21405 \\
914\end{array}$ \\
\hline \multicolumn{6}{|c|}{$\begin{array}{c}\text { DIMESIONAME } \\
\text { NTO E } \\
\text { DESMATAMEN } \\
\text { TO - UCS } \\
\text { AMAZONIA } \\
\text { PROTECAO } \\
\text { INTEGRAL } \\
\text { eig }\end{array}$} \\
\hline & & Percentag & $\begin{array}{l}\text { Percentag } \\
\text { em da } \\
\text { variância }\end{array}$ & & \\
\hline & $\begin{array}{l}\text { Autovalo } \\
\text { res } \\
1,85 \mathrm{E}-\end{array}$ & $\begin{array}{c}\text { em da } \\
\text { variância } \\
26,39911\end{array}$ & $\begin{array}{c}\text { cumulativ } \\
\text { a }\end{array}$ & & \\
\hline $\operatorname{dim} 1$ & $\begin{array}{c}001 \\
1,15 \mathrm{E}-\end{array}$ & $\begin{array}{c}346 \\
16,36962\end{array}$ & 26,39911 & & \\
\hline $\operatorname{dim} 2$ & $\begin{array}{c}001 \\
8,99 \mathrm{E}-\end{array}$ & $\begin{array}{c}694 \\
12,84373\end{array}$ & 42,76874 & & \\
\hline $\operatorname{dim} 3$ & $\begin{array}{c}002 \\
6,36 \mathrm{E}-\end{array}$ & $\begin{array}{c}531 \\
9,094148\end{array}$ & 55,61248 & & \\
\hline $\operatorname{dim} 4$ & $\begin{array}{c}002 \\
5,54 \mathrm{E}-\end{array}$ & $\begin{array}{c}52 \\
7,923728\end{array}$ & 64,70662 & & \\
\hline $\operatorname{dim} 5$ & $\begin{array}{c}002 \\
4,77 \mathrm{E}-\end{array}$ & $\begin{array}{c}77 \\
6,815440\end{array}$ & 72,63035 & & \\
\hline $\operatorname{dim} 6$ & $\begin{array}{c}002 \\
3,53 \mathrm{E}-\end{array}$ & $\begin{array}{c}61 \\
5,047571\end{array}$ & 79,44579 & & \\
\hline $\operatorname{dim} 7$ & $\begin{array}{c}002 \\
2,44 \mathrm{E}-\end{array}$ & $\begin{array}{c}21 \\
3,491039\end{array}$ & 84,49336 & & \\
\hline $\operatorname{dim} 8$ & $\begin{array}{c}002 \\
1,99 \mathrm{E}-\end{array}$ & $\begin{array}{c}74 \\
2,839257\end{array}$ & 87,9844 & & \\
\hline $\operatorname{dim} 9$ & $\begin{array}{c}002 \\
1,64 \mathrm{E}-\end{array}$ & $\begin{array}{c}16 \\
2,338600\end{array}$ & 90,82366 & & \\
\hline $\operatorname{dim} 10$ & $\begin{array}{c}002 \\
1,29 \mathrm{E}-\end{array}$ & $\begin{array}{c}94 \\
1,836984\end{array}$ & 93,16226 & & \\
\hline $\operatorname{dim} 11$ & $\begin{array}{c}002 \\
1,02 \mathrm{E}-\end{array}$ & $\begin{array}{c}37 \\
1,461437\end{array}$ & 94,99925 & & \\
\hline $\begin{array}{l}\operatorname{dim} 12 \\
\operatorname{dim} 13\end{array}$ & $\begin{array}{c}002 \\
8,16 \mathrm{E}- \\
003\end{array}$ & $\begin{array}{c}84 \\
1,165678 \\
55\end{array}$ & $\begin{array}{l}96,46068 \\
97,62636\end{array}$ & & \\
\hline
\end{tabular}




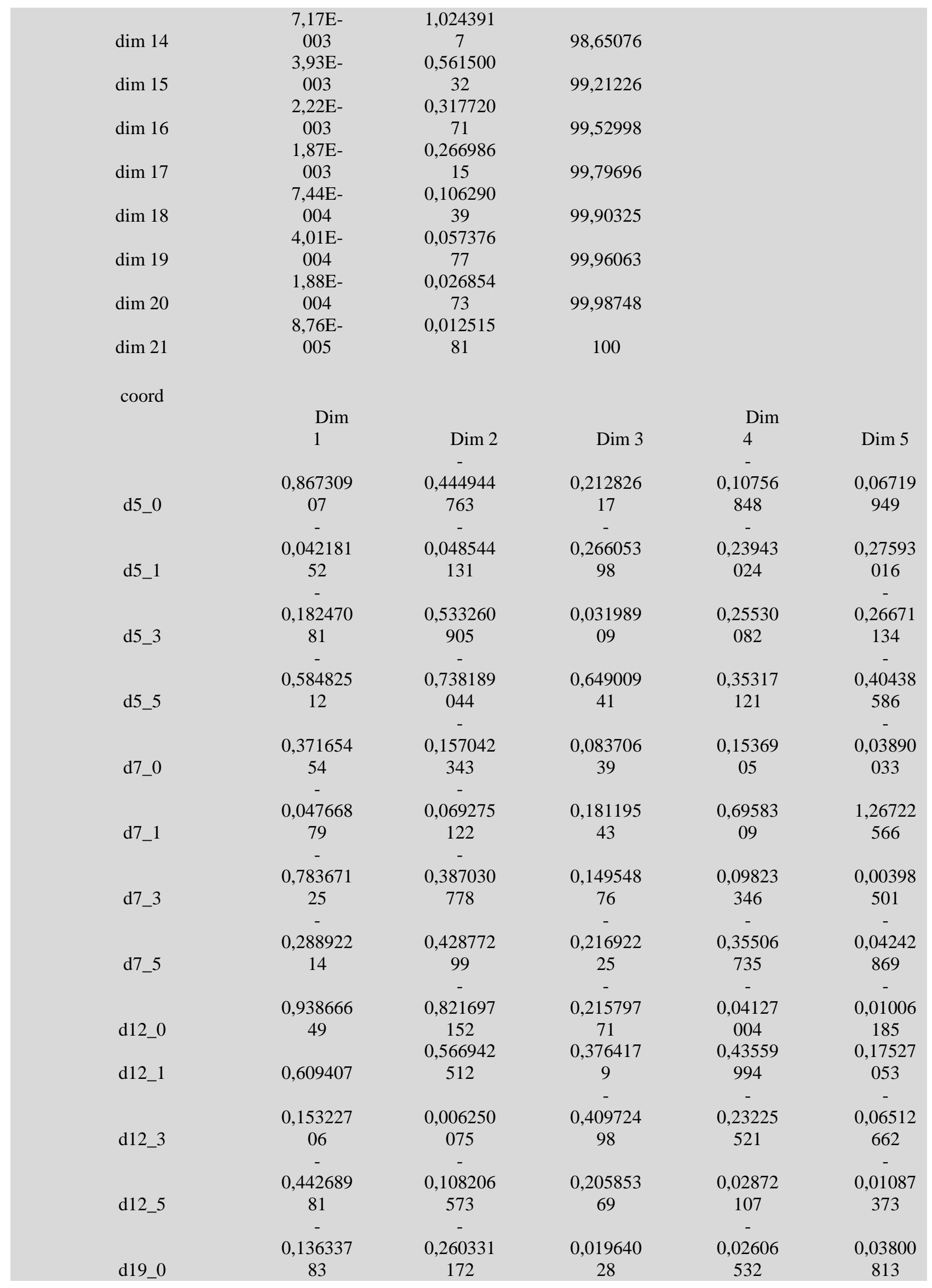




\begin{tabular}{|c|c|c|c|c|c|}
\hline \multirow[b]{2}{*}{ d19_1 } & 0,135836 & 0,353464 & 0,517969 & 0,70986 & 0,36364 \\
\hline & 29 & 205 & 92 & 922 & 138 \\
\hline d19_3 & $\begin{array}{c}0,466561 \\
19\end{array}$ & $\begin{array}{c}0,555191 \\
267\end{array}$ & $\begin{array}{c}0,536309 \\
96 \\
-\end{array}$ & $\begin{array}{c}- \\
0,49335 \\
603\end{array}$ & $\begin{array}{c}0,11759 \\
001 \\
-\end{array}$ \\
\hline d19_5 & $\begin{array}{c}0,384141 \\
23\end{array}$ & $\begin{array}{c}0,587758 \\
289 \\
-\end{array}$ & $\begin{array}{c}0,545662 \\
31 \\
-\end{array}$ & $\begin{array}{c}0,25743 \\
079\end{array}$ & $\begin{array}{c}1,03676 \\
956\end{array}$ \\
\hline d20_0 & $\begin{array}{c}0,486591 \\
99 \\
0,356003\end{array}$ & $\begin{array}{c}0,245050 \\
594 \\
0,681292\end{array}$ & $\begin{array}{c}0,180706 \\
41 \\
0,688538\end{array}$ & $\begin{array}{c}0,03833 \\
719 \\
0,09571\end{array}$ & $\begin{array}{c}0,01919 \\
112 \\
0,21867\end{array}$ \\
\hline d20_1 & $\begin{array}{l}21 \\
-\end{array}$ & 486 & 13 & $\begin{array}{c}723 \\
-\end{array}$ & $\begin{array}{c}055 \\
-\end{array}$ \\
\hline d20_3 & $\begin{array}{c}0,559070 \\
26 \\
-\end{array}$ & $\begin{array}{c}0,050787 \\
986\end{array}$ & $\begin{array}{c}0,175655 \\
1 \\
-\end{array}$ & $\begin{array}{c}0,15629 \\
693\end{array}$ & $\begin{array}{c}0,12292 \\
1\end{array}$ \\
\hline d20_5 & $\begin{array}{c}0,720305 \\
76\end{array}$ & $\begin{array}{c}0,802606 \\
721 \\
-\end{array}$ & $\begin{array}{c}0,723862 \\
72 \\
-\end{array}$ & $\begin{array}{c}0,68361 \\
645\end{array}$ & $\begin{array}{c}0,42118 \\
156 \\
-\end{array}$ \\
\hline d21_0 & $\begin{array}{c}0,304813 \\
39 \\
1,323074\end{array}$ & $\begin{array}{c}0,345790 \\
842 \\
0,991559\end{array}$ & $\begin{array}{c}0,078859 \\
48 \\
1,200428\end{array}$ & $\begin{array}{c}0,05382 \\
8 \\
0,20755\end{array}$ & $\begin{array}{c}0,22485 \\
066 \\
0,46529\end{array}$ \\
\hline d21_1 & $\begin{array}{c}98 \\
-\end{array}$ & 843 & $\begin{array}{c}64 \\
-\end{array}$ & 956 & 218 \\
\hline \multirow[t]{2}{*}{ d21_3 } & $\begin{array}{c}0,538524 \\
65 \\
-\end{array}$ & $\begin{array}{c}0,049503 \\
408\end{array}$ & $\begin{array}{c}0,146754 \\
94\end{array}$ & $\begin{array}{c}0,17221 \\
132 \\
-\end{array}$ & $\begin{array}{c}0,42407 \\
264 \\
-\end{array}$ \\
\hline & 0,278415 & 0,607845 & 0,129945 & 0,57509 & 0,32869 \\
\hline \multirow[t]{2}{*}{ d21_5 } & $\begin{array}{c}88 \\
-\end{array}$ & $\begin{array}{c}762 \\
-\end{array}$ & 45 & 317 & $\begin{array}{c}071 \\
-\end{array}$ \\
\hline & 0,474693 & 0,157356 & 0,396483 & 0,15216 & 0,11106 \\
\hline Des_0 & $\begin{array}{c}93 \\
-\end{array}$ & $\begin{array}{c}941 \\
-\end{array}$ & $\begin{array}{c}22 \\
-\end{array}$ & $\begin{array}{c}705 \\
-\end{array}$ & 344 \\
\hline Des_1 & $\begin{array}{c}0,178317 \\
36\end{array}$ & $\begin{array}{c}0,047588 \\
46\end{array}$ & $\begin{array}{c}0,492412 \\
34 \\
-\end{array}$ & $\begin{array}{c}0,12752 \\
647\end{array}$ & $\begin{array}{c}0,15030 \\
551 \\
-\end{array}$ \\
\hline Des_3 & $\begin{array}{c}0,462353 \\
76\end{array}$ & $\begin{array}{c}0,345314 \\
372 \\
-\end{array}$ & $\begin{array}{c}0,347778 \\
83\end{array}$ & $\begin{array}{c}0,28832 \\
475 \\
-\end{array}$ & $\begin{array}{c}0,21405 \\
736\end{array}$ \\
\hline \multirow{5}{*}{$\begin{array}{l}\text { Des_5 } \\
\text { contrib }\end{array}$} & $\begin{array}{c}0,429547 \\
01\end{array}$ & $\begin{array}{c}0,085185 \\
179\end{array}$ & $\begin{array}{c}0,239378 \\
31\end{array}$ & $\begin{array}{c}0,44411 \\
034\end{array}$ & $\begin{array}{c}0,27098 \\
71\end{array}$ \\
\hline & & & & & \\
\hline & Dim & Dim & Dim & Dim & \\
\hline & 1 & 2 & 3 & 4 & $\operatorname{Dim} 5$ \\
\hline & 9,186215 & 3,898985 & 1,136938 & 0,41019 & $1,84 \mathrm{E}-$ \\
\hline \multirow[t]{2}{*}{ d5_0 } & 44 & 398 & 34 & 11 & 001 \\
\hline & 0,057943 & 0,123760 & 4,738000 & 5,41929 & $8,26 \mathrm{E}+0$ \\
\hline \multirow[t]{2}{*}{ d5_1 } & 13 & 373 & 52 & 598 & 00 \\
\hline & 0,813215 & 11,20079 & 0,051371 & 4,62115 & $5,79 \mathrm{E}+0$ \\
\hline \multirow[t]{2}{*}{ d5_3 } & 46 & 62 & 29 & 533 & 00 \\
\hline & 2,784515 & 7,154566 & 7,048514 & 2,94778 & $4,44 \mathrm{E}+0$ \\
\hline \multirow[t]{2}{*}{ d5_5 } & 44 & 773 & 14 & 276 & 00 \\
\hline & 5,622720 & 1,619018 & 0,586249 & 2,79118 & $2,05 \mathrm{E}-$ \\
\hline \multirow{2}{*}{ d7_0 } & 21 & 042 & 91 & 711 & 001 \\
\hline & 0,004624 & 0,015752 & 0,137350 & 2,86070 & $1,09 \mathrm{E}+0$ \\
\hline d7_1 & 94 & 256 & 44 & 001 & 01 \\
\hline
\end{tabular}




\begin{tabular}{|c|c|c|c|c|c|}
\hline \multirow{3}{*}{ d7 $\_3$} & 6,249933 & 2,458380 & 0,467811 & 0,28507 & $5,38 \mathrm{E}-$ \\
\hline & 95 & 884 & 85 & 151 & 004 \\
\hline & 2,038827 & 7,241428 & 2,362245 & 8,93856 & $1,46 \mathrm{E}-$ \\
\hline \multirow[t]{2}{*}{ d7 _5 } & 6 & 462 & 49 & 149 & 001 \\
\hline & 3,586660 & 4,432428 & 0,389636 & 0,02012 & $1,37 \mathrm{E}-$ \\
\hline \multirow{2}{*}{ d12_0 } & 1 & 291 & 15 & 634 & 003 \\
\hline & & 6,330200 & 3,556537 & 6,72654 & $1,25 \mathrm{E}+0$ \\
\hline \multirow[t]{2}{*}{ d12_1 } & 4,535276 & 36 & 48 & 053 & 00 \\
\hline & 0,621229 & 0,001666 & 9,129854 & 4,14323 & $3,74 \mathrm{E}-$ \\
\hline \multirow{2}{*}{ d12_3 } & 25 & 871 & 05 & 125 & 001 \\
\hline & 6,780872 & 0,653347 & 3,013712 & 0,08285 & $1,36 \mathrm{E}-$ \\
\hline \multirow[t]{2}{*}{ d12_5 } & 37 & 702 & 6 & 429 & 002 \\
\hline & 0,945824 & 5,561353 & 0,040343 & 0,10035 & $2,45 \mathrm{E}-$ \\
\hline \multirow[t]{2}{*}{ d19_0 } & 03 & 656 & 24 & 317 & 001 \\
\hline & 0,150220 & 1,640359 & 4,489569 & 11,9091 & $3,59 \mathrm{E}+0$ \\
\hline \multirow{2}{*}{ d19_1 } & 5 & 472 & 13 & 724 & 00 \\
\hline & 2,658312 & 6,070502 & 7,219690 & 8,62853 & $5,63 \mathrm{E}-$ \\
\hline \multirow[t]{2}{*}{ d19_3 } & 72 & 77 & 23 & 446 & 001 \\
\hline & & 3,401785 & 3,736842 & 1,17464 & $2,19 \mathrm{E}+0$ \\
\hline \multirow{2}{*}{ d19_5 } & 0,901033 & 605 & 29 & 635 & 01 \\
\hline & 8,674411 & 3,547906 & 2,458981 & 0,15630 & $4,50 \mathrm{E}-$ \\
\hline \multirow[t]{2}{*}{ d20_0 } & 42 & 633 & 26 & 679 & 002 \\
\hline & 0,773867 & 4,570635 & 5,949943 & 0,16239 & $9,73 \mathrm{E}-$ \\
\hline \multirow[t]{2}{*}{ d20_1 } & 63 & 75 & 55 & 266 & 001 \\
\hline & 9,542488 & 0,126999 & 1,936191 & 2,16499 & $1,54 \mathrm{E}+0$ \\
\hline \multirow[t]{2}{*}{ d20_3 } & 47 & 32 & 71 & 572 & 00 \\
\hline & 2,112036 & 4,228864 & 4,384075 & 5,52229 & $2,41 \mathrm{E}+0$ \\
\hline \multirow[t]{2}{*}{ d20_5 } & 25 & 206 & 34 & 882 & 00 \\
\hline & 3,403910 & 7,064600 & 0,468291 & 0,30814 & $6,17 \mathrm{E}+0$ \\
\hline \multirow[t]{2}{*}{ d21_0 } & 99 & 998 & 13 & 411 & 00 \\
\hline & 7,125847 & 6,454402 & 12,05697 & 0,50907 & $2,94 \mathrm{E}+0$ \\
\hline \multirow[t]{2}{*}{ d21_1 } & 26 & 059 & 301 & 338 & 00 \\
\hline & 7,083208 & 0,096524 & 1,081190 & 2,10266 & $1,46 \mathrm{E}+0$ \\
\hline \multirow{2}{*}{ d21_3 } & 37 & 953 & 71 & 244 & 01 \\
\hline & 0,946622 & 7,276561 & 0,423846 & 11,7244 & $4,40 \mathrm{E}+0$ \\
\hline d21_5 & 54 & 362 & 86 & 523 & 00 \\
\hline & 5,962224 & 1,056582 & 8,549260 & 1,77848 & $1,09 \mathrm{E}+0$ \\
\hline Des_0 & 19 & 27 & 71 & 219 & 00 \\
\hline & 0,517743 & 0,059467 & 8,114905 & 0,76869 & $1,23 \mathrm{E}+0$ \\
\hline Des_1 & 71 & 742 & 03 & 767 & 00 \\
\hline & 3,915875 & 3,522572 & 4,553909 & 4,42049 & $2,80 \mathrm{E}+0$ \\
\hline Des_3 & 65 & 786 & 54 & 858 & 00 \\
\hline & 3,004339 & 0,190548 & 1,917763 & 9,32259 & $3,98 \mathrm{E}+0$ \\
\hline Des_5 & 39 & 806 & 99 & 136 & 00 \\
\hline $\cos 2$ & & & & & \\
\hline & Dim & Dim & Dim & & \\
\hline & 1 & 2 & 3 & $\operatorname{Dim} 4$ & Dim 5 \\
\hline & 0,553553 & $1,46 \mathrm{E}-$ & 0,033332 & 0,00851 & $3,32 \mathrm{E}-$ \\
\hline d5_0 & 67 & 001 & 05 & 495 & 003 \\
\hline & & $7,98 \mathrm{E}-$ & 0,239730 & 0,19415 & $2,58 \mathrm{E}-$ \\
\hline d5_1 & 0,006026 & 003 & 902 & 227 & 001 \\
\hline & 0,062695 & $5,35 \mathrm{E}-$ & 0,001926 & 0,12273 & $1,34 \mathrm{E}-$ \\
\hline d5_3 & 57 & 001 & 876 & 106 & 001 \\
\hline & 0,175209 & $2,79 \mathrm{E}-$ & 0,215777 & 0,06389 & $8,38 \mathrm{E}-$ \\
\hline d5_5 & 2 & 001 & 845 & 626 & 002 \\
\hline & 0,563019 & $1,01 \mathrm{E}-$ & 0,028560 & 0,09628 & $6,17 \mathrm{E}-$ \\
\hline d7_0 & 09 & 001 & 213 & 049 & 003 \\
\hline & 0,000321 & $6,80 \mathrm{E}-$ & 0,004649 & 0,06856 & $2,27 \mathrm{E}-$ \\
\hline d7_1 & 8 & 004 & 53 & 808 & 001 \\
\hline
\end{tabular}




\begin{tabular}{|c|c|c|c|c|c|}
\hline \multirow{2}{*}{ d7_3 } & 0,432927 & $1,06 \mathrm{E}-$ & 0,015765 & 0,00680 & $\begin{array}{c}1,12 \mathrm{E}- \\
005\end{array}$ \\
\hline & 14 & 001 & 677 & 246 & 005 \\
\hline \multirow{3}{*}{ d7_5 } & 0,150306 & 3,31E- & 0,084727 & 0,22700 & $3,24 \mathrm{E}-$ \\
\hline & 26 & 001 & 346 & 577 & 003 \\
\hline & 0,256319 & $1,96 \mathrm{E}-$ & 0,013547 & 0,00049 & $2,95 \mathrm{E}-$ \\
\hline \multirow{2}{*}{ d12_0 } & 96 & 001 & 322 & 548 & 005 \\
\hline & 0,272972 & $2,36 \mathrm{E}-$ & 0,104146 & 0,13946 & $2,26 \mathrm{E}-$ \\
\hline d12_1 & $\begin{array}{c}06 \\
0,059830\end{array}$ & $\begin{array}{c}001 \\
9,95 \mathrm{E}-\end{array}$ & $\begin{array}{c}304 \\
0,427792\end{array}$ & $\begin{array}{c}94 \\
0,13746\end{array}$ & $\begin{array}{c}002 \\
1,08 \mathrm{E}-\end{array}$ \\
\hline d12_3 & 04 & 005 & 565 & 093 & 002 \\
\hline \multirow{2}{*}{ d12_5 } & $\begin{array}{c}0,588430 \\
07\end{array}$ & $\begin{array}{c}3,52 \mathrm{E}- \\
002\end{array}$ & $\begin{array}{c}0,127236 \\
914\end{array}$ & $\begin{array}{c}0,00247 \\
684\end{array}$ & $\begin{array}{c}3,55 \mathrm{E}- \\
004\end{array}$ \\
\hline & 0,153883 & $5,61 \mathrm{E}-$ & 0,003193 & 0,00562 & $1,20 \mathrm{E}-$ \\
\hline \multirow[t]{2}{*}{ d19_0 } & 73 & 001 & 413 & 453 & 002 \\
\hline & 0,011123 & 7,53E- & 0,161742 & 0,30378 & 7,97E- \\
\hline \multirow[t]{2}{*}{ d19_1 } & 63 & 002 & 441 & 869 & 002 \\
\hline & 0,169619 & $2,40 \mathrm{E}-$ & 0,224125 & 0,18966 & $1,08 \mathrm{E}-$ \\
\hline \multirow[t]{2}{*}{ d19_3 } & 74 & 001 & 305 & 189 & 002 \\
\hline & 0,059713 & $1,40 \mathrm{E}-$ & 0,120486 & 0,02681 & $4,35 \mathrm{E}-$ \\
\hline \multirow[t]{2}{*}{ d19_5 } & 25 & 001 & 062 & 698 & 001 \\
\hline & 0,661627 & $1,68 \mathrm{E}-$ & 0,091249 & 0,00410 & $1,03 \mathrm{E}-$ \\
\hline \multirow[t]{2}{*}{ d20_0 } & 81 & 001 & 597 & 7 & 003 \\
\hline & 0,054153 & $1,98 \mathrm{E}-$ & 0,202570 & 0,00391 & $2,04 \mathrm{E}-$ \\
\hline d20_1 & 58 & 001 & 091 & 471 & 002 \\
\hline \multirow{3}{*}{ d20_3 } & 0,715541 & $5,91 \mathrm{E}-$ & 0,070635 & 0,05592 & $3,46 \mathrm{E}-$ \\
\hline & 23 & 003 & 558 & 458 & 002 \\
\hline & 0,126399 & $1,57 \mathrm{E}-$ & 0,127650 & 0,11385 & $4,32 \mathrm{E}-$ \\
\hline \multirow[t]{2}{*}{$\mathrm{d} 20 \_5$} & 56 & 001 & 994 & 099 & 002 \\
\hline & 0,314224 & 4,04E- & 0,021031 & 0,00979 & $1,71 \mathrm{E}-$ \\
\hline \multirow{2}{*}{ d21_0 } & 55 & 001 & 965 & 915 & 001 \\
\hline & 0,351318 & $1,97 \mathrm{E}-$ & 0,289204 & 0,00864 & $4,34 \mathrm{E}-$ \\
\hline \multirow{2}{*}{ d21_1 } & 37 & 001 & 229 & 604 & 002 \\
\hline & 0,506808 & $4,28 \mathrm{E}-$ & 0,037637 & 0,05182 & $3,14 \mathrm{E}-$ \\
\hline \multirow{2}{*}{ d21_3 } & 07 & 003 & 244 & 696 & 001 \\
\hline & 0,066872 & $3,19 \mathrm{E}-$ & 0,014567 & 0,28532 & $9,32 \mathrm{E}-$ \\
\hline \multirow[t]{2}{*}{ d21_5 } & 58 & 001 & 406 & 282 & 002 \\
\hline & 0,432166 & $4,75 \mathrm{E}-$ & 0,301490 & 0,04440 & $2,37 \mathrm{E}-$ \\
\hline Des_0 & 3 & 002 & 172 & 837 & 002 \\
\hline & 0,044639 & $3,18 \mathrm{E}-$ & 0,340400 & 0,02283 & $3,17 \mathrm{E}-$ \\
\hline Des 1 & 51 & 003 & 349 & 141 & 002 \\
\hline & 0,283732 & $1,58 \mathrm{E}-$ & 0,160534 & 0,11033 & $6,08 \mathrm{E}-$ \\
\hline Des_3 & 81 & 001 & 014 & 788 & 002 \\
\hline & 0,239379 & $9,41 \mathrm{E}-$ & 0,074342 & 0,25588 & $9,53 \mathrm{E}-$ \\
\hline Des_5 & 54 & 003 & 165 & 651 & 002 \\
\hline v.test & & & & & \\
\hline & Dim & & & Dim & Dim \\
\hline & 1 & Dim 2 & Dim 3 & 4 & 5 \\
\hline & & - & & - & \\
\hline & 2,284417 & 1,171945 & 0,560565 & 0,28332 & 0,17699 \\
\hline d5_0 & 02 & 99 & 7 & 607 & 765 \\
\hline & - & - & - & - & \\
\hline & 0,218812 & 0,251817 & 1,380127 & 1,24201 & 1,43135 \\
\hline d5_1 & 29 & 7 & 7 & 977 & 937 \\
\hline & 0.754046 & 2,203659 & 0,132192 & 1.05501 & 1.10216 \\
\hline d5_3 & 63 & 84 & 4 & 108 & 417 \\
\hline & - & - & & & - \\
\hline & 1,220161 & 1,540135 & & 0,73684 & 0,84369 \\
\hline d5_5 & 79 & 72 & 1,354074 & 593 & 867 \\
\hline
\end{tabular}




\begin{tabular}{|c|c|c|c|c|c|}
\hline d7_0 & $\begin{array}{c}2,382972 \\
59 \\
-\end{array}$ & $\begin{array}{c}- \\
1,006923 \\
26 \\
-\end{array}$ & $\begin{array}{c}0,536708 \\
2\end{array}$ & $\begin{array}{c}0,98543 \\
194\end{array}$ & $\begin{array}{c}- \\
0,24942 \\
09\end{array}$ \\
\hline d7_1 & $\begin{array}{c}0,047668 \\
79 \\
-\end{array}$ & $\begin{array}{c}0,069275 \\
12 \\
-\end{array}$ & $\begin{array}{c}0,181195 \\
4\end{array}$ & $\begin{array}{c}0,69583 \\
09\end{array}$ & $\begin{array}{c}1,26722 \\
566\end{array}$ \\
\hline d7_3 & $\begin{array}{c}1,855507 \\
89 \\
-\end{array}$ & $\begin{array}{c}0,916377 \\
46\end{array}$ & $\begin{array}{c}0,354088 \\
4 \\
-\end{array}$ & $\begin{array}{c}0,23258 \\
856 \\
-\end{array}$ & $\begin{array}{c}0,00943 \\
537 \\
-\end{array}$ \\
\hline d7_5 & $\begin{array}{c}1,193948 \\
63\end{array}$ & $\begin{array}{c}1,771871 \\
53 \\
-\end{array}$ & $\begin{array}{c}0,896414 \\
6 \\
-\end{array}$ & $\begin{array}{c}1,46728 \\
864 \\
-\end{array}$ & $\begin{array}{c}0,17533 \\
329 \\
-\end{array}$ \\
\hline $\begin{array}{l}\text { d12_0 } \\
\text { d12_1 }\end{array}$ & $\begin{array}{c}1,345785 \\
74 \\
1,605125 \\
28\end{array}$ & $\begin{array}{c}1,178084 \\
36 \\
1,493277 \\
5\end{array}$ & $\begin{array}{c}0,309393 \\
7 \\
0,991452 \\
2 \\
-\end{array}$ & $\begin{array}{c}0,05916 \\
972 \\
1,14733 \\
252 \\
-\end{array}$ & $\begin{array}{c}0,01442 \\
589 \\
0,46164 \\
74 \\
-\end{array}$ \\
\hline d12_3 & $\begin{array}{c}0,672106 \\
36 \\
-\end{array}$ & $\begin{array}{c}0,027414 \\
97 \\
-\end{array}$ & $\begin{array}{c}1,797194 \\
1\end{array}$ & $\begin{array}{c}1,01875 \\
088\end{array}$ & $\begin{array}{c}0,28566 \\
767 \\
-\end{array}$ \\
\hline d12_5 & $\begin{array}{c}2,422786 \\
81 \\
-\end{array}$ & $\begin{array}{c}0,592201 \\
25 \\
-\end{array}$ & $\begin{array}{c}1,126611 \\
9\end{array}$ & $\begin{array}{c}0,15718 \\
687 \\
-\end{array}$ & $\begin{array}{c}0,05951 \\
058\end{array}$ \\
\hline d19_0 & $\begin{array}{c}1,150046 \\
92 \\
-\end{array}$ & $\begin{array}{c}2,195964 \\
74\end{array}$ & $\begin{array}{c}0,165671 \\
1 \\
-\end{array}$ & $\begin{array}{c}0,21986 \\
813\end{array}$ & $\begin{array}{c}0,32060 \\
895\end{array}$ \\
\hline d19_1 & $\begin{array}{c}0,283404 \\
8\end{array}$ & $\begin{array}{c}0,737457 \\
23\end{array}$ & $\begin{array}{c}1,080677 \\
1\end{array}$ & $\begin{array}{c}1,48105 \\
008 \\
-\end{array}$ & $\begin{array}{c}0,75869 \\
058\end{array}$ \\
\hline d19_3 & $\begin{array}{c}1,228881 \\
79\end{array}$ & $\begin{array}{c}1,462325 \\
74\end{array}$ & 1,412594 & $\begin{array}{c}1,29945 \\
709\end{array}$ & $\begin{array}{c}0,30972 \\
19 \\
-\end{array}$ \\
\hline d19_5 & $\begin{array}{c}0,684098 \\
11\end{array}$ & $\begin{array}{c}1,046709 \\
65 \\
-\end{array}$ & $\begin{array}{c}-0,971743 \\
-\end{array}$ & $\begin{array}{c}0,45844 \\
576\end{array}$ & $\begin{array}{c}1,84633 \\
161\end{array}$ \\
\hline d20_0 & $\begin{array}{c}2,807935 \\
15 \\
0,633988\end{array}$ & $\begin{array}{c}1,414092 \\
69 \\
1,213280\end{array}$ & $\begin{array}{c}1,042787 \\
2 \\
1,226183\end{array}$ & $\begin{array}{c}0,22122 \\
915 \\
0,17045\end{array}$ & $\begin{array}{c}0,11074 \\
458 \\
0,38941\end{array}$ \\
\hline d20_1 & $\begin{array}{l}5 \\
-\end{array}$ & 08 & 5 & $\begin{array}{c}808 \\
-\end{array}$ & $\begin{array}{c}956 \\
-\end{array}$ \\
\hline d20_3 & $\begin{array}{c}2,746306 \\
26\end{array}$ & $\begin{array}{c}0,249484 \\
5\end{array}$ & $\begin{array}{c}0,862865 \\
9\end{array}$ & $\begin{array}{c}0,76777 \\
332\end{array}$ & $\begin{array}{c}0,60382 \\
161\end{array}$ \\
\hline $\mathrm{d} 20 \_5$ & $\begin{array}{c}1,032717 \\
4\end{array}$ & $\begin{array}{c}1,150714 \\
01 \\
-\end{array}$ & $\begin{array}{c}1,037817 \\
1 \\
-\end{array}$ & $\begin{array}{c}0,98011 \\
518\end{array}$ & $\begin{array}{c}0,60385 \\
68 \\
-\end{array}$ \\
\hline d21_0 & $\begin{array}{c}1,758960 \\
81 \\
1,896920\end{array}$ & $\begin{array}{c}1,995425 \\
89 \\
1,421620\end{array}$ & $\begin{array}{c}0,455067 \\
7 \\
1,721079\end{array}$ & $\begin{array}{c}0,31062 \\
067 \\
0,29758\end{array}$ & $\begin{array}{c}1,29752 \\
663 \\
0,66709\end{array}$ \\
\hline $\mathrm{d} 21 \_1$ & $\begin{array}{l}22 \\
-\end{array}$ & 05 & $\begin{array}{l}6 \\
-\end{array}$ & 248 & 912 \\
\hline $\mathrm{d} 21 \_3$ & $\begin{array}{c}2,225411 \\
86 \\
-\end{array}$ & $\begin{array}{c}0,204569 \\
04\end{array}$ & $\begin{array}{c}0,606453 \\
6\end{array}$ & $\begin{array}{c}0,71165 \\
01 \\
-\end{array}$ & $\begin{array}{c}1,75244 \\
771 \\
-\end{array}$ \\
\hline $\mathrm{d} 21 \_5$ & $\begin{array}{c}0,733323 \\
32 \\
-\end{array}$ & $\begin{array}{c}1,601013 \\
12 \\
-\end{array}$ & $\begin{array}{c}0,342265 \\
1\end{array}$ & $\begin{array}{c}1,51474 \\
562\end{array}$ & $\begin{array}{c}0,86574 \\
287 \\
-\end{array}$ \\
\hline Des_0 & $\begin{array}{c}2,082170 \\
12\end{array}$ & $\begin{array}{c}0,690221 \\
43\end{array}$ & $\begin{array}{c}1,739111 \\
2\end{array}$ & $\begin{array}{c}0,66745 \\
681\end{array}$ & $\begin{array}{c}0,48716 \\
227\end{array}$ \\
\hline
\end{tabular}




\begin{tabular}{|c|c|c|c|c|c|}
\hline \multirow[b]{3}{*}{ Des_1 } & - & - & - & - & \\
\hline & 0,560117 & 0,149481 & 1,546728 & 0,40057 & 0,47212 \\
\hline & 13 & 3 & 8 & 659 & 841 \\
\hline \multirow[b]{2}{*}{ Des_3 } & 1,566742 & 1,170139 & & 0,97702 & 0,72535 \\
\hline & 09 & 85 & $-1,178491$ & 357 & 947 \\
\hline \multirow[b]{2}{*}{ Des_5 } & 1,349260 & 0,267577 & 0,751917 & 1,39500 & 0,85120 \\
\hline & 89 & 3 & 2 & 611 & 438 \\
\hline \multicolumn{6}{|l|}{ eta2 } \\
\hline \multirow{5}{*}{ d5 } & & & & Dim & Dim \\
\hline & Dim 1 & Dim 2 & Dim 3 & 4 & 5 \\
\hline & 0,386337 & 0,530135 & 0,272264 & 0,23658 & 0,30769 \\
\hline & 9 & 1 & 43 & 03 & 187 \\
\hline & 0,418654 & & 0,074570 & 0,26266 & 0,18528 \\
\hline \multirow[t]{2}{*}{ d7 } & 9 & 0,268515 & 15 & 18 & 486 \\
\hline & 0,467028 & 0,270482 & & 0,19374 & 0,02701 \\
\hline \multirow{2}{*}{$\mathrm{d} 12$} & 2 & 8 & 0,337628 & 94 & 028 \\
\hline & 0,140053 & 0,395005 & 0,324968 & 0,38515 & 0,43283 \\
\hline \multirow{2}{*}{ d19 } & 7 & 4 & 42 & 39 & 165 \\
\hline & 0,634860 & 0,295517 & 0,309078 & 0,14136 & 0,08175 \\
\hline \multirow[t]{2}{*}{$\mathrm{d} 20$} & 9 & 4 & 18 & 44 & 736 \\
\hline & 0,558350 & 0,494931 & 0,294412 & 0,25857 & 0,46374 \\
\hline \multirow{2}{*}{$\mathrm{d} 21$} & 3 & 4 & 63 & 97 & 783 \\
\hline & 0,403133 & 0,114402 & 0,485483 & 0,28764 & 0,14987 \\
\hline des $10 c$ & 7 & 6 & 73 & 25 & 099 \\
\hline
\end{tabular}

LEGENDA: eig = Autovalores, percentagem da variância e percentagem da variância cumulativa; coord = valores das coordenadas das categorias em relação ao eixo (dimensão); contrib = Contribuição da variável para o eixo (ou dimensão); v.test $=($ teste $\mathrm{V}$ ) indica se o valor é significativo. (acima de 2 ou abaixo de -2); Eta2 = (variáveis categóricas) contém o quadrado da relação entre cada variável e as dimensões; $\cos 2=$ quadrado do cosseno. 
ANEXO XIII.TABELA DE SAÍDA DO $M C A$ ENTRE FATOR DE DIMENSIONAMENTO E DESMATAMENTO DAS UNIDADES DE CONSERVAÇÃO DE PROTEÇÃO INTEGRAL.

\begin{tabular}{|c|c|c|c|c|c|}
\hline & \multicolumn{5}{|c|}{ Percentagem } \\
\hline & & Percentagem & da variância & & \\
\hline & Autovalores & da variância & cumulativa & & \\
\hline $\operatorname{dim} 1$ & $1,85 \mathrm{E}-001$ & 26,39911346 & 26,39911 & & \\
\hline $\operatorname{dim} 2$ & $1,15 \mathrm{E}-001$ & 16,36962694 & 42,76874 & & \\
\hline $\operatorname{dim} 3$ & $8,99 \mathrm{E}-002$ & 12,84373531 & 55,61248 & & \\
\hline $\operatorname{dim} 4$ & $6,36 \mathrm{E}-002$ & 9,09414852 & 64,70662 & & \\
\hline $\operatorname{dim} 5$ & $5,54 \mathrm{E}-002$ & 7,92372877 & 72,63035 & & \\
\hline $\operatorname{dim} 6$ & 4,77E-002 & 6,81544061 & 79,44579 & & \\
\hline $\operatorname{dim} 7$ & $3,53 \mathrm{E}-002$ & 5,04757121 & 84,49336 & & \\
\hline $\operatorname{dim} 8$ & $2,44 \mathrm{E}-002$ & 3,49103974 & 87,9844 & & \\
\hline $\operatorname{dim} 9$ & 1,99E-002 & 2,83925716 & 90,82366 & & \\
\hline $\operatorname{dim} 10$ & $1,64 \mathrm{E}-002$ & 2,33860094 & 93,16226 & & \\
\hline $\operatorname{dim} 11$ & $1,29 \mathrm{E}-002$ & 1,83698437 & 94,99925 & & \\
\hline $\operatorname{dim} 12$ & $1,02 \mathrm{E}-002$ & 1,46143784 & 96,46068 & & \\
\hline $\operatorname{dim} 13$ & $8,16 \mathrm{E}-003$ & 1,16567855 & 97,62636 & & \\
\hline $\operatorname{dim} 14$ & 7,17E-003 & 1,0243917 & 98,65076 & & \\
\hline $\operatorname{dim} 15$ & 3,93E-003 & 0,56150032 & 99,21226 & & \\
\hline $\operatorname{dim} 16$ & 2,22E-003 & 0,31772071 & 99,52998 & & \\
\hline $\operatorname{dim} 17$ & $1,87 \mathrm{E}-003$ & 0,26698615 & 99,79696 & & \\
\hline $\operatorname{dim} 18$ & 7,44E-004 & 0,10629039 & 99,90325 & & \\
\hline $\operatorname{dim} 19$ & $4,01 \mathrm{E}-004$ & 0,05737677 & 99,96063 & & \\
\hline $\operatorname{dim} 20$ & $1,88 \mathrm{E}-004$ & 0,02685473 & 99,98748 & & \\
\hline $\operatorname{dim} 21$ & $8,76 \mathrm{E}-005$ & 0,01251581 & 100 & & \\
\hline \multicolumn{6}{|l|}{ coord } \\
\hline & \multirow[t]{2}{*}{ Dim 1} & Dim 2 & Dim 3 & $\operatorname{Dim} 4$ & $\operatorname{Dim} 5$ \\
\hline & & - & & - & \\
\hline \multirow[t]{2}{*}{ d5_0 } & 0,86730907 & 0,444944763 & 0,21282617 & 0,10756848 & 0,06719949 \\
\hline & - & - & & - & \\
\hline \multirow[t]{2}{*}{ d5_1 } & 0,04218152 & 0,048544131 & $-0,26605398$ & 0,23943024 & 0,27593016 \\
\hline & - & & & & - \\
\hline \multirow[t]{2}{*}{ d5_3 } & 0,18247081 & 0,533260905 & 0,03198909 & 0,25530082 & 0,26671134 \\
\hline & - & - & & & 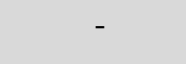 \\
\hline \multirow[t]{2}{*}{ d5_5 } & 0,58482512 & 0,738189044 & 0,64900941 & 0,35317121 & 0,40438586 \\
\hline & & - & & & - \\
\hline d7_0 & 0,37165454 & 0,157042343 & 0,08370639 & 0,1536905 & 0,03890033 \\
\hline
\end{tabular}




\begin{tabular}{|c|c|c|c|c|c|}
\hline \multirow[t]{2}{*}{ d7_1 } & 0,04766879 & 0,069275122 & 0,18119543 & 0,6958309 & 1,26722566 \\
\hline & - & - & & & \\
\hline \multirow[t]{2}{*}{ d7_3 } & 0,78367125 & 0,387030778 & 0,14954876 & 0,09823346 & 0,00398501 \\
\hline & - & & & - & - \\
\hline \multirow[t]{2}{*}{ d7_5 } & 0,28892214 & 0,42877299 & $-0,21692225$ & 0,35506735 & 0,04242869 \\
\hline & & - & & - & - \\
\hline d12_0 & 0,93866649 & 0,821697152 & $-0,21579771$ & 0,04127004 & 0,01006185 \\
\hline \multirow[t]{2}{*}{ d12_1 } & 0,609407 & 0,566942512 & 0,3764179 & 0,43559994 & 0,17527053 \\
\hline & & & & - & - \\
\hline \multirow[t]{2}{*}{ d12_3 } & 0,15322706 & 0,006250075 & $-0,40972498$ & 0,23225521 & 0,06512662 \\
\hline & - & - & & & - \\
\hline \multirow[t]{2}{*}{ d12_5 } & 0,44268981 & 0,108206573 & 0,20585369 & 0,02872107 & 0,01087373 \\
\hline & - & - & & - & \\
\hline \multirow[t]{2}{*}{ d19_0 } & 0,13633783 & 0,260331172 & 0,01964028 & 0,02606532 & 0,03800813 \\
\hline & - & & & & \\
\hline \multirow[t]{2}{*}{ d19_1 } & 0,13583629 & 0,353464205 & $-0,51796992$ & 0,70986922 & 0,36364138 \\
\hline & & & & - & \\
\hline \multirow[t]{2}{*}{ d19_3 } & 0,46656119 & 0,555191267 & 0,53630996 & 0,49335603 & 0,11759001 \\
\hline & & & & & - \\
\hline \multirow[t]{2}{*}{ d19_5 } & 0,38414123 & 0,587758289 & $-0,54566231$ & 0,25743079 & 1,03676956 \\
\hline & & - & & & \\
\hline d20_0 & 0,48659199 & 0,245050594 & $-0,18070641$ & 0,03833719 & 0,01919112 \\
\hline \multirow[t]{2}{*}{ d20_1 } & 0,35600321 & 0,681292486 & 0,68853813 & 0,09571723 & 0,21867055 \\
\hline & - & & & - & \\
\hline \multirow[t]{2}{*}{ d20_3 } & 0,55907026 & 0,050787986 & 0,1756551 & 0,15629693 & $-0,122921$ \\
\hline & - & & & & \\
\hline \multirow[t]{2}{*}{ d20_5 } & 0,72030576 & 0,802606721 & $-0,72386272$ & 0,68361645 & 0,42118156 \\
\hline & & - & & & - \\
\hline d21_0 & 0,30481339 & 0,345790842 & $-0,07885948$ & 0,053828 & 0,22485066 \\
\hline \multirow[t]{2}{*}{ d21_1 } & 1,32307498 & 0,991559843 & 1,20042864 & 0,20755956 & 0,46529218 \\
\hline & - & & & & \\
\hline \multirow[t]{2}{*}{ d21_3 } & 0,53852465 & 0,049503408 & $-0,14675494$ & 0,17221132 & 0,42407264 \\
\hline & - & & & - & - \\
\hline \multirow[t]{2}{*}{ d21_5 } & 0,27841588 & 0,607845762 & 0,12994545 & 0,57509317 & 0,32869071 \\
\hline & - & - & & & - \\
\hline \multirow[t]{2}{*}{ Des_0 } & 0,47469393 & 0,157356941 & 0,39648322 & 0,15216705 & 0,11106344 \\
\hline & - & & & - & \\
\hline Des_1 & 0,17831736 & $-0,04758846$ & $-0,49241234$ & 0,12752647 & 0,15030551 \\
\hline
\end{tabular}




\begin{tabular}{|c|c|c|c|c|c|}
\hline Des_3 & 0,46235376 & 0,345314372 & $-0,34777883$ & 0,28832475 & 0,21405736 \\
\hline \multirow{4}{*}{$\begin{array}{l}\text { Des_5 } \\
\text { contrib }\end{array}$} & & - & \multicolumn{3}{|c|}{-} \\
\hline & 0,42954701 & 0,085185179 & 0,23937831 & 0,44411034 & 0,2709871 \\
\hline & & & & & \\
\hline & Dim 1 & Dim 2 & Dim 3 & $\operatorname{Dim} 4$ & Dim 5 \\
\hline d5_0 & 9,18621544 & 3,898985398 & 1,13693834 & 0,4101911 & 1,84E-001 \\
\hline $\mathrm{d} 5 \_1$ & 0,05794313 & 0,123760373 & 4,73800052 & 5,41929598 & $8,26 \mathrm{E}+000$ \\
\hline d5_3 & 0,81321546 & 11,2007962 & 0,05137129 & 4,62115533 & $5,79 \mathrm{E}+000$ \\
\hline d5_5 & 2,78451544 & 7,154566773 & 7,04851414 & 2,94778276 & $4,44 \mathrm{E}+000$ \\
\hline d7_0 & 5,62272021 & 1,619018042 & 0,58624991 & 2,79118711 & $2,05 \mathrm{E}-001$ \\
\hline d7_1 & 0,00462494 & 0,015752256 & 0,13735044 & 2,86070001 & $1,09 \mathrm{E}+001$ \\
\hline d7_3 & 6,24993395 & 2,458380884 & 0,46781185 & 0,28507151 & $5,38 \mathrm{E}-004$ \\
\hline d7_5 & 2,0388276 & 7,241428462 & 2,36224549 & 8,93856149 & $1,46 \mathrm{E}-001$ \\
\hline d12_0 & 3,5866601 & 4,432428291 & 0,38963615 & 0,02012634 & 1,37E-003 \\
\hline d12_1 & 4,535276 & 6,33020036 & 3,55653748 & 6,72654053 & $1,25 \mathrm{E}+000$ \\
\hline d12_3 & 0,62122925 & 0,001666871 & 9,12985405 & 4,14323125 & $3,74 \mathrm{E}-001$ \\
\hline d12_5 & 6,78087237 & 0,653347702 & 3,0137126 & 0,08285429 & 1,36E-002 \\
\hline d19_0 & 0,94582403 & 5,561353656 & 0,04034324 & 0,10035317 & $2,45 \mathrm{E}-001$ \\
\hline d19_1 & 0,1502205 & 1,640359472 & 4,48956913 & 11,9091724 & $3,59 \mathrm{E}+000$ \\
\hline d19_3 & 2,65831272 & 6,07050277 & 7,21969023 & 8,62853446 & $5,63 \mathrm{E}-001$ \\
\hline d19_5 & 0,901033 & 3,401785605 & 3,73684229 & 1,17464635 & $2,19 \mathrm{E}+001$ \\
\hline d20_0 & 8,67441142 & 3,547906633 & 2,45898126 & 0,15630679 & $4,50 \mathrm{E}-002$ \\
\hline d20_1 & 0,77386763 & 4,57063575 & 5,94994355 & 0,16239266 & 9,73E-001 \\
\hline d20_3 & 9,54248847 & 0,12699932 & 1,93619171 & 2,16499572 & $1,54 \mathrm{E}+000$ \\
\hline $\mathrm{d} 20 \_5$ & 2,11203625 & 4,228864206 & 4,38407534 & 5,52229882 & $2,41 \mathrm{E}+000$ \\
\hline d21_0 & 3,40391099 & 7,064600998 & 0,46829113 & 0,30814411 & $6,17 \mathrm{E}+000$ \\
\hline $\mathrm{d} 21 \_1$ & 7,12584726 & 6,454402059 & 12,05697301 & 0,50907338 & $2,94 \mathrm{E}+000$ \\
\hline d21_3 & 7,08320837 & 0,096524953 & 1,08119071 & 2,10266244 & $1,46 \mathrm{E}+001$ \\
\hline $\mathrm{d} 21 \_5$ & 0,94662254 & 7,276561362 & 0,42384686 & 11,7244523 & $4,40 \mathrm{E}+000$ \\
\hline Des_0 & 5,96222419 & 1,05658227 & 8,54926071 & 1,77848219 & $1,09 \mathrm{E}+000$ \\
\hline Des_1 & 0,51774371 & 0,059467742 & 8,11490503 & 0,76869767 & $1,23 \mathrm{E}+000$ \\
\hline Des_3 & 3,91587565 & 3,522572786 & 4,55390954 & 4,42049858 & $2,80 \mathrm{E}+000$ \\
\hline Des_5 & 3,00433939 & 0,190548806 & 1,91776399 & 9,32259136 & $3,98 \mathrm{E}+000$ \\
\hline
\end{tabular}

$\cos 2$ 


\begin{tabular}{|c|c|c|c|c|c|}
\hline d5_0 & 0,55355367 & $1,46 \mathrm{E}-001$ & 0,03333205 & 0,00851495 & 3,32E-003 \\
\hline d5_1 & 0,006026 & $7,98 \mathrm{E}-003$ & 0,239730902 & 0,19415227 & 2,58E-001 \\
\hline d5_3 & 0,06269557 & $5,35 \mathrm{E}-001$ & 0,001926876 & 0,12273106 & 1,34E-001 \\
\hline d5_5 & 0,1752092 & 2,79E-001 & 0,215777845 & 0,06389626 & 8,38E-002 \\
\hline d7_0 & 0,56301909 & $1,01 \mathrm{E}-001$ & 0,028560213 & 0,09628049 & 6,17E-003 \\
\hline d7_1 & 0,0003218 & $6,80 \mathrm{E}-004$ & 0,00464953 & 0,06856808 & 2,27E-001 \\
\hline d7_3 & 0,43292714 & $1,06 \mathrm{E}-001$ & 0,015765677 & 0,00680246 & 1,12E-005 \\
\hline d7_5 & 0,15030626 & $3,31 \mathrm{E}-001$ & 0,084727346 & 0,22700577 & 3,24E-003 \\
\hline d12_0 & 0,25631996 & $1,96 \mathrm{E}-001$ & 0,013547322 & 0,00049548 & 2,95E-005 \\
\hline d12_1 & 0,27297206 & 2,36E-001 & 0,104146304 & 0,1394694 & 2,26E-002 \\
\hline d12_3 & 0,05983004 & $9,95 \mathrm{E}-005$ & 0,427792565 & 0,13746093 & 1,08E-002 \\
\hline d12_5 & 0,58843007 & $3,52 \mathrm{E}-002$ & 0,127236914 & 0,00247684 & $3,55 \mathrm{E}-004$ \\
\hline d19_0 & 0,15388373 & $5,61 \mathrm{E}-001$ & 0,003193413 & 0,00562453 & $1,20 \mathrm{E}-002$ \\
\hline d19_1 & 0,01112363 & $7,53 \mathrm{E}-002$ & 0,161742441 & 0,30378869 & 7,97E-002 \\
\hline d19_3 & 0,16961974 & $2,40 \mathrm{E}-001$ & 0,224125305 & 0,18966189 & 1,08E-002 \\
\hline d19_5 & 0,05971325 & $1,40 \mathrm{E}-001$ & 0,120486062 & 0,02681698 & 4,35E-001 \\
\hline d20_0 & 0,66162781 & $1,68 \mathrm{E}-001$ & 0,091249597 & 0,004107 & 1,03E-003 \\
\hline d20_1 & 0,05415358 & $1,98 \mathrm{E}-001$ & 0,202570091 & 0,00391471 & 2,04E-002 \\
\hline d20_3 & 0,71554123 & $5,91 \mathrm{E}-003$ & 0,070635558 & 0,05592458 & $3,46 \mathrm{E}-002$ \\
\hline $\mathrm{d} 20 \_5$ & 0,12639956 & $1,57 \mathrm{E}-001$ & 0,127650994 & 0,11385099 & 4,32E-002 \\
\hline d21_0 & 0,31422455 & 4,04E-001 & 0,021031965 & 0,00979915 & 1,71E-001 \\
\hline d21_1 & 0,35131837 & 1,97E-001 & 0,289204229 & 0,00864604 & 4,34E-002 \\
\hline d21_3 & 0,50680807 & $4,28 \mathrm{E}-003$ & 0,037637244 & 0,05182696 & $3,14 \mathrm{E}-001$ \\
\hline d21_5 & 0,06687258 & 3,19E-001 & 0,014567406 & 0,28532282 & 9,32E-002 \\
\hline Des_0 & 0,4321663 & $4,75 \mathrm{E}-002$ & 0,301490172 & 0,04440837 & 2,37E-002 \\
\hline Des_1 & 0,04463951 & $3,18 \mathrm{E}-003$ & 0,340400349 & 0,02283141 & $3,17 \mathrm{E}-002$ \\
\hline Des_3 & 0,28373281 & $1,58 \mathrm{E}-001$ & 0,160534014 & 0,11033788 & $6,08 \mathrm{E}-002$ \\
\hline Des_5 & 0,23937954 & $9,41 \mathrm{E}-003$ & 0,074342165 & 0,25588651 & $9,53 \mathrm{E}-002$ \\
\hline \multicolumn{6}{|l|}{ v.test } \\
\hline & Dim 1 & Dim 2 & Dim 3 & Dim 4 & Dim 5 \\
\hline & & & & - & \\
\hline d5_0 & 2,28441702 & $-1,17194599$ & 0,5605657 & 0,28332607 & 0,17699765 \\
\hline & - & & & - & \\
\hline d5_1 & 0,21881229 & $-0,2518177$ & $-1,3801277$ & 1,24201977 & 1,43135937 \\
\hline d5 3 & 0,75404663 & 2.20365984 & 0,1321924 & 1.05501108 & 1,10216417 \\
\hline
\end{tabular}




\begin{tabular}{|c|c|c|c|c|c|}
\hline d5_5 & 1,22016179 & $-1,54013572$ & 1,354074 & 0,73684593 & 0,84369867 \\
\hline \multirow[t]{2}{*}{ d7_0 } & 2,38297259 & $-1,00692326$ & 0,5367082 & 0,98543194 & $-0,2494209$ \\
\hline & - & & & & \\
\hline \multirow[t]{2}{*}{ d7_1 } & 0,04766879 & $-0,06927512$ & 0,1811954 & 0,6958309 & 1,26722566 \\
\hline & - & & & & \\
\hline \multirow[t]{2}{*}{ d7_3 } & 1,85550789 & $-0,91637746$ & 0,3540884 & 0,23258856 & 0,00943537 \\
\hline & - & & & - & - \\
\hline \multirow[t]{2}{*}{ d7_5 } & 1,19394863 & 1,77187153 & $-0,8964146$ & 1,46728864 & 0,17533329 \\
\hline & & & & - & - \\
\hline d12_0 & 1,34578574 & $-1,17808436$ & $-0,3093937$ & 0,05916972 & 0,01442589 \\
\hline \multirow[t]{2}{*}{ d12_1 } & 1,60512528 & 1,4932775 & 0,9914522 & 1,14733252 & 0,4616474 \\
\hline & & & & - & - \\
\hline \multirow[t]{2}{*}{ d12_3 } & 0,67210636 & 0,02741497 & $-1,7971941$ & 1,01875088 & 0,28566767 \\
\hline & - & & & & - \\
\hline \multirow[t]{2}{*}{ d12_5 } & 2,42278681 & $-0,59220125$ & 1,1266119 & 0,15718687 & 0,05951058 \\
\hline & - & & & - & \\
\hline d19_0 & 1,15004692 & $-2,19596474$ & 0,1656711 & 0,21986813 & 0,32060895 \\
\hline \multirow[t]{2}{*}{ d19_1 } & $-0,2834048$ & 0,73745723 & $-1,0806771$ & 1,48105008 & 0,75869058 \\
\hline & & & & - & \\
\hline d19_3 & 1,22888179 & 1,46232574 & 1,412594 & 1,29945709 & 0,3097219 \\
\hline d19_5 & 0,68409811 & 1,04670965 & $-0,971743$ & 0,45844576 & 1,84633161 \\
\hline d20_0 & 2,80793515 & $-1,41409269$ & $-1,0427872$ & 0,22122915 & 0,11074458 \\
\hline \multirow[t]{2}{*}{ d20_1 } & 0,6339885 & 1,21328008 & 1,2261835 & 0,17045808 & 0,38941956 \\
\hline & - & & & - & - \\
\hline d20_3 & 2,74630626 & 0,2494845 & 0,8628659 & 0,76777332 & 0,60382161 \\
\hline \multirow[t]{2}{*}{$\mathrm{d} 20 \_5$} & $-1,0327174$ & 1,15071401 & $-1,0378171$ & 0,98011518 & 0,6038568 \\
\hline & & & & & - \\
\hline d21_0 & 1,75896081 & $-1,99542589$ & $-0,4550677$ & 0,31062067 & 1,29752663 \\
\hline \multirow[t]{2}{*}{ d21_1 } & 1,89692022 & 1,42162005 & 1,7210796 & 0,29758248 & 0,66709912 \\
\hline & - & & & & \\
\hline \multirow[t]{2}{*}{ d21_3 } & 2,22541186 & 0,20456904 & $-0,6064536$ & 0,7116501 & 1,75244771 \\
\hline & - & & & - & - \\
\hline \multirow[t]{2}{*}{ d21_5 } & 0,73332332 & 1,60101312 & 0,3422651 & 1,51474562 & 0,86574287 \\
\hline & - & & & & - \\
\hline \multirow[t]{2}{*}{ Des_0 } & 2,08217012 & $-0,69022143$ & 1,7391112 & 0,66745681 & 0,48716227 \\
\hline & - & & & - & \\
\hline Des_1 & 0,56011713 & $-0,1494813$ & $-1,5467288$ & 0,40057659 & 0,47212841 \\
\hline
\end{tabular}




\begin{tabular}{|c|c|c|c|c|c|}
\hline Des_3 & 1,56674209 & 1,17013985 & $-1,178491$ & 0,97702357 & 0,72535947 \\
\hline Des_5 & 1,34926089 & $-0,2675773$ & 0,7519172 & $\begin{array}{c}- \\
1,39500611\end{array}$ & 0,85120438 \\
\hline \multicolumn{6}{|l|}{ eta2 } \\
\hline & Dim 1 & $\operatorname{Dim} 2$ & Dim 3 & $\operatorname{Dim} 4$ & $\operatorname{Dim} 5$ \\
\hline d5 & 0,3863379 & 0,5301351 & 0,27226443 & 0,2365803 & 0,30769187 \\
\hline d7 & 0,4186549 & 0,268515 & 0,07457015 & 0,2626618 & 0,18528486 \\
\hline $\mathrm{d} 12$ & 0,4670282 & 0,2704828 & 0,337628 & 0,1937494 & 0,02701028 \\
\hline d19 & 0,1400537 & 0,3950054 & 0,32496842 & 0,3851539 & 0,43283165 \\
\hline $\mathrm{d} 20$ & 0,6348609 & 0,2955174 & 0,30907818 & 0,1413644 & 0,08175736 \\
\hline $\mathrm{d} 21$ & 0,5583503 & 0,4949314 & 0,29441263 & 0,2585797 & 0,46374783 \\
\hline $\operatorname{des} 10 \mathrm{c}$ & 0,4031337 & 0,1144026 & 0,48548373 & 0,2876425 & 0,14987099 \\
\hline
\end{tabular}

LEGENDA: eig = Autovalores, percentagem da variância e percentagem da variância cumulativa; coord = valores das coordenadas das categorias em relação ao eixo (dimensão); contrib = Contribuição da variável para o eixo (ou dimensão); v.test $=($ teste $\mathrm{V}$ ) indica se o valor é significativo. (acima de 2 ou abaixo de -2); Eta2 = (variáveis categóricas) contém o quadrado da relação entre cada variável e as dimensões; $\cos 2$ = quadrado do cosseno. 
ANEXO XIV.TABELA DE SAÍDA DO $M C A$ ENTRE FATOR DE DIMENSIONAMENTO E DESMATAMENTO DAS UNIDADES DE CONSERVAÇÃO DE USO SUSTENTÁVEL.

\section{DIMESIONAMENTO E DESMATAMENTO - UCS AMAZONIA USO SUSTENTÁVEL}

eig

$\begin{array}{lccc} & & & \text { percentagem da } \\ & \text { autovalores } & \text { vercentagem da } & \text { variancia } \\ \operatorname{dim} 1 & 0,22461564 & 31,3362921 & \text { cumulativa } \\ \operatorname{dim} 2 & 0,098156421 & 13,693874 & 31,33629 \\ \operatorname{dim} 3 & 0,0795712 & 11,1010362 & 55,03017 \\ \operatorname{dim} 4 & 0,061382278 & 8,5634865 & 64,1312 \\ \operatorname{dim} 5 & 0,052475739 & 7,3209287 & 72,01562 \\ \operatorname{dim} 6 & 0,045545772 & 6,3541239 & 78,36974 \\ \operatorname{dim} 7 & 0,035579483 & 4,9637196 & 83,33346 \\ \operatorname{dim} 8 & 0,025113867 & 3,5036539 & 86,83711 \\ \operatorname{dim} 9 & 0,021985196 & 3,0671708 & 89,90429 \\ \operatorname{dim} 10 & 0,019558572 & 2,7286307 & 92,63292 \\ \operatorname{dim} 11 & 0,01724654 & 2,4060774 & 95,03899 \\ \operatorname{dim} 12 & 0,010736634 & 1,4978756 & 96,53687 \\ \operatorname{dim} 13 & 0,007124062 & 0,9938831 & 97,53075 \\ \operatorname{dim} 14 & 0,006237347 & 0,8701768 & 98,40093 \\ \operatorname{dim} 15 & 0,004399619 & 0,6137941 & 99,01472 \\ \operatorname{dim} 16 & 0,003845124 & 0,5364361 & 99,55116 \\ \operatorname{dim} 17 & 0,002247691 & 0,313577 & 99,86474 \\ \operatorname{dim} 18 & 0,000969557 & 0,1352636 & 100\end{array}$

coord

$\begin{array}{cccccc} & \text { Dim 1 } & \operatorname{Dim} 2 & \operatorname{Dim} 3 & \operatorname{Dim} 4 & \operatorname{Dim} 5 \\ \text { d5_0 } & 1,32615317 & -0,38919552 & -0,307333939 & -0,01344316 & -0,0530571 \\ \text { d5_1 } & 0,40929655 & 0,93236785 & -0,265144851 & 0,18028271 & 0,50703935 \\ \text { d5_3 } & -0,17945833 & -0,16344473 & 0,144094416 & -0,35492009 & -0,06214177 \\ \text { d5_5 } & -0,29815651 & -0,04822536 & 0,001906815 & 0,40014552 & -0,10593262 \\ \text { d7_0 } & 0,79815454 & -0,00011576 & -0,053626014 & -0,0508996 & 0,01326887 \\ \text { d7_1 } & -0,01334788 & -0,4159535 & 1,388491565 & 1,11827034 & 0,16945928 \\ \text { d7_3 } & -0,19082986 & 0,18786565 & 0,128890256 & -0,40006307 & 0,20825915 \\ \text { d7_5 } & -0,45390551 & -0,05532971 & -0,215942535 & 0,12412404 & -0,15220699 \\ \text { d12_0 } & 1,32553114 & -0,46290888 & -0,013576246 & -0,00417629 & -0,16978233 \\ \text { d12_1 } & 0,00724964 & 1,02492784 & 0,507685161 & -0,37833853 & -0,80010911 \\ \text { d12_3 } & 0,02436629 & 0,10625267 & 0,146113136 & 0,04471983 & 0,32294458 \\ \text { d12_5 } & -0,34333343 & -0,16428396 & -0,212989964 & 0,03185716 & -0,08737985 \\ \text { d20_0 } & 1,07575555 & -0,28035526 & 0,004914322 & -0,14412305 & -0,04775 \\ \text { d20_1 } & 0,14232564 & 1,11704864 & 0,12911417 & 0,43734129 & 0,43330447\end{array}$




$\begin{array}{llllll}\text { d20_3 } & -0,23810665 & -0,11641965 & 0,451428096 & -0,23637316 & 0,02137893 \\ \text { d20_5 } & -0,41934341 & -0,06742848 & -0,458975207 & 0,16934979 & -0,12165404 \\ \text { d21_0 } & 0,47847966 & -0,07850927 & -0,010899753 & 0,14424057 & -0,12581287 \\ \text { d21_1 } & -0,31456083 & 0,28892249 & 0,342817728 & -0,16779622 & -0,13924425 \\ \text { d21_3 } & -0,1018914 & 0,05959812 & -0,209123277 & -0,10986673 & 0,15993341 \\ \text { d21_5 } & -0,67543037 & -0,35364669 & -0,295265329 & 0,02316407 & 0,39152472 \\ \text { Des_0 } & -0,36722682 & -0,2665286 & -0,199030113 & -0,42585973 & 0,40802185 \\ \text { Des_1 } & -0,15107995 & -0,39054804 & 0,459285293 & 0,30512245 & 0,06606844 \\ \text { Des_3 } & -0,06435319 & 0,41004192 & -0,10812443 & 0,00043469 & -0,44752642 \\ \text { Des_5 } & 0,47570958 & 0,14657404 & -0,206433563 & -0,00747707 & 0,11821901\end{array}$

contrib

\begin{tabular}{|c|c|c|c|c|c|}
\hline & Dim 1 & $\operatorname{Dim} 2$ & Dim 3 & $\operatorname{Dim} 4$ & $\operatorname{Dim} 5$ \\
\hline d5_0 & $1,22 \mathrm{E}+001$ & $2,40 \mathrm{E}+000$ & $1,85 \mathrm{E}+000$ & $4,58 \mathrm{E}-003$ & 0,08344761 \\
\hline d5_1 & $1,66 \mathrm{E}+000$ & $1,97 \mathrm{E}+001$ & $1,96 \mathrm{E}+000$ & $1,18 \mathrm{E}+000$ & 10,8871008 \\
\hline d5_3 & $1,05 \mathrm{E}+000$ & $2,00 \mathrm{E}+000$ & $1,91 \mathrm{E}+000$ & $1,50 \mathrm{E}+001$ & 0,53964734 \\
\hline d5_5 & $2,20 \mathrm{E}+000$ & $1,32 \mathrm{E}-001$ & $2,54 \mathrm{E}-004$ & $1,45 \mathrm{E}+001$ & 1,18803262 \\
\hline d7_0 & $1,39 \mathrm{E}+001$ & $6,67 \mathrm{E}-007$ & 1,77E-001 & $2,06 \mathrm{E}-001$ & 0,01640285 \\
\hline d7_1 & $7,05 \mathrm{E}-004$ & $1,57 \mathrm{E}+000$ & $2,15 \mathrm{E}+001$ & $1,81 \mathrm{E}+001$ & 0,48642916 \\
\hline d7 33 & $6,49 \mathrm{E}-001$ & $1,44 \mathrm{E}+000$ & $8,35 \mathrm{E}-001$ & $1,04 \mathrm{E}+001$ & 3,3060514 \\
\hline d7 55 & $6,32 \mathrm{E}+000$ & $2,15 \mathrm{E}-001$ & $4,04 \mathrm{E}+000$ & $1,73 \mathrm{E}+000$ & 3,04130402 \\
\hline d12_0 & $1,39 \mathrm{E}+001$ & $3,88 \mathrm{E}+000$ & $4,12 \mathrm{E}-003$ & $5,05 \mathrm{E}-004$ & 0,97657118 \\
\hline d12_1 & $3,12 \mathrm{E}-004$ & $1,43 \mathrm{E}+001$ & $4,32 \mathrm{E}+000$ & $3,11 \mathrm{E}+000$ & 16,2659187 \\
\hline d12_3 & $1,64 \mathrm{E}-002$ & $7,16 \mathrm{E}-001$ & $1,67 \mathrm{E}+000$ & $2,03 \mathrm{E}-001$ & 12,3663904 \\
\hline d12_5 & $3,85 \mathrm{E}+000$ & $2,02 \mathrm{E}+000$ & $4,18 \mathrm{E}+000$ & $1,21 \mathrm{E}-001$ & 1,06700245 \\
\hline d20_0 & $1,72 \mathrm{E}+001$ & $2,67 \mathrm{E}+000$ & $1,01 \mathrm{E}-003$ & $1,13 \mathrm{E}+000$ & 0,1448328 \\
\hline d20_1 & $1,60 \mathrm{E}-001$ & $2,26 \mathrm{E}+001$ & $3,72 \mathrm{E}-001$ & $5,54 \mathrm{E}+000$ & 6,36070498 \\
\hline d20_3 & $1,40 \mathrm{E}+000$ & 7,67E-001 & $1,42 \mathrm{E}+001$ & $5,06 \mathrm{E}+000$ & 0,04838834 \\
\hline d20_5 & $4,70 \mathrm{E}+000$ & $2,78 \mathrm{E}-001$ & $1,59 \mathrm{E}+001$ & $2,80 \mathrm{E}+000$ & 1,69217675 \\
\hline d21_0 & $7,02 \mathrm{E}+000$ & 4,33E-001 & $1,03 \mathrm{E}-002$ & $2,33 \mathrm{E}+000$ & 2,07797699 \\
\hline d21_1 & $1,86 \mathrm{E}+000$ & $3,59 \mathrm{E}+000$ & $6,24 \mathrm{E}+000$ & $1,94 \mathrm{E}+000$ & 1,56004477 \\
\hline d21_3 & 1,44E-001 & $1,13 \mathrm{E}-001$ & $1,71 \mathrm{E}+000$ & $6,12 \mathrm{E}-001$ & 1,51647524 \\
\hline d21_5 & $4,96 \mathrm{E}+000$ & $3,11 \mathrm{E}+000$ & $2,68 \mathrm{E}+000$ & $2,14 \mathrm{E}-002$ & 7,14068686 \\
\hline Des_0 & $1,87 \mathrm{E}+000$ & $2,25 \mathrm{E}+000$ & $1,55 \mathrm{E}+000$ & $9,19 \mathrm{E}+000$ & 9,87015085 \\
\hline Des_1 & $4,52 \mathrm{E}-001$ & $6,91 \mathrm{E}+000$ & $1,18 \mathrm{E}+001$ & $6,74 \mathrm{E}+000$ & 0,36969792 \\
\hline Des_3 & $8,60 \mathrm{E}-002$ & $7,99 \mathrm{E}+000$ & $6,86 \mathrm{E}-001$ & $1,44 \mathrm{E}-005$ & 17,810888 \\
\hline Des_5 & $4,48 \mathrm{E}+000$ & $9,73 \mathrm{E}-001$ & $2,38 \mathrm{E}+000$ & $4,05 \mathrm{E}-003$ & 1,18367792 \\
\hline \multicolumn{6}{|l|}{$\cos 2$} \\
\hline & Dim 1 & Dim 2 & Dim 3 & Dim 4 & Dim 5 \\
\hline d5_0 & $6,62 \mathrm{E}-001$ & $5,70 \mathrm{E}-002$ & $3,56 \mathrm{E}-002$ & $6,81 \mathrm{E}-005$ & 0,00106016 \\
\hline d5_1 & $1,06 \mathrm{E}-001$ & $5,49 \mathrm{E}-001$ & 4,44E-002 & $2,05 \mathrm{E}-002$ & 0,16238146 \\
\hline d5_3 & $1,16 \mathrm{E}-001$ & $9,60 \mathrm{E}-002$ & $7,46 \mathrm{E}-002$ & $4,53 \mathrm{E}-001$ & 0,01387583 \\
\hline d5_5 & $2,13 \mathrm{E}-001$ & $5,56 \mathrm{E}-003$ & $8,70 \mathrm{E}-006$ & 3,83E-001 & 0,02684393 \\
\hline
\end{tabular}




\begin{tabular}{|c|c|c|c|c|c|}
\hline d7_0 & $8,40 \mathrm{E}-001$ & $1,77 \mathrm{E}-008$ & 3,79E-003 & $3,42 \mathrm{E}-003$ & 0,00023228 \\
\hline d7__1 & $4,53 \mathrm{E}-005$ & $4,40 \mathrm{E}-002$ & $4,90 \mathrm{E}-001$ & $3,18 \mathrm{E}-001$ & 0,00729825 \\
\hline d7 _3 & $5,97 \mathrm{E}-002$ & 5,79E-002 & $2,72 \mathrm{E}-002$ & $2,62 \mathrm{E}-001$ & 0,07113393 \\
\hline d7_5 & $5,38 \mathrm{E}-001$ & $8,00 \mathrm{E}-003$ & $1,22 \mathrm{E}-001$ & 4,03E-002 & 0,06053438 \\
\hline d12_0 & 7,01E-001 & $8,55 \mathrm{E}-002$ & 7,35E-005 & 6,96E-006 & 0,01149788 \\
\hline d12_1 & 2,07E-005 & $4,13 \mathrm{E}-001$ & $1,01 \mathrm{E}-001$ & $5,63 \mathrm{E}-002$ & 0,25173165 \\
\hline d12_3 & $1,94 \mathrm{E}-003$ & $3,69 \mathrm{E}-002$ & $6,98 \mathrm{E}-002$ & $6,54 \mathrm{E}-003$ & 0,34115028 \\
\hline d12_5 & $3,92 \mathrm{E}-001$ & 8,97E-002 & $1,51 \mathrm{E}-001$ & 3,37E-003 & 0,02536271 \\
\hline d20_0 & $8,32 \mathrm{E}-001$ & $5,65 \mathrm{E}-002$ & $1,74 \mathrm{E}-005$ & 1,49E-002 & 0,00163988 \\
\hline d20_1 & $1,03 \mathrm{E}-002$ & $6,37 \mathrm{E}-001$ & $8,50 \mathrm{E}-003$ & $9,76 \mathrm{E}-002$ & 0,09578462 \\
\hline d20_3 & $1,28 \mathrm{E}-001$ & $3,06 \mathrm{E}-002$ & $4,60 \mathrm{E}-001$ & $1,26 \mathrm{E}-001$ & 0,00103094 \\
\hline d20_5 & $3,67 \mathrm{E}-001$ & $9,49 \mathrm{E}-003$ & $4,40 \mathrm{E}-001$ & $5,98 \mathrm{E}-002$ & 0,03088376 \\
\hline d21_0 & $6,19 \mathrm{E}-001$ & $1,67 \mathrm{E}-002$ & $3,21 \mathrm{E}-004$ & $5,62 \mathrm{E}-002$ & 0,04277342 \\
\hline d21_1 & $1,60 \mathrm{E}-001$ & $1,35 \mathrm{E}-001$ & $1,90 \mathrm{E}-001$ & $4,55 \mathrm{E}-002$ & 0,03130004 \\
\hline d21_3 & $1,25 \mathrm{E}-002$ & $4,28 \mathrm{E}-003$ & $5,27 \mathrm{E}-002$ & $1,46 \mathrm{E}-002$ & 0,03083598 \\
\hline d21_5 & $3,38 \mathrm{E}-001$ & $9,25 \mathrm{E}-002$ & $6,45 \mathrm{E}-002$ & 3,97E-004 & 0,11341545 \\
\hline Des_0 & $1,43 \mathrm{E}-001$ & 7,53E-002 & $4,20 \mathrm{E}-002$ & 1,92E-001 & 0,17658587 \\
\hline Des_1 & $3,71 \mathrm{E}-002$ & $2,48 \mathrm{E}-001$ & 3,43E-001 & $1,51 \mathrm{E}-001$ & 0,00709309 \\
\hline Des_3 & 7,67E-003 & $3,11 \mathrm{E}-001$ & $2,16 \mathrm{E}-002$ & $3,50 \mathrm{E}-007$ & 0,37074324 \\
\hline Des_5 & $3,68 \mathrm{E}-001$ & $3,49 \mathrm{E}-002$ & $6,93 \mathrm{E}-002$ & 9,09E-005 & 0,02271246 \\
\hline \multicolumn{6}{|l|}{ v.test } \\
\hline & Dim 1 & $\operatorname{Dim} 2$ & Dim 3 & Dim 4 & $\operatorname{Dim} 5$ \\
\hline d5_0 & 3,66019406 & $-1,074182963$ & $-0.84824429-$ & 0,03710324 & $-0,14643804$ \\
\hline d5_1 & 1,3810114 & 3,145911276 & $-0,89462778$ & 0,60829363 & 1,71080631 \\
\hline d5_3 & $-1,36839604$ & $-1,246289953$ & $-1,09874101$ & 2,70631762 & $-0,47384006$ \\
\hline d5_5 & $-1,81361525$ & $-0,293343383$ & 0,0115987 & 2,43399015 & $-0,64436298$ \\
\hline d7_0 & 4,42360412 & $-0,000641575$ & $-0.29721093-$ & 0,28210035 & 0,07353991 \\
\hline d7__1 & $-0,02725391$ & $-0,849300657$ & 2,83504481 & 2,2833027 & 0,34600472 \\
\hline d7_3 & $-0,92248864$ & 0,908159371 & $-0,62306703$ & 1,93394069 & 1,00674336 \\
\hline d7_5 & $-3,2774481$ & $-0,399511025$ & $-1,55922419$ & 0,89624399 & $-1,09901844$ \\
\hline d12_0 & 3,94015574 & $-1,376001668$ & $-0.04035554-$ & 0,01241408 & $-0,50467983$ \\
\hline d12_1 & 0,01839007 & 2,599921459 & $-1,28783852$ & 0,95972656 & $-2,02962663$ \\
\hline d12_3 & 0,16178393 & 0,70548175 & 0,97014178 & 0,29692453 & 2,14424273 \\
\hline d12_5 & $-2,61796765$ & $-1,252689238$ & $-1,62407965$ & 0,24291552 & $-0,66628412$ \\
\hline d20_0 & 4,62699957 & $-1,205853573$ & $-0,0211373$ & 0,61989668 & $-0,20538052$ \\
\hline d20_1 & 0,42306453 & 3,320439228 & 0,38379327 & 1,30000173 & 1,28800226 \\
\hline d20_3 & $-1,4483462$ & $-0,708153065$ & $-2,74592991$ & 1,43780179 & 0,13004293 \\
\hline d20_5 & $-2,70549633$ & $-0,435031306$ & $-2,96119052$ & 1,0926015 & $-0,78488069$ \\
\hline d21_0 & 3,454887 & $-0,566880239$ & $-0,07870223$ & 1,04149644 & $-0,90843828$ \\
\hline d21_1 & $-1,57617082$ & 1,447704726 & $-1,71775776$ & 0,84077697 & $-0,69771156$ \\
\hline d21_3 & $-0,4199064$ & 0,245610843 & $-0.86182152-$ & 0,45277367 & 0,6591043 \\
\hline d21_5 & $-2,40881142$ & $-1,261222785$ & $-1,05301527$ & 0,08261084 & 1,39630858 \\
\hline Des_0 & $-1,51338475$ & $-1,098395593$ & $-0.82022641-$ & 1,75501785 & 1,68150583 \\
\hline
\end{tabular}




$\begin{array}{cccccc}\text { Des_1 } & -0,78371175 & -2,025927844 & 2,3824953 & 1,58279139 & 0,34272324 \\ \text { Des_3 } & -0,3452222 & 2,199666742 & -0,58003267 & 0,0023319 & -2,40075204 \\ \text { Des_5 } & 2,46769459 & 0,760337785 & -1.07085291- & 0,03878651 & 0,61324897 \\ & & & & \\ \text { eta2 } & \text { Dim 1 } & \text { Dim 2 } & \text { Dim 3 } & \text { Dim 4 } & \text { Dim 5 } \\ & 0,4858942 & 0,45507589 & 0,09687308 & 0,45669662 & 0,17453144 \\ \text { d5 } & 0,5924355 & 0,06052808 & 0,4499609 & 0,45300922 & 0,09415275 \\ \text { d7 } & 0,505361 & 0,3925488 & 0,17218291 & 0,05104338 & 0,42162621 \\ \text { d12 } & 0,666365 & 0,49464801 & 0,51597842 & 0,21595898 & 0,11333898 \\ \text { d20 } & 0,3978273 & 0,13629464 & 0,17998878 & 0,07291162 & 0,16899177 \\ \text { d21 } & 0,1957349 & 0,34070009 & 0,27751796 & 0,23690699 & 0,40181388 \\ \text { des10c } & & & & & \end{array}$

LEGENDA: eig = Autovalores, percentagem da variância e percentagem da variância cumulativa; coord = valores das coordenadas das categorias em relação ao eixo (dimensão); contrib = Contribuição da variável para o eixo (ou dimensão); v.test $=($ teste V) indica se o valor é significativo. (acima de 2 ou abaixo de -2); Eta2 = (variáveis categóricas) contÉm o quadrado da relação entre cada variável e as dimensões; $\cos 2$ = quadrado do cosseno. 